Universidad Politécnica de Madrid

Escuela Técnica Superior de Arquitectura

\title{
Paul Nelson y La Maison Suspendue. Creando la Matriz del Hombre
}



Departamento de Proyectos Arquitectónicos

Escuela Técnica Superior de Arquitectura

\section{Paul Nelson y La Maison Suspendue. Creando la Matriz del Hombre}

Tesis Doctoral

autor : Javier Escalonilla Morales

arquitecto

Directora: María Teresa Muñoz Jiménez

Doctor arquitecto

2017 

Tribunal nombrado por el Mgfco. Y Excmo. Sr. Rector de la Universidad Politénica de Madrid, el día

Presidente D.

Vocal D.

Vocal D.

Vocal D.

Secretario D.

Realizado el acto de defensa y lectura de Tesis el día

En la Escuela Técnica Superior de Arquitectura de Madrid

Calificación :

EL PRESIDENTE

LOS VOCALES

EL SECRETARIO 

Dedico esta tesis a mi mujer María y a nuestra hija Inés.

Y también a mis padres

Ascensión y Marino. 


\section{Agradecimientos}

Esta tesis no habría sido posible sin la ayuda de diferentes personas e instituciones, a todos ellos quiero agradecerles su apoyo.

En primer lugar a María Teresa Muñoz Jiménez por aceptar la labor de dirigir esta tesis, por su dedicación intelectual y por el trabajo crítico realizado durante todos estos años, que finalmente me ha conducido a la salida de la jaula.

A Olivier Cinqualbre, Consevador Jefe del Departamento de Arquitectura del MNAM-CCI Centre Georges Pompidou de París, por el reconocimiento de la importancia de esta investigación, por su interés y por la generosidad de compartir su información.

A Joseph Abram, profesor de la Escuela de Arquitectura de Nancy, por su interés por esta tesis y por sus investigaciones sobre Paul Nelson .

A los hijos de Paul Nelson, Ugo y Rory. A Ugo y a su esposa Aïcha por permitirme acceder a los archivos familiares y por su magnífico regalo. Y a Rory por sus aportaciones biográficas. También a la familia Le Cœur, Marianne Le Cœur y su hijo Marc, por sus crónicas y testimonios biográficos.

A María José Rodríguez, Doctora Arquitecta, por su generosidad, sus lecturas, sus sugerencias, sus correcciones y, sobre todo, por su confianza y su esfuerzo desinteresado para que este trabajo exista.

Y también, a Juan Antonio Villafáñez, filólogo, por su apoyo incesante, por sus lecturas, sus recomendaciones léxicas $\mathrm{y}$, sobre todo, por sus conversaciones y su amistad. 
A todas las instituciones y personas que me han ayudado en el proceso de búsqueda de la documentación.

Especialmente Valentina Moimas, María Pasuantisa, Anne-Marie Zuchelli, Sabine Vigoureux y Concetta Collura del Departamento de Arquitectura del MNAM-CCI Centre Pompidou. A Béatrice Sarno, Véronique Borgeaud, Didier Schulmann, Stéphanie Rivoire y Karine Bomel de la Bibliothèque Kandinsky.

A Jason C. Escalante de Avery Drawings \& Archives de Columbia University. A Tal Nadan de la Morgan Library \& Museum. A Teresa Montaner de la Fundació Joan Miró. A Esther Molina de la Fundació Pilar i Joan Miró. A Lola Fernández de la Successió Miró. A la Fondation Le Corbusier. A Elisabeth Thomas de los archivos del Museum of Modern Art (MoMA). A Rossy Mendez de la Seeley G. Mudd Manuscript Library de Princeton University. A Luam Melake de la Calder Foundation. A Albert Loeb de la galería Albert Loeb. A Didier Bondue de Saint-Gobain Archives. A Mercedes Valiente del Departamento de Expresión Gráfica de la ETS de Edificación (UPM). A todo el personal de la hemeroteca y de préstamo interbibliotecario de la Biblioteca Nacional de España. $\mathrm{Y}$ no quiero olvidarme del trabajo de Blanca García de la administración del DPA.

Durante todos estos años mi familia y mis amigos han sido un apoyo indispensable, su confianza y su silencio cómplice han sido decisivos para poder avanzar. Quiero agradecer su respeto y su afecto a mi hermana Pilar, a Juan y a Ana. Y también a María Inés y a Joaquín. 



\section{ÍNDICE}




\section{Índice}

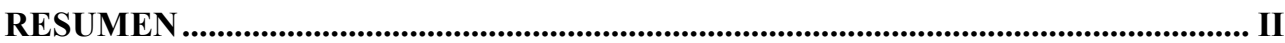

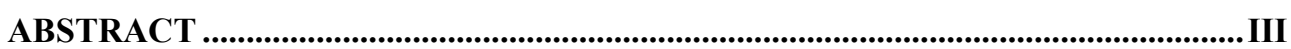

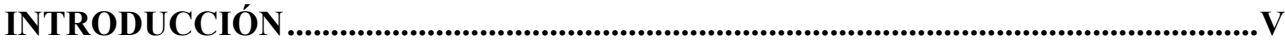

I PAUL NELSON. UN ARQUITECTO AVIADOR 1895-1979..................................1

1. Educación y formación............................................................................................................3

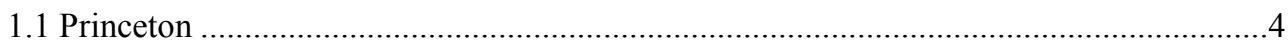

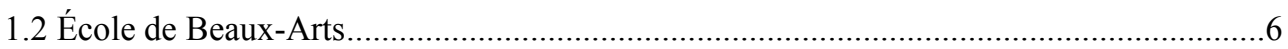

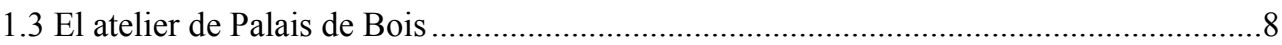

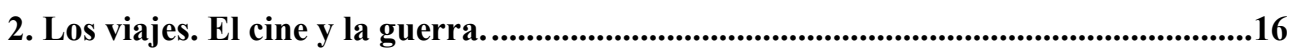

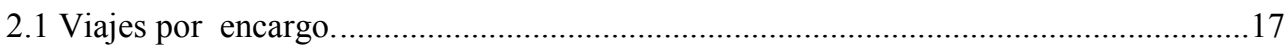

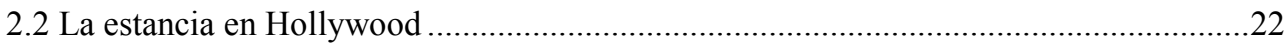

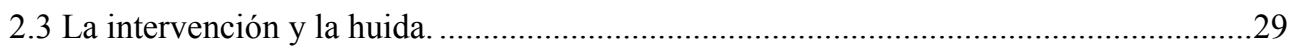

3. La investigación y la docencia ...............................................................................36

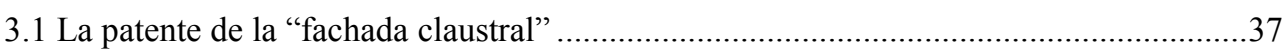

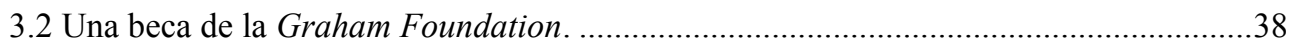

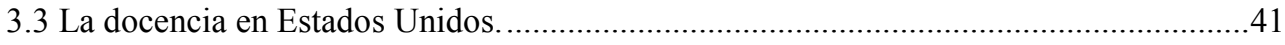

3.4 Los talleres internacionales de Beaux-Arts y de Marseille-Luminy. ...............................43

4. Francine y Maddalena. Las actrices principales..............................................................47

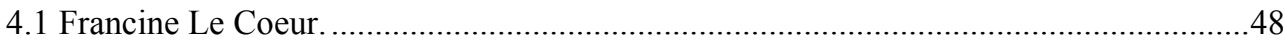

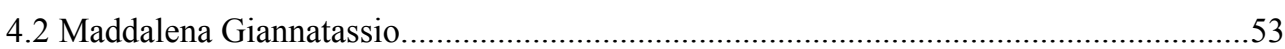

II APRENDIZAJE. ENTRE LA TECNOLOGÍA Y EL HUMANISMO..................61

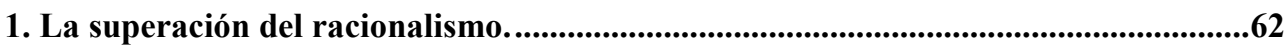

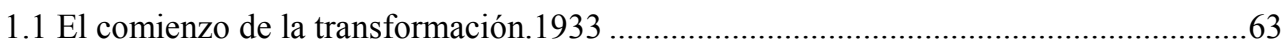

1.2 El final de la Escuela de París y la Exposición Internacional.1937 ..............................66

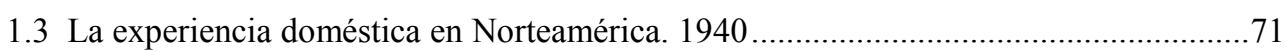

2. La influencia de los arquitectos coetáneos.............................................................74

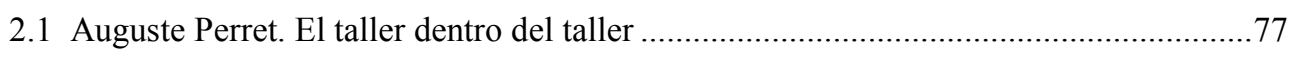

2.2 Le Corbusier. La mezzanine, la habitación aislada y el jardín suspendido.....................83 
2.3 R. Buckminster Fuller. Los procesos mecánicos y productivos de la vivienda

2.4 Pierre Chareau. La imagen industrial de la casa de vidrio. ........................................ 100

3. Los amigos artistas y la experiencia de pintor....................................................... 108

3.1 Georges Braque, el control sobre el espacio personal.............................................. 109

3.2 Jean Hélion. Términos de vida y términos de espacio............................................... 113

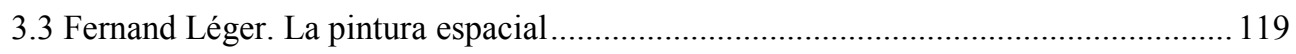

3.4 Alexander Calder. El valor revulsivo de lo imprevisto.......................................... 126

3.5 Paul Nelson. La práctica de la pintura. ............................................................... 132

4. La tecnología y la condición humana ….................................................................. 136

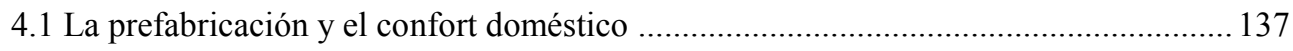

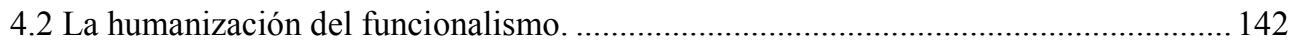

4.3 La síntesis como método de trabajo .......................................................................... 146

III LA MAISON SUSPENDUE. LA BÚSQUEDA DEL NUEVO HÁBITAT

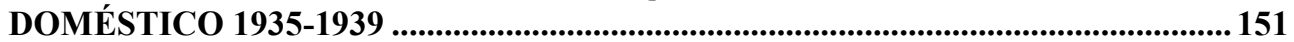

1. La casa. Manifiesto de un espacio suspendido.....................................................152

1.1 Proyectando desde el interior. De la sección a la volumetría....................................... 158

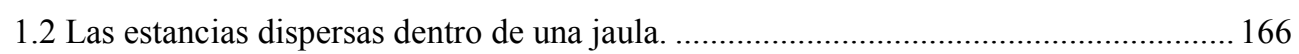

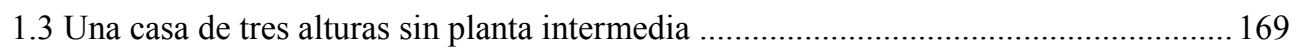

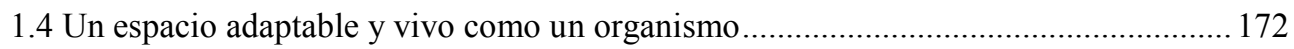

2. La no construcción y su difusión..........................................................................175

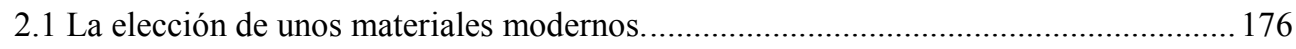

2.2 Wladimir Bodiansky. Las habitaciones suspendidas de la cubierta ........................... 179

2.3 La maqueta de Louis Dalbet. Un ensayo constructivo desaparecido ......................... 182

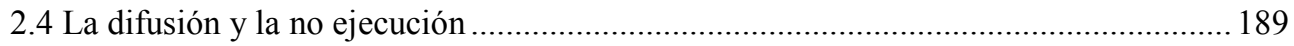

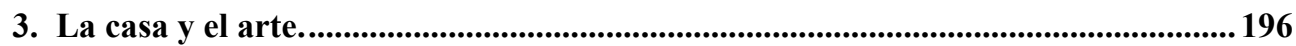

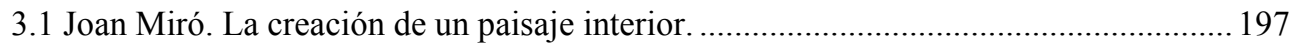

3.2 Fernand Léger. La irradiación del mediodía......................................................... 199

3.3 Jean Harp y Alexander Calder. La configuración de la terraza y el porche .................200

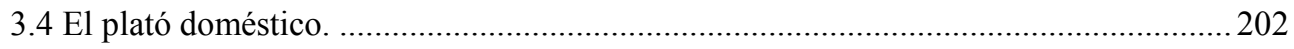

4. Una matriz con espacio inútil para el individuo ..................................................205

4.1 La retícula funcional de la familia y el desarrollo individual. .....................................206

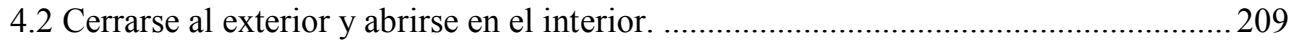

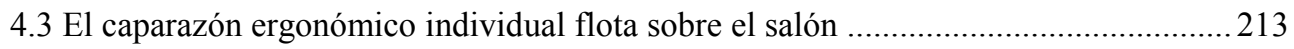

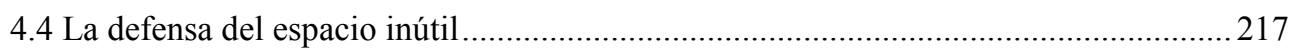


IV LA EXTENSIÓN DE LA MATRIZ DOMÉSTICA...............................................221

1. La proyección del espacio individual en la arquitectura residencial. ....................222

1.1 Aproximaciones. Modernidad y racionalismo.............................................................223

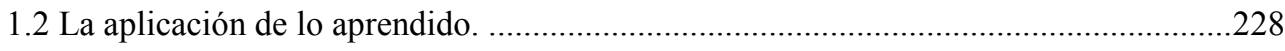

1.3 La construcción del hogar personal.......................................................................248

2. La presencia de lo doméstico en la obra pública......................................................261

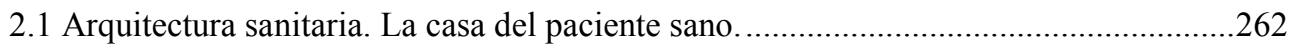

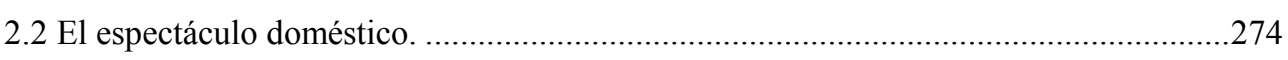

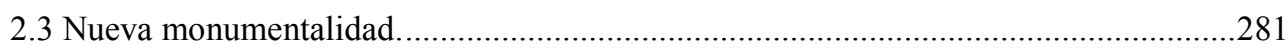

CONCLUSIONES. ..................................................................................................................289

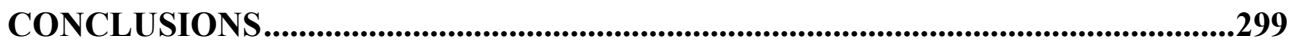

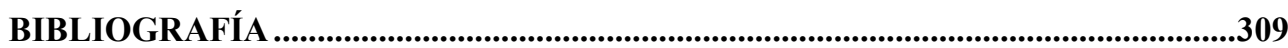

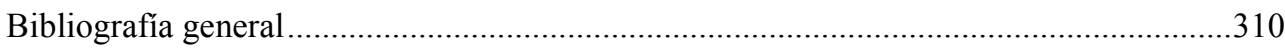

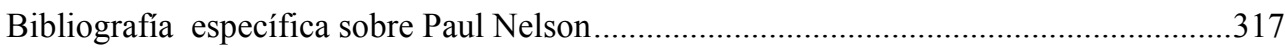

Bibliografía sobre La Maison Suspendue .............................................................................

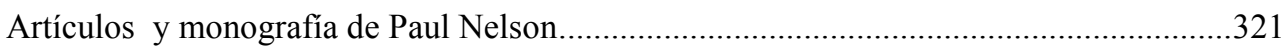

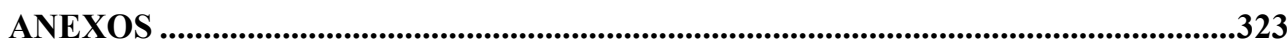

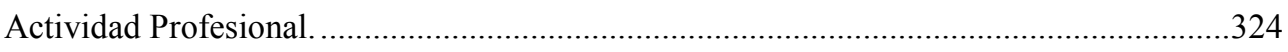

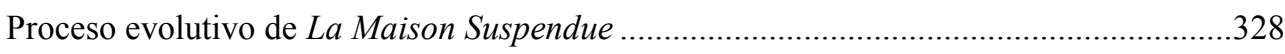





\section{RESUMEN}

Esta tesis se centra en el manifiesto teórico de vivienda La Maison Suspendue, proyectado entre 1935 y 1939 por Paul Nelson (Chicago 1895-Marsella 1979). El objetivo es verificar si Nelson utilizó la creación del espacio individual en su arquitectura residencial, como vía experimental para humanizar su obra pública.

El deseo de Nelson por construir una sociedad moderna se reflejó en su participación como piloto aliado en la Gran Guerra. Tras esta experiencia, renunció a su educación en Princeton y estudió arquitectura en Beaux-Arts como liberación personal. Sus viajes transatlánticos le convirtieron en testigo y embajador de la evolución de la arquitectura moderna. Toda su actividad, docente o proyectista, estuvo marcada por la investigación y su evolución como persona y arquitecto contó con el apoyo de sus dos mujeres, Francine Le Coeur y Maddalena Giannatassio.

Nelson adaptó la influencia del orden estructural de su maestro Auguste Perret, el orden espacial de Le Corbusier, el valor de la estandarización de Richard Buckminster Fuller y la imagen industrial de Pierre Chareau para indagar en su búsqueda del espacio individual. $Y$ desarrolló un sistema de trabajo interdisciplinar con ingenieros, sociólogos, economistas y artistas como Georges Braque, Jean Hélion, Fernand Léger y Alexander Calder que le permitió sistematizar un método deductivo de la forma, resultado de una síntesis entre la técnica y el humanismo.

La Maison Suspendue era un marco mínimo que servía de refugio y cubría todas las necesidades de una sociedad cambiante, incluido el retiro. Para ello se pensó en un "espacio inútil", sin uso predeterminado, capaz de incidir en el desarrollo intelectual del habitante. Se proyectaron dos pórticos de los que se colgó la cubierta y la planta superior; la parte mecánica se redujo al mínimo y se liberó un espacio vacío, continuo y fluido, en el que unas celdas individuales y desmontables estaban suspendidas sobre el lugar de reuniones. Las maquetas, que contenían obras de Fernand Léger, Joan Miró, Alexander Calder y Jean Arp, sirvieron para difundir la investigación y ensayar los efectos espaciales, constructivos y artísticos. En La Maison Suspendue se proyectaron soluciones abiertas, que posteriormente se traspusieron al resto de su obra, especialmente a sus hospitales. Su intención era liberar al hombre de cualquier programa funcional impuesto por la arquitectura $\mathrm{y}$, para lograrlo, no se buscó la disolución de la misma, sino que se trabajó para materializar unos espacios individuales en su interior que la hicieran más cercana. 


\section{ABSTRACT}

This thesis focuses on the theoretical manifest of The Suspended House, a dwelling designed between 1935 and 1939 by Paul Nelson (Chicago 1895-Marseille 1979). The objective is to verify whether Nelson used the creation of individual space in his residential Architecture, as an experimental way to humanize his public work.

His desire of building a modern society was manifested in his decision to participate as an Allied Pilot during The Great War. Following this experience, he waived his education at Princeton and instead he began his Architecture studies at Beaux-Arts as personal liberation. Thanks to his transatlantic voyages, he became a witness and an ambassador of modern Architecture. All his activity, as a Professor or a designer, was defined by research; and his development as a person and as an architect was supported by his two wives, Francine Le Coeur y Maddalena Giannatassio.

Nelson adapted diverse influences into his search for the individual space: the structural order from his Professor Auguste Perret, Le Corbusier's spatial order, the values of standardization of Richard Buckminster Fuller and the industrial image created by Pierre Chareau. And he developed a system of interdisciplinary work with engineers, sociologists, economists and artists such as Georges Braque, Jean Hélion, Fernand Léger and Alexander Calder which allowed him to systematize a deductive method about Shape, this method was the result of a synthesis between technique and humanism.

The Suspended House was a minimum framework that served as a refuge and it met all needs of a changing society, including the need for isolation. Because of this, it was thought about an "useless space", which had no predetermined usage, it was capable of influencing the intellectual development of inhabitant. It was designed two porticos from which roof and upper floor were hung; the mechanical area was reduced to a minimum, liberating an empty space, continuous and fluid, in which individual and detachable cells were suspended over a large meeting room. The models containing works by Fernand Léger, Joan Miró, Alexander Calder and Jean Arp, they were used to spread his research and to test spatial, constructive and artistic effects. In the Suspended House, open solutions were designed and later they were transplanted to the rest of his work, and specially in his hospitals. His intention was to free men of any functional programme imposed by Architecture, not by the dissolution of his Architecture itself but by materializing individual interior spaces, that would make it a more intimate place for men. 
INTRODUCCIÓN 


\section{Introducción}

Uno de mis lugares de juego favorito era el alfeizar de la ventana de la habitación de mis padres, este espacio intermedio, entre el interior y el exterior, entre el vidrio y la reja fue el primer rincón que sentí como lugar propio y desde el que me comunique con el exterior a cobijo. En mi vida profesional como arquitecto, comprobé como los habitantes de las viviendas que yo proyectaba reinventaban el fracaso doméstico, y convertían los garajes en su estancia principal, de esta manera, el uso inapropiado cambiaba el espacio y el significado de las casas. Sin este aprendizaje de lo disfuncional y sin la mirada inductiva del arquitecto holandés Herman Hertzberger, difícilmente habría podido aproximarme al arquitecto Paul Nelson (Chicago 1895 - Marsella 1979) y a su propuesta de casa, La Maison Suspendue, desarrollada en París entre 1935 y 1939. Recuerdo la imagen del proyecto como una jaula de pájaros con estancias flotando en su interior, similar a las que yo utilizaba para jugar y en las que nunca metí a ningún ser vivo.

Tanto los resortes autobiográficos como mi interés por los arquitectos secundarios se encauzaron cuando en el año 2008, participé en el curso de doctorado impartido por el profesor Antonio Juárez bajo el título de "La materia como nuevo paisaje de la arquitectura". Este periodo me llevó a reflexionar sobre el paisaje interior y el significado que el espacio individual había tenido en la arquitectura moderna, y este análisis finalmente desembocó en una investigación sobre la obra de Paul Nelson. Fue en el año 2009 cuando comencé a intuir el potencial que encerraba su trabajo y en especial La Maison Suspendue y cuando tras una conversación con la profesora María Teresa Muñoz le propuse utilizar esta pieza, como herramienta vertebradora de mi tesis doctoral. El desarrollo de esta tesis coincidió en el tiempo con la preparación del libro Jaulas y Trampas por parte de María Teresa Muñoz, que generosamente respetó mi campo de investigación. Y finalmente, esta tesis también se vio reforzada por una estancia de tres meses en el Musée National d'art ModerneCentre de Création Industrialle Centre Georges Pompidou de París en 2010, bajo la supervisión de Olivier Cinqualbre, conservador - jefe del departamento de Arquitectura. 
Así, esta tesis doctoral surgió de la necesidad de ordenar las ideas propias a partir de la intuición y la seducción por un autor y un proyecto que me resultaban desconocidos y de los que apenas tenía información. En el primer título previsto para esta tesis se adoptó el oxímoron "la provocación callada", con lo que se asumía una postura pretenciosa de revelador de la verdad sobre un arquitecto marginal. Una vez superada la fascinación por el personaje y analizados los estudios sobre su obra resultó obligado tomar distancia para reordenar la información y darle una nueva forma, cuya clave estaba en la experiencia doméstica. Fue esta reflexión la que me condujo a mirar la Maison Suspendue en relación a toda su obra y no como episodio aislado. De esta manera, comprendí como esta propuesta de vivienda se había convertido en el trabajo más representativo de su carrera, ya que era a la vez el resultado de una síntesis sobre reflexiones ya elaboradas, y un punto de partida que mostraba gran parte de los pensamientos que sostuvieron sus trabajos posteriores. Así, el título de la tesis evolucionó y se adoptó parcialmente el título del libro de Sibyl Moholy-Nagy The Matrix of Man, un texto que a juicio de Nelson era el referente a escala urbana de su pensamiento doméstico.

De toda la carrera profesional de Paul Nelson, lo más reconocido por la crítica ha sido su arquitectura hospitalaria y especialmente, sus proyectos de Saint-Lô y Arles realizados tras la Segunda Guerra Mundial. Su atracción por la arquitectura sanitaria ya se manifestó en su trabajo de diplomatura en 1927 y se mantuvo hasta el final de su trayectoria profesional, cuando en 1971 fue nombrado consejero para el Ministerio de Sanidad de Túnez. Como se verá, su obra sanitaria ha sido objeto de diversos estudios a diferencia de su arquitectura residencial. Incluso La Maison Suspendue considerada por la crítica como el proyecto más decisivo de su carrera, nunca ha sido objeto de un monográfico crítico.

Esta tesis pretende llenar el vacío de la historiografía moderna en relación a la figura de Paul Nelson para recuperar La Maison Suspendue no como un proyecto anecdótico sino como un experimento fundamental para entender su carrera en el contexto de la arquitectura moderna. Esta tesis pretende exponer y reordenar la información existente para permitir futuras investigaciones. 


\section{El estado de la cuestión.}

Durante los años treinta y ante la ausencia de obra construida, Paul Nelson utilizó los artículos de las revistas, tanto para difundir sus proyectos como para describir su método de trabajo y fijar su posición respecto de la arquitectura moderna. En 1933, se publicó el artículo más revelador de su pensamiento a través de una crítica sobre La Maison de Verre de Pierre Chareau ${ }^{1}$. En el texto se planteaba la muerte de la arquitectura moderna francesa representada por Le Corbusier y Auguste Perret y se daba la bienvenida a la nueva arquitectura tecnológica que representaba la obra de Pierre Chareau.

Ese mismo año, su amigo Christian Zervos, editor de la revista Cahiers d'Art, escribió la introducción de un monográfico sobre La Cité Hospitalière de Lille2. Para Christian Zervos lo más destacado del proyecto era la capacidad que manifestaba Nelson para conjugar los volúmenes y la proporción francesa con la organización de la gran escala americana.

En el año 1935 el pintor Jean Hélion escribió una crítica a propósito del proyecto del Centro de Cirugía desarrollado por Paul Nelson para la Compañía del Canal en Ismaïlia ${ }^{3}$ (Egipto). El texto sirvió como excusa a Jean Hélion para plantear una reflexión sobre el concepto del espacio doméstico de la arquitectura moderna y sugerir como se debía afrontar el proyecto de la casa del futuro. Esta propuesta de Jean Hélion provocó la respuesta de Paul Nelson mediante su proyecto de $L a$ Maison Suspendue.

La marcha de Paul Nelson a los Estados Unidos durante la Segunda Guerra Mundial supuso un corte en la difusión de su trabajo y como se ha señalado, el interés de los críticos por el trabajo de Nelson resurgió tras haber construido varios hospitales a partir de los años sesenta. En 1971, la historiadora y crítica Judith Applegatepublicó publicó una entrevista biográfica ${ }^{4}$ en la que se revistaban cronológicamente y a través

\footnotetext{
${ }^{1}$ Paul Nelson, "La Maison de la rue Saint Guillaume", L'Arquitecture d'aujourd'hui nº, noviembre-diciembre 1933,p.9.

${ }^{2}$ Christian Zervos, «Introducción», Cité Hospitalière de Lille. Paul Nelson, París: Cahiers d'Art 1933, pp. XI-XV.

${ }^{3}$ Jean Hélion, “ Termes de vie, termes d'space ”, Cahiers d'Art No 7-10, 1935, pp. 268-273.

${ }^{4}$ Judith Applegate, "Paul Nelson: an interview". Perspecta nº13-14, 1971. pp.75-128.
} 
de sus proyectos, su interés por la industria, la sociología, el medio ambiente, el arte y la política. La fórmula elegida no ofrecía una visión crítica, sino una retrospectiva contada desde el contexto de los años setenta ${ }^{5}$. Pero su validez residía en ser la primera vez que se publicaba una referencia amplia sobre Paul Nelson.

Una década después de su muerte en 1979, aparecieron los primeros monográficos sobre la figura de Paul Nelson y su obra. En 1989 se publicó en Francia el Bulletin de la IFA N ${ }^{\circ} 130^{6}$ dedicado Nelson y en 1990 en los Estados Unidos "The Filter of Reason Work of Paul Nelson" ${ }^{7}$, la segunda publicación era prácticamente una extensión de la primera. En los textos se presentaba a Paul Nelson como un arquitecto de formación interdisciplinar, un humanista que sometía sus ideas un método deductivo y razonado que justificaba la forma de sus proyectos. Se estudiaron sus relaciones con los artistas, sus inquietudes técnicas y su condición franco-americana. Kenneth Frampton contextualizaba a Paul Nelson dentro de "La Escuela de París" y destacaba la influencia que había ejercido La Maison de Verre $^{8}$ en al proyecto dela Maison Suspendue. Y el profesor Joseph Abram analizaba la incidencia de Auguste Perret en la formación de Paul Nelson y la relación con los artistas, se analizaban los vínculos entre la pintura y la arquitectura de Paul Nelson, sin establecer conclusiones ${ }^{9}$. Se destacaba el interés manifestado por Nelson en los años treinta por lograr una flexibilidad espacial, constructiva y psicológica, abandonando los postulados más deterministas del funcionalismo.

En los dos libros, la fragmentación del contenido por épocas o temas, impedía obtener una visión clara del conjunto. La obra residencial aparecía en un segundo

\footnotetext{
${ }^{5}$ Esta entrevista mantiene una distancia temporal de treinta años con algunos de sus trabajos, de ahí que se produzcan algunos desajustes de fechas, como en el caso de la exhibición de la maqueta de La Maison Suspendue en la galería de Pierre Loeb en París en 1937, esto es imposible ya que los planos para la ejecución de la maqueta son de 1938, año en el cual se construyó. Véase Judith Applegate, "Paul Nelson: an interview". Perspecta nº13-14, 1971.

${ }^{6}$ VV.AA Paul Nelson 1895-1979, Bulletin IFA Nº130 1989, París : Institut Français d'Architecture, 1989.

${ }^{7}$ Terence Riley, Joseph Abram, The Filter of Reason Work of Paul Nelson, catálogo de la exposición celebrada en la Arthur Ross Gallery de la Columbia University School of Architecture, entre el 2 de abril y el 4 mayo de 1990. New York: Rizzoli International Publications, 1990.

${ }^{8}$ Kenneth Frampton, "Paul Nelson et 1'École de Paris-1923-1938”, Bulletin d'Informations Architecturales (Ifa) n 130 abril 1989, pp.3-4.

${ }^{9}$ Joseph Abram, "Paul Nelson: le crible de la raison. 1920-1939: Peinture/ Architecture. Projets experimentaux", Bulletin d'Informations Architecturales (Ifa) no 130 abril 1989, pp.5-9.
} 
plano y no se establecían vínculos con otros tipos de arquitectura. La Maison Suspendue era analizada cronológicamenete con el resto de la obra sin profundizar en trasposiciones o influencias en otros proyectos, y tanto las referencias transversales con los artistas como los contactos con otros arquitectos se mantenían fundamentalmente en el plano narrativo e histórico.

Las relaciones de Paul Nelson con el arte han sido tratadas por dos textos. En1986, Donald Albrecht expuso la contribución que había supuesto la dirección artística de Paul Nelson en la película "What a Widow" 10 para la difusión de la arquitectura moderna a través del cine. El estudio se restringía a la película y no analizaba la repercusión que esta experiencia tuvo en la carrera de Paul Nelson, especialmente, en la concepción del espacio de reuniones sociales y en la importancia de los espacios de tránsito en sus viviendas.

En 2007, con motivo de la exposición centrada en la relación de Paul Nelson con el arte, se publicó el libro-catálogo " Un Architecte des Artiste. Paul Nelson, Léger, Calder, Brassaï, Hélion, Braque, Miró" ${ }^{\prime 1}$. Se describieron los vínculos de Paul Nelson los artistas, su experiencia pictórica y la presencia de obras de arte en su arquitectura. Pero en el texto no se analizan las posibles relaciones transversales entre los procesos compositivos o formales de las obras plásticas y de la creación de la arquitectura.

De todos los análisis de su arquitectura hospitalaria, el trabajo que resulta conceptualmente más próximo a esta Tesis es la investigación desarrollada en 2010 el profesor Donato Severo para su Tesis Doctoral "L'Hopital de Saint-Lô. Du project a L'Usage (1946-1999) ", ${ }^{\prime 2}$, un trabajo monográfico muy bien documentado, que en sus conclusiones considera que la búsqueda del humanismo era el hilo conductor del proyecto del hospital y que está búsqueda "podía ser" la aportación más importante que Paul Nelson hace a la arquitectura del siglo XX, Coincidiendo en parte con esta conclusión, desde este trabajo se pretende avanzar y analizar el

\footnotetext{
${ }^{10}$ Donald Albrecht, Designing dreams. Modern Architecture in the movies, New York: Marge Horvitz, 1986.

${ }^{11}$ VV.AA "Un Architecte des Artistas. Paul Nelson, Léger,Calder, Brassaï, Hélion,Braque, Miró." catálogo de la exposición celebrada en 2007 en el Musée Beaux-Arts de Gaillac.

${ }^{12}$ Donato Severo, “ L'Hoplital de Saint-Lô. du Project a l'usage (1946-1999) ”,n.p, director Gérard Monnier, UFR03 Histoire de l'art et Archéologie Formation doctorale en Histoire de 1'art, Université Paris I Panteón- Sorbonn. 2010, p.74
} 
vacío que deja el texto sobre la posible vía utilizada por Paul Nelson para humanizar su arquitectura.

A pesar de que Paul Nelson difundió La Maison Suspendue en un cuaderno publicado por L'Architecture Vivante en $1939^{13}$, pronunció varias conferencias y su maqueta se presentó en el MoMA en $1939^{14}$, en los libros de historia de la arquitectura moderna no hay referencias a este proyecto. En la actualidad no existe ningún análisis monográfico, crítico, dedicado a La Maison Suspendue.

El primer artículo sobre La Maison Suspendue se publicó en la revista Architectural Record en diciembre de 1938 y fue preparado por los arquitectos Mr Lömberg-Holm y Mr Theadore Larson ${ }^{15}$. El texto destacaba la ruptura entre el uso funcional y espacial, y analizaba la repercusión que se ejercía sobre las relaciones sociológicas de los habitantes. El artículo criticaba aspectos económicos como el coste de su ejecución o la imposibilidad de producir la casa industrialmente, pero no planteaba reflexiones ni sobre del espacio individual ni sobre la humanización de la vida doméstica. En 1939 el crítico de arte James Jonson Sweeney escribió un texto para el catálogo de la Golden Gate Internacional Exposition de San Francisco ${ }^{16}$ en el cual se destaca el valor del proyecto como resultado de una investigación y se apuntaban otros tipos arquitectónicos donde poder trasladar los resultados obtenidos.

Dos décadas después, en 1958, la revista Le Carré Bleu dedicó un número a la deshumanización de la arquitectura ${ }^{17}$ y el redactor Aulis Blomsted hizo referencia a La Maison Suspendue como el único ejemplo de una nueva "forma de la

\footnotetext{
${ }^{13}$ Paul Nelson, La Maison Suspendue. Recherche de Paul Nelson. (L'Architecture Vivante), París: Albert Morancé, 1939.

${ }^{14}$ El MoMA, inauguró su nueva sede en la primavera de 1939 con la muestra titulada Art In Our Time, el apartado de arquitectura se denominó Houses and Housing. El proyecto de La Maison Suspendue formaba parte de los trabajos expuestos como un ejemplo de la arquitectura que se estaba realizando en aquellos momentos.

${ }^{15}$ El artículo no está firmado, pero en una carta de Paul Nelson al editor del New York Times le remite a los arquitectos Mr Lömberg-Holm y Mr Theadore Larson como autores . "New Use of Space Determines Design of Proposed House. Paul Nelson, architect", Architectural Record, Volumen 84 N $^{\circ} 6$ diciembre 1938, pp. 38-41.

16 James Johson Sweeney, "The Suspended House", Official Catalog Deparment of Fine Arts,Division of decorative arts Golden Gate International Exposition, San Francisco: H. S. Crocker Company, 1939, pp.74-75.

${ }^{17}$ Aulis Blomsted, "La deshumanización de la arquitectura”, Le Carreé Bleu №2 1958, p. 4.
} 
arquitectura". En 1961, en otro artículo ${ }^{18}$, volvió a utilizar la casa de Paul Nelson, para explicar que la forma de la arquitectura no era algo meramente visual sino que estaba ligado a un campo invisible, donde lo importante eran las relaciones entre las partes. Proponía leer La Maison Suspendue como un proyecto humanista y clásico de la época moderna. En el año 1978, se volvió a publicar este texto de Aulis Blomsted precedido por unas notas de Anne Kandelman ${ }^{19}$, crítica de arte y biógrafa de Paul Nelson, en ellas defiende al arquitecto como una persona que creen en el cambio político como oportunidad para cambiar la arquitectura para mejorar la vida del hombre. Para esta Tesis, lo más interesante de estas notas es profundizar en la idea del urbanismo orgánico y estudiar si la posición que tendría el individuo en las nuevas comunidades era una traslación de sus experiencias domésticas al espacio urbano.

En 1987 el profesor Joseph Abram escribió un artículo sobre La Maison Suspendue ${ }^{20}$, en el que se presentaba este proyecto como heredero de las influencias recibidas, Braque, Perret y Hélion, y fruto de un proceso evolutivo de su propia obra. Se analizaban los aspectos espaciales, tecnológicos y artísticos de la casa, calificando el proyecto como expresionista-tecnológico. Aunque se reflejaba la opinión de Paul Nelson sobre las necesidades individuales, no se profundizaba en la presencia del espacio individual dentro de la casa ni en estudiar la posible herramienta humanizadora de la vivienda.

Una década más tarde, en la revista L'Architecture d'aujourd'hui se publicó un dossier elaborado por Jean-Paul Robert y Olivier Cinqualbre ${ }^{21}$. El texto, escrito por Jean-Paul Robert, estaba marcado por la incursión de fragmentos del pensamiento directo de Paul Nelson ya expresados en L'Architecture Vivante de 1938. Jean- Paul Robert inscribió la casa dentro del interés de la arquitectura americana del siglo XX por la búsqueda del espacio continuo. Y consideraba que la vivienda tenía tanto valor tanto por sí misma como por el rastro que dejaba en otras obras, lo cual serviría para analizar si verdaderamente hay una influencia reconocida en otras obras.

\footnotetext{
${ }^{18}$ Aulis Blomsted, “Le forme architecturale”, Le Carreé Bleu, Nº1 1961.

${ }^{19}$ Anne Kandelman, “Plaidoyer pour le Changement”, Le Carreé Bleu, №1 1978, pp. 11-12.

${ }^{20}$ Aulis Blomsted, "Le forme architecturale”, Le Carreé Bleu, Nº1 1961.

21 Jean Paul Robert, Olivier Cinqualbre, "Paul Nelson. La Maison Suspendue", L'Architecture d'aujourd'hui, No 316 , pp. 38-71.
} 
El proyecto de La Maison Suspendue sigue sido un referente utilizado por los críticos y los historiadores para analizar diversos aspectos de la arquitectura del siglo XX de todas ellas cabe destacar el análisis, ya mencionado, del arquitecto Herman Hertzberger $^{22}$, en este texto se presentaba el espacio libre y tridimensional de la casa, como resultado del diseño estructural y de los procesos de producción, sin explorar otras posibles causas de la solución.

Finalmente como testimonio, casi exclusivo, de los estudios realizados en España sobre este proyecto, el arquitecto y profesor José Antonio Sosa publicó en 2002 un artículo titulado "Una nube en una jaula. La Maison Suspendue de Paul Nelson"23 En el texto se intenta contextualizar el proyecto en el concepto de la modernidad, en la idea de crear a partir de cero. Se analizan las condiciones de continuidad y fluidez espacial, y las relaciones funcionales entre las estancias. En el artículo no se analiza la referencia sobre el espacio inútil formulada por Paul Nelson, ni se estudia la presencia de espacio individual, ni el interés del arquitecto por conseguir una arquitectura más humana.

En los testimonios críticos analizados sobre la obra de Paul Nelson, se reconoce que la principal aportación de su trabajo residía en su objetivo de hacer los hospitales más humanistas ${ }^{24}$. Estos argumentos se apoyan en el interés de Paul Nelson por incorporar factores psicológicos, sociales o artísticos a su arquitectura. En ninguno de los textos se analiza la repercusión que tuvo su obra doméstica sobre su arquitectura sanitaria.

Como conclusión del estudio de las investigaciones existentes sobre la Maison Suspendue cabe destacar que en ninguna de ellas se han analizado aspectos del proyecto que se consideran decisivos como son: la presencia del espacio individual y su repercusión pública, el significado doméstico del "espacio inútil”. Incluso siendo el proyecto de La Maison Suspendue reconocido por los críticos como el más

\footnotetext{
${ }^{22}$ Herman Hertzberger, Space and the Architect. Lessons in Architecture 2, 010 Rotterdam: Publishers, 2000, pp. 70-71.

${ }^{23}$ José Antonio Sosa Díaz-Saavedra, "Una nube en una jaula. La Maison Suspendue de Paul Nelson”, Arquitectura COAM , 328, 2002, pp. 20-27.

${ }^{24}$ En las dos monografías publicadas sobre la obra de Paul Nelson, su arquitectura hospitalaria ha sido descrita como una combinación de técnica y humanismo. Véase: AA. VV. Paul Nelson. 1895-1979, Bulletin, 1989,130. París: Ifa, 1989 / Terence Riley y Joseph Abram. The Filter of Reason. Work of Paul Nelson. Nueva York: Rizzol, 1990.
} 
importante de su carrera, no se han realizado estudios que analicen la trasposición que tuvo este trabajo en el resto de su obra.

Por lo tanto, existe un vacío de investigación que analice la repercusión que tuvo la arquitectura residencial de Paul Nelson en la configuración de una arquitectura humanista en sus hospitales. Con esta tesis se plantea una revisión de la obra de Paul Nelson a partir de su arquitectura residencial para determinar cuál fue la vía, sí la hubo, utilizada por Paul Nelson para humanizar su arquitectura

\section{Objetivos}

El objetivo principal de esta tesis es estudiar la humanización de la arquitectura pública de Paul Nelson a partir de la presencia del espacio individual en su obra residencial, teniendo como herramienta de referencia para realizar este análisis su proyecto de La Maison Suspendue.

El eje principal de la investigación está apoyado en las respuestas a unos objetivos secundarios, que en primer lugar, tratan de situar a Paul Nelson y su proyecto de $L a$ Maison Suspendue integrados en el contexto de la arquitectura de los años treinta, en segundo lugar, pretenden reivindicar la importancia de la arquitectura residencial dentro de la obra de Nelson, y comprobar como son las trasferencias recibidas desde el espacio doméstico las que dotan de singularidad a sus hospitales, aportando una nueva lectura de su trabajo, siempre analizado desde la óptica de su arquitectura sanitaria. $\mathrm{Y}$ en tercer lugar, intentan poner de manifiesto la importancia que tuvo para Nelson el espacio individual en sus proyectos y la defensa del espacio "inútil" o sin uso determinado, que interactuaba con el habitante para que este alcanzase su desarrollo intelectual. A estos objetivos secundarios se ha llegado formulado una serie de preguntas con respecto a cada uno de los vacíos detectados en las investigaciones existentes.

Paul Nelson, un arquitecto moderno:

- Cómo encaja la figura personal de Paul Nelson en el panorama de la arquitectura de entreguerras 
- Cuál es la evolución de pensamiento que va desde el racionalismo de un método deductivo hasta una posición más "humana" que pretende extender el funcionalismo al campo sociológico.

- Qué valor tiene en su condición de moderno su formación transversal, su contacto con otras disciplinas artísticas como la pintura y el cine, así como su relación con artistas como Georges Braque o Jean Hélion

- Cómo han influido en su arquitectura sus contactos con la arquitectura de Richard Buckminster Fuller o Pierre Chareau, y su condición de viajero entre los dos continentes en su intención por fusionar la técnica americana con el humanismo francés.

- Que aporta a la arquitectura moderna, su interés por las personas, como destinatarias últimas de la arquitectura, entendido al hombre en su doble condición individual y social.

La Maison Suspendue, un nuevo habitad doméstico en los años treinta:

- Cómo enlaza este proyecto con un contexto arquitectónico que considera superados los valores iniciales del Movimiento Moderno y explora nuevas vías de avance, en las cuales se intensifica el análisis de la influencia que la arquitectura puede ejercer sobre la componente espiritual del hombre.

- Es La Maison Suspendue un referente, a partir del cual la arquitectura moderna podría buscar su nueva vía como así lo consideraron Alvar Aalto y Vasili V. Kandinsky

- Qué repercusión tenía en la nueva concepción de una vivienda que la cualidad espacial más buscada fuera la de "lo inútil".

- Cuál es el valor que tiene un proyecto no construido como manifiesto de la búsqueda de un nuevo hábitat doméstico.

- Cuál es la importancia y la influencia que tiene este proyecto en toda la carrera de Nelson.

La arquitectura doméstica, un laboratorio experimental: 
- Por qué no existe ninguna visión de conjunto sobre su arquitectura doméstica

- Es la casa el laboratorio experimental de Paul Nelson, como sucedió con otros ejemplos de la arquitectura moderna.

- Es la traslación de los hallazgos en el espacio doméstico lo que dota de singularidad a su arquitectura pública y en especial a sus hospitales.

En definitiva, se trata de saber si el acto de "humanizar la arquitectura" se convirtió en la principal obsesión de Paul Nelson a lo largo de toda su carrera.

\section{Metodología}

La búsqueda de fuentes resultó complicada dada la fragmentación de la documentación dispersa en diversos archivos de Francia y de los Estados Unidos. A esta dificultad geográfica hay que unir la física, al tratarse de un proyecto no construido del cual sólo había dibujos, planos y maquetas, y parte de la documentación está desaparecida. De algunos elementos del proceso del proyecto, como la primera maqueta realizada, solo se conservan referencias descriptivas de textos e imágenes fotográficas, su rastro se perdió justo antes de la Segunda Guerra Mundial. Una parte importante de las fuentes primarias gráficas manejadas son inéditas, lo cual aporta un valor añadido a esta investigación.

La búsqueda de la documentación se produjo a partir de tres vías, la primera en archivos y bibliotecas, la segunda mediante visitas in situ a las obras construidas por Paul Nelson y la tercera vía fueron los testimonios orales de familiares, amigos y radiofónicos con entrevistas realizadas al propio arquitecto.

En Francia, las fuentes primarias más importantes estaban distribuidas en los siguientes archivos: en primer lugar, el Musée National d'Art Moderne Centre de Création Industrialle Georges Pompidou de París, aquí se ha investigado en dos ámbitos, la Bibliothèque Kandinsky, donde se han localizado manuscritos, referencia a proyectos, contactos personales, fotografías, libros y revistas. Y la Reserve Graphique donde se ha trabajado con las adquisiciones de material referente 
a La Mison Suspendue compuesta por 103 planos, dibujos y croquis. Y en segundo lugar, están los archivos personales de la familia Nelson, una documentación sin clasificar, que contenía planos y croquis de varios proyectos inéditos, que han sido rescatados, obra plástica de Paul Nelson, documentos biográficos oficiales y notas de prensa.

Las fuentes primarias más importantes de los Estados Unidos han sido localizadas en los archivos del Museum of Modern Art de New York (MoMA), donde se ha obtenido la información referente a las exposiciones de la Maison Suspendue, a través de los boletines de prensa y los catálogos, pero lo más importante han sido las imágenes de la segunda maqueta, que actualmente se encuentra en los talleres de restauración del museo. También se ha localizado información inédita sobre las maquetas en la Morgan Library de New York, que ponen en cuestión la desaparición de la primera maqueta. Y en la Avery library de Columbia University donde se ha obtenido correspondencia.

Para buscar las fuentes documentales de su biografía, en Francia se ha contactado con diferentes instituciones como La École de Beaux Arts - Biblioteque Paris Malaquais, donde se han obtenido datos de su formación y su expediente académico. En los Archives de la Merie de Varengeville se ha obtenido información personal, su acta matrimonial, y su pertenencia a la comunidad y en los Archives Departamentaux de Dieppe, se ha localizado información sobre su ejercicio profesional. En los Estados Unidos se ha contactado con la Seeley G. Mudd Manuscript Library de Princeton University de donde se obtuvo información sobre su formación académica, sus inicios con en el dibujo arquitectónico y sus relaciones con F. Scott Fitzgerald.

Para investigar en su relación con los artistas se ha contactado con diferentes fundaciones en Francia, los Estados Unidos y España. Donde se ha encontrado correspondencia y referencias de hemerotecas. Estas instituciones han sido: Fondation Le Corbusier, Musée National Fernand Léger, Calder Foundation, Graham Foundation, Fundació Pilar i Joan Miró, Fundació Joan Miró, Succesió Miró.

Con el fin de cubrir la parte técnica y constructiva de la investigación, se entró en contacto con los archivos de la empresa Saint Gobain, en Francia, de donde se 
obtuvo correspondencia mantenida en contacto con Paul Nelson y Jean Prouvé a propósito de la participación en el cerramiento de la vivienda.

Para localizar todas las fuentes secundarias se ha investigado en diversas bibliotecas y hemerotecas, tanto en París como en Madrid.

Se han visitado cuatro obras ejecutadas por Paul Nelson, la Maison Brooks en París, el Hospital Americano de Neully, la Maison de Sceaux y el taller de Braque en Varengeville, de las cuales se han tomado fotografías y se han realizado dibujos. Y también se han visitado dos lugares que fueron muy importantes en su vida personal y profesional, su taller- estudio, 98 Boulevard Blanqui en París y su casa de vacaciones Varengeville, en la costa de la Alta Normandía. Donde también se han tomado fotografías y se han realizados apuntes gráficos.

Las entrevistas más importantes fueron con sus hijos. Msr. Ugo Nelson, arquitecto, y Msr Rory Nelson, músico. Sus relatos han sido decisivos para configurar la biografía de su padre y de su madre Maddalena Gianastasio y su relación con el arte. También fue muy importante el encuentro con Marian Le Coeur, arquitecta, sobrina- nieta de Francine Nelson y con su hijo Marc Le Coeur historiador, ellos ayudaron a construir la genealogía de la familia Le Coeur y sus vinculaciones con la arquitectura y la pintura francesa de los siglos XIX - XX. Los actuales propietarios de la casa Varengeville, conocieron a Paul Nelson y la relación que él tenía con ese lugar. La información anterior fue complementada con la entrevista, en la Maison Rodin, con el arquitecto, pintor, historiador y profesor Joseph Abram, el mayor especialista en la figura de Auguste Perret y uno de los investigadores que más han analizado la arquitectura de entreguerras en Francia. Sus testimonios fueron decisivos para, entender las relaciones de Paul Nelson y Auguste Perret y para determinar las posibles influencias entre el pintor Jean Hélion, a quien conoció personalmente, y la arquitectura de Paul Nelson.

Hubo otros contactos que ayudaron a obtener información más específica sobre aspectos concretos de los cuales me interesa destacar dos, el encuentro con el galerista parisino Albert Loeb, hijo de Pierre Loeb, dueño de la galería homónima donde se expuso por primera vez La Maison Suspendue. De esta entrevista se han obtenido imágenes fotográficas de la galería, notas de prensa y la descripción del panorama artístico del París de los años treinta. Y con Federico Neder, autor del libro Fuller Houses: R. Buckminster Fuller's Dymaxion Dwellings and Other 
Domestic Adventures y profesor del Institut d'architecture at the University of Geneva, con objeto de profundizar en la relación entre Fuller y Nelson.

Una vez localizada la documentación, los textos se clasificaron en cuatro temas: Contexto de la arquitectura moderna, figura del arquitecto Paul Nelson, obra profesional y proyecto de La Maison Suspendue. Una vez organizados, de cada texto se hizo un análisis crítico y se realizaron unas fichas para contrastarlas mediante un método comparativo. El fin era el de verificar los datos y obtener unos resultados más completos. Este método de trabajo permite comprobar los temas tratados, los puntos de vista desarrollados y los vacíos existentes en los textos.

Respecto de los documentos gráficos, lo primero que se hizo fue redibujar a mano alzada los 103 documentos del (MNAM/CCI G.P- R.G). Se trataba de entender espacial y compositivamente el proyecto, utilizando el dibujo como herramienta de investigación. En una segunda fase se elaboró un proceso evolutivo y para ello se identificaron ocho versiones en torno a dos fechas, abril de 1936 y abril-mayo 1938. Además se pretendía dar una visión más amplia sobre La Maison Suspendue relacionándola con la obra pictórica de Paul Nelson. Y para ello se han analizado las posibles transposiciones existentes entre sus procesos pictóricos y arquitectónicos.

El análisis obtenido del método comparativo de las fichas ha permitido elaborar una versión propia de la documentación que ha ayudado a interpretar las fuentes secundarias desde una nueva perspectiva. Además la detección de los vacíos permite ordenar la investigación en función de los objetivos de la tesis. 


\section{Estructura de la tesis}

El análisis de la investigación se ha estructurado en cuatro capítulos que van de la figura de Paul Nelson al estudio del espacio individual en su obra. La incorporación de la biografía de Paul Nelson como parte fundamental de esta tesis revela la manera en la que la propia vida del arquitecto se integra, como fase primera de un proceso de trabajo experimental que llega a su punto de mayor intensidad con La Maison Suspendue, un proyecto de autoencargo.Y como desde este proyecto se trasponen soluciones a otras obras más generales.

En al capítulo primero, "Paul Nelson. Un arquitecto aviador 1895-1979", se analizan los acontecimientos que marcaron su carrera como un arquitecto viajero, con formación humanista, piloto de guerra, director artístico, profesor e investigador, que estuvo apoyado en su trabajo por sus dos mujeres. En el capítulo segundo, "Aprendizaje, entre la tecnología y el humanismo", se estudia el proceso de formación como arquitecto en el contexto de los años treinta. Se investiga cómo trata de superar el racionalismo y construir su propia vía de trabajo, a través de las influencias de arquitectos coetáneos como Auguste Perret, Richard Buckminster Fuller, Pierre Charea y Le Corbusier y los contactos transversales con otros artistas como Georges Braque, Fernand Léger, Jean Hélion y Calder. Se estudia cómo crea su propio método de trabajo como síntesis de la tecnología y el humanismo. En el capítulo tercero, “La Maison Suspendue. La búsqueda del nuevo hábitat doméstico", se analiza el proyecto atendiendo a su carácter de manifiesto, de obra no construida que fue difundida a través de sus maquetas, se analiza el proceso evolutivo del proyecto y la importancia de la técnica y la psicología en la definición del espacio doméstico, cuya cualidad espacial más importante era la inutilidad, también se analiza el papel que juega el arte dentro de la casa como herramienta de configuración espacial. Y en el cuarto y último capítulo, "La extensión de la matriz doméstica", se estudia la repercusión que tiene el proyecto de La Maison Suspendue, y especialmente la creación de su espacio individual, tanto en la arquitectura residencial de Paul Nelson como en el resto de sus proyectos. 


\section{Archivos y centros de documentación}

MNAM/CCI G.P- BK :Musée National d'Art Moderne Centre de Création Industrialle Georges Pompidou de París. Bibliothèque Kandinsky

Fonds Paul Nelson.

19 cajas, correspondencia, artículos, referencia a proyectos, contactos y

fotografías. Especialmente en la caja $\mathrm{N}^{\circ} 6$, dedicada a la Maison Suspendue.

Fonds Louis Dalbet, Christian Zervos, Cahiers d'art, Pierre Loeb, Pierre

Chareau, Sonia Delaunay y Alexader CaldeDe estos fondos se ha obtenido artículos, correspondencias y referencias a Colaboraciones. Libros y revistas.

Artículos

MNAM/CCI G.P- R.G :Musée National d'Art Moderne Centre de Création Industrialle Georges Pompidou de París. Reserve Graphique.

Adquisiciones (AM-1994-1) (AM-1998-2) (AM-2008-2) de Archivos correspondientes a La Maison Suspendue. Un total de 103 dibujos, planos y croquis.

A.F.N : Archivos personales de la familia Nelson. Documentación sin clasificar.

Planos y croquis, inéditos de varios proyectos.

Obra plástica de Paul Nelson.

Testimónios radiofónico y visuales.

Documentos oficiales biográficos y notas de prensa.

MoMA: Museum of Modern Art de New York.

Archives.

Boletines de prensa de las exposiciones

Imágenes de la segunda maqueta

Library.

Catálogo exposiciones

M.L :Morgan Library.

Archives Pierre Matisse Gallery

Documentación relativa a las maquetas 
S.G.A: Saint Gobain Archives.

Correspondencia.

F. P.J. M: Fundació Pilar i Joan Miró/ F.J.M.B: Fundació Joán Miró Barcelona / S.M:Successió Miró

Correspondencia y hemeroteca

F.L: Fondation Le Corbusier.

Correspondencia.

A.L.C.U:Avery Library Columbia University.

Drawings \& Archives

Correspondencia con Richard BuckminsterFuller

Ecole Architecture Beaux Arts -Bibliotheque Paris Malaquais.

Datos academicos.

Princeton University

Datos académicos y documentación fotográfica

Archives Meirie de Varengeville.

Registre civil

Acta matrimonio Francine Le Coeur.

Archives Departamentaux a Dieppe. Registre.

Maison Georges Braque.

Biblioteca ETSAM/ Biblioteca COAM/ Biblioteca Museo Nacional de Arte Reina Sofía/ Bibliotca Nacional. 
Paul Nelson y La Maison Suspendue. Creando la Matriz del Hombre 



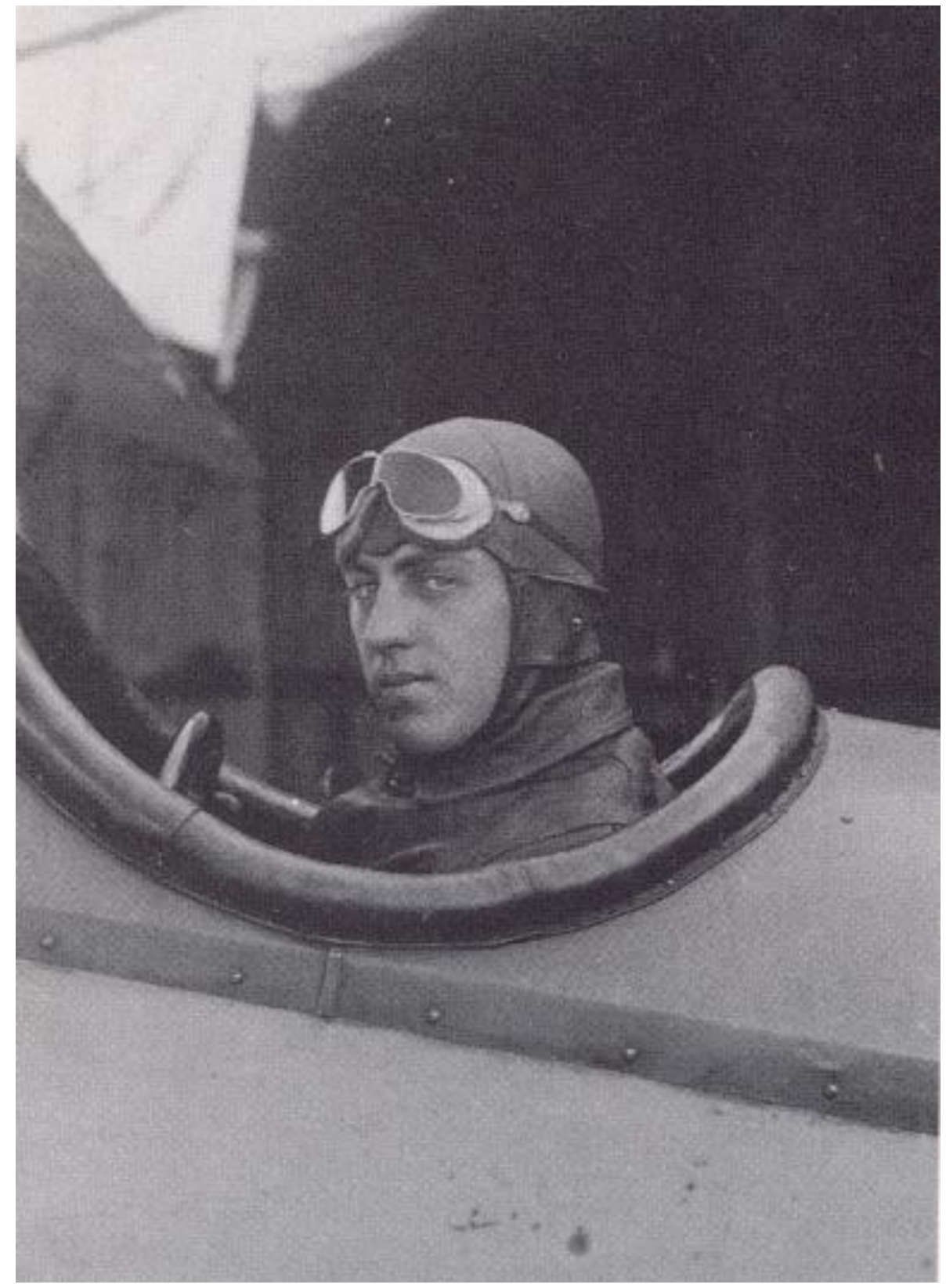

I. 1 Paul Nelson, piloto de La Fayette Escadrille, ca. 1918.

I PAUl NELSON. UN ARQUITECTO AVIADOR 1895-1979. 
El arquitecto Paul Nelson (Chicago, 1895 - Marsella, 1979) fue un intelectual interesado por el arte, que inició sus estudios de arquitectura después de haberse diplomado en literatura. Se formó y desarrolló su carrera profesional fuera de su país natal y viajó entre las dos orillas del Océano Atlántico de manera constante a lo largo de su vida. Participó en las dos Guerras Mundiales junto al bando de los aliados y trabajó para sumar conocimientos con independencia de su lugar de origen. Estos hechos le convirtieron en un eterno extranjero: para los norteamericanos era una persona que vivía en Francia y pasaba sus vacaciones en Estados Unidos y para los franceses era un norteamericano que residía en París. Cuando cruzó el Atlántico por vez primera no trataba de que se le reconociera su nacionalidad, no reivindicaba su origen; lo que deseaba era estar presente donde se estaba decidiendo la nueva concepción internacional del mundo.

Los viajes realizados por trabajo, los desplazamientos provocados por las contiendas y su experiencia como creador de decorados cinematográficos, le descubrieron la sensación de movimiento, y la certeza de que la sociedad de la que él formaba parte estaba en cambio constante. El tiempo era un factor tan importante como los recorridos que determinaban ese tiempo, por lo tanto, incorporó los lugares de tránsito a su concepto espacial. Su necesidad de contribuir a la transformación de la sociedad afectó a su forma de proyectar, ya que cada vez se hizo más flexible. En su filosofía mantenía que la intervención del arquitecto debía resolver el programa mediante una actuación susceptible de ser alterada para seguir cumpliendo con nuevas demandas. Incluso en sus planteamientos docentes utilizó el significado del término internacional para construir una singularidad que residía en la permeabilidad al cambio. Las dos mujeres con las que estuvo casado también contribuyeron a la formación de ese espíritu internacional, pues le ayudaron a ver el mundo desde una perspectiva más amplia y le abrieron las puertas de nuevos campos creativos.

Gran parte de las referencias biográficas utilizadas por los diversos autores que han trabajado sobre la figura de Paul Nelson provienen de Anne Kandelman ${ }^{25}$. Aunque nunca llegó a publicar un documento completo con una recopilación detallada de la totalidad de los proyectos, pues algunos no aparecen recogidos, su texto también ha sido utilizado como referente para realizar la investigación biográfica de esta tesis.

\footnotetext{
${ }^{25}$ Anne Kandelman era historiadora y crítica de arte. Preparó un trabajo de investigación sobre la obra de Paul Nelson, sus notas biográficas fechadas en 1978 han sido el referente para otros autores. Su trabajo fue controlado y corregido por el propio Paul Nelson. Véase : Notes biographiques 1978 (révisée par Anne Kandelman) inédito,1978 MNAM/CCI, Bibliothèque Kandinsky, fonds Nelson.
} 


\section{Educación y formación.}

Paul Daniel Nelson nació en Chicago el 8 de noviembre de 1885 en una familia irlandesa de tradición católica. Sus padres, Nicholas J. Nelson y Katherine M. Murphy, tenían una empresa de decoración. El negocio familiar lo inició su abuelo paterno con una tienda de pintura para paredes, que su padre amplió al sector textil y a los mubles artesanos; el negocio creció e incluso editaron un catálogo de objetos decorativos siguiendo una línea art noveau. En 1901 la compañía "W.P.Nelson.Co" ya tenía una tienda en New York y, durante esta primera década, la empresa recibió encargos de decoración de edificios públicos procedentes de todo Estados Unidos. La familia, que había vivido en el campo, en Wheaton, se trasladó a la ciudad de Chicago en 1915, y su padre se convirtió en una persona influyente. Fue miembro del Building Construction Employers Association the Illinois y del Art Institute of Chicago $^{26}$. Paul Nelson tenía un sentimiento contradictorio con respecto a su familia, a la que definía como "adorable y petrificante a la vez"27. Este sentimiento se manifestó sobre todo en la relación con su padre, ya que su figura le marcó hasta que tuvo más de cuarenta años.

\footnotetext{
${ }^{26}$ Josiah Seymour, Chicago: its historyand his builders, a Century of Marvelous Growth. Chicago: S.J. Clarke Publishing, 1912, pp.379-380.

${ }^{27}$ Anne Kandelman, Notes biographiques 1978 (révisée par Anne Kandelman), op cit.
} 


\subsection{Princeton}

Se educó en el internado católico de Newman School en Hackensack, donde fue compañero de Scott Fitzgerald. En 1912 comenzó a estudiar Literatura en la Universidad de Princeton, donde ambos volvieron a coincidir; colaborando en el montaje de algunas obras de teatro en el Triangle Club, con canciones escritas por Scott Fitzgerald. Durante su estancia en la universidad formó parte de la vida cultural y se inició en otras disciplinas fuera de la literatura como la música y el dibujo. En su expediente académico figuraba su inscripción en el departamento de arte y arqueología. Como también se deduce su interés por la arquitectura, ya que en 1915 se matriculó en un curso de dibujo arquitectónico y el siguiente año lo hizo en un programa de de proyectos de arquitectura. Tras diplomarse en literatura en 1917, su intención era comenzar la carrera de arquitectura en la nueva escuela que se abriría en Princeton, pero el estallido de la Gran Guerra alteró todos los planes ${ }^{28}$. Él decidió alistarse y marcharse a Europa.

Tras su participación en la Gran Guerra, en otoño de 1919 volvió a los Estados Unidos para trabajar en un banco en Wall Street. Después de un breve periodo de tiempo, se ocupó del negocio familiar de la decoración. Y en la primavera de 1920 decidió abandonar su país y la empresa familiar y regresar a Francia para estudiar arquitectura. Aunque en un principio se planteó ir al Massachusetts Institute Technology (M.I.T,) en Norteamérica se consideraba que para llegar a ser un arquitecto de prestigio era necesario estudiar en Beaux-Arts de París. Había que formarse en la tradición académica para ser reconocido, además el origen de la disciplina estaba en Europa y en aquellos momentos las escuelas de arquitectura de Estados Unidos impartían una formación más cercana a la ingeniería que al arte.

Pero había otra cuestión más personal que motivó su decisión: la necesidad de romper con la tradición familiar, con su educación y con el planteamiento de una trayectoria de una vida que le venía impuesta desde su familia. Según Anne Kandelman, Paul Nelson le expresó que tras la guerra se había visto obligado a despojarse de todo lo que había heredado de su educación en Princeton. Se había replanteado algunos conceptos y no sabía con seguridad lo que buscaba, aunque

\footnotetext{
${ }^{28}$ Carta de Sherley W. Morgan, director del Princeton School of Architecture en 1937, donde se especifican datos sobre la relación académica de Paul Nelson con la arquitectura, aparecida el 12 de febrero de 1937 en Princeton Alumni Weekly, Vol 37, No 18. New Jersey : Princeton University Press, 1937, p. 400.
} 


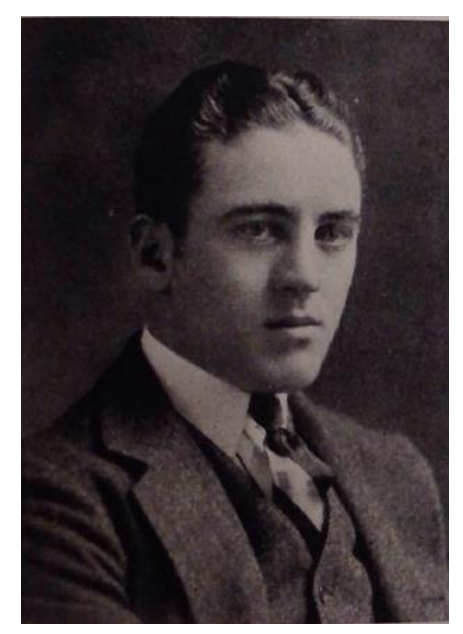

I. 3 Paul Nelson en Princeton. ca 1917.

tenía claro que tras su participación en la contienda su vida no podía seguir siendo igual. "Yo me sublevé contra mi educación de Princeton. No puedes sublevarte contra nada, tienes que hacerlo contra algo; para avanzar tú tienes que "matar al padre" ${ }^{, 29}$.

Tras la Guerra, Estados Unidos experimentó un desarrollo importante debido al impulso de la industrialización y la mecanización, la población rural se desplazó a los núcleos urbanos y las infraestructuras resultaron insuficientes para ofrecer los servicios necesarios a los nuevos habitantes. Para muchas de las personas que habían participado en la contienda, el retorno a su país supuso una gran decepción, se habían marchado voluntarios para "cambiar el mundo" y a su vuelta se encontraron con una involución, con un país más puritano, más provinciano, donde incluso se quemaban libros como el "Ulysses" de James Joyce, por ser moralmente reprobables. Había un culto por el dinero que animaba a saltarse todos los límites. F. Scott Fitzgerald retrata esta situación en "The Great Gatsby" ${ }^{30}$

Este escenario provocó en algunos intelectuales la necesidad de escapar. Se sintieron atraídos Europa y más concretamente por París, que se convirtió en el referente cultural para muchos. En esta ciudad los expatriados norteamericanos formaron una comunidad que vivía al margen de las condiciones morales de la sociedad francesa.

\footnotetext{
${ }^{29}$ Judith Applegate, "Paul Nelson: an interview". Perspecta nº13-14, 1971, p. 76.

${ }^{30}$ Michael Grawe, Expatriate American Authors in Paris. Disillusionment with the American Lifestyle as Reflected in Selected Works of Ernest Hemingwayand Scott Fitzgerald. Munich: Grin Verlag, 2008.
} 
Encontraron una infraestructura cultural atractiva y un clima de internacionalización, pues se publicaban revistas con artículos en inglés y los artistas podían encontrar marchantes para sus obras. Todo esto, unido a unas condiciones económicas favorables para los americanos, provocó que también muchos estudiantes se decidieran por Francia y fue en este contexto en el que Paul Nelson tomó la decisión de volver. Esta experiencia provocó en él, como en otros expatriados, una manera distinta de ver Norteamérica y de aprender a descubrir la identidad de su país, un lugar sin historia, desde el exterior.

\section{2 École de Beaux-Arts}

En otoño de 1920, Nelson comenzó a estudiar en la École de Beaux-Arts, con veinticinco años, sin hablar francés y, sin una formación sólida en dibujo, inició su aprendizaje teórico. El sistema pedagógico de Beaux-Arts establecía un proceso de admisión donde el alumno se enfrentaba al estudio de materias teóricas y a la copia dibujada de modelos clásicos. Superado este periodo inicial, se pasaba a unas clases en distintos talleres con arquitectos de prestigio, donde el alumno estaba en contacto directo con el trabajo profesional. ${ }^{31}$

Tras ese periodo inicial, ingresó en el taller de Emmanuel Pontrémoli ${ }^{32}$, que era el arquitecto conservador del Museo Nacional de Historia Natural, una persona muy interesada por la arqueología. En su taller se seguían los dictados de Beaux - Arts, que recomendaban el aprendizaje a través de la cultura clásica. También se iniciaba a los alumnos en un conocimiento básico de la técnicas constructivas. Pero sobre todo su enseñanza se basaba en el aprendizaje de los procesos compositivos, ya que para Emmanuel Pontrémoli, la composición era uno de los pilares de la arquitectura.

Componer, es disponer las diferentes partes de un edificio cualquiera de tal manera que la interdependencia de cada uno de los elementos crea un cuerpo organizado y donde cada uno de ellos está en su justo lugar ---- nada puede ser

\footnotetext{
${ }^{31}$ José Manuel Prieto, Aprendiendo a ser Arquitectos, creación y desarrollo de la escuela de arquitectura de Madrid 1844-1914.Madrid: CSIC, 2004, pp.511-512.

32 Emmanuel Pontrémoli (1865-1956) alumno de Beaux Arts de Paris en 1883, Gran Premio de Roma en 1890, Gran Premio de Arquitectura en la Exposición Universal de París 1900, profesor y posteriormente director de la École des Beaux-Arts entre 1932 y 1937.
} 
modificado, cambiado, sin arruinar completamente el equilibrio de la composición ${ }^{33}$.

Según el criterio de Emmanuel Pontrémoli, el objetivo de la composición en el conjunto del edificio era conseguir que las partes encajasen de manera armónica y sin perder su identidad. Las partes interiores debían tener sus propias formas características y jugar con el contraste, consiguiendo un equilibrio de llenos y vacíos, sin perjuicio de que existiera una gran fachada única. Emmanuel Pontrémoli consideraba que el usuario descubría las diferentes formas de las estancias, a través de un recorrido continuo por la planta, de esta manera el visitante apreciaba los juegos volumétricos del edificio. Esta concepción de la composición espacial incidió en el trabajo de Paul Nelson, ya que la explicación que ofreció sobre La Maison Suspendue recogía esta misma idea, de relación entre las partes y de continuidad espacial.

Emmanuel Pontrémoli era una persona culta, con una gran biblioteca donde predominaban los tratados antiguos, como los de Vitruvio, pero donde no faltaban las nuevas publicaciones de revistas como L'Architecture d'aujourd'hui y La Construction moderne. Tenía un espíritu abierto, reconocía la racionalidad y la capacidad analítica de su "alumno americano" para resolver cada uno de los problemas planteados, pero no entendía que la imagen del resultado de los proyectos estuviera influenciada por Le Corbusier. Se preguntaba por qué Paul Nelson, que había ido a París para formarse en el espíritu francés, terminaba copiando a un "suizo" que no tenía título de arquitecto. Por el contrario, en esos momentos, el interés de Paul Nelson ya no estaba en imbuirse de la tradición de Beaux-Arts para ser después su embajador en Estados Unidos, sino en ser receptor del nuevo movimiento que se estaba produciendo en la arquitectura europea.

Su falta de destreza con el dibujo le llevó a tomar clases de apoyó en la academia Ranson, ${ }^{34}$ donde tuvo como profesor a Roger Bissière, amigo del pintor Georges Braque. La enseñanza en Ranson estaba marcada por la referencia a las tendencias pictóricas de las vanguardias, fundamentalmente al cubismo. Esta formación le permitió entender el espacio de una manera más libre, diferente a las soluciones restrictivas de Beaux-Arts, donde todas las discusiones giraban en torno a la

\footnotetext{
${ }^{33}$ Jacques Lucan, Composition, non-composition. Architecture et théories, XIXe-XXe siècles. Lausanne : Presses polytechniques et universitaries normandes, 2009, pp. 24-25.

${ }^{34}$ Joseph Abram, “ Paul Nelson: La Maison Suspendue”. AMC nº15, marzo 1987, pp. 81-95.
} 
idoneidad del estilo clásico escogido y al uso adecuado de los elementos decorativos. Los contactos con las nuevas corrientes pictóricas influyeron en su deseo de trabajar en una dirección contraria al lenguaje clásico y revelarse contra el canon de la institución. Intentaba buscar nuevas soluciones formales y constructivas, y esto le hacía mirar a lo publicado sobre Le Corbusier, cuyo trabajo comenzaba a ser conocido, especialmente entre los estudiantes, gracias a la revista "L'Esprit Noveau".

En el año 1923, Paul Nelson abandonó el taller de Emmanuel Pontrémolli e intentó trabajar con Le Corbusier pero fue rechazado. Cuando habló con Le Corbusier le manifestó su deseo de colaborar en el estudio para formarse en la técnica del hormigón armado, pero Le Corbusier le sugirió que se dirigiera al estudio de Auguste Perret, ya que consideraba que era la persona más docta en el tema y además su taller era el lugar donde él mismo había aprendido la técnica.

Auguste Perret no estaba diplomado en arquitectura, ya que había abandonado Beaux-Arts para incorporarse a la empresa familiar de construcción junto a su hermano. Gracias a su trabajo, Perret tenía un contacto directo con la obra y con la parte más "profesional" de la arquitectura, de modo que para algunos arquitectos coetáneos simplemente era un excelente contratista. Tenía un gran interés por los nuevos materiales constructivos y especialmente por la técnica del hormigón armado y su uso como elemento estructural.

\subsection{El atelier de Palais de Bois}

A principios de los años veinte, en la École des Beaux-Arts se produjeron fricciones entre los profesores encargados de los talleres debido a las diferencias de criterio sobre la docencia académica. Se trataba de conseguir un sistema de aprendizaje alternativo a los grupos ya establecidos, los solicitantes del cambio demandaban unos talleres externos a la escuela, más libres, donde los alumnos se formasen con un maestro elegido por ellos. Aunque se mantenía que todos los alumnos tenían que superar la aprobación de un jurado para obtener su diploma final de Beaux-Arts. Uno de los nuevos talleres que surgieron de ese contexto fue el dirigido por Auguste Perret, que fue denominado el atelier de Palais de Bois. 


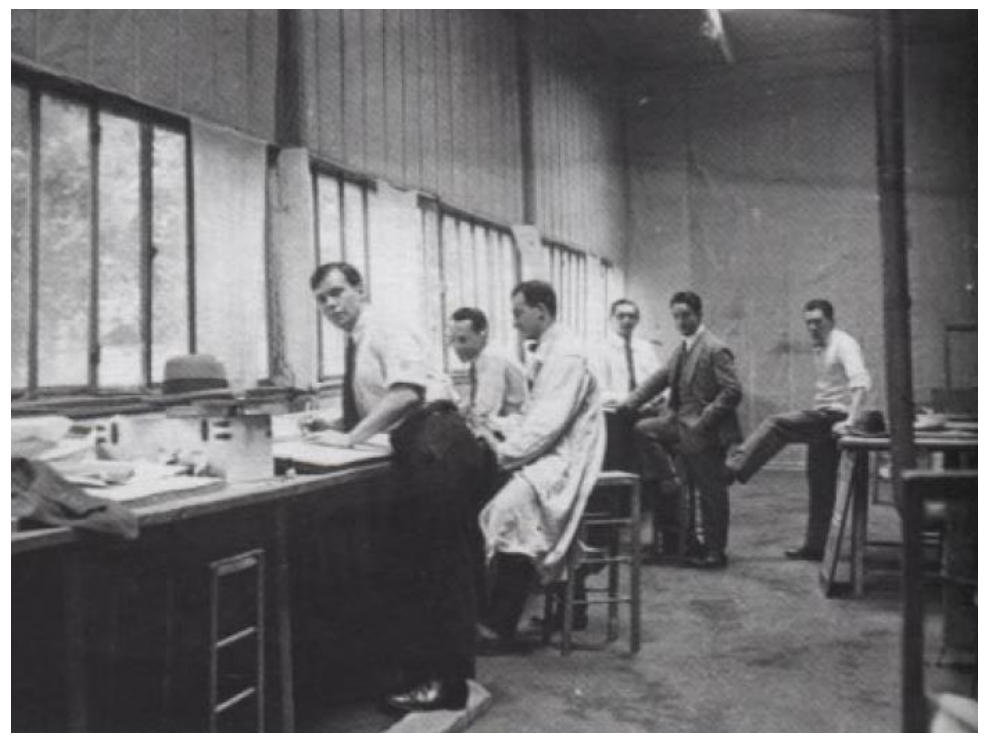

I. 4 Interior del taller de Auguste Perret en el Palais de Bois ca.1924.

El edificio habilitado para taller era un antiguo pabellón desmontable, que había sido construido por Auguste Perret para usos expositivos. Era un espacio rectangular con una luz libre de $5 \mathrm{~m}$, tenía unos acabados sin revestimientos, realizados con paneles prefabricados de madera encajados en la estructura vista, sus ventanas estaban orientadas hacia al bosque de Bolonia. Un ejemplo de austeridad decorativa y de manifestación constructiva, en la línea argumental del profesor. ( I. 4).

En 1924 Paul Nelson ingresó en el Palais de Bois y allí coincidió con un grupo de estudiantes extranjeros, Berthold Lubetkin de Rusia, Oscar Nitzchké de Alemania, y Ërno Goldfinger de Hungría, que aportaban al estudio un ambiente internacional. El taller suponía para los alumnos la oportunidad de proseguir con su formación en otra dirección distinta a la que hasta ese momento había marcado la enseñanza oficial. Aunque para alumnos como Oscar Nitzchké la ruptura con lo académico no fue tan profunda como lo esperado, ya que Auguste Perret seguía recomendando el lenguaje clásico aunque introdujera otras variantes constructivas. En torno al maestro se creó un grupo que había tomado la decisión de hacerlo su director, ellos conocían su obra a través de las publicaciones como L'Architecture Vivante y sabían como trabajaba. Esta generación de estudiantes, denominada L'Ecole du Classicisme Structural ${ }^{35}$, aspiraba a encontrar la innovación fuera del ámbito docente tradicional, al cual consideraban incapaz de generar un debate sobre la nueva arquitectura. Paul Nelson

${ }^{35}$ Joseph Abram, Perret et L'Ecole du Clasiccisme Structurel (1910-1960), Tomo 1, Nancy : École d'Architecture de Nancy- S.R.A, 1985. 
al describir lo que significaba este taller escribió: “... La lucha de un equipo de alumnos que habían abandonado sus talleres académicos de Beaux-Arts revueltos contra la imagen incoherente que dominaba la enseñanza". ${ }^{36}$

El atelier, aparte del espacio de trabajo de las mesas contaba con una biblioteca en la cual los alumnos tenían tanto los tratados clásicos de arquitectura y de construcción, asi como una colección de revistas internacionales, con dibujos de Frank Lloyd Wright y copias de las obras de Le Corbusier y de Walter Gropius. A esta información del panorama internacional de la arquitectura, había que añadirle el espíritu transveral de las visitas y las charlas de algunos pintores como Georges Braque o ingenieros como Eugène Freyssinet, algo impensable en Beaux-Arts.

El vínculo de Auguste Perret con la empresa de construcción familiar también impregnó su manera de enseñar la arquitectura. Sus alumnos aprendían tanto de la dirección de una obra como del trabajo sobre plano, la construcción del edifico era una parte fundamental, era la meta. Rechazaba cualquier proyecto de sus alumnos que no pudiera ser ejecutado, aunque estuviera hábilmente dibujado. Solo la belleza de la imagen no podía condicionar el juicio sobre la valía de proyecto. Exigía a sus alumnos precisión en los detalles dibujados, una exactitud que permitiera ejecutarlos para construir el edificio. Esta manera de enseñar a crear el edificio partiendo de la unión de las partes más pequeñas, era herencia de su formación como alumno de Beaux-Arts, pero había una novedad, mientras en la escuela el aprendizaje se suponía a través de la composición formal de los detalles para encajar en el conjunto, Perret instruía a sus alumnos en el valor del detalle constructivo, considerándolo como elemento principal para edificar el conjunto.

La enseñanza principal que sus alumnos debían asimilar era la importancia de utilizar el orden estructural como herramienta para definir la arquitectura. Los alumnos aprendían a buscar el equilibrio entre la estructura y el espacio arquitectónico. Para resolver la estructura les proponía la utilización de hormigón armado, aunque no les explicaba la técnica directamente, sino que les transmitía las posibilidades que tenía el material. Para Aguste Perret, el espacio debía resolverse con un lenguaje clásico, organizado con esquemas simétricos de geometrías regulares. Tenía unos principios doctrinales que sus alumnos debían adoptar en sus

\footnotetext{
${ }^{36}$ Paul Nelson, "Auguste Perret, 1'Enseignant. Premier atelier de 1'Ecole des Beaux-Arts", Architectes 1974. Citado Joseph de Abram, Perret et L'Ecole du Clasiccisme Structurel (1910-1960), p.158.
} 
proyectos, debían optar por la ventana en altura, la presencia de la cornisa y la resistencia de los puntos de apoyo. ${ }^{37}$

La identificación que establecía Auguste Perret de la construcción con la verdad, la convertía en la moral de la arquitectura. El edificio no existía si no se podía construir, todos los materiales utilizados se debían a su función constructiva y la estructura se manifestaba claramente, quedando patente incluso en la fachada. Pero no todos sus alumnos aceptaron seguir esa visión moralizante de la arquitectura desde el punto de vista constructivo y estructural, algunos como Paul Nelson optaron por ejecutar estructuras ligeras en acero que desafiaban la gravedad.

Durante su estancia en el taller de Auguste Perret, trabajó en cinco proyectos: un campo de tiro, un embalse, un palacio de exposiciones, una sala de fiestas y un centro homeopático ${ }^{38}$. Este aprendizaje que asimiló a través de los dos últimos proyectos tuvo su repercusión en La Maison Suspendue. La sala de fiestas fue un proyecto desarrollado en 1926 ( I. 5 ), se trataba de un edificio de gran escala donde utilizaba elementos de la "doctrina de Aguste Perret", como la estructura vista y la cornisa, que le otorgaban un aspecto de templo clásico. La retícula estructural vista, la cubierta plana con el remate de la cornisa o el estilóbato de la base, forman parte del lenguaje del clasicismo estructural, y la enseñanza de Perret no trataba de convertirse en la imposición de una imagen, sino una filosofía y una manera de entender la arquitectura que cada alumno interpretaba. En este sentido, la principal novedad del ejercicio con respecto de las lecciones del maestro, estaba en la separación total entre el cerramiento y la estructura; dejando exentos los pilares del perímetro y retranqueando el volumen construido, creando a su alrededor un peristilo.

\footnotetext{
${ }^{37}$ Joseph Abram, Perret et L'Ecole du Clasiccisme Structurel (1910-1960), Tomo 1, Nancy : École d'Architecture de Nancy- S.R.A, 1985 Joseph Abram, Perret et L'Ecole du Clasiccisme Structurel (1910-1960), Tomo 2, Nancy : École d'Architecture de Nancy- S.R.A, 1985. p.65.

38 Joseph Abram, "Paul Nelson: le crible de la raison. 1920-1939: Peinture/ Architecture. Projets experimentaux", Bulletin d'Informations Architecturales (IFA) nº 130 abril 1989.
} 


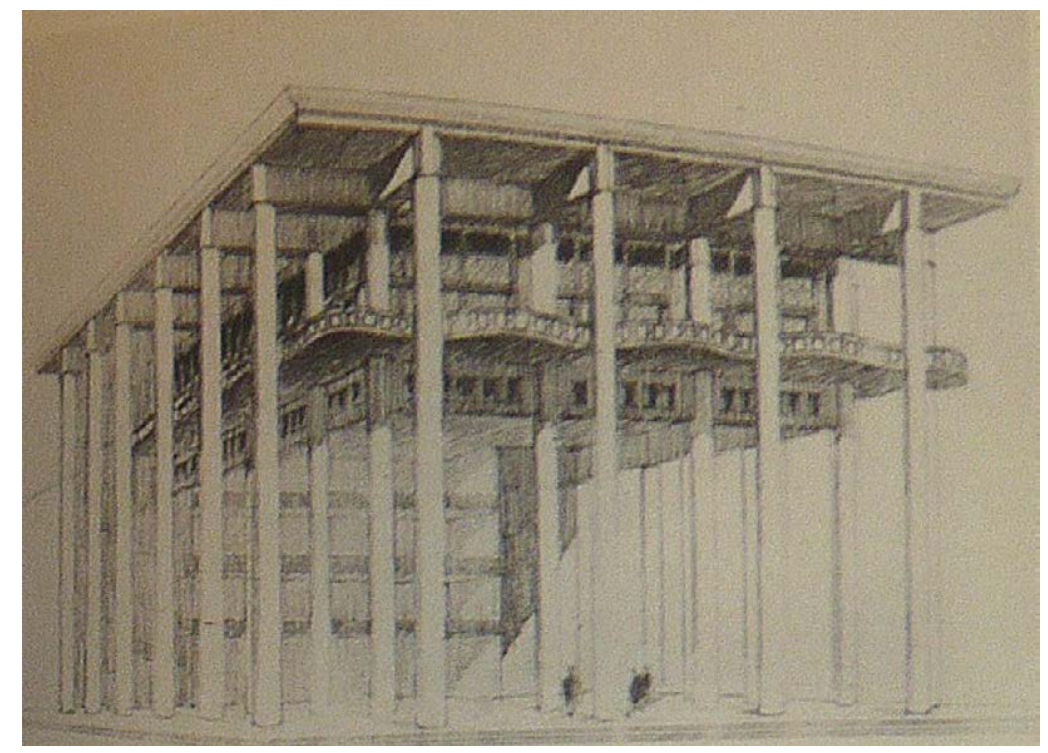

I. 5 Sala de fiestas, perspectiva. Paul Nelson, ca. 1926.

A ese desplazamiento de la línea de fachada hacia el interior le acompañaban otras decisiones como eran: la eliminación de los pilares en esquina, la aparición de un balcón perimetral en las últimas plantas y un espacio en el acceso con una altura libre de cuatro alturas. Estos elementos, a demás de suponer una exploración espacial personal a partir de las premisas de Auguste Perret, se materializaron diez años más tarde en el proyecto de La Maison Suspendue. Tanto la gran cubierta plana con las jácenas vistas de la sala de fiestas, como la concentración de la estructura en cuatro puntos de apoyo y la suspensión de planta superior de la cubierta fueron revisados y reutilizados. Por lo tanto este proyecto de la sala de fiestas sirvió a Paul Nelson de aprendizaje espacial y estructural.

El último proyecto realizado en el atelier del Palais de Bois fue un centro homeopático (I. 6). Con este trabajo Paul Nelson obtuvo su diploma de arquitecto en Beaux-Arts. El ejercicio era una propuesta de intervención sobre una manzana de entorno urbano. Proyectó un complejo médico formado por cuatro edificios exentos situados en los extremos de dos ejes ortogonales. Los espacios intermedios entre los edificios estaban resueltos con jardines y el conjunto estaba rodeado también por límites vegetales. Además de resolver las circulaciones peatonales dentro del recinto también se proyectaban las zonas de aparcamiento y las conexiones con las vías urbanas. Cada uno de los cuatro edificios mantenía su identidad dentro del conjunto ya que tenían diferentes escalas, sintaxis constructivas, volumetrías y también estaban dedicados a funciones distintas. 


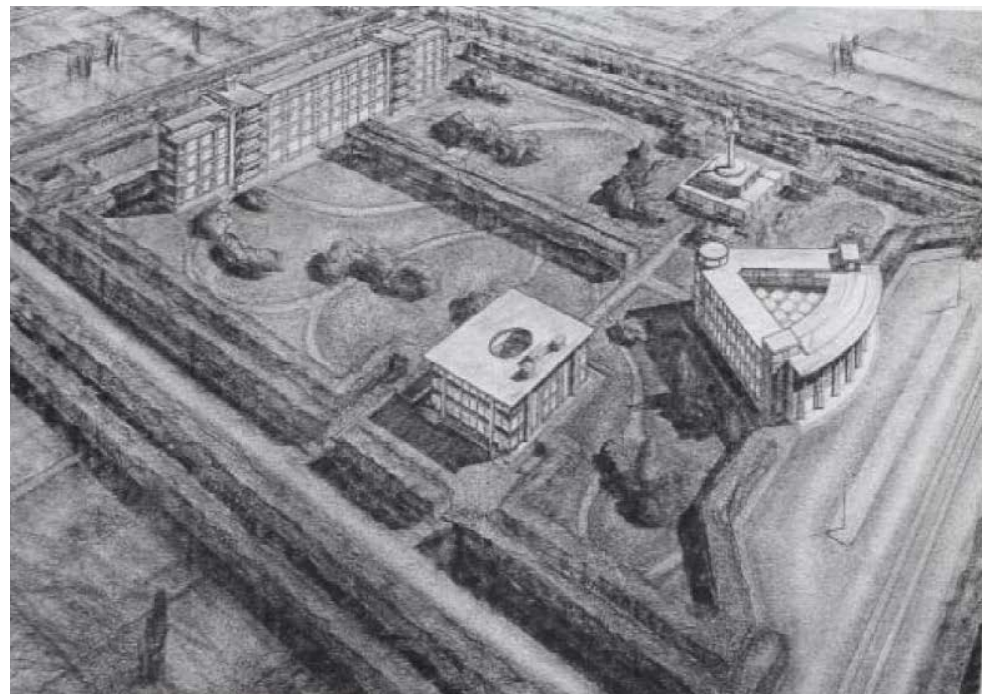

I. 6 Centro homeopático, perspectiva. Paul Nelson, ca. 1927

El objetivo de este proyecto era obtener el diploma, por lo tanto había que cumplir con los criterios marcados por la Escuela, se tenía que trabajar tanto el desarrollo del edifico como en su entorno, y este era un tema que no había sido tratado en otros proyectos resueltos y corregidos por Auguste Perret. En el ejercicio no debían manifestarse las referencias al lenguaje del maestro, si existían, estas no debían marcar la esencia del proyecto, ya que esto podía condicionar a un jurado adverso. El entorno del edificio había sido un elemento importante en los trabajos finales de los alumnos de Beaux-Arts que tradicionalmente se resolvía con un lenguaje romántico, con más presencia, incluso, que el propio proyecto. Paul Nelson proyectó un gran espacio ajardinado, alejado de las soluciones de referencias clásicas. El jardín no formaba parte del cuerpo doctrinal de Auguste Perret por lo tanto para buscar la referencias de un espacio verde acorde con su arquitectura tuvo que mirar fuera y la dirección fue Le Corbusier y sus propuestas urbanas de los años veinte.

Las referencias a Le Corbusier también aparecieron en las diferentes soluciones adoptadas para los propios edificios. Había volúmenes que se podían entender más próximos a la arquitectura de Le Corbusier y otros más cercanos al lenguaje de Auguste Perret. Así la pieza destinada a uso hospitalario estaba influida por Le Corbusier, y en ella se podían distinguir, gracias al uso de huecos horizontales, los volúmenes destinados a comunicaciones de los cuerpos de estancia, mientras el edificio que se encontraba enfrentado al hospital era un volumen de planta triangular, proyectado siguiendo las directrices de Auguste Perret. Era un edificio 
representativo, con una entrada porticada rematada por una gran cornisa. En el eje ortogonal al definido anteriormente, había un prisma con una estructura exterior vista que estaba rematado por una cubierta plana con un vaciado circular central en un lado, y un volumen escalonado rematado por una escultura en el extremo opuesto.

La misma volumetría en cuña del edifico de la entrada, fue utilizado posteriormente por Auguste Perret para su Musée des Travaux Publics construido entre 1936 y 1948. Los dos edificios tenían la misma planta triangular, en la que dos de sus lados convergen en una circunferencia y el tercero era un arco. Los dos proyectos liberaban un espacio triangular central y estaban resueltos con el mismo lenguaje formal y estructural. La diferencia fundamental estaba en la disposición opuesta de las entradas, ya que Paul Nelson la situaba en el espacio porticado del lado curvo y Auguste Perret en la rotonda que articulaba las dos alas del triángulo. A pesar de las diferencias de programa y de la distribución interna, esta composición triangular fue compartida por los dos. Auguste Perret también experimentó con ella en otros proyectos como en el apartamento de la parcela en esquina de la Rue Raynouard, en París (1929- 1932).

Hubo otros aspectos secundarios, pero que también formaron parte del aprendizaje en el estudio de Auguste Perret y que eran los relacionados con la representación, la utilización de la perspectiva constructiva seccionada como herramienta de dibujo, frente al clásico planta, elevación y sección de Beaux-Arts. Esto representaba una manera nueva de entender el espacio en sus tres dimensiones, pero sobre todo se trataba de mostrar que el edificio era construible gracias a una lógica estructural.

El proyecto del Centro Homeopático representaba un momento importante en el aprendizaje de Paul Nelson, en este trabajo quedaron patentes sus primeras influencias, Auguste Perret y Le Corbusier, y su interés por la arquitectura hospitalaria, uno de los temas que fueron más decisivos de su carrera. El ejercicio reflejaba una posición intermedia entre la modernidad y el clasicismo estructural, donde convivían la gran escala de las columnas y cornisas de espacio porticado con la ventana horizontal de la escala de habitación del hospital y donde un prisma perfecto con un vacío cilíndrico se contraponía a un edificio escultórico escalonado. En este ejercicio Paul Nelson también ensayó con el espacio intermedio utilizando el manto vegetal para resolver la conexión entre las piezas y propuso una continuidad arbórea en el perímetro para crear la idea de conjunto unitario. 
I. 7 Diploma de arquitecto de Paul Nelson, 8 de noviembre de 1927.

Esta manera de componer a partir de las partes y su integración en el conjunto fue una constante en la obra de Paul Nelson. El aprendizaje de este proceso derivó de su época de formación, primero de su paso por Beaux-Arts, con la composición a partir de los detalles y posteriormente su estancia en el atelier de Palais de Bois y su concepción del edificio a partir de los detalles constructivos. En su trabajo de fin de carrera, el conjunto se generaba a partir de cuatro edificios inconexos. Este proceso de creación evolucionó hasta el proyecto de La Maison Suspendue, donde trabajó con la compatibilidad entre las partes y el todo, entre la unidad particular y el conjunto.

Paul Nelson terminó sus estudios y obtuvo su diploma el 8 noviembre de 1927 (I. 7). Fue el primer alumno formado en el taller de Auguste Perret que se diplomó en Beaux-Arts. Su maestro no tenía ninguna influencia en el jurado y con frecuencia sus alumnos resultaban excluidos de los premios. Pero aún así, el jurado le concedió la máxima calificación e incluso recibió una mención, aunque también se consideró que su ejercicio era un proyecto más propio de ingenieros. 


\section{Los viajes. El cine y la guerra.}

La experiencia del viaje ha sido trascendental para muchos arquitectos, su descubrimiento de otra realidad sumado a su biografía les proporcionaba su visión singular del mundo. Los viajes se realizaban con diversos objetivos, pero en todos se compartía el sentimiento de búsqueda. Unos tenían fecha y lugar de retorno, otros no, y en otros casos eran constantes. Hubo arquitectos que viajaron con su cuaderno de notas para contar sus impresiones a la vuelta, como los del XIX o Le Corbusier; otros viajaron para transmitir su conocimiento, como los maestros del Movimiento Moderno que se trasladaron a los Estados Unidos en los años treinta sin fecha de vuelta. Y había otros que viajaban de manera constante, trayendo y llevando novedades entre los puntos de origen y el destino y viceversa. Es en este grupo de arquitectos viajeros donde había que ubicar a Paul Nelson, sobre todo en el periodo de entreguerras que era cuando los desplazamientos fueron más habituales. Esta posición en continuo movimiento le permitió ser observador directo y embajador de lo que sucedía en el panorama de la arquitectura internacional

Desde su primer viaje en 1917 para participar en La Gran Guerra en Francia hasta su última estancia en los años sesenta como profesor en los Estados Unidos, la vida de Paul Nelson estuvo jalonada por continuas idas y venidas entre los dos lados del Atlántico. Se han analizado los viajes realizados entre (1927-1940), la primera fecha es la de su vuelta a Norteamérica tras obtener el diploma como arquitecto y la segunda es el año en el que abandona Francia huyendo de la Segunda Guerra Mundial. Los viajes se han agrupado bajo tres epígrafes correspondientes a las causas que los desencadenan, así tenemos viajes realizados por razones de encargos, el viaje a Hollywood para ser director artístico y los dos viajes provocados como consecuencia de las dos guerras mundiales.

Durante este periodo de entreguerras comprobó como el ritmo de la evolución tecnológica de Estados Unidos superaba al de Europa. Y mientras en una orilla del Atlático se trabajaba por elevar la altura de los edificios, en la otra, en ausencia de grandes proyectos y con la amenaza de la guerra, se mantenían las discusiones arquitectónicas sobre la modernidad. Pero en los dos lados se compartía la idea de que era necesario un cambio respecto de la década anterior. 


\subsection{Viajes por encargo.}

De este periodo, se han seleccionado tres viajes que por su carácter representativo ayudan a comprender en qué medida estos desplazamientos incidieron en algunos aspectos de su investigación sobre la vivienda y el espacio. Dos de ellos tuvieron como destino Estados Unidos y el otro Egipto. Todos estos viajes tenían en común su relación con encargos que nunca se materializaron, de tal manera que Paul Nelson nunca construyó en Norteamérica un proyecto para ser habitado.

Otoño de 1927- verano de 1928.

A los pocos meses de haber obtenido su diploma en París, Paul Nelson realizó su primer viaje como arquitecto a Estados Unidos. Se trasladó a Chicago con el objetivo de instalarse allí. Un arquitecto procedente de Beaux-Arts era bien recibido Norteamérica, se le suponía un prestigio para abordar los grandes edificios. Además, su padre tenía contacto con los principales arquitectos de la ciudad gracias a su empresa de decoración. También su amigo, el arquitecto John A. Holabird ${ }^{39}$, le había explicado cómo estaba el mercado de la arquitectura americana, y la suma de todos estos factores le animó a tomar la decisión del viaje. Permaneció en Chicago diez meses en los que finalmente solo realizó la reforma de un apartamento y el anteproyecto de un garaje en altura ${ }^{40}$. Deseaba mostrar lo que había aprendido sobre la nueva arquitectura moderna europea, pero en su ciudad se esperaba que realizase proyectos en la línea Beaux-Arts, igual que se estaba construyendo en Nueva York, para levantar el país desde un lenguaje estético importado.

Durante su estancia en Chicago publicó el artículo Modern Architecture is Based on Current Life $^{41}$. En este texto identificaba la arquitectura moderna con el funcionalismo y consideraba que el progreso de esta arquitectura, surgía de la producción estandarizada a partir de la selección correcta del modelo. Para ilustrar esta nueva arquitectura que se estaba proyectando en Europa, utilizó una imagen del Palacio de la Sociedad de Naciones en Ginebra de Le Corbusier y P.Jeanneret

\footnotetext{
${ }^{39}$ John A. Holabird, ( 1886-1945) fue un importante arquitecto nacido en Chicago, que como Paul Nelson había estudiado en Beaux-Arts en París, hijo del también arquitecto William Holabird (Holabird \& Root) quien realizó varios edificios Art Deco como el Chicago Daily News de 1929 o el Chicago Board of Trade de 1930.

40 John Barney, "Paul Nelson'17, Architect". Princeton Alumni Weekly, Vol XXXVII n¹6, enero 1937, pp.351-352.

${ }^{41}$ Paul Nelson, "Modern Architecture is Based on Curret Life", Chicago Evening Post. Magazine of the art world, 17 de abril de 1928, p.3.
} 
En el artículo también reivindicaba el papel que debía desarrollar Estados Unidos para crear su propio arte y su propia modernidad, con independencia de la tutela histórica de Europa.

Aunque no ejecutó ningún proyecto, durante este viaje realizó dos contactos que fueron muy importantes en su carrera; uno con la actriz Gloria Swanson y otro con Richard Buckminster Fuller. La actriz le introdujo en el mundo del cine, esta experiencia le permitió profundizar en la relación espacio-tiempo dentro de la arquitectura. Y su relación con Fuller, en esos inicios de su carrera, le proporcionó el acercamiento a los sistemas constructivos de la estandarización y la industrialización. Estos contactos se formalizaron en dos contratos en los que Paul Nelson debía convertirse en embajador de la arquitectura. Desde el cine se demandaba su conocimiento de la arquitectura moderna europea para representarla en Norteamérica y Fuller necesitaba a alguien para difundir sus ideas en Europa y pensó que Paul Nelson era la persona adecuada.

El resto de los viajes realizados a Estados Unidos durante esta primera mitad de los años treinta, con excepción de su paso por Hollywood, fueron estancias breves. La mayor parte del año estaba en París, donde en 1928 abrió su estudio en el Boulevard Blanqui N ${ }^{\circ}$ 98. En 1932 ganó el concurso para la Ciudad Hospitalaria de Lille, con un programa de organización a gran escala de inspiración americana, que agrupaba la facultad de medicina, el hospital y el centro de consultas externas en un mismo recinto $^{42}$.

Tras proyectar 1933 un consultorio médico en París, con una estructura de pilotis, viajó a Norteamérica y a su vuelta escribió un artículo donde proclamaba la muerte de la arquitectura moderna representada por Auguste Perret y Le Corbusier. Y el nacimiento de una nueva arquitectura que se estaba desarrollando en América: la arquitectura tecnológica ${ }^{43}$.

A partir de entonces, su arquitectura cambió y no volvió a utilizar estructura de hormigón hasta sus proyectos de posguerra en los años cincuenta. El uso del acero le permitía construir una estructura exterior vista y ligera, que se alejaba del carácter

\footnotetext{
${ }^{42}$ Christian Zervos, “«Introducción», Cité Hospitalière de Lille. Paul Nelson”, Cahiers d'Art 1933, p. XI-XV.

${ }^{43}$ Paul Nelson, "La Maison de la rue Saint Guillaume", L'Arquitecture d'aujourd'hui nº, noviembre- diciembre 1933, p.9.
} 


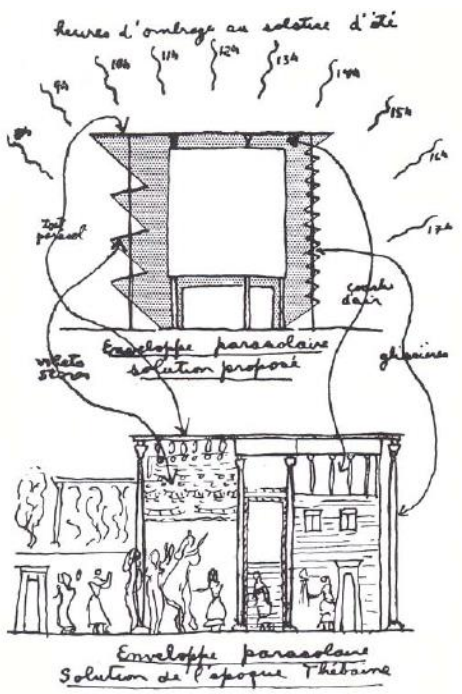

I. 8 Esquema de sección de templo egipcio y de su trasposición al hospital del Canal de Suez. Paul Nelson, $c a .1934$.

monumental marcado por la estructura de las obras de Auguste Perret y que libera el cerramiento del tratamiento plástico de los huecos que utilizaba Le Corbusier. Esta manera de entender los sistemas constructivos le llevaron a convertir sus fachadas en pieles con una gran autonomía, donde cada partición podía tener sus propias cualidades, con el objetivo de diferenciar los espacios interiores.

Invierno de 1934-1935.

Paul Nelson viajó a Egipto para visitar el lugar donde debía construir un nuevo hospital para la Compañía del Canal de Suez. Allí comprobó como el clima incidía en la morfología de la arquitectura doméstica vernácula y descubrió el carácter funcional de la cornisa. Entendió por qué la proporción del vuelo de la cornisa sobre la fachada, a parte de ser un pieza con lenguaje simbólico, servía de protección frente al sol y al polvo del desierto (I. 8). La revisión de este elemento le llevó a adoptar para el hospital que proyectaba una sobrecubierta ligera, apoyada en una estructura externa al prisma del edificio, idea que posteriormente retomó en la cubierta del proyecto de La Maison Suspendue. En este viaje también quedó impresionado por las pinturas en el interior de las tumbas del Valle de los Reyes. Y, cuando en 1937 explicó la sensación que le producían las pinturas murales de Fernand Léger, recordó que era similar al efecto de irradiación espacial que había tenido en las tumbas egipcias ${ }^{44}$.

\footnotetext{
${ }^{44}$ Paul Nelson, "Peinture spatiale et architecturale. Á propos des dernières oeuvres de Léger", Cahiers d'Arts, nº1-3, junio 1937, p. 86.
} 
Otoño 1936- invierno de 1937.

A principios del verano de 1936 recibió un encargo de la Columbia Broadcasting System (C.B.S) para realizar su nueva sede en Park Avenue en Nueva York. Antes de trasladarse a la ciudad, la compañía le sugirió visitar las nuevas estaciones de radio que se habían construido en Europa y ese verano viajó a Londres, Hilversum y Berlín. Este recorrido también le permitió ser testigo de la nueva arquitectura desarrollada en los diferentes países. En otoño llegó a Nueva York para desarrollar el encargo, pero dada su situación profesional de no habilitado en Estados Unidos, se vio obligado a buscar un socio arquitecto registrado legalmente en la ciudad. Y fue de esta manera como entró en contacto con los estudios americanos, el equipo que más le interesó fue el formado por Shereve, Lamb \& Harmon, autores del Empire State Building.

Paul Nelson, junto a su colaborador Oscar Nitzchké ${ }^{45}$, proyectaba realizar su primera construcción en altura en Norteamérica, por lo tanto los mejores socios para este encargo eran los autores del edifico más alto del mundo, el Empire State Building. Las bases del contrato estaban llenas de requisitos ambiciosos: el edificio debía tener la estructura más alta del mundo, debía ser el primero de Manhattan construido con una estructura de acero soldada, el más ligero del mundo, el primero que permitiese la flexibilidad funcional y el que dispusiera de plazas de aparcamiento para todos sus ocupantes ${ }^{46}$.

Estos objetivos estaban relacionados con el desarrollo de la técnica americana de la construcción en altura y suponían un cambio respecto de los postulados funcionalistas que defendió, por escrito, en su primer viaje. Si antes proponía un modelo ajustado a un funcionamiento perfecto del programa, en este momento defendía la flexibilidad funcional. Lo que no varió fue su interés por el sistema estructural de los edificios, abandonó la herencia del hormigón armado y comenzó a proyectar las estructuras con acero; siguiendo el modelo en el que se estaban levantando los grandes edificios de Estados Unidos en esos momentos. También su

\footnotetext{
${ }^{45}$ Oscar Nitzchké, (1900-1991) fue un arquitecto alemán que se formó en Beaux-Arts y fue compañero de Paul Nelson en el estudio de Auguste Perret y también trabajó para Le Corbusier. En 1938 se marchó a Estados Unidos donde desarrolló su carrera profesional, fue profesor en Yale y trabajó en la oficina de Harrison \& Abramowitz, donde colaboró en el proyectó el edifico de las Naciones Unidas en Nueva York.

${ }^{46}$ Notas referentes al contrato de Paul Nelson para el edifico de la Columbia Broadcasting System. Anónimo, texto mecan, 4 de Sep 1936, MNAM/CCI, Bibliothèque Kandinsky, fonds Nelson.
} 
socio y colaborador Oscar Nitzchké, había utilizado estructura metálica en su proyecto de 1935 de La Maison de la Publicité.

El proyecto no se construyó, la compañía C.B.S deseaba un edificio representativo con una decoración y unos acabados, similares a los utilizados en la estación de tren de Cincinatti $^{47}$, y Paul Nelson por su parte propuso la construcción de un interior moderno de líneas rectas y superficies planas, alejado del recuerdo de Beaux-Arts. A finales de invierno en 1937, regresó a Francia defraudado y con la idea de no volver nunca a construir en su país.

Aunque no logró su objetivo, en su segunda experiencia constructiva en Norteamérica aprendió una manera de entender el trabajo del arquitecto diferente a la que le habían enseñado en Francia. El arquitecto americano, a diferencia del europeo, trabajaba como un director de orquesta colaboraba con los técnicos especialistas desde el principio; lo mismo con los ingenieros para concebir la estructura, que con los artistas para decidir la presencia de obras de arte en la edificación. Fue en este sentido, de relación con los artistas, en la que su estancia en Nueva York le resultó más enriquecedora, ya que Paul Nelson y su esposa Francine vivieron en el mismo edificio de Alexander Calder. Los contactos entre las dos familias fueron muy estrechos, y a estas reuniones también se unía el pintor Jean Hèlion ${ }^{48}$. Estos dos artistas fueron muy importantes en su carrera profesional, Jean Hèlion había escrito un año antes un artículo sobre el proyecto del hospital de Egipto y Alexander Calder realizó esculturas para sus proyectos.

El proyecto de la C.B.S fue coetáneo de La Maison Suspendue, incluso supuso una interrupción en el proceso de creación de la casa, ya que la primera versión fechada era de abril de 1936, unos meses antes de que Paul Nelson se marchase a Nueva York para construir la estación de radio. A su vuelta de América y dado que no tenía encargos, retomó su investigación doméstica; la principal transformación que sufrió el proyecto se produjo en la morfología de la cubierta y de los pilares, como resultado de haber sustituido la anterior estructura por otra más ligera.

\footnotetext{
47 Carta, de 10 diciembre 1936, que dirige Paul Nelson a su padre, MNAM/CCI, Bibliothèque Kandinsky, fonds Nelson.

48 Jean Helion, Lettres d'Amérique. Correspondance avec Raymond Queneau 1934-1967. Paris : imec éditions, 1996, p. 20.
} 


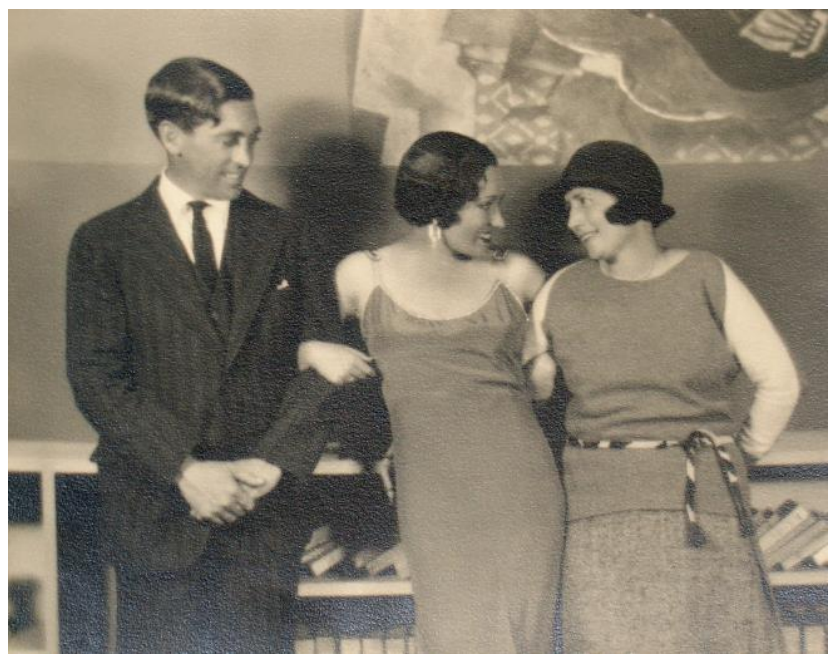

I. 9 Paul Nelson, Gloria Swanson y otra, Hollywood ca. 1929.

\subsection{La estancia en Hollywood}

1929-1930

Los decorados victorianos, que se habían utilizado en Hollywood para representar la forma de vida de la clase alta americana, resultaban desfasados para situar una nueva sociedad menos conservadora. Incluso la moda Art Deco impulsada desde la exposición de artes decorativas de 1925 en París era insuficiente para contextualizar a una sociedad más urbana y optimista que deseaba ser más internacional. La difusión del Art Deco llegó a Estados Unidos en 1926 con una exposición itinerante patrocinada por La American Association of Museums. El cine asimiló este estilo y lo adoptó como signo de identidad. Pero los directores necesitaban mostrar nuevos espacios que encajasen con las narraciones y consideraban que la arquitectura moderna europea era la adecuada para encarnar ese nuevo espíritu ${ }^{49}$. El cine generaba en la población americana, golpeada por la Gran Depresión, unas expectativas positivas. A través las vidas de los personajes, los espectadores podían imaginarse en esos interiores que les seducían por su novedad.

La actriz Gloria Swanson era una de las principales estrellas de Hollywood en aquellos momentos. Su gusto por la moda le hacía viajar con frecuencia a París. a través de estos viajes entró en contacto con las vanguardias y con la arquitectura moderna francesa, gracias a su amiga la diseñadora de tejidos Sonia Delaunay. Pero fue el rencuentro con su amigo Paul Nelson en Los Angeles y el entusiasmo por la

${ }^{49}$ Donald Albrecht, Designing dreams. Modern Architecture in the movies. New York: Marge Horvitz, 1986, p. XII. 


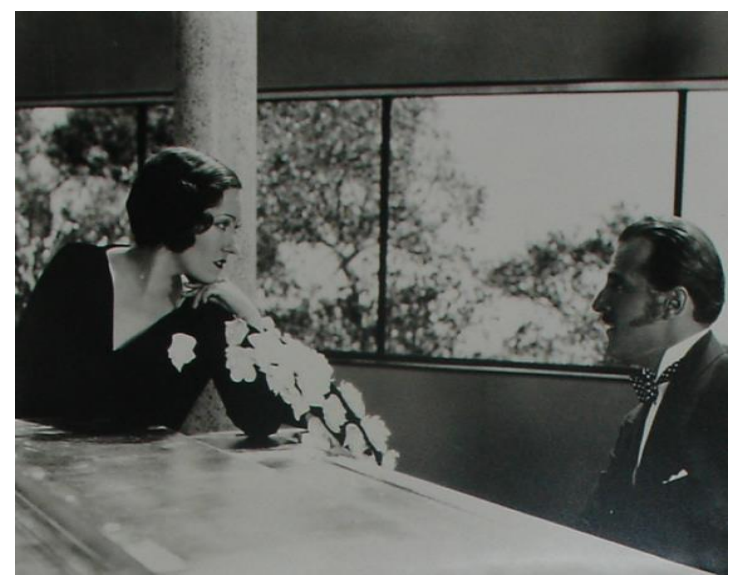

I. 10 Sala Música, What a Widow.dirección artística de Paul Nelson, ca.1929.

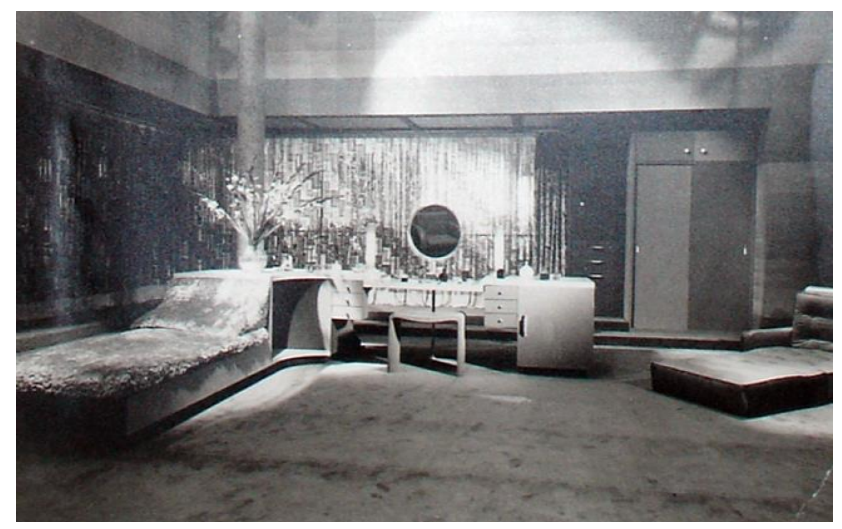

I. 11 Dormitorio principal, What a Widow.dirección artística de Paul Nelson, ca.1929.

arquitectura que le transmitió, lo que animó a Gloria Swanson a proponerle como director artístico de su nueva película. El productor Joseph P. Kennedy, padre del presidente John F. Kennedy, no era proclive a la participación de Paul Nelson, pero al final los deseos de la actriz se cumplieron y la arquitectura moderna se mostró en la pantalla, (I. 9).

La película se tituló What a Widow y fue dirigida por Allan Dwan entre 1929 y 1930. Narraba la historia de una viuda millonaria americana que viajaba a París. El personaje de Gloria Swanson se movía entre áticos, tiendas de lujo y trasatlánticos. Para proyectar unos interiores modernos, Paul Nelson recurrió a la imagen de la Arquitectura de Le Corbusier ${ }^{50}$. Utilizó espacios continuos y fluidos, con muros curvos y huecos horizontales que enmarcan el paisaje e incluso aparecen pilares

\footnotetext{
${ }^{50}$ Paul Nelson comenzó los decorados de What a Widow! a la vez que Le Corbusier terminaba La Villa Savoye (1929).
} 
circulares exentos sin función estructural cuya presencia era evocadora de uno de los elementos principales del lenguaje de Le Corbusier. El repertorio de las referencias era amplio, entre ellas estaban el salón proyectado para la casa parisina de Gloria Swanson, donde utilizó una caja de escaleras curva que recordaba a la subida a la biblioteca utilizada en 1922 para el taller del pintor Amédée Ozenfant y la sala de música con un cerramiento curvo y un hueco horizontal como el salón de la Villa La Roche, (

I. 10).

Le Corbusier no fue la única referencia a la arquitectura moderna francesa que utilizó en la escenografía, el dormitorio de la protagonista era un espacio lujoso y acogedor, en el que la cama aparecía cubierta por un elemento similar al del suelo, que generaba una continuidad semejante a la conseguida por Adolf Loos en el dormitorio para su esposa Lina en 1903. Con un tocador y un sofá que recordaban el mobiliario diseñado por la arquitecta Eileen Gray e incluso el interior de una tienda de sombreros, estaba inspirado en la boutique "Jean Désert" que tenía la propia diseñadora en París, (I. 11).

Además del mobiliario diseñado por los arquitectos, la presencia de obras de arte de vanguardia era otro elemento imprescindible en la vivienda moderna y esto se trasladó a los decorados de la película. Ya en 1926 Robert y Sonia Delaunay habían realizado los decorados de "Le P'tit Parigot" y habían mostrado algunas de sus propias obras. Paul Nelson utilizó obras cubistas de Georges Braque y de Pablo Picasso; pero no las introdujo como simples reproducciones, sino que se fabricaron versiones tridimensionales que permitían conseguir mayores contrastes entre luces y sombras. Tanto a las obras de arte como a otras piezas de mobiliario se les añadieron lámparas fluorescentes que funcionaban como contrapunto de los objetos. Así, estos elementos tomaban su propio protagonismo al quedar iluminados, induciendo la mirada del espectador hacia la modernidad. La luz y el color eran dos elementos nuevos a los cuales no se había enfrentado de manera significativa en su experiencia como arquitecto y que debía resolverlos como escenógrafo. Generalmente los directores artísticos solo utilizaban blancos y negros para los muros de sus decorados, pero en What a Widow trabajó con otros colores, pintó los diferentes elementos en una amplia gama de grises y utilizó texturas de metálicas y superficies translucidas iluminadas en su parte posterior para obtener nuevos efectos de luz. ( I. 12). 


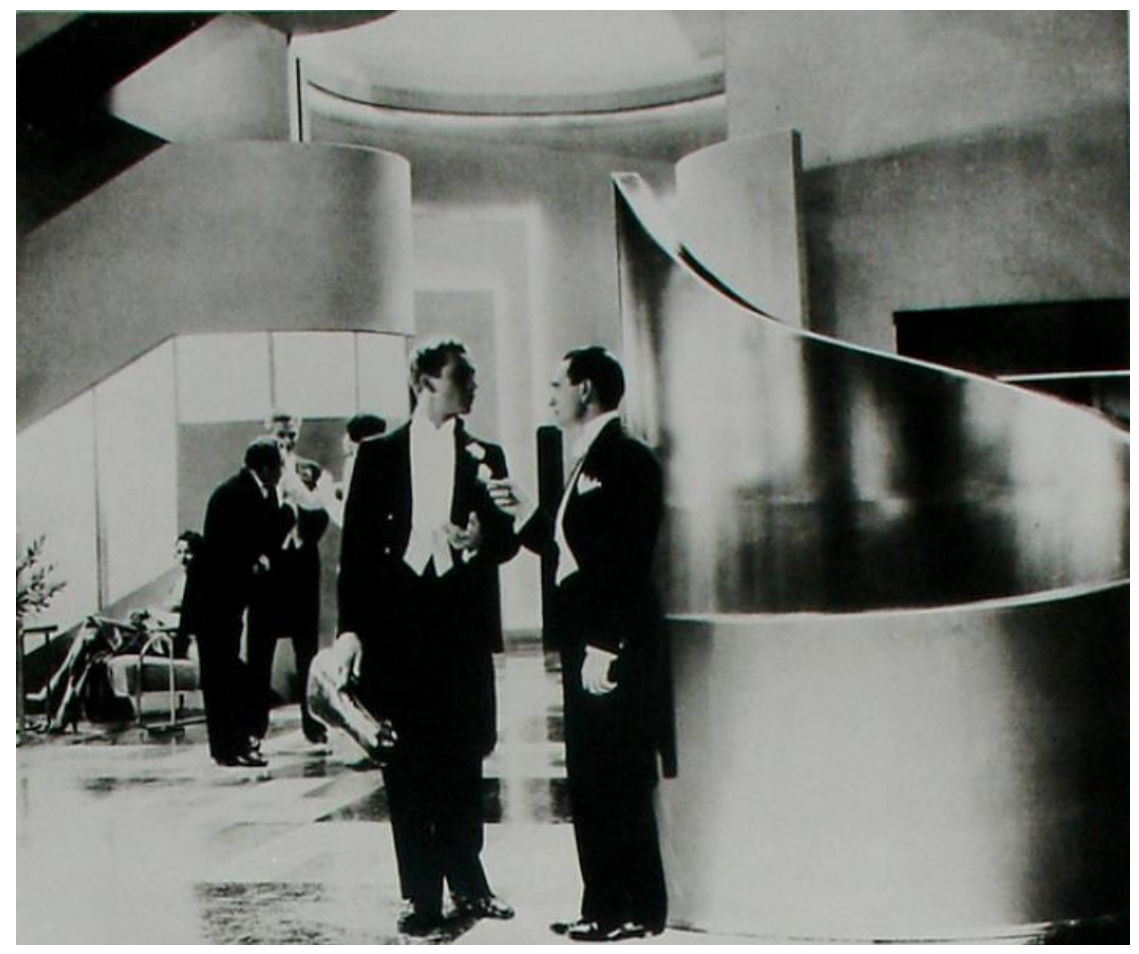

I. 12 Salón principal, What a Widow.dirección artística de Paul Nelson, ca.1929.

En el interior que recreaba los dormitorios de la casa de París, tanto las paredes como el pavimento estaban pintados con figuras geométricas siguiendo una alternancia de claros-oscuros; en el salón de la protagonista, los brillos metálicos de los elementos curvos exentos contrastaban con la austeridad de los muros satinados del fondo. Con esto consiguió una riqueza cromática y de contrastes superior a la alcanzada hasta ese momento con la misma potencia lumínica ${ }^{51}$.

Paul Nelson se marchó a Hollywood para mostrar su idea de arquitectura moderna en la pantalla. Esta era una vía importante para transmitir su conocimiento a la cultura popular de los norteamericanos, dada la imposibilidad de construirla para ser contemplada en vivo, miles de personas podrían ver las imágenes en un solo día y juzgarla. Por eso y como ya se ha visto, prestó interés a aspectos como la iluminación, el color, la textura y el movimiento de las personas en el espacio, aunque estos elementos eran imprescindibles para la calidad de la película, también mostraban sus intereses personales y reflejaban la calidad y el confort que la arquitectura moderna podía ofrecer. Su aportación se produjo dos años antes de la

\footnotetext{
${ }^{51}$ Donald Albrecht, Designing dreams. Modern Architecture in the movies, New York: Marge Horvitz, 1986, p. XVIII.
} 
exposición "The International Style" de 1932 en el Museum of Modern Art de New York (MoMA).

Aunque la modernidad cinematográfica que consiguió coincidió con la arquitectónica en el uso del mismo lenguaje, el mobiliario de líneas rectas, las superficies lisas sin molduras y el gusto por materiales como el hormigón, el acero y el vidrio; sin embargo de las imágenes no se desprendía la condición de modelo ideal a reproducir, como sucedía en arquitectura. Los interiores de la película representaban la singularidad de unos personajes cosmopolitas y adinerados, lo que contrastaba con la conciencia social que preocupa a los arquitectos modernos. Paul Nelson trató de hacer convivir en sus decorados el lujo con la estandarización y lo industrial con lo artesanal. Intentó seducir al público americano sin romper de manera radical con los entornos que estaban acostumbrados a ver en el cine, se trataba de llegar a un amplio espectro de potenciales clientes.

Tras realizar los decorados, en 1930 recibió el encargo para proyectar una sala de cine para la residencia particular del productor Joseph Kennedy en Bronxville (f.I.9). Propuso un volumen de planta rectangular, en el cual el lateral que comunicaba con el jardín era un muro totalmente de vidrio. Proyectó la estructura con pilares circulares de hormigón, exentos en el interior, formando dos líneas de apoyos retranqueadas de fachada. El objetivo principal era conseguir una buena acústica en la sala, tanto para cine y como para teatro, de tal manera que entró en contacto con ingenieros americanos, quienes estudiaron el sonido como un elemento dinámico y variable, ellos le propusieron realizar unas piezas suspendidas del techo para conseguir un efecto sonoro próximo a la realidad.

El proyecto no se construyó, pero la propuesta fue importante para el futuro de su carrera profesional ya que desarrolló un aprendizaje a partir de la sección, y así, un plano que hasta ese momento había surgido de las plantas adquirió la autonomía suficiente para organizar el proyecto. Definió un contenedor regular con una geometría independiente en su interior, que era curva en su parte superior y con tres niveles distintos en el suelo, el acceso, el patio de butacas y el escenario. La decisión constructiva de separar el cerramiento de la estructura y utilizar unas fachadas con paños de vidrio de suelo a techo insertados en una carpintería metálica ligera; coincidió en el tiempo con el Pabellón de Barcelona de L. Mies van der Rohe y con el hueco del salón a la terraza en la Villa Savoye de Le Corbusier. Paul Nelson ensayó con este proyecto la construcción de un contenedor de espacio único con elementos suspendidos en su interior. 
I. 13 Anteproyecto de sala de cine para Joseph Kennedy en Bronxville., perspectiva. Paul Nelson, 1930.

Nunca volvió a trabajar como director artístico, pero su experiencia cinematográfica se manifestó en otros trabajos durante la década de los treinta, fundamentalmente en un hospital para Ismaïlia y en el Palais de la Découverte, en las perspectivas interiores situó el punto de vista en una posición poco frecuente, ubicándolo en posición cenital o a ras del suelo, y a una gran distancia con el hecho observado. Las perspectivas eran muy forzadas y en ellas la escala humana resultaba muy pequeña en relación con el espacio que acogía a las personas. A esto se añadía la iluminación dramática de las imágenes, lo cual provocaba un efecto cercano al expresionismo cinematográfico.

Tanto en el interior del vestíbulo del hospital de Isamailia como en el espacio central de exposiciones científicas del El Palais de la Découverte, se mostraba un espectáculo. En el primero era la visión de las barcazas navegando por el Nilo tras los grandes paños de vidrio (I. 14) y en el segundo era la magia de los inventos. Las imágenes trasmitía al observador la idea de que sus edificios proporcionan algo más que la mera funcionalidad material, en sus proyectos las personas disfrutaban del espacio escénico y del movimiento dentro de estos lugares y se convertían en los actores. Con estos trabajos ponía al alcance de los usuarios, los interiores grandiosos y efectistas que el público veía en las pantallas. A la vez también se estaba poniendo de manifiesto la asepsia y la frialdad de estas grandes salas, estos lugares 


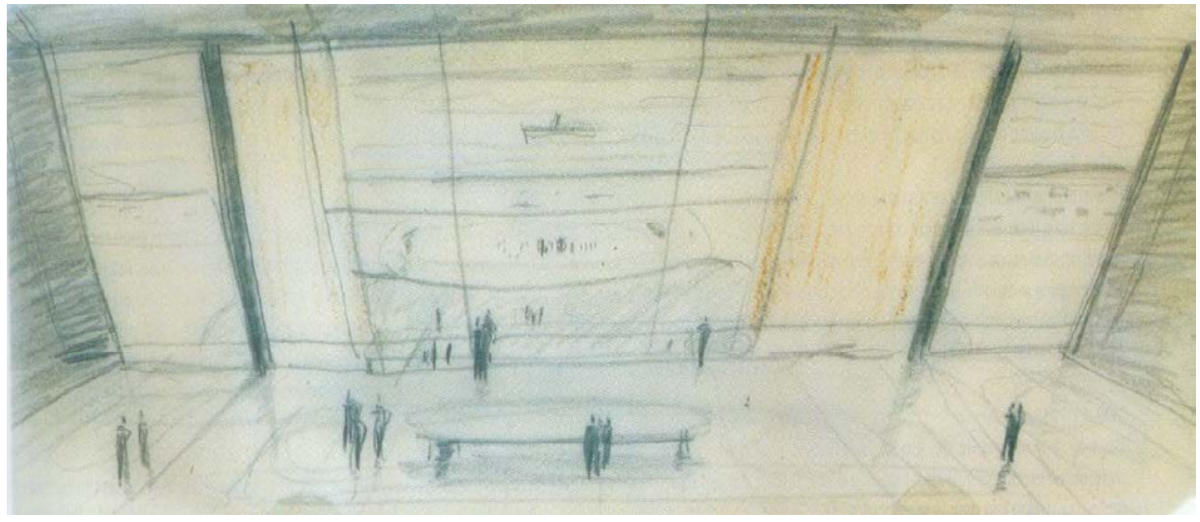

I. 14 Pabellón de Cirugía de Ismaïlia, perspectiva del vestíbulo principal, Paul Nelson, 1934.

públicos donde el individuo se sentía perdido y abrumado. En esas imágenes las personas podían percibir el espectáculo a su alrededor pero todavía no habían logrado encontrar su lugar.

Las consideraciones sobre las nuevas necesidades y los deseos humanos que se insinuaban en estos proyectos, fueron apareciendo de manera paulatina hasta configurar una de las principales hipótesis de partida de La Maison Suspendue. Pero la lección más importante que Paul Nelson se trajo de Hollywwood fue la relación que se establecía entre el espacio y el tiempo, y las consecuencias que esta vinculación tenía tanto para el observador como para el observado. A partir de ese momento, las circulaciones en sus proyectos tuvieron un valor que trascendía lo funcional. Comenzó a considerar los recorridos como recintos, incluidos los núcleos de comunicación, que se hicieron más visibles formando parte del escenario de la vivienda; para lograrlo los sacó de su posición residual habitual entre dependencias y en algunos proyectos se convirtieron en los protagonistas del espacio público. 


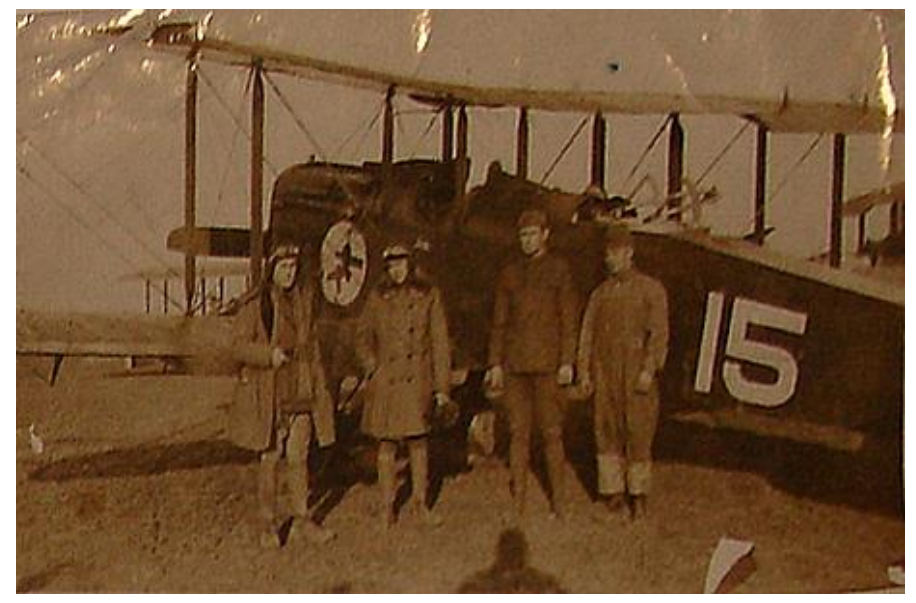

I. 15 Paul Nelson ( segundo por la izquierda), Francia 1918.

\subsection{La intervención y la huida.}

Las dos guerras mundiales sorprendieron a Paul Nelson en el lado inadecuado del Atlántico por lo que se vió obligado a viajar a la otra orilla para defender sus intereses. En la Gran Guerra se encontraba en Estados Unidos y decidió marcharse al frente francés para combatir y en la Segunda Guerra Mundial estaba en Francia, donde no pudo alistarse y tuvo que huir a Norteamérica. De tal manera que en una de ellas participó directamente y en la otra desarrolló un papel de ayuda muy activo pero desde la distancia, ya que se vió obligado a escapar de la persecución Partido Nacionalsocialista Alemán. En las dos contiendas estuvo del lado de su país, apoyó al bando de los aliados, por lo que "ganó las dos guerras". Estas experiencias cambiaron su manera de afrontar la vida y esto se reflejó en sus decisiones profesionales.

1917-1919

Para muchos jóvenes norteamericanos, la participación en la Gran Guerra en apoyo del bando aliado suponía una manera de contribuir a la creación de una nueva sociedad a nivel mundial. Veían en la lucha un camino para cambiar su propio país y pasar de una estructura social conservadora a otra moderna, que consideraban mas libre. Algunos de los intelectuales que apoyaban la intervención en la Gran Guerra, pensaban que su participación directa podía enriquecer sus carreras, para muchos este era su primer viaje fuera de su país, incluso algunos solo lo veían como un divertimento o juego entre buenos y malos. Este clima en defensa del orden internacional, difundido desde el gobierno y apoyado desde la universidad, incidió en la decisión de Paul Nelson de adoptar una postura activa. En una entrevista con 
su biógrafa hablaba sobre los motivos que le llevaron a participar en la Gran Guerra (...) Esta guerra, como ves, surge del deseo de tomar parte del nuevo mundo ${ }^{.52}$.

En su último año de universidad tomó clases de vuelo en la Princeton Flying School, su intención era formarse como piloto y estar preparado para participar cuando Estados Unidos entrase en la Guerra. En verano de 1917, con 22 años, se alistó como voluntario en la Aviación Americana marchándose a Francia donde se integró en la escuadrilla franco-americana de La Fáyette. Fue nombrado teniente, se hizo instructor de vuelo y posteriormente participó en los ataques de St Michele y Argonne. En primavera de 1919, fue desmovilizado del ejército pero permaneció en Francia, en la zona del frente, hasta el verano cuando regresó a los Estados Unidos.

La participación en la Gran Guerra fue una experiencia que marcó su vida ${ }^{53}$. En primer lugar, este era su primer contacto con Europa, nunca había realizado un viaje fuera de su país, su vida hasta ese momento estaba marcada por su educación familiar y su formación en la universidad americana. En segundo lugar, estaba el descubrimiento de las fuerzas aéreas. $\mathrm{Y}$ en tercer lugar, tenía que enfrentarse a un hecho bélico, estaba participando en una batalla. La experiencia como piloto le sirvió para madurar y le ayudó a enfrentarse a los problemas de manera individual, ya que los pilotos estaban obligados a tomar sus propias decisiones, no existía una estructura clara dentro del grupo y en el aire, el ejército norteamericano no estaba organizado como sucedía en la marina. La sociedad americana no contaba con unos avances científicos capaces de generar una verdadera industria de la aviación. Lo mismo que sucedía en aquellas primeras décadas con los artistas y los arquitectos, ya que estos todavía no eran capaces de ofrecer lo que demandaba la sociedad emergente ${ }^{54}$.

$\mathrm{Su}$ experiencia como aviador también le permitió tener nuevas sensaciones no vividas hasta aquel momento. La más inmediata fue la de poder percibir el mundo desde una nueva perspectiva, la visión aérea, que le permitía mirar la tierra desde un punto de vista superior al habitual. También le marcaron la posibilidad de flotar, el

\footnotetext{
52 Anne Kandelman, texto meca, n/p, mayo 1978, MNAM/CCI, Bibliothèque Kandinsky, fonds Nelson.

${ }^{53}$ Texto escrito el 18 de noviembre de 1918, donde Paul Nelson describe sus sentimientos y su experiencia como piloto de la Gran Guerra, MNAM/CCI, Bibliothèque Kandinsky, fonds Nelson.

${ }^{54}$ Judith Applegate, "Paul Nelson: an interview". Perspecta nº13-14, 1971, p. 76-77.
} 
estar aislado del mundo en un recinto controlado por él, y el hecho de poder desplazarse libremente por el espacio sin un recorrido fijo y sin ataduras a ninguna estructura. Señaló que de todas las sensaciones percibidas la que más le impactó fue experimentar la cuarta dimensión, percibir el tiempo moviéndose solo, en el interior de su cabina de vuelo. ${ }^{55}$

Todas estas percepciones derivadas de su capacidad de volar incidieron en su manera de afrontar la vida, lo definía como un avance en su desarrollo personal que le permitía ser más libre, adoptando sus propias decisiones y desviándose del camino que tenía marcado. Pero lo más importante era ver cómo estas metáforas se trasladaban a su trabajo como arquitecto y comprobar cómo estos pensamientos surgían de nuevo en la búsqueda de su identidad profesional. A medida que avanzaba la década de los años treinta y buscaba su propio camino como arquitecto, volvieron a su mente las experiencias vividas volando dentro de las carcasas metálicas de los aviones. Sus edificios se hicieron más ligeros, tanto en el uso estructural como en los procesos constructivos y a la vez, sus espacios también evolucionaron hacia una mayor continuidad y sus circulaciones proporcionaban una variedad en los desplazamientos. En La Maison Suspendue se recuperó la idea de la cabina del avión, como un recinto "ingrávido" que satisfizo sus necesidades espaciales de aislamiento, y se transpuso a los espacios personales. Se construyeron habitaciones exentas colgadas del techo, que generaban en sus ocupantes la sensación de estar flotando.

1940-1945

Tras la invasión de Francia por los Nazis el 10 de marzo de 1940 y la imposibilidad de alistarse por no ser ciudadano francés, Paul Nelson se marchó a los Estados Unidos en el último barco que partió del puerto de Royan. Permaneció allí cinco años, hasta el final de la guerra. Fue presidente de la Comisión Nacional Americana "France Forever" 56 de apoyo para la liberación de Francia, el cometido de estos ciudadanos en el exilio era prepararse para afrontar la reconstrucción del país galo una vez terminada la contienda. Se marcho a vivir a Maryland junto a su esposa Francine, el matrimonio afrontaba esta nueva etapa con la mente puesta en la guerra

\footnotetext{
${ }^{55}$ Ibidem.

56 "France Forever", fue una organización constituida en el estado de Pennsylvania, cuya misión era crear, mantener e incluso acentuar los lazos culturales y las relaciones amistosas entre Francia y los Estados Unidos y por supuesto su objetivo principal durante la guerra era perseguir la lucha hasta el final para liberar Francia y rehabilitarla. Véase: Èmile Lemelin, ¿Qu'est-ce France forever? Le Travailleur, 6 de abril 1944, p.1.
} 
y desde la distancia forzada aportaron sus esfuerzos para contribuir al final de la contienda $^{57}$. Para recabar apoyos a la causa francesa, solicitó la colaboración de su amigo Alexander Calder quien dio una conferencia sobre el futuro de Francia como un país libre y creativo. Regresó a Francia en 1945, en el primer barco que cruzó el Atlántico.

Durante esta nueva vida americana, trabajó en planeamiento urbanístico y en proyectos residenciales. Uno de los problemas más importantes del gobierno de Estados Unidos era cubrir las necesidades de alojamiento de los "trabajadores de la guerra" y para conseguirlo crearon agencias estatales de la vivienda. Nelson fue Consejero Técnico para The Federal Public Housing Authority (F.P.H.A.), The National Housing Agency y Board of Economic Warfare, donde trabajó a todas las escalas, desde la ordenación urbana hasta los detalles de la construcción. Tenía como prioridad de sus cometidos, la reconstrucción de los países liberados y en especial la rehabilitación de los terrenos franceses devastados.

Desarrolló un plan de ordenación para la F.P.H.A. denominado "Duration Dormitories" (I. 16). El objetivo del Estado era proporcionar una residencia digna a los trabajadores para conseguir que su producción industrial aumentase. La administración adoptó dos estrategias de planeamiento encaminadas a mejorar el ocio de los trabajadores. Por un lado, para aumentar el tiempo de disfrute, las unidades residenciales se ubicaron en las proximidades de las plantas de trabajo, reduciendo de esta manera los tiempos en los desplazamientos. Y por otro lado, se consideró que estas unidades residenciales tuvieran un centro de ocio, que mejorasen su calidad de vida de los trabajadores.

La propuesta estaba compuesta por grupos de viviendas conectadas a un núcleo central de dotaciones. Los alojamientos proyectados estaban condicionados por una serie de premisas: eran temporales, prefabricados y debían estar construidos con materiales ligeros que no fuesen utilizados en la industria de la guerra y que se transportasen con facilidad. Su trabajo en la agencia se centró en el estudio de estas materias: los procesos productivos, la configuración espacial, la incorporación de nuevos materiales y las necesidades sociales.

\footnotetext{
${ }^{57}$ Paul Nelson intentó en varias ocasiones alistarse para combatir, incluso en 1943 trató de viajar a Londres y unirse allí al Comité de liberación National pero no lo consiguió ya que el gobierno de los Estados Unidos no le dio la autorización. Véase : Anne Kandekman Notes biographiques 1978 (révisée par Anne Kandelman), op.cit.
} 


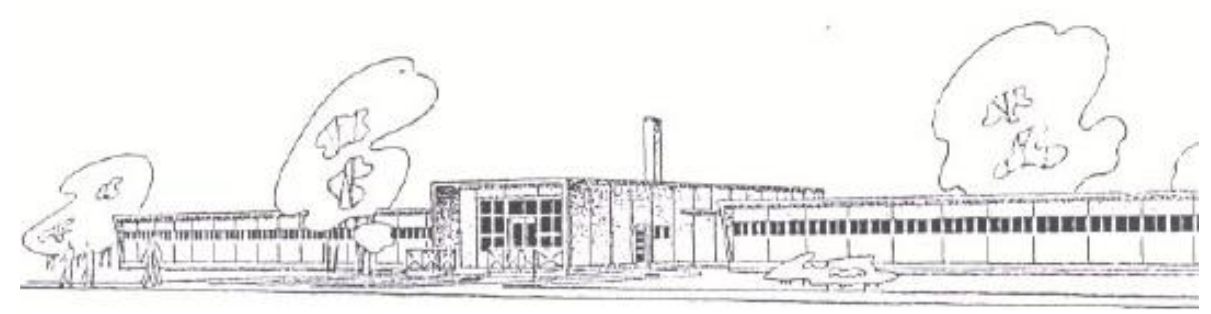

I. 16 Duration Dormitories, perspectiva. Paul Nelson, 1942.

Esta era la primera vez que se enfrentaba a la construcción de un modelo residencial de bajo coste y propuso crear un alojamiento estandarizado, pensado para ser ensamblado por completo en obra a partir de piezas producidas y controladas en taller. El bajo coste se lograba por la compra de grandes cantidades de material, la reducción del presupuesto en ningun caso se debía producir como consecuencia del detrimento de los aspectos cualitativos de las viviendas. Con respecto al modelo espacial, proponía unas plantas de unidades residenciales generadas a partir de la adición unidades de descanso estandarizadas. Dentro de cada unidad proponía resolver los baños con elementos monobloc y utilizar paneles sándwich y aislamientos acústicos en los cerramientos. Con estos bloques pretendía hacer frente a una nueva realidad social con la incorporación de la mujer al mundo laboral, la inmediatez de la demanda y la aparición de nuevas realidades familiares.

Los sistemas de prefabricación constructiva que había introducido de manera experimental en sus propuestas de los años treinta, como La Maison Suspendue, eran recuperados y transformados en los proyectos pragmáticos de la guerra. Si en la década anterior había proyectado la incorporación de unidades prefabricadas dentro de la vivienda, en la etapa de la guerra aplicó este sistema constructivo al conjunto de la vivienda, cada unidad residencial se pensó para ser ejecutada en su totalidad en fábrica. Este cambio en el concepto de prefabricación también tuvo sus consecuencias espaciales de la casa; si en los años treinta la industrialización le abrió las puertas al espacio individual, durante la II Guerra Mundial la prefabricación buscaba la urgencia del alojamiento social. 


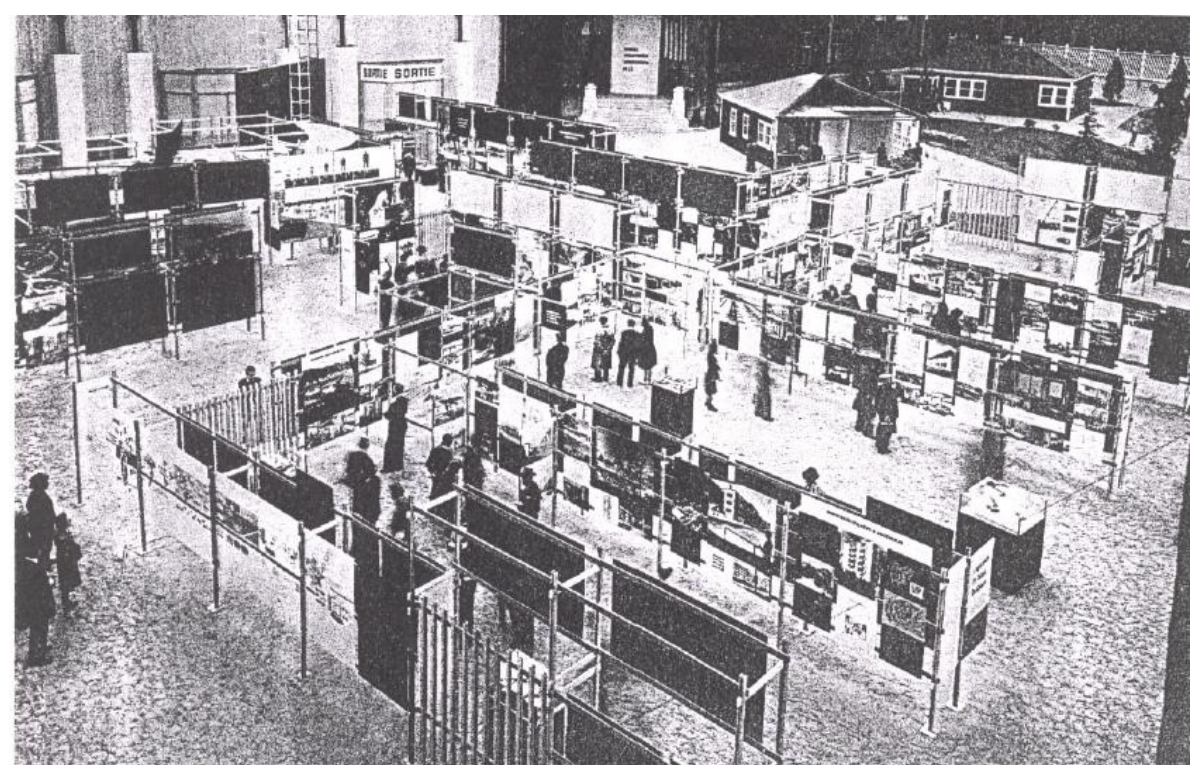

I. 17 Exposición de Techniques américaines de l'habitation et de l'urbanisme 1939-194X. Paul Nelson, París, 1946.

A su vuelta a Francia, tras la guerra, el Ministerio del Urbanismo y la Reconstrucción (MRU) con el apoyo de Estados Unidos, le encargó la exposición "Techniques Américaines de 1'Habitation et de 1'Urbanisme 1939-194X"58 (I. 17). Su experiencia durante la guerra le permitía transmitir, tanto a los especialistas relacionados con la edificación como al público francés en general, como se habían desarrollado las técnicas de construcción en Norteamérica y sugerir las vías para encauzar la situación en un país que terminaba de salir de una guerra y que demandaba viviendas a gran velocidad. Así mismo, trató de hacer ver a las empresas constructoras francesas las nuevas oportunidades de mercado.

La Segunda Guerra Mundial cambió su manera de proyectar volviéndose más pragmático. Si la década anterior había estado marcada por proyectos no construidos y por trabajos destinados a la investigación personal, a partir de la guerra la necesidad constructiva estuvo por encima de otras intenciones, teniendo siempre presentes los avances tecnológicos. Su arquitectura también se hizo más pesada, retomó las estructuras de hormigón y los cerramientos pesados con prefabricados de piedra y hormigón. El uso del acero se limitó a elementos puntuales pero no volvió a plantear ninguna estructura completa con este material. Sus espacios, a excepción de sus viviendas, perdieron flexibilidad y continuidad, proyectó las estancias encajadas en volúmenes regulares, adosadas al perímetro y apoyadas en forjados superpuestos.

\footnotetext{
${ }^{58}$ La exposición "Techniques Américaines de 1'Habitation et de 1'Urbanisme 1939-194X" tuvo lugar entre el 14 de junio y el 21 julio de 1946, en el Grand Palais de París.
} 
En la biografía, escrita por Anne Kandelman y supervisada por Nelson, las guerras ocupan su propio epígrafe, con ello Paul Nelson daba a estos acontecimientos la misma importancia que a su vida profesional. En el orden general de la biografía, el epígrafe de las guerras aparece después de los méritos y los títulos académicos y antes de la actividad como arquitecto. La participación en las guerras no era algo marginal, formaba una parte importante de su vida y así quiso que se trasladase. Pero este hecho también refleja su actitud activa frente a los acontecimientos que cambiaban el mundo. Consideraba que la transformación se podría llevar a cabo desde diferentes ámbitos, incluida la arquitectura. Así protestó por otra guerra que consideraba injusta, la de Vietnam, y criticó la intervención de los Estados Unidos. Publicó un artículo titulado Mutation ou Cessation donde propuso invertir todo el conocimiento en la construcción de la paz frente a la idea destructora de la guerra utilizando como herramienta el urbanismo ${ }^{59}$.

\footnotetext{
${ }^{59}$ Paul Nelson, “Mutation ou cessation”, Le carré bleu n³-4, 1969, p.1 y 8.
} 


\section{La investigación y la docencia}

En paralelo a su labor como proyectista, Paul Nelson desarrolló otras actividades profesionales vinculadas a la búsqueda y a la difusión del conocimiento arquitectónico. En diferentes momentos de su carrera, trabajó como investigador y en las últimas dos décadas de su vida profesional lo hizo como docente. Algunos maestros de la arquitectura moderna también habían desarrollado estas dos actividades como parte de su carrera. L. Mies van der Rohe y Walter Gropius fueron profesores en la Bauhaus y posteriormente en Norteamérica, Le Corbusier dedicó una parte muy importante de su trabajo a la investigación y a su divulgación, y R. Buckminter Fuller trabajó toda su vida en la investigación arquitectónica y en la docencia.

Paul Nelson desarrolló su actividad investigadora desde dos ámbitos: el académico y el profesional. La universidad había sido tradicionalmente un lugar propicio para poder desarrollar una búsqueda del conocimiento, aunque a veces estuviera muy sujeto a las propias reglas de la institución. El ámbito profesional, sobre todo en Europa, era poco innovador, pues las investigaciones se producían para satisfacer demandas concretas de los profesionales. En el caso de Nelson, hasta que inició su carrera académica, la investigación se desarrollaba en colaboración con las empresas y los especialistas en los diferentes temas tratados para cada proyecto. Para la difusión de sus conocimientos utilizó tres vías : la docencia, la prensa escrita y las exposiciones. A través de las enseñanzas a sus alumnos podía introducir nuevas líneas de pensamiento, sus artículos en revistas le permitían llegar a un público más especializado y las exposiciones de sus trabajos en los museos le acercaban a un público más amplio. La enseñanza no fue una meta buscada desde un principio, sino que le llegó tras ser reconocido por la crítica como un especialista en la construcción de hospitales. La docencia fue una vía inesperada que le permitió experimentar el conocimiento y el desarrollo de su pensamiento a través de los alumnos.

Como referente de su labor investigadora se han considerado dos ejemplos: el desarrollo de un nuevo tipo de fachada para la ciudad hospitalaria de Lille y su propuesta de modelo urbano presentado en la Graham Foundation de Chicago. La primera representaba un modelo de investigación práctica, en contacto directo con las empresas, y la segunda era un ejemplo de búsqueda teórica y no realizable destinada al debate intelectual. De su actividad docente se han seleccionado dos ejemplos: sus estancias en las universidades de Norteamérica y su última etapa en 
las escuelas francesas. Los objetivos buscados con esta actividad en los dos países fueron distintos. En Estados Unidos transmitía sus ideas a sus alumnos para que pudieran afrontar sus proyectos y en Francia su labor se centró en desarrollar un nuevo modelo pedagógico.

\subsection{La patente de la "fachada claustral"}

El proyecto de Paul Nelson para el concurso de la ciudad hospitalaria de Lille de 1932 incorporaba el aire acondicionado como uno de los avances técnicos que mejoraban la calidad de vida de los enfermos y, gracias a esta solución, los problemas térmicos quedaban resueltos al poder controlar mecánicamente todo el edificio. Esta innovación requería que la proporción de huecos practicables fuera nula, ya que el modelo utilizado en esos momentos en los cerramientos de los hospitales con grandes ventanales no servía. Necesitaba resolver una fachada hermética que le permitiera reducir los costes de calefacción y refrigeración y también, dadas las nuevas funciones hospitalarias surgidas como consecuencia de los continuos avances científicos, existía la necesidad de alojar estos nuevos usos en espacios imprevistos. Por lo tanto, se planteó construir un muro exterior flexible, que le permitiera ubicar en su parte interior las distintas funciones hospitalarias y sus futuras evoluciones espaciales, sin el condicionante predefinido por los huecos.

Se proyectó una fachada adaptable que podía sufrir transformaciones sin que se viese modificada su estructura general y esto le llevó a desarrollar un proceso de investigación arquitectónica basado en la búsqueda de una nueva técnica constructiva, creando una nueva fachada, un elemento que no existía en el mercado, que patentó y denominó "le mur claustra". Dicha fachada estaba constituida por una retícula metálica generada a partir de un módulo de 49x49.cm. En los huecos de esta trama se insertaban elementos vítreos con diversos grados de transparencia que se disponían en función de las exigencias lumínicas y térmicas de los espacios interiores. Estas piezas no eran practicables, pero podían sustituirse o intercambiarse con otras según las necesidades. Estaba previsto que el sistema de fijación se realizase desde el exterior para conseguir, según los ingenieros, una mayor protección frente al viento y un grado de hermetismo elevado (I.18). 


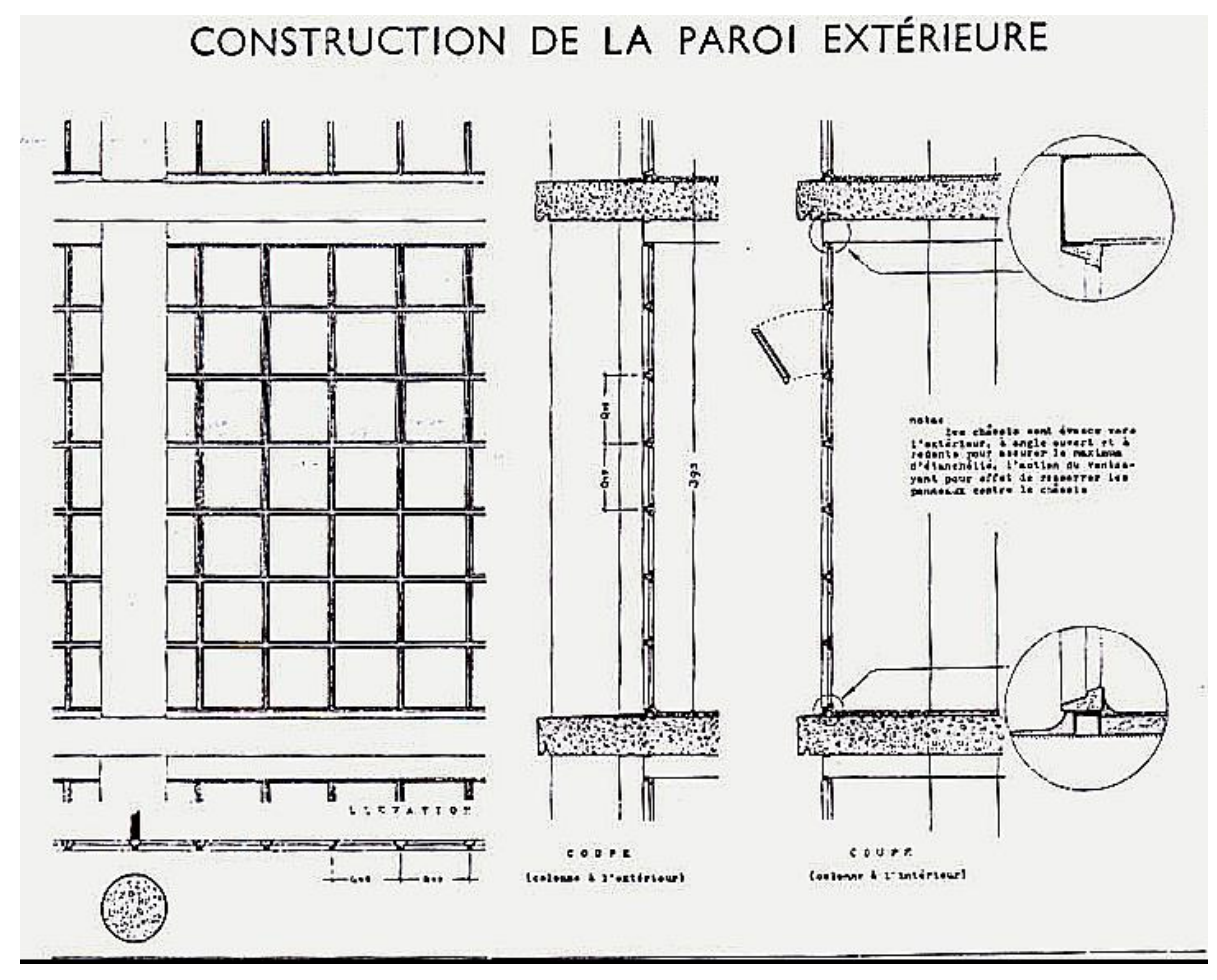

I. 18 Concurso del Hospital de Lille, "le mur claustra", detalles de alzado y sección, Paul Nelson, 1932.

Esta fachada suponía para Paul Nelson una solución y un avance frente a otros sistemas de piezas de vidrio ya experimentados, como los muros neutralisant usados por Le Corbusier y Pierre Jeanneret, ya que estos eran cerramientos homogéneos y permanentes, que no permitían ningún tipo de flexibilidad ni lumínica ni térmica. La solución de la fachada de Lille, además de resolver de manera estandarizada un problema técnico, aportaba una solución que podía utilizarse por otros arquitectos en otros proyectos. Paul Nelson la incluyó en otros proyectos de viviendas e incluso este trabajo le sirvió como punto de partida para definir el cerramiento de La Maison Suspendue, en la cual utilizó otro tipo de malla y un soporte más ligero. La investigación de la "fachada claustral" suponía entender la arquitectura como un elemento flexible y adaptable, que el cliente podía manipular, contrario al modelo ideal e inalterable defendido por su maestro Auguste Perret.

\subsection{Una beca de la Graham Foundation.}

La Graham Foundation de Chicago otorgó una beca de investigación a Paul Nelson en el año 1957, lo que le llevó a trasladarse con su segunda esposa Maddalene y sus hijos Ugo y Rory a Norteamérica y establecerse allí en busca de nuevas 
oportunidades. La Graham Foundation planteó un seminario para estudiar el desarrollo de la creación artística en un país con una fuerte implantación industrial, como era Estados Unidos, intentando situar al hombre en el debate del arte y de la arquitectura treinta años después del final de las vanguardias y de la aparición de la arquitectura moderna. Para participar en dicho seminario se contactó con especialistas en diferentes disciplinas relacionadas con el arte y, entre otros, se invitó a Paul Nelson. Una vez presentadas las propuestas ante un grupo de intelectuales, los artistas debían explicar sus obras desde el punto de vista del servicio que estas prestaban al hombre y se desarrollaron debates en los que se confrontaba el proceso de pensamiento individual del creador con el pensamiento colectivo de la sociedad a la que iba dirigido.

Del seminario se extrajeron dos conclusiones principales: la primera era la necesidad de trazar vínculos transversales entre las diversas disciplinas para tener visiones más amplias y enriquecidas, puesto que no era muy útil que un creador hubiese avanzado mucho en una disciplina si este conocimiento no se proyectaba más allá del propio interés del artista. Por lo tanto, el avance se debía producir de manera interdisciplinar. La segunda consideración hacía referencia a la necesidad de no olvidar que su trabajo estaba dirigido hacia el hombre: el artista debía ser consciente de que trabajaba para una sociedad y su obra tenía un contexto en el que influía. Se constataba así cómo el desarrollo de dicha sociedad estaba vinculado de alguna manera a la evolución y a la producción artística.

Paul Nelson inició su investigación analizando el patrón de desarrollo urbano de la sociedad norteamericana y encontró que estaba compuesto por tres tramas: la primera de ellas era heredada, la segunda era el resultado de la ciudad industrial y la tercera era producto de las relaciones humanas. Llegó a la conclusión de que estas tramas no encajaban y se planteó solucionarlo mediante un proyecto que recuperase la idea del ágora griega. Propuso así la creación de unos centros experimentales de ocio con un espacio público convertido en el elemento principal de estos lugares, unos recintos donde los ciudadanos pudiesen intercambiar sus conocimientos. ${ }^{60}$

En su planteamiento de humanización del espacio urbano, con el fin de construir ciudades donde los hombres se sintieran más felices, planteaba utilizar siempre la técnica en beneficio del hombre y no al contrario. El individuo nunca debía

\footnotetext{
${ }^{60}$ Danielle Valeix,“ Vers un nouvel humanisme ", L'Architecture d'aujour'hui $\mathrm{n}^{\circ} 72$, juniojulio 1957, p V y VII.
} 
someterse a la máquina. Pensaba que la investigación en arquitectura no debía ceñirse a los aspectos puramente funcionales, constructivos y espaciales, sino que debía ampliarse al plano humano, involucrando a las empresas en este recorrido de búsqueda de una mejora de la condición del hombre. Con este trabajo retomaba su tesis de los años treinta sobre el desarrollo del hombre, apoyada en una vía individual y otra social. La primera vía había inspirado el desarrollo espacial de $L a$ Maison Suspendue y ahora proponía desarrollar la segunda, la de los centros de relación social, para terminar su investigación y poder presentar su tesis completa.

Ya se ha mencionado la importancia que Nelson concedió a la investigación, sobre todo en los años treinta, cuando la ausencia de encargos le indujo a ofrecer sus proyectos al gobierno, único cliente posible. Así desarrolló un recinto para mostrar los descubrimientos donde solicitó la colaboración de diversos científicos y expertos en museología. La colaboración con otras disciplinas y el ritmo en el que se producían los descubrimientos también le condujeron a abandonar el planteamiento de la arquitectura rígida y monumental y proyectar desde una perspectiva sujeta a los cambios.

El ejemplo más importante de estas investigaciones, y el de mayor repercusión en toda su carrera, fue su propuesta de La Maison Suspendue, que se pensó como un trabajo de investigación y no para ser construido. Con esta concepción eliminaba el edificio físico como el resultado definitivo de la búsqueda y establecía una separación entre el acto de investigar y el de proyectar. Cada una de estas actividades tenía su propio método de desarrollo, ya que la investigación tenía un valor autónomo independiente de la construcción del edificio y del método de trabajo que se utilizaba para proyectar. Concentraba la investigación en una primera fase analítica donde no se realizaban aproximaciones gráficas y este proceso de búsqueda se sustentaba en un proceso racionalista que partía de unas hipótesis estructuradas en tres bloques (filosófico-social, espacial-formal y tecnológicoconstructivo) y finalizaba, mediante un método deductivo, en una concepción espacial.

Aunque los dos ejemplos de investigación analizados, la "fachada claustral" y la beca de la Graham Foundation, tenían puntos de partida diferentes y entre ellos existe un salto temporal de veinticinco años, los dos compartían la preocupación por la posición del hombre dentro del espacio y su relación con el entorno, los dos perseguían la humanización de la arquitectura por medio de una aproximación a la 
creación de espacio individual. En uno, el espacio individual quedaba determinado por la variedad térmica y visual que proporcionaba la fachada; y en el otro, venía definido por acotar un lugar para uso individual dentro de un recinto público. En los dos casos, la herramienta utilizada para conseguir los objetivos era técnica, la industria puesta al servicio del hombre.

\subsection{La docencia en Estados Unidos.}

Después de participar en el seminario de la Graham Foundation en 1957, se inicia una nueva etapa en la que trabajó como profesor en varias universidades norteamericanas. Paul Nelson ya había construido los hospitales de Saint Lô y Neuilly y cuando volvió a Estados Unidos para impartir clases ya contaba con el reconocimiento de la crítica por su arquitectura hospitalaria. Durante su nueva estancia de cuatro años en Norteamérica, se hizo miembro del American Institute of Architecture (A.I.A) y de la Boston Society of Architects. También fue socio de la firma de arquitectura Ketchum and Scharpp de Nueva York, con la que colaboró en proyectos de hospitales y, aunque su cometido era la docencia, mantenía un deseo por construir en su país. Dio clases en los siguientes universidades: el Pratt Institute, Yale, Harvard y el M.I.T., a lo que habría que añadir las conferencias impartidas en otros centros.

El primer semestre de 1957 trabajó en la Achitectural School of Pratt Institute de Nueva York, donde colaboró como profesor visitante junto al Dean Olindo Grossi. Ese año, los alumnos trabajaron en un desarrollo urbano para la ciudad de New Jersey Meadows, donde la expansión urbana había transformado los campos de cultivo y las granjas en barrios residenciales desordenados ${ }^{61}$. Las propuestas debían definir el carácter del centro de la ciudad con todos los equipamientos y debían plantear estructuras urbanas donde fuese compatible un crecimiento orgánico con el desarrollo de una nueva villa lineal. Así se integran los modelos del campo y la ciudad, de modo que pudiesen convivir los sectores: agrícola, residencial, industrial y los servicios públicos.

\footnotetext{
61 "East Meadow, L. I. Marks 300years; Former Hempstead Town Pasture Now a Thriving Community of 56.000" New York Times 12 enero 1958, p.48.
} 
En el cuatrimestre de la primavera del curso 1958-1959 fue profesor visitante en la universidad de Yale. Coincidiendo con su participación como jurado en el concurso de un centro de salud mental en la ciudad de New Haven, sus alumnos también trabajaron en la concepción de un espacio sanitario; un centro en el cual se pudiese integrar el Grace New Haven Teaching Hospital y un área de salud mental. Se pedía a los alumnos que desarrollaran una reflexión sobre la capacidad de la arquitectura de los psiquiátricos para poder reinsertar individuos en la sociedad.

A través del trabajo de sus alumnos, profundizó en sus ideas sobre el concepto de hospital, entendido como el lugar para prevenir y mantener tanto la salud física como mental. En términos de proyecto, esto significaba la incorporación de espacios dedicados a personas sanas y la convivencia dentro de un mismo recinto de enfermos con diferentes niveles de gravedad, que requerían distintos grados de atención y de protección. Por lo tanto, este era un proyecto que, a parte de tener un programa complejo, debía abordar una componente sociológica, por lo que Paul Nelson solicitaba que sus alumnos explorasen las relaciones humanas dentro del recinto hospitalario.

En el primer semestre del curso 1959-1960 fue asistente de los profesores Josep Lluis Sert y Huson Jackson en la Universidad de Harvard y ese año sus alumnos trabajaron en un centro hospitalario. Y el segundo semestre del curso dio clases en el M.I.T de Cambridge, donde propuso como ejercicio realizar una nueva versión de su proyecto Palais de la Découverte, con lo que se pretendía que realizaran una reflexión sobre el ocio y el intercambio social en las nuevas comunidades urbanas.

Durante esta etapa académica también impartió cursos y seminarios en otros lugares. En su antigua universidad de Princeton, en 1958, pronunció una conferencia titulada "Le développement du rôle de la synthèse" y el año siguiente, impartió otra en un seminario para adultos que no eran estudiantes de universidad, denominada "An Appraisal of Modern Architecture", en la que hizo una valoración de la incidencia que la arquitectura moderna había tenido en la sociedad. La última conferencia pronunciada antes de su regreso a Francia fue en 1960 en el M.I.T y la tituló "Méthode d'analyse Architecturale" donde describió la sistematización de su método de trabajo. Los títulos de estas conferencias reflejaban el interés de Paul Nelson por difundir su método de trabajo y sus procesos de investigación.

Esta experiencia docente le permitió reflexionar sobre la escala urbana, de modo que el problema del arquitecto ya no estaba solo en resolver de manera acertada un 
proyecto específico, sino en trabajar e investigar el desarrollo de las ciudades. Este era el cambio fundamental respecto a su trabajo anterior, el enfrentarse a la ciudad. Tras la guerra y la expansión industrial, el urbanismo pasó a ser una de las actividades en las que más se especializaban los arquitectos. Su principal objetivo como docente era transmitir a los alumnos sus experiencias en los proyectos residenciales y de ocio para que ellos lo aplicasen a la escala urbana y, para ello, recuperó sus investigaciones de los años treinta y les trasladó sus conclusiones sobre la flexibilidad de las propuestas y la capacidad de adaptación de los edificios. Las ciudades americanas estaban en continua transformación y su crecimiento debía facilitar la movilidad y el intercambio entre los ciudadanos. Nelson llegó a la conclusion de que la trama ortogonal no podía extenderse hasta el infinito, puesto que la consideración del entorno, los recursos y las infraestructuras debían ser los parámetros que marcasen el tamaño de las ciudades.

\subsection{Los talleres internacionales de Beaux-Arts y de Marseille-Luminy.}

Al inicio de la década de los años sesenta, regresó a Francia y retomó su trabajo profesional compaginándolo con la docencia, primero como profesor en la École de Beaux-Arts de París y después en la École de Marseille-Luminy. Sus primeros cuatro años en Beaux-Arts los dedicó a tratar de recuperar el espíritu cosmopolita e internacional en el que el se había formado junto a otros muchos estudiantes norteamericanos e intentó restablecer el sistema de formación en talleres de arquitectos de reconocido prestigio. $\mathrm{Y}$, para generar un clima internacional, propuso invitar a los arquitectos más importantes de los dos países a participar en sesiones críticas conjuntas sobre los trabajos de sus alumnos, esta mecánica les ayudaría a generar debates desde diferentes puntos de vista ${ }^{62}$. Consideraba que la escuela de París ofrecía una formación consolidada, que podía resultar atractiva para los estudiantes americanos, pero a la vez pensaba que se tenía que potenciar la labor investigadora. Para apoyar esta causa, él aportaba su experiencia como docente en las universidades americanas, donde había comprobado la importancia de la colaboración interdisciplinar y de la participación de las empresas en el desarrollo de los proyectos. Entendía que esta renovación pedagógica en Francía debía ser

${ }^{62}$ T.Johnston Graham, Ridge Smith, Princeton alumni weekly del 21 septiembre de 1965, p.49. Se recogen las intenciones de Paul Nelson respecto del taller franco-americano de Beaux-Arts. 
impulsada desde el Estado, a diferencia de lo que sucedía en Estados Unidos donde las principales universidades eran centros privados.

En el año 1964, consiguió que el ministro de Cultura francés André Malraux le nombrase director del taller franco-americano de Beaux-Arts, pero esta experiencia solo duró tres años. Paul Nelson no logró sus objetivos, no contó con la financiación solicitada y tampoco tuvo la respuesta esperada, ni de los estudiantes norteamericanos ni de las instituciones ${ }^{63}$. El desarrollo del taller coincidió con un momento de cambió en el sistema docente francés que, a partir de 1968, transformó las escuelas de arquitectura en unidades pedagógicas. Esto significaba que el alumno debía superar los diferentes cursos para conseguir su diploma, con lo que se abandonaba el sistema del taller donde estaban integrados diferentes niveles.

Una de las nuevas unidades pedagógicas provinciales fue la de Marsella, donde se incorporó como profesor Paul Nelson a partir de 1967 y lo hizo con el objetivo de crear un nuevo taller docente con un carácter experimental inspirado en el modelo didáctico de la Bauhaus ${ }^{64}$. Esta vez el objetivo era más global que el constituido en Beaux-Arts, por lo que lo denominó L`Atelier Franco-Internacional; su intención era que hubiera alumnos de todo el mundo y no solo norteamericanos. El programa docente proponía instruir a los alumnos en las disciplinas que recuperasen la arquitectura como acto creativo frente a la enseñanza de la arquitectura a través de la informática. Había que ayudar a los alumnos a proyectar siguiendo un método de síntesis, que debía partir del análisis y el encuentro de hipótesis opuestas ${ }^{65}$ y no de una creación gráfica. Su intención en los últimos años fue convertir su taller en un periodo de especialización e investigación previa para obtener el diploma.

\footnotetext{
${ }^{63}$ Carta, 18 julio de 1966, de Paul Nelson dirigida al director del departamento de arquitectura del MoMA, explicándole sus proyectos al frente del taller franco-americano y solicitándole financiación. MNAM/CCI, Bibliothèque Kandinsky, fonds Nelson. Ya lo había intentado en 1963 entrando en contactado con las entidades americanas F.A.I.A-A.C.S.A. pero no recibió ninguna ayuda económica. Véase: Jean-Pierre Epron, "Un enseignement suspendu. Paul Nelson, Professeur", Bulletin d'Informations Architecturales (IFA) n 130, abril 1989.

${ }^{64}$ Tras los cambios establecidos en 1968 para la enseñanza de la arquitectura, en la Unidad Pedagógica de Marsella se crean tres talleres, el de André Dunoyer de Segonzac especializado en la arquitectura de reconstrucción de postguerra, el taller de Paul Quintrand, que impartía la enseñanza utilizando métodos informática y el taller franco internacional de Paul Nelson. Véase : Jean Baptiste Leccia À l'école d'architecture: Chroniques grinçantes 1968-2011, París : L'Harmattan, 2011, p.269.

${ }^{65}$ Jean-Pierre Epron, "Un enseignement suspendu. PaulNelson, Professeur", Bulletin d'Informations Architecturales (IFA) nº 130, abril 1989, p. 21-23.
} 
En esta última etapa siguió explicando los temas relacionados con el crecimiento urbano desarrollados en su experiencia americana. El medio y el entorno de los proyectos tomaron cada vez mayor protagonismo en los trabajos propuestos a sus alumnos, como en el ejercicio para desarrollar una propuesta de crecimiento ideal para la ciudad de Martigues. Esta población estaba enclavada en un lugar junto a las montañas y frente al mar Mediterráneo, unos condicionantes que sus alumnos debían analizar para elaborar sus propuestas. Pero a parte del interés por el entorno, en estos últimos años como profesor de Marsellille-Luminy, su actividad se volcó en dos objetivos: en primer lugar, estaba redefinir la enseñanza de la arquitectura en función del nuevo papel que debía realizar el arquitecto en la sociedad; y en segundo lugar, en intentar construir su proyecto de La Maison Suspendue.

Nelson pensaba que la casa se podía convertir en un reclamo y en un referente para los estudiantes extranjeros y propuso al director de la escuela que La Maison Suspendue se construyera para que él y su mujer, que era pintora, pudiesen alojar a los alumnos de arte y arquitectura extranjeros e incluso a importantes artistas que visitasen temporalmente la universidad. Puso como ejemplo la casa construida por Josep Lluis Sert en el campus de la Universidad de Harvard, pero nunca hubo respuesta por parte del director a esta propuesta. En 1976 fue cesado como profesor concluyendo así su actividad como docente a los 81 años.

En los últimos años, en los que no tuvo más encargos que su propia casa, Paul Nelson utilizó la docencia como vía para transmitir conocimiento y como medio para definir el papel del arquitecto en el futuro. Manifestó que la enseñanza en las escuelas debía adaptarse y anticiparse a los cambios sociales y, dado que el perfil de los potenciales clientes era muy amplio y estaba asentado sobre una producción industrial, el conocimiento teórico a impartir en las universidades debía ser más flexible y más innovador ${ }^{66}$.

Para lograr estos objetivos, propuso enfocar la enseñanza desde una perspectiva internacional. Tenía asimilado este valor desde su propia experiencia, a través de su formación en un país extranjero rodeado por compañeros de diferentes nacionalidades, por sus viajes trasatlánticos y su labor docente en Norteamérica, un lugar que tras la Segunda Guerra Mundial se había convertido en el destino de ciudadanos de diferentes países. Si algo tuvieron en común las diferentes obras del Movimiento Moderno fue su carácter de internacional, algo que también había

${ }^{66}$ Paul Nelson, " l'industrialisation du bâtiment... et le rôle de l'architecte”, Arts de France n ${ }^{\circ}$ 25-26, 1948, pp. 52-60. 
influido en la trayectoria profesional de Paul Nelson; por lo tanto, frente a la enseñanza introspectiva de cada país, proponía que los alumnos aprendiesen el valor de lo internacional, pues defendía que el espíritu de las escuelas debía ser el aprendizaje a partir de la diferencia.

Paul Nelson pensó que la enseñanza debía anticiparse a las demandas sociales y con este objeto proponía desarrollar el aprendizaje mediante un proceso de investigación interdisciplinar. La academia debía encauzar su búsqueda del conocimiento para mejorar las condiciones sociales. El ciclo que generaba cualquier proyecto se debía iniciar con la síntesis de ideas obtenidas del trabajo colectivo y continuo de todos los agentes que participaban en la industria de la construcción y que abarcaba desde los arquitectos hasta los agentes inmobiliarios y en todas las fases se debía buscar la innovación a través de la colaboración. En esta enseñanza basada en un método de análisis racional, el aprendizaje a partir de la idea inicial de un esquema compositivo dejaba de tener sentido, rechazándose la investigación que surgía únicamente a partir del análisis formal. El aprendizaje ya no debía concentrarse solo en el dibujo. Finalmente el arquitecto ya no podía abordar con el mismo rigor todos los aspectos del proyecto, por lo tanto era necesario formar a arquitectos más productivos, especializados en diferentes tipos de arquitectura, que aportasen investigaciones sólidas a la sociedad. Por lo tanto, las escuelas debían fomentar la investigación, lo interdisciplinar, lo internacional y la especialización.

Paul Nelson aprovechó la enseñanza para desarrollar su idea de estrechar los vínculos entre la arquitectura y el hombre, y propuso que la formación en dicha disciplina se hiciese desde una perspectiva humanizadora del espacio, lo que también suponía poner la enseñanza al servicio de la vida del hombre. 


\section{Francine y Maddalena. Las actrices principales.}

$\mathrm{Al}$ igual que su vida profesional discurrió entre los dos continentes, la vida personal de Paul Nelson estuvo marcada por la presencia de sus dos mujeres, una francesa y la otra italiana, Francine y Maddalena. El primer matrimonio duró desde 1920 hasta la muerte de Francine en 1951, y el segundo, se inició en 1952 y terminó en 1979 con la muerte de Paul Nelson. Las dos mujeres pertenecían a familias relacionadas con el mundo del arte y mantenían vínculos con la arquitectura. ${ }^{67}$

Con su primera esposa, Francine compartió los años de formación, la década experimental de los años treinta, la guerra en Norteamérica, su vuelta a la Francia de posguerra y el inicio de la carrera hospitalaria. Por su parte, con Maddalena tuvo a sus hijos Ugo y Rory. Ella, además, fue testigo de su reconocimiento como arquitecto especialista en la construcción de hospitales, de la etapa de docencia e investigación en Estados Unidos y de su vuelta definitiva a Francia; estuvo junto a él en la construcción de sus nuevos proyectos de hospitales y en los últimos años de su vida profesional, en los que se dedicó a la docencia, primero en Beaux Arts y después en Marseille-Luminy.

La vida de Paul Nelson podía servir como guion para una película. El argumento contaría el desarrollo y la consolidación de los Estados Unidos como primera potencia industrial y cultural, visto a través de un protagonista muy americano, un descendiente de irlandeses que participó en las dos guerras junto al bando de los vencedores. En esta ficción, aparte del actor protagonista, habría que reconocer el papel de las actrices principales, Francine y Maddalena. El guión lo habría escrito Scott Fitzgerald. El director artístico, en este caso, coincidiría con el actor protagonista y los decorados serían los diferentes proyectos realizados a lo largo de cincuenta años. La banda sonora, sería una obra de Johann Sebastián Bach ${ }^{68}$.

Pero el verdadero tema sería la historia de un viaje, de una búsqueda personal, de un hombre que intentó vivir lo que pensaba, un luchador incansable que contó con el apoyo de sus dos mujeres, que le ayudaron o le dirigieron a revelarse contra un futuro preestablecido y a incorporarse a la modernidad.

\footnotetext{
${ }^{67}$ Anne Kandelman, Notes biographiques 1978 (révisée par Anne Kandelman), np

${ }^{68}$ Ugo Nelson, arquitecto, hijo de Paul Nelson manifestó que el compositor favorito de su padre era Johann Sebastián Bach. Entrevista mantenida el 26 de febrero de 2011.
} 


\subsection{Francine Le Coeur.}

I. 19 Francine Le Coeur, carboncillo sobre papel, Paul Nelson, 1923.

Francine Geneviève Le Coeur nació en 1890 en el parisino boulevard de Montparnasse. Era la segunda de tres hermanos. Su padre, Théodore Joseph Le Cœur, era ingeniero de artes y oficios y dirigía una empresa familiar denominada "Le Coeur et Compagnie", que se dedicaba a la fabricación de mobiliario desde el siglo XVIII. La compañía trabajó para muchos arquitectos del movimiento Art Noveau, como Hector Guimard. En la familia paterna de Francine había una tradición profesional; los hombres eran arquitectos y las mujeres se dedicaban a la decoración y al diseño de muebles. Su abuelo, Charles Le Cœur, fue el arquitecto encargado de realizar el prototipo de los liceos de la tercera república francesa y a la vez fue el primer mecenas del pintor Auguste Renoir. Su tío paterno, François Le Cœur ${ }^{69}$, fue uno de los primeros arquitectos franceses que utilizó el hormigón armado, era amigo de Auguste Perret y de Le Corbusier y trabajó como arquitecto para la compañía francesa de correos y telégrafos.

Francine y su hermana Yvonne Marguerite Le Cœur, siguiendo con la tradición profesional de las mujeres, trabajaron en la compañía familiar, donde se ocuparon del diseño y la realización de las piezas de decoración y textiles. Algunas de estas obras se expusieron en la World Fair de Golden Gate de San Francisco de 1939, representando a Francia en el pabellón de Artes Decorativas. Esta no era la primera vez que la compañía participaba en una Exposición Universal; con anterioridad la

${ }^{69}$ Marc Le Cœur, Charles Le Cour (1830-1906), architecte et premier amateur de Renoir (Exposición celebrada en París, Musée d'Orsay, 16 octubre 1965 al 5 enero 1997). Paris: Réunion des musées nationaux, 1996. 
empresa ya había ejecutado encargos para estos eventos. Así, el padre Théodore Joseph Le Cœur estaba al frente de la "Le Cœur et Compagnie" cuando se realizaron varias piezas que se expusieron en el pabellón francés de la Exposición Colombina de Chicago de 1893.

El mismo año de su llegada a París, Paul Nelson se casó con Francine Le Coeur. La boda se celebró el 25 de septiembre de 1920 en el ayuntamiento de Varengeville, el lugar de vacaciones de la familia Le Coeur en la Alta Normadía. Actuaron de testigos el escultor Paul Jouve y la diseñadora Lucie Renaudot ${ }^{70}$, que eran íntimos amigos de Francine. Este matrimonio fue trascendental en la vida de Paul Nelson, ya que Francine pertenecía a la alta burguesía y esto le abrió las puertas de París; le pusieron en contacto con la vanguardia artística y arquitectónica de la capital. La primera referencia del domicilio conyugal ubicaba la residencia en el 70 bis de Notre Dame des Champs, un apartamento que había sido el anterior domicilio del escritor Ezra Pound. El desahogo económico y las propiedades de la familia Le Coeur fueron muy importantes en la etapa inicial del matrimonio, cuando Paul Nelson aun estudiaba y no aportaba ingresos por su trabajo. Posteriormente, en la década de los treinta, esa estabilidad económica fue un apoyo que le permitió afrontar la arquitectura fuera del ámbito comercial.

Paul Nelson consideraba a Francine una persona culta e inteligente, que le ayudó a introducirse en París e iniciar su formación en Beaux-Arts ${ }^{71}$. En aquellos momentos él no hablaba francés y fue su esposa quien le acompañó, asistiendo a las clases en los primeros meses de su carrera y haciendo de intérprete. Cuando R. Buckminster Fuller conoció a Nelson (1928) se quedó impresionado por la personalidad de Francine, le pareció muy inteligente e incluso pensó que sus conocimientos sobre la arquitectura la convertían en la persona perfecta para traducir su proyecto de las casas 4D al francés. En una carta dirigida Paul Nelson, le sugirió que debían trabajar siempre los dos juntos, como un equipo ${ }^{72}$.

\footnotetext{
${ }^{70}$ En el acta de matrimonio, 25 de septiembre de 1920, Paul Nelson figuraba con la profesión de arquitecto y Francine sin profesión. Este documento se ha obtenido gracias a la colaboración de Doña Mariane Le Coeur, sobrina nieta de Francine y ahijada del matrimonio Nelson, de profesión arquitecto. La Maire de Varengeville sur mer, Registre Civil.

${ }^{71}$ Judith Applegate, "Paul Nelson: an interview". Perspecta nº13-14, 1971, op.cit. p. 76.

72 Carta, de 17 de agosto de 1928, de Richard Buckminster Fuller a Paull Nelson, Columbia University, Avery Architectural and Fine Arts Library, Dept. of Drawings \& Archives, Paul Nelson architectural records and papers.
} 
Oscar Nitzchké, socio y amigo de Paul Nelson desde finales de los años treinta, destacaba la participación de Francine en el trabajo del estudio y calificaba esa colaboración como "esencial", afirmando: "Francine era una persona maravillosa y una gran influencia para Nelson". ${ }^{73}$ Aunque no tenía formación como arquitecto, participó de manera activa en los proyectos hasta su muerte; en algunos casos queda constancia de su intervención por el reconocimiento explícito de su marido y en otros porque sus propias cartas fueron testimonio de su trabajo.

Por un lado, con motivo de la publicación de un monográfico sobre la ciudad hospitalaria de Lille en 1933, Paul Nelson escribió en los agradecimientos: "Dedico esta obra a Francine Le Coeur Nelson, el más preciado de mis colaboradores"74. Y por otro, tanto la correspondencia dirigida a Le Corbusier como las cartas sobre la maqueta de La Maison Suspendue dirigidas al maquetista, permitían entender su implicación en el estudio en la década de los treinta. Su última colaboración fue en 1951, junto a su hermana Yvone, en la decoración de la ampliación del Hospital Americano de Neuilly, especialmente en la decisión de la utilización de las piezas textiles ${ }^{75}$.

Francine tenía asignado dentro del estudio el papel de las relaciones sociales, pues su dominio de los dos idiomas y sus contactos le permitieron afrontar esta tarea; era ella quien escribía las cartas consensuadas que su marido firmaba. Incluso en la introducción de algunas cartas escribía frases personales, dada su cercanía al destinatario, y posteriormente se planteaba el motivo de la carta. Sus contactos eran la clave que abría algunas puertas infranqueables, como fue el caso de una carta enviada a Le Corbusier, que introdujo dándole las gracias por el apoyo recibido tras la muerte de su tío, François Le Cœur, y a continuación era Paul Nelson quien escribía una parte más breve, donde le informaba a Le Corbusier sobre un proyecto de hospital en Ismailia. Francine nunca olvidaba agradecer su trabajo a los colaboradores externos, sobre todo en el caso del maquetista Louis Dalbet. "Mi querido Dalbet: la maqueta ha llegado admirablemente bien, está aquí en el taller en el estado

\footnotetext{
${ }^{73}$ Texto mecanografiado anónimo, entrevista a Oskar Nitzchké. MNAM/CCI, Bibliothèque Kandinsky, fonds Nelson.

${ }^{73}$ Paul Nelson, Cité Hospitalière de Lille, Cahiers d’Art 1933, p.VI.

${ }^{74}$ Ibidem.

${ }^{75}$ Anonimo, "Hôpital américain de Paris", L'Architecture d'Aujourd'hui nº 40, abril 1952, p.74.
} 


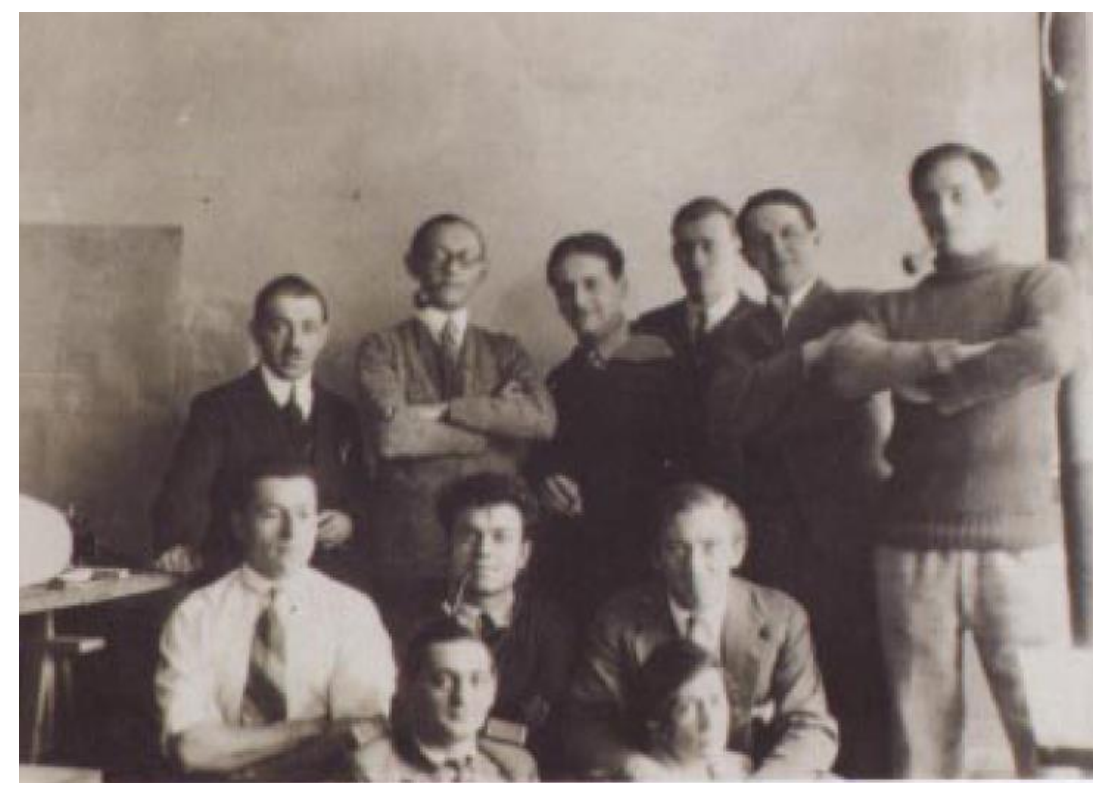

I. 20 Francine, (a la derecha, primera fila) junto a colaboradores del estudio del Boulevard Blanqui 81, París, ca 1930 .

exacto en que se la habíamos pedido. Gracias... Nos gustaría mucho recibirle aquí algún día, habrá que ocuparse de eso." 76

En el proyecto de La Maison Suspendue fue donde Francine se involucró de manera decisiva. Entre los meses de agosto y de noviembre de 1938, mantuvo una correspondencia muy frecuente con el maquetista, donde le hacía recomendaciones sobre la ejecución de la maqueta. Francine abordaba tanto los temas económicos como los técnicos y le hacía sugerencias y peticiones. Las observaciones que realizaba iban desde la resistencia que debía soportar el modelo, hasta los tipos de materiales nuevos que debía emplear, detallando todos los datos descritos de manera minuciosa.

...En resumen: esta maqueta tiene que poder viajar por América y por lo tanto hay que construirla teniendo en cuenta esta idea.

Otra cosa de la que he olvidado hablarle es del tema de la base, actualmente de madera, sobre la que está la maqueta. Esta madera se ha combado, cosa que aquí les ocurre, por otro lado, a todas las cosas de madera que vienen de Europa debido al clima. Actualmente está abombada en el centro, y entre 5 y $6 \mathrm{~m} / \mathrm{m}$ más baja por los bordes. ¿Sería posible pensar en una base de metal?. Desde luego sería más

\footnotetext{
${ }^{76}$ Tarjeta postal, de 31 de agosto de 1938, de Francine Nelson al maquetista Louis Dalbet, MNAM/CCI, Bibliothèque Kandinsky, fonds Nelson.
} 
pesada, pero lo que cuenta una vez más es la solidez y la resistencia a este país, y a los choques...77

Este inventario de las soluciones constructivas para la maqueta solo podía estar realizado por una persona que conociera el proyecto con precisión. De la lectura de estas cartas, a parte de los detalles técnicos, se deduce el entusiasmo y la intensidad con la que describía el trabajo realizado por su marido. Tenía la conciencia de que estaba realizando algo trascendente, un trabajo muy importante no solo para la arquitectura sino para el futuro del hombre.

\footnotetext{
...hay una verdadera campaña, orquestada por gente importante, a la que antes desconocíamos, para tratar de construir la Maison Suspendue en la Exposición Internacional de Nueva York. No sé si lo conseguirán, en primer lugar porque falta poco tiempo para la exposición, y en este tipo de acontecimientos hay tantos intereses creados a los que enfrentarse, y nosotros no queremos esperar demasiado para realizar un sueño tan hermoso... en cualquier caso el hecho incuestionable es el interés suscitado por el trabajo de Paul y la gran publicidad que le reporta todo esto. $^{78}$
}

El verano de 1951, Francine Nelson falleció mientras descansaban en Varengeville. Aunque ella no era arquitecto, la revista L'Architecture d'aujourd'hui le dedicó una nota necrológica ${ }^{79}$. En el texto se reconocía la intensidad y la constancia en el apoyo del trabajo de su marido, se mencionaba su participación mediante una colaboración directa en los proyectos del periodo de entreguerras y su ayuda en la redacción de artículos y conferencias, así como su contribución en la preparación de la exposición de las Techniques Américaines del Gran Palais de París de 1946. El texto terminaba con un reconocimiento a su participación en apoyo de los combatientes franceses desde Estados Unidos.

Las familias de Francine Le Coeur y de Paul Nelson se dedicaban a la misma actividad profesional, la decoración, incluso los trabajos respectivos de ambas compañías familiares se mostraron en el mismo espacio, la Exposición Colombina de Chicago de 1893, antes de que ellos se conocieran. Pero los gustos de las dos compañías evolucionaron de manera distinta. Así, mientras la "WP Nelson.Co." se

77 Carta, de 11 de noviembre de 1938, Francine Nelson, MNAM/CCI, Bibliothèque Kandinsky, fonds Nelson.

${ }^{78}$ Íbidem.

${ }^{79}$ Nota de la editorial, L'Architecture d'Aujourd'hui no 36, agosto 1951, p. XXXI. 
especializó en piezas Art Noveau, la "Le Coeur et Compagnie" siguió evolucionando e incorporando nuevos diseños de los arquitectos modernos.

Este espíritu de renovación y de revolución contra el orden establecido, que formaba parte del criterio de su familia, fue lo que Francine transmitió a Paul Nelson. Ella formó parte del empuje que le hizo cambiar su visión del mundo. Hasta su encuentro, la vida de Nelson había estado centrada en su familia y en la formación tradicional norteamericana, pero ella le ayudó a descubrir el valor de lo diferente y de lo internacional. Por lo tanto, aparte de su estrecha y evidente colaboración profesional y de su relación matrimonial, la influencia más importante que Francine ejerció sobre Nelson se produjo en su concepción de la vida. Le ayudó a iniciar su propia búsqueda interior y a crear su personalidad. Nelson afirmó: "Me casé con una chica francesa que era muy inteligente, y ella me dirigió en mi revolución ... una profunda revolución contra todo. Yo aprendí a odiar todo lo que era decoración". ${ }^{80}$

\subsection{Maddalena Giannatassio.}

Maddalena Giannatassio, su segunda esposa, nació en Roma en 1922. Su padre era el pintor futurista italiano Ugo Giannatassio, que vivió en París en la primera década del siglo XX donde conoció al pintor Gino Severino y al fundador del futurismo, el poeta Filippo Tommaso Marinetti. Ugo Giannatassio participó en los debates ideológicos acerca de la repercusión de las artes plásticas sobre las emociones humanas y expuso sus ideas sobre arte y política en la revista L'action d'art, vinculada a teorías anarquistas. ${ }^{81}$ En 1915 volvió a Italia y abandonó el arte para ingresar en el ejército. Cuando estalló la Segunda Guerra Mundial, rechazó la posición de Italia y fue prisionero de los nazis en Alemania. Tras la guerra retomó su carrera artística en Turín. ${ }^{82}$

\footnotetext{
${ }^{80}$ Judith Applegate, "Paul Nelson: an interview". Perspecta nº13-14, 1971, p.76.

${ }^{81}$ Mark Antliff, "Cubism, Futurism, Anarchis: The "Aestheticism"of the Action d'art Grou, 1906-1920", Oxford Art Journal, 21 de febrero de 1998, pp.99-120.

${ }^{82}$ Ugo Giannattasio volvió a pintar, y en 1954 formó parte del consejo editorial de la revista de arte "I 4 Soli", digida por Adriano Parisot ; esta revista publico una entrevista con Paul Nelson en 1957, con motivo de su estancia en la Graham Foundation.
} 


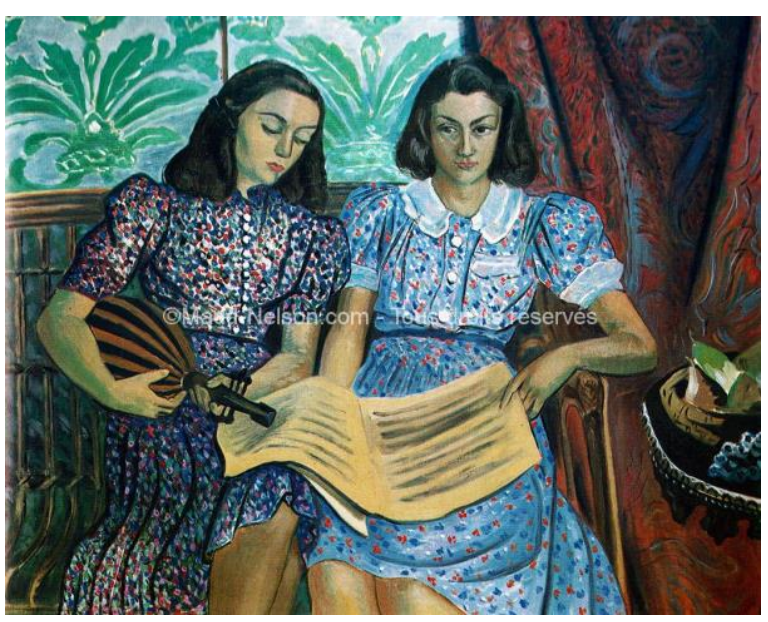

I. 21 Le figlie di Ugo Giannattassio, Maddalena Giannatassio ( derecha) y su hermana, Gino Severini, 1942.

Maddalena continuó la carrera artística de su padre y se diplomó en el Liceo Artístico de Roma. Después compaginó sus estudios de Bellas Artes en la Scuola Libero del Nudo en Roma con su asistencia a la academia de Gino Severino, quien la retrató junto a su hermana en 1942. A pesar de que la familia de su madre, los Vaccaro, pertenecían a la aristocracia de Roma y tuvieron una buena posición social y económica durante el régimen de Benito Mussolini ${ }^{83}$, en 1946 Maddalena y su familia tuvieron que trasladarse a Turín en busca de un futuro mejor, donde se dedicó a realizar trabajos de publicista, los únicos encargos que le proporcionaban ingresos. A principios de la década de los años cincuenta se trasladó a París para desarrollar su carrera de pintora y allí se instaló en la casa de su antiguo profesor.

En aquellos años, Gino Severini exploraba en su pintura una nueva visión del cubismo y del futurismo. Estuvo investigando con las artes aplicadas y realizó unos mosaicos que expuso en la galería Cahiers D'Art, propiedad de Christian Zervos, amigo personal de Paul Nelson. Gino Severini introdujo a Maddalena en los círculos artísticos de la capital y el primer encargo que recibió fue realizar la decoración de un apartamento en París, aunque ella había dedicado su carrera artística a la pintura y nunca había trabajado como decoradora, no tenía ningún conocimiento acerca de la distribución de una vivienda, ni de los materiales a utilizar. Dada su falta de experiencia, Gino Severini le aconsejó que buscara la colaboración de algún arquitecto, y así entró en contacto con Paul Nelson. El pintor

\footnotetext{
${ }^{83}$ Giorgio Vacco, un hermano de su madre, fue general en el ejercito italiano durante la Segunda Guerra Mundial.
} 


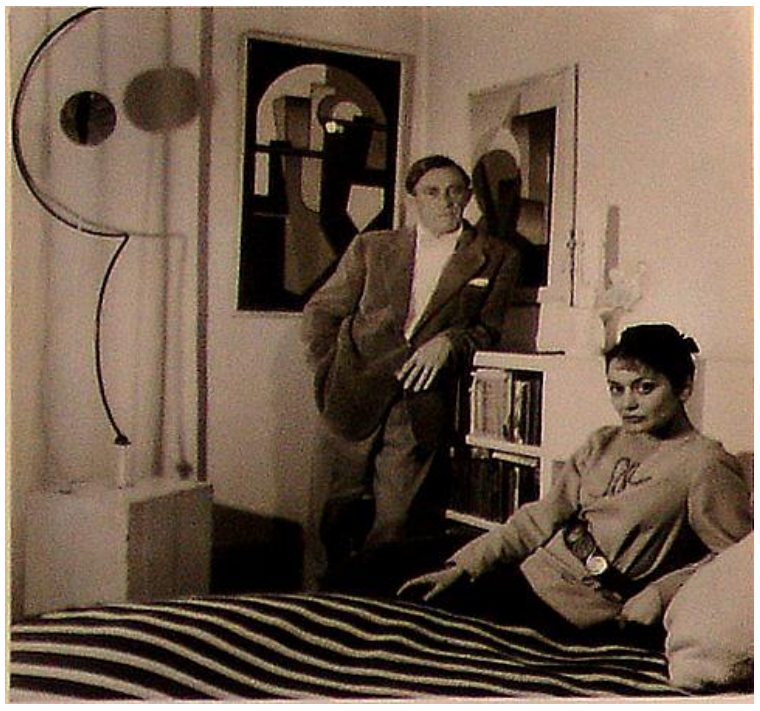

I. 22 Paul Nelson y Maddalena en su apartamento de París, delante de obras de Calder, Giacometti, y Giannattasio 1952.

les presentó en la Closerie des Lilas en el barrio latino, un lugar frecuentado por los artistas y, aunque en ese primer encuentro Paul Nelson fue muy crítico con el aspecto y el maquillaje de Maddalena, finalmente le ofreció su ayuda para realizar los planos de encargo ${ }^{84}$.

La pareja comenzó su relación y se casó en Londres en septiembre de 1952, ya que los trámites eran más rápidos que en París y actuó como testigo el antiguo compañero de carrera, el arquitecto Ernö Goldfinger, que vivía en la ciudad. Fijaron su residencia en el 98 del Boulevard Blanqui, en el mismo edificio donde estaba el estudio de Paul Nelson. El matrimonio tuvo dos hijos, Ugo, que nació en 1954, y Rory, en 1955, que se decantaron por la arquitectura y la música respectivamente.

Maddalena no desarrollaba su actividad pictórica durante aquellos años, pero las obras de arte estaban muy presentes en su vida. En su apartamento de París, aparte de los cuadros realizados por su padre, Ugo Giannatassio, tenían esculturas de Alexander Calder, Alberto Giacometti y Jean Hélion. Incluso A. Calder realizó para ella varias joyas en bronce y J. Hélión le dedicó alguno de sus cuadros. Durante su estancia en Estados Unidos, la familia tuvo que vender algunas obras para conseguir dinero.

\footnotetext{
${ }^{84}$ Datos biográficos facilitados por los hijos del matrimonio, Ugo y Rory Nelson.
} 
A su regreso a Francia a principios de los años sesenta, Maddalena retomó su actividad pictórica e instaló su taller en la casa familiar de Varengeville, en la Normandía. El entorno de la casa, situada frente al mar, marcó sus composiciones paisajísticas iniciales. Ella siempre había estado rodeada por artistas, primero su padre y sus amigos y después los amigos artistas de su marido, (A.Calder, J.Hélion, etc.), quienes la animaron a buscar su propio estilo y a convertirse en una verdadera artista. Sobre todo, fue el pintor Georges Braque uno de los que mas influyeron en su decisión. Maddalena venía de Norteamérica donde había podido ver la evolución de toda la pintura de posguerra. Y muy cerca, como vecino, tenía a Georges Braque, que estaba pintando sus interpretaciones paisajísticas inspiradas en la naturaleza de la Normadía. Su pintura comenzó siendo una mezcla de estas dos vías, y sus obras de los primeros años sesenta eran composiciones con temas marinos, ejecutadas a base trazos sueltos y manchas de color.

Cuando Paul Nelson aceptó la oferta de profesor en Marsella-Luminy, el matrimonio se trasladó a Marsella, donde comenzó a participar en la vida social y cultural de su comunidad, formando parte de la asociación cultural de su distrito. Se interesaron por los problemas ciudadanos y fueron impulsores de la creación de un nuevo espacio socio-cultural para el barrio. Se trataba de un centro destinado al ocio donde podían celebrarse exposiciones, conferencias o teatro. Paul Nelson propuso resolver el recinto con una estructura ligera y desmontable ya que se trataba de realizar una intervención mínima, económica y que no provocase alteraciones en el medio. Maddalena se involucró en la propuesta y, para apoyarla, formó parte de comité de expertos culturales encargados de seleccionar las obras de arte que se iban a exponer en este espacio, pero este proyecto no llegó a consolidarse. ${ }^{85}$

Posteriormente el matrimonio decidió marcharse a vivir al campo y se construyó una casa, La Maison Nelson, que fue el único proyecto arquitectónico que desarrollaron juntos. La vivienda estaba situada en la ladera de una montaña, desde donde se podía ver el Mediterráneo, y Maddalena volvió a instalar allí su taller; pero esta vez el estudio no ocupaba una edificación separada de la vivienda, sino que estaba integrado dentro del ámbito doméstico.

\footnotetext{
${ }^{85}$ Liens, Bulletin association du Centre Socio-Culturel du Roy d'Espagne, $\mathrm{n}^{\mathrm{o}} 11$, noviembre 1968.
} 
I. 23 Maddalena Giannattasio, pintando en la casa de Trets.

En una primera versión de proyecto, el espacio para el taller estaba situado en la planta primera, era una sala abuhardillada con luz cenital. Pero finalmente no se construyó la planta superior de la vivienda y el estudio se situó en la planta baja, en contacto directo con el jardín e iluminación a través del cerramiento del vidrio de la fachada. Solo disfrutaron de esta casa tres años ya que el 30 de agosto de 1979 Paul Nelson falleció en un hospital de Marsella. Maddalena continuó pintando primero en la casa y posteriormente se instaló en región de Albi, donde murió en 2008.

La aportación de Maddalena al trabajo de su marido no fue fruto de su intervención en los proyectos, no colaboró como artista en las obras, ni formó parte de las personas que trabajaron en el estudio. La influencia se produjo a través de sus críticas, sus observaciones y su juicio creativo sobre los proyectos. Esto la convirtió en referente y en el principal apoyo para Paul Nelson. Le acompañó en sus viajes profesionales y le ayudó a mantener su amistad con los amigos artistas y arquitectos, especialmente con el matrimonio Calder y con Tibor Freesz, antiguo colaborador, y su esposa Suzanne. Maddalena le proporcionó estabilidad, seguridad y juventud, Cuando muchos de sus compañeros de Princeton estaban ya retirados, él comenzaba a crear una nueva familia e iniciaba una etapa con encargos públicos. La elección de los encargos profesionales estaba vinculada a la vida familiar. Así sucedió cuando se marcharon a Estados Unidos. El matrimonio entendió que podía ser una buena experiencia para sus hijos. Este periodo coincidió con un cambio en su manera de abordar su trabajo, su arquitectura se fue transformando, perdió ligereza y volvió a utilizar estructuras de hormigón y cerramientos más pesados. 


\subsection{Las actrices y sus casas.}

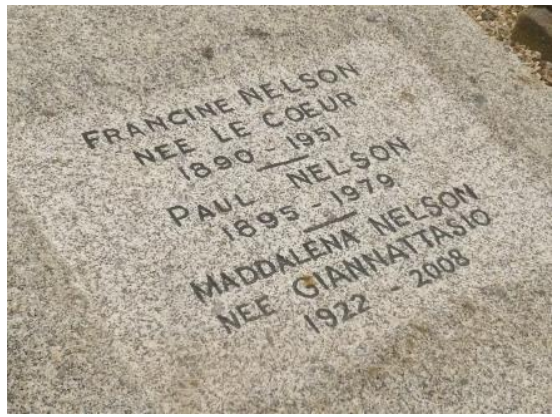

I. 24 Tumba de Francine Le Cœur, Paul Nelson y Maddalena Giannattasio.

Sus dos matrimonios culminaron con dos viviendas, una no ejecutada, La Maison Suspendue, y la otra construida en 1976, La Maison Nelson. Las dos casas fueron concebidas con cuarenta años de diferencia y una guerra entre ellas. La primera representaba la condensación de una investigación experimental, de un arquitecto joven; y la segunda fue el resultado de una carrera profesional, representaba la madurez. Las dos viviendas se correspondían con dos tiempos históricos y dos modelos de vida doméstica diferentes: la de los años treinta respondía a un concepto de familia cosmopolita, donde las relaciones con los artistas y los amigos estaban muy presentes; en la casa de los años setenta el programa y las dimensiones se redujeron y la vivienda se convirtió en algo muy apegado al entorno, fundamentalmente era un refugio. Las dos casas fueron testimonios biográficos de Paul Nelson y en ambas sus mujeres participaron de manera importante. Francine lo hizo con su aportación directa y su apoyo a la casa-manifiesto de 1938 y Maddalena con el planteamiento de sus necesidades y sus deseos de construir la casa-testamento de 1976.

Los restos de Paul Nelson reposan en la misma tumba que los de Francine y Maddalena, en el cementerio marítimo de Varengeville-sur-Mer.(I. 24) 
Paul Nelson. Un arquitecto aviador 1895-1979 



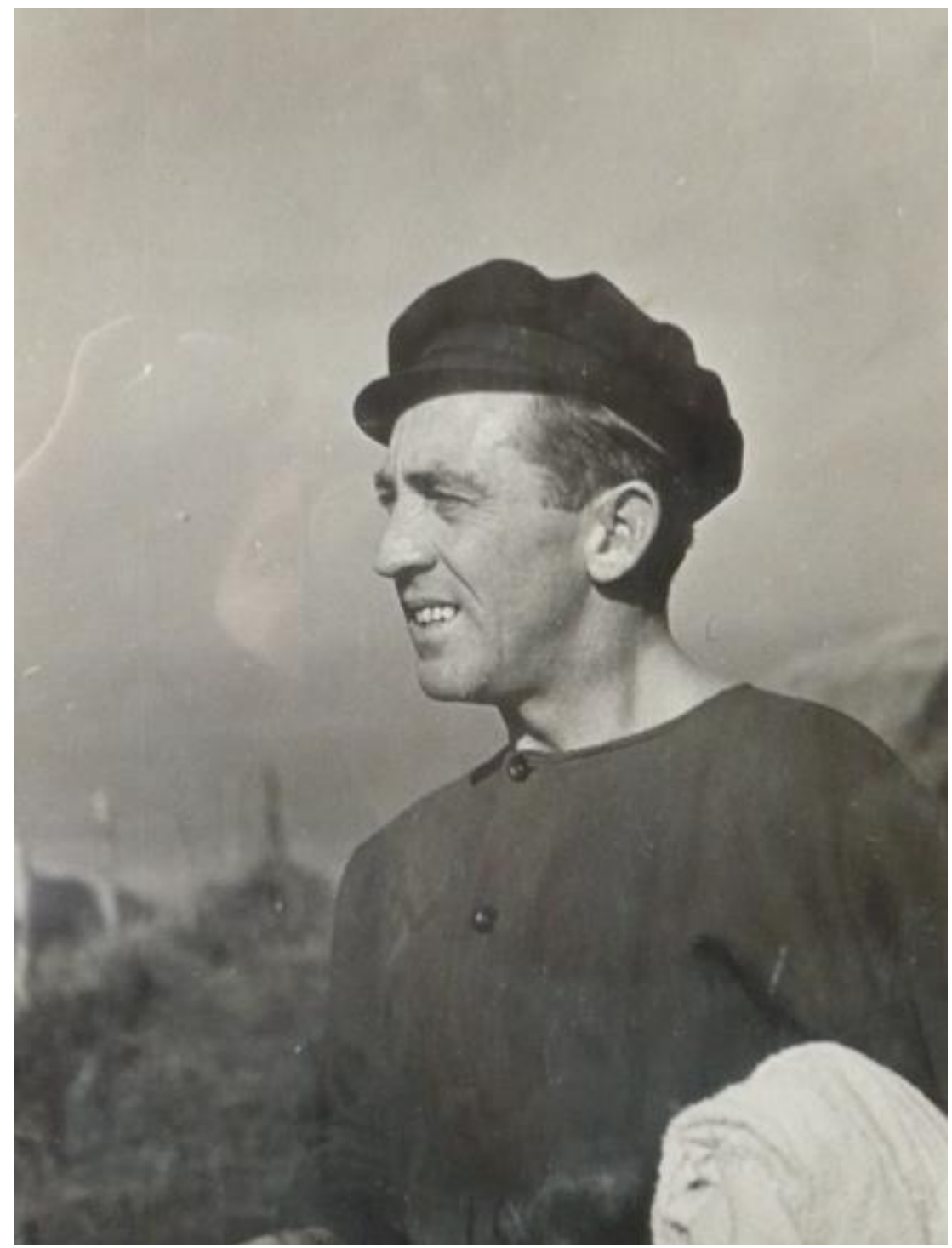

II. 1 Paul Nelson frente al Canal de la Mancha, Varengeville, ca 1937

\section{APRENDIZAJE, ENTRE LA TECNOLOGÍA Y EL HUMANISMO}




\section{La superación del racionalismo.}

Durante la década de los treinta, la obra de Paul Nelson evolucionó, acorde con el marco del cambio que estaba experimentado la arquitectura moderna, con respecto a los años precedentes. Paul Nelson, a través de artículos ${ }^{86}$ y anticipándose a lo que hicieron los críticos de arquitectura después de la II Guerra Mundial, comenzó a replantearse la vigencia de los postulados del Movimiento Moderno, que eran los que habían marcado la pauta de su trabajo hasta aquel momento. Y consideró que esos conceptos modernos eran tan dogmáticos como los que habían caracterizado a Beaux-Arts y resultaban insuficientes para cubrir las necesidades de la sociedad, por lo que era prioritario desarrollar una transformación. "La solución sobrepasará a la simple arquitectura utilitaria y se convertirá en un logro arquitectural” ${ }^{17}$

\footnotetext{
...Gracias a la obra excelente de ciertos predecesores que todos conocemos, se ha logrado la revolución ténica y estética. Esto marca el final de un periodo, lo que se requiere ahora para el futuro desarrollo de la arquitectura contemporánea es la aplicación de esos logros a la vida... ${ }^{88}$
}

Para los críticos de posguerra, la arquitectura de los años treinta, siendo heredera del Movimiento Moderno, comenzó a experimentar una transición hacia una nueva etapa que se vio marcada por la II Guerra Mundial ${ }^{89}$. Este proceso evolutivo internacional que experimentó la arquitectura tuvo consecuencias en la obra y en el pensamiento de Paul Nelson. La primera fue considerar que la arquitectura europea, y especialmente la francesa, había dejado de ser su único referente ya que la

\footnotetext{
${ }^{86}$ Paul Nelson, que no construyó ningún proyecto de escala pública durante los años treinta, utilizó los artículos en revistas especializadas para expresar su opinión sobre la arquitectura contemporánea.

${ }^{87}$ Paul Nelson, “A Method of Procedure in Architectural Design”, Architéctural Record June 1937, p.53.

${ }^{88}$ Ibidem.

${ }^{89}$ Para Sigfried Giedion, en esta se ha alcanzado un desarrollo que permitía saltar de lo racional-funcional a lo irracional-orgánico. El crítico Bruno Zevi pensaba que en esta década se habían fijando las bases de una nueva arquitectura más humanizadora, la "arquitectura orgánica", cuyo mayor impulsor era Frank Lloyd Wright. El historiador Reyner Banham mantuvo una visión más crítica con el funcionalismo que los otros dos profesores; consideraba que el Movimiento Moderno había sido incapaz de canalizar los avances mecánicos para definir un nuevo espacio y una verdadera transformación de la arquitectura. Reyner Banham consideró que en los años treinta hubo una ruptura con respecto a los años precedentes. Para Reyner Banham el único arquitecto que representó la imagen de la traslación de la técnica a la arquitectura fue Richard Buckminster Fuller.
} 
arquitectura norteamericana le ofrecía otro nuevo panorama, donde los avances técnicos habrían más posibilidades de evolución. La segunda fue comprobar cómo los valores del funcionalismo no habían sido erróneos, sino que resultaban insuficientes ante las demandas de la sociedad; y la tercera, pensar que para avanzar en arquitectura había que incorporar valores humanizadores. A partir de 1933, a los caracteres funcionales, constructivos y estéticos de su obra, les añadió dos nuevos valores: la técnica y la humanización.

\subsection{El comienzo de la transformación. 1933}

El año 1933 fue el momento clave en la carrera de Paul Nelson, pasó de proyectar una arquitectura masiva, de cerramientos pesados y estructuras in situ, a pensar en una obra ejecutada con una estructura y unos materiales más ligeros, que incorporaba los procesos de fabricación idustrial. Esta evolución fue plasmada por escrito, especialmente en un artículo dedicado a La Maison de Verre, haciendo un reconocimiento a la industria norteamericana, e incluso llegó a desarrollar un método de trabajo para sistematizar su nuevo proceso de creación, en el que incorporaba a su labor de arquitectura los modos de producción de la industria norteamericana. Este proceso tuvo su culminación en la investigación de La Maison Suspendue.

El contexto social, político, cultural y económico de los años treinta era diferente a cuando había surgido la arquitectura moderna. Durante la gran depresión de 1929, la industrialización norteamericana había generado grandes suburbios carentes de infraestructuras. En Francia, la izquierda salió del gobierno y la vanguardia cultural de París comenzó a desvanecerse. En Alemania, el partido nazi llegó al poder, cerró la Bauhaus y construyó una arquitectura monumental que retomaba el clasicismo como símbolo de su fuerza. Y en España, la Guerra Civil hizo que la amenaza del fascismo se extendiese a toda Europa.

En Estados Unidos, Paul Nelson pudo comprobar, a través de sus viajes transatlánticos, la celeridad con la que se implantaba la máquina, proclamada por Henry Ford, el nuevo "mesías" de la industria americana. Este desarrollo técnico se trasladó a la construcción, lo que convirtió a Nueva York en el paradigma del crecimiento vertical. Para Estados Unidos el mundo exterior había dejado de ser el enemigo, se pasó de una mirada cultural introspectiva a aceptar que los maestros 
II. 2 Farmacia en París, Paul Nelson, 1931.

europeos Walter Gropius, Mies van der Rhoe o Laszlo Moholy Nagy fueran los difusores de la arquitectura moderna a través de la docencia en las universidades americanas. Las exposiciones desarrollaron un papel importante en la difusión de la arquitectura moderna, y Paul Nelson logró estar presente en tres de las más importantes. Así en la muestra "The International Style" de 1932 celebrada en el Museum of Modern Art de New York (MoMA) se expuso la fotografía de una farmacia que había construido en París en $1931^{90}$. Y tanto en la Exposición Internacional de San Francisco en 1938 como en la de Nueva York en 1939, que fueron las dos últimas oportunidades que tuvo los Estados Unidos antes de la Segunda Guerra Mundial para mostrar al mundo el potencial de su industria y de su arquitectura, y poder compararlo con lo que se estaba realizando en otros países. Paul Nelson estuvo presente con La Maison Suspendue.

En Francia, el Frente Popular de izquierdas de Léon Blum, con el que simpatizaba Paul Nelson, perdió el poder en 1938. Los programas sociales de vivienda se paralizaron y disminuyó el apoyo a la arquitectura moderna por la falta de encargos institucionales. Para el profesor Gérard Monnier ${ }^{91}$, este periodo estuvo marcado por

\footnotetext{
${ }^{90}$ La farmacia de Paul Nelson se mostró como parte del contexto arquitectónico moderno francés.Véase: Philip Johnson, Henry Russell Hitchock, JR. "Extent of Modern Architecture", Modern architecture: international exhibition, New York, Feb. 10 to March 23, 1932, New York: The Museum of Modern Art,1932. pp.22 y 25.

91 Gérard Monnier, (n.1935) historiador de la arquitectura, profesor Universidad París-I Panthéon-Sorbonne, es autor de varios libros sobre la arquitectura francesa del siglo XX.
} 
una desaceleración sin precedentes en la industria de la construcción. Los arquitectos franceses buscaron nuevas oportunidades en el extranjero, incluso Le Corbusier viajó a Argel y a Estados Unidos para abrir su campo de trabajo. Paul Nelson, que no construyó ningún proyecto público en este periodo, también tuvo sus principales encargos en el extranjero: el proyecto para el hospital de Ismaïlia en Egipto y la estación de radio para la C.B.S en Nueva York.

Algunas galerías de París volvieron a mostrar unos cuadros neoconservadores, alejados de las vanguardias, en los que proliferaban los paisajes bucólicos de la vida fuera de la ciudad. Esta idea de vuelta al campo y a lo vernáculo también se manifestó en la arquitectura. Gustave Umbdenstock ${ }^{92}$, historiador y profesor de Beaux-Arts, escribió en 1930 un libro con una recopilación arquitectónica del regionalismo historicista francés. En su texto proponía una vuelta a una arquitectura que expresara el sentimiento francés y reivindicaba la labor de los canteros franceses como los artífices de la mejor arquitectura de Francia. Frente al discurso de carácter internacional que había impregnado la cultura de las décadas de los años veinte, propugnaba una revisión de la arquitectura local. Paul Nelson huyó de la nostalgia a la tradición francesa y proyectó su mirada hacia la incipiente arquitectura americana y sus medios de producción; en Estados Unidos la modernidad era un hecho imparable.

La crisis económica también afectó a los materiales utilizados para fabricar el mobiliario de sus viviendas. En Francia, la madera se convirtió en el material más demandado, lo que provocó el estancamiento industrial y la vuelta a los oficios tradicionales $^{93}$. El cambio de los tubos metálicos, como pieza básica del mobiliario

Gérard Monnier, L'architecture en France : une histoire critique,1918-1950. Paris : Philippe Sers Editeur, 1990, p.327.

${ }^{92}$ Gustave Umbdenstock (1866-1940). Arquitecto, fue profesor en L'École polytechnique y en Beaux Arts de París ; obra destacada: Lycée Pasteur en Neuilly-sur-Seine (1912-1923), Pont du Carrousel en Paris (1935-1939). Escribió varios textos en defensa de la arquitectura francesa tradicional. La Défense des métiers de main des artistes et des arttisans français, París : 1932 Véase: Romy Golan, Modernity and Nostalgia: Art and politics in France between the wars, New Haven: Yale University Press 1995

${ }^{93}$ En el año 1935, Fernand Léger, Le Corbusier y Charlotte Perriand, fueron invitados por la Union des Arts Décoratifs Modernes (U.A.M) y el Congrès Internationaux d'Architecture Moderne (C.I.A.M) a participar en el pabellón francés de la Exposición Internacional de Bruselas. Con la recreación del hogar de la familia francesa, la propuesta de mobiliario de estos creadores estaba ejecutada fundamentalmente en madera, lo cual suponía un giro de $180^{\circ}$ respecto de los muebles de tubo metálico creados en la década de los veinte. Véase : Romy Golan, Modernity and Nostalgia: Art and politics in France between the wars, New Haven: Yale University Press 1995, p. 96. 
moderno de los años veinte, por la madera, ponía de manifiesto la vuelta a lo artesano, y la lucha entre al oficio manual y la producción industrial. Esto se hizo extensible a la arquitectura, así el mencionado historiador Gustave Umbdenstock demandaba una arquitectura más cercana a la manera tradicional de vivir de una masa de población no cualificada frente a una concepción de la vivienda más restrictiva y pensada para una élite intelectual, tal y como a su juicio la había desarrollado Le Corbusier. Paul Nelson coincidía con ese sentimiento y también pensaba que su arquitectura debía tomar un camino que la hiciese más cercana al hombre; pero, a diferencia de Gustave Umbdenstock, no concebía que la solución fuese una vuelta atrás, a lo local. Para Nelson la arquitectura moderna había logrado unos valores sobre los cuales había que avanzar, su postura era de integración de la técnica con la naturaleza.

\subsection{El final de la Escuela de París y la Exposición Internacional.1937}

El año 1937 fue un momento decisivo en la carrera de Paul Nelson. Desde su vuelta de Estados Unidos, en primavera, se dedicó de manera intensa a desarrollar el proyecto de La Maison Suspendue, que había quedado interrumpido en el verano del año anterior. El proceso evolutivo del proyecto coincidió con un acontecimiento importante para la ciudad de París, La Exposición Internacional, donde Paul Nelson tuvo la oportunidad de ver la arquitectura que se estaba haciendo en otros países.

La referencia profesional más próxima a Nelson había sido la labor desarrollada por los arquitectos de La Escuela de París ${ }^{94}$, aquellos que habían realizado su trabajo en la capital francesa en el periodo de entreguerras. Junto a los nombres de Rob MalletStevens, Auguste Perret, Le Corbusier y Pierre Chareau, estaban los de Paul Nelson y sus compañeros, Berthold Lubetkin, Oscar Nitzchké, Ërno Goldfinger y Pierre Forestier, todos ellos alumnos de Augute Perret. A estos arquitectos había que añadirles a los ingenieros Vladimir Bodiansky, quien calculó las estructuras de los proyectos de Paul Nelson en los años treinta; Jean Prouvé, con quien también colaboró, y Gaston Le Marec, que construyó el aeródromo de Chalais-Meudon, uno de los edificios favoritos de Paul Nelson.

\footnotetext{
94 Kenneth Frampton, "Paul Nelson et l'École de Paris-1923-1938", Bulletin d'Informations Architecturales (IFA) no 130 abril 1989, p. 3-4.
} 


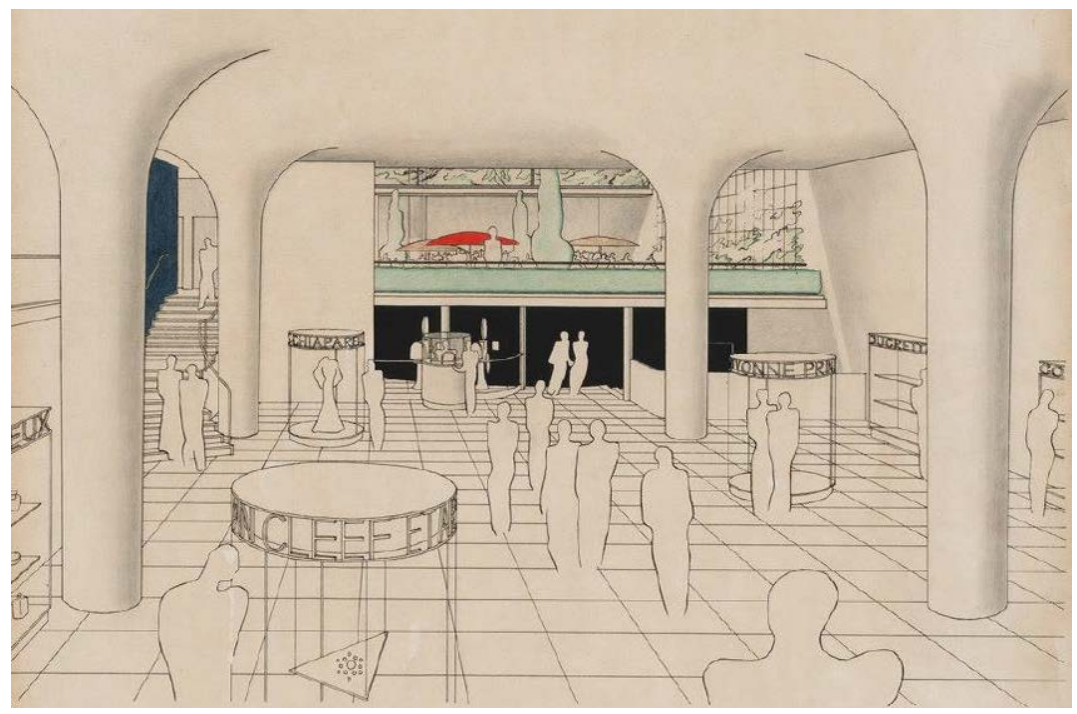

II. 3 La Maison de la Publicité, perspectiva desde los Champs Elysées de París, Oscar Nitzchke,1935

De entre todos sus compañeros, Oscar Nitzchké fue su más estrecho colaborador durante la década de los treinta; aunque los dos arquitectos buscaron caminos diferentes para desarrollar sus proyectos, tanto Oscar Nitzchké como Paul Nelson mantuvieron el referente del clasicismo estructural como orden superior que permitía dotar de libertad espacial al proyecto. En 1935 Oscar Nitzchké proyectó La Maison de la Publicité (II. 3), un edificio situado en los Champs Elysées de París con una fachada ligera de vidrio y metal, accesible y con uso publicitario. Todo el peso del volumen en fachada quedaba soportado por cuatro columnas, de tal manera que el vestíbulo principal se podía organizar de manera flexible a través de unos expositores cilíndricos. Esta manera de organizar el espacio público a partir del mobiliario también fue utilizada por Paul Nelson en sus proyectos y especialmente en La Maison Suspendue.

La colaboración y el contacto con Oscar Nitzchké y con otros antiguos compañeros de carrera, del Atelier del Palais de Bois de Auguste Perret, también le permitió observar otras maneras de pensar la vivienda. En 1929, Andrien Brelet, André Ledonne y Oscar Nitzchké, que fue su colaborador en los años treinta, desarrollaron un prototipo de vivienda metálica (II. 4), ejecutada con paneles prefabricados. 


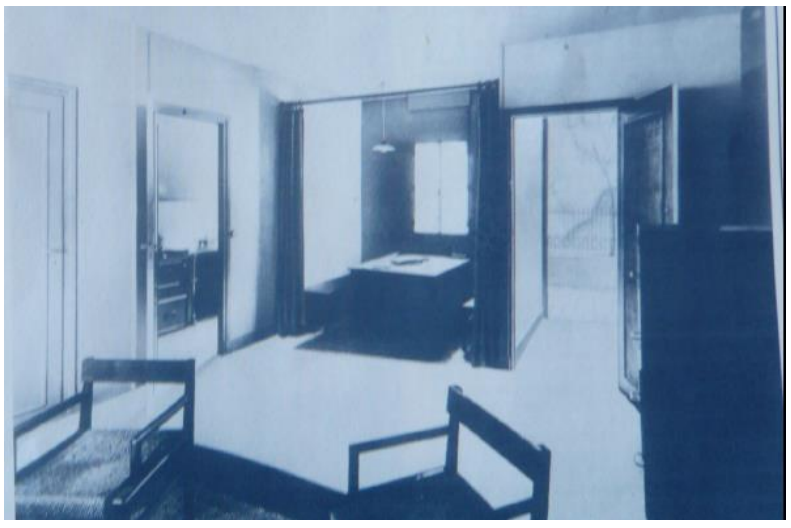

II. 4 Maison métalique, al fondo de la imagen y delimitado por cortinas, se encuentra un espacio privado dentro del salón familiar Andrien Brelet, André Ledonne y Oscar Nitzchké, 1929.

La casa no buscaba una innovación espacial, la distribución respondía a criterios funcionales. Pero dentro del salón de esta vivienda, de una planta, había un pequeño espacio de comedor, con una mesa y dos bancos, que podía quedar aislado o conectado con el resto de la estancia gracias a unas cortinas. Esta decisión permitía que el espacio público pudiese albergar varias funciones simultáneamente y que hubiese diferentes categorías de aislamiento. Esta idea fue desarrollada por Paul Nelson en su propuesta de vivienda, y profundizó sobre la aportación que la creación de un espacio similar podía tener en el desarrollo individual de los habitantes.

Según Kenneth Frampton, el final de La Escuela de París lo marcó la Exposición Internacional en París de 1937. Era el final de una época y también era la última esperanza para muchos arquitectos modernos de conseguir un encargo. Paul Nelson no había construido ningún encargo oficial en esa década, ni siquiera para la Exposición; sin embargo, ofreció, junto a Frantz Jourdain y a Oscar Nitzchké, una propuesta al Estado para levantar un espacio expositivo estable, donde mostrar los descubrimientos científicos, que finalmente no fue construido.

Durante la Exposición Internacional, Nelson comprobó que los conceptos espaciales, materiales y técnicos que habían utilizado los arquitectos en sus pabellones eran similares a los que estaba desarrollando en su investigación ${ }^{95}$. Paul

\footnotetext{
${ }^{95}$ En el número especial que la revista L'Architecture d'aujourd'hui dedicó a la Exposición Internacional de París de 1937, aparecía un texto anónimo titulado "Formes 1937", en el que se reflexionaba sobre las formas y los tipos estructurales más utilizados entre los pabellones. La nota estaba ilustrada por una serie de esquemas donde predominaban las estructuras metálicas, combinando cerchas, pilares y elementos de suspensión y de tracción. Los dos dibujos superiores correspondían a dos sistemas de montaje, uno era una grúa puente, de la que pendía un forjado metálico, y otro una unidad prefabricada colgada del brazo de un elevador. En todos los proyectos elegidos había una presencia protagonista de la rampa,
} 


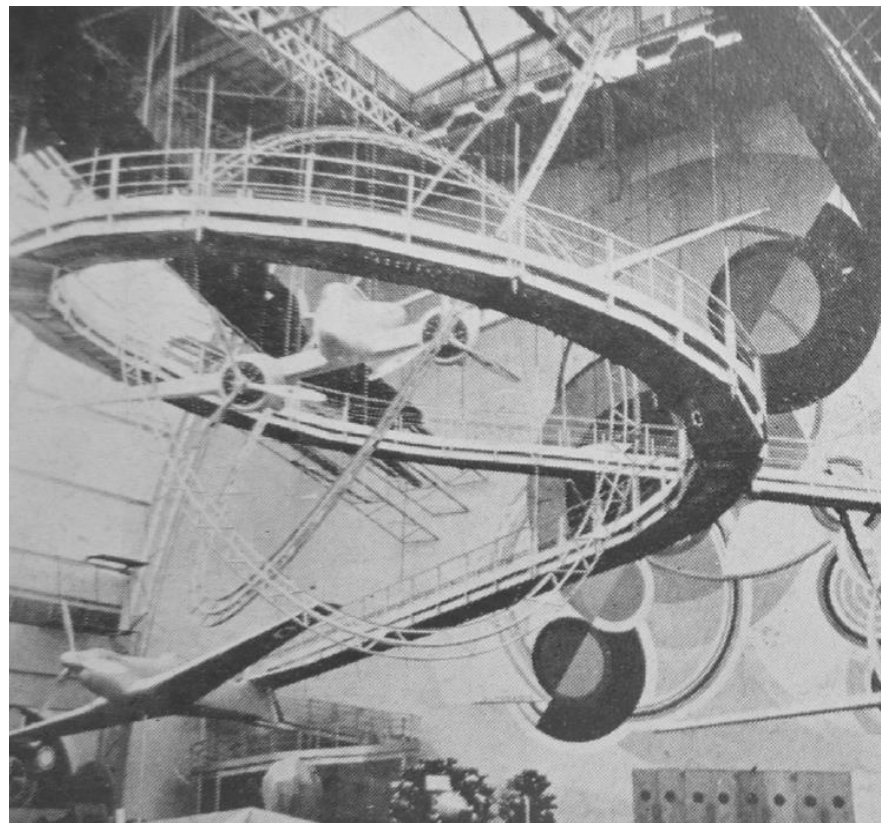

II. 5 Palacio de la aerodinámica, Exposición Internacional de París. Audoul, Hartwig y Gérodias, 1937

Nelson estaba trabajando en la idea de un pabellón-casa, que se pudiese ejecutar con una estructura metálica desmontable y flexible, una vivienda donde se exhibían obras de arte.

En el palacio de la aerodinámica, construido por los arquitectos Audoul, Hartwig y Gérodias (II. 5), se utilizó el concepto del hangar, un contenedor de vidrio con piezas independientes en su interior. Este fue el mismo planteamiento al que recurrió Paul Nelson en el espacio interior de su vivienda. Los arquitectos del pabellón proyectaron un gran espacio central con aviones suspendidos de una cúpula de acero y cristal. Una rampa en espiral, suspendida del techo sobre el vestíbulo principal, permitía al visitante desplazarse entre los diversos aeroplanos y experimentar la sensación de la ingravidez, similar a la relación que Nelson desaba alcanzar con la rampa que proyectaba para la casa. Y también, como sucedió posteriormente en La Maison Suspendue, el arte estaba presente en los espacios representativos: dado que en uno de los muros del espacio expositivo había murales pintados por Robert Delaunay.

convirtiendo las comunicaciones y los desplazamientos en los pabellones en objetivos prioritarios. Véase: L'Archquitecture d'aujourd'hui nº 9, septiembre 1937 


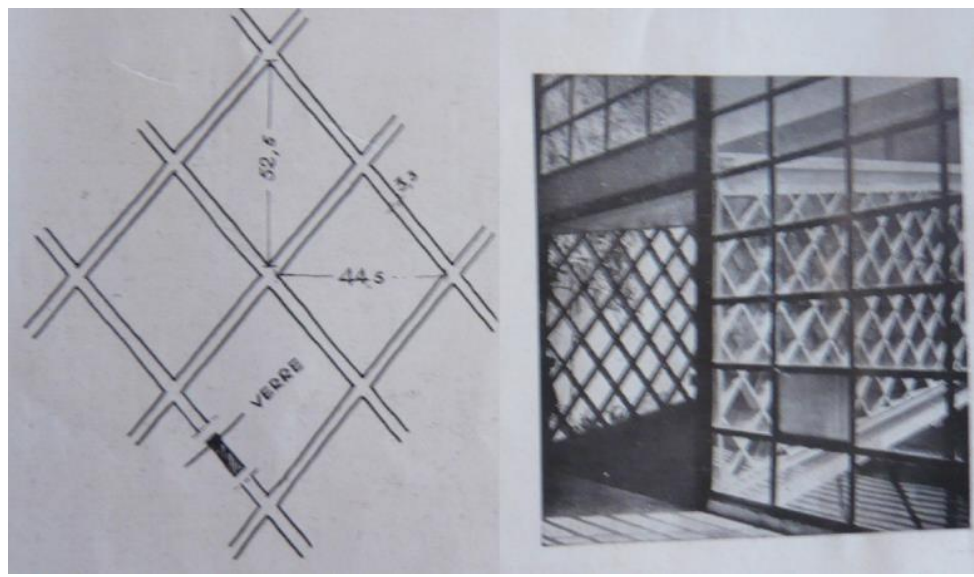

II. 6 Pabellón de Japón, Exposición Internacional de París. Junzo Sakakura,1937

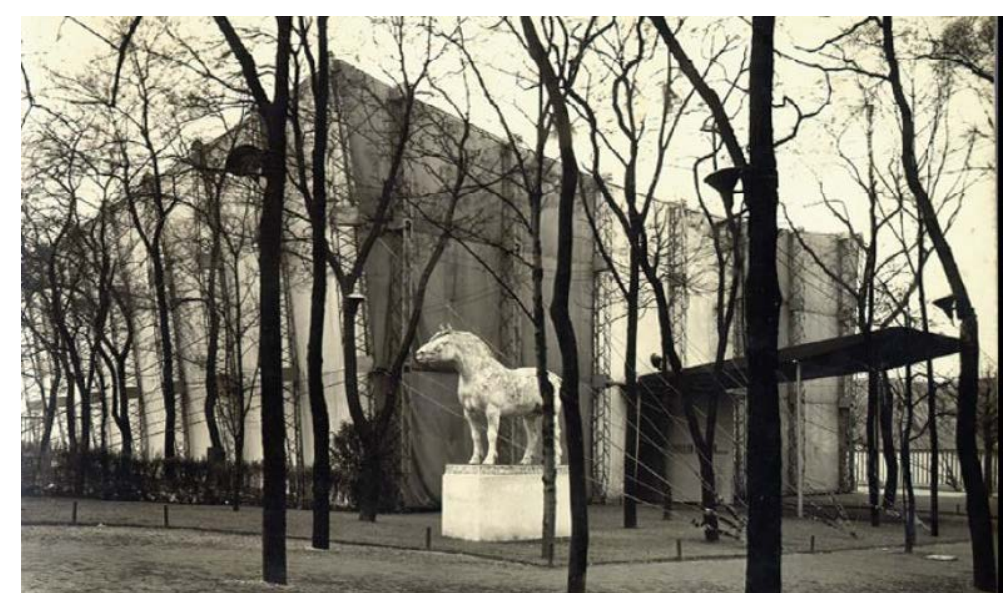

II. 7 Pabellón des Temps Nouveaux, Exposición Internacional de París. Le Corbusier,1937

El pabellón de Japón (II. 6), proyectado por Junzo Sakakura, estaba compuesto por dos cuerpos conectados a través de una rampa exterior y tenía como cerramiento una celosía de madera de tipo romboidal que garantizaba la unidad del conjunto. El módulo utilizado en la trama de rombos era menor que el utilizado un año después por Paul Nelson en la fachada de su casa.

Le Corbusier fue el encargado de construir el pabellón des Temps Nouveaux (II. 7), reflejo del espíritu de la exposición. En su proyecto, al igual que había hecho Paul Nelson en la solución de su vivienda, utilizó una estructura metálica porticada con cables traccionados. En el caso de Le Corbusier, los pórticos estaban construidos con celosías tridimensionales, atirantadas al suelo mediante cables. En el interior del pabellón también se mostraba un mural, que tenía como tema el trabajo, y era un montaje de fotografía y pintura, realizado por Fernand Léger, quien colaboró posteriormente en La Maison Suspendue. 


\subsection{La experiencia doméstica en Norteamérica. 1940}

Conforme la década de los treinta fue avanzando y sus contactos con Norteamérica fueron más intensos, Paul Nelson observó la evolución que estaba experimentando la vivienda. El panorama que se encontró fue el descrito en 1940 por James Ford y Katherine Morrow Ford ${ }^{96}$ en su análisis de la casa americana de los años treinta. Los autores consideraban, al igual que Paul Nelson cuando inició su investigación, que en 1935 la influencia europea ya estaba superada. Los autores del análisis y Paul Nelson también coincidían al proclamar que frente al planteamiento de las décadas anteriores, la nueva vivienda debía crecer desde el interior hacia el exterior, y nunca a partir de una idea de fachada.

El análisis de James Ford y Katherine Morrow establecía que la construcción de la vivienda en Estados Unidos en los años treinta se regía por otros parámetros diferentes a los del Internacional Style, que habían derivado en una imagen propia de la arquitectura doméstica norteamericana. Señalaban que los factores que habían hecho posible ese cambio eran: los avances técnicos de la producción industrial, los cambios en los modos de vida de las familias, el valor de los materiales naturales, la noción de confort controlado, la reducción de superficie doméstica necesaria (dado que algunas funciones se desarrollaban en lugares comunes de la ciudad), las demandas de un espacio individual y la relación de la vivienda con el entorno.

Todos estos factores, que apuntaron James Ford y Katherine Morrow al final de la década, ya habían sido tenidos en cuenta anteriormente por Nelson en La Maison Suspendue. De esta manera su pensamiento sobre la evolución de la casa moderna coincidía con el contexto y el proceso evolutivo que había seguido el desarrollo de la vivienda en Estados Unidos. Tanto para Paul Nelson como para James Ford y Katherine Morrow, estos objetivos acordes con los intereses humanos y con sus valores anunciaban una nueva arquitectura, que no suponía una ruptura radical con el pasado, sino un avance, que estaba basada en lo orgánico, en un proyecto de casa viva.

\footnotetext{
${ }^{96}$ James Ford, Katherine Morrow, The Modern House in America, New York: Architectural Book Publishing Co. 1940.
} 


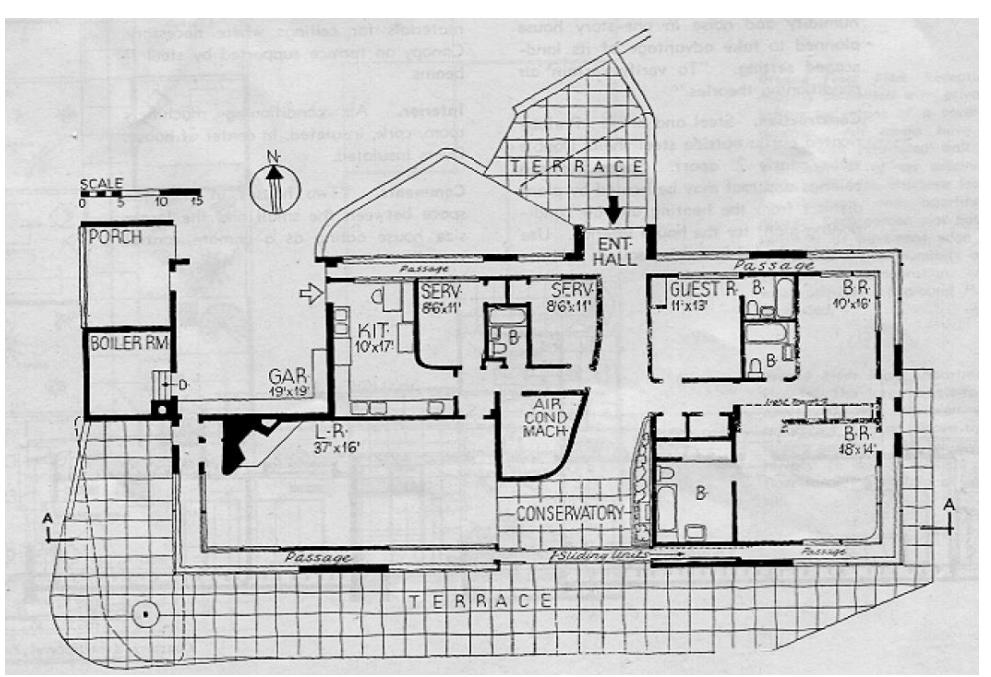

II. 8 Casa Afred Loomis, planta, Tuxedo Park, New York. William Lescaze, 1937.

De todas las viviendas norteamericanas analizadas por James Ford y Katherine Morrow, la casa que construyó el arquitecto William Lescaze para Alfred Loomis, en Tuxedo Park, New York, en 1937 (II. 8), era la única que compartía con La Maison Suspendue la misma idea espacial: construir una casa a partir de unidades funcionales dentro de una envolvente superior, aunque la manera de resolver la relación entre las piezas interiores y el contenedor externo era diferente en cada vivienda. William Lescaze construyó su vivienda con un doble cerramiento, de vidrios paralelos, siguiendo el modelo de homotecia de las muñecas rusas. Por el contrario, en la casa de Nelson, las geometrías interiores y la envolvente exterior eran opuestas, lo cual facilitaba su reconocimiento. La vivienda de William Lescaze nació a partir de la idea del propietario de poder vivir en una casa de cristal con vistas sobre el lago y tener un perfecto control del ambiente interno, desde el aire acondicionado, la humedad, el ruido e incluso el polvo; por eso la propuesta del arquitecto fue construir una casa dentro de otra. Paul Nelson en su vivienda también se interesó por los temas de confort de una manera integral, y por lo tanto el modelo de casa cerrada era el que mejor se ajustaba a ese control. Pero lo que le llevó a tomar la solución de la vivienda cerrada era su idea de considerar la vivienda como un refugio del habitante. Los dos arquitectos utilizaron el espacio intermedio que se creaba entre los dos cerramientos, pero mientras William Lescaze lo hacía para conseguir el control ambiental, Paul Nelson lo utiliza para dotar de unidad al conjunto de las diversas unidades funcionales.

En texto de James Ford y Katherine Morrow no se analizaba la obra de Frank Lloyd Wright, ya que su trabajo fue objeto de un monográfico posterior, decisión que reflejaba la importancia y la singularidad de su trabajo. 


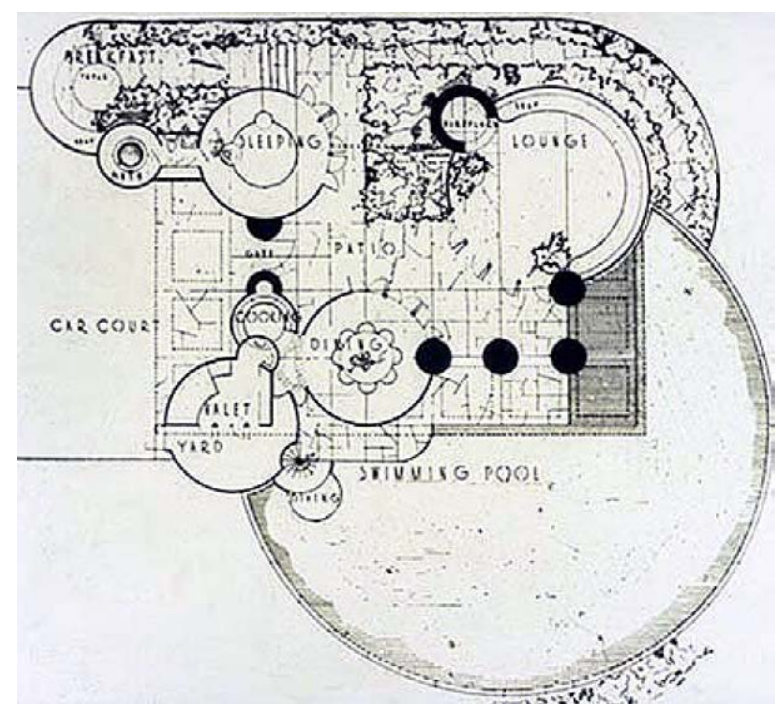

II. 9 Casa Ralph Jester, planta acceso, Palos Verdes. Fank Lloyd Wright,1938.

Frank Lloyd Wright, que no había sido tenido en cuenta en el debate público de la arquitectura de los años veinte, obtuvo su reconocimiento una década después. Paul Nelson conocía el trabajo de Frank Lloyd Wright desde su etapa de estudiante con Perret, en cuya biblioteca ya había revistas con dibujos y fotos de su obra.

En 1938 Frank Lloyd Wright proyectó una casa para Ralph Jester (II. 9), en Palos Verdes. Era una vivienda para una sola persona, en un clima árido y en el entorno de una ladera de acusada pendiente. Frank Lloyd Wright estaba desarrollando un modelo de vivienda, las llamadas Usonian Houses, más pequeña y más económica. En la casa de Palos Verdes (f.II.5), Frank Lloyd Wright experimentó una solución espacial, que no volvió a retomar en otros proyectos domésticos, y que coincidía con la que había utilizando Paul Nelson para concretar su Maison Suspendue ese mismo año. Ambos arquitectos decidieron separar las habitaciones e introducir espacios vacíos entre ellas; Wright proyectó un patio rectangular, cubierto por una plataforma horizontal, bajo la cual distribuyó el programa. Todas las estancias tenían planta circular, estaban aisladas y albergaban funciones diferentes, de tal manera que el tránsito espacial se convertía en un elemento importante del proyecto, donde se fundían el interior y el exterior. Paul Nelson también dispersó las estancias de su vivienda dentro de un contenedor cúbico; por lo tanto, los recorridos también eran los protagonistas. Los dos arquitectos buscaron en sus respectivas viviendas la introducción del entorno. Wright lo hizo de una manera natural, al dejar abierta la casa y permitir que el aire exterior rodease sus estancias, y Paul Nelson lo hizo de una manera artificial, mediante el cierre total del conjunto y la creación de su propio paisaje. 


\section{La influencia de los arquitectos coetáneos}

En el año 1933, Paul Nelson dio un giro trascendental a su carrera y cambió de referencias, inició su crítica a los arquitectos del Movimiento Moderno y comenzó a reconocer la influencia de la arquitectura norteamericana. En un artículo que escribió sobre La Maison de Verre en diciembre de ese año ${ }^{97}$, contrastaba el trabajo realizado por los maestros franceses de la arquitectura moderna con las arquitecturas de rascacielos que se estaban levantando en Estados Unidos mediante unas técnicas constructivas industriales. "La arquitectura moderna se está muriendo. Se ha derivado a un romanticismo, un sentimentalismo que se expresan mejor en la literatura o en la música." Con estas palabras enfrentaba lo que para él era el ejemplo de la nueva arquitectura francesa, La Maison de Verre de Pierre Chareau, con las obras de Auguste Perret y Le Corbusier, a las cuales consideraba anticuadas.

Centró sus críticas en el uso que hacían los dos arquitectos del hormigón armado, un material que había sido seña de identidad de la modernidad y que él consideraba demasiado rígido para albergar un espacio flexible. Pensaba que aunque Perret manejaba con destreza el hormigón, esto no se había traducido en una transformación espacial de su arquitectura, la cual seguía teniendo una gran rigidez, resultaba masiva y su composición era clásica y monumental. Y consideraba que Le Corbusier hacía un uso del hormigón excesivamente plástico, con el fin último de conseguir unos volúmenes puros, para poder levantar divisiones internas con formas curvas y donde los huecos de forjados pudiesen comunicar dos alturas. ${ }^{98}$

Si en su etapa de formación y en sus primeros años de carrera, el hormigón armado fue el único elemento utilizado para resolver sus estructuras, a partir de 1933, tras los proyectos de la ciudad hospitalaria de Lille y de su Maison de Santé Type Minimun, su idea sobre los elementos estructurales cambió y buscó un nuevo elemento para realizar una arquitectura más ligera y flexible. Cambió de técnica estructural y pasó del hormigón al acero. Este material le permitía resolver los problemas de resistencia y de concentración puntual de la estructura, con el hormigón, y le aportaba una mayor flexibilidad para ordenar con el programa dentro de la retícula, ya que la sección de los pilares era inferior. En sus proyectos previos a la Segunda Guerra Mundial no volvió a trabajar con estructuras de hormigón. Y por

\footnotetext{
${ }^{97}$ Paul Nelson, "La Maison de la rue Saint Guillaume", L'Arquitecture d'aujourd'hui n9, noviembre- diciembre 1933, p.9.

${ }^{98}$ Íbídem. p.9.
} 
lo tanto sus referentes ya no eran Perret ni Le Corbusier, sino aquellos que utilizaban la estructura de acero y las técnicas de producción industrial de los metales, como Richard Buckminster Fuller y Pierre Chareau.

Paul Nelson mantuvo una relación de aprendizaje, maestro-alumno, tanto con Auguste Perret como con Le Corbusier, pero nunca se trazó un vínculo de amistad. Con Perret aprendió de manera directa y con Le Corbusier a través de las publicaciones. Formó parte de los alumnos del taller del Palais de Bois de Auguste Perret (§ I. 1.). y tanto este aprendizaje como la obra del maestro, fueron dos influencias decisivas en su formación como arquitecto. Durante los cuatro años de preparación en el taller de Perret, Paul Nelson visitó junto al resto de sus compañeros las obras que ejecutaba la oficina de su profesor y aprendió la manera directa de construir un edificio. La oficina de Auguste Perret realizó importantes encargos públicos y construyó varios edificios industriales, con lo cual pudo ver el proceso de construcción de edificios de gran escala.

En 1924 Paul Nelson intentó ingresar en el estudio de Le Corbusier pero fue rechazado. Este primer encuentro marcó una serie de aproximaciones y admiraciones, que no obtuvieron respuesta por parte de Le Corbusier, con la excepción del reconocimiento que este hizo del proyecto del hospital de Lille. Al año siguiente de publicar Vers une Architecture, Paul Nelson solicitó una entrevista a Le Corbusier para hablar sobre el libro, pero el encuentro no se produjo ya que a Le Corbusier no le interesaba su opinión. A pesar de lo cual, Nelson siguió con una gran atención la obra de Le Corbusier ${ }^{99}$ y trabajó bajo su influencia, sobre todo en los primeros años profesionales. Nelson era consciente de la importancia de Le Corbusier como representante de la arquitectura moderna, y conocía el interés que su obra estaba suscitando en Norteamérica, por lo tanto tener un contacto directo con Le Corbusier podía repercutir en su trabajo en Estados Unidos ${ }^{100}$.

La admiración por Le Corbusier que marcó los primeros trabajos se transformó en una mirada crítica y en un rechazo a partir de 1932. En sus artículos posteriores, la figura de Le Corbusier era el referente para criticar la arquitectura del Movimiento

\footnotetext{
99 Jean Hélion, Lettres d'Amérique. Correspondance avec Raymond Queneau 1934-1967. Paris: imec éditions, 1996, p. 20.

100 Para escribir su primer artículo sobre arquitectura moderna europea en un medio americano, utilizó como referente a Le Corbusier. Véase : Pau Nelson, "Modern Architecture is Based on Curret Life", Chicago Evening Post. Magazine of the art world, 17 de abril de 1928 , p.3.
} 
Moderno. Manifestó que una de las causas por las que desarrolló el proyecto de $\mathrm{La}$ Maison Suspendue fue para dar la réplica a la afirmación de Le Corbusier de que "la casa es una máquina para vivir""101.

Con motivo de la publicación de su proyecto de "la ciudad hospitalaria de Lille", Le Corbusier le escribió unas palabras de reconocimiento señalando las virtudes de la propuesta $^{102}$. Consideraba que Lille representaba los tiempos modernos, ya que resolvía de manera sencilla una complejidad desconocida, a partir de cero, invirtiendo el sentido de todas las tradiciones y elevando el edifico sobre el suelo. A pesar de estas apreciaciones, recordó a Paul Nelson que si deseaba emplear muros de vidrio "neutralisants" debía mencionarle a él como autor de la idea ${ }^{103}$.

Con Richard Buckminster Fuller y Pierre Chareau coincidió en las inquietudes profesionales; ya que tenían una misma sintonía respecto a la introducción de la fabricación industrial en la concepción de la casa. Con Fuller y con Chareau mantuvo una relación de amistad cuyos vínculos, a diferencia de los que mantuvo con Perret y con Le Corbusier, se mantuvieron durante varias décadas ${ }^{104}$. Estas relaciones se transformaron en apoyos mutuos en público; así, tanto Fuller como Chareau, solicitaron el apoyo de Paul Nelson como avalista de las respectivas casas y viceversa.

El cambio que experimentó su arquitectura se inició primero a través de sus textos y posteriormente lo trasladó a sus proyectos. El encargo para un hospital en Ismaïlia en 1934 fue el primero de sus trabajos en el que mostró de manera rotunda su interés por desarrollar una arquitectura más ligera, aunque aun sin abandonar definitivamente la estructura ejecutada en hormigón, fruto de sus años de aprendizaje. Este proceso de transformación se manifestó de manera más evidente en un espacio expositivo para los descubrimientos en 1937, y llegó a su punto más elevado con el proyecto de La Maison Suspendue.

\footnotetext{
${ }^{101}$ Judith Applegate, "Paul Nelson: an interview". Perspecta nº13-14, 1971, p. 102.

${ }^{102}$ Le Corbusier, "La Cité hospitalière de Lille", Cahiers d'Art, 1932, p 57.

${ }^{103}$ Carta, de 10 de diciembre de 1932, remitida por Le Corbusier a Paul Nelson, Fondation Le Corbusier, E217

${ }^{104}$ En todas las agendas personales de Paul Nelson, figuran los nombres y los datos de R.B. Fuller y de Pierre Chareau. En algunas junto al nombre de Fuller, aparecen anotaciones y dibujos de una trama de rombos. MNAM/CCI, Bibliothèque Kandinsky, fonds Nelson.
} 
Sus nuevos referentes fueron Richard Buckminster Fuller, en América y Pierre Chareau, en París. Para Nelson, las construcciones de Fuller y de Chareau representaban una nueva vía de exploración dentro de la arquitectura doméstica; era la construcción de un proceso arquitectónico que avanzaba en paralelo al proceso evolutivo de la técnica, proporcionando la imagen de la nueva casa acorde a esos cambios tecnológicos. Las viviendas planteadas por ambos arquitectos surgían de una revisión de los valores que había enunciado el Movimiento Moderno y se proponían conseguir sus objetivos incorporando el potencial de la técnica y de la construcción industrializada.

\subsection{Auguste Perret. El taller dentro del taller}

El periodo de mayor influencia de la obra de Auguste Perret sobre la arquitectura de Paul Nelson se produjo entre 1924 y 1933, que se corresponden con el primer año de su estancia en taller del Palais de Bois y el año que Paul Nelson manifestó su oposición hacia la labor de Auguste Perret, emprendiendo otro camino diferente para forjarse su propia identidad. Se han analizado tres viviendas y un proyecto público.

En la segunda mitad de los años veinte, los hermanos Perret construyeron una serie de casas-taller para los artistas Mela Muter, Georges Braque, Chana Orloff y Dora Gordine. Todas ellas tenían un programa común, que combinaba el propio ámbito doméstico con un lugar de trabajo y una sala de exposiciones. El taller era el espacio sobre el que los artistas planteaban más requerimientos funcionales, como la luz y la altura. Este tipo de encargos y la solución de las demandas planteadas también fueron el campo de experimentación de otros compañeros como Le Corbusier o Robert Mallet- Stevens.

Auguste Perret utilizó la doble altura y los balcones interiores en los salones públicos, como habían hecho sus colegas, pero en sus proyectos no había, a diferencia de lo que sucedía en los de otros arquitectos, una prioridad por la búsqueda "formal". Y tampoco la condición de artistas de sus clientes motivó una exploración morfológica específica Perret practicaba una actitud "anti-plástica", en palabras del profesor Joseph Abram. ${ }^{105}$

105 Transcripción de conferencia pronunciada por Joseph Abram, profesor de L'École Nationale Supérieure d'Architecture de Nancy, Auguste Perret, un intellectuel constructor, Miércoles, 28 noviembre de 2007. 


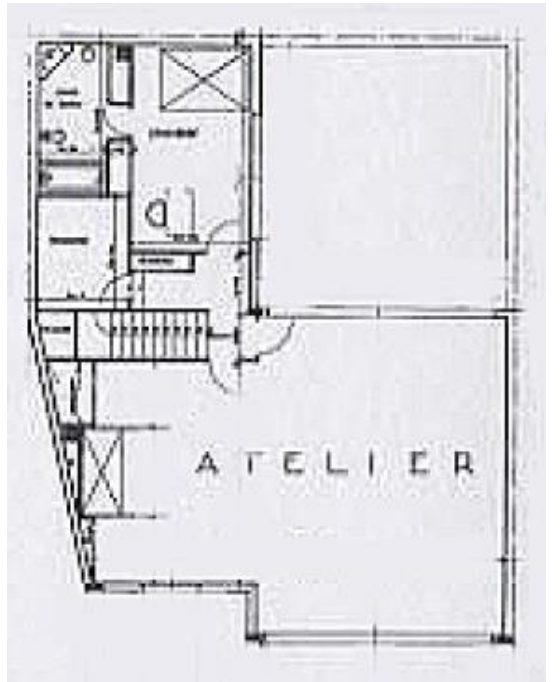

II. 10 Casa-taller Marie Mela Muter, planta primera, espacio de trabajo en el taller. Auguste Perret,1928.

Los talleres eran viviendas de pequeño tamaño donde Perret fijaba una estructura que permitiese un desarrollo funcional pragmático. El esquema de distribución fue el mismo, con excepción del taller para Georges Braque; se disponía una sala expositiva en planta baja comunicada con el taller situado en la planta intermedia y una planta superior dedicada al ámbito doméstico. En la casa de Braque la estratificación funcional se invirtió y el taller se situó en la planta superior. En todos los proyectos, el taller quedaba fragmentado en dos espacios: uno más amplio, puramente de trabajo, y otro de menores dimensiones, dedicado a la reflexión. ${ }^{106}$

Las fachadas de estas viviendas combinaban los grandes huecos de los talleres con las ventanas de los espacios domésticos, ambos insertados en los paños de ladrillo visto que rellenaban la retícula de la estructura de hormigón. Estos cerramientos transmitían al exterior la dualidad funcional de la vivienda de diferentes maneras. En el primer proyecto, en la casa de Braque, los amplios huecos abuhardillados del taller contrastan con el sobrio cerramiento de ladrillo de las planta inferiores. En el segundo caso, el taller para Chana Orloff, los volúmenes complementarios de taller y sala expositiva compartían los cerramientos de vidrio de las plantas bajas frente al muro de la vivienda de la planta superior y finalmente, en el caso de del estudio de Mela Muter (II. 10), agrupaba los dos volúmenes, con un sentido funcional que se refleja al exterior mediante el retranqueo de uno de los bloques. ${ }^{107}$

106 Gilles Ragot, Georges Braque-Mela Muter-Chana Orloff. Véase: Encyclopédie Perret, París: Éditions du patrimoine y Éditions du Moniteur, 2002.

${ }^{107}$ Karla Britton, Auguste Perret, London: Phaidon Press, 2001, p.107. 


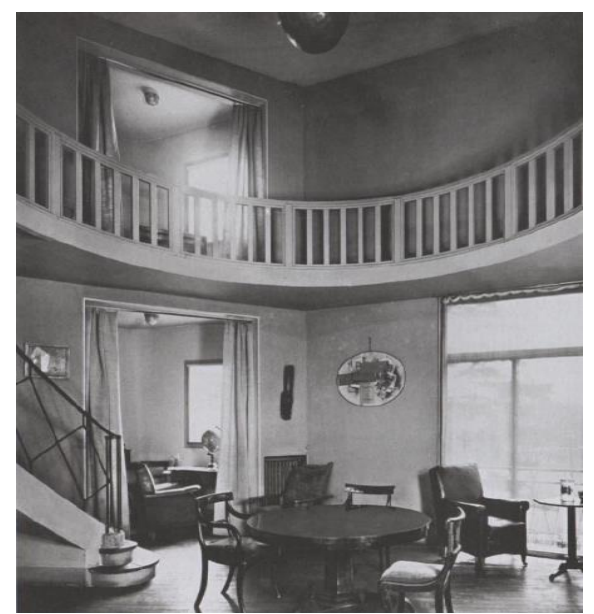

II. 11 Casa Pierre Gaut, salón hexagonal y corredor circular, París. Auguste Perret,1923

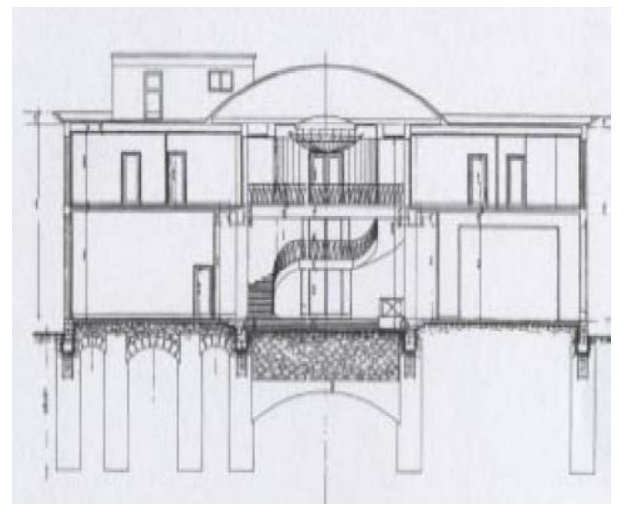

II. 12 Villa Aghion, sección del vestíbulo central, Alejandría. Auguste Perret,1926-1927

Auguste Perret trabajó en estos proyectos con dos conceptos: la idea de fragmentación funcional en dos bloques y la idea de convivencia de todas las funciones en un único espacio. Utilizaba los tamaños de los huecos y los materiales de cerramiento para marcar diferencias, y la estructura vista de hormigón y la cubierta como elementos de unidad. La retícula era un elemento de atado que garantizaba el funcionamiento interno y la cubierta era el remate final que homogeneizaba todos los volúmenes.

Aunque no era una casa-taller, la vivienda que hizo para el marchante Pierre Gaut (II. 11) tenía en común con estas casas la necesidad de una sala donde mostrar la colección. El solar configuraba una esquina, donde Perrert proyectó una salón de planta hexagonal de doble altura, con una escalera curva que desembocaba en un balcón perimetral que conducía a las dependencias de la planta superior. Este 
esquema del espacio central circular que contenía la escalera también lo repitió en su proyecto para la Villa Aghion en Alejandría. ${ }^{108}$ (II. 12).

La influencia que las intervenciones de Auguste Perret tuvieron sobre la obra doméstica de Paul Nelson y más concretamente en el origen de La Maison Suspendue se manifestó en la estructura, a la que se considera una herencia indiscutible, y otros dos elementos: el orden espacial de la vivienda y el cerramiento. Como ya se ha dicho, estas casas tenían doble funcionalidad, vivienda y taller, y este esquema fue recogido y readaptado por Nelson en su casa, con un espacio mínimo de funcionamiento doméstico maquinista y un espacio más amplio dedicado al ocio del hombre. La sala principal de La Maison Suspendue era heredera de los espacios de reunión y exposición de las viviendas de Perret; incluso usó los mismos recursos espaciales que había usado su maestro, los balcones interiores en las estancias de varias alturas y la consideración de la importancia de los núcleos de comunicación, ocupando los espacios más representativos. La traslación se manifestaba de manera más clara entre el salón de la casa Gaut y en el espacio central de la casa Nelson, con la escalera curva y el corredor superior también curvo. Siguiendo con el esquema de Perret, Nelson ubicó los espacios privados y de descanso en la planta superior. Pero la aportación más interesante se produjo al desarrollar la idea que tuvo Perret de fragmentar el taller en dos espacios, uno de los cuales obedecía a un planteamiento del espacio personal; esta duplicidad llevaba asociada una búsqueda de un espacio más personal destinado a la reflexión intelectual. Y esta fue una dependencia que tuvo su eco en las casas de Paul Nelson, donde evolucionó hasta la construcción de un recinto individual y aislado, como sucedió en La Maison Suspendue.

El primer encargo de Paul Nelson en París fue en 1928. Se trataba de una casa para un compatriota suyo, el escritor Alden Brooks (II. 14). Se construyó en estructura de hormigón armado, siguiendo el modelo de las casas taller de Perrert, diferenciando en la fachada la retícula estructural y los paños de ladrillo. La estructura era el elemento que mantenía el orden simétrico en el alzado frente a la disposición de los huecos, cuyas variaciones formales también sirvieron, como en el caso de su maestro, para trasladar la condición de privacidad de los espacios interiores. Con respecto a las fachadas, en la Maison Suspendue también se utilizaron dos tipos distintos de cerramiento, como hacía Perret, uno ligero y otro masivo para diferenciar las dos partes de la casa; la principal diferencia estaba en que las fachadas de las casas de Auguste Perret identificaban los espacios

${ }^{108}$ Íbidem, p. 118 y 127. 

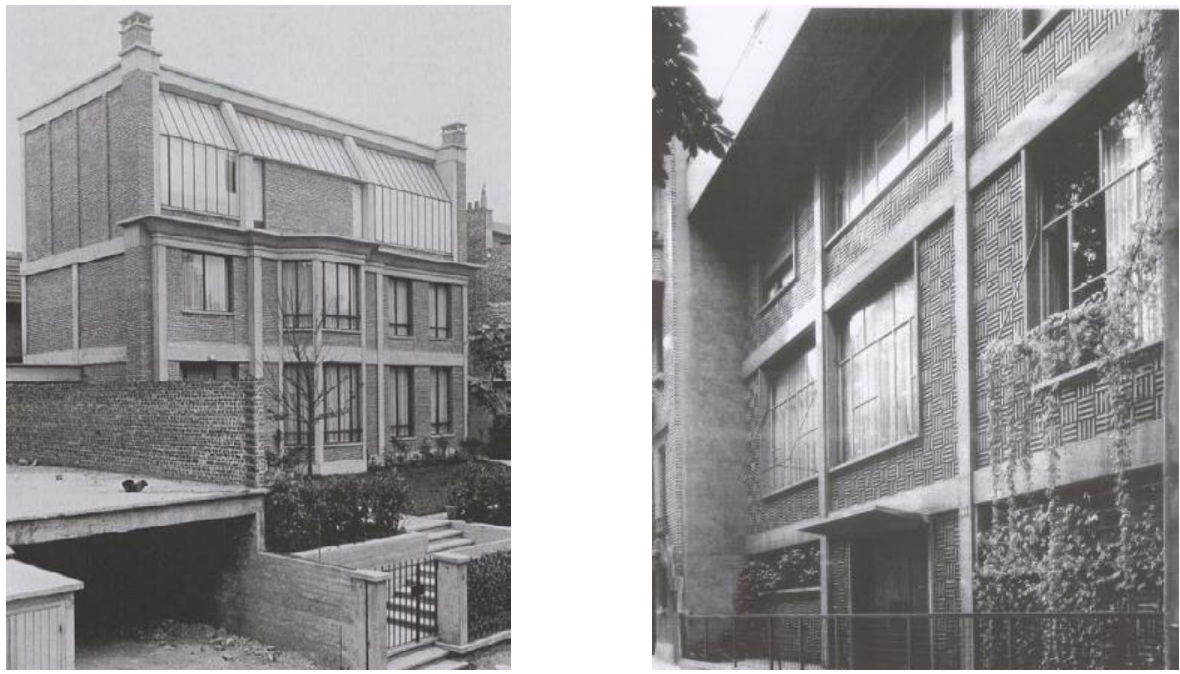

II. 13 Casa-taller Georges Braque, fachada, París. Auguste Perret, 1927-1930.

II. 14 Casa Alden Brooks, fachada a Boulevard Arago, París. Paul Nelson, 1928-1930.

interiores mediante la singularidad de los huecos (II. 13) y en las fachadas de Paul Nelson las diferencias se hacían de manera más sutil, por una simple alteración de las propiedades de los cerramientos construidos con tramas estandarizadas.

Mientras Paul Nelson se formaba en el taller del Palais de Bois, en 1925, Auguste Perret construía una librería para el editor Albert Levy (II. 15). En la exposición de Artes Decorativas de Paris Se trataba de una caja elevada sobre cuatro soportes externos, que permitían situar la pieza en un muelle del Sena y resolver la diferencia de cotas entre el río y la calle, liberando el espacio inferior. El pabellón tenía una cubierta plana rematada por una cornisa y la fachada estaba construida con una trama ortogonal de vidrio y acero. Este tipo de concepción estructural de una pieza superior sujeta por apoyos externos y resuelta con un cerramiento de trama metálica coincidía con algunas de las decisiones que Paul Nelson adoptó en su vivienda. Una caja ligera que se apoyaba en dos pórticos metálicos externos, con un cerramiento ejecutado con una trama de vidrio en forma de rombos.

Paul Nelson aprendió de Aguste Perret la importancia de la estructura, como la pieza, sin el cual no se podía construir la arquitectura. La estructura había servido a Perret para dotar al espacio de orden, mientras que para Nelson era la herramienta que le permitía flexibilizar la arquitectura; partiendo de un mismo concepto llegaron a resultados distintos, acordes con sus intereses. 


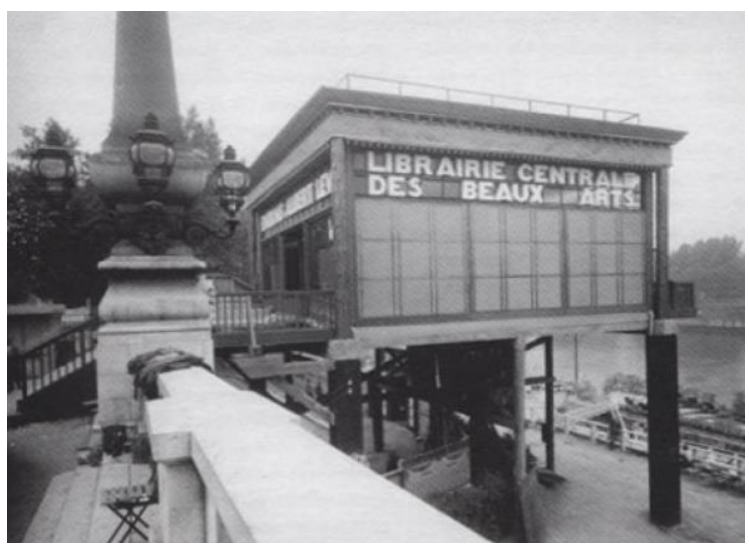

II. 15 Librería Albert Levy, Exposición de Artes Decorativas, París. Auguste Perret, 1925.

El soporte que avanzaba sobre el cerramiento de la librería Albert Levy, que permitía realizar la fachada de vidrio y ordenar el espacio interior, tuvo como referente el pórtico metálico de La Maison Suspendue, que soportaba la cubierta y la planta de habitación, pasando del sistema adintelado a un sistema porticado.

Paul Nelson continuó utilizando la estructura como hacía Auguste Perret, para conseguir la unidad en el conjunto del edificio. Incluso esta idea se manifestó de manera más evidente al asociar la estructura y la cubierta, convirtiéndolas en un único elemento, como sucedió en La Maison Suspendue. La estructura ya no era la retícula donde se integraba el programa, sino el porche bajo el cual se organizaba libremente la casa.

Pero si había algo que distanciaba a Aguste Perret y a Paul Nelson era su concepción de la escala humana. Perret estableció una diferencia entre la escala humana doméstica y la de sus espacios públicos. Mientras en sus viviendas los espacios y los huecos se proyectaban en función de las necesidades y de las dimensiones de los habitantes, esto no sucedía en sus edificios públicos, y los proyectos, independientemente de su programa, adoptaban un carácter monumental. En el caso de Paul Nelson, la escala humana se manifestaba en todos sus edificios, tanto públicos como privados; resultaba más equilibrada y no se producía el salto tan radical que se apreciaba en la obra de Perret. La presencia del hombre en el edifico era más patente que la estructura, en tanto que el factor humano era el nuevo orden que había escogido Paul Nelson para organizar sus edificios. 
2.2 Le Corbusier. La mezzanine, la habitación aislada y el jardín suspendido.
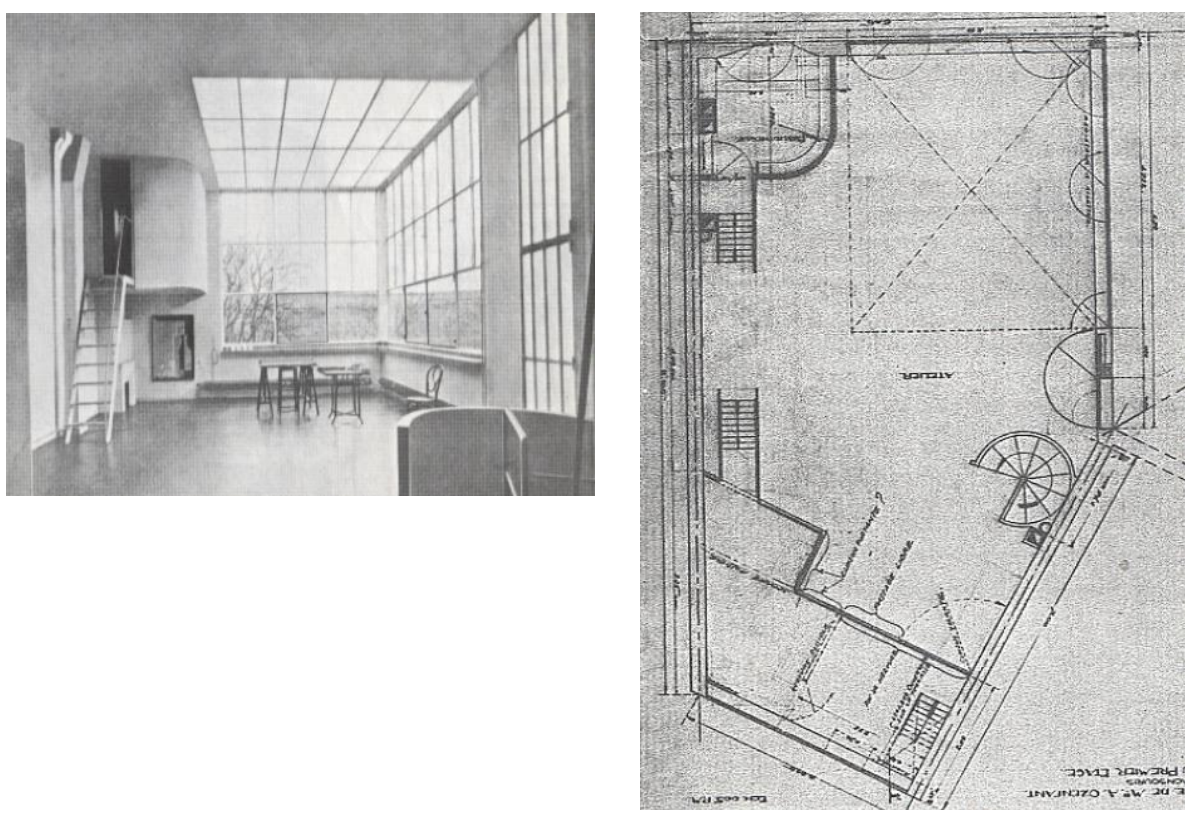

II. 16 Atelier Amédée Ozenfant. Interior, planta segunda, taller y biblioteca, París. Le Corbusier,1922.

Se ha considerado la obra de Le Corbusier previa a la investigación de La Maison Suspendue, especialmente su arquitectura doméstica, y finalmente se ha elaborado una comparación con la Villa Savoye.

Ya se ha visto cómo desde su trabajo final en Beaux-Arts, Paul Nelson adoptó soluciones formales para sus edificios que recordaban a las de Le Corbusier. Esto se produjo en sus proyectos de edificios públicos de los primeros años treinta, en los que se apreciaban algunos de "los cinco puntos de la arquitectura" enunciados por Le Corbusier en 1926. Los edificios se levantaban del suelo sobre pilotes de hormigón retranqueados, daban continuidad al espacio verde del suelo y proporcionaban un desarrollo libre en la planta y en la fachada. Las terrazas se convirtieron en lugares de esparcimiento y en los cerramientos optó por la ventana horizontal. Utilizó además volumetrías puras, diferenciadas funcionalmente. Su proyecto de Maison de Sante Type Minimun de 1932, es un ejemplo de ese lenguaje. Este esquema de plantas en cascada con terrazas, era similar al que desarrolló Le Corbusier para el residencial Dourand de Le Corbusier para Argel. 
Le Corbusier también utilizó la singularidad que tenían los proyectos de casa-taller para artistas como oportunidad para desarrollar su investigación espacial. El cliente estaba abierto a nuevas propuestas y el programa permitía explorar otras vías fuera del ámbito meramente residencial. En general, en estas viviendas proponía una estancia principal de doble altura destinada a taller-sala de exposiciones, con una mezzanine, intermedia, abierta al volumen principal ${ }^{109}$. De este tipo de viviendas interesa analizar dos ejemplos ( La Maison du peintre Amédée Ozenfant en París, de 1922 y Les maisons en série pour artisans, de 1924), ya que ambos trabajos se anticipan en más de una década, formal y conceptualmente a La Maison Suspendue.

El taller del pintor Amédée Ozenfant ocupaba la planta segunda de la casa que le construyeron Le Corbusier y su primo Pierre Jeanneret. Era una sala de doble altura iluminada por dos paños verticales de vidrio que definían la esquina y un plano en el techo que difundía la luz de dos lucernarios. Desde el espacio de trabajo y a través de dos escaleras distintas (II. 16), se accedía respectivamente a un altillo y a una biblioteca, situadas en los dos extremos opuestos de la planta. Esta configuración espacial de un contenedor, construido con una retícula de vidrio, que alojaba un balcón interior de traza oblicua y una dependencia adosada al techo, fue recuperada posteriormente por Paul Nelson para su casa. Incluso en las primeras versiones de La Maison Suspendue, anteriores a 1936, las dependencias aisladas se adosaban a las esquinas en disposiciones similares a las de Le Corbusier, que proyectó la biblioteca de Ozenfant en esa posición, en voladizo, apoyada en la esquina y con un muro de cerramiento curvo. Las fotos del interior del taller mostraban esta pieza flotando, dada la ligereza de la escalera de acceso, que contrastaba con el cerramiento del triedro de vidrio de la esquina, una imagen que continuó y desarrolló Paul Nelson años después, con sus celdas exentas de planta curva colgadas de la planta de habitaciones. Pero las referencias de este proyecto en la casa de Paul Nelson no se limitaron a la configuración espacial, sino que también incidieron en lo conceptual, ya que ambos entendían que la actividad de la inteligencia creadora necesitaba un espacio independiente, incluso dentro del espacio de trabajo del artista. En el caso de la vivienda de Paul Nelson, la aparición de estas unidades derivaba del planteamiento de las relaciones sociales de los habitantes, previstas dentro de la vivienda y, por lo tanto, trabajó con el concepto espacial de Le Corbusier y lo aplicó a sus objetivos, al concepto del espacio individual dentro de la casa.

\footnotetext{
${ }^{109}$ Nicolás Maruri, tesis doctoral, La cabina de la máquina. Evolución del espacio vertical en los proyectos domésticos de Le Corbusier, n.p. Departamento de Proyectos Arquitectónicos, Universidad Politécnica de Madrid.2006
} 


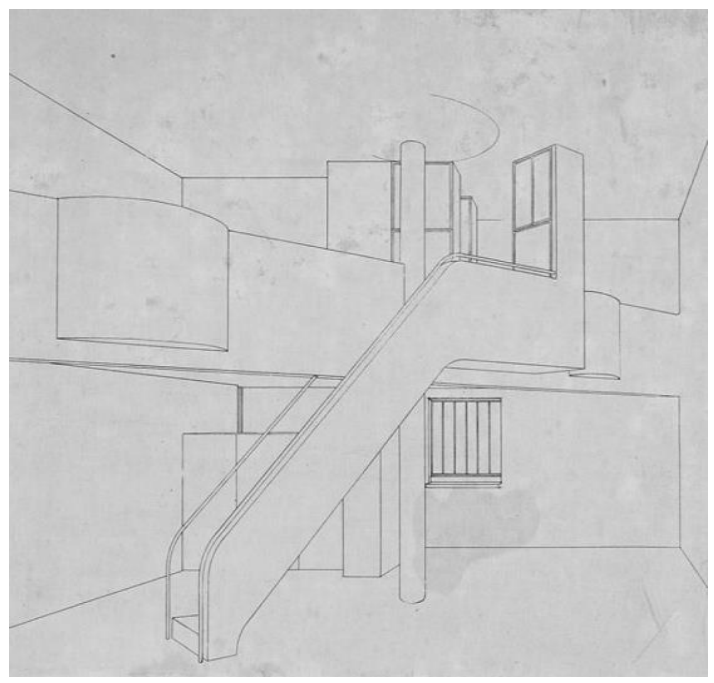

II. 17 Casas en serie para artesanos. Salón y mezzanine oblicua, Le Corbusier, 1924.

Dos años después, en 1924, Le Corbusier desarrolló un modelo para construir una vivienda estandarizada para artesanos (II. 17). El programa contemplaba una sala con un espacio de trabajo a doble altura en planta baja y una zona de descanso, abierta al volumen principal, en la planta primera. Proyectó un volumen cúbico, con una planta baja cuadrada, de 7 metros de lado y una planta primera triangular, que ocupaba la mitad del cuadrado. La estructura de la cubierta plana se apoyaba en un único pilar central, con sección de anillo, ejecutado en hormigón cuyo vacío servía como bajante. En esta vivienda aparecían cinco elementos que después fueron utilizados y readaptados por Nelson en su casa: el volumen cúbico, el balcón interior de traza oblicua volcado a la sala principal, la reducción de superficie de la unidad de descanso y su ubicación en la planta superior, la posición central de la escalera y, finalmente, la concentración de la estructura en un solo apoyo.

La primera decisión, la del volumen cúbico, fue aumentada de escala por Paul Nelson y le sirvió para albergar todo el programa de su vivienda, a excepción de los espacios servidores. En ambas casas, la disposición oblicua del balcón de la planta primera permitía tener una visión frontal de la esquina y una percepción limpia de la mayor dimensión en planta, la diagonal, lo que proporcionaba al observador la imagen total del volumen principal de la casa, inundado de luz con independencia del espacio exterior. También coincidían en la ubicación del espacio de descanso y en reducir al mínimo la superficie que ocupaba; incluso propusieron unos dormitorios, a excepción del principal, sin ventilación ni iluminación directa. Paul Nelson profundizó en le tratamiento de las diferencias entre las habitaciones y 
obtuvo unos resultados más contundentes. Así, mientras el dormitorio principal pasaba de tener una ventana a tener su propia terraza, los dormitorios individuales se convirtieron en cabinas totalmente cerradas. Las escaleras ocupaban una posición central dentro del salón en las dos casas y conectaban con la mezzanine de manera tangencial, lo cual le llevó a Le Corbusier a rematar la trayectoria con un armario cilíndrico y a Paul Nelson a continuar hasta la planta superior y conectar a su paso estancias de planta circular. Respecto del último elemento común en las dos viviendas, el pilar central, Paul Nelson ensayó, en una versión anterior a 1936, la idea de concentrar la estructura de su vivienda en un único apoyo central; intentó aumentarle el diámetro al apoyo circular y situar en su interior la escalera de servicio. En la versión definitiva optó por otro tipo de estructura y varió la posición central del núcleo de comunicación de servicio.

Paul Nelson utilizó los referentes formales y compositivos de "la casa para artesano" de Le Corbusier, un modelo de casa en serie, para la definición espacial de su proyecto de La Maison Suspendue, una vivienda que no se pensó para ser repetida de manera estandarizada. Nelson recogió la aportación de Le Corbusier para definir la relación vertical ente el salón y el balcón interior y la transformó mediante un proceso de industrialización en un hogar adaptado a cada familia. Tomó un modelo rígido e ideal y lo transformó en uno flexible y desmontable que incorporaba las necesidades singulares de cada uno de sus habitantes.

En el año 1933, Le Corbusier presentó su proyecto residencial "Durand" para Oled-Ouchaia en Argel (II. 18). Aunque esta no era una vivienda-taller como las casas precedentes, compartía con estas el esquema de sección en altura en "L"de la sala principal, con la doble altura, conectada a la planta primera mediante una escalera dispuesta en posición tangencial respecto del forjado de dicha planta. Esto, como ya se ha visto, coincidía con la disposición que utilizó Paul Nelson en $L a$ Maison Suspendue. La novedad que aportaba esta vivienda era la presencia en la planta primera de una habitación aislada del resto, situada junto a la terraza y comunicada con el resto de las estancias de la planta por un corredor abierto. La longitud de esta dependencia era inferior al ancho libre de la vivienda, estaba adosada a uno de los muros y se apoyaba sobre un pilar en el otro extremo. La función de esta pieza fue cambiando: primero estuvo pensada como sala de trabajo y después se convirtió en el dormitorio principal. Igualmente fue variando la forma del corredor, que en las fases previas tuvo una directriz oblicua, pero finalmente su geometría siguió el orden ortogonal de la planta. 


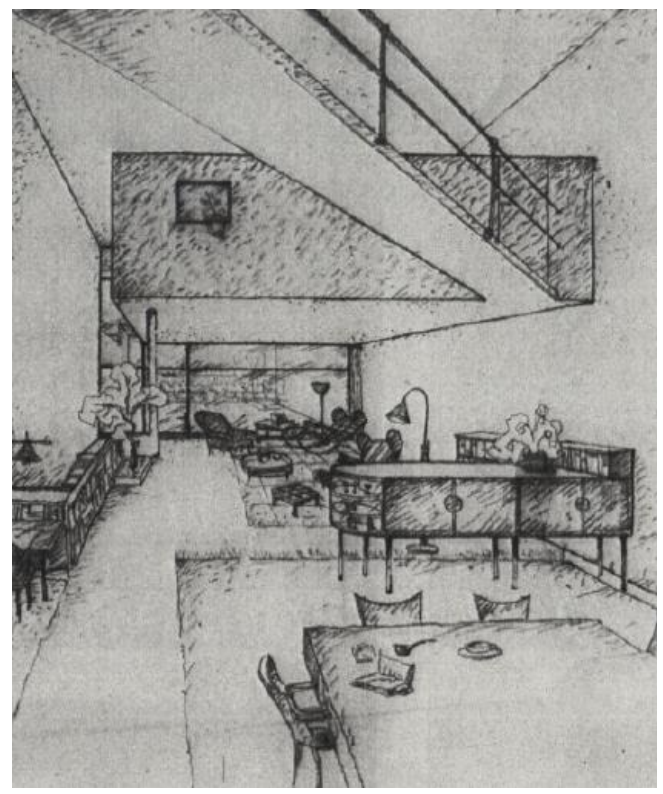

II. 18 Residencial Durand, perspec. Salón y dormitorio principal, Argel. Le Corbusier, 1933

Tres años después, esta idea de Le Corbusier de construir dependencias aisladas conectadas mediante corredores al resto de la casa, reapareció en La Maison Suspendue, aunque las razones que llevaron a Paul Nelson a ese planteamiento fueron diferentes y el uso de esos espacios también. En las viviendas del conjunto "Durand", Le Corbusier inició una investigación espacial sobre la que Nelson trabajó después; utilizando una tecnología y una estructura diferentes pudo eliminar el pilar de apoyo de las habitaciones exentas y proyectarlas suspendidas del techo.

La Villa Savoye de 1929 también influyó sobre la casa de Paul Nelson. Le Corbusier se adelantó al plantear algunas de las premisas, que posteriormente Nelson readaptó y transformó en su vivienda .

La casa como laboratorio.

Primero Le Corbusier y después Nelson utilizaron la vivienda como laboratorio de experimentación espacial, transponiendo posteriormente los resultados a otros proyectos de mayor escala. En el caso de Paul Nelson, su casa estaba planteada como una investigación sobre papel que no iba a ser construida, su objetivo era configurar una propuesta de vida doméstica extrapolable. Y respecto de Le Corbusier, él se propuso construir la Villa Savoye como una síntesis de sus tipos de vivienda de los años veinte, como un modelo que sirviese de referencia. 

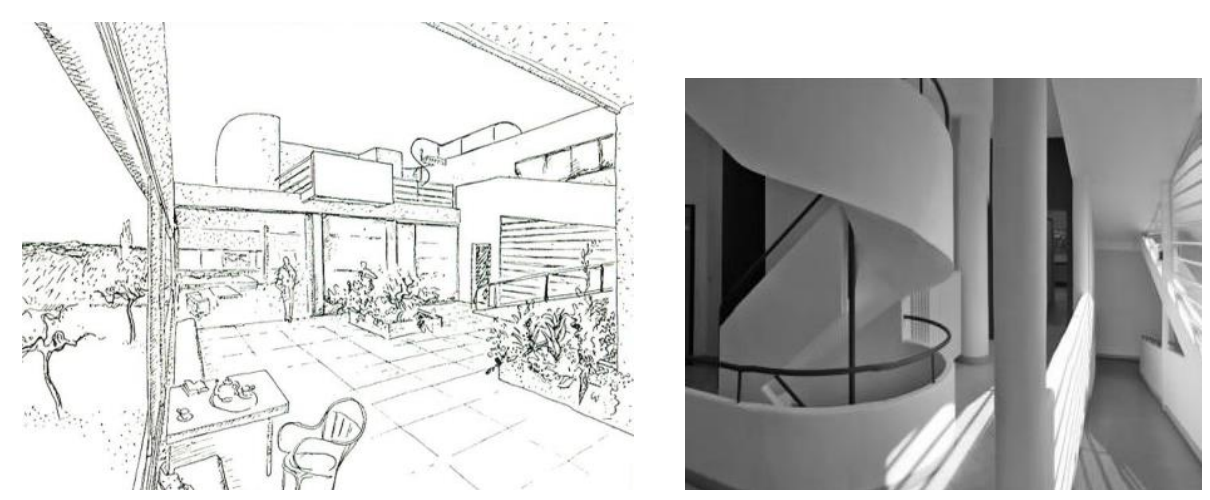

II. 19 Villa Savoye, perspectiva de terraza. Le Corbusier-P. Jeanneret,1929.

II. 20 Villa Savoye, vista interior de la rampa y la escalera. Le Corbusier-P. Jeanneret,1929.

La casa tipo "villa".

De todas las formas posibles de vivienda, los dos optaron por el tipo "villa" para desarrollar sus respectivos estudios. La villa era una casa burguesa situada fuera de la ciudad y rodeada de vegetación, que respondía a un programa funcional en el que se combinaban el ocio y el contacto con el entorno. ${ }^{110}$ Entre los objetivos de los dos arquitectos no estaban ni la configuración de unidades mínimas habitables, ni la solución de una estructura doméstica adaptada a unas condiciones urbanas concretas, ni la necesidad espacial que requerían las casas-taller. Por lo tanto, el programa de "la villa" no estaba sujeto a condicionantes funcionales estrictos y esto facilitaba la exploración de las posibilidades de disfrute de los usuarios.

El patio interior.

Cuando Paul Nelson realizó su investigación sobre la vivienda, lo primero que hizo fue estudiar la evolución histórica del concepto de vivienda y tras analizar las transformaciones espaciales, Nelson llegó a la conclusión de que el cambio más importante se había experimentado en la "casa patio" romana, al introducir el exterior dentro de los muros de la de la vivienda. ${ }^{111}$ Le Corbusier construyó la Villa Savoye en torno a un elemento exterior, la terraza. Esta pieza era algo más que el quinto punto de su arquitectura: este espacio era la habitación exterior "chambre d'été" y el verdadero jardín de la casa (II. 19) un lugar central para reuniones sociales

\footnotetext{
110 Josep Quetglas, Les Heures Claires: proyecto y arquitectura en La villa Savoye de Le Corbusier y Pierre Jeneret, Barcelona: Associació d'idees, 2009.

${ }^{111}$ Judith Applegate, "Paul Nelson: an interview". Perspecta nº13-14, 1971, p. 101.
} 

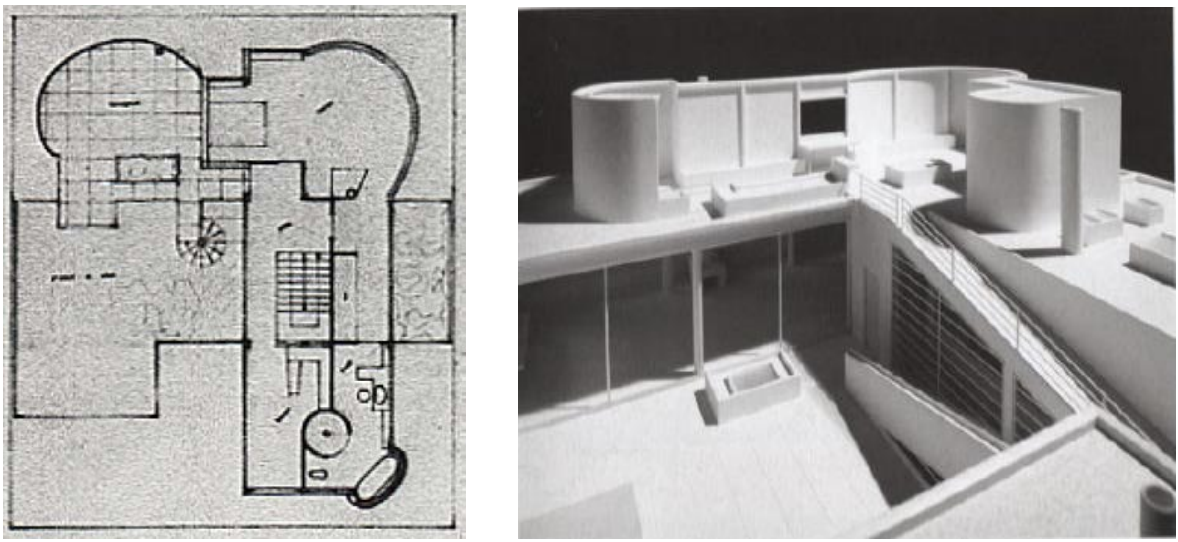

II. 21 Villa Savoye, Planta segunda, solarium, dormitorio, baño y espacio de trabajo. Le CorbusierP.Jeanneret, 1928.

II. 22 Villa Savoye, Vista de terraza y solarium, maqueta, Josep Quetglas,2004.

le jardin suspendu ${ }^{I 12}$. Paul Nelson retomó la idea del patio y convirtió el salón en el vacío principal dentro del volumen de la casa, en torno al cual se organizaban las dependencias en las tres direcciones del espacio. Además construyó un jardín controlado y aislado del exterior que el pintor Joan Miró interpretó como un paisaje.

La duplicidad de los núcleos de comunicación.

El vacío interior de las dos viviendas estaba conectado en altura con el resto de las dependencias mediante dos núcleos de comunicación, una escalera con tramos curvos situada en una posición secundaria y una rampa ubicada en la posición central de la planta. La rampa, en zigzag, que permitía el paseo y el descubrimiento cinético de la Villa Savoye, se curvaba y levitaba sobre el salón de La Maison Suspendue haciendo del recorrido un espectáculo. En las dos viviendas, el ascenso se podía realizar como un acto mecánico y meramente funcional o como un movimiento que se prolongaba en el tiempo y que convertía la conexión con los espacios privados de la vivienda en un rito. (II. 20).

El espacio individual.

En una versión de 1928 de la Villa Savoye, el programa de la terraza incluía el dormitorio principal, la sala de baños, un espacio para trabajar y un solarium (II. 21). En la versión definitiva, solo se conservó el espacio de solarium, configurado por

${ }^{112}$ María Candela Suarez, tesis doctoral, "Las Villas Meyer y Hutheesing- Shodhan de Le Corbusier". n.p, Departamento de Proyectos Arquitectónicos, Universitat Politécnica de Cataluña, 2006. 
dos tramos de muro curvo unidos por un paño recto en el que se abrió un hueco horizontal hacia el paisaje (II. 22). Esta envolvente permitía que el habitante quedase abrigado y protegido por el muro, que tuviera un contacto directo con el exterior a través del hueco o que controlase el movimiento dentro del vacío de la terraza. Casi una década después, cuando Paul Nelson pensó en sus dependencias para uso individual, volvió a tomar ese programa y lo redefinió. Proyectó unas estancias de planta circular con huecos abiertos al vacío del salón, tomó el desplegable que Le Corbusier había posado en la terraza de la Villa Savoye y lo enrolló.

La síntesis formal y la estructura.

El crítico Kenneth Frampton señala que Le Corbusier construyó sus casas de finales de los años veinte tratando de reconciliar dos tipos de vivienda, la residencia de campo Arts and Crafts con planta asimétrica y la casa de Palladio, un prisma regular y simétrico ${ }^{113}$. Y fue esa combinación la que influyó en la solución tomada por Nelson para su vivienda: un exterior ortogonal que contenía en su interior una distribución organizada libremente. Los dos llegaban a la misma solución partiendo de la estructura. A Le Corbusier el uso de los pilotis le llevó a conseguir la planta libre y la fachada libre; y a Paul Nelson la utilización de pórticos le permitió sujetar la planta superior y ordenar de manera libre tanto las plantas inferiores como la sección. En los dos proyectos, la vivienda se presentaba desafiando a la gravedad: la casa de Le Corbusier flotaba sobre los pilotis y la de Nelson se pensó colgada.

Respecto de las posibles influencias estructurales directas que Le Corbusier ejerció sobre Paul Nelson, Kenneth Frampton apunta a las semejanzas constructivas entre le Pavillon de Les Temps Noveaux y Le Palais de la Découverte de Paul Nelson basadas en el uso de las estructuras traccionadas y suspendidas con cables ${ }^{114}$. Pero esta teoría se enfrenta a la dificultad de que los dos proyectos se desarrollaron en el mismo año (1937). A esto habría que sumarle que el primer proyecto fechado de $L a$ Maison Suspendue era de abril de 1936 y en esta versión ya aparecían estructuras traccionadas, pues la planta superior estaba colgada de la cubierta. Lo que sí se puede constatar es que los dos arquitectos coincidieron en su interés por ese tipo de estructuras en esos años, aunque después ninguno las volvió a utilizar.

\footnotetext{
${ }^{113}$ Kenneth Frampton, Le Corbusier, Madrid: Akal, 2000, p. 55.

${ }^{114}$ Kenneth Frampton, "Paul Nelson et l'École de Paris 1923-1938” Bulletin d'Informations Architecturales IFA n ${ }^{\circ} 130$ de abril del año 1989, p. 4.
} 


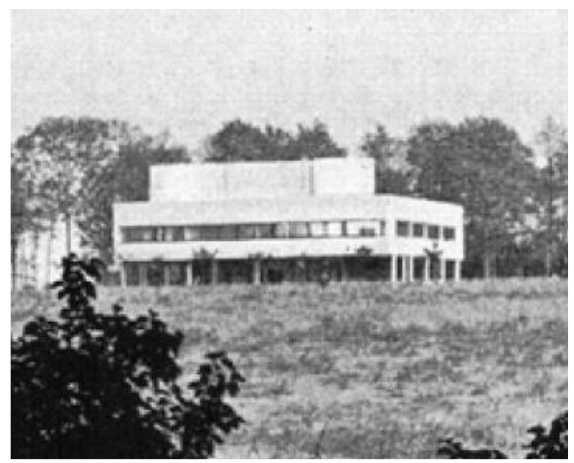

II. 23 Villa Savoye, Imagen del entorno. Le Corbusier-Pierre Jeanneret.1929.

El templo.

La exhibición de las respectivas estructuras, los pilotis y los pórticos, unida a la composición simétrica de las fachadas, trasladó la imagen de templo de estas viviendas. La utilización de volúmenes puros y del lenguaje de la columna, construían la referencia clásica, que les dotaba de un aspecto sagrado, a lo que también contribuía la manera de acceder a estas casas. En la Villa Savoye la entrada se producía atravesando el peristilo y en La Masion Suspendue a través del nártex . La primera vivienda se convirtió en un altar, elevado y abierto (II. 23) y la segunda en un lugar de culto, bajo palio y protegido.

En resumen, Paul Nelson, a pesar de situarse a sí mismo en una posición contraria a Le Corbusier y de plantear La Maison Suspendue como una alternativa a la arquitectura doméstica de este, estuvo influenciado por su manera de concebir el espacio. Recogió sus teorías y las modificó. Apoyado en el desarrollo de la técnica y en la elección de un sistema estructural distinto, consiguió construir algunos elementos que Le Corbusier había dejado enunciados. Con su propuesta, intentó trasladar el concepto de planta libre a las tres dimensiones para poder distribuir libremente todo el espacio doméstico. Aunque sus concepciones del programa doméstico y las necesidades de uso espacial eran diferentes, la experiencia de Le Corbusier fue un referente para Nelson. La relación unívoca entre función y estancia, que estableció Le Corbusier, no le servía a Paul Nelson, ya que en su concepto de vivienda reservaba estancias individuales sin una función predeterminada; la única condición de estas dependencias era la relación espacial con el resto de la casa, ya que debían ser exentas y estar separadas. Y Aunque Le Corbusier nunca construyó dependencias con estas características, sí que inició el camino para la creación de piezas aisladas. Por lo tanto, Paul Nelson partió del modelo espacial de "la máquina para vivir" y lo transformó, buscando adaptarlo a un concepto sociológico para el desarrollo del individuo. 


\subsection{R. Buckminster Fuller. Los procesos mecánicos y productivos de la vivienda}

Cuando en 1928 Richard Buckminster Fuller leyó el artículo sobre la arquitectura moderna que había escrito Paul Nelson ${ }^{115}$, decidió que tenía que contactar con él. En el texto se describía cómo los valores del funcionalismo habían dado forma a la arquitectura moderna europea y se defendía la creación de un modelo estético y una marca de arquitectura americana, basado en la estandarización de las necesidades de la sociedad moderna, y decía "nosotros necesitamos un Ford en arquitectura". Fuller $^{116}$, que trabajaba en un prototipo de vivienda industrializada, la "4D House", vio reflejados en el texto algunas de sus ideas y en la figura de Paul Nelson, a un arquitecto americano, que estaba informado de lo que sucedía en Europa. Esto le llevó a mantener una entrevista con él y proponerle una colaboración ${ }^{117}$.

Antes de regresar a Francia en la primavera de 1928, Paul Nelson firmó un contrato por cinco años que le convertía en "codiseñador" de la casa "4D" y, en contrapartida, se comprometía a ser el mentor y el embajador del proyecto en Europa. Para facilitar la difusión del proyecto en Francia, R.B. Fuller propuso a Francine Nelson que tradujera el texto al francés y así lo hizo, aunque nunca lo terminó. Fuller envió a Nelson un ejemplar del texto de "4D time lock", con una perspectiva de la torre de viviendas "4D" (II. 24), que tenía planta hexagonal con el suelo despiezado en triángulos coloreados con acuarela. Aunque Fuller era consciente de la falta de rigor matemático de esa representación, pensó que el dibujo sería lo suficientemente útil para poder transmitir la idea de su vivienda. (II. 25).

\footnotetext{
115 Paul Nelson, "Modern Architecture is Based on Curret Life", Chicago Evening Post. Magazine of the art world, 17 de abril de 1928, p.3.

${ }^{116}$ Ibidem.

${ }^{117}$ Carta, de 11 de agosto de 1928, de Richard Buckminster Fuller a su hermana Rosamond Lucilla Fuler, de este texto se deduce que R.B.Fuller entendió de manera equivocada algunos datos sobre la biografía de Paul Nelson y Francine, ya que ella no era hija de ningún ministro francés y Paul Nelson no había trabajó con Le Corbusier. Y estos errores le indujeron a pensar que el matrimonio era un buen contacto en París. Columbia University, Avery Architectural and Fine Arts Library, Dept. of Drawings \& Archives, Paul Nelson architectural records and papers.
} 

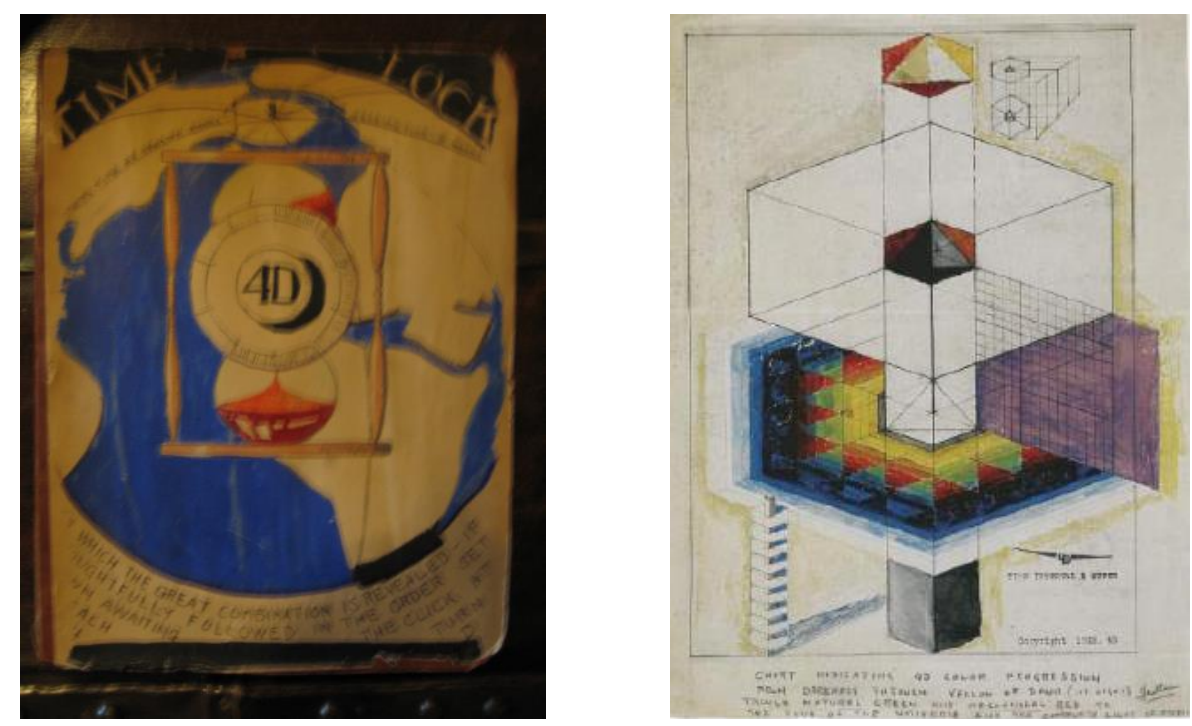

II. 24 4D Time Lock, ejemplar cedido por Richard Buckminster Fuller a Paul Nelson.1928.

II. 25 4D Tower, perspectiva, acuarela , cedido por Richard Buckminster Fuller.1928.

Fuller, como Le Corbusier, se propuso construir su propia "máquina para vivir" usando la tecnología que aportaba el desarrollo industrial y los procesos productivos de Estados Unidos. Para completar su investigación, a esas herramientas que le permitían construir su espacio doméstico, les añadió el concepto de dinamismo y de movilidad de la propia casa. De esta forma, la vivienda se incorporaba como un elemento más del equipaje a la nueva era de los viajes y de las comunicaciones. Frente a la metáfora de la máquina utilizada por los arquitectos del Movimiento Moderno, Fuller trabajó con el valor que aportaba la mecánica de los servicios domésticos y pensó su casa a partir de las oportunidades de las instalaciones como señala Reyner Baham ${ }^{118}$ Fuller, frente a la posición del Movimiento Moderno, se interesó más por lo que sucedía dentro del muro que por la superficie. Desde los años veinte hasta los años cincuenta, desarrolló una investigación sobre la vivienda en serie a la que denominó Dymaxion. En 1928 presentó su primera versión denominada $4 D$ House, el año siguiente mostró el nuevo modelo definido como Dymaxion House y, en 1944, el proceso culminó con el proyecto Wichita, Dymaxion Dwelling Machine.

El proyecto Dymaxion tenía como filosofía la búsqueda de la eficiencia energética, la producción en serie a bajo coste, la ligereza de peso y la flexibilidad de

${ }^{118}$ Reyner Banham, Teoría y diseño en la primera era de la máquina, Barcelona: Paidós, 1985, pp.317-319. [Theory and Design in the First Machine Age, London : Architectural Press, 1960]. 
adaptación al entorno. La Dymaxion House era una vivienda de planta hexagonal que se elevaba del suelo sobre un mástil central, y tenía tres alturas: la planta baja para acceso y garaje, la planta primera donde estaba el espacio de vivienda y la planta superior dedicada a terraza. Las divisiones en aspa del espacio interior organizaban la planta cuatro unidades, descanso, estar, cocina y biblioteca. La comunicación vertical se establecía por un ascensor central y dos escaleras de caracol e incorporaba un amplio programa de instalaciones mecánicas, que se ubicaban en el mástil central, que debían funcionar de manera autónoma. La casa tenía controladas las funciones de: la temperatura, la ventilación, la limpieza o la iluminación. La estructura estaba resuelta con tubos de acero traccionados, ensamblados, que se ataban mediante cables tensionados al apoyo central de duraluminio, y los cerramientos se construyeron mediante paneles dobles, prefabricados, que adaptan sus propiedades de transparencia a las necesidades de los usuarios.

El planteamiento de Fuller de una estructura colgada de un solo punto, era un elemento nuevo que contrastaba con lo que Paul Nelson había aprendido de Auguste Perret. En la Dymaxion House se trabajaba con otras hipótesis de resistencia, la flexión y la tracción, que ayudaban a que la casa no tuviera como único modelo la compresión y por lo tanto se pudiese aligerar su peso. Cuando Nelson pensó en un modelo que le permitiese liberar el espacio inferior de su vivienda, utilizó el referente de Fuller. En lugar de apoyar su casa en una retícula de pilares como hizo Le Corbusier, decidió sujetar la planta desde un elemento superior, y al igual que Fuller, utilizó cables traccionados para sujetar su cubierta.Nelson no estaba desarrollando un modelo mínimo de vivienda, la superficie en planta del cuerpo principal era de $186,3 \mathrm{~m}^{2}$, por lo tanto recurrió a otro sistema de anclaje superior en varios puntos, suspendiendo la planta de dos pórticos metálicos. Ambos arquitectos decidieron colgar sus viviendas, pero las razones que les condujeron a tomar esa decisión fueron diferentes. Mientras Fuller buscaba construir una casa elevada, desvinculada de la tierra, Paul Nelson buscaba una nueva condición espacial en el interior de la vivienda, que fuera totalmente libre, sin elementos que lo interrumpieran. (II. 26).

Los dos compartieron el gusto por los metales y el vidrio como materiales constructivos, utilizaron el acero y el aluminio, tanto en su condición de elemento estructural como en chapas de cerramientos. Para Fuller, la utilización del acero en arquitectura, debía aproximarse al uso que se estaba realizando en la construcción 


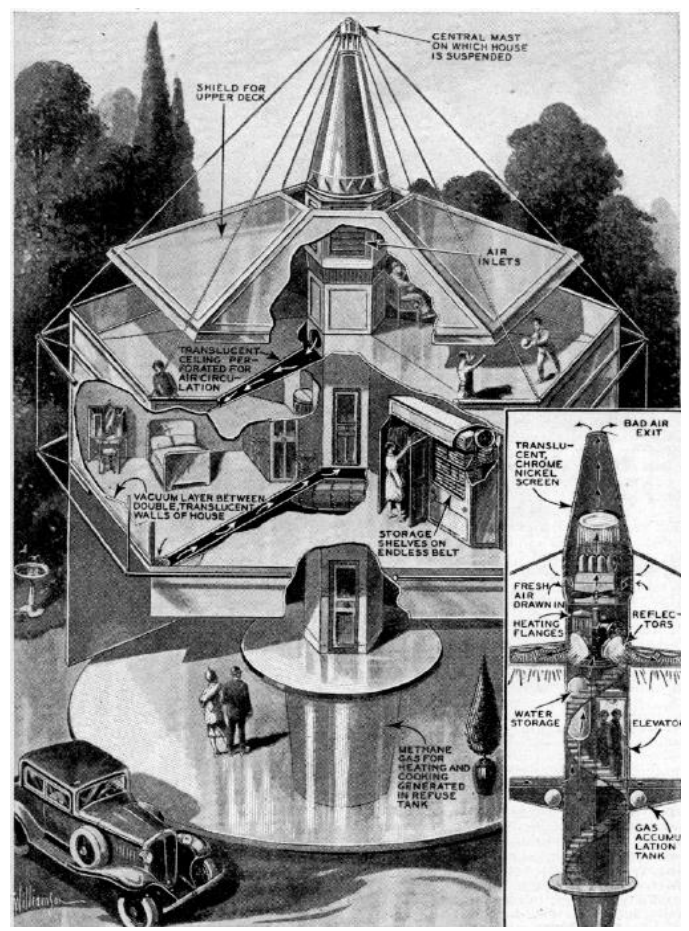

II. 26 Dymaxion House, perspec. seccionada e instalacion. Richard Buckminster Fuller,1929.

de barcos o trenes, de manera estandarizada, frente al uso del hormigón que consideraba narcisista. Para Fuller, el proceso de producción industrial de la construcción vivienda debía estar en una evolución permanente, lo que definió como:“...tendencia sin posibilidad de detención hacia el cambio en constante aceleración"119. A Nelson lo que interesaba era el proceso de industrialización de los metales, ya que no sólo eran buenos elementos para ser trabajados en serie, sino que tenían propiedades, como la resistencia a tracción, que convertían a la chapa en el material preciso para construir elementos verticales curvos y continuos de gran tamaño, pudiendo ser moldeados en fábrica según los deseos del cliente. Algo parecido sucedía con el control de los vidrios. Para Fuller, el tratamiento del cristal industrialmente permitía mejorar las condiciones de confort de los habitantes, mientras que para Nelson significaba la posibilidad de modificar cada elemento en función de los deseos particulares de cada usuario. El proceso de producción industrial, que condujo a Fuller a la estandarización, al abaratamiento de costes y a la perfección del modelo, fue utilizado y transformado por Nelson en su Maison Suspendue para mejorar la vida del hombre.

119 Afirmación de Fuller en Reyner Banham, Teoría y diseño en la primera era de la máquina, Barcelona: Paidós, 1985, p. 319. [Theory and Design in the First Machine Age, London: Architectural Press, 1960]. 
En ninguna de las propuestas, la relación con el medio condicionaba los proyectos. Las dos viviendas estaban protegidas del exterior y tenían un interior controlado que permitía un funcionamiento autónomo. La vivienda de Fuller nació para no aferrase al territorio y llevaba implícito un carácter nómada, y la construcción de Paul Nelson era la proyección de un mundo interior, no tenía un territorio concreto como referencia, ambas casas eran refugios. La Dymaxion House, con la excepción de los anclajes de los cables, solo tenía un punto de contacto con la tierra, el vástago central, y La Maison Suspendue, haciendo una reducción al volumen principal, solo tenía cuatro puntos de contacto. Las dos podían ser desmanteladas y el territorio no se vería afectado ${ }^{120}$.

La Dymaxion House estaba pensada para no perdurar ni en el lugar ni en el tiempo, si el dueño se marchaba a otro territorio podía trasladarse con su vivienda, y si aparecían nuevos avances científicos que afectasen al espacio doméstico, estos debían ser incorporados a las nuevas producciones, quedando las antiguas casas obsoletas. La vivienda de Fuller, en su conjunto, era flexible y se adaptaba a las necesidades del nuevo lugar, ayudaba al individuo a moverse con libertad y llevaba asociada la idea norteamericana de conquistar el territorio a través de un alojamiento.

Paul Nelson también utilizó la flexibilidad y la adaptación de la vivienda para que el individuo tuviera mayor grado de libertad, pero esta propiedad no afectaba la transformación del conjunto de la vivienda, sino a la modificación interna y temporal de algunos elementos. La longevidad de la casa era un proceso evolutivo que culminaba con la fase de desaparición. Paul Nelson tomó de Fuller las ideas sobre la movilidad y la flexibilidad, que permitían al hombre tener un mayor libertad y lo aplicó a la movilidad dentro de su territorio, el interior de su vivienda. Con esa idea de la transformación interior, construyó unos caparazones ergonómicos desmontables.

\footnotetext{
${ }^{120}$ Hay que señalar que las dos viviendas contemplaban la construcción de un espacio subterráneo, dedicado a estructura o instalaciones.
} 


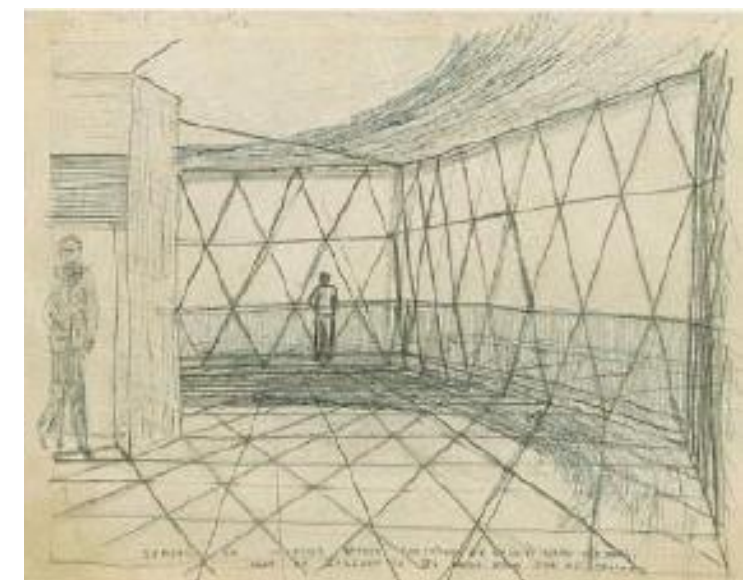

II. 27 4D Tower, perspectiva interior, Richard Buckminster Fuller .1928.

Richard Buckminster Fuller, rehuyó el lenguaje estilístico del Movimiento Moderno, importado desde Europa, para definir la imagen de su casa. Rechazó participar en lo que para él no era un desnudo real, como el que practicaban los ingenieros, sino un juego de cambio de traje, como hacían los arquitectos del Movimiento Moderno, sustituyendo los elementos decorativos de Beaux-Arts por la superficie lisa y pura que imitaba el metal de la máquina. Para conseguir una imagen externa de la casa acorde con la mecánica interna, utilizó los materiales y las estructuras que proporcionaban unas fachadas menos rígidas y más abstractas; sin composición de las ventanas y sin necesidad de enmarcar ningún paisaje, ya que este podía variar.

Aparte de la técnica, la imagen industrial y el concepto de prefabricación de la Dymaxion House, su sistema de cerramiento estuvo presente en el trabajo de Nelson en La Maison Suspendue. La utilización de la malla romboidal como cerramiento, tuvo su precedente directo en la fachada de la Dymaxion House (II. 27). Paul Nelson encontró en la trama de casa de Fuller la imagen contínua y ligera para cerrar su vivienda.

Hubo un elemento que Paul Nelson tomó, sin modificar, del desarrollo Dymaxion, que fue el bloque sanitario, Una cabina de metal que integraba todos los elementos del baño. La pieza tenía una planta cuadrada en su perímetro externo y su interior estaba dividido en dos espacios ovalados iguales, en uno de ellos estaba la duchabañera, y en el otro el inodoro y el lavabo. Desde 1927 hasta 1938, Fuller desarrolló varios modelos para que fuesen fabricados en serie por la Phelps Dodge Copper Company. Paul Nelson, tras dibujar varias versiones del baño principal de su vivienda, tomó el de Fuller y lo insertó sin modificarlo. Nelson explicaba que el baño era el fruto de la colaboración conjunta y que por eso lo incorporó a su 


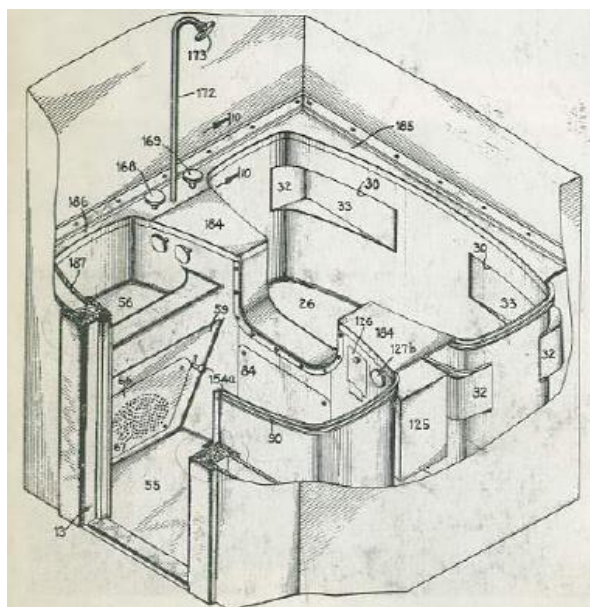

II. 28 Dymaxion Bathroom, perspectiva, Richard Buckminster Fuller .1936-1938.

proyecto íntegramente. De esta manera Paul Nelson introducía a través del baño un elemento real y fabricado en metal, una unidad completa, fabricada en taller y montada en obra, que podía desmontarse y cambiarse por otro modelo sin alterar el conjunto. (II. 28).

Tanto para la difusión de la Dymaxion House como para La Maison Suspendue, la presentación de modelos tridimensionales a escala jugó un papel fundamental y sus fotografías se convirtieron en la seña de identidad de ambos proyectos. La presencia de las maquetas en las exposiciones era la manera directa para llegar al gran público. Estas exhibiciones también sirvieron a sus autores para testar sus proyectos frente a unos espectadores no profesionales, las maquetas se convertían a su vez en microlaboratorios y los arquitectos modificaban sus modelos para que los visitantes comprendiesen mejor los proyectos ${ }^{121}$. Las dos casas fueron exhibidas juntas en 1939, en la exposición “Art in Our Time” que se celebró en el MoMA de Nueva York, con motivo de su reapertura ${ }^{122}$. Y en 1979 La Maison Suspendue

${ }^{121}$ Cuando Fuller presentó La "Dymaxion House" en abril de 1929, en el Marshall Field de Chicago. La planta pasó de ser cuadrada a ser hexagonal y las paredes se realizaron con elementos plásticos, este cambio más que con una intención de proyecto tuvo su razón en una estrategia didáctica que permitiese al público comprender mejor la propuesta. Esto es algo que también le sucedió a Nelson, tras la exposición en la Pierre Mattise Gallery de Nueva York en otoño de 1938, Paul Nelson sugirió al maquetista que para el segundo modelo insertase algunas piezas de plástico de colores en la malla romboidal para que él público pueda entender el cerramiento, ya que había generado bastantes dudas entre los visitantes.

122 The Museum of Modern Art, "Art in Our Time", an exhibition to celebrate the Tenth Anniversary of the Museum of Modern Art and the opening of its new building, 1939, Nueva York, The Museum of Modern Art, 1939, p.306-307. 
Aparte de coincidir en el punto de partida de algunas ideas, Richard Buckminster Fuller y Paul Nelson tenían algunos paralelismos en sus vidas personales, ambos eran norteamericanos y habían nacido en el mismo año (1895), ambos se alistaron como voluntarios en el ejército, Fuller en la armada y Nelson en la aviación, y los dos fueron pilotos. Igual que Nelson tuvo una gran amistad con el pintor Georges Braque, Fuller encontró en el escultor Isamu Noguchi a uno de sus mejores defensores. Y, tanto a Fuller como a Nelson, el reconocimiento a su trabajo les llegó tras la Segunda Guerra Mundial. A partir del primer encuentro en (1928) Fuller y Nelson, que nunca construyeron juntos ningún proyecto, mantuvieron una larga relación ${ }^{123}$. Cuando Paul Nelson presentó su proyecto de La Maison Suspendue, por vez primera en Nueva York, en la Pierre Matisse Gallery en 1938, Fuller estuvo presente y habló en el acto, lo que provocó la confunsión de sus nombres en algunas reseñas periodísticas.

En resumen, y con independencia de que la Dymaxion House estuviera pensada para ser construida y La Maison Suspendue era una concepción principalmente teórica, las dos casas tuvieron muchos elementos en común ${ }^{124}$. Pero la principal aportación de Richad Buckminster Fuller a la obra de Paul Nelson fue la transmisión del valor de la técnica y de la industria, como herramientas para cambiar el concepto de la casa y hacerla más flexible, más ligera y más mecánica, consiguiendo un recinto controlado al interior, protegido del exterior, que se beneficia del entorno. Paul Nelson tomó estas ideas y trató de humanizarlas mediante un proceso que permitiera la adaptación de modelo al uso singular de esos servicios mecánicos.

\footnotetext{
${ }^{123}$ Federico Neder, Fuller Houses. R. Buckminster Fuller's, Dymaxion Dwellings and Other DomesticAdventures, Zürich,Lars Müler Publishers,2008, p.107.

${ }^{124}$. Ibidem (p.106).
} 


\subsection{Pierre Chareau. La imagen industrial de la casa de vidrio.}

Paul Nelson escribió en 1933 un artículo sobre la Maiosn de Verre, en el texto que situaba esta casa como referente de la nueva arquitectura, se afirmaba que esto no hubiese sido posible sin la oportunidad que el cliente, el doctor Jean Dalsace, le brindó al arquitecto Pierre Chareau. De esta forma, Nelson apuntaba que la construcción de esta casa se había convertido en un laboratorio donde Chareau ensayó un nuevo espacio arquitectónico. ${ }^{125}$

Kenneth Frampton, en un artículo sobre la Ecóle de París (1923-1938), distngue dos grupos de arquitectos en función del tipo estructural de sus obras. Entre los que trabajaban con estructuras pesadas, de hormigón, estaban: Auguste Perret, Le Corbusier o Mallet-Stevens y, entre los utilizaban estructuras ligeras, de acero, figuraban: Paul Nelson, Pierre Chareau y Oscar Nitschké. Utilizando las referencias utilizadas por Nelson sobre la Maison de Verre en su artículo, Frampton sugería la posibilidad de entender La Maison Suspendue como una versión industrializada, destinada a la clase media, de la Maison de Verre ${ }^{126}$. Para apoyar esta teoría, Frampton comparó los elementos que tenían en común las dos viviendas y analizó los proyectos en función del contexto.

La Maison de Verre, situada en la 31 de la Rue St-Guillaume de París, fue proyectada por Pierre Chareau en colaboración con el arquitecto holandés Bernard Bijvoet. La vivienda se construyó entre 1927 y 1932 y en ella intervino el herrero Louis D'Albet, que fue maquetista de Paul Nelson. La casa era un encargo del doctor Jean Dalsace y su esposa, con un programa, en el que convivían la vivienda y la consulta ginecológica de manera autónoma. ${ }^{127}$ Pierre Chareau ubicó en la planta baja el acceso, los espacios de la clínica, las dependencias de servicio y la salida al jardín posterior; en la planta primera, la cocina, comedor, estar, salón y gabinete de trabajo; y en la planta segunda los dormitorios, los aseos y la terraza sobre jardín. Todas las dependencias tenían una sola planta, salvo la sala de espera, la consulta, y el salón que se construyeron con doble altura.

\footnotetext{
${ }^{125}$ Paul Nelson, "La Maison de la rue Saint Guillaume", L'Arquitecture d'aujourd'hui n no, noviembre- diciembre 1933,op.cit, p.9.

${ }^{126}$ Kenneth Frampton, "Paul Nelson et 1'École de Paris-1923-1938". Bulletin d'Informations Architecturales (IFA) nº 130 abril 1989, op.cit, pp. 3-4.

${ }^{127}$ El encargo inicial no incluía la consulta ginecológica del doctor Jean Dalsace, aunque sí su despacho y su biblioteca.
} 


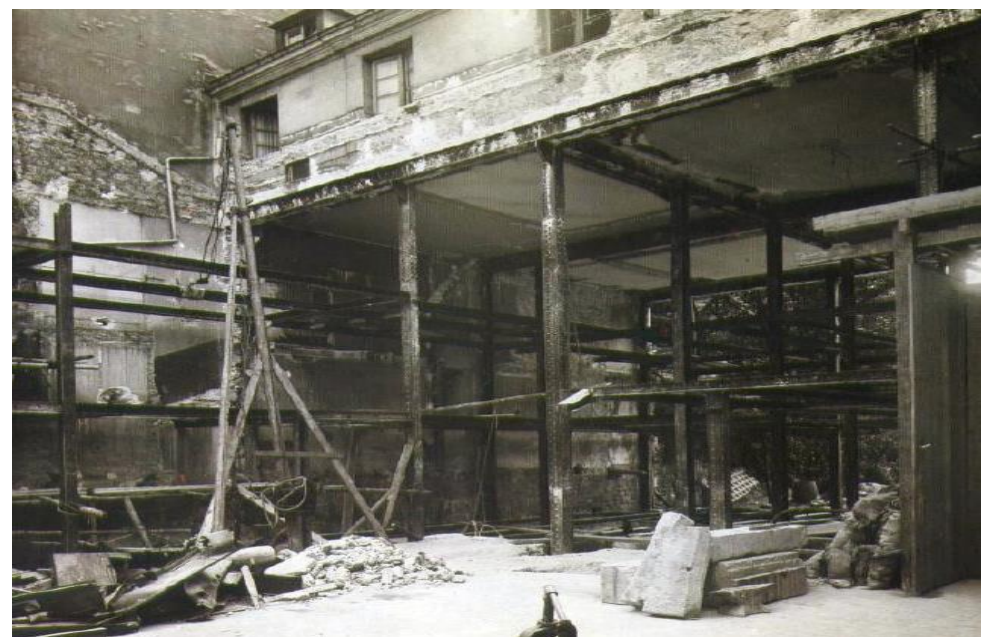

II. 29 Maison de Verre, Vivienda superior, ejecución. París. Pierre Chareau.1927-1932.

El proyecto tenía dos condicionantes externos: su ubicación en el interior del patio de manzana entre medianeras, y la necesidad de mantener la vivienda de la tercera planta del edificio existente. La nueva casa solo podía ocupar las tres plantas inferiores. Para edificar La Maison de Verre, Pierre Chareau apoyó el apartamento de la tercera planta sobre una estructura metálica vista y construyó debajo de esa vivienda un contenedor de piel translúcida con tres alturas (II. 29). Planteó una distribución de las plantas libre, independiente de las fachadas y sin determinaciones estructurales. Tanto la distribución del programa como el orden espacial y la imagen exterior de La Maison de Verre estuvieron muy presentes en la casa de Paul Nelson.

En los interiores de La Maison de Verre, se buscaba la continuidad espacial, minimizando el impacto visual de los elementos de separación, a través del uso de materiales ligeros o mediante mecanismos de desplazamiento de paneles y de mobiliario. Para conseguir este objetivo, Pierre Chareau proyectó circulaciones paralelas comunicadas entre sí. Verticalmente, las plantas quedaban conectadas a través de los espacios de doble altura. Paul Nelson incorporó el modelo de continuidad espacial y de planta libre, que había construido Pierre Chareau, y retomó la idea de la transformación espacial de La Maison de Verre a través de la flexibilidad del mobiliario. Nelson no lo aplicó a los muebles sino a las dependencias y con la intención de obtener más flexibilidad, proyectó habitaciones desmontables. De esta forma Nelson respondía a un programa concreto y aunque su vivienda nació con la intención de crear un espacio flexible, no estaba prevista para asumir una transformación de orden general, como le sucedía a la Maison Suspendue. 

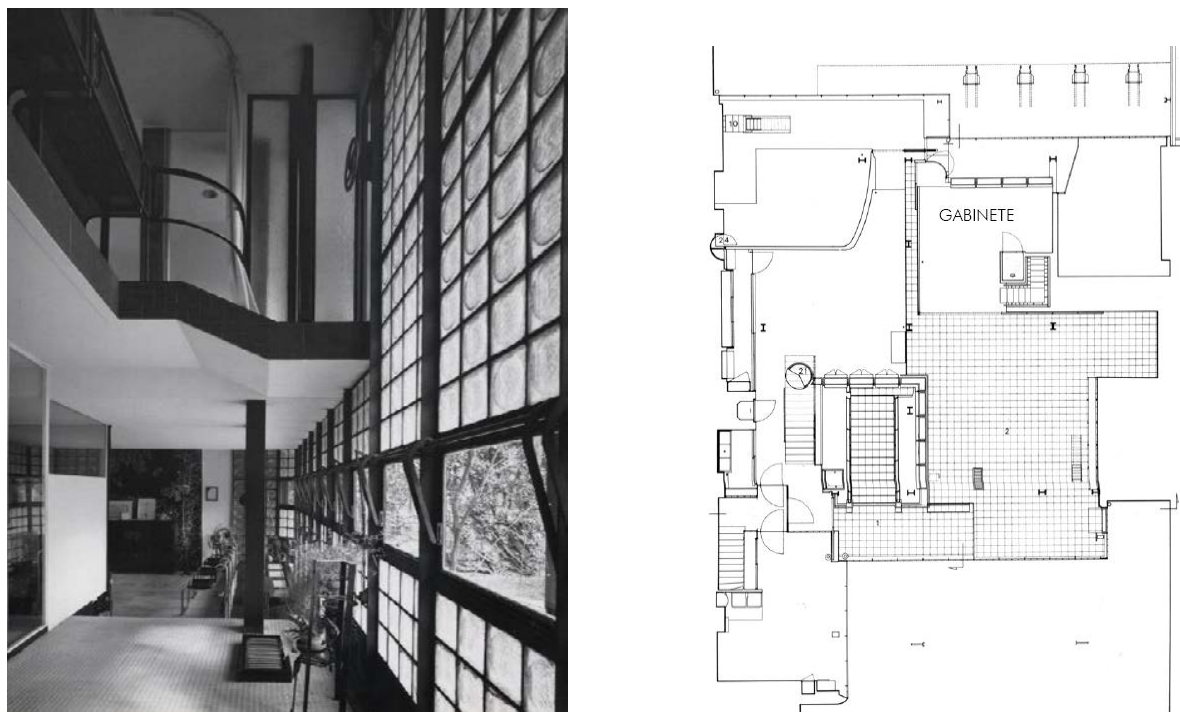

II. 30 Maison de Verre, Gabinete Dr Dalsace sobre sala de espera. París. Pierre Chareau.1927-1932

II. 31 Maison de Verre, planta primera, salón y gabinete. París. Pierre Chareau.1927-1932

En la planta primera de la Maison de Verre, Pierre Chareau construyó un gabinete de trabajo para el doctor Dalsace, una estancia exenta que comunicaba con el salón mediante una corredera y que estaba separada del muro del jardín a través de un vacío, que permitía el control del espacio inferior de la sala de espera (II. 30). En 1937, Pierre Chareau escribió “...los hombres demandan poder aislarse, pero también poder agruparse cómodamente y desplazarse con facilidad"128 . Ese mismo año, Paul Nelson estaba rehaciendo la primera versión de su proyecto (1936), donde ya aparecían unas celdas individuales exentas, colgadas de la planta superior, desde las que se podía tener acceso a lo que estaba sucediendo en el salón inferior. Pierre Chareau se anticipó a Paul Nelson en la proyección de habitaciones individuales para el trabajo intelectual, ambos arquitectos buscaban crear espacios de privacidad, pero mientras el gabinete de La Maison de Verre era una pieza conectada con el resto de la casa, Paul Nelso pensó en estas estancias como recintos aislados.

Paul Nelson señaló que la casa de Pierre Chareau planteaba una nueva forma de concebir el espacio de la vivienda, la cinematográfica, donde el tiempo tenía su propia dimensión. ${ }^{129}$

\footnotetext{
${ }^{128}$ Olivier Cinqualbre, Pierre Chareau : La Maison de Verre1928-1933. París: Éditions Jean Michel Place,2001, p.39.

${ }^{129}$ Paul Nelson, "La Maison de la rue Saint Guillaume", L'Arquitecture d'aujourd'hui nº, noviembre-diciembre 1933, p.9.
} 


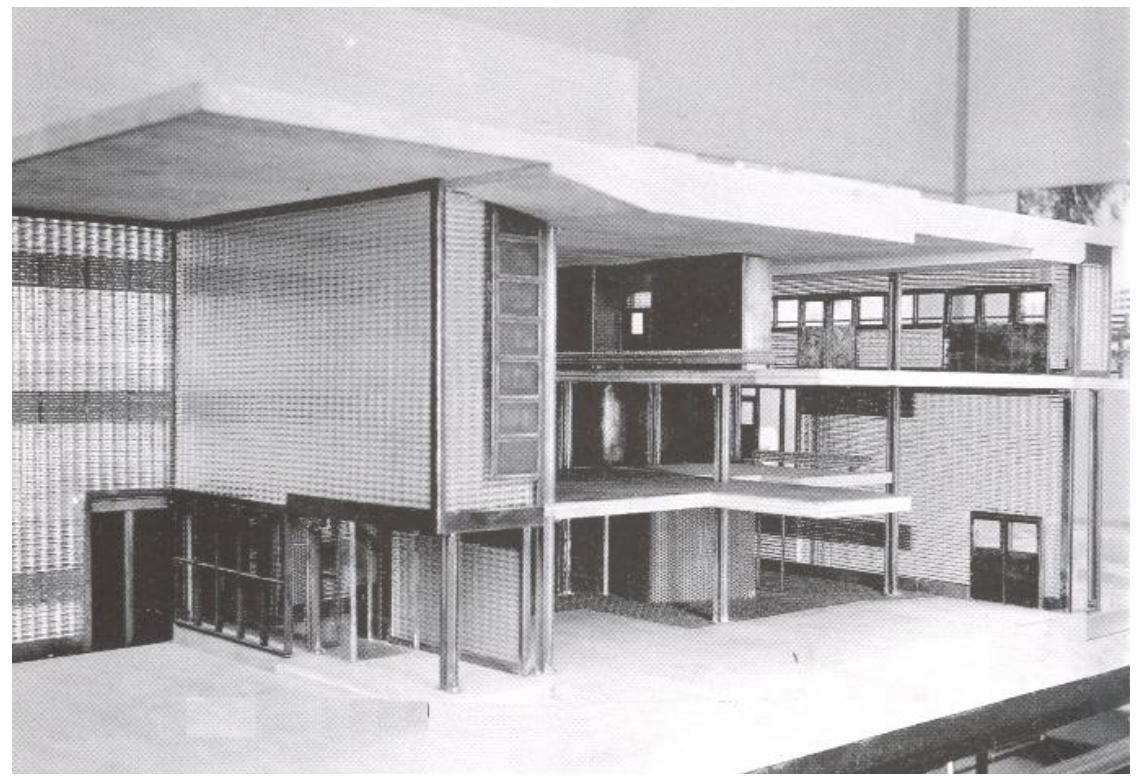

II. 32 Maison de Verre, maqueta seccionada expuesta en la Galerie Vignon París. Pierre Chareau,1933.

A Nelson le interesaba la sensación de movimiento que el hombre podía experimentar dentro de esta casa, gracias a la delimitación del espacio interior por el cerramiento translúcido; este material permitía el paso de la luz y la iluminación a contraluz de cada mueble y de cada desplazamiento ${ }^{130}$. Nelson vió el diferente tratamiento que dio a los dos núcleos de comunicaciones Pierre Chareau, y comprendó el protagonismo que adquiría la escalera principal exenta y situada en una posición central, su tratamiento formal la acercaba a una pieza escultórica.

Ni Chareau, ni posteriormente Nelson utilizaron el hormigón como estructura para sus viviendas. La necesidad de apoyo de la tercera planta, llevó a Chareau a plantearse una estructura metálica que le permitía trabajar con mayor libertad en el proceso de ejecución. Por su parte Nelson, también se propuso sujetar la planta superior de su vivienda de una estructura metálica. En los dos proyectos, gracias a la luz que inundaba el volumen del salón, las imágenes reflejaban la idea de una planta superior ingrávida, la estructura metálica en la casa de Pierre Chareau era tan esbelta respecto del volumen, que tendía a difuminarse y en la vivienda de Paul Nelson la idea de suspensión era más evidente, ya que la estructura había desaparecido del espacio interior.

\footnotetext{
${ }^{130}$ Recordar que Paul Nelson en su experiencia como director artístico de "Whay a Widow" (1929-1930) había utilizado lo paneles translúcidos iluminados desde el exterior para conseguir un mejor efecto lumínico de las escenas. véase Donald Albrecht, Designing dreams. Modern Architecture in the movies. New York Edit: Marge Horvitz, 1986, p. XII.
} 
Una de las cuestiones que Nelson reconoció, como reflejo de los nuevos tiempos, en la arquitectura de La Maison de Verre, fue la utilización de una técnica constructiva basada en la industrialización, que tenía como materiales principales: el acero, el vidrio y el aluminio, transformados en perfiles, chapas o bloques modulares. Los dos arquitectos coincidían en utilizar la investigación para resolver problemas concretos, su colaboración con las empresas les ayudaba a resolver las soluciones. Ambos se enfrentaron a la construcción de fachadas de vidrio a partir de bloques estandarizados. Pero cuando Chareau hacía referencia a la estandarización, entendía que esta debía de realizarse por artesanos que controlasen el proceso hasta el más mínimo detalle. Su casa resultó ser un trabajo de encaje manual donde las piezas industrializadas se ajustaban a medida en la obra.

Los dos proyectos planteaban un funcionamiento autónomo respecto del entorno donde se asentaban, en ninguna de las viviendas se establecía una estrecha dependencia del medio exterior. La Maison de Verre, aunque nació a partir de los condicionantes externos ya mencionados, se construyó como una caja cerrada dentro del contenedor urbano del patio de manzana. La casa se levantó en una posición intermedia entre el court d'honor que la separaba de la calle y un jardín posterior. El proyecto de La Maison Suspendue nació descontextualizado y por lo tanto no había ninguna relación previa con el medio. En ambas casas se buscaba crear un refugio, un espacio interior controlado. La Maison de Verre permitía aislarse de la ciudad tras un patio de manzana y La Maison Suspendue creaba un lugar donde refugiarse del medio exterior y ambas viviendas quedaban resguardadas bajo una gran cubierta.

La casa de Chareau, insertada dentro de un recinto superior, tenía delante el espacio social del patio, al cual abrían todas las ventanas de los edificios colindantes (II. 33). De tal manera que la Maison de Verre se convirtió en la pieza diferente a la cual se dirigían las miradas. Chareau construyó un cerramiento translúcido e invertirtió los términos de relación con el entorno, dejando a criterio del propietario el grado de exhibición al que deseaba estar sometido (II. 34). Este esquema de relaciones entre el espacio colectivo y el individual, pero a escala diferente, lo utilizó posteriormente Paul Nelson en las estancias individuales de su casa para determinar la relación entre el espacio individual y el familiar. 

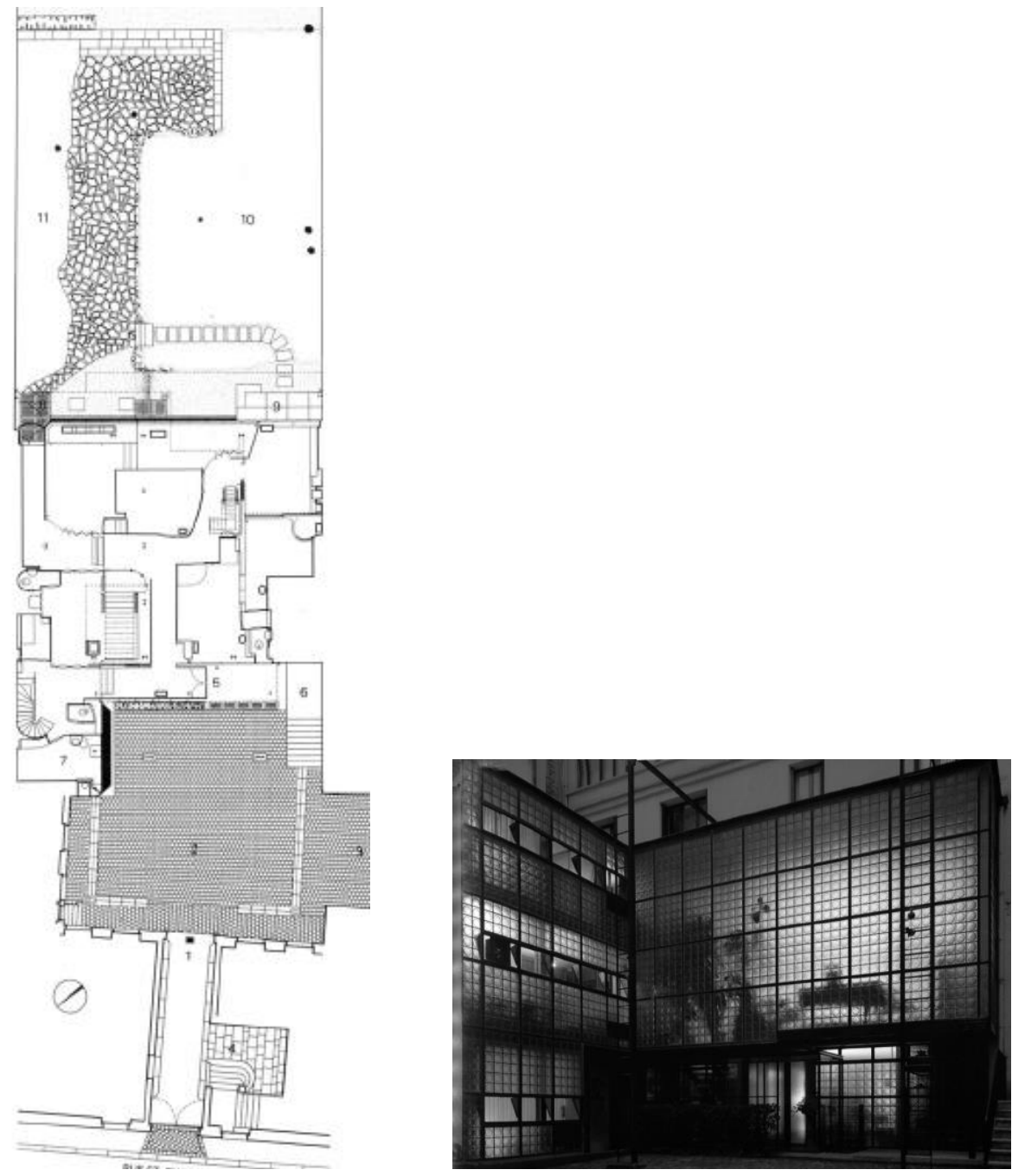

II. 33 Maison de Verre, planta baja, patio delantero y jardín. París. Pierre Chareau,1927-1932.

II. 34 Maison de Verre, fachada principal dentro de patio. París. Pierre Chareau,1927-1932.

Paul Nelson hacía una observación sobre la presencia de los huecos en la vivienda y la repercusión que tenían en la configuración del espacio interior protegido.

...(la ventana, en el muro transparente, en el fondo es una vinculación directa con el exterior y destruye la sensación de espacio. Por lo tanto debe ser empleada con mucha discreción, solo donde exista una función definida). ${ }^{131}$

${ }^{131}$ Paul, Nelson, "La Maison de la rue Saint Guillaume", L'Arquitecture d'aujourd'hui $\mathrm{n}^{\circ} 9$, noviembre-diciembre 1933, p.9. 
Las soluciones adoptadas para resolver las fachadas en los dos casos eran similares, proyectaron construir unas pieles de vidrio, sin una composición de los huecos vinculada al exterior. A través de unas mallas, donde se insertaban las piezas de vidrio estandarizadas, construían unos volúmenes isótropos donde las fachadas no tenían categorías. Pero aun admirando la fachada "industrial" de la Maison de Verre, Paul Nelson buscaba que el movimiento y la flexibilidad espacial se adaptasen a las necesidades del hombre y para lograrlo, utilizó la técnica. El mismo año en el que Chareau terminó La Maison de Verre, él estaba desarrollando la fachada "claustral", con piezas modulares practicables para el proyecto del hospital de Lille (§ I.3.).

La relación de los dos arquitectos respecto de las propuestas domésticas del Movimiento Moderno, especialmente de las de Le Corbusier, era de rechazo. Ya se ha explicado la posición de Nelson (§ II.2.) y, para Pierre Chareau, la casa debía ser útil para el hombre que la habitaba y la adaptaba a sus deseos, la vivienda no era un cronograma espacial que conminaba al hombre a determinadas funciones, no era una "máquina para vivir". Su construcción debía responder a las relaciones sociales de los clientes y no a los intereses personales del arquitecto. "...la casa no es ni un avión, ni un trasatlántico, ni un laboratorio - aceptamos antes la religión de los Dioses del lugar que la tiranía del Dios Maquina”"132.

En resumen, las dos casas trataron de dar una respuesta a la vivienda burguesa moderna. La Maison de Verre lo hizo a través de la construcción de un encargo concreto y La Maison Suspendue lo desarrolló como una declaración proyectada. Ambas propuestas compartieron intereses: la continuidad espacial, el uso de estructura metálica, el empleo de materiales industriales, la creación de un espacio interior autónomo y la incorporación del valor del movimiento. Pero cada uno los adaptó a sus propios objetivos. Ninguno de los dos proyectos nació para convertirse en un tipo estandarizado, la casa de Chareau por que estaba ubicada en un entorno concreto y la de Nelson por que buscaba ser mas una referencia que un modelo de casa. Por lo tanto, no resulta sencillo establecer una línea de continuidad directa entre ambos trabajos. La amistad entre los dos arquitectos y del interés que $L a$ Maison de Verre suscitó en Paul Nelson, le llevó a citarla como inspiración directa de su propio trabajo:

... para mi las fases de desarrollo de la "Maison Suspendue" comenzaron con "l'Opera de 4 Heures" de Giacometti, y a continuación por la "Maison de

${ }^{132}$ Olivier Cinqualbre, Pierre Charea : La Maison de Verre1928-1933. París : Éditions Jean Michel Place ,2001, pp.36-39. 
Verre". Por lo tanto, sería para mí un honor formar parte de la defensa de la "Maison de Verre" como ejemplo histórico del desarrollo del hábitat del futuro. $^{133}$

Sin embargo, no es posible establecer con claridad una traslación de modelo entre ambas casas. Para Paul Nelson, la Maison de Verre significaba ver construidos algunos de sus objetivos con cinco años de anticipación, pero no le ofreció las soluciones estratégicas espaciales, ni técnicas, ni sociales, que definían su proyecto. Para Paul Nelson, lo más importante de la Maison de Verre fue su imagen de arquitectura doméstica industrial.

${ }^{133}$ Carta, 18 junio de 1976, de Paul Nelson dirigida al doctor Pierre Vellay y a su esposa Aline, propietarios de la Maison de Verre, en respuesta a una solicitud para incorporarse a la creación de un comité de honor de defensa de la Maison de Verre, para crear una asoción de amigos de la casa. MNAM/CCI, Bibliothèque Kandinsky, fonds Nelson. 


\section{Los amigos artistas y la experiencia de pintor.}

Cuando Paul Nelson llegó a París en 1920, la capital francesa estaba inmersa en una intensa actividad artística, era una etapa de transición entre el cubismo y el surrealismo. El primer artista al que conoció fue Georges Braque, que le introdujo en los círculos artísticos de la capital francesa y entre sus íntimos amigos estuvieron: Jean Hélion, Fernad Léger, Alexander Calder, Joan Miró y Aberto Giacometti. Esta experiencia le sirvió para completar su formación artística en Beaux-Arts y aplicarla a su arquitectura. Paul Nelson tuvo un aprendizaje transversal a partir del arte, tanto directo, a través de los artistas que colaboraron en sus proyectos, como indirecto, a través del pensamiento de aquellos que eran amigos aunque no participaron en su obra. Estas relaciones le aportaron concepciones espaciales, sociológicas y técnicas, que le sirvieron como base para reflexionar sobre la necesidad del arte en la vida cotidiana, y para desarrollar su propia incursión en la práctica de la pintura, con la que experimentó hasta la segunda mitad de los años treinta.

Paul Nelson conoció a Georges Braque y a Jean Hélion por el interés que le inspiraban sus respectivas obras y tanto las reflexiones como las críticas que estos artistas realizaron sobre su arquitectura incidieron de un modo decisivo en la manera de afrontar su trabajo. Los dos pintores representaban dos caminos diferentes de entender el cambio que había experimentado la pintura en las primeras décadas del siglo XX, pero fue fundamentalmente su pensamiento y su manera de entender la vida, lo que más influyó en el trabajo de Nelson. Su arquitectura, sin embargo no es ni una transposición tridimensional, del concepto de la pintura cubista de Georges Braque, ni una mezcla de la configuración abstracta y figurativa de Jean Hélion.

Fernad Léger y Alexander Calder fueron los artistas que más colaboraciones realizaron con Paul Nelson. A partir de la incorporación del trabajo de los dos artistas en su obra, extrajo las conclusiones que le permitieron fijar su postura respecto a la relación de apoyo entre la pintura o la escultura y la arquitectura. Entendía que el trabajo del arquitecto debía tener un apoyo interdisciplinar, que incluía a los artistas, y consideraba que la presencia de las obras de arte en su arquitectura tenía una función espiritual, que incidía en el ánimo de los usuarios.

Nunca intervino con una obra de arte propia en sus proyectos, siempre recurrió a sus amigos artistas para que realizasen esta labor, separando de esta manera su faceta de pintor de su oficio de arquitecto. 
3.1 Georges Braque, el control sobre el espacio personal.

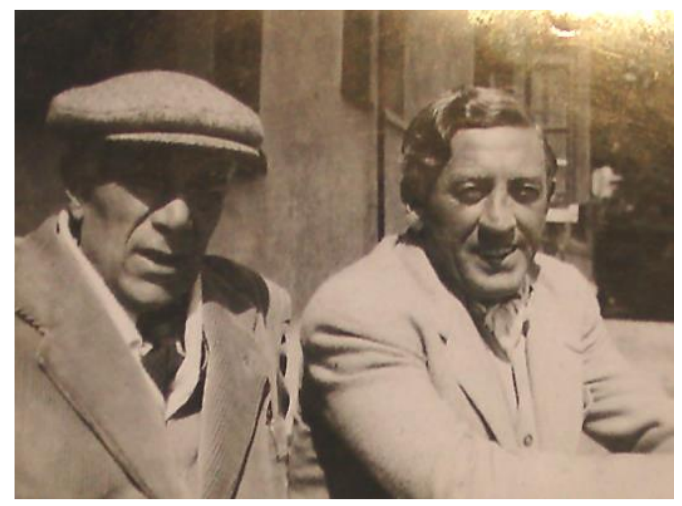

II. 35 Georges Braque y Paul Nelson. Casa de G. Braque, Varengeville

Entre los años 1922 y 1927, Paul Nelson y el pintor Georges Braque se vieron casi a diario. Durante ese tiempo no hablaron de manera directa una palabra sobre arte, ya que, según Nelson, vivían el arte, "su vida estaba imbuida por el gusto"134. Su relación con Georges Braque le ayudó a tener conciencia de sí mismo a través de sus dibujos, generando la razón que le sirvió para decantarse por la arquitectura ${ }^{135}$. En 1928, Paul Nelson invitó a Georges Braque a su casa en Varengeville-sur-Mer, una población situada frente al Canal de la Mancha, que era el lugar de vacaciones de la clase alta parisina y la aristocracia inglesa. Georges Braque se sintió atraído por el lugar, los bosques, la iglesia y el cementerio sobre los acantilados y en 1929 compró un terreno y encargó a Paul Nelson el proyecto para construir una casa y un taller. ${ }^{136}$ Aunque estas edificaciones no representaron ninguna innovación espacial ni tecnológica en la carrera de Paul Nelson, el contacto con su cliente fue muy enriquecedor.

\footnotetext{
${ }^{134}$ Charles Galpérine, "Un americain a Paris. Interview de Paul Nelson”, Notre Republique, viernes 3 de febrero de 1967

${ }^{135}$ Nelson tras un periodo de confusión intelectual, se planteó abandonar la arquitectura y seguir expresándose en otras disciplinas como la pintura o la música. Trataba de manifestar su rechazo a Beaux Arts y todo lo que representaba. Y fue Georges Braque quien le animó a revisar sus trabajos, para identificar cuales eran los elementos que se repetían en sus obras, de esta forma él podría reconocerse en esos elementos y eliminar las cosas que no le interesaban. Así consiguió encauzar sus intereses en una dirección que le permitió expresarse con mayor personalidad. Véase Paul Nelson, Mon ami Georges Braque. Souvenirs de Paul Nelson, souvenirs recueillis par Georges Boudaille, Les Lettres françaises n ${ }^{\circ}$ 942, 6 septiembre 1962.

${ }^{136}$ La construcción de la vivienda y el taller de Georges Braque se realizó tras la vuelta de Paul Nelson de Hollywood, la casa figura inscrita en el catastro de 1932, como nueva contribución. Archives Departementaux de Dieppe. Copie de la matrice générale. Contributions directes, Departement de la Senne- Inferieur, commune Varengeville sur mer, caja $\mathrm{n}^{\circ} 235$, folio 64 .
} 


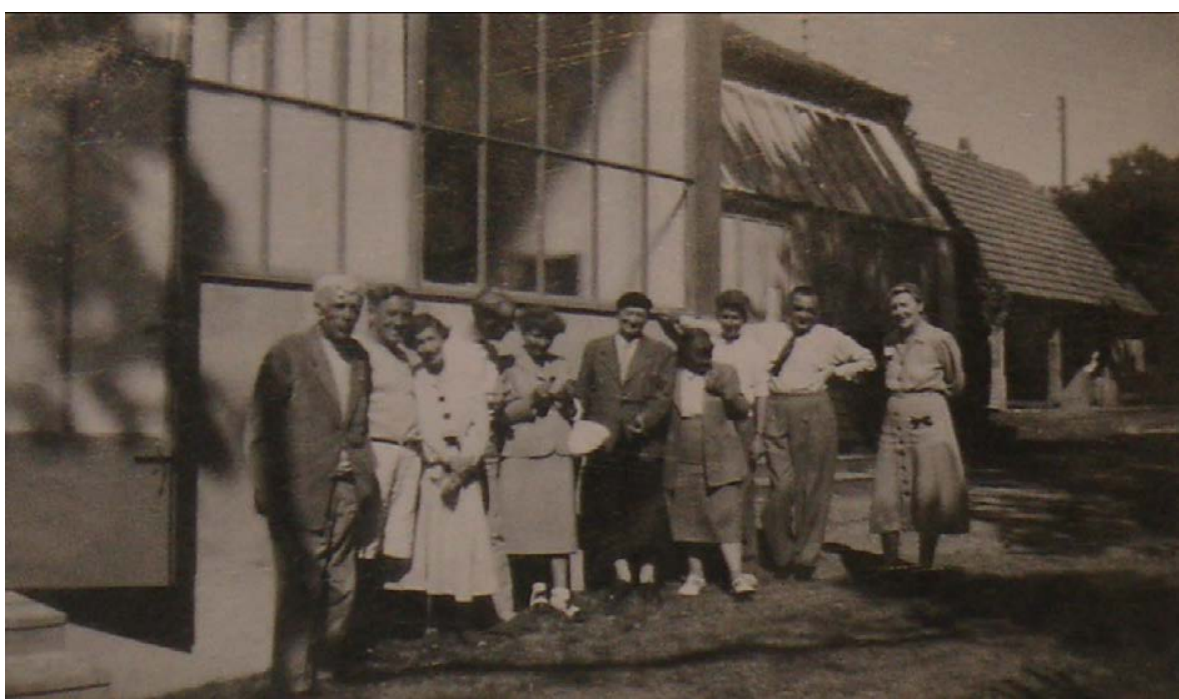

II. 36 Taller y casa de Georges Braque, Varengeville, G. Braque, Paul y Francine Nelson y otros.

Paul Nelson propuso cerrar la fachada occidental del estudio con bloques de vidrio, para homogeneizar la entrada de la luz, pero Georges Braque se opuso, ya que no sólo estaba preocupado por el factor cualitativo de la luz, sino también por el efecto psíquico de la temperatura. Quería que su estudio estuviese iluminado desde del Sur como los de los pintores del Quatroccento, con una luz cambiante, que pudiese ser controlada desde el interior mediante mecanismos de protección textil, y conseguir de esta manera un amplia variedad de matices.

... tú estás haciendo la casa de Nelson y yo quiero la casa de Braque, una casa que yo pueda dominar,... no quiero una pared de vidrio de primera calidad, los cristales son demasiado limpios y transparentes, cuando yo abro las ventanas de mi estudio deseo ver la naturaleza de manera distinta y diferente a cuando estoy en el exterior. ${ }^{137}$

Esta observación de Georges Braque, le proporcionó a Paul Nelson una de las claves que marcaron su carrera. A partir de ese momento comprendió que el arquitecto debía limitarse a la construcción de un marco lo suficientemente flexible como para que el cliente, en este caso el pintor, pudiera desarrollarse y controlar cada instante de su vida o su creación.Y aplicó esta filosofía constructiva en un segundo estudio que construyó adosado al primero. Nelson se planteó este encargo como una intervención inapreciable que fijase la estructura mínima, que el pintor pudiese controlar espacialmente a su antojo. (II. 36). ${ }^{137}$ Paul Nelson, "Mon ami Georges Braque. Souvenirs de Paul Nelson, souvenirs recueillis
par Georges Boudaille", Les Lettres françaises $n^{\circ} 942,6$ septiembre 1962. op.cit 
II. 37 Taller de Gorges Brauqe, hueco para trabajo-lectura, Varengeville. Paul Nelson ca.1934.

Paul Nelson pensó en un taller alejado de cualquier concepción formal, construido con un sistema de ejecución rápida. Este estudio tenía mayor tamaño que el primero y proporcionaba un espacio más amplio para trabajar el gran formato. Tenía el aspecto de las construcciones agrícolas del lugar, se trataba de un prisma con una cubierta en diente de sierra, ejecutado con una estructura metálica, sus cerramientos estaban recubiertos en el exterior por tableros de madera, y revocados al interior, pintados en gris y el suelo era de madera de teka procedente de los barcos. La pieza tenía un gran hueco en la fachada Sur y lucernarios.

El fotógrafo Alexander Liberman visitó a Georges Braque y quedó impresionado por el sistema de mecanismos iluminación que permitían ajustar la luz mediante lonas interiores y conseguir que se viese el espacio entre los objetos. El estudio se había convertido en un instrumento que transformaba la luz en la energía que generaba el proceso de creación ${ }^{138}$.

Paul Nelson repitió el esquema de crear un espacio individual de reflexión dentro del taller de Braque, igual que lo había hecho antes Auguste Perret en el taller que había construido para el pintor en París.(§ .II. 2). Paul Nelson abrió un pequeño hueco en el testero Oeste, a la altura de una persona sentada, y cambió el tratamiento de la pared introduciendo una franja oscura de zócalo (II. 37). Con esta actuación en

${ }^{138}$ Alex Danchev, Georges Braque a life, Nueva York: Arcade Publishing, 2005, p. CCLXXI. 
la esquina, y sin construir una separación física, creó un espacio de trabajo intelectual para de Georges Braque, un lugar de uso personal dentro del ámbito del estudio.

Coincidiendo con la finalización de su nuevo taller, Georges Braque desarrolló como tema de trabajo una serie de recreaciones interiores de su propio estudio, de su mundo interior (II. 38). Las imágenes del taller fueron una constante entre 1949 y 1956, en ellas aparecían siempre los mismos objetos: paletas, caballetes, bustos femeninos, pájaros y jarrones; estaban situados en planos superpuestos con diferente grado de definición. Después de haber roto la perspectiva, el problema que preocupaba a Braque, era definir el espacio que existía entre las cosas: la profundidad. El pintor coincidía con Paul Nelson, que también había trabajado en esa misma búsqueda del espacio intermedio en la Maison Suspendue. Y para hacerlo perceptible, había utilizado los mismos recursos que utilizó Georges Braque: el juego de luces y el contraste formal a través de los volúmenes y las siluetas. Por lo tanto, la construcción del taller pudo influir en la concepción espacial de los dos creadores.

Tanto Paul Nelson como Georges Braque utilizaron los objetos cotidianos para iniciar sus respectivas investigaciones, Nelson partió de las estancias de la casa y Braque de las vasijas de pinceles y los caballetes, e intentaron transformar la realidad espacial vigente y la descompusieron en diferentes unidades, estableciendo nuevos mecanismos de conexión y de relación. Finalmente, crearon un marco externo para cerrar el nuevo mundo que habían creado, construyeron jaulas controladas, que les permitían mostraban desde el exterior sus respectivas visiones del mundo.

Aunque los dos creadores mantuvieron el vínculo a lo largo de toda su vida, Paul Nelson nunca propuso a Georges Braque que hiciese una obra para sus edificios ${ }^{139}$. A pesar de su amistad y de que Braques realizó intervenciones de pintura mural en la arquitectura, como la de 1954 para Margarite y Aimé Maeght en su casa de Saint Paul de Vence. Paul Nelson no solicitó a Georges Braque una obra de arte para incluirla en las maquetas de La Maison Suspendue.

139 Olivier Cinqualbre, "Braque Bâtisseur", catálogo de la exposición George Braque L'espace, Museo Malraux de Le Havre, París: Adam Biro,1999, p. 97. 


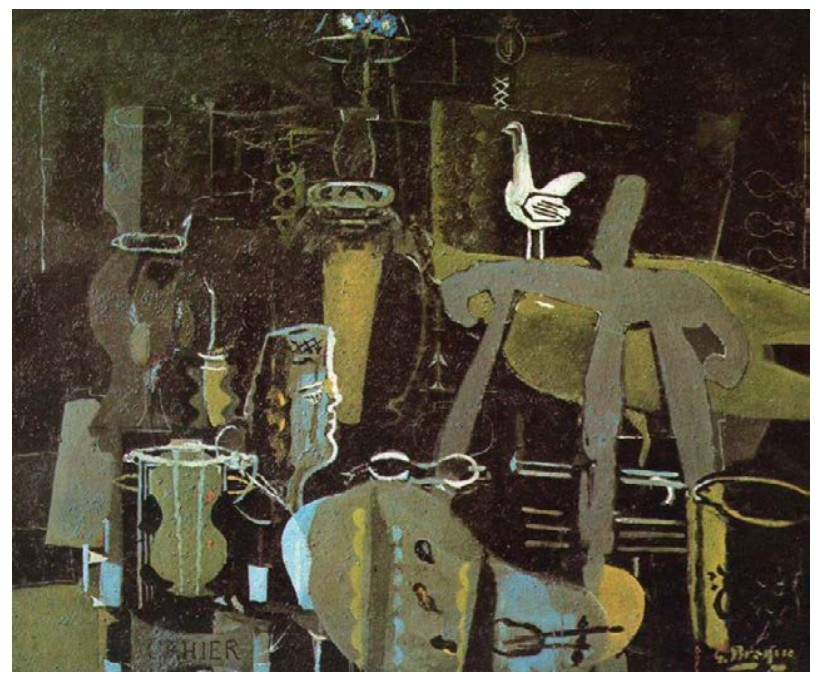

II. 38 Atelier VI, Georges Braque, 1951.

En resumen, la verdadera influencia de Georges Braque sobre Paul Nelson se produjo a partir de la relación profesional, en la confirmación de que la casa o el lugar de trabajo debían de estar al servicio del cliente individual. El trabajo del arquitecto era construir unos límites lo suficientemente flexibles como para adaptarse a las demandas del usuario.

\subsection{Jean Hélion. Términos de vida y términos de espacio.}

Alexander Calder presentó a Paul Nelson y al pintor Jean Hélion en $1934^{140}$ y desde ese momento y hasta la muerte de Nelson mantuvieron una relación prolongada, con algunos desacuerdos, motivados por la opinión que Jean Hélion tenía sobre la dudosa ideología de Paul Nelson ${ }^{141}$ y porque Nelson nunca solicitó la colaboraron de Hélion. La vida de Jean Hélion también estuvo marcada por su condición viajera entre Francia y Estados Unidos, y ambos compartieron amigos artistas como Fernand Léger y marchantes de arte como Pierre Loeb. En los años treinta la

\footnotetext{
${ }^{140}$ Jean Hélion, (1904-1987) pintor francés que desarrolló uno de los caminos más singulares de la pintura francesa. Hastá los años 40 su proceso evolutivo explora diferentes vías que desembocaron en la abstracción y a partir de los años 40 surge en su trabajo una nueva línea de expresión que trata de presentar una realidad figurativa, la cual mantuvo hasta el final de su carrera. Aunque exploró diversas técnicas, Hélion apostó por el reconocimiento formal de la realidad e incorporó lo cotidiano a su obra, la calle se transformó en lugar de inspiración. Y el observador se convirtió en un personaje más de la escenografía urbana representada.

${ }^{141}$ Describe a Nelson como un burgués, con perro, criada y dos apartamentos, que puede comer lo que quiere. Véase : Jean Hélion, Lettres d'Amérique. Correspondance avec Raymond Queneau 1934-1967. Paris : IMEC éditions, 1996, p.20.
} 
relación fue muy intensa, especialmente en el otoño de 1936, cuando coincidieron en Nueva York mientras Paul Nelson trabajaba en el proyecto para la C.B.S (§. I. 2 )

En 1935, el pintor Jean Hélion publicó una crítica de arquitectura sobre el hospital que Paul Nelson había proyectado para la ciudad de Ismaïlia en el Canal de Suez (Egipto). Utilizó el proyecto para describir lo que él consideraba que debía de ser el camino de la arquitectura. Establecía, como premisa principal, que el tema fundamental de la arquitectura era la casa: "toda arquitectura debe plantear una calidad de vida y el problema de la arquitectura se concentra en la casa" ${ }^{142}$ y a partir de aquí extrapolaba sus conclusiones al resto de los proyectos. En su discurso hacía un análisis crítico sobre el concepto de vivienda del Movimiento Moderno y formulaba una serie de propuestas destinadas a superarlo.

Jean Hélion centró su análisis crítico en el agotamiento del funcionalismo como proceso para concebir una vivienda, ya que consideraba que la arquitectura moderna obedecía a un programa "inorgánico" de la casa, basado en resolver necesidades funcionales consecutivas y fragmentadas en el tiempo, que no avanzaban ni ofrecían una respuesta conjunta a un nuevo tipo de vida. La casa no funcionaba como una máquina. Igualmente, pensaba que la imagen desnuda de la fachada moderna era un artificio, y el concepto espacial de plantas superpuestas con escasa comunicación interna insuficiente para lograr un espacio continuo total.

Jean Hélion proponía desarrollar un "funcionalismo trascendental" en el que la casa respondiese a un plan de vida individual, lleno de complejidades, con una componente de relación social que resolviera todas necesidades materiales y espirituales de cada instante y que fuese flexible en la visión de futuro. La vivienda debía tener un carácter propositivo que ofreciese diversas oportunidades para habitarla. La clave del proyecto estaba en resolver los espacios colectivos, especialmente los lugares de tránsito entre las estancias, con el mismo interés que se ponía en las habitaciones, y en hacer un planteamiento global de todas las partes que integraban el ámbito doméstico. Hélion consideraba que las arquitecturas de espacio único, como el hangar, eran las más apropiadas para resolver cualquier programa, un contenedor externo con una geometría clara, que permitía resolver en su interior diáfano las habitaciones como unidades practicables y comunicadas entre sí.

${ }^{142}$ Jean Hélion, “Termes de vie-Termes d'espace”, Cahiers d'art, n7-10, 1935, pp. 268-273. 


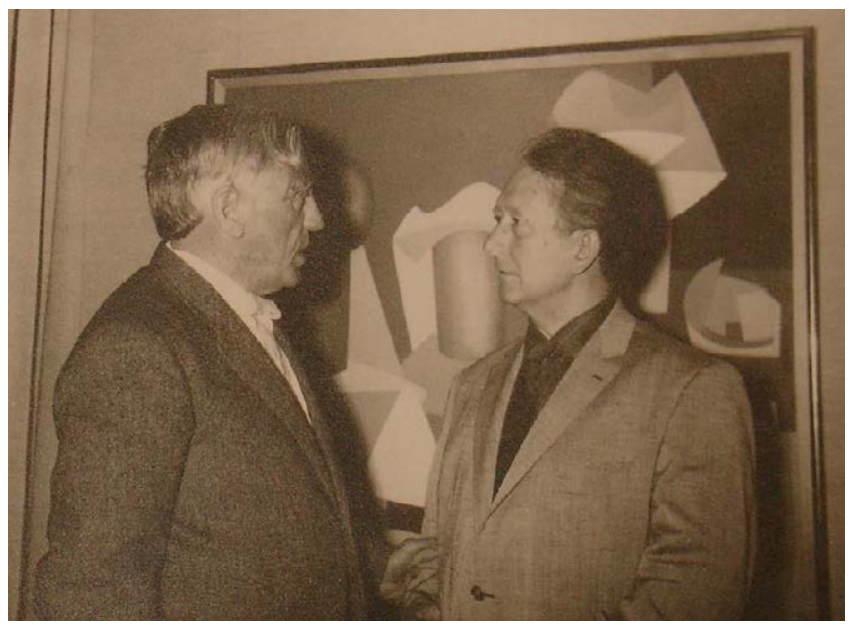

II. 39 Paul Nelson y Jean Hélion ca 1945.

Jean Hélion también pensaba que la arquitectura debía permitir el juego y la integración de los volúmenes contrarios, tratando de crear "ritmo" en la vivienda a través de la construcción de los espacios intermedios. Coincidiendo con el criterio compositivo que él mismo utilizaba en su pintura, agrupando los objetos similares y ajustando los diferentes, proponía que existiese una relación de intercambio entre la casa y el medio que facilitase que el exterior penetrara en el interior y viceversa ${ }^{143}$. Se trataba, según su criterio, de no construir límites, sino espacios de borde para el contacto, y también proponía que la presencia de la pintura en la vivienda sirviese como medio para generar espacio público.

Hélion reconocía en la industria una herramienta capaz de ayudar a lograr los objetivos de la arquitectura, su imagen debía servir de referencia, ya que la técnica permitía construir una vivienda duradera y funcional sin necesidad de levantar un edificio pesado y las instalaciones ayudaban a controlar el confort integral de todas las estancias. Según Hèlion la proyección razonada de un espacio "grande y diáfano" ayudaba a conseguir una arquitectura más flexible y coherente. En definitiva, la industria y la razón eran medios que facilitaban que la arquitectura mejorase la calidad de la vida del hombre.

\footnotetext{
${ }^{143}$ Jean Hélion describe cómo en su primer estudio en París estaba agobiado por la rígida distribución espacial y por la ausencia de contacto con el entorno inmediato con el exterior, de tal forma que para tener una sensación espacial de integración placentera, decidió pintar en la pared de su estudio la silueta de la chimenea exterior y los trazados de las instalaciones que estaban ocultos. Véase: Jean Hélion, "Termes de vie-Termes d'espace", Cahiers d'art, nº710,1935 , p. 273.
} 


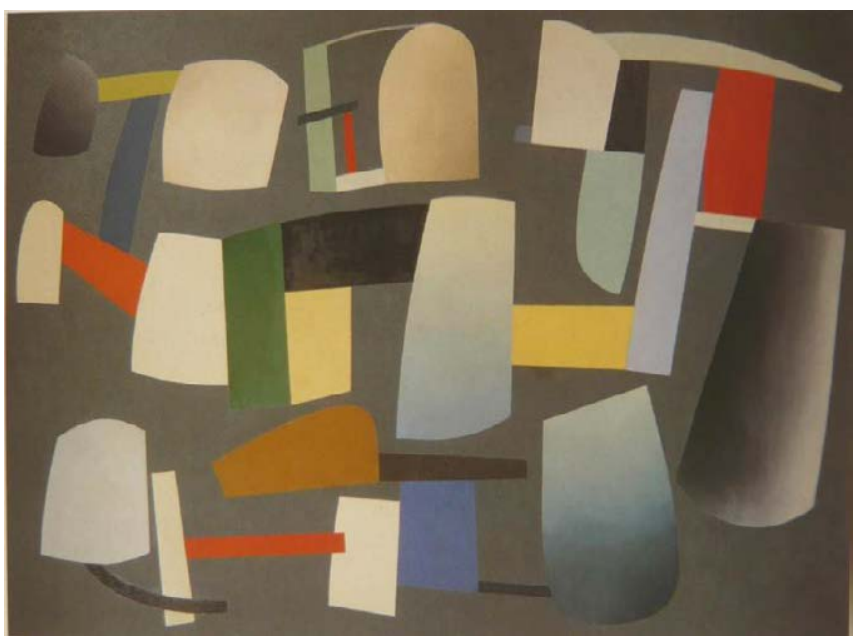

II. 40 Composition, óleo sobre tela, regalo a Paul Nelson, Jean Hélion, 1934.

Cuando Jean Hélion escribió este artículo en 1935, se encontraba en una fase artística de transición entre una abstracción que consideraba agotada y la vuelta a una nueva pintura figurativa, que encontraba más cercana al observador. La evolución de su proceso pictórico surgió a partir de la incidencia de la luz sobre las manchas planas de color, generando volúmenes y espacios intermedios entre ellos, (II. 40) y a partir de 1939 los volúmenes se transformaron en figuras. Hélion intentaba crear una nueva construcción espacial que involucrase al espectador, un ejemplo de esta pintura eran sus cuadros de escaparates, que definían un espacio, una escenografía, que se completaba con la mirada y la presencia de cada observador.

Para Paul Nelson, el texto de Hélion representaba una obra maestra de la crítica arquitectónica, a la que había que dar una respuesta y a la vez había que superar. Pero el artículo estaba escrito utilizando como referencia el proyecto del hospital de Ismaïlia, por lo que, gran parte de las propuestas que Jean Hélion señalaba como la base de la arquitectura doméstica, ya estaban presentes en ese hospital proyectado por Nelson: la extensión funcional a otros aspectos sociales para mejorar la calidad de vida de los usuarios, el estudio de los espacios colectivos, la relación con el exterior y la utilización de la industria que permitía construir un edifico ligero, donde las partes estaban integradas. Con estas soluciones, Paul Nelson se había adelantado a las ideas de Jean Helión y por lo tanto La Maison Suspendue no era la respuesta material directa a los postulados de Helión, sino un avance de su línea de trabajo iniciada en Ismaïlia. 
La principal repercusión del texto de Jean Helión sobre el posterior trabajo de Paul Nelson, se produjo en la elección de la casa como objeto de investigación, asumiendo así la premisa de Hélion sobre el principal problema de la arquitectura. Nelson retomó las observaciones sobre su trabajo y avanzó sobre cada una de ellas: convirtió la casa en un refugio del individuo y extendió lo funcional a lo espiritual, utilizó la industria y la técnica para mejorar la condición de los habitantes y conseguir un espacio único y flexible, en cuyo interior podía apreciarse el juego de volúmenes diferentes, y donde las estancias podían desmontarse sin altear al conjunto. Todo ello con la intención de crear un ámbito doméstico vivo que pudiera cubrir todas las demandas del hombre, incluso aquellas no previstas.

Pero si hay algo en lo que Paul Nelson profundizó, sin la sugerencia previa de Jean Helión, fue en el desarrollo del espacio individual dentro de la casa. No solo se limitó a estudiar y configurar el espacio colectivo intermedio como proclamaba Helión, sino que proyectó estancias sin función determinante, lugares en las que el hombre podía aislarse, esta era una de las señas de identidad de su investigación.

En respuesta a unas preguntas formuladas por Mrs Bernard Schipper, una historiadora americana que preparó una tesis de Jean Hélion, sobre las posibles influencias de Hélion en su arquitectura, Paul Nelson respondió:

"No reconozco la influencia de la pintura y de la composición de Hélion en mi forma de proyectar, cosa que sí me sucedía con Miró, Léger o Picasso. Y, sin embargo, yo nunca pensaría que la relación de Hélion con la arquitectura moderna se estableciera en términos diferentes a su manera de componer" ${ }^{144}$.

Para Paul Nelson, Hélion era un ante todo un gran intelectual, el artista más intelectual que había conocido y por lo tanto creía que la posible influencia del pintor sobre su arquitectura no se había producido en el terreno plástico sino en el plano filosófico, de pensamiento.

144 Carta, de abril de 1974, de Paul Nelson a Mrs Bernard Schipper, MNAM/CCI, Bibliothèque Kandinsky, fonds Nelson. 


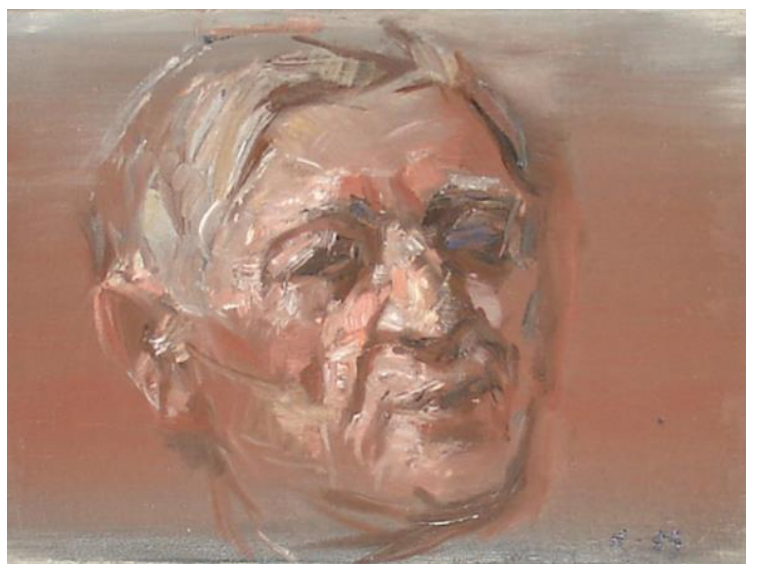

II. 41 Retrato de Paul Nelson ,óleo sobre tabla, Jean Hélion, 1959.

Por su parte Jean Helión, refiriéndose a la colaboración entre ambos, contó al escritor Raymond Queneau ${ }^{145}$ :

“...me gustaría comenzar una colaboración pintor-escritor, como la que había iniciado con Nelson (pintor-arquitecto), aunque Nelson, a quien yo aprecio mucho, carece de cierta lucidez y de certeza ya que el arquitecto aunque sea admirador del racionalismo industrial no se da cuenta que en sus proyectos sólo juega a desvestir la mediocridad ..."

Pero Nelson no solicitó nunca la colaboración directa de Jean Hélion para ninguno de sus proyectos. Preguntado por la historiadora Bernard Schipper sobre el tema, y por su ausencia entre los artistas que intervinieron en la Maison Suspendue, Paul Nelson respondió que la causa fue la distancia geográfica, ya que en esos años Jean Hélion se había trasladado a Estados Unidos, aunque la realidad fue que en 1936, cuando Paul Nelson ya estaba desarrollando La Maison Suspendue, coincidieron en Nueva York durante varios meses. Posteriormente, Jean Helión permaneció en Francia el primer trimestre de 1938, justo cuando Nelson estaba ultimando los detalles del proyecto y la primera maqueta en la que colaboraron Jean Arp, Fernand Léger y Joan Miró estaba aun sin realizarse.

La amistad entre ellos tuvo momentos tristes. En una conversación mantenida con el historiador y profesor de la Escuela de Arquitectura de Nancy, Joseph Abram, en junio de 2010, en La Maison Rodin París, comentó que había sido comisario de la

\footnotetext{
${ }^{145}$ Jean Hélion, Lettres d'Amérique. Correspondance avec Raymond Queneau 1934-1967. Paris : IMEC éditions, 1996, op.cit, pp.44 -45.
} 
última exposición celebrada de Jean Hélion. Y un día en que mantenía una charla con Jean Hélion sobre la relación con sus amigos artistas, Joseph Abram le mencionó a Paul Nelson y el pintor comenzó a llorar desde sus ojos ciegos. De esta amistad nos queda el recuerdo del texto crítico en el que Jean Hélion invitó a Nelson a reflexionar sobre la casa y un retrato realizado por Helión del arquitecto en el año 1959. (II. 41)

\subsection{Fernand Léger. La pintura espacial}

A diferencia de lo que sucedió con Jean Hélion, Paul Nelson sí colaboró con Fernand Léger. El pintor ya había mantenido contactos con la arquitectura antes de trabajar junto a Paul Nelson, ya que comenzó su carrera como dibujante en el estudio de Corbin, un arquitecto de Argentan, y allí se familiarizó con los conceptos de la proyección y la construcción. ${ }^{146}$ En el año 1924, viajó a Estados Unidos y conoció a Frederick Kiesler y a Richard Buckminster Fuller y un año después, Mallet-Stevens le encargó unos cuadros abstractos para la exposición de Artes Decorativas de París. Alvar Aalto le mostró como los propietarios de algunas de sus viviendas las habían transformado añadiendo color a los interiores blancos, y esta experiencia le permitió entender que cada individuo tenía una relación cromática con su casa. En 1938, Fernand Léger pintó unos murales en el apartamento de Nelson Rockefeller en Nueva York y en el verano de ese año, Paul Nelson solicitó su colaboración para intervenir con una obra en La Maison Suspendue.

Paul Nelson y Fernand Léger se conocieron gracias a Charlotte Perriand y entre ellos se forjó una relación de amistad y de colaboración que les llevó a trabajar juntos en varios proyectos, desde los años treinta hasta la muerte de Fernad Léger en 1955. Para Paul Nelson, Fernand Léger era principalmente un soñador, un creador a quien respetaba más como artista que como intelectual ${ }^{147}$. Tras la muerte de Fernand, su esposa Nadia con el apoyo del ayuntamiento de Biot, encargó a Paul Nelson un museo para su obra, en el que trabajó en este proyecto durante dos años, pero finalmente no construyó. Posteriormente, Nadia Léger le encargó que proyectase su casa, pero esta tampoco se realizó.

\footnotetext{
146 Olivier Cinqualbre, Un rendez-vous à jamais reporté. Léger et l'architecture, Expo MNAM-CCI 199723.

${ }^{147}$ Judith Applegate, "Paul Nelson: an interview". Perspecta nº13-14, 1971, p.77.
} 
Nelson y Léger compartían dos pasiones: la afición por el circo y el gusto por los viajes transatlánticos. El entusiasmo por el espectáculo del circo era algo común entre los artistas de la época ${ }^{148}$, Fernand Léger plasmó en sus cuadros, la atracción por el riesgo, por el equilibrio y la ingravidez, y Paul Nelson proyectó su casa desafiando las leyes de la gravedad, colgando las estancias de techo. Los dos atravesaron el Atlántico con frecuencia, se sentían atraídos por una cultura y un paisaje diferente al de su país de origen. Fernand Léger pintó en varias ocasiones la ciudad industrial americana y Paul Nelson utilizó el racionalismo y la cultura francesa como parte de su método de trabajo.

También compartían puntos de vista sobre la evolución de la pintura moderna en los años treinta y su relación con la arquitectura. Ambos coincidían en que las dos disciplinas habían sufrido procesos estéticos de transformación similares, pasando de la figuración y el historicismo a la abstracción. Coincidían en pensar que el salto de la pintura de caballete a la pintura mural había sido un paso decisivo, que tenía un valor físico por lo que implicaba de relación y de dependencia entre las dos disciplinas y un valor sociológico, que para Léger tenía carácter colectivo ${ }^{149}$ y para Nelson carácter individual. Mientras para Fernand Léger, la pintura de caballete tenía un tamaño pequeño, transportable y atendía el gusto de un determinado cliente, la pintura mural tenía mayores dimensiones, se concebía en un soporte fijo y su creación buscaba una mirada colectiva. Para Paul Nelson la pintura mural necesitaba una pared que, paradójicamente, la arquitectura moderna había eliminado y que él consideraba que había que recuperar como lugar perfecto para satisfacer las necesidades del espíritu individual ${ }^{150}$.

El día que los amantes del arte comprendan que una obra de pintura o de escultura no toman su verdadero significado nada más que dentro de una determinada arquitectura, ese día se creará arquitectura, por que permitirá a nuestros arquitectos concebir el excedente, que responda a las

\footnotetext{
148 Artistas, escritores, y arquitectos, como el propio Paul Nelson, acudían al gimnasio construido por el arquitecto georgiano Berthold Lubetkin en París en 1928 para el trapecista Roland Toutin y se divertían en el trapecio, experimentando la sensación de volar. Véase Pierre Mardaga, Berthold Lubetkin, un Moderne en Angleterre, catálogo de la exposición del ifa, 1983.

${ }^{149}$ Fernand Léger, Funciones de la pintura, Barcelona: Paidós Ibérica, S.A. 1990 [Fonctions de la peinture, París : Gonthier, 1965]

${ }^{150}$ Paul Nelson, "Peinture Spatiale et Architecture. À propos des dernières oeuvres de Léger", Cahiers d'Art no 1-3, 1937, pp.85-89.
} 


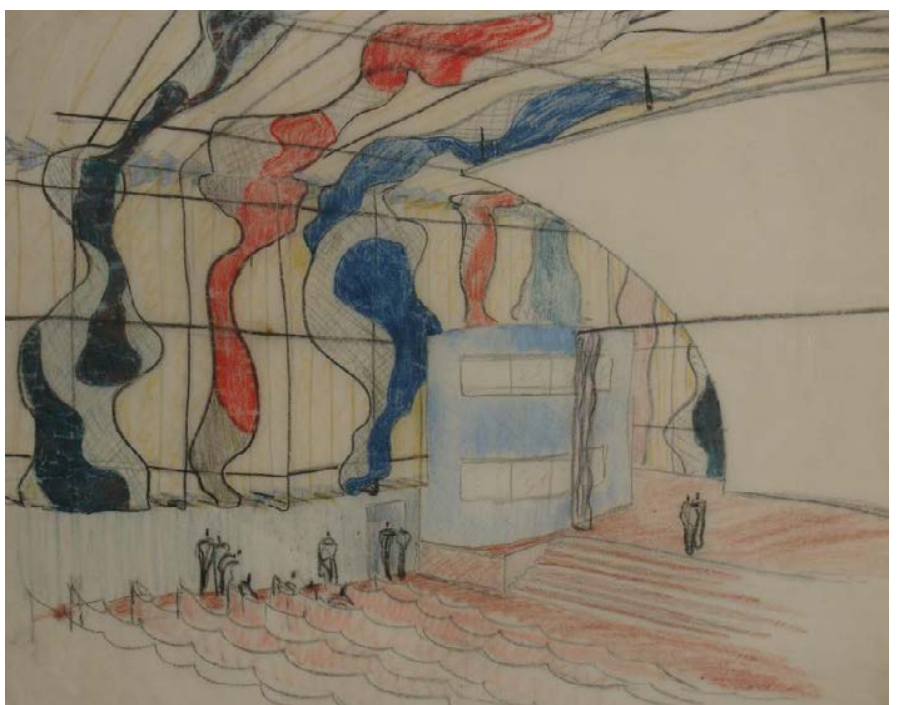

II. 42 Concurso auditorio W.G.N Chicago, tratamiento muros, Paul Nelson y Fernand Léger, 1938.

funciones espirituales del hombre, en oposición a la idea restrictiva y puramente utilitaria que se hace en los últimos tiempos y que ha desembocado en la máquina de vivir. ${ }^{151}$

Esta reflexión de Paul Nelson reflejaba una manera de entender el muro y el espacio diferente a la que se había establecido por el Movimiento Moderno, que consideraba que el muro había perdido su función tradicional como estructura y a la vez era un elemento que impedía conseguir la planta libre y el espacio continuo. Paul Nelson, que coincidía con el Movimiento Moderno en buscar esos dos objetivos, proponía utilizar ese muro "inservible" para conseguirlo y trataba de generar una mayor continuidad espacial a partir de la presencia objetos intermedios. Esta manera de generar la continuidad espacial, fue la que utilizó y desarrolló en La Maison Suspendue.

Tanto Nelson como Léger coincidían en pensar que la influencia de la pintura mural sobre la arquitectura llevaba, por un lado, a la demanda de una superficie como soporte y, por otro lado, ejercía una incorporación del espacio de su entorno que incidía sobre el estado de ánimo del observador. Auque mantenían diferentes opiniones acerca del papel que la pintura tenía con respecto de la arquitectura, si era acompañamiento o subordinación, ambos eran conscientes de que esta pintura no era decoración sino que tenía su propio valor, y de que la colaboración conjunta era un

${ }^{151}$ Ibídem, p.86. 
nuevo campo experimental, que reflejaba la nueva forma de aprender a través del trabajo de otras disciplinas ${ }^{152}$.

En 1938, Paul Nelson participó en un concurso para la transformación del interior del auditorio de la W.G.N Broadcasting Radio de Chicago (II. 42). El teatro se proyectó a partir de los objetivos marcados en 1930 en la sala de cine para Joseph P. Kennedy (§.I.2), que estaban dirigidos a mejorar la acústica de la sala. Nelson propuso construir, una lámina curva suspendida del techo y unas gruesas lamas verticales pivotantes, separadas del cerramiento. El elemento suspendido se convertía en un reflector de sonido y los elementos verticales móviles en cuerpos absorbentes o reflectantes según las necesidades, de esta forma conseguía una envolvente flexible, con la que se lograba una buena calidad del sonido. Para desarrollar esta labor de construcción interior, de una pieza dentro de otra ya existente, pidió ayuda a Fernand Léger, quien se encargó del tratamiento de los muros que estaban detrás de los paneles. Pintó unas bandas sinuosas, paralelas, con colores planos, que recorrían los dos laterales y el techo dando continuidad al conjunto, y que sólo eran visibles cuando los paneles estaban abiertos.

No ganaron el concurso, pero con este proyecto sentaron las bases de sus futuras colaboraciones. Paul Nelson, consecuente con sus pensamientos, cedió el espacio mural, que carecía de función "útil", para que un pintor desarrollase su arte y Fernand Léger utilizó el color como valor fundamental de su obra e intentó que su pintura avanzase desde el fondo y se situase delante de los paneles abiertos. De esta forma, proporcionaba a Paul Nelson el complemento que buscaba para su arquitectura, por un lado, le ayudaba a deshacer el concepto de límite y de caja cerrada, y por otro, le ayudaba a construir un efecto psicológico que incidiera sobre el sentimiento de los espectadores.

El siguiente trabajo que realizaron juntos fue en 1954, en el cerramiento de la casa Badin en Sceaux, cerca de París. Paul Nelson había proyectado una "fachada claustral", como la ensayada en el Hospital de Lille (§.I.3), construida con módulos de vidrio insertados en una retícula metálica, y contactó con Fernad Léger para conseguir una flexibilidad en los paños del cerramiento, sin alterar el orden general,

\footnotetext{
${ }^{152}$ La primacía de una disciplina sobre otra, fue cambiando en los diversos proyectos, así mientras en las maquetas de La Maison Suspendue,(1938) Fernad Léger se ajustaba a lo marcado por Nelson previamente, en el proyecto de la Maison Badin en Sceaux (1955), Léger impuso sus propias reglas cromáticas y Nelson las aceptó.
} 


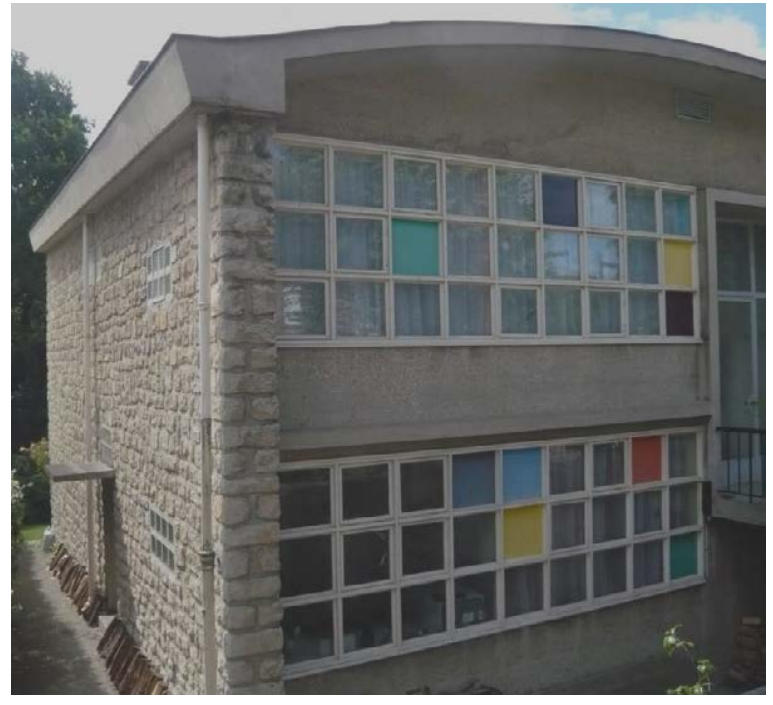

II. 43 Maison Badin, detalle fachada claustral vidrios tratados por Fernand Leger, 1954-1955.

le propuso a Léger que hiciese diferentes tratamientos de los vidrios para evitar una fachada homogénea delante de las diferentes estancias. Nelson sugurió distribuir los colores por su calidez y Léger lo hizo, pero invirtiendo el orden aconsejado, lo que sorprendió gratamente a Paul Nelson, ya que la disposición de los colores fríos en la parte superior hacía más dinámica la composición (II. 43). Paul Nelson había construido la estructura y Fernad Léger le ayudó a convertirla en un elemento vivo. Esta técnica había sido enunciada ya en La Maison Suspendue, donde estaba previsto un cerramiento metálico con una celosía de rombos con vidrios coloreados, y gracias a Léger logró construirla.

El último proyecto para el que solicitó la colaboración de Léger fue el tratamiento de las fachadas del hospital de Sain Lô. Este trabajó coincidío en el tiempo con la obra de la casa Badin y quedó interrumpido por la muerte de Léger en 1955. A partir de la maqueta Léger realizó una investigación de policromía de las fachadas a Norte. Propuso pintar sobre ellas rectángulos de diferentes tamaños en colores vivos (II. 44), pero finalmente no lo ejecutó, ${ }^{153}$ en las fachadas a Sur desarrolló una versión de la "fachada claustral" y para el muro del porche de la entrada realizó un mosaico de cerámica, alegórica de la ayuda que Estados Unidos había prestado a Francia durante la Segunda Guerra Mundial. (II. 46). En los jardines de acceso propuso

\footnotetext{
${ }^{153}$ La comisión encargada de las obras no lo aceptó, pensó que la presencia de estos colores no se adecuaba a la superficie, desvirtuaba el sentido de la fachada, criticaron el aspecto de circo del hospital. Véase: Donato Severo, tesis doctoral, L'Hoplital de Saint-Lô. du Project a l'usage (1946-1999),n.p, UFR03 Histoire de l'art et Archéologie Formation doctorale en Histoire de 1'art, Université Paris I Panteón- Sorbonn. 2010, p.74.
} 


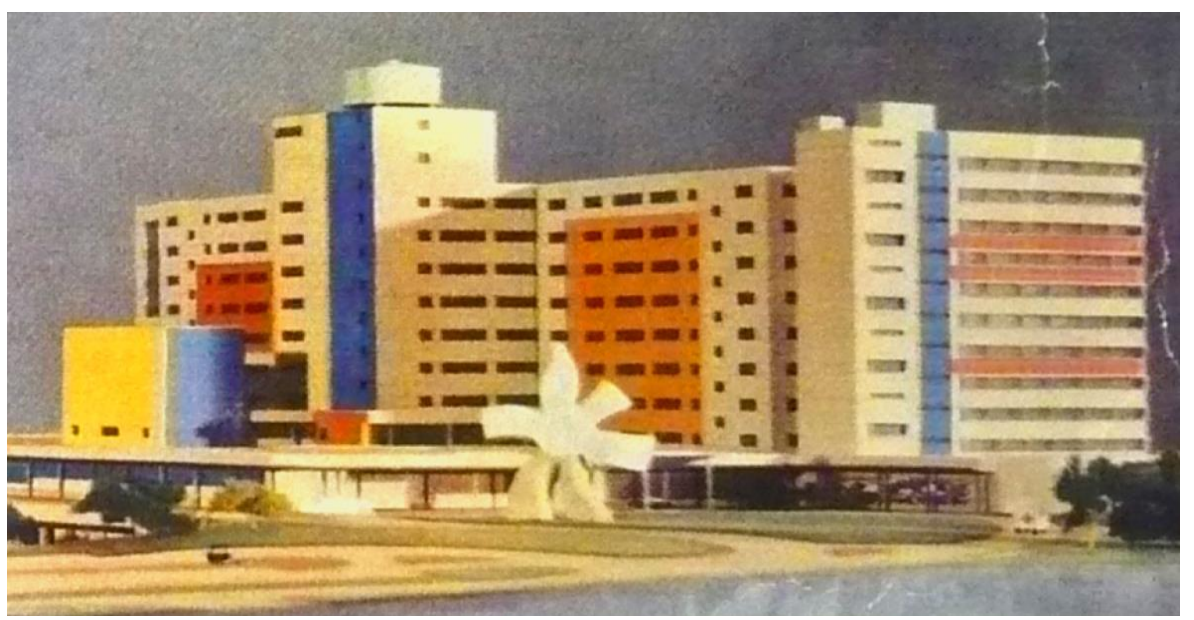

II. 44 Hospital Memorial de Saint Lô, policromía de fachadas, Fernand Léger, 1953-1955.
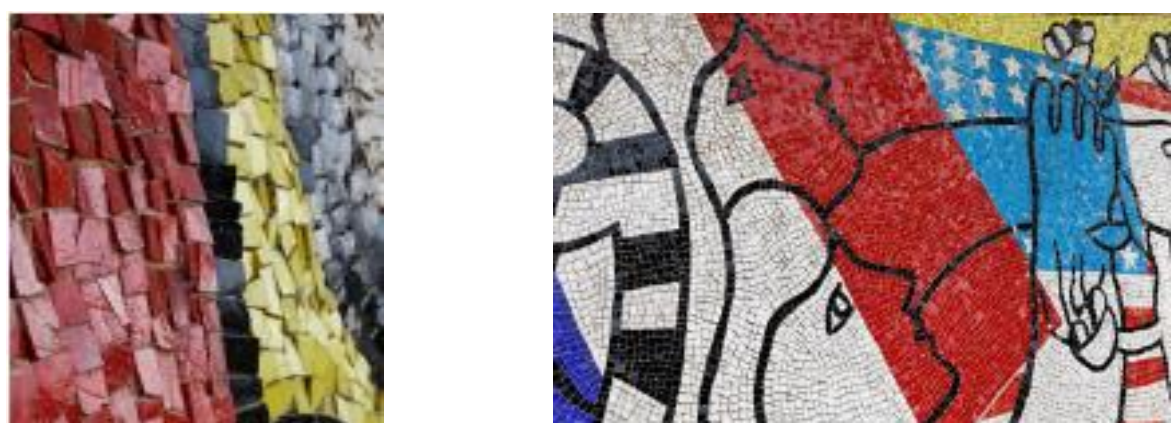

II. 45 Hospital Memorial de Saint Lô, detalle mosaico cerámica coloreada, F. Léger, 1955.

II. 46 Hospital Memorial de Saint Lô, mosaico de cerámica coloreada. Fernand Léger, 1955.

una flor de grandes dimensiones y de geometría irregular, que contrastaba con los volúmenes ortogonales del edificio.

Fernand Léger utilizó el soporte de la arquitectura pública que le brindaba Paul Nelson para realizar su obra mural, un trabajo que a su juicio sólo podía exhibirse en un espacio colectivo, a diferencia de la pintura de caballete. Por su parte, Paul Nelson lograba a través de la intervención de Léger, que su edificio transmitiera una sensación de movimiento favorable a la generación del bienestar de los visitantes.

Tras la muerte de Fernan Léger, Paul Nelson recibió el encargo para construir el museo de Léger (f.II.43). El solar para el museo estaba ubicado en una colina, en el casco de la ciudad de Biot, en la Costa azul. Paul Nelson propuso una primera versión con una pieza situada a media ladera, semienterrada, que liberaba una plaza pública en su parte superior, y situando en ella réplicas de las esculturas a gran 
II. 47 Museo Fernand Léger en Biôt, sección, primera versión, Paul Nelson, 1956.

tamaño mezcladas con vegetación, que convertían este acceso en un mural transitable. La entrada del edificio se producía por esta cubierta, a través de una marquesina ligera y se descendía a dos salas, paralelas, comunicadas entre sí que tenían alturas diferentes, para exhibir obras de tamaños distintos.

En 1956 hizó otra segunda versión, en la que la planta se dispuso siguiendo la línea de máxima pendiente y la plaza superior de acceso desapareció, proyectando en su lugar una cubierta abóvedada. Esta decisión trasladó el protegonismo a las fachadas longitudinales, sobre todo la Sur, en la que proyectó una composición con un tamaño creciente de los huecos rematada por un gran mural a modo de frontón.

Finalmente esta colaboración póstuma no se realizó y no se pudo comprobar como funcionaba el contenedor que Paul Nelson ideó para albergar las piezas de Léger.

Fernand Léger y Paul Nelson trabajaron de manera conjunta para lograr que el color introdujese la vitalidad de una obra, buscaron dinamizar la actividad diaria de los edificios mediante el uso de diferentes tonos, y recuperar al hombre de la sensación de vacío en el que le había dejado la abstracción, de la pared blanca y desnuda del Movimiento Moderno. Con sus intervenciones buscaron la belleza y el equilibrio para conseguir una sensación de satisfacción física y moral de los usuarios de los edificios. El pintor, el muro y el arquitecto, se pusieron de acuerdo para mejorar la realidad del hombre. 


\subsection{Alexander Calder. El valor revulsivo de lo imprevisto.}
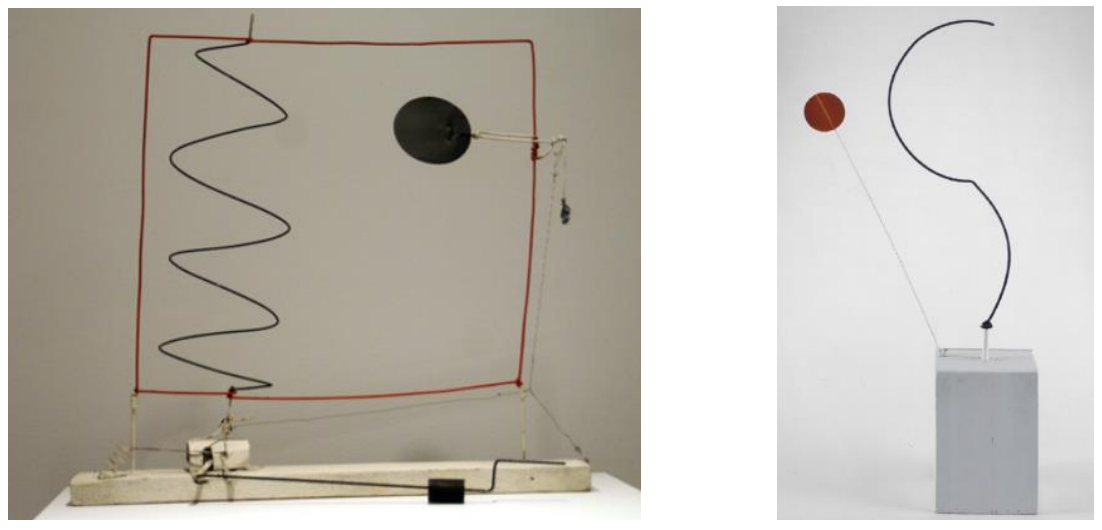

II. 48 Drawing in spaceo,Regalo a Paul Nelson, Alexander Calder, 1933.

II. 49 Medio círculo, cuarto de círculo, esfera.Regalo a Paul Nelson, Alexander Calder, 1932.

Alexander Calder y Paul Nelson además de colaborar en varios proyectos, mantuvieron una larga relación personal, sus biografías tuvieron varios puntos en común, los dos eran americanos, Alexander Calder, nació tres años después que Paul Nelson y murió tres años antes que él y ambos se dedicaron respectivamente al arte y a la arquitectura en una etapa de madurez y tras habers asistido a la Universidad. Y los dos vivieron en el París de los años veinte. La relación entre ambos se inició a principios de los años treinta y continuó hasta la muerte de Alexander Calder en 1976. La amistad se extendió a sus respectivas familias, pasaron días de vacaciones juntos en la Normandía e incluso llegaron a compartir un apartamento en Nueva York.

Durante la segunda mitad de los años veinte Alexander Calder se dedicó a realizar esculturas con alambre, utilizando la línea para construir el espacio. Con sus piezas de alambre construyó un circo, convirtiendo las esculturas en un objeto lúdico. El año 1930, visitó el estudio de Piet Mondrian en París, y quedó impresionado por el orden y por el tratamiento de las paredes recubiertas con unas geometrías regulares. Pensó que este espacio podía tener más fuerza, si los rectángulos blancos y negros de los muros, pudiesen girar. Esto le hizo ser consciente del poder de la abstracción y de la visión del arte en movimiento. A partir de ese momento Alexander Calder introdujo en sus esculturas la movilidad y la ingravidez. Aunque como señala Francisco Calvo Serraller, este proceso, no fue debido exclusivamente ni a una intuición, ni a unos conocimientos de ingeniería mecánica, sino que estaba enmarcado en el panorama creativo de los años treinta, una década de fusión y de 

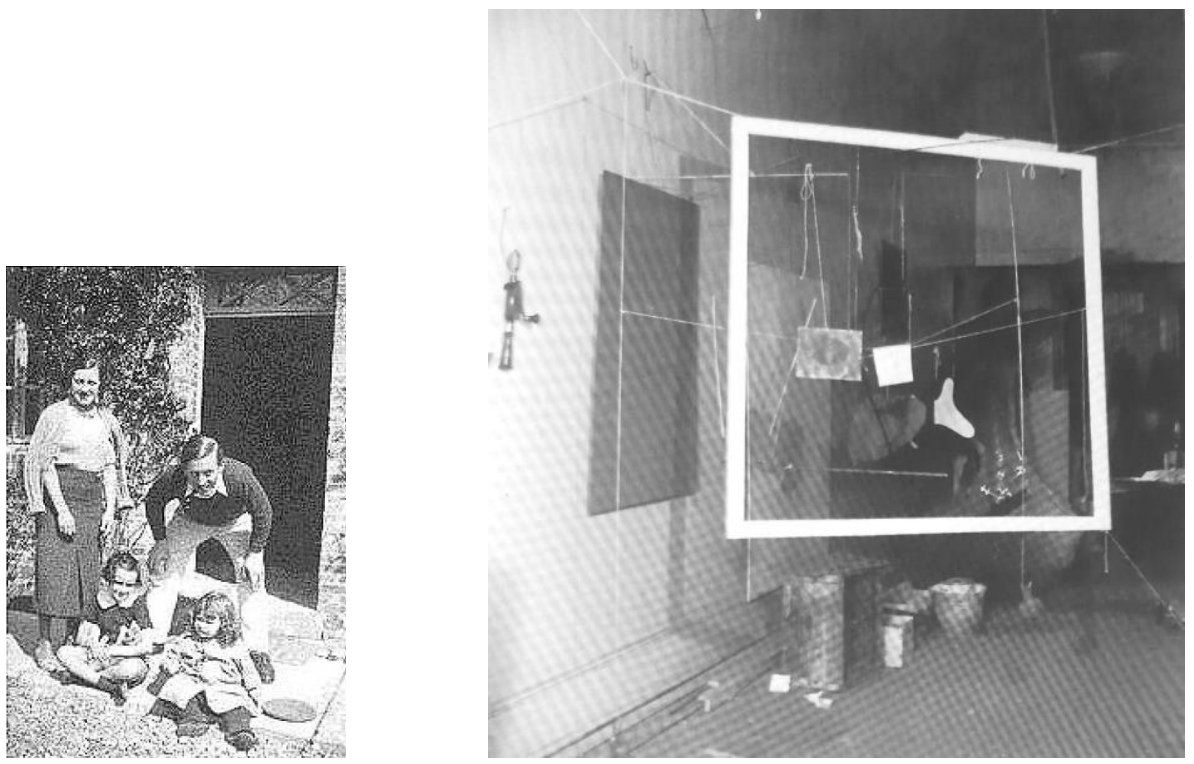

II. 50 Paul Nelson, Pilar Miró, Dolores Miró y Sandra Calder, Varengeville, verano de 1937.

II. 51 The frame for Snake and the Cross, Alexander Calder, Nueva York, invierno de 1936.

síntesis $^{154}$, así Calder tomó las formas geométricas abstractas y las combinó con las biomórficas.

En la segunda mitad de los teinta, Alexander Calder ya había construido sus móviles suspendidos y trabajaba en unas composiciones planas, despegadas del plano de la pared. Estas obras estaban constituidas por un marco cuadrado, colgado en vertical, dentro del cual había varios elementos de diversos materiales y tamaños, que a su vez estaban suspendidos de dicho marco (II. 51).La imagen era la de unas piezas con forma orgánica, flotando dentro de una geometría ortogonal. Esto coincidió en el tiempo con la investigación de La Maison Suspendue, que estaba desarrollando Paul Nelson, en la que estaba trabajando con un juego de geometrías opuestas y donde también había estancias que estaban suspendidas y en una posición de ingravidez.

Alexander Calder y Paul Nelson compartieron el contexto de creación formal del periodo de entreguerras y coincidieron en la incorporación de nuevos elementos en sus obras, ambos decidieron usar los metales en sus trabajos para aligerar las estructuras, y pensaban que el paso del tiempo debía tener incidencia en sus proyectos, lo cual repercutió en la manera de concebir sus obras. Sus trabajos eran la

${ }^{154}$ Francisco Calvo Serraller, "Calder: la gravedad y la gracia”, Catálogo de la exposición La Levedad y la gracia, Museo Guggenheim Bilbao marzo-octubre de 2003, Bilbao: Guggenheim Bilbao 2003, p.31. 
unión de dos partes, una rígida y estable y otra flexible y cambiante. Calder creó sus "móviles-estables", esculturas móviles sujetas a una base inferior fija y Paul Nelson proyectó su Maison Suspendue ensamblado dos partes, una rígida y otra flexible.

Los dos abandonaron una concepción estática de sus creaciones e incorporaron el movimiento, Calder introdujo los motores en sus piezas y comenzó a investigar y a construir sus móviles y Paul Nelson comenzó a dar más protagonismo a los núcleos de comunicación y a los espacios de los recorridos. Esta postura, de considerar la movilidad, les llevó a aceptar los cambios imprevistos y aprovecharlos en beneficio de sus respectivos trabajos. Alexander Calder construyó sus esculturas móviles de exterior, e incorporó el ritmo descontrolado que aportaba el viento y Paul Nelson proyectó La Maison Suspendue, con una estructura espacial flexible y adaptada a posibles cambios de uso no previstos, construyendo una casa viva como un organismo. De esta manera, Nelson y Calder incorporaban el factor sorpresa como un nuevo elemento del proceso creativo.

En el otoño de 1936 Paul Nelson y su esposa Francine se marcharon a Nueva York, con motivo del encargo de la estación de radio para la C.B.S, a su llegada a la ciudad ocuparon el apartamento de Alexander Calder y después se instalaron en un apartamento contiguo y permanecieron allí hasta su regreso a Francia en el invierno de 1937. Durante estos meses el contacto fue muy estrecho, cada uno fue testigo directo del trabajo del otro. Calder y su familia llegaron en primavera de ese año a París, ivitados por Los Nelson, y se instalaron durante unos meses en la primera casa que había proyectado Paul Nelson, situada en el Boulevard Arago. Se trataba de una vivienda de cuatro alturas, entre las medianeras de un solar rectangular estrecho. La casa tenía un único acceso centrado, que comunicaba a través de un zaguán, la calle con el jardín posterior, donde había un garaje. En un principio, los Calder compartieron la casa con los antiguos propietarios y ocuparon solo algunas dependencias, pero tras la marcha de los dueños, fueron colonizando la vivienda vacía y adaptaron las estancias a sus necesidades. Acomodaron la casa semivacía de muebles, en una suerte de campamento ${ }^{155}$.

\footnotetext{
${ }^{155}$ Alexander Calder, Calder. Autobiographie, París: Maegh éditeur, 1972, p.92.
} 


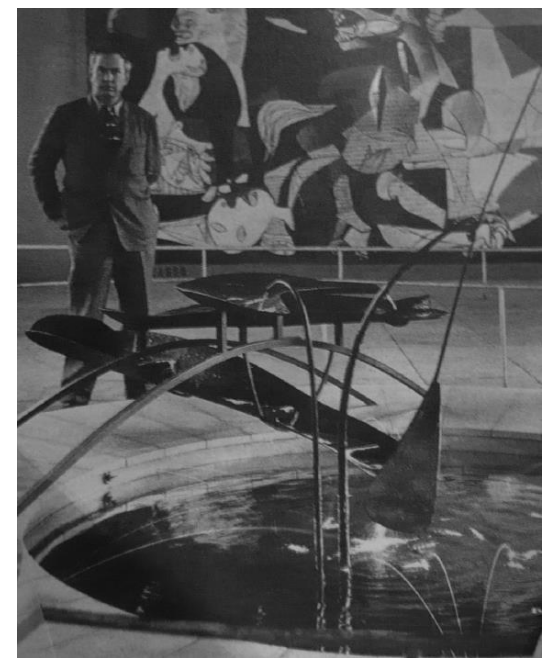

II. 52 Fuente de mercurio de Alexander Calder, pabellón de España Expo. Interna. París 1937.

En este proceso de apropiación, también ocuparon el zaguán, que había sido concebido por Nelson como lugar de paso, un espacio de tránsito, previo a los núcleos de comunicación y al garaje situado al fondo. Pero, dado que el escultor no tenía vehículo, esta pieza fue destinada a estancia de salón y de comedor, un espacio fresco en contacto con la calle y el jardín, y fue rehabilitado para los encuentros sociales. Allí recibieron al arquitecto Alvar Aalto, al escultor Alberto Sánchez y al pintor Joan Miró. De estos encuentros, surgió el encargo para que Alexander Calder realizase la Fuente de Mercurio, para el Pabellón Español en la Exposición Internacional de París de 1937. (II. 52).

El garaje había sido una pieza clave del encargo, ya que su ubicación generaba en el jardín una condición de servidumbre, agudizada por la dificultad para realizar la maniobra de giro. Para evitar la salida del vehículo marcha atrás, Paul Nelson ideó un artilugio, construyó una plataforma circular de $5 \mathrm{~m}$ de diámetro que permitía introducir el coche y hacer girar la base con el pie $180^{\circ}$ para que el vehículo pudiera salir hacia delante sin maniobrar. Como Alexander Calder no tenía necesidad de garaje, lo ocupó y convirtió esta pieza en su nuevo taller.

Calder y Nelson tuvieron la oportunidad de aprender y disfrutar durante un breve período de tiempo del uso "inadecuado" del lugar. El escultor trabajó durante unos meses sobre una plataforma inestable para construir sus móviles. Y el arquitecto observó dos cosas: la primera, cómo el espacio para el desarrollo personal e intelectual se alojaba en un garaje y la segunda, cómo el arte, como objeto inútil, ocupaba su lugar, un espacio disfuncional. 
Alexander Calder trabajó desde una base móvil, la invención de Paul Nelson era un juguete perfecto para que Alexander Calder se identificase con el lugar, y experimentase el movimiento durante la creación de sus obras. Alli desarrolló la construcción de La Fuente de Mercurio y lo hizo en colaboración con el herrero Louis Dalbet, el maquetista de La Maison Suspendue, En esta obra Alexander Calder mostró la técnica (el mecanismo para hacer circular el mercurio) y el arte (las formas de las bandejas de acero cubiertas con alquitrán) juntos por vez primera. Era una pieza para ser ubicada en el exterior con una nueva escala, lo que le sirvió de referente para abordar sus posteriores obras de gran tamaño ${ }^{156}$.

A Paul Nelson, este acto de ocupación imprevista de la vivienda, le proporcionó la confirmación de algunas hipótesis planteadas en su búsqueda de un nuevo hábitat doméstico. Esto le llevó a interrogarse sobre el éxito y la pertinencia de trabajar con el binomio espacio y función doméstica. Y esta intervención de Calder en su arquitectura, a través del uso, también le llevó a plantearse que el espacio más necesario para el individuo en el ámbito doméstico era el intermedio, el de tránsito, aquél que sin tener un uso definido, era una provocación para que el habitante lo moldease a según su deseo.

Un año después de la estancia en París, Nelson pidió a Calder que realizase unas esculturas para su segunda maqueta de La Maison Suspendue. Posteriormente, durante los años de la Segunda Guerra Mundial, Paul Nelson, que desde Estados Unidos contribuía con la resistencia francesa, volvió a solicitar la colaboración de Alexander Calder, pero esta vez no para aportar una obra de arte sino para que diese su apoyo a Francia, como un país ejemplo de la libertad.

\footnotetext{
${ }^{156}$ Johnson Sweeney, Alexander Calder, exhibition, catalogue, New York: The Museum of
} Modern Art, 1943 


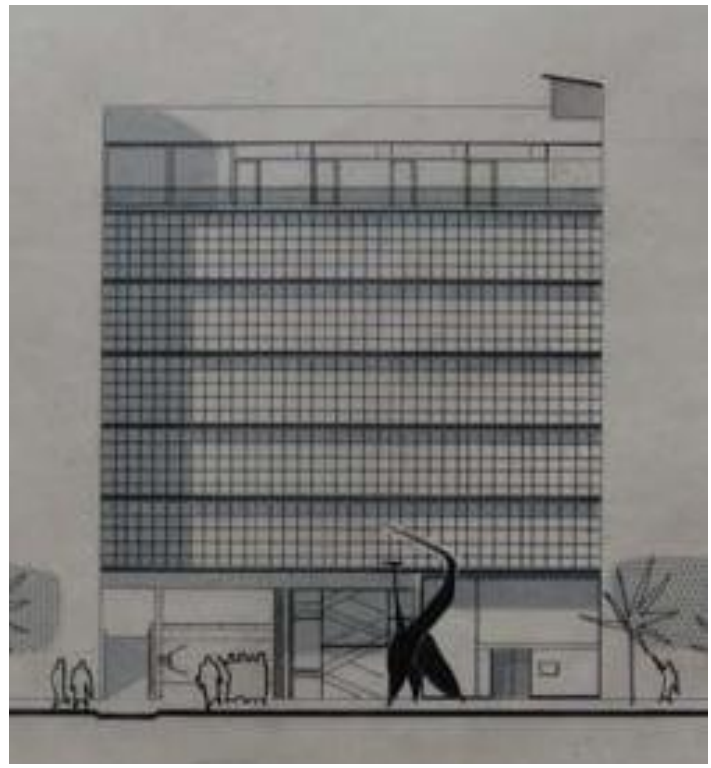

II. 53 Sede Compañía Walter Thompson, Paul Nelson. Escultura de Alexander Calder

1961.

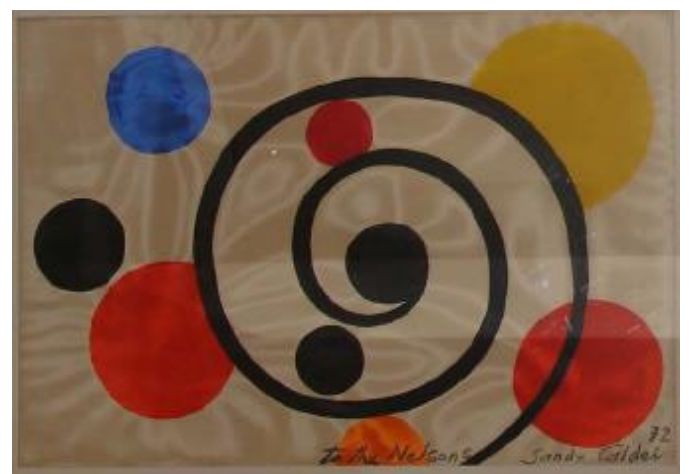

II. 54 Espiral, guache sobre papel. Regalo a los Nelson, Alexander Calder 1972.

Su última colaboración profesional fue en 1961, con motivo de un anteproyecto de un edifico de oficinas en Los Campos Elíseos de París, para la agencia de publicidad J. Walter Thompson, (f.II.49). Paul Nelson proyectó un edificio de siete plantas entre medianeras, con estructura prefabricada resuelta en aluminio, por primera vez en la historia. El edificio se disponía retranqueado, liberando un espacio donde se situaba un "stabile", una pieza fija de gran tamaño, de Alexander Calder. En el muro derecho estaba previsto un mosaico de Joan Miró y en la medianera izquierda un gran luminoso de publicidad. La geometría orgánica de la pieza de Calder contrastaba con la trama ortogonal de la fachada claustral. Este proyecto no se construyó y esta fue la última vez en la que Paul Nelson trató de construir un espacio urbano, de socialización, donde conviviesen dos de los elementos formales más utilizados por los artistas del siglo XX, el biomorfismo y la retícula. 


\subsection{Paul Nelson. La práctica de la pintura.}

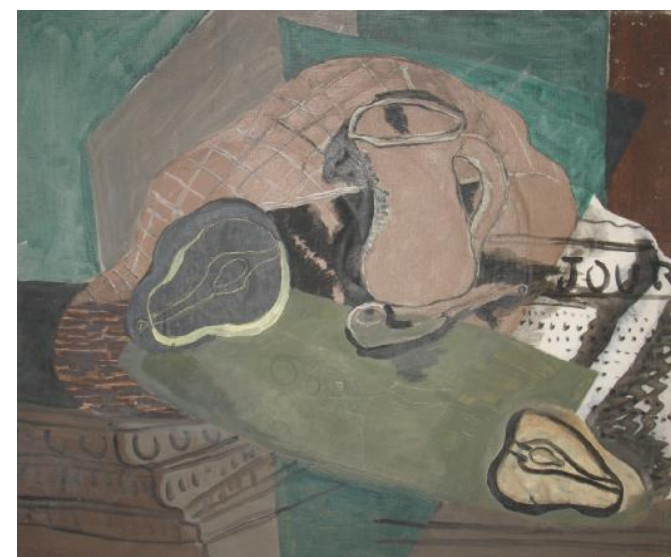

II. 55 Francine, carboncillo, Paul Nelson, ca.1920.

II. 56 Bodegón, oleo sobre tela, Paul Nelson, ca.1925.

A su aprendizaje a partir de los artistas, había que añadirle la propia actividad de Paul Nelson como pintor y la repercusión que esta afición tuvo en su carrera de arquitecto, aunque no estableció ningún paralelismo entre la práctica de las dos disciplinas. El profesor Joseph Abram, ${ }^{157}$ describió el proceso creador de Paul Nelson como arquitecto y como pintor utilizando la metáfora una cordillera, de un lado, situaba lo oscuro y lo amorfo y, del otro, la claridad, lo razonado. Pensaba que Nelson subía y bajaba constantemente de un lado a otro. En el lado "oscuro" situaba la actividad pictórica y en el lado de la luz su labor de arquitecto. Pero Paul Nelson nunca explicó, con detalle, como se generaban las formas en la arquitectura. Negaba la idea del dibujo como punto inicial del proyecto, y en la descripción de su método de trabajo no reflejaba la manera en la que los pensamientos se transformaban en imágenes, entre el análisis filosófico y la conclusión formal existía un vacío.

Paul Nelson practicó la pintura después de concluir sus estudios en Beaux-Arts e interrumpió esta actividad a mediados de los años treinta, coincidiendo con el cambio que experimentó su arquitectura. Su actividad pictórica se dividió en cuatro

157 Joseph Abram,"Paul Nelson: le crible de la raison. 1920-1939: Peinture/ Architecture. Projets experimentaux”. Bulletin d'Informations Architecturales (IFA) nº 130 abril 1989, p.5. 


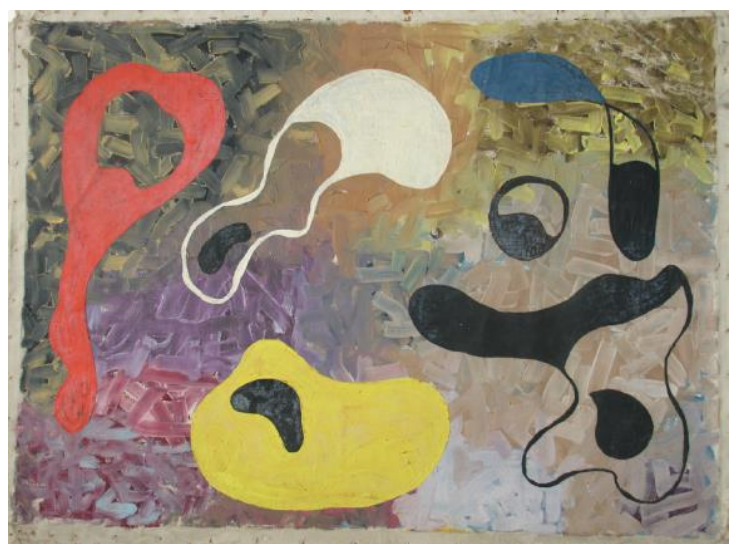

II. 57 Sin título, óleo sobre tabla, Paul Nelson ca. 1938

etapas: en la primera, comenzó haciendo una pintura realista de paisajes y figuras (II. 55); en la segunda, utilizó la técnica cubista para representar bodegones ( II. 56) ; en la tercera, desarrolló una pintura formalista de siluetas planas con colores brillantes sobre fondos negros (II. 57), y en la cuarta etapa, practicó una pintura surrealista, recuperó la silueta humana y la descompuso en varios planos contrastados cromáticamente, en blancos y negros, a la manera cubista, estas imágenes aparecían encerradas en un diedro (II. 58). El resultado fue una pintura orgánica, donde la geometría ortogonal de los planos del fondo quedaba vinculada a las siluetas perforadas del primer plano, mediante cadenas, vinculando a las figuras con su entorno. 
Las transposiciones entre la arquitectura y la pintura de Paul Nelson no han sido exploradas por los críticos, dada la falta de referencias directas y las distancias marcadas por el propio arquitecto, al eludir el análisis de la composición formal de sus proyectos. Las influencias que recibieron tanto su pintura como su arquitectura, se generaron a partir de la obra de otros artistas, y la incidencia de su propia experiencia pictórica en su arquitectura sólo se produjo en el plano compositivo, que era el mismo que compartía con otros artistas, unas creaciones donde las figuras contrarias se enfrentaban en el interior de un marco ordenado. El color estuvo muy presente en todos sus esquemas, unas veces lo utilizó como tanteo para la aplicación cromática real en sus proyectos y otras veces como elemento simbólico, que caracterizaba una función del espacio. Destacaba el uso del rojo, en la rampa y en los recorridos, para reflejar los espacios dinámicos, y el azul en los vacíos, para expresar la continuidad.

En la segunda mitad de los años treinta, coincidiendo con el desarrollo de su investigación doméstica, Paul Nelson pintó un autorretrato siguiendo la técnica cubista, recompuso su figura a través de fragmentos yuxtapuestos (II. 59). a los que incorporó un rostro definido. Paul Nelson, utilizó este mismo procedimiento, de recomponer el conjunto a través de la unión de los fragmentos, en una versión que realizó entre 1936 y 1938, de la planta segunda de Maison Suspendue. Siempre manejó en sus plantas un cerramiento cuadrado, cerrado, dentro del cual los objetos redisponían libremente. Pero tanteó otra posibilidad en la cual el contorno regular del perímetro quedaba fragmentado por desplazamiento de las distintas unidades funcionales, mediante avances y retranqueos, creando un conjunto de piezas, contiguas, yuxtapuestas que compartían el centro de la planta. Esta idea no prevaleció y retomo la composición de las piezas dentro del contenedor. ( II. 60). 

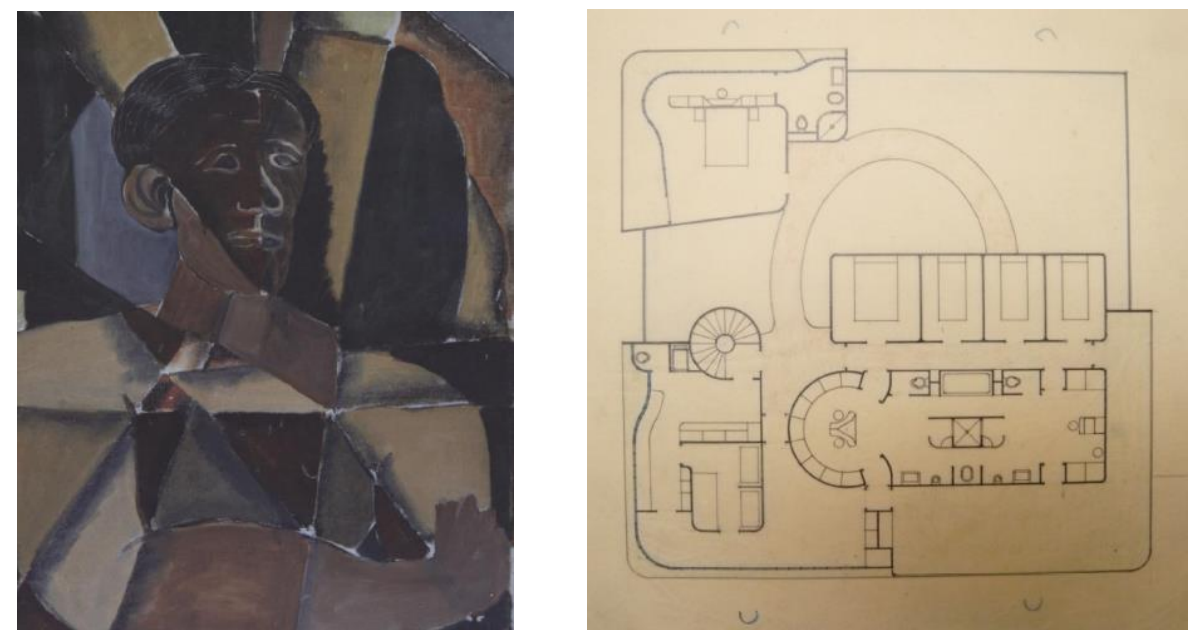

II. 59 Autorretrato, óleo sobre tela, Paul Nelson, ca 1932.

II. 60 Maison Suspendue, planta segunda, fragmentación en unidades funcionales, Paul Nelson, versión de 1938.

El reconocimiento de los galeristas Pierre Loeb, en París, y Pierre Mattisse, en Nueva York, fue muy importante en las relaciones de Paul Nelson con el arte y resultaron decisivas en el proceso de difusión de la maqueta de La Maison Suspendue, ya que esta, se expuso por vez primera en Francia y en Norteamérica en sus respectivas galerías. Paul Nelson participó, como pintor, por primera vez en una exposición colectiva en 1936, en la galería de Pierre Loeb, junto a Jean Arp, Alberto Giacometti y Jean Hélion. La galería de Pierre Loeb fue uno de los espacios fundamentales de exposición para los pintores de entreguerras en París, y exhibió las primeras obras cubistas de Picasso. La galería de Pierre Mattisse se convirtió en la principal difusora del arte moderno procedente de Europa en Estados Unidos. 


\section{La tecnología y la condición humana}

En la primera mitad de los años treinta, Paul Nelson pensaba que la celeridad con la que avanzaban las investigaciones científicas e industriales era tan intensa, que las propuestas puramente funcionalistas quedaban desfasadas, ya que en la vivienda se introducían nuevos mecanismos e instalaciones que alteraban el orden funcional predefinido. Nelson consideraba que el Movimiento Moderno acusaba de cierta rigidez que le impedía dar una respuesta flexible acorde con la evolución de la ciencia, y esto repercutía en el orden sociológico donde las necesidades tampoco se estaban resolviendo.

Nelson pensaba que el futuro de la arquitectura, fundamentalmente de la arquitectura residencial, debía tener como prioridad mejorar las condiciones de vida de los hombres. Por lo tanto, si el programa funcional no resolvía con flexibilidad las hipótesis planteadas, lo que él proponía era proyectar estancias cuya cualidad fundamental fuera la indefinición del uso, sin ajustarse a unas condiciones previas.

Paul Nelson criticó la incapacidad del Movimiento Moderno de construir una imagen acorde con la nueva arquitectura, consideraba que todo se había convertido en un gesto por el que se desnudaba de decoración al pasado, pero no se aportaba nada nuevo. Para Paul Nelson, el Movimiento Moderno no había logrado una nueva concepción espacial de la vivienda, debido a que no se había avanzado en las relaciones entre el hombre y el espacio que le rodeaba.

\footnotetext{
“...lo único que había cambiado en el periodo del movimiento moderno fue el uso de nuevos materiales y estructuras, pero esto no cambió el concepto esencial de la casa. Incluso si decides pintar las tuberías en verde y amarillo, como hicieron los primeros arquitectos modernos en Holanda, este equipamiento de la máquina no era suficiente para cambiar la esencia, lo importante, aquello que la casa debía ofrecerte..."158
}

Nelson pensaba que una de las herramientas para lograr este objetivo, de la casa como lugar al servicio del individuo, era la utilización de la ciencia a través de la invención tecnológica y su objetivo principal, a partir de ese momento, fue trabajar por incorporar a la casa todos los avances técnicos que facilitasen el desarrollo de cada uno de los habitantes. Trató de unir la sociología con la técnica, teniendo muy

158 Judith Applegate, "Paul Nelson: an interview". Perspecta nº13-14, 1971, p. 102. 
presente la investigación formal de la década anterior, y es así como surgió $L a$ Maison Suspendue. Con este proyecto extendió su aprendizaje y su pensamiento buscando que la vida fuese la principal función de la casa .

Esta actitud crítica, respecto de la vivienda construida por el último gran movimiento arquitectónico que se había producido en el siglo XX, no era exclusiva de Paul Nelson, como ya se ha visto (§ II.1.) era el reflejo de un cambio general en los objetivos principales de los proyectos domésticos de este periodo de entreguerras. Si durante los años veinte, el principal elemento de investigación, y casi el único, había sido el espacio, en los años treinta se incorporaron otros valores que tenían como referente principal al habitante. El objetivo principal para los arquitectos era conseguir acercar la vivienda al hombre y hacerla más humana.

\subsection{La prefabricación y el confort doméstico}

A principios de los años treinta, la población urbana de los Estados Unidos superó a la población rural y esto provocó una fuerte demanda de alojamientos en las ciudades y los bancos, a pesar de la Gran Depresión de 1929, ofrecían créditos para construir las nuevas viviendas ${ }^{159}$. La demanda hizo que las industrias de la construcción viesen una oportunidad en los alojamientos de bajo coste y esto supuso un auge de las empresas de casas prefabricadas. Esto, a su vez, desencadenó una reactivación de la industria del acero y de los procesos de producción de tableros industriales de madera. En Norteamérica, a diferencia de lo que sucedía en Europa, las empresas de prefabricación contaron con el apoyo de universidades y de instituciones, como la Purdue University ${ }^{160}$ o la U. S. Forest Products Laboratory, lo cual significaba entender la evolución de la industria como una cuestión de Estado.

El contacto con estos procesos constructivos industriales, resultó decisivo para la evolución de la carrera de Paul Nelson. Y así, sus proyectos ya no debían de permanecer para la eternidad sino que tenían su propio ciclo vital que culminaba con la demolición del edificio, siguiendo los criterios de producción industrial,

159 Margaret Kentgens-Craig, The Bauhaus and America. First contacts 1919-1936, Cambridge: MIT Press Paperback Edition, 2001, pp.4-5.

${ }^{160}$ La Purdue University fundó en 1935 el Housing Research Project, un programa destinado a investigar los alojamientos prefabicados de bajo coste. Véase : Douglas Knerr, Suburban Steel: The Magnificent Failure of the Lustron Corporation, 1945-1951, Columbus: The Ohio State University Press, 2004, p.47. 
II. 61 Esquema del ciclo de producción de una vivienda, 1 investigación, 2 diseño, 3ejecución, 4 distribución, 5 utilización, 6 eliminación, Paul Nelson, ca 1934

contemplo seis faseses:1 análisis-investigación, 2 diseño gráfico del proyecto, 3 construcción-ejecución, 4 distribución espacial, 5 uso y 6 destrucción (II. 61). Por primera vez, hizo un ensayo con sistemas de producción industrial, en la construcción del taller de Braque en Varengeville ( $§$ II.3). La producción industrial estandarizada, le proporcionaba dos ventajas respecto de la construcción tradicional: la reducción del coste económico y el control sobre el material. Ante la falta de infraestructura local para ejecutar una estructura en hormigón, Nelson propuso fabricarla en taller y ensamblarla después, y así, construyó una estructura metálica de cerchas y pilares apartir de perfiles montados en obra, y creó los cerramientos mediante tableros de madera insertados entre los perfiles de los pilares.

Paul Nelson encontró en el desarrollo tecnológico norteamericano la solución a la contrapartida de la estandarización y así la pérdida de identidad de los deseos del cliente por estar obligado a adaptarse a los modelos del mercado, quedaba resuelto gracias a la elaboración de diferentes tipos de vivienda a partir de un modelo, sin tener un sobrecoste excesivo ${ }^{161}$. Además había empresas especializadas en prefabricar la casa en fragmentos o construir unidades funcionales adaptables. Las industrias que aportaban el confort ambiental a la casa, experimentaron un gran avance y los nuevos mecanismos y electrodomésticos que aparecían se incorporaban a la vida doméstica, con lo cual se mejoraban las condiciones de salud, de seguridad y de confort.

${ }^{161}$ La empresa American Motohomes, editó un folleto donde a partir de un cuadrado, que contenía : salón, cocina, baño y dos dormitorios, añadiendo otros cuerpos rectangulares se llegaban a configurar 14 modelos diferentes de vivienda. Véase: Arnt Cobbers, Olivier Jahn, Prefab Houses, Köln: Taschen, 2010, pp.64-65. 
Esta evolución industrial ayudó a Paul Nelson a plantearse un nuevo concepto de vivienda, acorde con su idea de construir el espacio a partir de las relaciones entre las partes y el todo. Nelson proyectó La Maison Suspendue con la hipótesis de que la estructura general podía permanecer inalterada aunque las unidades funcionales fuesen sustituidas o modificadas. Y contactó con las empresas que lo hacían posible.

Para el arquitecto, el contratista y el promotor inmobiliario, el baño "Modulaire" representa un triunfo esencial, de fácil colocación y con un precio de coste sorprendente. Entregado, listo para empalmarlo y conectarlo de manera rápida, esto permite una mejor planificación de las obras, contribuye al ajuste de los costes y hace atractivo su uso por el confort y su control de calidad ${ }^{162}$.

Uno de los modelos de vivienda americana manufacturada más singulares, fue el concebido a partir de la suspensión de la casa de un apoyo superior y el referente fue la Dimaxyon House (§ II.2) de Richard Buckminster Fuller. Esta vivienda sirvió de modelo a otros arquitectos como: George y William Keck, Eero Saarinen, Richard Neutra, Peter Pfisterer y Leland Atwood ${ }^{163}$.

En 1931, el antiguo colaborador de Le Corbusier, Albert Frey junto al arquitecto Alfred Lawrence Kocher, presentaron su modelo de casa prefabricada Aluminaire house. Dos años después, se celebró en Chicago la exposición "Century of Progress", en la que George y William Keck mostraron la House of tomorrow. Ambas viviendas se anticiparon a La Maison Suspendue. Tenían una estructura acero y un cerramiento de paneles de metálicos y paños de virio, contaban con sistemas de aire acondicionado e incorporaban algunos electrodomésticos como el lavavajillas ${ }^{164}$. El programa de ambas casas era similar, tenían tres alturas y situaban la zona vividera en planta primera, pero, a diferencia de la casa de Paul Nelson, entre los objetivos prioritarios de estas viviendas no estaba ni la investigación espacial ni la social de la vivienda.

\footnotetext{
162 Carta, sin fecha, de Mr Thomee, marketing manager home Systems ACEC-Heating Division, a Paul Nelson, MNAM/CCI, Bibliothèque Kandinsky, fonds Nelson.

${ }^{163}$ Burnham Kelly, "The radical approach" Prefabrication of Houses: A Study by the Albert Farwell Bemis Foundation of the Prefabrication Industry in the United States, Cambridge: MIT Press and John Wiley and Sons, 1951, p.26.

${ }^{164}$ Arnt Cobbers, Olivier Jahn, Prefab Houses, Köln: Taschen, 2010, pp.16-17.
} 


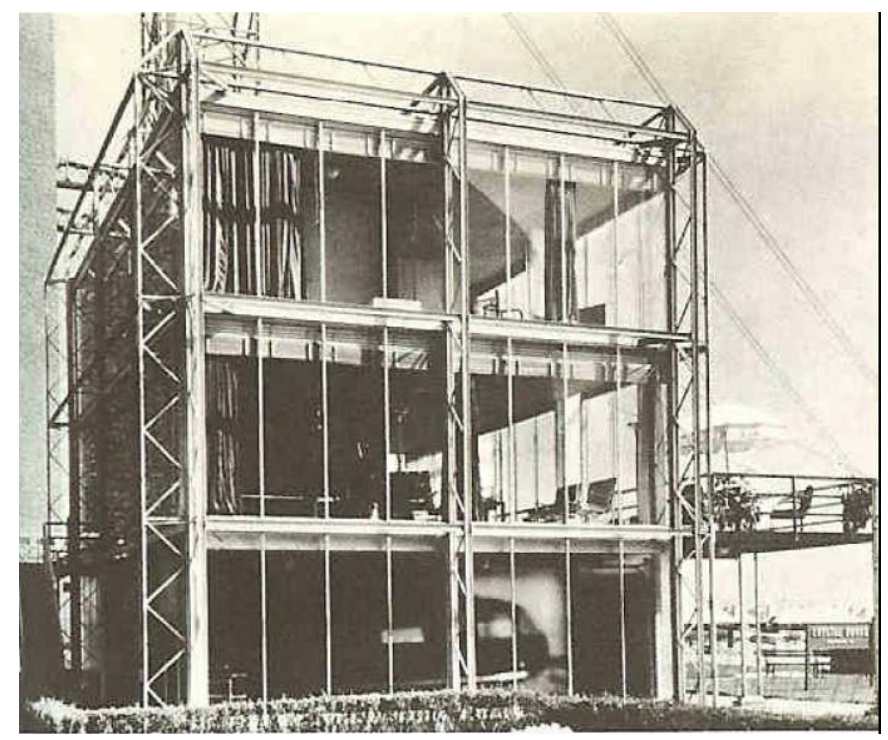

II. 62 Crystal House, Chicago World's Fair “ A Century of Progress”, George Fred Keck, 1933-34

George y William Keck, exhibieron otro prototipo de casa prefabricada, la Crystal House en la "A Century of Progress Exposition"de Chicago de 1933 ( II. 62). Algunas de las premisas que inspiraron el concepto de esta vivienda fueron utilizadas por Paul Nelson dos años más tarde e incluso, en las dos viviendas se adoptaron soluciones estructurales similares, que eran poco habituales en arquitectura residencial. Los autores de la Crystal House, pretendían dar una respuesta rápida y fácil de construir, que ofreciese un espacio libre para que los habitantes pudiesen controlarlo, ordenarlo, iluminarlo, calentarlo y disfrutarlo de una manera libre y que repercutiese en beneficio de su salud. La solución permitía que los propietarios pudiesen adaptar el modelo estandarizado a su gusto personal, haciendo compatible la producción en masa con la expresión individual. Sin que esto tuviese asociado un aumento excesivo del precio. Así, George y William Keck avanzaron elementos tecnológicos y sociales con los que Paul Nelson trabajó posteriormente, proyectaron una estructura metálica de pórticos externos en los que sujetaban los forjados, para facilitar una distribución libre del espacio interior, este planteamiento estaba dirigido a lograr una vivienda que estuviese al servicio de los habitantes y nunca al revés ${ }^{165}$ Posteriormente, Paul Nelson trabajó sobre estos conceptos en La Maison Suspendue, y trató de profundizar en otros aspectos que en

\footnotetext{
${ }^{165}$ Véase: Barry Bergdoll, Ken Tadashi Oshima y Rasmus Wærn, Home Delivery:

Fabricating the Modern Dwelling. New York: Barry Bergdoll y Peter Christensen,2008, p.68.
} 
este prototipo solo estaban enunciados, como la prefabricación de unidades funcionales y de estancias.

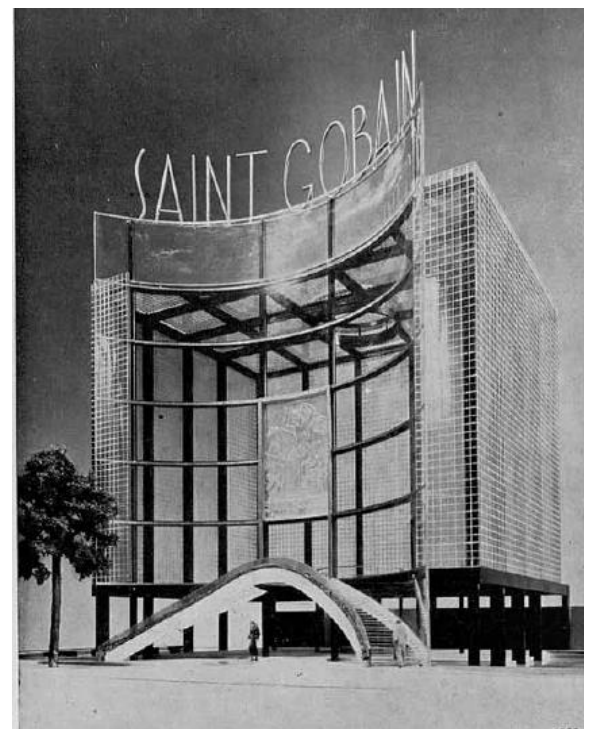

II. 63 Pabellón de Saint Gobain, maqueta, Exposición Internacional de París, René Coulon,1937

En 1937, se celebró en París la Exposición Internacional, con el título de "Art et Technique", en la que las industrias francesas de la construcción estuvieron presentes con sus propios pabellones. Era una oportunidad para mostrar sus productos al gran público. La empresa de cerramientos de vidrios y aislantes Saint Gobain participó con un pabellón del arquitecto René Coulon (II. 63), una gran jaula de acero revestida con ladrillos de vidrios y elevada sobre una base de pilotes. El efecto de la fachada translúcida del pabellón y la utilización de vidrios moldeados, ensamblados en una retícula, como única piel del cerramiento, coincidía con lo que Paul Nelson solicitó a esta empresa cuando les pidió su colaboración para fabricar los vidrios de la fachada de su vivienda .

La Exposición Internacional tuvo una amplia difusión en la presa especializada. En el verano de 1937, L'architecture d'aujourd'hui,dedicó un número al pabellón de L'Union des Artistes Modernes (L'U.A.M) ${ }^{166}$, asociación a la que pertenecía Paul Nelson, en la introducción se explicaba que el primer objetivo con este proyecto era lograr un trabajo de síntesis entre el arte y la industria. En el pabellón se repasó la historia de los diez últimos años de L'U.A.M, entre las imágenes de mobiliario

${ }^{166}{ }^{\prime}$ 'Architecture de A'ujoud' hui, no 7, julio 1937 


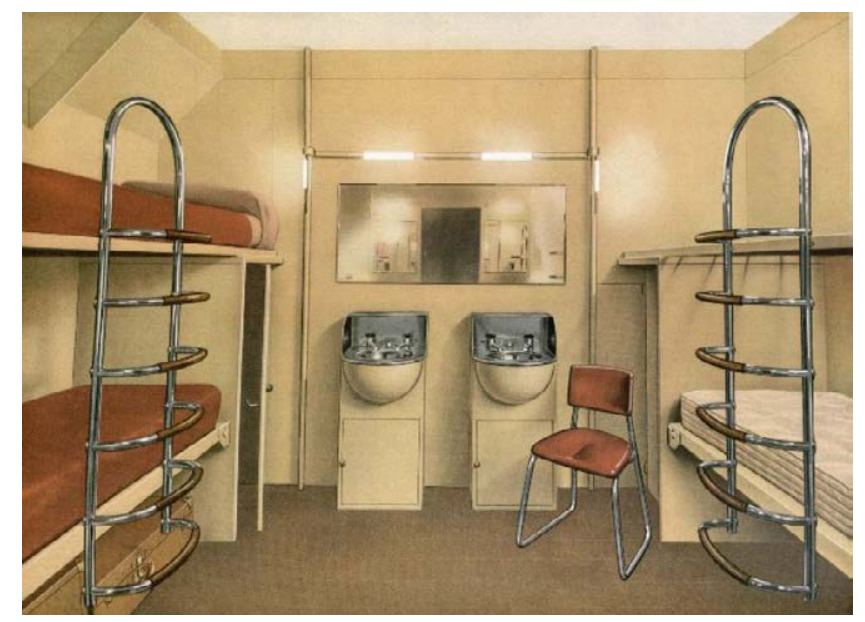

II. 64 Interior de camarote de barco, Jean Prouvé y Marcel Gascoin, 1935

mostrado, aparecía una colaboración del ingeniero Jean Prouvé y del decorador Marcel Gascoin, de 1935 (II. 64 ). En una fotografía del equipamiento de un camarote de un barco, se mostraban dos literas con sus respectivas mesas de noche, esta cabina anticipaba un espacio mínimo similar al que después utilizó Paul Nelson en las habitaciones individuales de La Maison Suspendue.

Desde que Paul Nelson inició su investigación en 1935, siempre pensó que la técnica era uno de las herramientas decisivas para lograr su objetivo. Por esa razón incorporó los avances que ofrecía la industria de la construcción, tanto en Estados Unidos como en Francia.

\subsection{La humanización del funcionalismo.}

La formación de humanista que tuvo Paul Nelson incidió en su manera de entender el trabajo en arquitectura desde una perspectiva interdisciplinar. Su interés por la sociología y por las relaciones entre los individuos le hicieron decantarse por la arquitectura, para poder contribuir a mejorar la manera de vivir de los hombres. Su objetivo era realizar una arquitectura cercana al hombre y para conseguirlo se apoyo en su formación iterdisciplinar y en experiencia personal. Por lo tanto, su deseo por humanizar la arquitectura no fue el resultado directo y exclusivo de haber tenido una educación humanística, sino que también fue consecuencia de su investigación sobre el funcionalismo, y su decisión de prolongar el concepto de función a los niveles espirituales del hombre. 
Es necesario abrazar los conceptos espaciales y los equipamientos de ayer y de hoy para emprender con la ayuda de la tecnología moderna, de la sociología, y la psicología, unas investigaciones que avancen sobre las necesidades funcionales del individuo dentro del mundo moderno ${ }^{167}$

El historiador Geoffrey Scott analizó en 1914 la relación que existía entre el hombre del Renacimiento y el espacio que habitaba, y su conclusión fue que el hombre tenía necesidad de sentirse mas confortable ${ }^{168}$ y para lograrlo se proyectaba en las formas y en los volúmenes que le rodeaban, y lo hacía mediante una arquitectura de composición armónica y sin sorpresas. Para Paul Nelson, la relación entre el hombre y su espacio envolvente, era la manera fundamental de crear el hábitat doméstico. Pero, a diferencia de Geoffrey Scott, pensaba que la sorpresa formal y el contraste volumétrico enriquecían el espacio y hacían más agradable su recorrido y por lo tanto la vida del habitante. Nelson no se limitó al análisis de los aspectos antropomórficos de la arquitectura, como proponía Geoffrey Scott, sino que trató de ampliar el objetivo a otras variables como el uso, la función o la técnica.

El trabajo de Paul Nelson, consistió en cambiar el discurso de la pureza formal, utilizado por el Movimiento Moderno, por la satisfacción estética producida por las formas. Lo importante no eran las formas en sí, sino el estado de ánimo que podían producir. Para conseguir su objetivo de convertir la vivienda en un sueño individual, se enfrentó a un dilema: por un lado, rechazaba el carácter homogéneo del espacio creado por el Movimiento Moderno.

¿Qué sueño individual pueden tener los habitantes de las fortalezas de vidrio a través de las cuales miles de personas encerradas en las mismas células dirigen su mirada hacia el mismo campo de visión y en cuyo interior la repetición sistemática de los mismos módulos y de las mismas tramas de arquitectura deja poco a la actitud del orden personal y de la expresión de cada uno? ${ }^{169}$

\footnotetext{
${ }^{167}$ Paul Nelson, "L'homme, l'architecture et l'industrie du batiment", Technique et architecture $\mathrm{n}^{\circ} 4$ mayo-junio 1965

${ }^{168}$ Geoffrey Scott, The Architecture of Humanism. A Study in the History of Taste, Boston: Houghton Mifflin Company, 1914.

169 Michel-Louis Lacoste, "Paul Nelson.Un architecte humaniste", Informations et Documents, U.S. Embasy no 189, p 21-25. november 1963.
} 
y por otro, pensaba que la exclusividad formal tampoco era la solución, ya que el excesivo protagonismo de las partes podía alterar la visión de conjunto. Buscó una manera de hacer compatible el lenguaje de la retícula moderna y el volumen ergonómico del espacio individual. Esta síntesis formal afectó al desarrollo de los espacios de tránsito y de comunicación entre las partes, haciéndoles más visibles y habitables para los hombres, este proceso se reforzó mediante la singularidad de sus formas, que hasta ese momento tenían la forma residual existente entre las estancias.

Para Paul Nelson, un programa en el que las funciones similares se agruparan en unidades superiores, y estas a su vez se adosaran a otras funciones diferentes, sin fluidez y sin continuidad, era un modelo en el que las relaciones espaciales entre las habitantes y la casa estaban limitadas. Estas relaciones debían de ser vivas, como sucedía en el interior de cualquier organismo para adaptarse a los cambios surgidos en el tiempo. El habitante era quien definía su tipo de vida y la vivienda no debía de imponer el suyo, el espacio doméstico debía ser propositivo y no determinante.

Uno de las herramientas que Paul Nelson utilizó para humanizar su arquitectura fue el uso o mejor la indefinición del uso. Consideraba que la arquitectura moderna había contribuido a una rigidez temporal y funcional del uso del espacio, limitando la simultaneidad de las actividades dentro de estancias y estableciendo una separación rígida entre espacio de uso colectivo y espacio de uso individual. Él propuso romper esos límites y construir una vivienda donde cada habitante decidiera los vínculos que mantenía con el espacio que le rodeaba, por lo tanto la variedad de los usos característicos debía aumentar y permitir su compatibilidad, sin necesidad de fragmentación espacial. De la misma forma que la casa era un contenedor que se enriquecía albergando volúmenes opuestos, la vivienda también debía ser un órgano vivo donde se pudiese disfrutar del espacio colectivo e individual simultáneamente

En un texto de 1940, dedicado a la humanización de la arquitectura, Alvar Aalto ${ }^{170}$ consideraba que el camino para lograrlo era extender los valores alcanzados por el funcionalismo y el racionalismo a los aspectos psicofísicos del hombre, con lo cual establecía que humanismo y funcionalismo no eran conceptos opuestos, sino que humanismo respondía a una visión amplia del término función. Para explicarlo utilizaba como ejemplo su Sanatorio de tuberculosos de Paimio (II. 65) y exponía los criterios cromáticos y formales adoptados. y la repercusión que esas actuaciones

\footnotetext{
${ }^{170}$ Alvar Aalto, La Humanización de la arquitectura , Barcelona : Tusquets Editores, 1977, pp. 25-35. ["The humanizing of architecture," The Technology Review, noviembre 1940].
} 


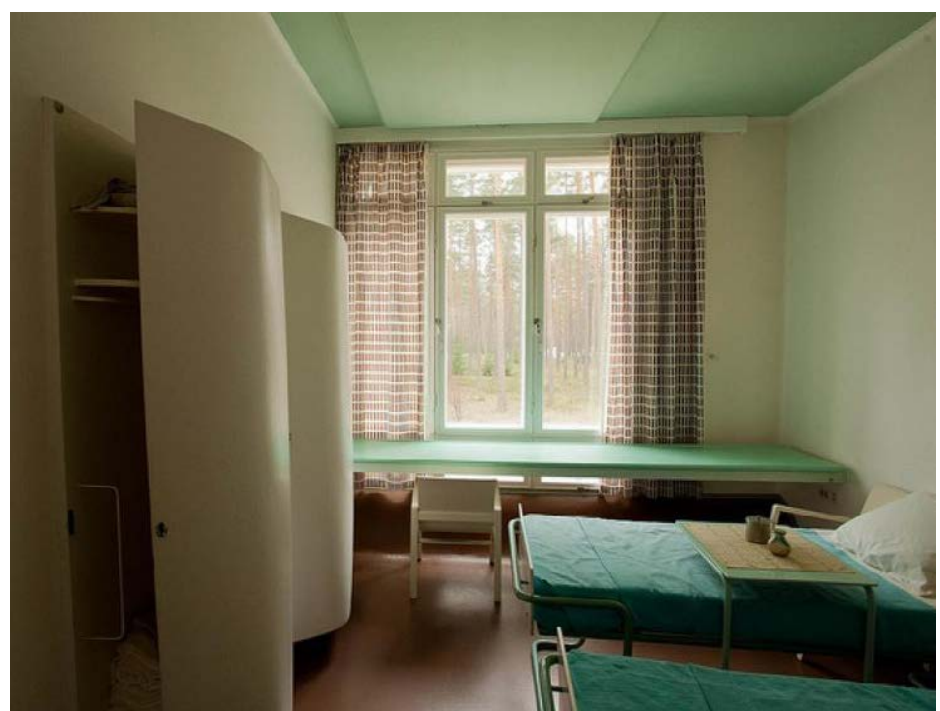

II. 65 Interior del Sanatorio de tuberculosos de Paimio, Alvar Aalto, 1928-1933

habían tenido en la salud de los enfermos, ya que en estado convaleciente las personas eran más sensibles, y cómo esta experiencia le sirvió para trasladarlo posteriormente a su arquitectura residencial. Paul Nelson coincidía plenamente con estas reflexiones de Alvar Aalto y también experimentó en su arquitectura hospitalaria con las mismas intenciones. Pero hubo dos diferencias entre ambos, la primera fue que Paul Nelson tenía como prioridad proyectar espacios individuales dentro de sus viviendas y Alvar Alto no. Y la segunda, que Paul Nelson trasladó sus conclusiones del ámbito residencial al público y Alvar Alto actuó de manera contaria. 


\subsection{La síntesis como método de trabajo}

Paul Nelson trasladó su carácter internacional, de ciudadano que no se identificaba con una nacionalidad concreta, al espíritu a su obra. Durante toda su carrera, incorporó los conocimientos que estimó más oportunos, con independencia de la procedencia de las teorías del conocimiento. Su labor estuvo marcada por la integración y por la inclusión de pensamientos opuestos y unió su formación humanista, su compromiso social, el racionalismo francés, la investigación espacial y funcional del Movimiento Moderno y la colaboración con los artistas con el pragmatismo de los procesos de producción del mercado americano, la investigación tecnológica de la industria americana, la imagen de ligereza de la prefabricación ,y la corriente humanizadora y orgánica de la arquitectura que se extendía en Estados Unidos. Nelson, combinó esos factores y ordenó las conclusiones en un método de trabajo, que le permitió sistematizar la manera de abordar su arquitectura. " La síntesis" se convirtió en la principal herramienta su método.

En el año 1936, Paul Nelson ensayó su método de trabajo para realizar el proyecto de la C.B.S fortaleciendo las relaciones con los agentes que intervenían en el proyecto, pero no fue hasta el año siguiente, cuando lo desarrolló plenamente, coincidiendo con su de investigación de La Maison Suspendue. Escribió un artículo en el que describía su sistema para proyectar ${ }^{171}$, en cuyo título utilizó de la expresión "método de producción en arquitectura", esta era una manera de asociar la arquitectura a los procesos industriales y de expresar que la creación de arquitectura no se basaba exclusivamente en un proyecto gráfico, al cual se le aplicaba una técnica constructiva, sino que debía ser el resultado de una colaboración con todos los especialistas: sociólogos, ingenieros, artistas, economistas etc, para poder obtener una visión completa de la realidad, que permitiese al arquitecto, afrontar la aproximación al diseño de la arquitectura desde una perspectiva abierta.

Proponía un método deductivo para llegar las formas del proyecto, partía de unas hipótesis basadas en las necesidades humanas y concluía el proyecto con la materialización de la "forma viva" de la arquitectura. Estructuró el proceso de trabajo en tres fases: 1, era una etapa exógena a la arquitectura, donde se planteaban todos los temas, se trabajaba con otras disciplinas y se definía "la ideología" del análisis, sin realizar ningún boceto; 2 , tenía como objetivo definir el esquema de las

${ }^{171}$ Paul Nelson, "A Method of Procedure in Architectural Design", Architectural Record, junio 1937, pp.52-57. 
relaciones espaciales, que permitiese desarrollar un programa, que había sido el fruto del análisis de las hipótesis; y 3, era en la que se desarrollaba gráficamente el proyecto, donde se ajustaban los problemas técnicos, económicos y constructivos. Era donde el arquitecto interpretaba y cristalizaba la arquitectura. ${ }^{172}$ Paul Nelson calificó a la arquitectura que surgía a partir de su método de la siguiente manera:

La arquitectura resultante será imprevista, por que el programa de la vida con sus imponderables es el que inspiró estas formas arquitectónicas, esas armonías múltiples y complejas, que ningún arquitecto podía haber anticipado. ${ }^{173}$

Este método de proyectar tuvo su efecto sobre la arquitectura de Nelson : en primer lugar, la calificación de la fase inicial, como no-arquitectonica desplazaba a las hipótesis fuera del territorio de la arquitectura y consideraba que la verdadera arquitectura llegaba cuando se dibujaba la forma, esto que era coherente con su postura de rechazo al dibujo como, idea inicial de la arquitectura, suponía que no había proyecto hasta que la forma no se dibujada. En segundo lugar, la arquitectura se asentaba sobre los vínculos existentes entre dos principios: las relaciones humanas y las relaciones espaciales, cada uno con sus respectivos factores sociales, artísticos o técnicos. La incidencia de la técnica en el proyecto era importante pero no decisiva, ya que el ajuste a los cambios resultaba una misión incierta dada la celeridad con la que unos descubrimientos sustituían a los anteriores. Y en tercer lugar, la arquitectura que se proyectaba siguiendo este método no era el resultado directo de una función material, ya que el determinismo del uso no servía en un proceso en el que intervenían una serie de factores variables, que el arquitecto debía saber interpretar, sintetizar e incorporar, para dar una respuesta flexible.

En un artículo titulado El funcionalismo radical, el profesor y arquitecto suizo Bruno Reichlin, analizaba por qué arquitectos como: Frederick Kiesler, Richard Buckminster Fuller, Paul Nelson, Oscar Nitzchké y a Jean Prouvé, habían quedado marginados en los relatos sobre el funcionalismo por críticos de arquitectura como Walter Curt Behrendt, Sigfried Giedion, Herry- Russell Hitchcock o Leonardo Benenolo, y concluyó manifestando que esto era así por qué estos arquitectos habían perfeccionado el método funcionalista.

\footnotetext{
172 Paul Nelson definió las tres etapas de su método de la siguiente manera: primer escenario, el análisis no-arquitectónico; segundo escenario, análisis arquitectónico; tercer escenario, la síntesis arquitectónica. Véase: Paul Nelson, "A Method of Procedure in Architectural Design”, Architectural Record, junio 1937, op. cit , p.54.

${ }^{173}$ Ibidem, p. 54.
} 
II. 66 Esquema reversible para abordar el proyecto, nuevas necesidades, nuevas formas y nuevos medios, Paul Nelson, ca 1934

En el caso de Paul Nelson, no sólo trató de avanzar sobre el método funcionalista sino que creó el suyo propio. Mantuvo la estructura de los tres representantes del funcionalismo a escenarios, a lo largo de toda su carrera, y lo que si varió sustancialmente, fue la relación entre ellos, ya que pasó de un esquema lineal, descendente y deductivo que terminaba en la forma, a un esquema triangular donde las operaciones entre los tres escenarios eran reversibles. 
Aprendizaje, entre la tecnología y el humanismo 


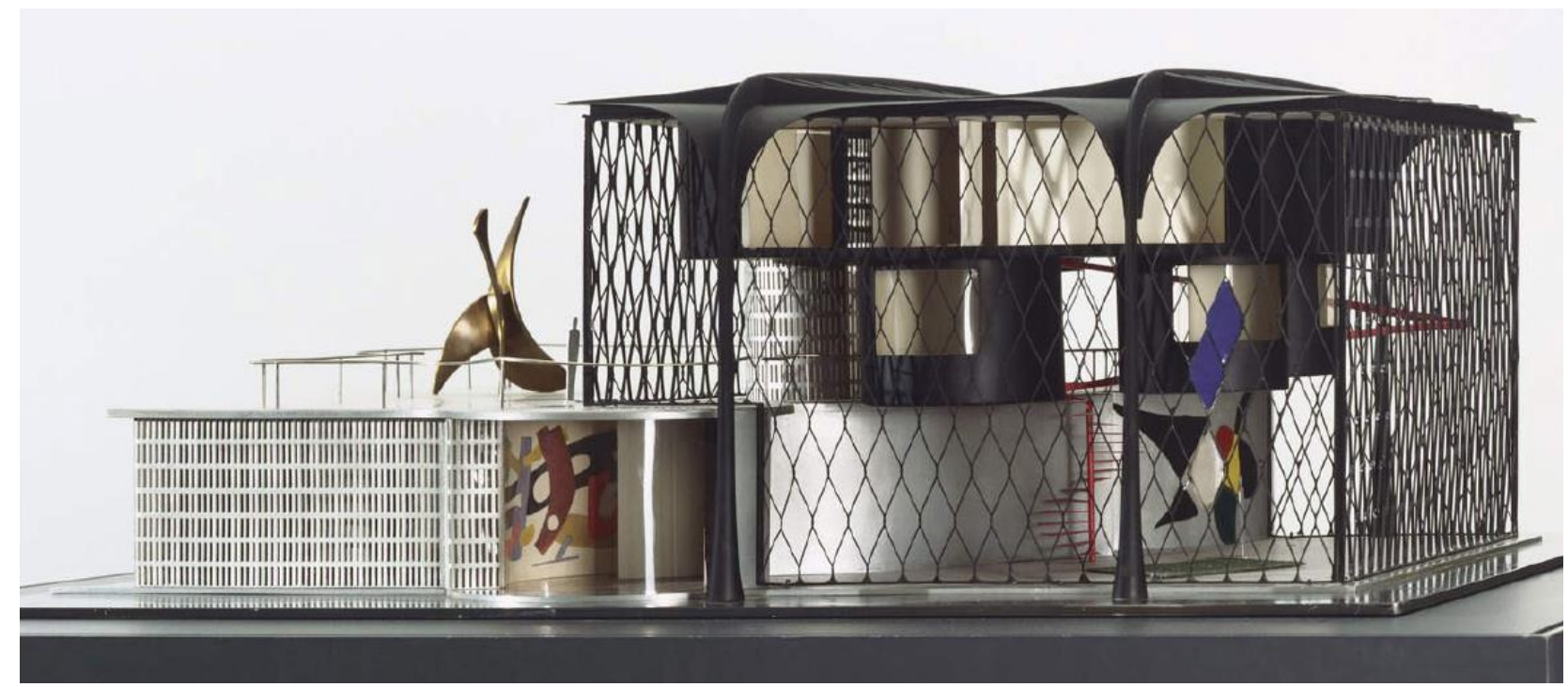

III. 1 La Maison Suspendue, segunda maqueta. Paul Nelson, 1938

III LA MAISON SUSPENDUE. LA BÚSQUEDA DEL NUEVO HÁBITAT DOMÉSTICO 1935-1939 
1. La casa. Manifiesto de un espacio suspendido.

La Maison Suspendue fue un proyecto de vivienda, no construido que surgió a partir de la investigación desarrollada por Paul Nelson entre los años 1935 y 1939. Este trabajo era un manifiesto espacial, cuyo objetivo era propiciar una relación entre el hombre y el espacio doméstico que habitaba, para incidir en su desarrollo intelectual. Paul Nelson partió de unas hipótesis sociológicas, examinó los criterios del uso y la función doméstica, analizó la repercusión de la técnica en la vida de la casa, exploró las influencias del contraste volumétrico en la percepción de la vivienda y estudió la incidencia que ejercía el arte moderno sobre los habitantes. La casa era un recinto con un espacio único, continuo e integrador, capaz de asumir las diferentes transformaciones surgidas en el tiempo, debidas a la variedad de relaciones y necesidades de los habitantes. La vivienda debía ser un entorno vivo, que estimulase a las personas que la ocupaban, para ordenar, disfrutar, y dirigir su plan de vida.

La vivienda era un proyecto de autoencargo, fruto de un proceso introspectivo, donde el autor seleccionaba las hipótesis y los objetivos que deseaba resolver ${ }^{174}$. Paul Nelson, igual que otros arquitectos coetáneos ${ }^{175}$, utilizó la vivienda como laboratorio en el que mezcló una concepción espacial genérica con sus necesidades personales. Esto hacía que La Maison Suspendue fuese a la vez un referente espacial moderno y una creación exclusiva. La casa estaba pensada a partir de una ruptura con el pasado, el objetivo era convertirla en el punto de partida para proyectar otra realidad. Alvar Aalto dijo : "Paul Nelson ha creado un punto en el espacio desde el cual se irradiarán los futuros desarrollos" ${ }^{176}$. La vivienda nunca fue concebida como un prototipo para ser desarrollada en serie, tenía una componente individual que la alejaba de la generalidad moderna y la adaptaba a las demandas personales del propio autor.

174 El proyecto no tenía previsto ningún emplazamiento. Paul Nelson eligió para su investigación. un tipo de vivienda burguesa suburbana, de $536,2 \mathrm{~m}^{2}$ de superficie. El programa inicial no sufrió grandes transformaciones, incluía amplios espacios de ocio, un bloque de estancias para personal de servicio, un garaje y zonas ajardinadas.

${ }^{175}$ La vivienda que Walter Gropius se construyó en Lincoln en 1937, y el apartamento que Le Corbusier realizó en Porte Monitor en Paris en 1933, son dos ejemplos de casas donde los arquitectos ensayaron algunos elementos arquitectónicos que desarrollaron posteriormente.

${ }^{176}$ Alvar Aalto, conferencia pronunciada en el MoMA en 1938. Véase: Judith Applegate, "Paul Nelson: an interview", Perspecta n ${ }^{\circ} 13-14,1971$, p. 102. 


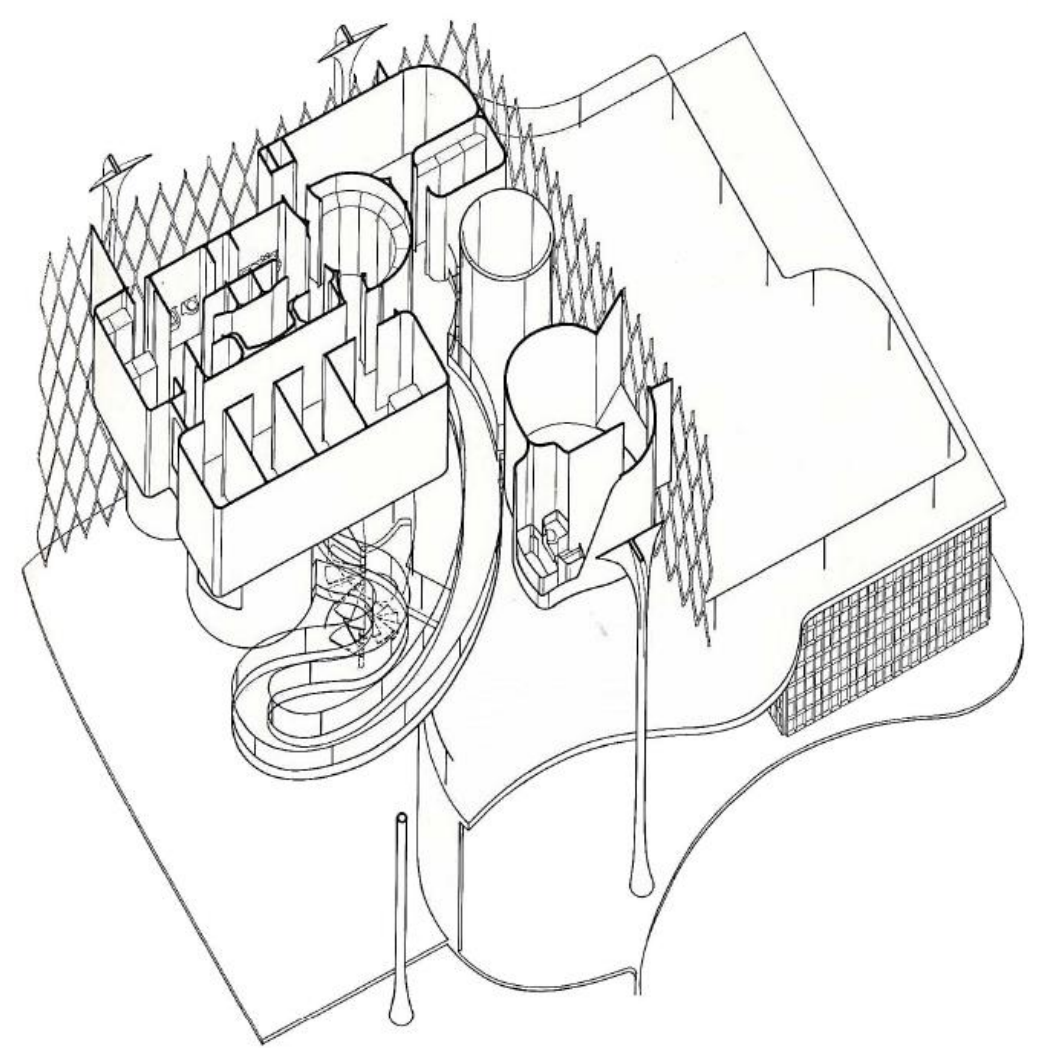

III. 2 La Maison Suspendue, axonometría, versión definitiva. Paul Nelson, ca. 1938.

La Maison Suspendue, era una vivienda compacta y cerrada, apoyada sobre un plano horizontal abstracto (III. 2). Su volumetría era el resultado de la intersección de dos prismas ${ }^{177}$, uno ligero de vidrio y metal, de tres alturas, y otro masivo de hormigón, de una altura. La planta baja estaba destinada a espacios servidores y estancias sociales, la planta primera al ocio familiar y personal, y la planta segunda al descanso y al ejercicio físico. Las principales novedades del proyecto se encontraban en la organización espacial y en el sistema estructural. Paul Nelson concentró la parte funcional-mecánica del programa en el prisma de una altura y en la planta segunda del prisma de tres alturas, y dejó libre el resto de la casa. Así el vacío ocupó el mayor volumen dentro de la vivienda y se convirtió en el lugar protagonista, que facilitaba la integración de todas las dependencias en un cuerpo superior. Nelson proyectó un sistema estructural de pórticos externos del que colgó las plantas superiores, esto convertía la estructura en un marco dentro del cual el espacio se podía ordenar sin límites.

${ }^{177}$ El prisma superior tenía unas dimensiones de 13,6m x 13,6m x 8,6m, y el prisma inferior medía: $8,7 \mathrm{~m} \mathrm{x} 13,6 \mathrm{~m} \times 3,2 \mathrm{~m}$. 


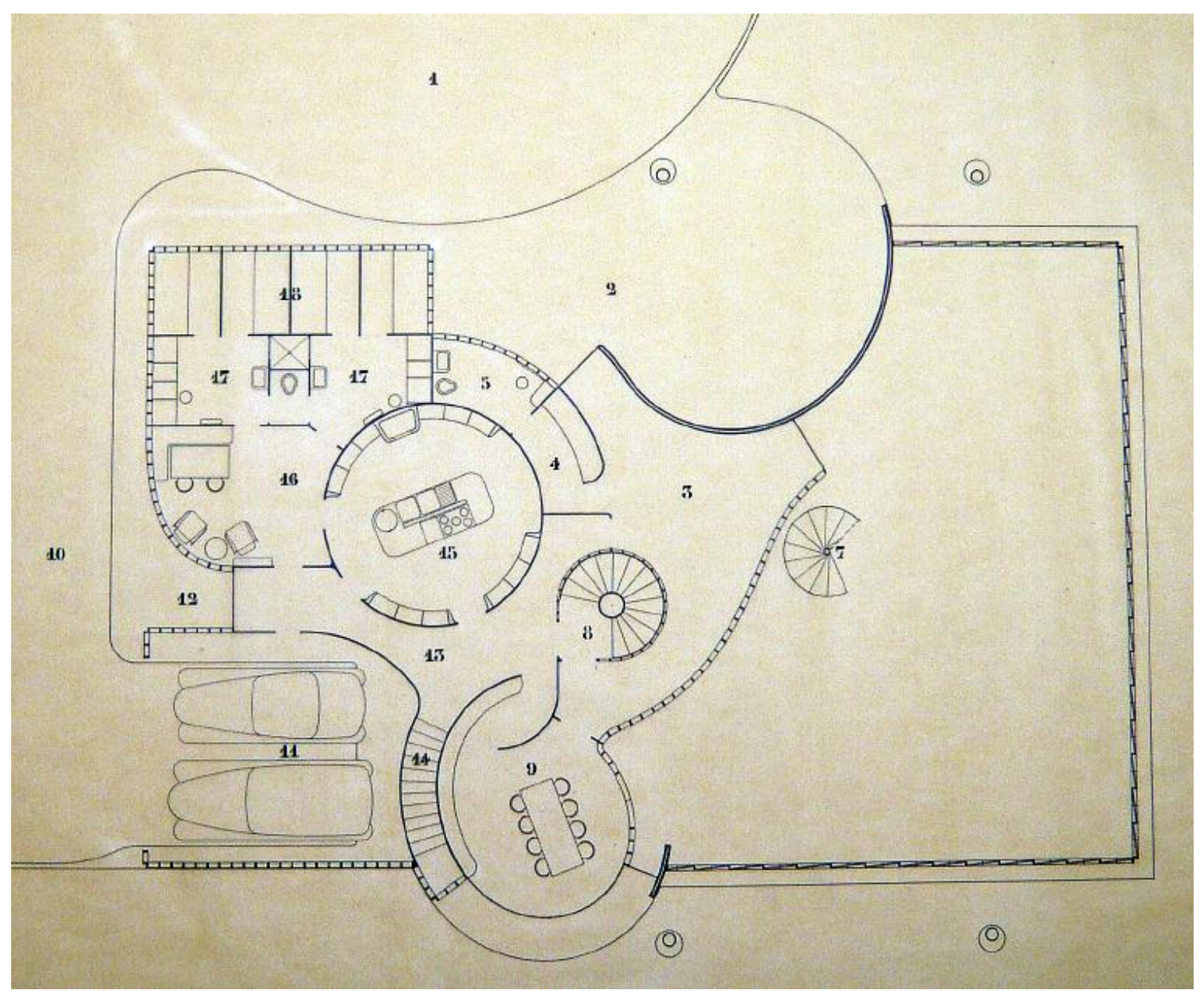

III. 3 La Maison Suspendue, planta baja. Paul Nelson, ca. 1938

1 acceso principal de vehículos, $\mathbf{2}$ porche de entrada, $\mathbf{3}$ vestíbulo, 4 vestíbulo-ropero, $\mathbf{5}$ aseo, 7 escalera principal, $\mathbf{8}$ escalera de servicio, $\mathbf{9}$ comedor, $\mathbf{1 0}$ acceso vehículos (servicio), $\mathbf{1 1}$ garaje, $\mathbf{1 2}$ entrada de servicio, $\mathbf{1 3}$ corredor de servicio, $\mathbf{1 4}$ escalera al sótano, $\mathbf{1 5}$ cocina, $\mathbf{1 6}$ comedor de servicio, $\mathbf{1 7}$ vestidor y duchas de servicio, $\mathbf{1 8}$ dormitorio servicio. 


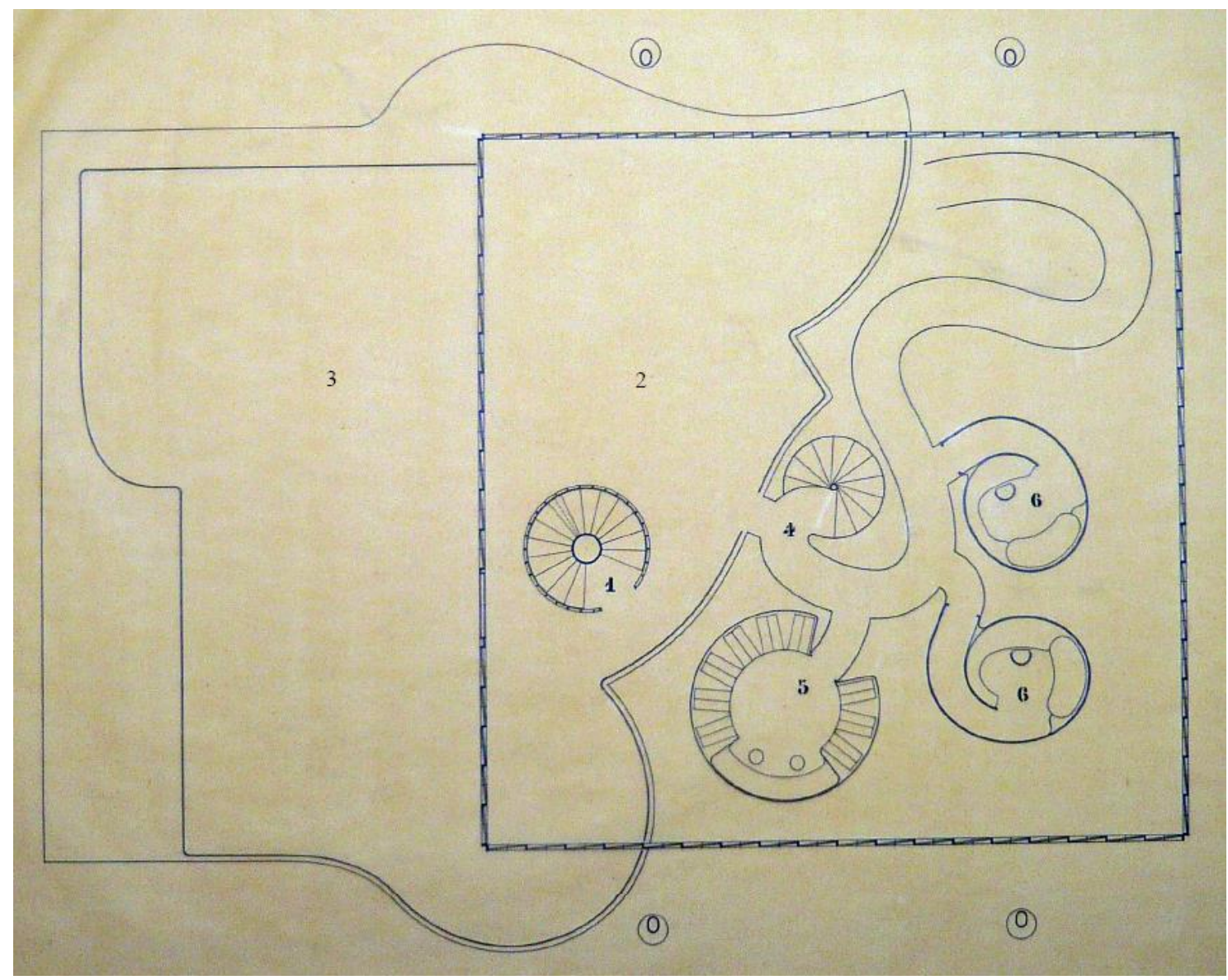

III. 4 La Maison Suspendue, planta primera. Paul Nelson, ca. 1938

1 escalera de servicio, 2 balcón para ocio familiar, 3 terraza, 4 rampa, 5 biblioteca suspendida, 6 salas de trabajo individual suspendida 


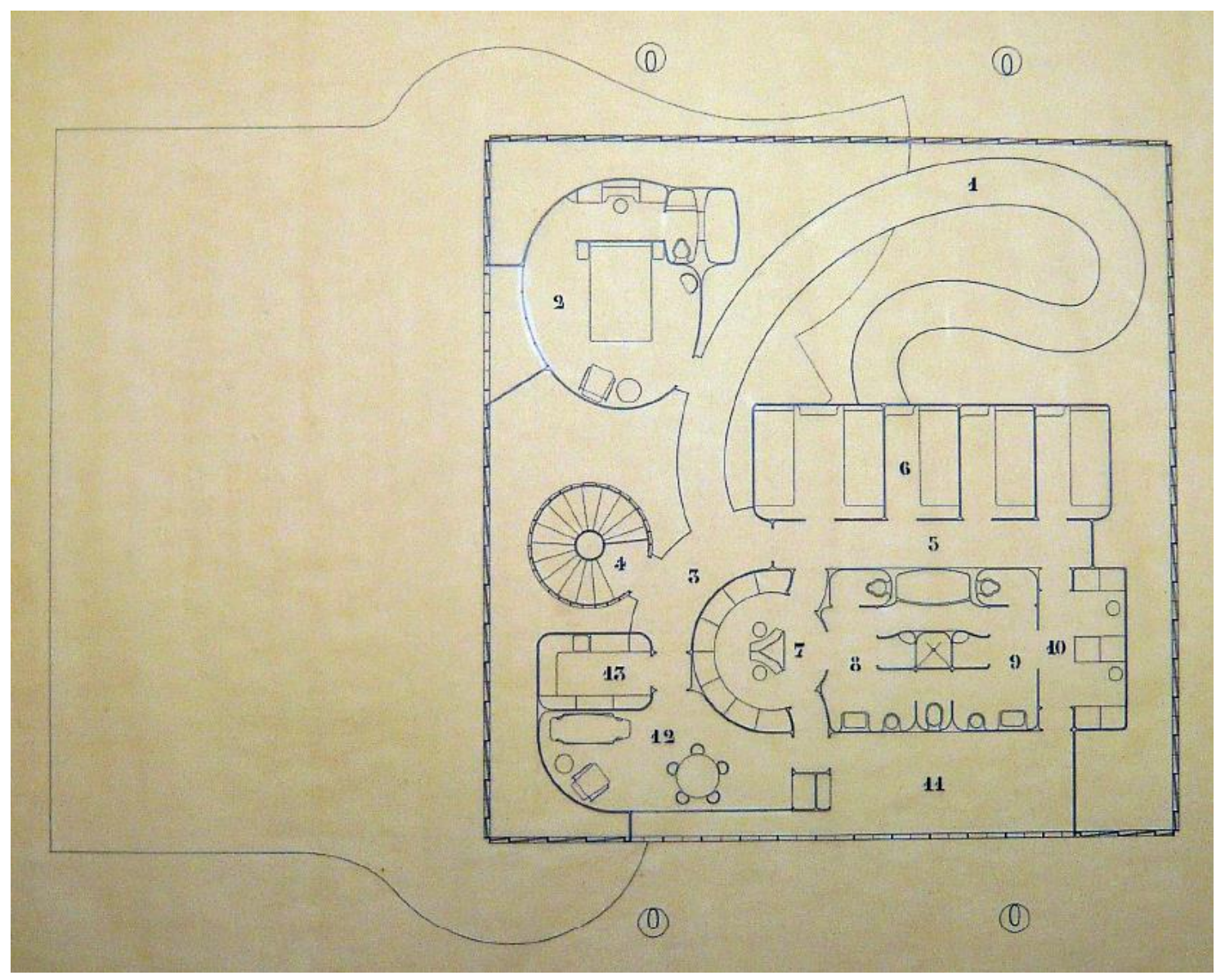

III. 5 La Maison Suspendue, planta segunda. Paul Nelson, ca. 1938

1 rampa, 2 dormitorio principal con baño, 3 corredor de llegada, 4 escalera de servicio, 5 pasillo, 6 cabinas dormitorio, 7 vestidor de señoras, $\mathbf{8}$ baño y aseo de señoras, 9 baño y aseo de caballeros, 10 vestidor de caballeros, $\mathbf{1 1}$ solarium y ejercicio físico, $\mathbf{1 2}$ sala de juegos infantiles, $\mathbf{1 3}$ lencería de casa. 


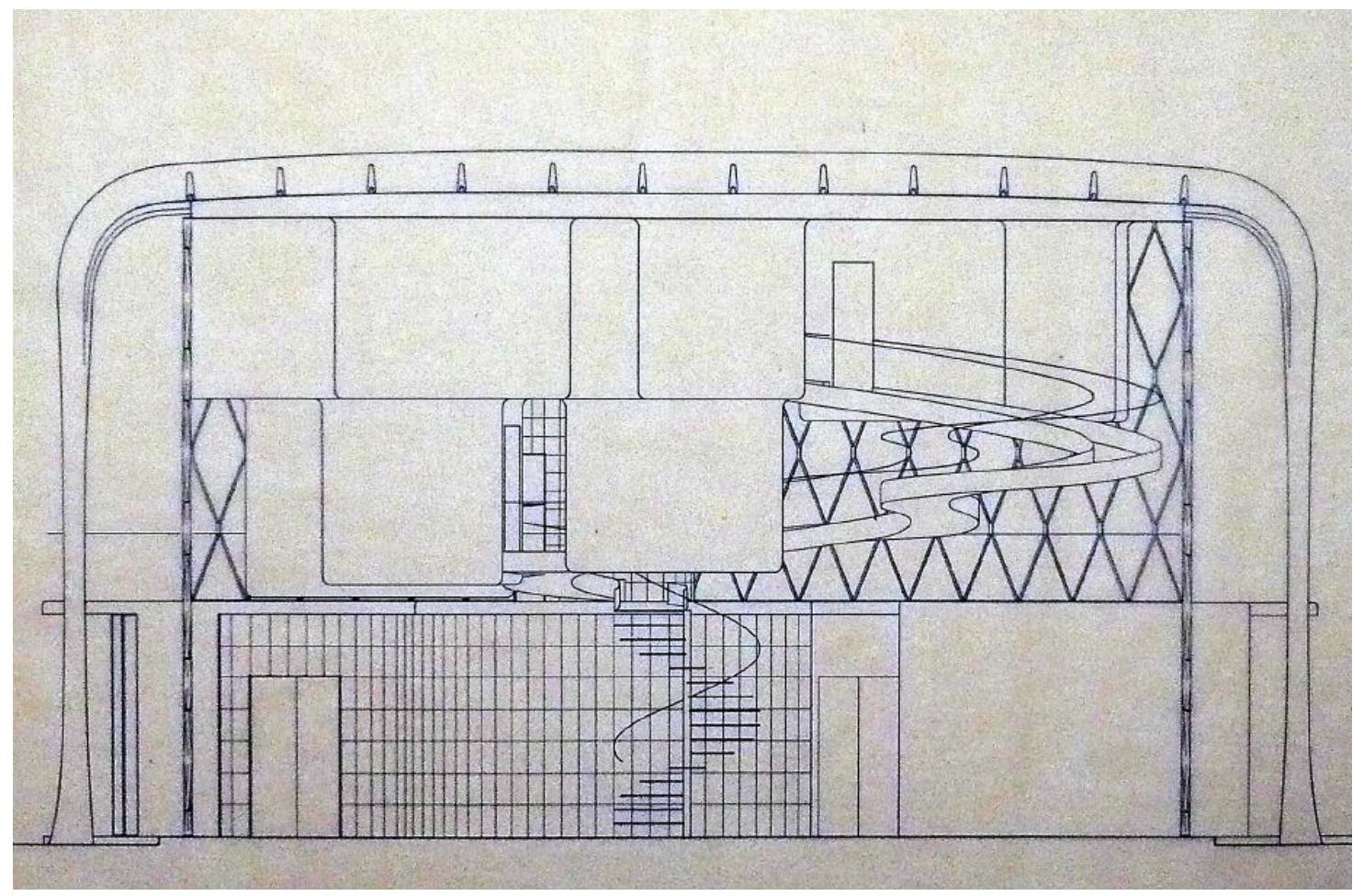

III. 6 La Maison Suspendue, sección transversal. Paul Nelson, ca. 1938 


\subsection{Proyectando desde el interior. De la sección a la volumetría.}

La arquitectura de Paul Nelson estaba marcada por un concepto de crecimiento, en espiral, que tenía su núcleo de origen en el espacio central y finalizaba en el perímetro $^{178}$. El arquitecto consideraba que el proyecto no podía comenzar con la definición del exterior a través de una volumetría perfecta, en la que después se encajaba un programa, sino con un trabajo simultáneo en planta, alzado y sección, que permitiese resolver las diferentes relaciones espaciales internas. El objetivo de Nelson era construir un espacio total que funcionase igual en todas las direcciones, y para conseguirlo utilizó como herramientas la continuidad, la flexibilidad y la fluidez del espacio vacío. Nelson comenzó a desarrollar el proyecto gráficamente y partió de tres concepciones espaciales diferentes. En la planta baja trabajó con una idea orgánica, en la planta primera con un orden libre y en la planta segunda con un esquema funcional. Todas ellas se fueron ensamblando a medida que el proyecto fue avanzando en su desarrollo hasta conseguir el espacio único.

El proyecto gráfico de La Maison Suspendue se desarrolló entre 1936 y $1938 .{ }^{179}$ Realizó seis versiones antes de lograr, en abril de 1936, una solución espacial que mantuvo inalterada hasta la versión definitiva. Inició su aproximación al proyecto a través de volumetrías genéricas, ya que resultaba complicado explicar el concepto tridimensional sin precedentes, de este espacio doméstico, utilizando un sistema de representación tradicional. Posteriormente, trabajó con las plantas y las secciones hasta que tuvo definido el espacio interior habitable. La decisión técnica de la suspensión de las habitaciones fue clave para el desarrollo gráfico, facilitó la ordenación interna y el encaje de la sección, que se convirtió en el plano que mostraba de manera más explícita el concepto espacial de la vivienda. A partir de esa fecha en la que se consolidó la imagen interna de la casa, los cambios más significativos afectaron a la morfología de la estructura y a la definición de los alzados. Ya en la etapa final, retomó la imagen tridimensional de la casa, para construir el volumen exterior.

\footnotetext{
${ }^{178}$ Paul Nelson, La Maison Suspendue. Recherche de Paul Nelson. (L'Architecture Vivante), París: Albert Morancé, 1939.

${ }^{179}$ En la documentación consultada (106 dibujos), solo había dos series de planos fechados, eran las correspondientes a abril de 1936, cuando resolvió el orden espacial, y a junio de 1938, cuando entregó los planos al maquetista.
} 
Versión 1. Tanteos iniciales y perspectivas.

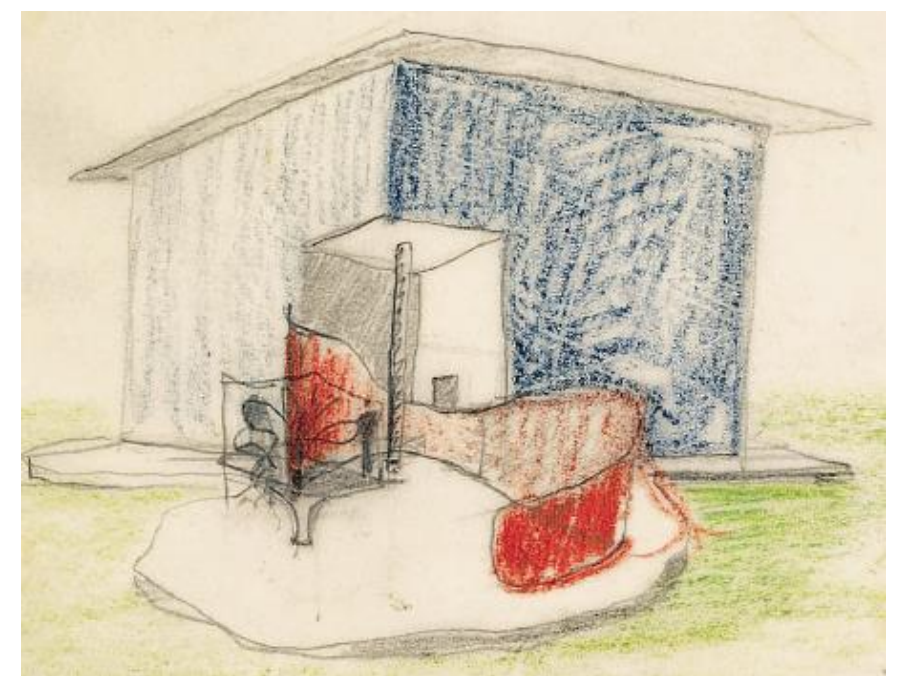

III. 7 La Maison Suspendue, volumetría, versión 1, Paul Nelson ca.1936

Los primeros croquis fueron perspectivas exteriores que representaban una casa exenta, descontextualizada ${ }^{180}$ y de tamaño medio, cuya volumetría nacía del contraste entre materia construida y masa vaciada, entre espacio encerrado y liberado. Paul Nelson trabajó para integrar estas dos cualidades contrapuestas dentro de la vivienda, sin que perdiesen sus respectivas identidades. La casa mantenía una total independencia con el espacio exterior, no había huecos, y esto provocaba que la envolvente fuese una superficie continua sin jerarquía de fachadas. La Maison Suspendue, quedaba encajonada entre dos planos horizontales, el de la cubierta y el de la base de apoyo, cuyos límites sobrepasaban el contorno de la volumetría encerrada.

En las primeras representaciones (III. 7) quedaron expresadas algunas de las ideas que se mantuvieron a lo largo del proyecto: la casa estaba compuesta de dos cuerpos diferentes, en tamaño, forma y estructura. El prisma principal era un cubo hermético, que estaba protegido bajo la cornisa de una cubierta plana. La vivienda no llegaba al suelo, sino que se apoyaba sobre un estilóbato, su entrada se creaba por un vaciado de la fachada que liberaba un pilar. Como consecuencia de la ausencia de forjados intermedios en ese hueco se facilitaba la conexión en altura, y la inclusión de esculturas en estos bocetos era un indicador de la importancia del arte en la casa.

180 Aunque la casa no estaba pensada para ser ubicada en un entorno determinado, Paul Nelson, dispuso los dos prismas, uno a continuación del otro, de manera casi simétrica, respecto del eje Este-Oeste. Y desde los primeros croquis, situó la entrada de la casa en la fachada Norte y el comedor al Sur, en el único hueco previsto en la vivienda. 
Versión 2. La distribución del programa y la estructura de hormigón.

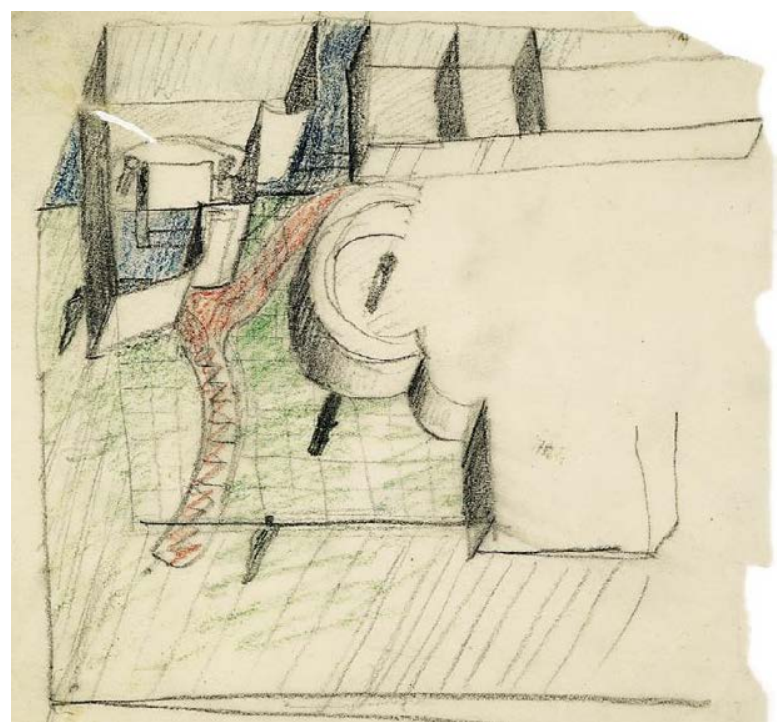

III. 8 La Maison Suspendue, axonometría interior, versión 2, Paul Nelson, ca. 1936.

En esta versión se avanzó hacia la definición de las plantas, la distribución del programa y la propuesta de una estructura de hormigón. Comenzó con una amalgama de estancias superpuestas apoyadas sobre forjados paralelos y ajustadas al perímetro, que mantenían como única separación los espacios vacíos de transición. Analizó el papel que estos ámbitos no funcionales desempeñaban en las relaciones entre las habitaciones, y comprobó que podían formar una entidad común dentro de la casa que ayudase a obtener la unidad del conjunto. Incluyó estos ámbitos sin actividad en la distribución del programa, con la intención de conectarlos para que funcionasen como aglutinante del resto de las estancias. Este nuevo componente espacial podía estar localizado en cualquier coordenada, y para poder avanzar hacia una conexión entre las diferentes ubicaciones, Paul Nelson comenzó a perforar los forjados (III. 8). Esta decisión provocaba nuevos problemas constructivos y estructurales que se manifestaban en el orden espacial de la planta baja. Reflexionó sobre la incidencia que la continuidad y la flexibilidad de los ámbitos, que no estaban destinados a una función concreta, ejercían sobre el desarrollo de la vida de la casa, y comprobó que ambas propiedades estaban muy limitadas, como fruto de la estratificación del programa y de la rigidez estructural de forjados y pilares. La solución obtenida todavía reflejaba una jerarquía espacial, donde las estancias eran las protagonistas, y los espacios intermedios los ámbitos residuales. Por lo tanto, la idea de integración en un espacio equilibrado común, no estaba todavía resuelta. 
Versión 3. Conexión del espacio vertical y agrupación funcional.

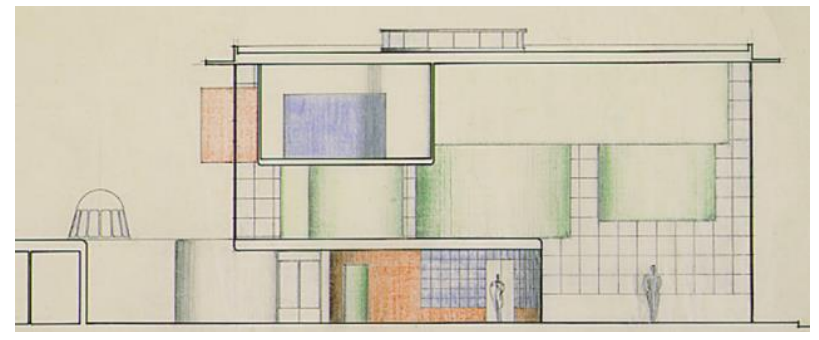

III. 9 Maison Suspendue, sección longitudinal, versión 3, Paul Nelson, ca. 1936.

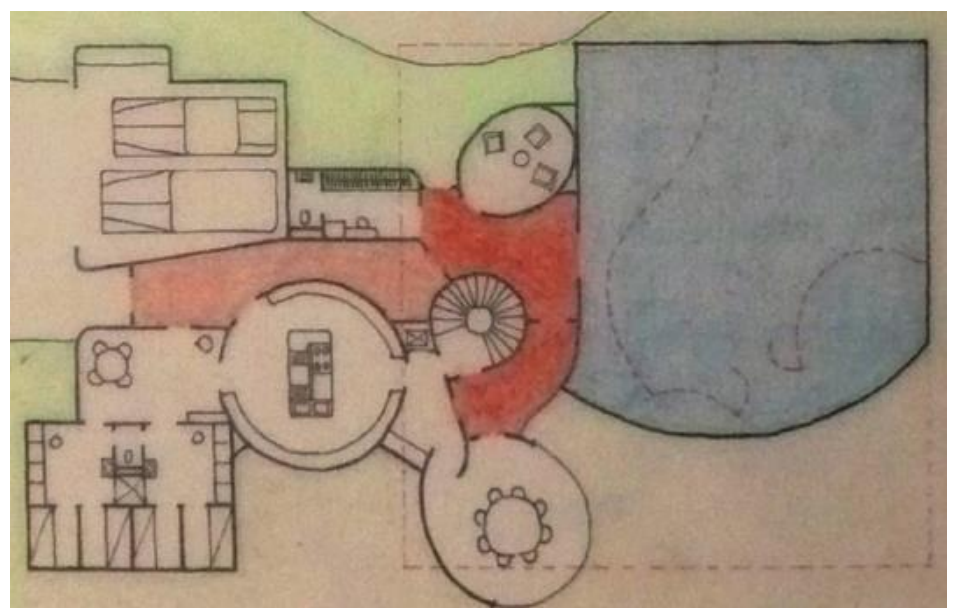

III. 10 Maison Suspendue, planta baja, versión 3, Paul Nelson, ca. 1936.

En esta fase, Nelson se centró en transformar el espacio vacío mediante la conexión vertical y la agrupación funcional de las estancias. Para aumentar la unión vertical fragmentó las plantas y la casa pasó de tres alturas fijas a cinco alturas variables y comunicadas (III. 9). Superpuso las trazas de dos plantas sobre el mismo plano (III. 10) y analizó las relaciones entre las estancias situadas en cotas diferentes. Agrupó las actividades en torno a una habitación principal, redujo su tamaño al mínimo y en paralelo liberó una mayor proporción de lugares desocupados para los ámbitos no funcionales. Esto generó un mayor contraste entre densidades espaciales, a la vez que aumentó la libertad compositiva para encajar las estancias en su posición definitiva, sin alterar su morfología. La consecuencia del uso de geometrías curvas para construir las conexiones supuso un avance hacia una mayor fluidez y articulación espacial. Paul Nelson comprobó que la sintaxis entre los bloques funcionales no estaba articulada, lo cual limitaba la continuidad del conjunto. No había logrado un orden espacial único, ya que la planta baja no tenía un contorno definido y en las plantas superiores las estancias permanecían adosadas al perímetro, sin integración. Además, los pilares habían desaparecidos en algunas plantas. 
Versión 4. Dispersión e independencia.

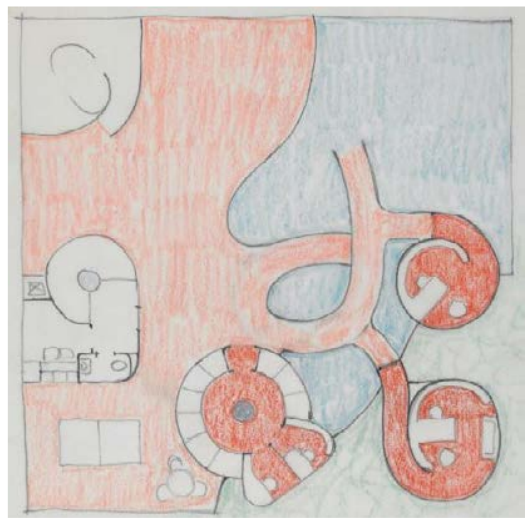

III. 11 Maison Suspendue, planta primera, versión 4. Paul Nelson, ca. 1936

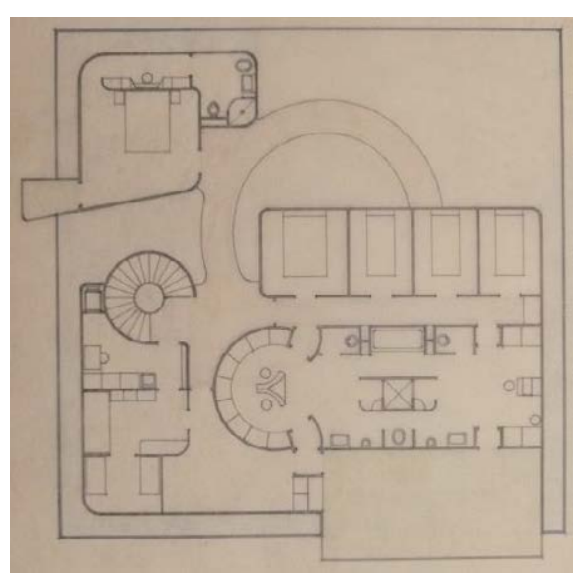

III. 12 Maison Suspendue, planta segunda, versión 4. Paul Nelson, ca. 1936

Se redujo al mínimo la superficie de los forjados, se duplicaron los recorridos, se dispersaron las estancias de manera aleatoria, se las aisló del perímetro. Este proceso contribuyó a la consolidación de unas estancias interiores totalmente autónomas (III. 11) y a la construcción de una mayor continuidad entre el conjunto de los vacíos habitables. De esta manera, el contenedor perdió protagonismo y pasó de ser el elemento que definía el orden de la vivienda a la herramienta que ayudaba a cerrarla. La casa crecía desde dentro y el espacio interior alcanzaba una intensidad que se traslada al perímetro, donde se exploró una nueva relación con el exterior mediante la apertura de huecos y la disposición de balcones (III. 12), pero finalmente esta operación fue desechada. Aunque Paul Nelson, había logrado independizar las estancias en las plantas superiores y avanzar hacia los objetivos espaciales buscados, en la planta baja, las unidades funcionales se mantenían yuxtapuestas y sin un orden de continuidad. Además seguían sin resolverse tanto la intersección entre los dos volúmenes principales como la estructura del edificio. 
Versión 5. La suspensión.

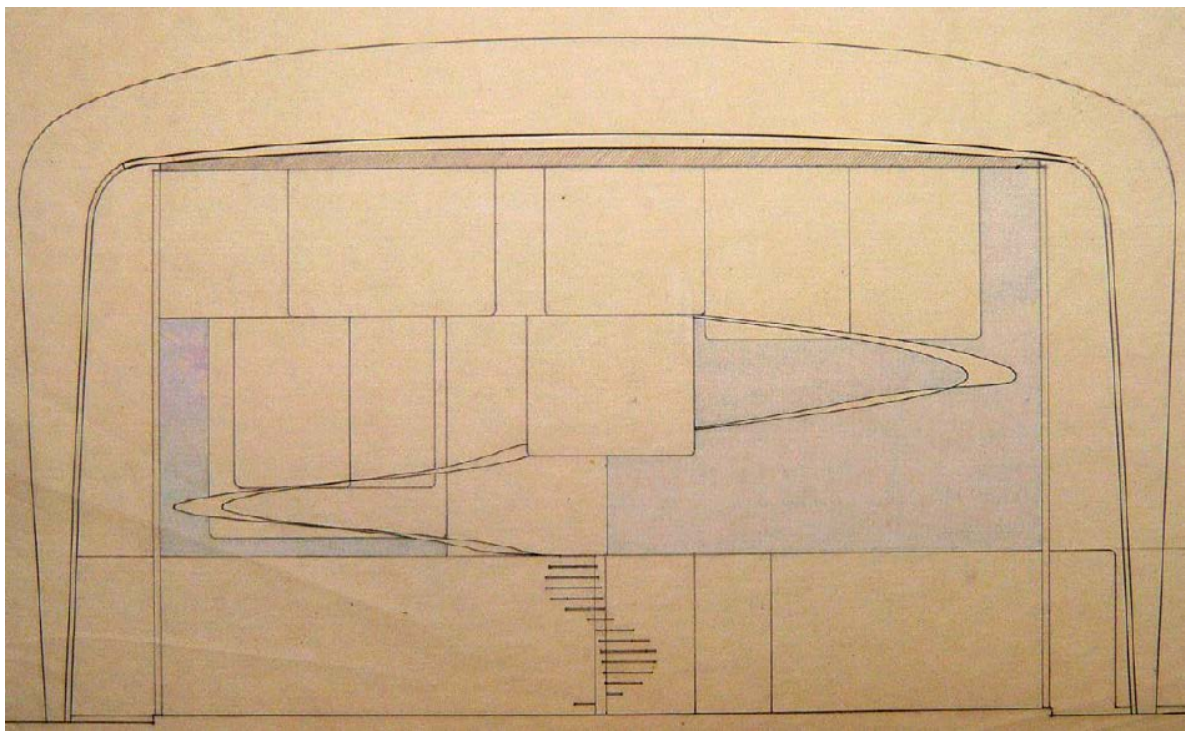

III. 13 Maison Suspendue, volumetría, versión 5, Paul Nelson, abril de 1936.

Esta fue la fase clave del proyecto, ya que en ella se logró la esencia del objetivo espacial. Paul Nelson siguió el criterio de los arquitectos modernos, de llegar a la solución, a través de la descomposición de los sistemas constructivos tradicionales ${ }^{181}$. Proyectó una estructura suspendida que le permitió disponer habitaciones aisladas y crear tensiones entre ellas. En esta versión, se dieron por vez primera varias circunstancias: utilizó una estructura metálica de pórticos exteriores que sujetaba las plantas superiores, los planos estaban dibujados a escala, contenían acotaciones y se hacía referencia a los materiales constructivos, eran los primeros planos con fecha ${ }^{182}$. El plano más representativo era la sección, en él se condensaban todos los avances y se explicaba el orden espacial (III. 13). Además, la sección no representaba una imagen permanente y acabada del interior, sino que era una ilustración temporal, consecuencia de la transformación cuantitativa y morfologíca a la que estaba sometida la pervivencia de las celdas individuales. La falta de definición era utilizada como herramienta para mostrar su concepto de la casa, como un objeto que nunca estaba terminado.

\footnotetext{
${ }^{181}$ Frank Lloyd Wright rompió “ la caja” y dispuso los planos superpuestos para conseguir la fluidez espacial y Mies van der Rohe separó el cerramiento de la estructura, utilizó la retícula para lograr la planta libre y mostró fragmentos de muro aislado, para tensionar el espacio

182 Tras la primavera de 1936, Paul Nelson se marchó a Nueva York, y permaneció allí hasta finales del invierno de 1937. Durante esos meses el desarrollo del proyecto estuvo paralizado, por lo tanto la fecha de abril de 1936, supuso tanto la culminación de un periodo como una interrupción en la evolución de La Maison Suspendue.
} 
Versión 6. La construcción y la técnica.

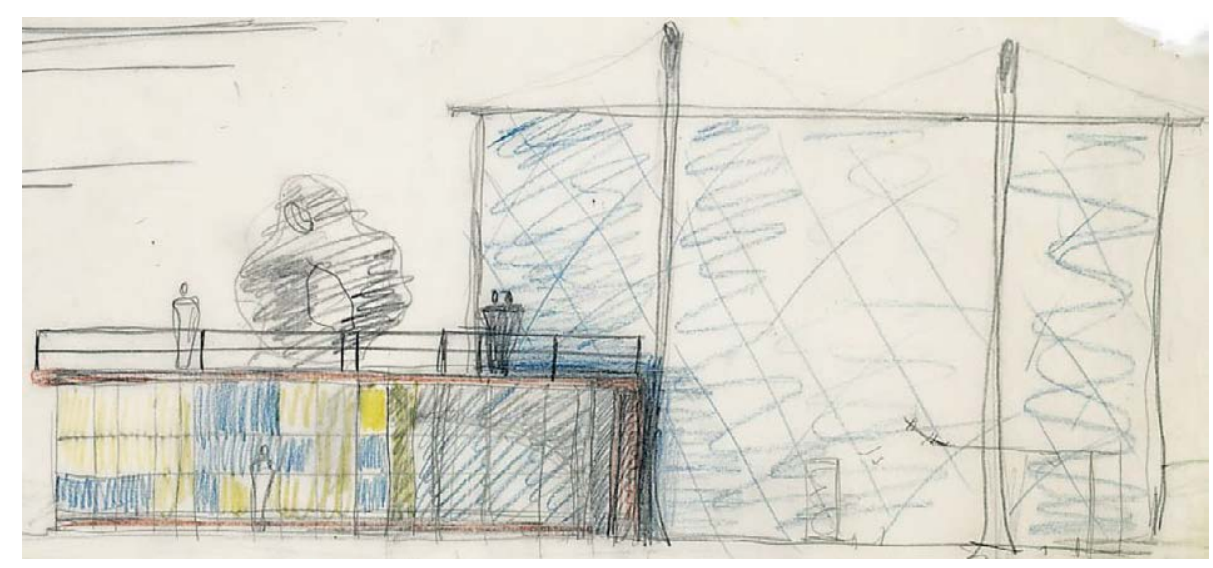

III. 14 Maison Suspendue, alzado Sur, versión 6. Paul Nelson, ca.1937

Antes de la versión definitiva, Paul Nelson ajustó los diseños de la estructura mediante unos pilares más esbeltos y una cubierta totalmente plana, redefinió la geometría de la rampa, redujo su desarrollo para permitir encastrar todas las estancias en su lado externo, y ensayó la definición de tres de los alzados ${ }^{183}$ a partir del contraste entre las dos tramas, oblicua y ortogonal (III. 14). Este era el primer croquis del alzado Sur, en el que se dibujaba la terraza sobre el área de servicio y se recuperaba una de las ideas que formuló en las primeras perspectivas, la utilización de esculturas como elementos que servían para ordenar los espacios sociales.

Las fachadas reflejaban la incorporación de la industrialización al proceso constructivo de la vivienda. Así los cerramientos se construían a partir de unos entramados metálicos en los que se insertaban paneles de vidrio o de metal. El peto de terraza estaba previsto ejecutarlo con tubos de metal ensamblados y la cubierta de chapa se sujetaba mediante un sistema de cables traccionados. La estructura porticada, formada por pilares de acero, también estaba proyectada para ser elaborada en taller y montada en obra. Los alzados ponían de manifiesto la flexibilidad de la malla ortogonal, para asumir la apertura de huecos, frente a la rigidez de la trama de rombos. Nelson intentó ubicar dos puertas de salida en la fachada Sur del volumen principal y comprobó la incompatibilidad geométrica que se producía entre la dirección oblicua del cerramiento y la dirección ortogonal de las puertas, finalmente prescindió de estos huecos.

${ }^{183}$ El único croquis existe del alzado Oeste era previo a esta versión. Y la única serie completa, que contenía el alzado occidental era la de los planos entregados al maquetista, aunque este dibujo era un esquema muy general donde no aparecía el hueco previsto para la puerta de salida a la terraza desde el balcón interior. 
La versión definitiva y la volumetría.

Como ya se ha señalado, Paul Nelson trabajó en las modificaciones de La Maison Suspendue hasta la fase final en la primavera de $1938^{184}$ (§ III. 1.). Procedió a la redefinición geométrica de cada pieza para su ajuste dentro del conjunto, incorporó una disposición del mobiliario en planta para definir las funciones y organizó una numeración de las estancias siguiendo los recorridos, que se iniciaba en los accesos exteriores y conducía hasta la planta segunda. Nelson definió el espacio interior a través de dos cortes ortogonales, la sección transversal y el plano de la planta primera. En estos dos planos, se recogían las características espaciales ya mencionadas, sobre las conexiones entre las partes y el todo, y dos conceptos que identificaban al proyecto: la ligereza estructural y la técnica constructiva prefabricada.

Durante el proceso logró resolver las relaciones internas entre las estancias y construir un cuerpo continuo y ordenado. Pero esta actuación era insuficiente para garantizar que la casa fuese considerada como una unidad espacial, necesitaba concluir con un elemento separador del exterior.

...¿¿cómo encerrar esas formas?. Yo no podía dejarlas suspendidas libremente en el aire con el viento pasando entre ellas. Tenían que estar encerradas en un recinto con capacidad para controlar completamente el ambiente... ${ }^{185}$

Después de tener realizados los planos definitivos, Paul Nelson dibujó una axonometría (III. 2). El objetivo de esta representación no era exhibir el volumen de un sólido cerrado y construido, sino mostrar el espacio interior, para lo cual retiró la cubierta, dos de sus fachadas y seccionó la volumetría. Con esta operación el cerramiento se desmaterializó, a la vez que se mantuvo íntegro el volumen de las piezas interiores. De esta manera explicaba al público lo que más le interesaba de su proyecto, los vínculos internos entre las diferentes estancias. Y de este modo, Nelson siguió la tradición de los arquitectos modernos y utilizó la ruptura de límites entre el interior y el exterior como vía para contar la solución de su vivienda.Presentó La Maison Suspendue con una imagen abierta, lo cual contrastaba con el planteamiento inicial en el que la casa era un cuerpo cerrado y aislado del exterior.

\footnotetext{
${ }^{184}$ La versión definitiva comprendía desde el plano de planta baja (III. 3) al plano de sección (III.6). Esta serie ha sido la base utilizada en esta Tesis para analizar todo el proyecto.

${ }^{185}$ Judith Applegate, "Paul Nelson: an interview”, Perspecta nº13-14, 1971, p. 105.
} 


\subsection{Las estancias dispersas dentro de una jaula.}

Paul Nelson recurrió a la obra de su amigo Alberto Giacometti “El palacio a las cuatro de la madrugada", creada entre 1932 y 1933 (III. 15), para explicar el origen del concepto espacial de Maison Suspendue. Alberto Giacometti construyó su palacio mediante un entramado de varillas, que configuraban las aristas de varios prismas, y dentro de esas volumetrías abiertas suspendió los objetos. Creó un modelo de espacio continuo, que era simultáneamente infinito y fragmentado, donde cada una de las piezas estaba atravesada y rodeada por el aire en todas las direcciones. Realizó una estructura autónoma para cada prisma, que era a la vez lo suficientemente perceptible como para dotar de unidad al conjunto, y lo suficientemente flexible y liviana, como para que en su interior, el espacio se pudiera organizar de manera libre. Las separaciones entre los diferentes cuerpos ponían de manifiesto los vínculos y las tensiones existentes entre las piezas.

\footnotetext{
...los grandes encuentros como el de Giacometti, han sido un gran revulsivo para mi. "El palacio a las cuatro de la madrugada" expuesto en la Porte de Versailles, (París) era una caja, con un interior, donde los objetos estaban libres. Entonces, por primera vez comprendí que el objeto no era lo importante, sino el espacio entorno a ese objeto, la tensión dentro de ese espacio. Esto es la arquitectura, esto es el urbanismo ${ }^{186}$.
}

La escultura de Alberto Giacometti, ayudó a Paul Nelson a percibir el espacio de manera diferente a como lo había entendido hasta ese momento y a trasladarlo a su arquitectura. Era un sistema contrario al método convencional de forjados apilados, donde las habitaciones estaban encajadas detrás del cerramiento, unas a continuación de otras y sobre cotas fijas. El modelo de dispersión espacial, propuesto por Alberto Giacometti, le sugirió proyectar otro tipo de casa, construida a partir de estancias interiores separadas mediante espacio vacío, que podían ocupar cualquier coordenada. Esto permitía construir libremente en las tres direcciones del espacio y pasar de la planta libre al espacio libre. La Maison Suspendue suponía el salto del modelo Dom-ino, configurado a partir de unos forjados planos, equidistantes, que se apoyaban en una estructura retranqueada, al modelo tridimensional, construido a partir de unas habitaciones que estaban suspendidas de una estructura externa a ellas.

\footnotetext{
${ }^{186}$ Charles Galpérine, “Un americain a Paris. Interview de Paul Nelson”, Notre Republique, viernes 3 de febrero de 1967.
} 


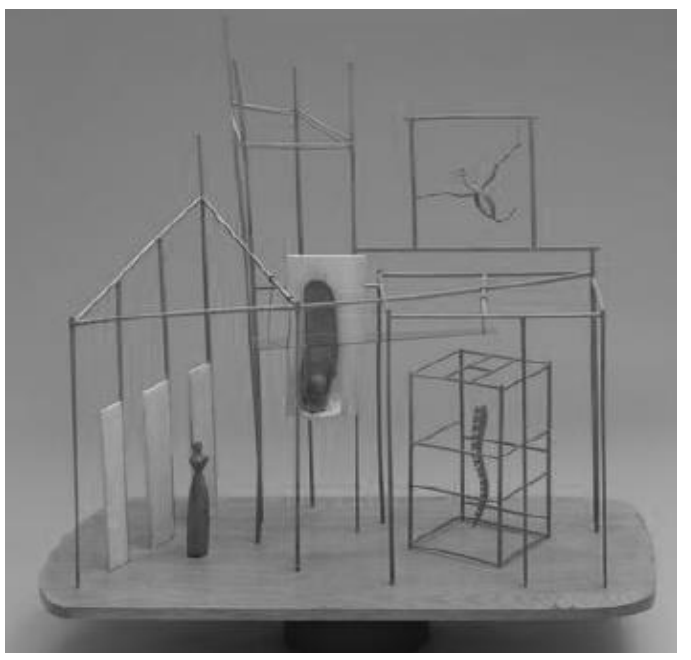

III. 15 Palacio a las cuatro de la madrugada. Alberto Giacometti, 1932-1933

Una vez decidido el modelo de espacio interior, Paul Nelson tuvo que resolver las relaciones internas entre las piezas que componían la vivienda y la vinculación que estas dependencias tenían con el cerramiento. Su objetivo era crear un espacio protegido del exterior, donde las estancias, que estaban separadas de la envolvente por un forro de espacio libre, se disponían entorno al vacío principal que ocupaba el salón ${ }^{187}$. Sus reflexiones sobre la riqueza que aportaban los contrastes morfológicos, técnicos y sociológicos a la vida de la casa, le llevaron a definir una volumetría ortogonal para el cerramiento general y una geometría curva para las estancias del interior.

Su vivienda fue el resultado de una disposición espacial centrífuga de las estancias, dentro del contenedor regular. Ubicó las dependencias funcionales en una posición periférica, liberando el núcleo central de la casa para actividades no definidas. Esta distribución exenta y aislada de las piezas facilitaba tanto el reconocimiento de los diferentes volúmenes como la morfología de sus espacios intermedios. A su vez, la ausencia de ejes y de un centro, en esta composición, dificultaba la comprensión de un orden general. El contraste volumétrico entre las estancias era muy intenso y esto propiciaba que el recorrido por esta casa fuese una concatenación de sorpresas para el habitante. A pesar de ello, el tránsito de un lugar a otro se desarrollaba siguiendo la concepción general de fluidez, lo que permitía atravesar libremente el espacio sin interrupciones.

\footnotetext{
${ }^{187}$ Esta manera de disponer las habitaciones en torno a una pieza central, a diferentes alturas, comunicadas por núcleos de comunicación vistos y todo contenido dentro de un prisma único, ya había sido ensayada por Adolf Loos en la casa Moller ( 1927-1928) y en la casa Müller (1928-1930), es lo que se denominó Raumplan
} 
Paul Nelson buscó la unidad de la vivienda, pero no lo hizo a partir de una homogeneización formal ni constructiva, sino que lo desarrolló, como ya se ha mencionado, a través de la continuidad espacial que proporcionaba la conexión de todos los espacios vacíos (§ III. 1.), aquellos elementos que no tenían peso. La casa, no tenía entidad como resultado de una acción constructiva material masiva, sino que era el fruto de una interpretación etérea del espacio. La vivienda, no se concretaba en unos términos delimitados por muros o forjados, sino que quedaba definida por el espacio encerrado y suspendido entre las estancias. Los lugares de reunión y de ocio, las superficies de conexión entre las estancias y los volúmenes de separación entre ellas, formaban un entramado continuo dentro de la casa, que soportaba todo lo construido.

Nelson trataba de crear un espacio isótropo a través de la integración de elementos diferentes y para lograrlo realizó dos operaciones. Por un lado, proyectó un vacío aglutinador de contrarios, con una capacidad lo suficientemente flexible como para insertar dependencias aisladas y percibir las tensiones externas que las mantenían unidas. Y por otro lado, aumentó las alternativas de acceso a las habitaciones, combinando los esquemas radiales con los circulares, e incluso incorporó partes de las estancias a los trayectos de conexión, lo cual suponía una fusión de geometrías.

Para mantener las tensiones entre las piezas necesitaba encerrarlas, y para poder entender el conjunto de manera global necesitaba verlo desde el exterior, por lo tanto prescindió de la fachada tradicional y consideró que cada pieza tenía su propia fachada, creó una vivienda compuesta de pequeñas casas en su interior. Esto le llevó a tomar el modelo "jaula" de Alberto Giacometti como referencia y construyó el cerramiento mediante un entramado ligero de barras, que se repetían con el mismo orden en todas las fachadas, generando una continuidad en todo el perímetro. Además, en las imágenes generales de las maquetas, que acompañaban a la explicación de la casa, el espacio interior siempre quedaba controlado a través de una celosía. El término "jaula" ha sido utilizado por varios autores para referirse a La Maison Suspendue ${ }^{188}$, pero habría que recordar que la celosía exterior estaba pensada para insertar en ella una plementería de vidrio. Por lo tanto, la imagen final sería la de un cofre de cristales, con diferentes reflejos que impedirían controlar el interior.

${ }^{188}$ José Antonio Sosa Díaz-Saavedra, "Una nube en una jaula. La Maison Suspendue de Paul Nelson". Arquitectura COAM n 328, 2002, p. 23. 


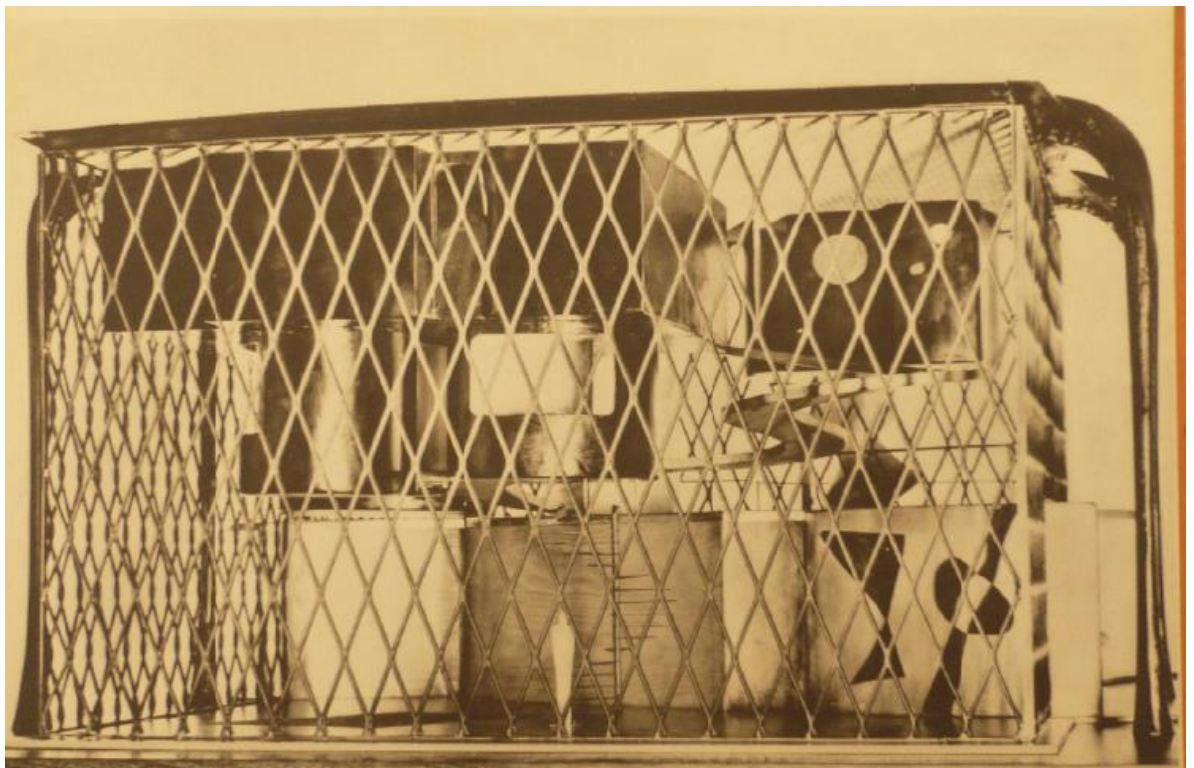

III. 16 La Maison Suspendue, fachada Este, primera maqueta. Paul Nelson, ca. 1938

\subsection{Una casa de tres alturas sin planta intermedia}

Paul Nelson evitó construir un forjado intermedio, entre la cota de acceso y la planta segunda, con el fin de no interrumpir la continuidad espacial. Rechazó la creación de un nivel fijo donde apoyar la planta primera y consideró que las habitaciones eran piezas autónomas, con su propio suelo, que no necesitaban un soporte inferior al estar sujetas de la planta superior. La parte fija del nivel intermedio quedó reducida a un balcón interior y una rampa curva, que enlazaba a diferentes alturas todas las habitaciones. (III. 16)

Con este modelo, se creó la conexión de todo el volumen interior. Las tres alturas estaban comunicadas entre sí, física y visualmente, y las habitaciones quedaban vinculadas unas a otras de manera directa. La desaparición de la planta primera dejó un hueco vacante en el que se ubicó la rampa que se convirtió en el elemento protagonista dentro del espacio más significativo de la casa: el vacío. Su trayectoria, a diferencia de lo que tradicionalmente sucedía con los núcleos de comunicación doméstica, se hacía visible desde todos los puntos y no se ajustaba a lo meramente funcional, sino que tenía vocación de incidir en la construcción del espacio libre existente a su alrededor, a través de la generación de una serie de fuerzas que introducían orden y escala dentro en ese volumen desocupado. 
La rampa tenía su origen en una escalera de caracol, de pequeño tamaño ${ }^{189}$, que desembarcaba en el centro de gravedad de la casa. En ese punto se producía la metamorfosis del recorrido, pasando de lo fragmentado a lo continuo. Este fenómeno tenía asociado el factor del tiempo y la construcción en las tres dimensiones. Por un lado, se prolongaba el trayecto de manera innecesaria, el recorrido hasta la planta segunda se hacía más lento y se convertía en un paseo interior por la casa, equivalente a la "promenade" de Le Corbusier. Y por otro lado, al desaparecer la superficie de forjado y tener la necesidad de ordenar el espacio a partir de un elemento lineal, se tuvo que construir un serpentín con el suficiente desarrollo para engarzar las habitaciones a diferentes cotas, aprovechando el margen de altura libre correspondiente a la planta segunda.

Paul Nelson realizó varias versiones del trazado de la rampa, para evitar que los tramos quedasen superpuestos. Este recorrido generaba unas tensiones tridimensionales con el resto de las habitaciones que los habitantes percibían al recorrerla. La rampa fue el elemento que sirvió a Nelson para modificar el concepto de ocupación espacial de la vivienda (III. 17). Su uso le permitió construir una alternativa a la del forjado plano y dotar de nuevo valor a los recorridos, equiparando estos lugares con las estancias destinadas a las relaciones sociales.

La supresión de la planta intermedia convirtió el espacio desocupado en el volumen de mayor capacidad dentro de la casa. El vacío de la vivienda, que comprendía dos terceras partes del contenedor principal, constituía una entidad autónoma, independiente del uso potencial que pudiese tener cualquiera de sus ámbitos. De todo este volumen, sólo era transitable la superficie del salón de la planta baja y el balcón de ocio familiar de la planta primera, lo que reflejaba el interés de Paul Nelson, en que una parte importante del espacio de la casa no fuese ocupada por ningún uso, ni siquiera por el ocio. Se fijaba un volumen de reserva para usos imprevistos. Como ya se ha señalado, la distribución del programa dentro de $L a$ Maison Suspendue, no era distinto al de una vivienda convencional, con los espacios más sociales en la planta baja y los más íntimos en la planta segunda (§ III. 1.). Lo que sí resultaba novedoso, era la manera de exponer estas actividades ante los habitantes de la casa. Paul Nelson dispuso las funciones superpuestas, sin elementos de separación entre ellas.

\footnotetext{
${ }^{189}$ La escalera estaba apoyada en un fuste cilíndrico de $0,15 \mathrm{~m}$ de diámetro, con un ancho de paso libre de $0,90 \mathrm{~m}$, el mismo que el de la escalera de servicio.
} 
III. 17 La Maison Suspendue, esquina Noreste, segunda maqueta. Paul Nelson, ca 1939

El espacio continuo generaba unas vinculaciones entre las diferentes áreas funcionales que convertían la casa en un recinto sujeto a transformaciones constantes, que eran visibles desde cualquier posición.

Su idea de inclusión espacial buscaba la convivencia de los opuestos, tanto desde un punto de vista funcional como desde un punto de vista morfológico. En este sentido, la ausencia de un plano intermedio favorecía la incorporación de las estancias individuales, destinadas al ocio personal, dentro del espacio del salón de uso social. Esta decisión situaba a las piezas en una posición central y exenta, que las hacía ser foco de atención al suscitar un contraste entre la materia construida y el ámbito desocupado. La Maison Suspendue surgía del encuentro entre los ámbitos de ocio y descanso, los movimientos y la ocupación en cada uno de estos dos espacios generaban tensiones recíprocas entre ellos, a lo que contribuía la presión que ejercía el volumen de las habitaciones sobre el vacío del salón. Estas fuerzas ensamblaban las dos partes y ayudaban a construir un espacio común.

La distancia de 6 metros, que separaba las plantas fijas permitía que el habitante disfrutase viendo las contraposiciones volumétricas de las estancias, entendiendo de esta manera la autonomía de cada una de ellas. La mirada desde el salón hacia la parte superior de la vivienda proporcionaba una imagen de volúmenes superpuestos, que dejaban a la vista los huecos verticales desocupados. Esto ayudaba a los habitantes a comprender la fluidez y la conexión de todo el espacio interior. 


\subsection{Un espacio adaptable y vivo como un organismo}

La búsqueda de la flexibilidad, como una de las propiedades fundamentales del proyecto $^{190}$, alejaba a Paul Nelson de las tesis del funcionalismo, que vinculaban cada estancia con una actividad, y lo situaba ante una nueva manera de pensar la arquitectura, que estaba basada en la transformación y en la interacción con el tiempo. El proyecto estaba pensado para adaptarse a una sociedad que evolucionaba de manera rápida y en la que un nuevo hombre necesitaba proyectos vivos $\mathrm{y}$ versátiles, capaces de asumir cambios funcionales. Este proceso de proyección, incidía tanto en la manera de componer el espacio como en la de construirlo. Por lo tanto, había que contar con una industria capaz de construir ese tipo de arquitectura.

Para Nelson el tiempo tenía una doble acepción que incidía en la concepción de su espacio doméstico. Pensaba que el tiempo era tanto un instante como un proceso evolutivo. El tiempo considerado como una suma de instantes consecutivos, contribuía a que el funcionamiento de la casa se viese afectado por la concatenación de usos espontáneos, que podían superponerse. La fragmentación del tiempo en instantes era incompatible con la ordenación espacial de la vivienda, establecida a partir de una relación constante entre la actividad, el tiempo y la habitación propia, del funcionalismo.El instante era un término impreciso, no cuantificable, que impedía ajustar el espacio de las funciones domésticas a unas franjas horarias concretas. Y el tiempo entendido como un proceso evolutivo debía aplicarse tanto a la totalidad de la propia vivienda como a sus partes. Esta acepción temporal repercutía en la vida útil de la propia casa y de sus estancias, y se prolongaba hasta su desaparición. ${ }^{191}$. “...La vida dinámica de nuestra época se puede denominar «La era móvil». Esta es la movilidad de la vida del hombre que avanza...”192.

\footnotetext{
${ }^{190}$ Paul Nelson explicaba en la descripción de su proyecto El Palais de la Découverte, el cambio que suponía considerar a la arquitectura dentro de un contexto en el cual todo estaba en movimiento, frente a una concepción rígida. El Palais de la Découverte, fue un modelo proyectado junto a Oscar Nitzschké y Frantz-Jourdain, en paralelo a La Maison Suspendue, donde ensayó la arquitectura flexible. Véase: Paul Nelson, "Projet d'un Palais de la Découverte, 1937", Cahiers d'art n³-4, 1940.

${ }^{191}$ El libro Planning for Productivity de Knud Lömberg y Carl Theodore Larson publicado en 1940, fue un referente para Paul Nelson. En este texto vio reflejada su idea de temporalidad sobre la casa. Los autores entendían la producción arquitectónica como un proceso industrial y fijaban como última categoría del proceso la demolición. Este pensamiento corroboró la idea de Paul Nelson de que la arquitectura no era eterna. Véase: Judith Applegate, "Paul Nelson: an interview", Perspecta $\mathrm{n}^{\circ} 13-14,1971$, p. 79.

${ }^{192}$ Paul Nelson, “Projet d'un Palais de la Découverte, 1937”, Cahiers d'art n³-4, 1940.
} 


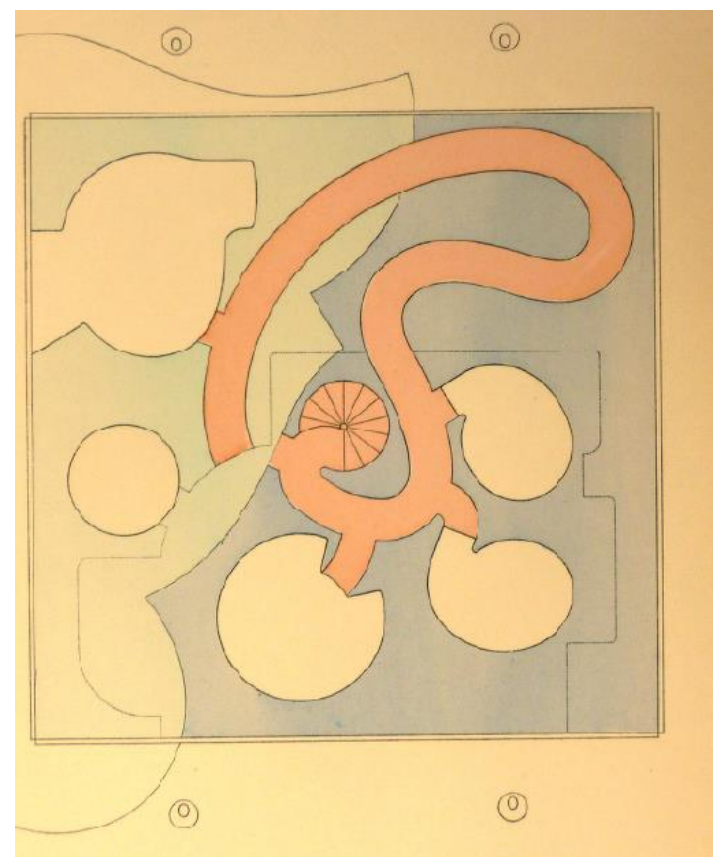

III. 18 La Maison Suspendue, plantas primera y segunda superpuestas. Paul Nelson, ca 1939.

Nelson contemplaba la posibilidad de que en una misma estancia se pudiesen producir varias actividades de manera simultánea, las funciones podían ser interrumpidas y retomadas posteriormente y su desarrollo, a excepción de las actividades puramente mecánicas, podía ocupar diferentes espacios de la vivienda. Por lo tanto, la tradicional distribución del programa en cajas estancas planteaba una rigidez que impedía asimilar esas variaciones. El nuevo espacio doméstico debía permitir la improvisación. Y, para conseguir una vivienda con esas características, proyectó un espacio interior cuya cualidad principal era la de ser adaptable a una función versátil, las unidades desmontables se representaban vacías de referentes funcionales. (III. 18) .

La consideración del tiempo como concatenación de instantes también llevó a Paul Nelson a incorporar en la vida de la casa todos y cada uno de los espacios, incluidos aquellos destinados a instantes de transición, de recorrido o aquellos lugares que no estaban concebidos para una ocupación concreta. Los desplazamientos por el interior contribuían a mantener las conexiones entre las partes vivas. La variedad de recorridos propuestos flexibilizaba los contactos, de modo que los usuarios decidían la relación que deseaban mantener con el espacio de la casa a través del movimiento interno. Los recorridos se superponían a las dependencias, contaminando su uso principal, convirtiéndolas en lugares de tránsito donde el binomio forma-función 
resultaba inservible. Lo que sucedía en estas habitaciones era un reflejo del concepto de flexibilidad y transformación espacial que se producía en los espacios de reunión con las actividades simultáneas, donde podían convivir usos colectivos con disfrutes personales.

La aplicación de la idea de una casa sometida a una metamorfosis constante tuvo como consecuencia la creación de un sistema de habitaciones desmontables, que se podían añadir o retirar en función de las necesidades de los habitantes. La vivienda debía contar con unos mecanismos que permitiesen asumir las coyunturas temporales, sin que estos cambios afectasen a la integridad del conjunto. Esta decisión, llevó a plantearse un tipo de alojamiento en el que cada elemento aportaba al conjunto un grado diferente de pervivencia en el tiempo. La vivienda era el resultado de conjugar unos elementos fijos y rígidos, con otros cambiantes y flexibles. Los primeros afectaban al orden general de la vivienda, fundamentalmente a la estructura, y los segundos al desarrollo interno, especialmente a las divisiones del espacio y a las unidades de ocio. Paul Nelson proyectó para La Maison Suspendue, una estructura hiperestática, a la manera de un gran dosel ortogonal, bajo el cual las estancias con sus diferentes morfologías podían ordenarse de diferentes maneras.

Nelson, a diferencia de los arquitectos modernos ${ }^{193}$, extendió su idea de flexibilidad a la técnica y a la construcción. Utilizó chapa, para construir tabiques curvos desmontables, proyectó una cubierta metálica, que a la vez servía de estructura y construyó un cerramiento ligero, para desmaterializar la fachada, con el objetivo de facilitar el crecimiento y la extensibilidad del proyecto. Entendió que la envolvente era un elemento flexible, capaz de aumentar o disminuir de volumen, en función de los requerimientos, sin que esto afectase al concepto global de la vivienda. $\mathrm{Y}$ en el año 1932 ensayó un modelo de fachada adaptable para el Hospital de Lille, (§ I. 3.), que revisó para resolver el cerramiento de La Maison Suspendue. La solución adoptada era una celosía ligera de acero, que se podía reducir o extender, tanto en longitud como en altura, ya que no había huecos en posiciones fijas que se viesen alterados por los cambios, ni se mantenía una traslación al exterior del volumen interior.

\footnotetext{
193 Algunos arquitectos modernos adoptaban una rigidez constructiva que les llevaba a no utilizar un mismo material para resolver diferentes funciones. Cada material tenía adjudicada una ubicación en la obra y difícilmente esta posición se veía alterada.
} 


\section{La no construcción y su difusión.}

La Maison Suspendue fue una casa pensada para no ser construida, que se desarrolló desde un punto de vista teórico atendiendo a unas características genéricas. La casa tampoco respondía a la creación de un modelo ideal, que podía estandarizarse y ser trasladado a cualquier latitud. No se conservan detalles gráficos constructivos de la vivienda y, a diferencia de lo que sucedió con la profusión de dibujos destinados a la modificación formal del espacio interior, las referencias a la técnica constructiva y a los materiales aparecían en muy pocos croquis. Paul Nelson solo realizó descripciones escritas, muy básicas, del proceso de ejecución. La decisión de no construir la vivienda centró la solución del proyecto en la definición espacial y desplazó a un segundo plano otros aspectos como el coste de la obra o el análisis del proceso evolutivo de su ejecución. Por el contrario, esta decisión ofrecía al arquitecto la posibilidad de experimentar sin restricciones con una vivienda.

Tanto la incorporación de nuevos métodos de construcción, como la de los materiales previstos y el uso que se hacía de ellos contribuyeron a generar una imagen industrial de la casa que la alejaba del modelo de hogar tradicional e incluso de su versión moderna. La estructura vista de acero inoxidable y la cubierta de acero, incluida la cornisa, el cerramiento de celosía de vidrios y acero y las estancias interiores de chapas de metal, configuraban una idea de vivienda más próxima a un edificio industrial o a un pabellón efímero desmontable que a una casa concebida como una construcción estable. Todas las decisiones técnicas estaban encaminadas a favorecer el ajuste a las futuras modificaciones del espacio doméstico. Por lo tanto, Nelson no proyectó una casa prefabricada en su conjunto, sino una suma de accesorios adaptables.

Paul Nelson tenía como objetivo transmitir las conclusiones de su trabajo, y ante la improbable construcción real de La Maison Suspendue, pensó que la realización de una maqueta era fundamental, para que el público no especializado pudiese entender su proyecto. Por otra parte, estaba interesado en difundir su trabajo entre sus colegas y mostrar la maqueta mediante imágenes, para lo que contó con el apoyo de la revista americana Architéctural Record y de la revista L'architecture Vivante. 


\subsection{La elección de unos materiales modernos.}

En la segunda mitad de los años treinta, en los Estados Unidos se produjo el auge de la prefabricación industrial aplicada a la vivienda ${ }^{194}$, lo cual influyó en el planteamiento inicial de La Maison Suspendue. Nelson que había concebido su casa a partir de una relación entre las partes y el todo, trasladó esta idea al desarrollo constructivo y planteó la solución constructiva a partir de unidades prefabricadas y ensambladas. Esta vivienda, a diferencia de las casas prefabricadas disponibles en el mercado norteamericano, no fue pensada para ser prefabricada como un solo bloque. La idea, de entender la construcción de La Maison Suspendue a partir de unidades inferiores provocó que la industrialización del proceso constructivo no se extendiese con la misma intensidad a toda la obra, ni afectase de manera homogénea a cada uno de los materiales. Al igual que ocurrió con la solución espacial, unas partes de la casa fueron desarrolladas industrialmente más que otras.

Aunque durante la definición del proyecto se trabajó con diferentes técnicas constructivas y estructurales, los materiales elegidos para la construcción de $\mathrm{La}$ Maison Suspendue eran los mismos con los que se había desarrollado la arquitectura moderna: el hormigón, el acero, el vidrio y el aluminio ${ }^{195}$. La novedad se producía en el uso que se hacía de estos materiales. Se utilizó el hormigón, mezclado con ladrillos de vidrio, como material de cerramiento y no como elemento estructural. Se ejecutó con acero inoxidable la estructura y la cubierta, en lugar de utilizar el hormigón o el acero. Se cortó el vidrio en forma de rombo, para insertarlo en la trama de acero del cerramiento, a diferencia del uso de trazas ortogonales empleadas para el muro cortina. Y se construyeron con chapa de aluminio y de acero las divisiones interiores de la casa, en lugar de utilizar fábricas ligeras.

\footnotetext{
${ }^{194}$ Hubo tres factores que resultaron decisivos para el desarrollo de la industria de la prefabricación de viviendas en Norteamérica. El primer factor era económico, tras "La Gran Depresión" era necesario proporcionar alojamientos económicos. El segundo era de carácter social, este nuevo mercado era una oportunidad de empleo para muchas personas, y el tercero era un factor técnico, dado el desarrollo que habían experimentado las industrias de la madera o la producción de hierro en láminas continuas. Véase: Burnham Kelly, The prefabrication of houses,Cambridge: M.I.T. Technology Press and John Wiley and Sons,1951, pp.28-30.

${ }^{195}$ El hormigón fue el material elegido por Le Corbusier y Auguste Perret para construir las estructuras de sus edificios, el acero permitió a los arquitectos de Nueva York levantar sus rascacielos, el vidrio fue el material utilizado para cerramiento por Mies van der Rohe y Walter Gropius, y el aluminio fue proyectado para crear mobiliario y casas prefabricadas por Marcel Breuer y R. Buckminster Fuller, respectivamente.
} 
III. 19 La Maison Suspendue, fachada Sur, segunda maqueta. Paul Nelson, ca 1939.

La casa se pensó como un sistema constructivo mixto, que combinaba los procesos industriales de estandarización con los ajustes manuales. Se proyectaron dos sistemas de ejecución diferentes, uno para cada uno de los volúmenes principales del edificio. Para el cuerpo principal, se utilizaron sistemas prefabricados de vidrio y metal, con piezas de taller estandarizadas que eran montadas en la obra en seco, y para el cuerpo secundario, se proyectó una construcción de hormigón armado ejecutado en obra. Entre ambos volúmenes, Nelson insertó, a modo de articulación, la pieza del comedor, que resolvió con un gran vidrio panorámico curvo. (III. 19).

Aunque en un principio, Paul Nelson pensó resolver el cuerpo de la servidumbre con una fachada de paneles ensamblados, finalmente desestimó esta posibilidad y proyectó un muro de hormigón ejecutado y encofrado in situ, al cual había que incorporarle manualmente ladrillos de vidrio moldeado, con lo que se lograba aligerar peso, pero esta intervención manual suponía un control en obra que aproximaba el proceso a una labor artesanal. También estaba previsto ejecutar en hormigón armado la cubierta transitable de la terraza. En el caso del cuerpo principal, Nelson decidió fragmentar las superficies de las fachadas en unidades más pequeñas, para poder transportarlas y posteriormente ajustarlas en el montaje. El cubo del volumen principal se proyectó a partir del ensamble de cuatro planos independientes, constituidos por un bastidor de acero en el que se encastraba una 
trama metálica ${ }^{196}$, con forma de rombos, preparada para recibir vidrios ${ }^{197}$. Las diagonales de la celosía tenían una sección superior a la requerida, ya que a parte de resistir el peso de los cristales, debían facilitar la inserción en los cercos, considerando que estos vidrios tenían diferentes espesores. La flexibilidad para encajar el vidrio estaba supeditada a la permisividad de una disposición oblicua respecto del plano vertical de la malla. El ajuste constructivo para este cerramiento, convertía a La Maison Suspendue en un trabajo de orfebrería a gran escala.

Las habitaciones fueron los elementos de la casa donde Paul Nelson aplicó, con mayor rotundidad, sus criterios sobre la prefabricación, ya que estas piezas podían ser encastradas o retiradas de la estructura, gracias a su sistema de anclaje. Se proyectaron unidades ligeras, fáciles de transportar y de ensamblar. En una primera versión, se pensó construirlas a partir de piezas prefabricadas de aluminio que se montaban en obra, como las carrocerías de los vehículos ${ }^{198}$. Finalmente, se decidió que todas las piezas suspendidas se construyeran con planchas de acero, unidas mediante soldadura eléctrica. Esta decisión suponía un ahorro en el montaje, ya que las láminas de acero no necesitaban de una subestructura como las de aluminio. Su espesor permitía crear unas paredes curvas que funcionaban bien a tracción, para construir la estancia como un bloque autónomo, con todo el equipamiento incluido, que podía ser conectado al conjunto. Nelson también incorporó a su vivienda el módulo de baño patentado por Richard Buckminster Fuller, en cuya concepción el había participado. (§ II. 2.)

La casa incluía avances técnicos de control ambiental que garantizaban el confort, contaba con aire acondicionado mediante ventilación forzada en todas sus dependencias. Para evitar tolvas y tuberías voluminosas, la pieza central del salón se convertía en un gran depósito, de donde las cápsulas colgadas tomaban el aire directamente, mediante unidades de reconducción. Se planteó crear un cuarto de instalaciones en planta sótano, al que se accedía desde la escalera del comedor, pero de esta planta no se conservan dibujos.

\footnotetext{
${ }^{196}$ Los bastidores de acero tenían una dimensión de 8,60m de alto por 13,80m de largo. y los rombos tenían $2 \mathrm{~m}$ de alto y $0,75 \mathrm{~m}$ de ancho.

${ }^{197}$ Los vidrios estaban compuestos por dos paños separados mediante una película aislante, los cristales podían presentar diferentes acabados y distintos grados de transparencia.

${ }^{198}$ Paul Nelson contactó con la empresa de automóviles Ford, para solicitarles un estudio de viabilidad sobre la posibilidad de que sus factorías prefabricasen diversos modelos de las unidades individuales y consiguió que la compañía se comprometiese a construir estas piezas por el mismo coste de un pequeño utilitario.
} 


\subsection{Wladimir Bodiansky. Las habitaciones suspendidas de la cubierta}

Después de separar entre sí las estancias, Paul Nelson llegó a la conclusión, de que si las situaba a diferentes cotas, sin disponerlas sobre forjados, podía construir su objetivo: un espacio continuo en las tres dimensiones. Y que si evitaba apoyar las dependencias de las plantas superiores sobre una retícula inferior de pilares, lograba una planta totalmente libre. Así, sujetó la planta segunda de una estructura monolítica superior, como hacían los árboles, eliminando de esa forma los apoyos inferiores bajo la planta. Antes de abril de 1936, realizó una versión en hormigón, en la que una azotea transitable, delimitada por un peto y prolongada por una cornisa, descansaba todo su peso sobre un cilindro central de hormigón, que contenía la caja de escaleras. En esta fase, el área de descanso estaba apoyado sobre una estructura mixta, constituida por el cerramiento exterior y el pilar central interior. Finalmente, desechó la idea del hormigón y se planteó la ejecución en acero.

Para afrontar la nueva fase de proyecto, solicitó la colaboración del ingeniero Wladimir Bodiansky ${ }^{199}$, que planteó un modelo estructural distinto para cada uno de los dos volúmenes. Bodiansky propuso ejecutar el prisma inferior de La Maison Suspendue mediante una estructura rígida, construida con muros autoportantes de hormigón armado cimentados sobre una losa. Por el contrario, para el prisma superior concibió una estructura flexible, resuelta mediante dos pórticos de acero inoxidable externos al volumen de la casa, construidos con unos pilares tubulares de sección variable, y una jácena plana, cuya cara superior era curva. Los pórticos estaban rigidizados entre sí mediante costillas transversales, estas piezas creaban una subestrutura a la cual se sujetaban las áreas de aseo y descanso a modo de bandeja invertida, de la que a su vez pendían las dos piezas individuales y la biblioteca.

Entre la primavera de 1936 y la de 1938, la estructura fue uno de los elementos de la casa que sufrió más transformaciones. Todas ellas estaban encaminadas a producir ajustes capaces de conseguir la máxima eficacia con la mínima cantidad de material. Paul Nelson buscaba una casa con una imagen de estructura ligera, que mantuviese la coherencia con la idea de prefabricar la vivienda mediante unidades de obra. Esta

199 Wladimir Bodiansky, Kharkov (Ukrania) 1894- París 1966, ingeniero de canales y puentes de Moscú también fue piloto junto a la legión francesa en la Primera Guerra Mundial, desarrolló trabajos para la industria aeronáutica y fue colaborador habitual de la firma francesa Lods-Beaudoin. En 1935 trabajó en el proyecto de la Maison du Peuple en el Marché de Clichy, colaboró con Le Corbusier en La Unité de Marsella y con Paul Nelson en varios proyectos además de la La Maison Suspendue, como el Hospital de Saint-Lo y el Hospital americano de Neuilly. 
concepción le llevó a plantearse, que tanto los pórticos como la subestructura de la cubierta debían ser prefabricados en taller y posteriormente montados en la obra. La consecuencia directa de esta decisión sobre la estructura fue la de proyectar unas secciones mínimas, para construir unas piezas ligeras que fuesen fácilmente transportables. La secciones de los pilares pasaron de ser triangulares a ser tubulares, para conseguir una mayor esbeltez (III. 20). Por su parte, la sección del alma de los pórticos se redujo dos tercios, gracias al redimensionado de las costillas rigidizadoras. Las divisiones internas de la vivienda sólo debían sujetar su propio peso, lo que permitía el uso de unos muros de mínimo espesor y de una geometría variada.

Con la ayuda del ingeniero Wladimir Bodiansky, Paul Nelson invirtió el orden tradicional de transmisión de la carga estructural y construyó en contra de la gravedad. Colgó parte de las estancias de dos pórticos hiperestáticos, que transmitían las cargas al terreno a través de cuatro puntos situados fuera del cerramiento. La estructura pasó de ser invasora a ser liberadora con respecto de la configuración espacial. Gracias a este modelo de sujeción, Nelson podía distribuir el espacio doméstico sin limitaciones y decidió vaciarlo para crear las condiciones mínimas de refugio. A través de la técnica resolvió un espacio para responder a las demandas del hombre. La solución estructural de la suspensión fue tan importante para lograr los objetivos planteados en sus hipótesis, que Paul Nelson decidió utilizar el término "suspendida" para singularizar su proyecto ${ }^{200}$.

Paul Nelson definió su proyecto de la siguiente manera: "La Maison Suspendue es una investigación arquitectónica, que aunque puede ser realizable en nuestros días, representa ante todo un trabajo de anticipación y de exploración." ${ }^{201}$ Con esta afirmación relegaba el hecho constructivo de la vivienda a un segundo plano, poniendo de manifiesto que lo verdaderamente relevante de su proyecto eran su carácter de anticipación respecto de otras propuestas futuras y el desarrollo a través de un proceso de exploración.

\footnotetext{
${ }^{200}$ El adjetivo suspendida fue aplicado por Nelson tanto en sus textos francés, La Maison Suspendue, como en inglés, The Suspended House. Nunca utilizó el adjetivo de colgada para referirse a la casa, ya que este término no tenía asociada la idea de un espacio libre inferior, como sucedía con la definición de suspendida.

201 Paul Nelson, La Maison Suspendue. Recherche de Paul Nelson. (L'Architecture Vivante), París: Albert Morancé, 1939.
} 

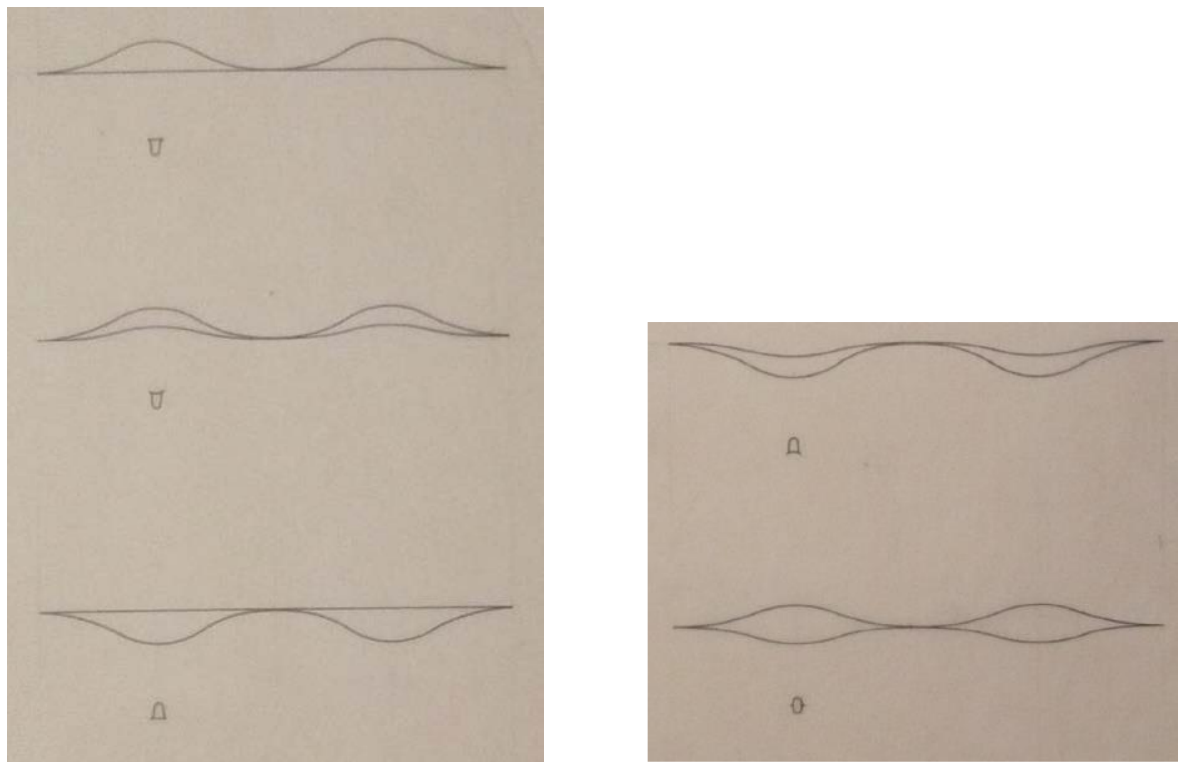

III. 20 La Maison Suspendue, secuencia evolutiva de diagramas estructurales en función de las secciones de los pilares ca 1938

Aunque la solución constructiva real fuese diferente, los objetivos principales ya estaban enunciados y el método también. Ninguna de las críticas que se realizaron sobre La Maison Suspendue, cuando Paul Nelson presentó su proyecto, puso en cuestión su posible ejecución real ni el funcionamiento de su estructura.

Con esta nueva disposición estructural logró tres objetivos. En primero lugar, consiguió plantear una distribución espacial sin restricciones, el programa no quedaba encorsetado por el orden de la retícula estructural, sino que podía extenderse y variar. En segundo lugar, contribuyó a que a la vivienda se le pudiesen añadir o retirar nuevas estancias suspendidas, sin que el orden general de los pórticos se viese afectado. Y en tercer lugar, facilitó la creación de aislamiento, tanto por la posibilidad de ubicar las estancias exentas en el lugar deseado como por la ausencia de un vínculo físico inferior con el terreno. Nelson proyectó la construcción de un espacio total donde el hombre pudiera experimentar la sensación de aislamiento en todas las direcciones. El individuo habitaba un lugar ingrávido, cuya ausencia de apoyo aumentaba el sentimiento de lejanía de la realidad, tanto física y como conceptual. 


\subsection{La maqueta de Louis Dalbet. Un ensayo constructivo desaparecido}

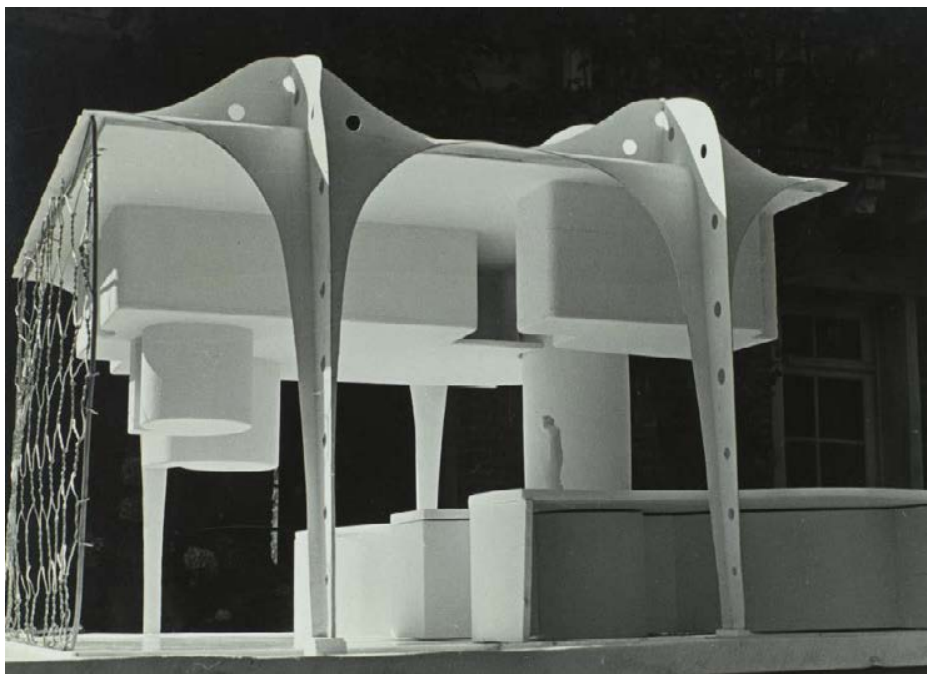

III. 21 La Maison Suspendue, maqueta de trabajo. Paul Nelson, $c a .1936$

En abril de 1936, se realizó una maqueta de trabajo, solo con los volúmenes principales, sin detalles, para ensayar la solución en tres dimensiones del proyecto (III. 21). ${ }^{202}$ En la maqueta se generaba un contraste entre los componentes previstos en la casa, mientras algunos elementos se manifestaban de manera rotunda, como la estructura, mientras otros elementos estaban ausentes, como la rampa. La construcción de la maqueta supuso dos novedades con respecto del proceso gráfico, la primera, fue la aportación del referente visual de la escala humana, y la segunda, la percepción de manera íntegra del espacio continuo.

Tras este modelo inicial, Paul Nelson encargó una primera maqueta al herrero Louis Dalbet $^{203}$, que la ejecutó siguiendo los planos dibujados por Thibaud Freesz ${ }^{204}$. Para colaborar en este primer modelo, Nelson solicitó la participación de sus amigos los artistas Fernand Léger, Joan Miró y Jean Harp.

\footnotetext{
${ }^{202}$ Solamente se conservan fotos de esta maqueta. De todos los materiales empleados en su ejecución, la celosía metálica era la única que hacía referencia a su acabado a escala real.

${ }^{203}$ Louis Dalbet, ,(1879-1950) herrero, artesano y maquetista, que trabajó junto a Pierre Chareau en la construcción de la Maison de Verre de 1928-1932. Había realizado para Paul Nelson la maqueta del hospital de Ismaïlia, en 1934, y el mobiliario para el doctor Kalmanovitch, en 1937. Recibió el encargo de La Maison Suspendue el día 15 de junio de 1938

204 Thibaud/ Tibor Freesz, (Budapest 1905-Seattle 1982), arquitecto húngaro colaborador de Paul Nelson en los años treinta. Finalizó los planos de la maqueta, a escala real, el 8 de junio de 1938.
} 


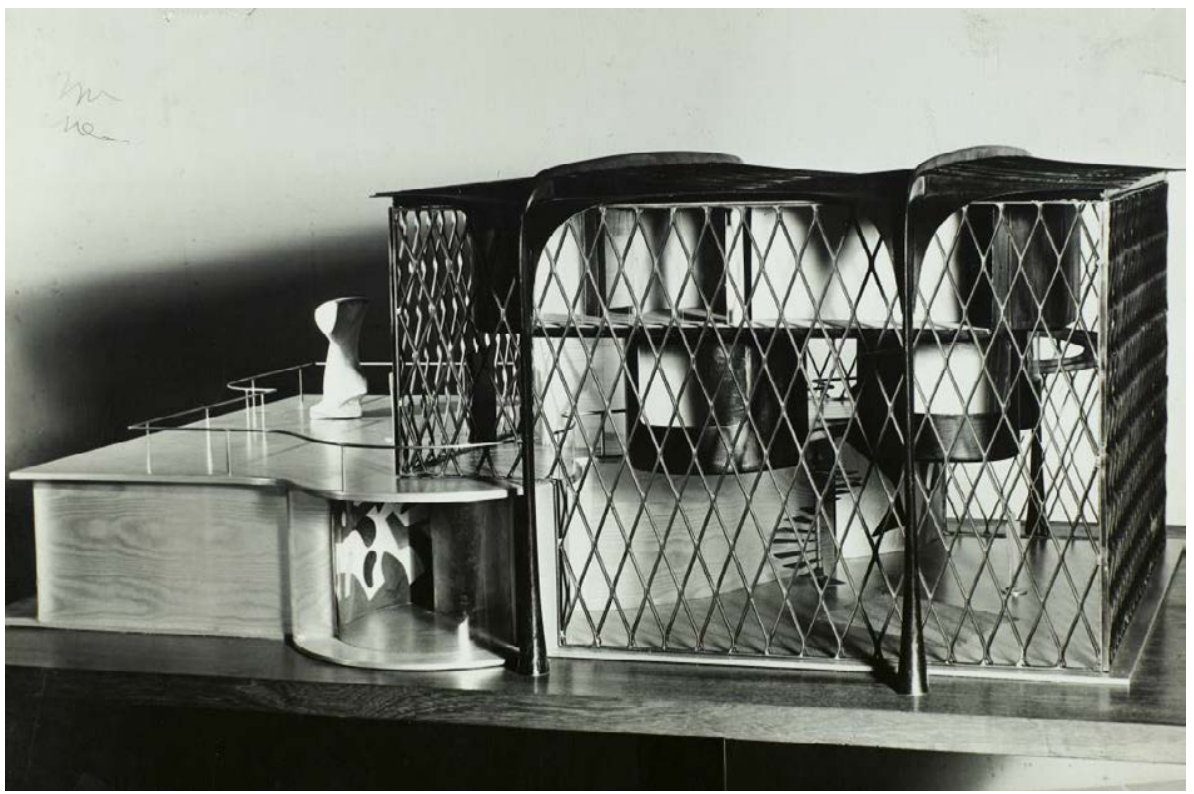

III. 22 La Maison Suspendue, Paul Nelson. Primera maqueta ejecutada por Louis Dalbet, 1938

La maqueta se construyó a principios del verano de 1938, a escala 1:30, y una vez terminada fue enviada a Varengeville ${ }^{205}$. Esta primera maqueta (III. 22) se construyó de manera detallada, con el objetivo de ofrecer una información completa a un público no profesional. A diferencia de la maqueta de cartón, con este nuevo trabajo se buscaba conseguir un grado de realidad constructiva que hiciese verosímil el proyecto ante los espectadores. Se trataba de aproximar la investigación abstracta a una realidad figurativa, que anticipase una hipotética ejecución a escala real del proyecto. Para Nelson era preciso explicar cada detalle que pudiese interesar al público:

... También, le voy a recordar el tema de las ventanas de las piezas suspendidas. Yo creo, como le había dicho al principio, que sería necesario dejar prevista la posibilidad de introducir en sus aberturas materia transparente, como la mica por ejemplo, para explicar bien que se trata de ventanas cerradas... ${ }^{206}$

La maqueta, que tenía una función didáctica, también se convirtió en un laboratorio donde se podían ensayar los sistemas constructivos, las propiedades de los materiales, los efectos lumínicos, los contrastes volumétricos y la incidencia del arte.

\footnotetext{
205 Tarjeta Postal de Francine Lecoeur el 31 de agosto a Dalbet, que anunciaba la llegada de la maqueta a Varengeville, lugar de descanso familiar, donde la podían ver sus amigos Miró y Braque: Fonds Louis Dalbet Centre Pompidou

206 Carta, de 16 agosto 1938, que dirige Paul Nelson al maquetista Louis Dalbet con especificaciones sobre los materiales y las fechas de entrega de la primera maqueta, MNAM/CCI, Bibliothèque Kandinsky, fonds Dalbet.
} 
Tanto en las intervenciones de los artistas como en la construcción de la maqueta se pretendía transmitir una imagen cercana a la realidad y para lograrlo se decidió que algunos de los materiales de la maqueta fuesen autorrefenciales de los utilizados en una construcción real y así poder comprobar su efecto. La elección de ciertos materiales para la maqueta estuvo más condicionada por la fidelidad a las propiedades físicas de estos que por un rigor geométrico y formal ajustado a lo definido en el proyecto ${ }^{207}$.

En otoño de 1938, la maqueta fue mostrada por vez primera en la galería Pierre Loeb de París ${ }^{208}$. Sus amigos artistas discutieron sobre La Maison Suspendue y formularon críticas contrapuestas. Kandinsky la consideró como la síntesis de lo que los artistas modernos estaban buscando y, para Picasso, la obra solo era "una jaula para ratones"209. Tras la exposición en París, Nelson facturó la maqueta a través del consulado ${ }^{210}$, para exhibirla en la galería Pierre Matisse ${ }^{211}$ de Nueva York. Durante el trayecto sufrió daños importantes, según Fancine Le Coeur:

... a nuestra llegada... Toda a trozos... debió de sufrir golpes muy fuertes en el costado, lo que hizo que los soportes de la planta baja que no estaban reforzados no resistieran, toda la mica se hundió, lo que tiró del gran muro exterior, es decir de la jaula, que se abrió, el techo se cayó con la rampa y las piezas suspendidas.

${ }^{207}$ Para la trama del cerramiento se escogió una pieza de metal existente en el mercado, de la empresa Le Métal Déployé , con una proporción de rombos mas tupida que la diseñada para el proyecto, lo que obligó a componer fachadas específicas para la maqueta, MNAM/CCI, Bibliothèque Kandinsky, fonds Dalbet.

${ }^{208}$ A principios de octubre 1938, la maqueta se expuso durante una semana en París en la galería de Pierre Loeb, amigo de Nelson, que estuvo muy vinculado al cubismo. En los textos que hacen referencia a la primera exhibición de La Maison Suspendue se estableció, erróneamente, la fecha del otoño de 1937, momento en la que esta maqueta no estaba construida. Veasé “Judith Applegate, Paul Nelson: an interview”, Perspecta n ${ }^{\circ} 13-14,1971$. p. 105 .

${ }^{209}$ Oscar Nitzchke, socio de Nelson hasta 1937, desveló en una entrevista la opinión que tenía Picasso sobre La Maison Suspendue. MNAM/CCI, Bibliothèque Kandinsky, fonds Paul Nelson.

${ }^{210}$ En el formulario se declaraba "artista americano", que residía temporalmente en Francia. En la documentación se describía el material embalado, compuesto por dos cajas, una para la base de apoyo y otra con la propia maqueta, que incluía un duplicado de las piezas ejecutadas en plástico, para ser sustituidas en caso de desperfectos, y un juego de seis planos enmarcados. Archives Pierre Matisse Gallery, The Morgan Library of New York.

${ }^{211}$ La galería de Pierre Matisse se había convertido en la gran difusora en Nueva York de los artistas de las vanguardias europeas. Recomendaron que el envío de la maqueta se efectuase por valija diplomática para hacerla llegar directamente a la galería y evitar posibles daños. La maqueta se expuso junto a la obra de Fernand Léger entre el 25 de octubre y el 12 de noviembre. Archives Pierre Matisse Gallery, The Morgan Library of New York. 


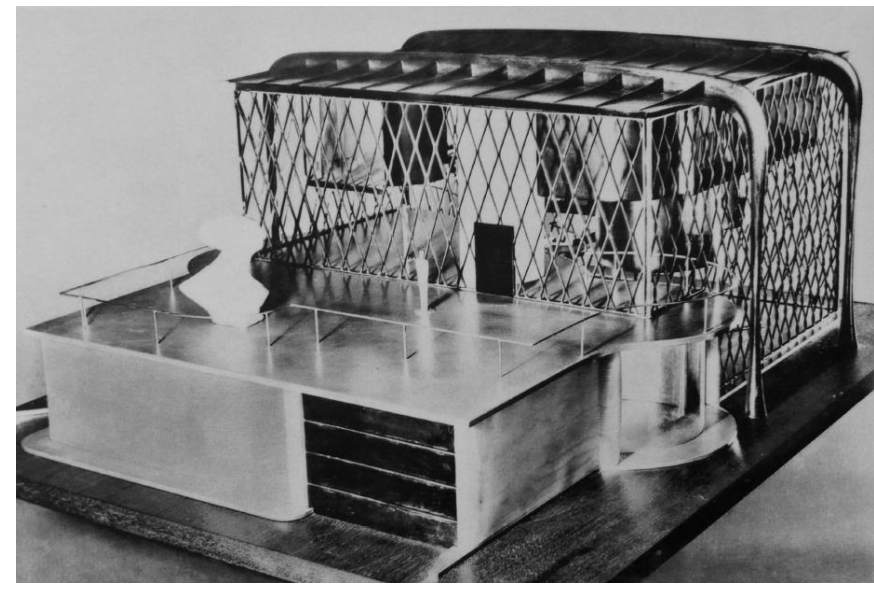

III. 23 La Maison Suspendue, Paul Nelson. Primera maqueta restaurada, 1938

Horrible... Paul la llevó a un maquetista que soldó el techo al tejado, para que no bajara y soldó la rampa a cada una de las piezas suspendidas. Luego sustituyó la mica por una pieza de madera, recubriéndolo por fuera con un hule plateado... ${ }^{212}$

Estos acontecimientos pusieron de manifiesto la fragilidad de su resistencia constructiva, la idoneidad de los materiales elegidos y lo que para Nelson era más importante : el modelo de arquitectura ligera. Así lo expresaba Francine Le Coeur: “... Evidentemente, en conjunto, para nosotros, ha perdido parte de la virtud de ligereza que tenía ..."213. Estos desperfectos fueron el referente para afrontar una restauración en la que primó el criterio de rigidez para las piezas. El viaje también sirvió de ensayo para descubrir cómo la idea de concebir una casa a partir unidades prefabricadas debía de estar respaldada por una seguridad de los ensambles, ya que en las uniones de las esquinas la maqueta no había podido mantener su resistencia. En la imagen (III. 23) se muestra el estado de la fachada Oeste tras la restauración de la primera maqueta. Con el fin de dar mayor rigidez al conjunto, se eliminó la entrada de la servidumbre de este muro y solo se mantuvo la del garaje. La noticia más relevante para Paul Nelson fue el interés que suscitó la exhibición entre los responsables de la Exposición Universal de Nueva York de 1939, quienes pensaron que sería oportuno difundir el proyecto mediante una construcción a escala real, pero finalmente la casa no llegó a realizarse ${ }^{214}$.

212 Carta, de 11 de noviembre de 1938, Francine Nelson a Louis Dalbet, MNAM/CCI, Bibliothèque Kandinsky, fonds Louis Dalbet.

${ }^{213}$ Ibídem.

${ }^{214}$ La respuesta que recibió Paul Nelson del director de la Exposición Universal de Nueva York fue la falta de tiempo. Veasé Judith Applegate, Paul Nelson: an interview.Perspecta no13-14, 1971, p. 105. 


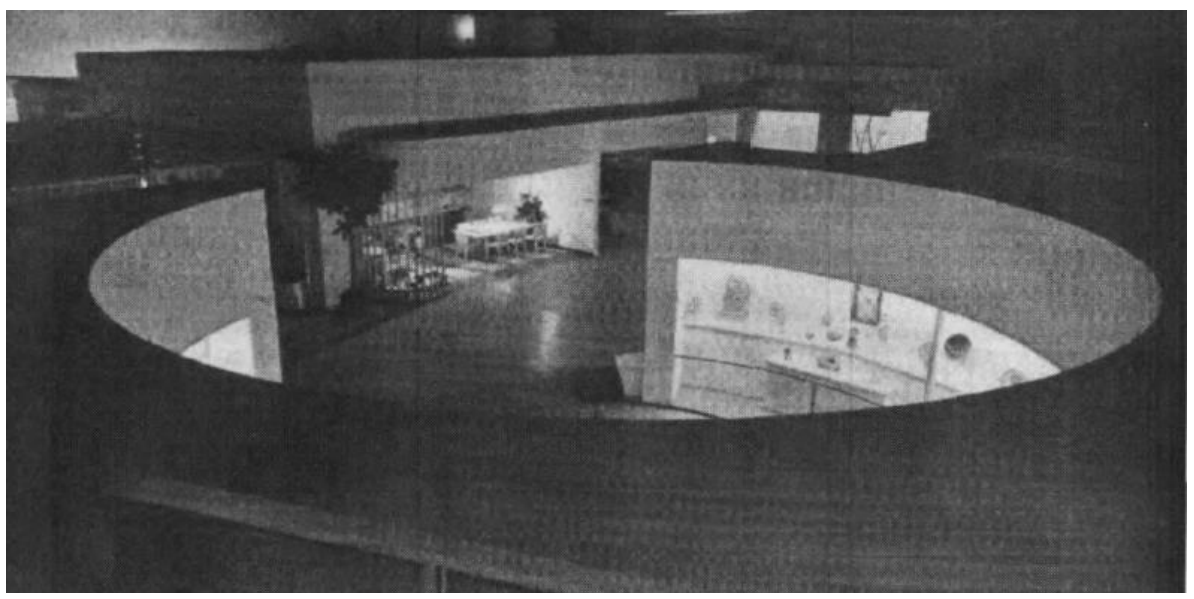

III. 24 Sala de artes decorativas del Palacio de las Bellas Artes en la Golden Gate Internacional Exhibition de San Francisco, 1939.

Antes de llegar a su destino definitivo en San Francisco, la primera maqueta se exhibió en la nueva Escuela de Arquitectura del M.I.T ${ }^{215}$ y posteriormente fue expuesta en la galería Katharine Kuh de Chicago ${ }^{216}$. Finalmente, la maqueta se mostró en la Golden Gate Internacional Exhibition ${ }^{217}$, en el Palacio de las Bellas Artes, dentro de la sección de artes decorativas, junto a sillas proyectadas por J.J.P Oud y piezas de vidrio diseñadas por Alvar Aalto. La presentación de La Maison Suspendue en esta sala de elementos decorativos (III. 24) puso en relieve dos aspectos de la obra que preocupaban a Paul Nelson: la relación de la casa con el arte y su construcción prefabricada. Por un lado, la maqueta siempre se había difundido en galerías de arte, como una pieza artística que a su vez contenía obras de arte en miniatura, y por otro lado, estaba el interés de Nelson por incorporar los procesos de producción industrial a determinadas unidades de la vivienda. La exposición lograba la unión de estos dos propósitos al equiparar su trabajo arquitectónico con los objetos fabricados en serie por Alvar Aalto o Sonia Delaunay.

\footnotetext{
${ }^{215}$ La primera maqueta se expuso en la sala William Emerson del M.I.T entre los días 29 y 30 de noviembre de 1938, se contó con el apoyo de la Albert Farell Foundation. Paul Nelson impartió una conferencia el día 29 de noviembre.

${ }^{216}$ La galería Katharine Kuh de Chicago estaba especializada en arte moderno y experimental, expuso la obra de Josef Albers, Wassily Kandinsky, Fernand Léger y en ella se exhibió la primera maqueta de La Maison Suspendue entre el 7 y el 17 de diciembre de 1938. Con motivo de esta exposición, se realizaron unos debates en los que participaron los artistas Julio de Diego, Robert Wolf, Rudolph Weisenborn y Carlos Mérida. Y entre los arquitectos estuvo presente George Fred Keck.

${ }^{217}$ La maqueta fue expuesta entre el 18 de febrero y 2 de diciembre de 1939. La comisaria de la muestra fue la decoradora y artista Dorothy Liebes. La Maison Suspendue se exhibió en el salón central del Palacio de las Bellas Artes, junto a otras veinte piezas de artes decorativas procedentes de Europa.
} 


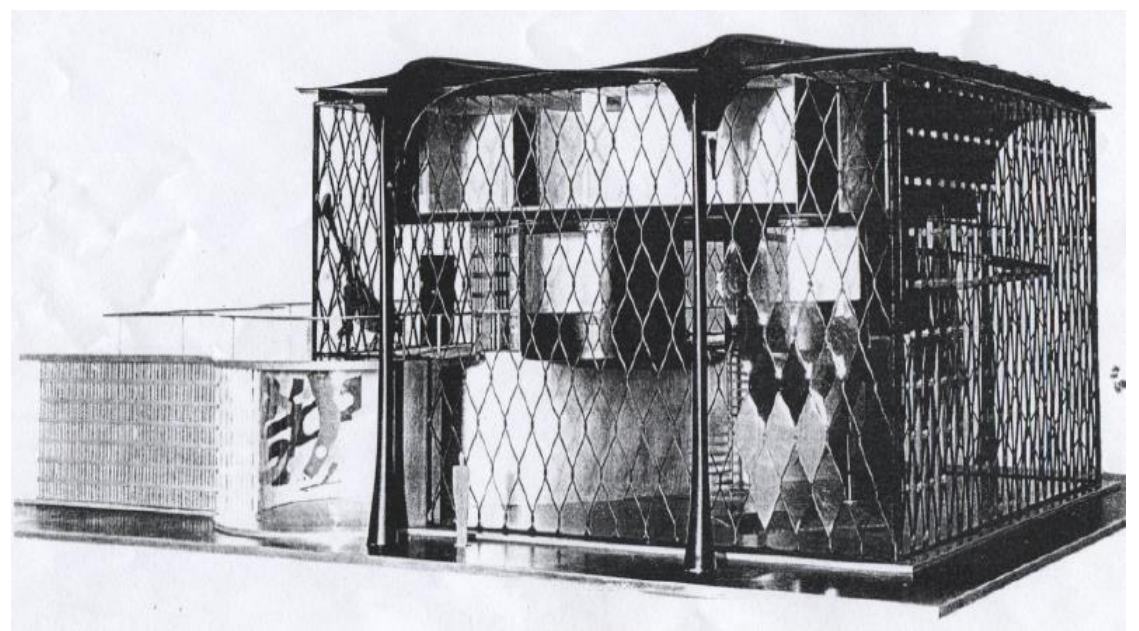

III. 25 La Maison Suspendue, Paul Nelson. Segunda maqueta, ejecutada por Louis Dalbet, 1939

La presentación de la primera maqueta en la galería Pierre Matisse propició que el MoMA solicitase una copia, para exhibirla en la inauguración de su nueva sede, en la primavera de 1939. De esta manera, Louis Dalbet recibió el encargo de la segunda maqueta (III. 25). Para construir el nuevo modelo, se tuvieron en cuenta tres factores, el primero, fue la sugerencia de resistencia constructiva aportada por Paul Nelson, el segundo, la previsión de la incursión de las nuevas obras de arte, y el tercero, el tratamiento del cerramiento de cristal $^{218}$. Para esta segunda maqueta, Nelson volvió a contar con la colaboración de Fernand Léger y de Joan Miró, pero para crear las esculturas solicitó el apoyo de Alexander Calder. El trabajo se terminó a principios de 1939 y se mostró en París en la galería D`Anjou, con el apoyo de L'Union des Architectes. En el acto de presentación, hubo unas palabras de introducción de Joán Miró y posteriormente Paul Nelson pronunció una conferencia titulada "La búsqueda de la casa prefabricada" ${ }^{219}$.

Durante la exposición de la primera maqueta, Paul Nelson comprobó la confusión que generaba el entramado metálico del cerramiento en los visitantes, al no mostrarse completo con todos los cristales. Para solventarlo, propuso a Louis Dalbet que contactara con Joan Miró, con el fin de decidir qué elementos, de vidrio o

\footnotetext{
${ }^{218}$ Carta de 23 de diciembre de 1938, Paul Nelson a Louis Dalbet, MNAM/CCI, Bibliothèque Kandinsky, fonds Louis Dalbet.

219 Tras haber recibido algunas críticas sobre los valores constructivos de la casa, en su itinerario expositivo por los Estados Unidos, Paul Nelson regresó a Francia y el día 27 de febrero de 1939 presentó su segunda maqueta en París. Durante ese acto, pronunció una conferencia en la que se centró en describir los procesos constructivos de prefabricación incorporados en su proyecto. Después de la presentación, la maqueta se envió al MoMA.
} 
plástico coloreado, debían ser insertados en el carramiento. Se trataba de hacer de $L a$ Maison Suspendue un espacio más cercano al hombre, en el cual hubiese desaparecido la idea de vivir dentro de una jaula que provocaba la visión de la primera maqueta y donde el espectador pudiese disfrutar de la sensación de libertad experimentada por los habitantes de la casa, al poder particularizar el cerramiento mediante el cambio de algunos materiales. Otro de los elementos que había perturbado al público era la utilización de un mismo material para representar tanto la base de la primera maqueta como el muro de cerramiento de la caja de servicio. Para resolver este problema, se utilizó una trama perforada, simulando vidrios, tanto en el cerramiento como en la caja de escaleras y se fijó una lámina de metal para delimitar el perímetro del terreno. Con esta intervención también se buscaba la transformación del espacio de trabajo en un lugar mas transparente, que mantenía una relación lumínica con el medio.

La segunda maqueta se expuso en el apartado de "Houses and Housing" ${ }^{220}$ de la muestra "Art in our time", que sirvió para inaugurar la nueva sede del MoMA de Nueva York. El boletín de prensa del MoMA denominó la casa "Space House" y resaltó dos aspectos del trabajo. Por un lado, el interés de Paul Nelson por integrar el arte moderno dentro de la vivienda y, por otro lado, la capacidad de influencia de la casa en otras obras, ya que según el museo, aunque en su origen fue pensada para no ser construida, era un referente en la concepción de la vivienda moderna.

El destino de estas dos maquetas, construidas con seis meses de separación, fue muy diferente. La primera maqueta, tras su exposición en San Francisco, sufrió una serie de acontecimientos desafortunados que culminaron con su desaparición. La falta de conexión entre los agentes implicados en su devolución y el contexto previo al comienzo de la Segunda Guerra Mundial, provocaron que esta maqueta nunca retornase a París ${ }^{221}$. La segunda maqueta, fue exhibida en otras ocasiones ${ }^{222}$ y en 1974 fue adquirida por Mrs Rockefeller y posteriormente fue donada al MoMA.

\footnotetext{
${ }^{220}$ La exposición Art in our time tuvo lugar entre el 10 de mayo y el 30 de septiembre de 1939. La Maison Suspendue se expuso junto a la Robie House de Frank Lloyd Wright, la Tugendhat House de Ludwig Mies van der Rohe, la Villa Saboye de Le Corbusier y la Dymaxion House de Richard Buckminster Fuller. Posteriormente la muestra continuó con un itinerario expositivo por otras ciudades de los Estados Unidos.

${ }^{221}$ El 22 de diciembre de 1939, Dorothy Liebes comunicó a la galería Pierre Matisse de Nueva York, que ante la imposibilidad de obtener un seguro por causa de la guerra y la falta de espacio se veían obligados a devolverles la maqueta. El envió se produjo el día 30 de diciembre y se recibió en Nueva York el día 8 de enero de 1940. La compañía Budworth \& Son, encargada de la custodia, comunicó el día 22 de enero a la galería Pierre que la maqueta podía ser recogida. Paul Nelson, pidió explicaciones a Dorothy Liebes el día 21 de febrero, y
} 


\subsection{La difusión y la no ejecución}
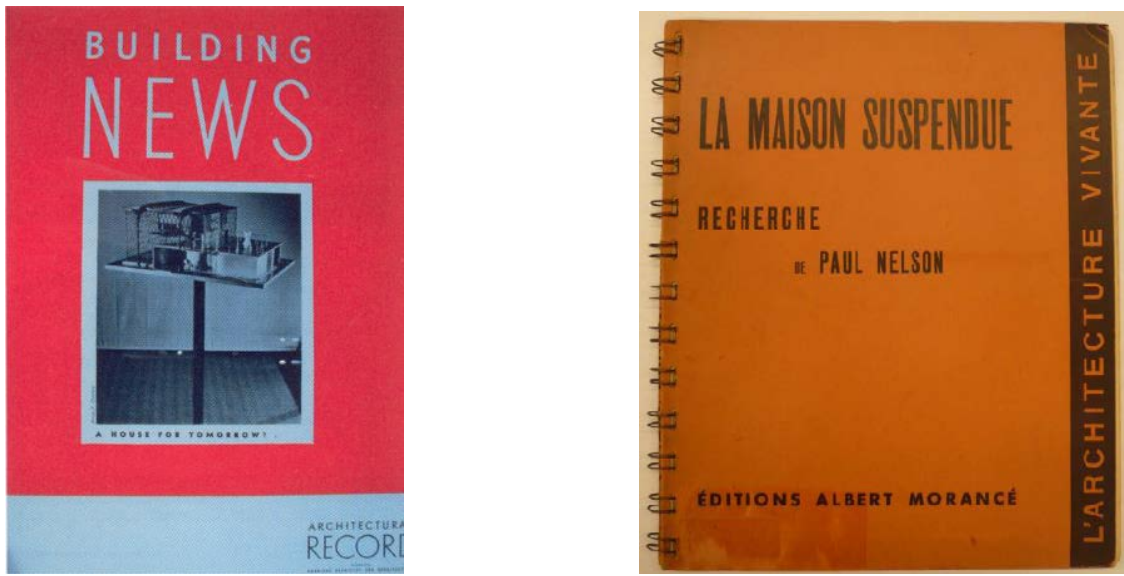

III. 26 Architectural Record, Volumen 84 nº, diciembre 1938.

III. 27 L'architectureVivante, monográfico La Maison Suspendue. Recherche de Paul Nelson, ca 1939.

La difusión de La Maison Suspendue se produjo tanto en las revistas especializadas, como a través de los artículos surgidos en la prensa, a raíz de la exhibición de las maquetas. El primer artículo publicado sobre la vivienda en un medio profesional, apareció en los Estados Unidos en diciembre de 1938, en la revista Architectural Record $^{223}$ (III. 26). Este texto fue escrito por los arquitectos Mr Lömberg-Holm y Mr Theadore Larson ${ }^{224}$, quienes recogían los argumentos de Paul Nelson y los exponían de una manera descriptiva. La parte crítica del texto se centró en tres aspectos: en el primero, se expresaban las dudas sobre valor práctico como casa para el futuro, en el segundo, se demandaban explicaciones rigurosas que justificasen una posible

le respondió K. E. Slaugther, el director del Palace of Fine Arts, el 13 de marzo, remitiendole a la galería Pierre Matisse. Esto provocó la ira de Paul Nelson, quien el día 8 de abril volvió a solicitar a Dorothy Liebes que realizase las gestiones para la devolución de la obra. Aquí se perdió el rastro de la maqueta. Ya que no se reenvió a París, por lo cual no se perdió en el mar como se ha sostenido hasta la fecha por muchos autores, entre ellos su biógrafa Anne Kandelaman. Archives Pierre Matisse Gallery, The Morgan Library of New York.

${ }^{222}$ La Maison Suspendue se ha exhibido en el MoMA en varias ocasiones. Primero en la muestra "Visionary Architecture" celebrada entre el 28 septiembre y el 4 diciembre de 1960 , en la cual también se expusieron la Endless House de Frederick Kiesler y la "City Tower" de Louis Kahn. Posteriormente se mostró en la exposición "Three Houses" que se desarrolló entre el 21 de abril y el 20 de mayo de 1979, en la que se exhibieron la Wichita House de R. Buckminster Fuller y la "Simulated dwelling for a family of five" de David Jacob.

223 " New Use of Space determines design of proposed house", Architectural Record Volumen 84 nº, 1938, pp.38-41.

${ }^{224}$ Aunque el texto no estaba firmado, en una carta del 15 de febrero de 1939, Paul Nelson anunciaba a Waldenman Kaempffert, editor del New York Times, que los arquitectos $\mathrm{Mr}$ Lömberg-Holm y Mr Theadore Larson eran los encargados de preparar este artículo. 
producción industrial de la vivienda, y en el tercero, se manifestaba la incertidumbre sobre la integración de la arquitectura con respecto a la pintura.

Unos meses después del artículo americano, La Maison Suspendue se publicó en Francia. La editorial de Albert Morancé le dedicó un monográfico titulado: "La Maison Suspendue, una investigación de Paul Nelson” (III. 27) ${ }^{225}$. El encargado de esta edición fue el arquitecto Jean Badovici ${ }^{226}$. El texto estaba redactado por Paul Nelson y fechado el 12 de enero de 1939 en París. Era un escrito justificativo del proyecto en el que el autor describía sus hipótesis y llegaba a la forma de la vivienda mediante un proceso deductivo. En el texto se avanzaba hacia una fase propositiva de construcción del proyecto y para argumentarlo se recogían las opiniones favorables, expresadas por el artista Wassily Kandinsky, el crítico de arte James Johnson Sweeney ${ }^{227}$ y la industria y los intelectuales norteamericanos ${ }^{228}$. De esta manera Paul Nelson avalaba cada uno de sus objetivos mediante un apoyo de prestigio. Nelson cerraba esta segunda parte con su propia opinión, cuestionando la capacidad del mercado inmobiliario para poder afrontar su proyecto y para utilizar la técnica para liberar al hombre.

Los dos textos reflejaban la posición de Nelson, uno a través de una interpretación y el otro de manera directa, por lo tanto obedecían a puntos de vista muy próximos. Ambos artículos comenzaban y concluían resaltando el carácter de investigación de La Maison Suspendue. La diferencia estaba en que, mientras en el artículo de

${ }^{225}$ La revista L'Architecture Vivante, "Documents sur l'activité constructive", estaba editada por Albert Morancé. En el año 1939 publicó un monográfico dedicado a La Maison Suspendue. las bibliografías sobre Paul Nelson datan, erróneamente, este documento en 1937. Sin embargo esto no era posible por dos razones. La primera, era que en el texto aparecía una nota con fecha de 1939, y la segunda, que la maqueta fotografiada en la publicación, no se ejecutó hasta el verano de 1938. El monográfico apareció en el invierno de 1939, como lo corroboraba la referencia publicitaria aparecida sobre el mismo en la revista L'Architecture $\mathrm{n}^{\circ} 3$ marzo de 1939. Véase Paul Nelson, La Maison Suspendue. Recherche de Paul Nelson. (L'Architecture Vivante), París: Albert Morancé, 1939.

${ }^{226}$ Jean Badovici (Bucarest 1893-Mónaco 1956) arquitecto de origen rumano que fue director de la revista L'Architecture Vivante entre 1923-1933 y colaboró con la arquitecta Eileen Gray en el proyecto de la casa al bode del mar "E-1027".

${ }^{227}$ James Jonson Sweeney (1900-1986) fue crítico de arte y trabajó como conservador MoMA (1935-40) y como director de Guggenheim NY (1952-60).

${ }^{228}$ Las únicas afirmaciones de apoyo manifestadas por escrito fueron las de James Johnson Sweeney. En el texto no aparecían referencias exactas sobre las afirmaciones de W. Kandinsky, ni sobre quienes eran las personas que para Paul Nelson configuran los grupos de intelectuales americanos. Véase: James Johnson, Sweenwy, "The Suspended House", Official Catalog department of fine arts, division of decorative arts. Golden Gate Exposition. San Francisco 1939, pp.74-75. 
Architectural Record este dato era utilizado para prevenir al lector sobre un proyecto no construido, en el artículo de Architecture Vivante fue utilizado por Nelson para añadirle un valor científico a su trabajo. En los dos textos faltaba un proceso de análisis crítico, sobre la repercusión que tenía el espacio individual en la configuración de esta nueva vivienda.

En su texto para la Architecture Vivante, Paul Nelson no mantuvo su discurso justificativo con la misma intensidad en todos los aspectos. Fundamentalmente, carecía de una articulación argumental entre la humanización de la arquitectura y la ocupación espacial por parte de los individuos. No aclaró las ventajas que aportaban la fragmentación espacial y el aislamiento en el espacio social de la familia. Evitó formular una explicación sobre la implantación de la casa en el medio, ya que la única referencia geográfica era la orientación. En el artículo, en términos generales, tampoco se especificaba porqué se trabajó con esa geometría concreta y se rehuyó cualquier referencia al proceso formal, y tampoco hacía mención a la decisión de elegir a esos artistas y no a otros.

Mientras en la prensa francesa solo apareció una referencia a la primera presentación en París, la prensa norteamericana se hizo amplio eco del itinerario expositivo de las maquetas. La única crítica aparecida en Francia reconocía lo arriesgado de la apuesta y destacaba el espíritu sociológico que la inspiraba y la participación de los $\operatorname{artistas}^{229}$. En los Estados Unidos la prensa valoró, con matices, las hipótesis sociológicas como punto de partida, la apuesta por una tecnología ligera basada en la suspensión y en la prefabricación, la riqueza espacial destinada al ocio y la presencia del arte. Edward Alden Jewell, en su crónica para el New York Times, ${ }^{230}$ definió La Maison Suspendue como: "el hogar del futuro" y expresó la necesidad de ver el espacio en sus tres dimensiones, mediante la maqueta, para ser entendido. En el periódico Christian Science Monitor ${ }^{231}$, lo más significativo fue la utilización de la

\footnotetext{
${ }^{229}$ Crítica sobre la exposición en la galería Pierre Loeb de París.Véase : Le marchand de couleurs, "La Maison Suspendue, Marianne", Courrier des Arts, 12 de octubre de 1938, p. 9

${ }^{230}$ En la crítica sobre la exposición de La Maison Suspendue en la galería Pierre Matisse se informaba de que sólo estaban expuestos la maqueta y los planos de plantas. En el artículo se citaba erróneamente a Richard Buckminster Fuller como el autor, como consecuencia de la introducción que hizo Fuller sobre las diferentes maneras de abordar el concepto de suspensión en sus respectivas propuestas de vivienda, la Dimaxion House y la Maison Suspendue Edward Alden Jewell, "Suspended House", New York Times, 26 de octubre de 1938, p.24.

231 "New Type House like Suspended Bird Cage",Christian Science Monitor, el 14 de noviembre 1938
} 
metáfora de "la jaula de pájaros" para referirse a la casa. June Provines ${ }^{232}$, en su crítica sobre la muestra en la galería Katherina Kuh de Chicago, apuntaba a la necesidad de reflexionar sobre las ideas que sostenían la propuesta. Y Eleanor Jewett ${ }^{233}$, se mostró más crítica y escribió que el proyecto era más un laberinto para realizar estudios psicológicos que a una vivienda para el futuro y consideraba que la propuesta era un invento poco práctico, con gran cantidad de espacio perdido y dudaba de su idoneidad como alojamiento.

Jack James y Earle Weller Pisani ${ }^{234}$, en su libro sobre la Golden Gate Internacional Exhibition de San Francisco, denominaron el trabajo de Nelson como "House in Space" y destacaron como rasgo fundamental de la casa sus valores constructivos y su configuración a partir de una rejilla de vidrio y de acero. Por su parte, el crítico de arte James Johnson Sweeney ${ }^{235}$ ponía La Maison Suspendue como ejemplo de la investigación creativa contemporánea que se anticipaba a los problemas. El autor valoraba muy positivamente el uso que había hecho Paul Nelson de la prefabricación constructiva, como herramienta para resolver las bases sociológicas de partida. Sweeney consideraba que con esta actuación se había abierto las puertas a un nuevo campo de investigación, para abordar otros tipos de construcciones tanto arquitectónicos como industriales.

Las críticas de la prensa norteamericana sobre La Maison Suspendue se centraron en los aspectos funcionales. En los artículos no se indagaba ni en los componentes compositivos ni en los formales y tampoco se hacía referencia al carácter humanizador de la arquitectura de la casa.

\footnotetext{
232 June Provines, “The Suspended House”, Chicago Daily Tribune, 7 diciembre 1938

${ }^{233}$ Véase Jewett, Eleanor, Chicago Daily Tribune, 9 diciembre 1938, (p.27). "City Maintains a Full Quota of Art Exhibitions". Chicago Daily Tribune, 11 diciembre 1938, (p.F5). "Critic Urges Pictures for Yule Presents", Chicago Daily Tribune, 18 diciembre 1938, p.F4.

234 James Jack and Earle Weller Pisani, The Story of the Goden Gate Internacional Exposition, Old Masters and Art in Action, capitulo XI, San Francisco: Pisani printing and publishing Co, 1941, p. 133.

235 James Johnson Sweenwy, "The Suspended House", Official Catalog Department of Fine Arts, Division of Decorative Arts. Golden Gate Exposition. San Francisco, 1939, pp.74-75.
} 


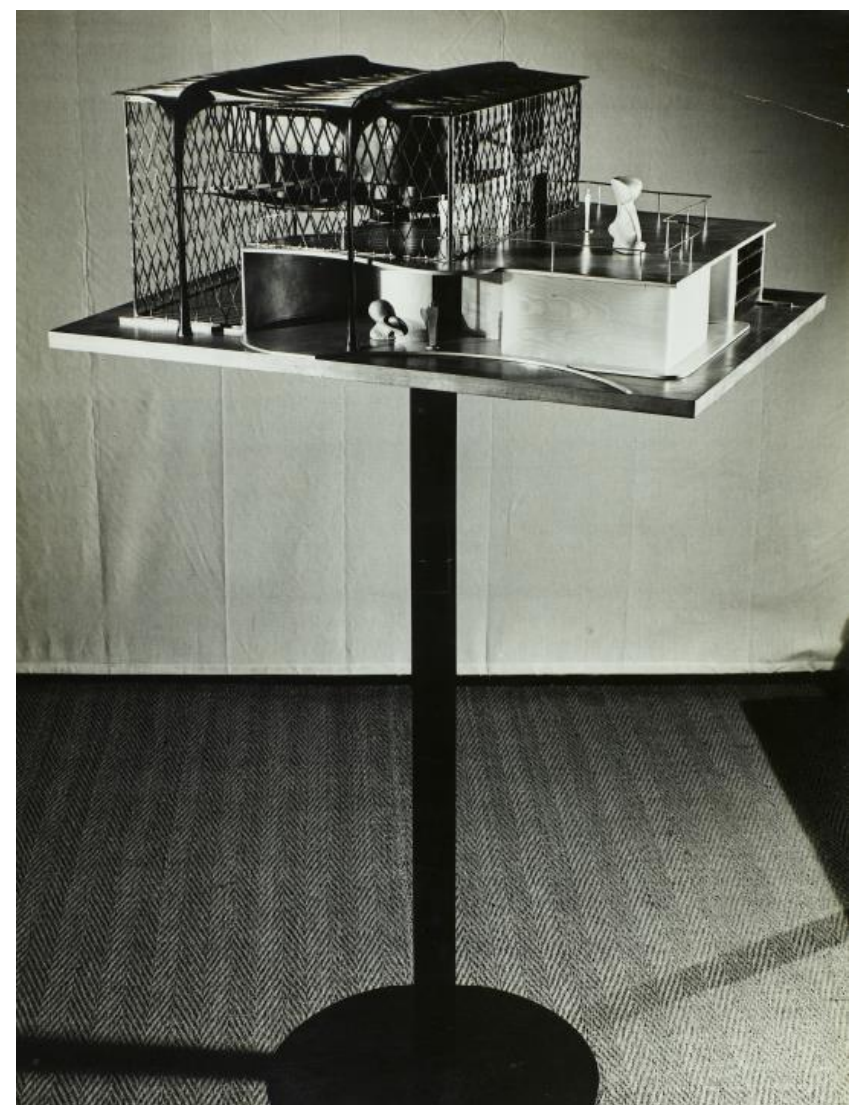

III. 28 La Maison Suspendue, Paul Nelson. Primera maqueta, ca 1938, foto Hugo Paul Herdeg

Las imágenes fotográficas de la maqueta que acompañaban a los textos resultaron decisivas para poder explicar el proyecto a los lectores. Aunque en las revistas especializadas se incluían los planos a escala, las imágenes de la maqueta transmitían, de una manera más evidente, el espacio tridimensional que albergaba la casa. Las fotografías aparecidas en los medios, que sirvieron para difundir $L a$ Maiosn Suspendue fueron tomadas de la primera maqueta ${ }^{236}$. De este modelo se realizaron dos series fotográficas con finalidades diferentes. La primera en Francia, realizada por el fotógrafo suizo Hugo Paul Herdeg ${ }^{237}$ (III. 28). En la que todos los enfoques realizados eran de la volumetría exterior, el espacio interior, siempre se

\footnotetext{
${ }^{236}$ Las primeras fotos de la segunda maqueta aparecieron en las revistas especializadas en los años sesenta, cuando se retomó el interés por el proyecto

${ }^{237}$ Hugo Paul Herdeg (1909-1953) fue un fotógrafo suizo que se trasladó a París en 1930 y realizó las fotos para la revista Cahiers d'art dirigida por Christian Zervos, amigo de Paul Nelson. En 1937 la revista le encargó fotografiar la Exposición Universal de París. Paul Nelson facilitó a la prensa norteamericana las fotos de Herdeg, que también fueron las imágenes utilizadas en el monográfico del proyecto. Véase: Paul Nelson, La Maison Suspendue. Recherche de Paul Nelson. (L'Architecture Vivante), París: Albert Morancé, 1939.
} 


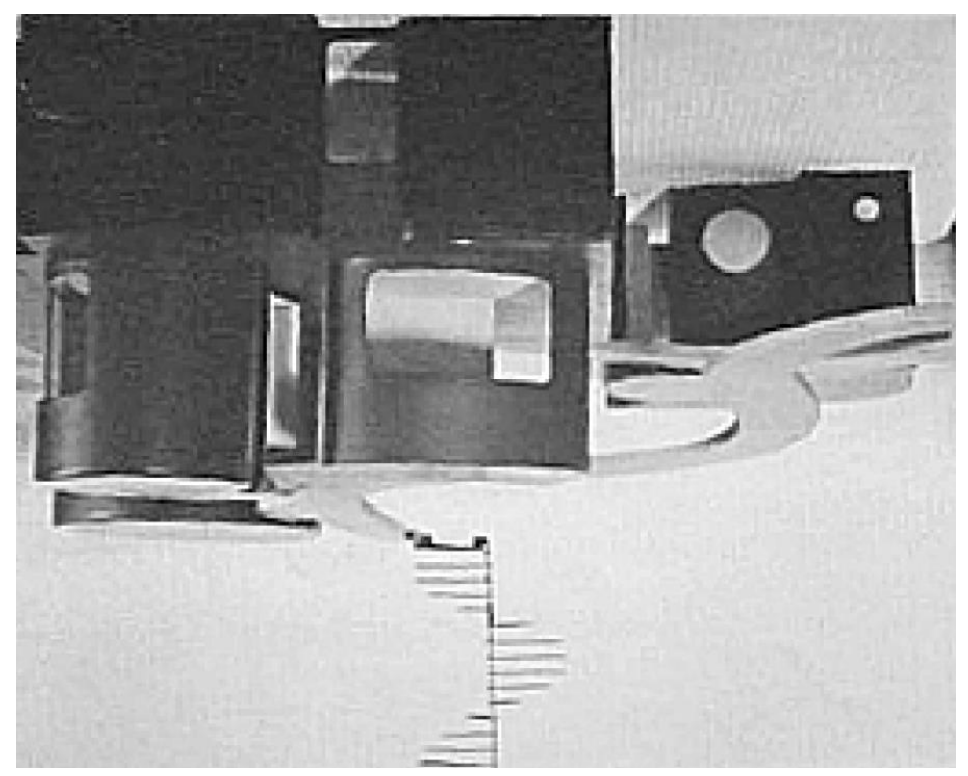

III. 29 La Maison Suspendue, Paul Nelson. Primera maqueta, ca 1938, foto Saint Thomas

mostraba encerrado detrás de las celosías. Por el contrario, la segunda serie fue realizada en Norteamérica por el fotógrafo Saint-Thomas ${ }^{238}$ (III. 29), que se centró en exhibir el espacio interior de la vivienda. El objetivo era trasladar la imagen de las habitaciones suspendidas sobre el salón y, para expresar sus intenciones, el fotógrafo prescindió de toda referencia externa y eliminó el cerramiento. El enfoque se redujo al volumen principal de las estancias superiores, incluso se eliminó el mural de Joan Miró y el balcón de la planta primera. Entre estas dos formas distintas de retratar la casa sucedió un hecho importante, la ruptura y fragmentación de la maqueta en diferentes partes, la maqueta pasó de ser un elemento rígido a uno desmontable, lo que facilitaba el trabajo para captar el espacio interno. En cualquiera de los casos, estas dos series fotográficas fueron las elegidas por Paul Nelson para difundirla en cada uno de los dos países, en Francia se mostraba la jaula y el arte, y en los Estados Unidos el espacio interior y la técnica suspendida.

Tras descubrir, en 1938, el interés del MoMA por el proyecto y explorar la posibilidad de ejecutarlo a tamaño real para la "New York World's Fair" de 1939, Paul Nelson no abandonó la idea de ver construida La Maison Suspendue a escala real. En 1959, consideró que su trabajo podía mostrarse en el jardín del MoMA,

\footnotetext{
${ }^{238}$ Saint-Thomas realizó las fotos de La Maison Suspendue en paralelo al encargo recibido de Architctural Record, para fotografiar el proceso constructivo de los edificios de la World's Fair de New York de 1939. Según el encargo, debía fijar su objetivo en la estructura y en el montaje, se trataba de contar una visión emocionante, previa a la fase final. Este trabajo estaba relacionado con la visión incompleta que mostró de La Maison Suspendue.
} 
dentro del programa del museo, de construcción de prototipos de viviendas modernas. El director, Arthur Drexler, consciente del impacto que podía tener la vivienda, le ofreció construirla en el verano de $1961^{239}$, pero finalmente no se ejecutó. Fracasada la experiencia americana, en 1966 contactó con André Malraux, ministro de cultura francés, quien reconoció el valor del proyecto pero no se comprometió a ejecutarlo. El último intento se produjo en 1973, cuando planteó construir la casa junto a la Escuela de Arquitectura de Marsella- Luminy ${ }^{240}$, donde era profesor, pero esta petición no obtuvo respuesta.

En su empeño por construir la casa, Nelson también contactó con diferentes empresas para solicitarles su apoyo al proyecto, pidió a la factoría automovilística Ford que valorase el coste de las unidades desmontables, solicitó a la empresa de aislantes Saint Gobain, a través de Jean Prouvé, que participase en la creación del cerramiento de vidrio, y contactó con la empresa $\mathrm{ACEC}^{241}$ para que se comprometiese con la ejecución de las unidades de baño prefabricado. Nelson intentó que las empresas de la construcción viesen en La Maison Suspendue una oportunidad para ampliar su mercado de trabajo, pero tampoco recibió el apoyo deseado.

A pesar de los esfuerzos realizados para construir la vivienda, no se volvió a realizar ninguna revisión de los planos del proyecto, Paul Nelson mantuvo intacta la versión de 1938, los materiales, y los detalles constructivos. Su objetivo era conservar viva la esencia de este proyecto, que fue el más trascendente de toda su carrera.

\footnotetext{
${ }^{239}$ Carta 28 de mayo de 1959, Arthur Drexler, Director del departamento de Arquitectura y Diseño del MoMA, a Paul Nelson. Arthur Drexler manifestaba su certeza sobre el impacto, que la construcción de la obra causaría entre los arquitectos y lo importante que era el proyecto para la industria de la arquitectura. El director le informó que las estructuras de Buckminster Fuller se mostrarían en el verano de 1959 y para la siguiente temporada de 1960 estaba prevista una exhibición sobre la "Endless House" de Frederick Kiesler.

${ }^{240}$ Carta 27 de Noviembre de 1973, de Paul Nelson a François Bret director de la Escuela de Arte y Arquitectura de Marsella-Luminy solicitando permiso para construir su casa en unos terrenos cedidos por el ayuntamiento. Explicaba que en su vivienda experimental, para él y para su mujer pintora, podrían recibir a los alumnos de arte y arquitectura y a los artistas importantes y ponía como ejemplo la casa de José Luis Sert en Harvard.

241 ACEC eran los representantes para Europa del sistema "ECHO Module Systems" de EEUU, que comercializaba bloques compactos de baños. MNAM/CCI, Bibliothèque Kandinsky, fonds Louis Dalbet.
} 


\section{La casa y el arte.}

Paul Nelson desarrolló un trabajo interdisciplinar e integrador, con la inclusión de obras de arte en la vivienda. Su objetivo no era incorporar las intervenciones de los pintores y de los escultores como ornamentos decorativos, al final del proceso arquitectónico, sino que buscaba la confluencia de estas disciplinas con la arquitectura para la construcción de espacios concretos en la casa, desde el inicio del proyecto. Y para conseguirlo, Nelson no se planteaba la desaparición de la arquitectura, sino su creación de acuerdo con la pintura y la escultura. Esta predisposición de la arquitectura, estaba presente tanto en la configuración formal de las estancias como en la funcional. El arte, al igual que sucedía con el orden estructural, formaba parte de la esencia de la casa, era el sustrato espiritual de la vida doméstica. Su emplazamiento en los espacios comunes generaba emociónes y era la transposición de la esencia de la celda personal al ámbito familiar.

...A día de hoy, todo lo que se puede afirmar es que esta solución de "casa máxima”, en la que domina el espacio inútil -sin funciones estrictas- debería facilitar el empleo de la pintura y de la escultura que son artes inútiles por definición, sin razón de ser ni necesidad imperiosa... ${ }^{242}$

Paul Nelson, a diferencia de otros arquitectos-artistas como Le Corbusier, no intervino plásticamente en la casa, sino que solicitó a sus amigos obras de arte en miniatura para incluirlas en las maquetas. Este apoyo, de artistas reconocidos a un arquitecto que solo había construido una casa y que no figuraba entre los primeros nombres de la arquitectura moderna, suponía la aceptación de los vínculos entre la casa y el arte, a la vez que convertía a la vivienda en una obra de arte, que posteriormente se exhibiría en galerías y en el MoMA. Las piezas estaban vinculadas a una posición fija en los espacios sociales ${ }^{243}$, la condición material de los murales y las esculturas no facilitaba su traslado e incluso en las maquetas se mantuvo el número y la ubicación. Las intervenciones interiores fueron realizadas por Joan Miró y Fernand Léger. Y las intervenciones exteriores fueron ejecutadas primero por Jean Harp y posteriormente por Aleaxander Calder.

\footnotetext{
${ }^{242}$ Paul Nelson, La Maison Suspendue. Recherche de Paul Nelson. (L'Architecture Vivante), París: Albert Morancé, 1939.

${ }^{243}$ Para Nelson, la libertad del cliente no se veía coaccionada por la introducción de obras de arte en la casa por el arquitecto, ya que existía un conocimiento previo y exhaustivo de los gustos del propietario. Véase : Judith Applegate, "Paul Nelson: an interview", Perspecta n¹3-14, 1971, pp.79-80.
} 


\subsection{Joan Miró. La creación de un paisaje interior.}

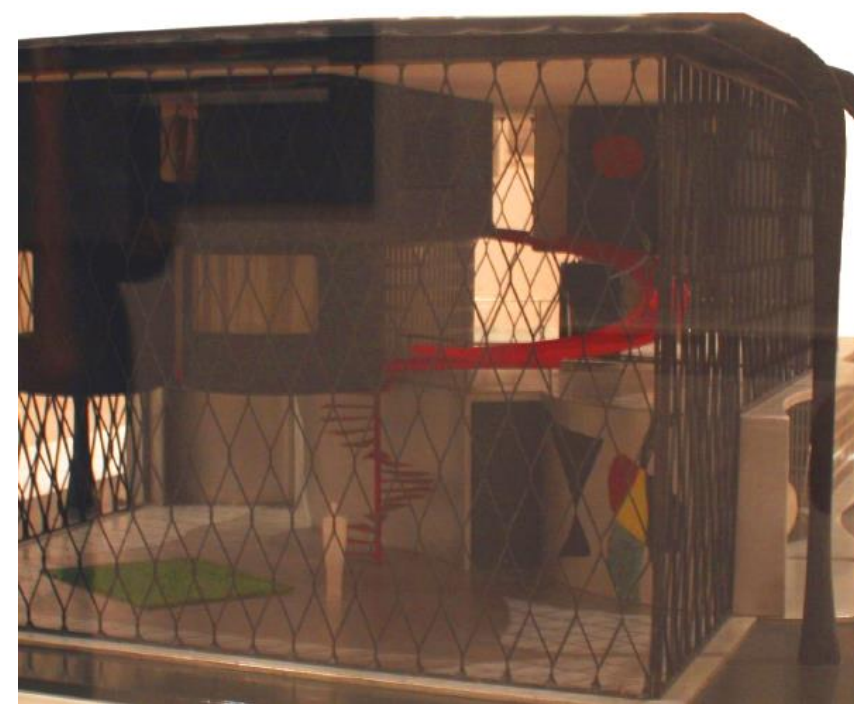

III. 30 Segunda maqueta, Intervención en el mural, la rampa y la alfombra del salón, Joan Miró 1938

Cuando Paul Nelson enseñó la maqueta a su amigo el pintor Joan Miró ${ }^{244}$, este le expresó su sensación de estar viendo un paisaje y le propuso realizar una intervención cromática en el salón, que pusiera de manifiesto esta idea. Joan Miró tintó la rampa de rojo, la alfombra de verde y en el muro blanco pintó una composición con manchas planas de colores ${ }^{245}$ ( III. 30).

...él ha considerado la maqueta como un paisaje en el que ha tratado la rampa como si fuera una flor, una parte del suelo como hierba; ha pintado de azul -como el cielo- el techo, la parte baja, de una de las piezas colgadas; viéndose constelaciones en la parte alta en el costado del dormitorio... ${ }^{246}$

Por un lado, la respuesta de Joan Miró llevó a Paul Nelson a pensar que el principal espacio interior de La Maison Suspendue no tenía la apariencia funcional del salón de una casa, sino que era visto por Miró como un lugar evocador que demandaba

\footnotetext{
${ }^{244}$ Joan Miró y Paul Nelson frecuentaban el mismo círculo de amigos. En 1937, Paul Nelson proporcionó alojamiento y taller a Joan Miró en el mismo edifico en el que él vivía y en verano la familia Miró fue invitada a pasar unos días de descanso en la casa de los Nelson en Varengeville sur Mer, donde Joan Miró pintó unos frescos al año siguiente.

245 Joan Miró intervino en los mismos espacios en las dos maquetas, la única variación se produjo en la morfología de una de las figuras del muro del salón.

${ }^{246}$ Paul Nelson, La Maison Suspendue. Recherche de Paul Nelons. (L'Architecture Vivante), París: Albert Morancé, 1939.
} 
una intervención, de lo que dedujo que el espacio vacío de su vivienda era un volumen disfuncional, que no tenía adscrito ningún uso exclusivo y por lo tanto, era el marco perfecto para ubicar el arte. Por otro lado, la sala de reuniones con sus componentes arquitectónicos ya definidos sirvió a Joan Miro como punto de partida para apoyar su intervención. Utilizó como soportes fragmentos de elementos arquitectónicos: el lienzo curvo del muro, el paño del suelo, la cara inferior del forjado de las celdas individuales y la curva de la rampa, y sobre ellos aplicó los colores de manera simbólica. Creó una composición tridimensional basada en la tensión generada por la disposición conjunta de estos elementos. El objetivo era construir un paisaje sincrético de referencia propio, ya que con la proyección de la casa como un objeto aislado, se había perdido el vínculo con la naturaleza.

La intervención artística convirtió las piezas internas en nuevas referencias espaciales, que ayudaban a entender mejor el espacio habitable. El cromatismo construía unos límites superficiales, que acercaban la arquitectura a la escala humana, dentro del mayor volumen vacío de la vivienda. Joan Miró construyó una estancia abierta dentro del perímetro cerrado del prisma cúbico, que proporcionaba a los individuos la sensación de ocupar un recinto vivo, cargado de una tensión espacial que contrastaba con la relación de indiferencia establecida con los límites del cerramiento. De todas las sugerencias de la propuesta de Joan Miró, la utilización de la alfombra era la que aportaba mayor novedad al concepto tridimensional de La Maison Suspendue, ya que incorporaba el suelo de la vivienda al campo de tensiones creado entre los diferentes volúmenes. Mientras para Paul Nelson el suelo era únicamente la tabla rasa desde la cual arrancada su vivienda, para Joan Miró el suelo era una herramienta más, de la cual él solo necesitaba un fragmento que le permitiese construir su propia arquitectura dentro de la casa.

La intervención de Joan Miró reforzaba la idea de Paul Nelson de dar mayor protagonismo al espacio continuo y flotante que existía entre las estancias, ya que la obra no estaba constreñida a la superficie que ocupaba, sino que su influencia trascendía al resto del espacio al enfrentarse con las otras piezas de arte. La intención era provocar la participación personal del individuo en el disfrute de este ámbito y conseguir su integración plena en el espacio público. Paul Nelson contó con la complicidad de Joan Miró para construir una carcasa de arte abierta que inspirase al individuo, que al sentirse rodeado tuviese la necesidad de recorrer el espacio. 


\subsection{Fernand Léger. La irradiación del mediodía.}
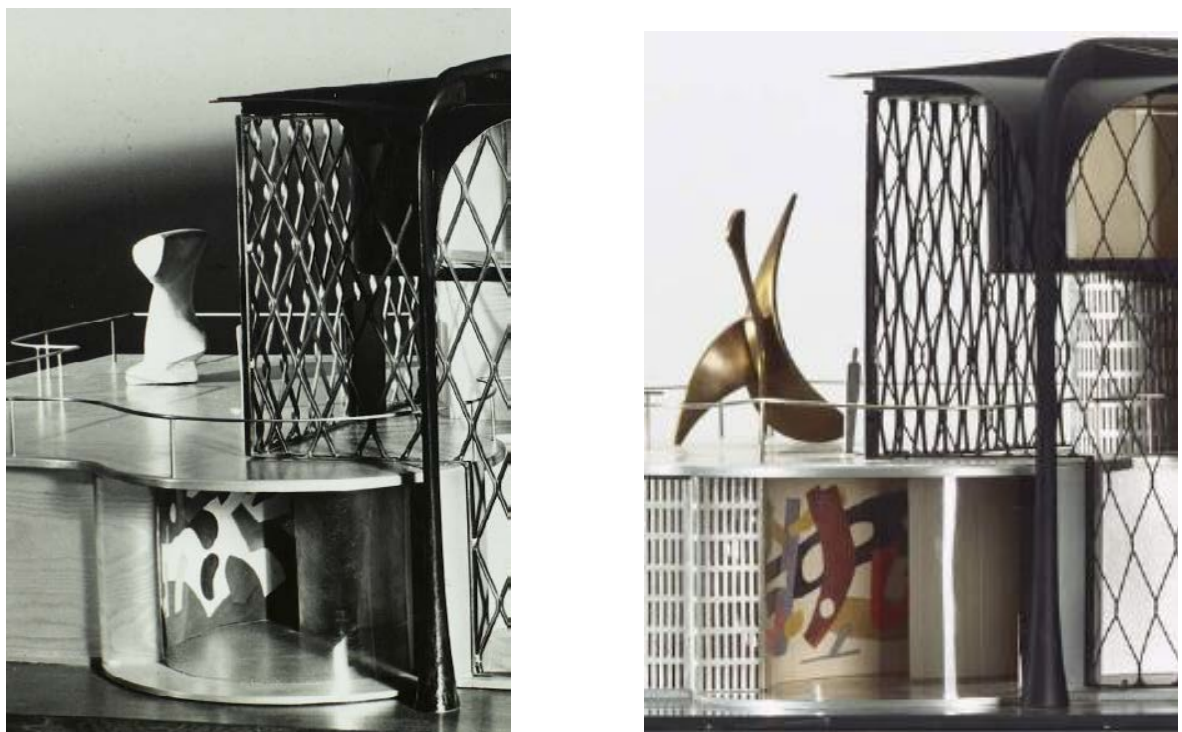

III. 31 Primera maqueta, mural en el comedor, Fernand Léger. 1938

III. 32 Segunda maqueta, mural en el comedor, Fernand Léger. 1938

Como ya se ha visto, el pintor Fernand Léger fue el artista que mas veces colaboró con Paul Nelson (§ II. 3.). Su intervención en La Maison Suspendue se centró en el muro cóncavo del comedor, la única estancia de uso social expuesta al exterior. Fernand Léger, al igual que hizo Joan Miró, no repitió la misma pintura en las dos maquetas, sino que creó un mural específico para cada una de ellas. En la primera maqueta, Fernand Léger utilizó manchas planas de figuras que estaban apoyadas en el perímetro del muro de soporte. Las figuras perdían su silueta a medida que se aproximaban al borde. En la segunda maqueta, realizó una composición mediante figuras planas, que flotaban en el espacio y se superponían en una secuencia de planos, manteniendo sus colores.

Fernand Léger actuó sobre la pared interior más iluminada de la casa y, por lo tanto, la que desprendía mayores reflejos. Este efecto se tradujo en sus pinturas y, aunque tenía como soporte la misma superficie, actuó con criterios diferentes. En la primera (III. 31) realizó una obra de arte que acompañaba al muro, haciendo coincidir los límites de la pintura y la arquitectura. Léger pintó sus figuras sin volumen, inscritas dentro del plano curvo que había preparado Paul Nelson. Por el contrario, en su segunda actuación (III. 32) realizó una pintura que buscaba la destrucción del muro para lograr su propia autonomía. En este mural, las figuras que flotaban sobre el 
soporte, se sujetaban entre ellas en planos superpuestos, sin someterse a los condicionantes del formato de la arquitectura.

Fernand Léger, apoyado por la luz, generó una tensión espacial derivada del contraste entre su actuación sobre un elemento masivo y el hueco desmaterializado. Con la primera intervención reforzó la condición de límite que ejercía el muro curvo, frente a la fuerza centrífuga que generaba la espiral de la planta. La curvatura definida por el mural también contribuyó a canalizar la fluidez espacial desde el comedor hacia el interior de la casa. Con la segunda intervención, el soporte arquitectónico desaparecía y las figuras se manifestaban exentas, ocupando parte del volumen de la sala y liberando vacíos entre ellas, que provocaban una continuidad espacial por la cual el medio exterior se adentraba en la casa. De esta manera, el comedor se transformaba en una pieza de transición entre el orden artificial y el natural. El primer mural era una capa funcional, que servía de protección para, que el individuo se sentase frente al mundo para observarlo, y marcaba el recorrido a la información procedente del exterior. Con el segundo mural, el hombre se imbuía en un campo de fuerzas cruzadas, entre el interior y el exterior de la casa, como resultado de la irradiación del color. Este proceso, el individuo pasaba de ser un sujeto pasivo y se convertía en actor.

\subsection{Jean Harp y Alexander Calder. La configuración de la terraza y el porche}

Si las colaboraciones en los espacios interiores de La Maison Suspendue estaban apoyadas en superficies y tenían un carácter, fundamentalmente, de mural, las intervenciones en el entorno de la vivienda fueron tridimensionales, mediante esculturas.

Jean Harp realizó las dos esculturas para la primera maqueta de La Maison Suspendue, una para el porche de la entrada y otra para la terraza (III. 33). Se trataba de unas piezas no figurativas cuya geometría curva necesitaba ser rodeada para ser entendida. Estaban ejecutadas en un único material, de consistencia masiva, y no tenían base. Las esculturas estaban ubicadas en una posición equidistante entre los cerramientos y los elementos que marcaban los límites exteriores, que eran la barandilla en la terraza y el borde del estilóbato en el porche. Por lo tanto, su posición introdujo un nuevo orden espacial en el vacío que circundaba la vivienda 


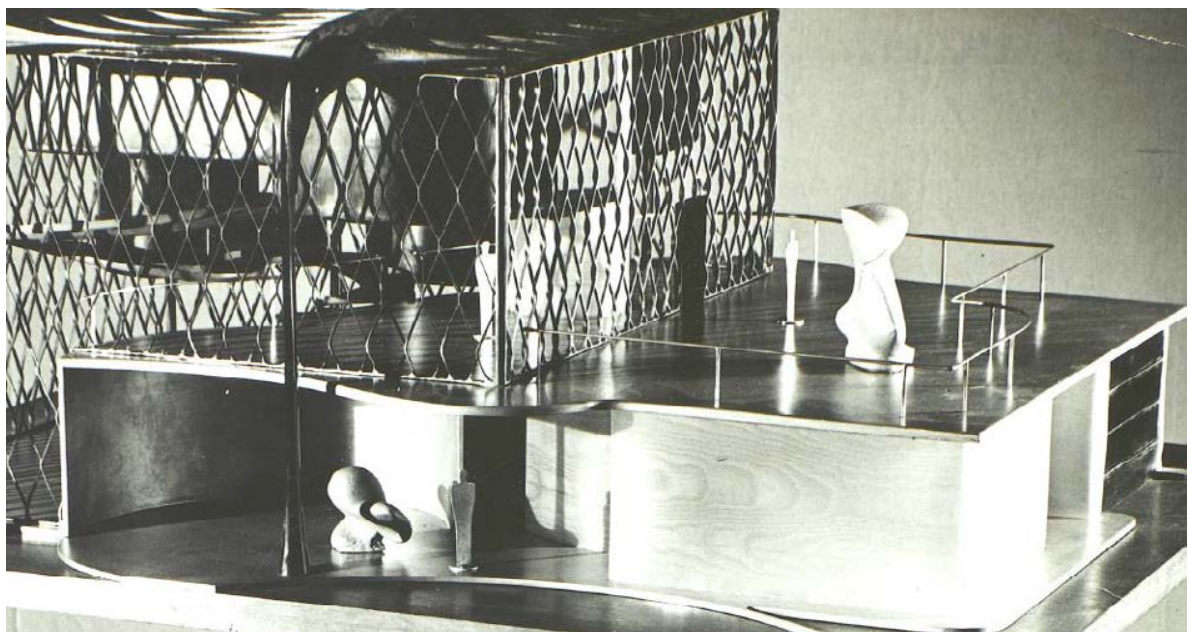

III. 33 Primera maqueta, intervención escultórica en el porche y en la terraza, Jean Harp. 1938

La disposición de las esculturas en lugares representativos del exterior, creaba dos nuevos centros de atracción social próximos a la vivienda, que competían funcionalmente con el salón. Esta tensión entre interior y el exterior generaba una continuidad espacial basada en el uso inmaterial de la casa, que suponía la prolongación del concepto de espacio familiar espiritual en el entorno próximo de la vivienda. Por lo tanto, si la casa era el lugar de protección, las esculturas, que habían desdibujado el límite físico del muro, marcaban la línea de salvaguarda del individuo. El porche era el nártex cultural que predisponía para acceder a la casa.

Alexander Calder elaboró para la segunda maqueta las dos obras, que sustituyeron a las de Jean Harp (III. 34) y, aunque los dos escultores compartían objetivos, existían diferencias formales y conceptuales entre ellos. Las esculturas de Alexander Calder eran más ligeras, acordes con una visión más próxima a la construcción de la propia casa. La incorporación de las fuerzas de equilibrio derivadas del peso resultaron decisivas en la concepción de los apoyos de las esculturas y se consiguió un contacto mínimo con la arquitectura que servía de plano de sujeción. Esto generó una tensión, que convertía las esculturas en piezas más autónomas respecto de la arquitectura. Esta relación de independencia se manifestaba con mayor intensidad en la escultura "estable" ${ }^{247}$ propuesta para la terraza, una pieza creada a partir del ensamble de chapas, que permitían el paso del aire entre ellas, lo cual transformaba a estas esculturas en un conducto de transmisión espacial que facilitaba la continuidad.

\footnotetext{
${ }^{247}$ La escultura de la terraza seguía el modelo de las piezas que Alexander Calder denominó "estables" y que comenzó a construir a partir de los años treinta. Estas esculturas eran realizadas en maquetas de pequeña escala y posteriormente se ejecutaban con chapas de acero a tamaño real.
} 
III. 34 Segunda maqueta, intervención escultórica en el porche y en la terraza, Alexander Calder. 1938.

\subsection{El plató doméstico.}

La reflexión de Beatriz Colomina sobre la Space House de Frederick Kiesler, considerándola un modelo de espacio expositivo y teatral ${ }^{248}$, podía ser transpuesta a La Maison Suspendue. Por lo tanto, a las influencias que ejercieron las artes plásticas había que sumarles la repercusión que tuvieron las artes escénicas del cine y del teatro. Su estancia en Hollywood (§ I. 2.), proporcionó a Paul Nelson un conocimiento nuevo del uso de la luz, el color, el tiempo y el enfoque, que se plasmó en su arquitectura, de tal forma que la aplicación de las herramientas cinematográficas dinamizó su concepto de la vivienda.

Paul Nelson retomó su experiencia como director artístico, de iluminar los paneles translúcidos de cerramiento desde el exterior, y lo aplicó al paso de la luz natural a través de su muro de vidrio. De esta forma, el ciclo diario de iluminación sometía a los habitantes a un proceso de exposición que convertía a cualquier persona u objeto próximo a la fachada en una silueta a contraluz, para cualquier observador. Los cuerpos habían perdido su volumen y su imagen se fusionaba con el plano del fondo. Por el contrario, la luz que lograba llegar al espacio central era muy homogénea y tenía una baja intensidad, lo que provocaba una indefinición de los contornos, como en el interior de un espacio acuoso. La luz natural convertía a los que deambulaban ${ }^{248}$ Beatriz Colomina, Doble exposición. Arquitectura a través del arte. Madrid: Akal, 2006,
p.77. 


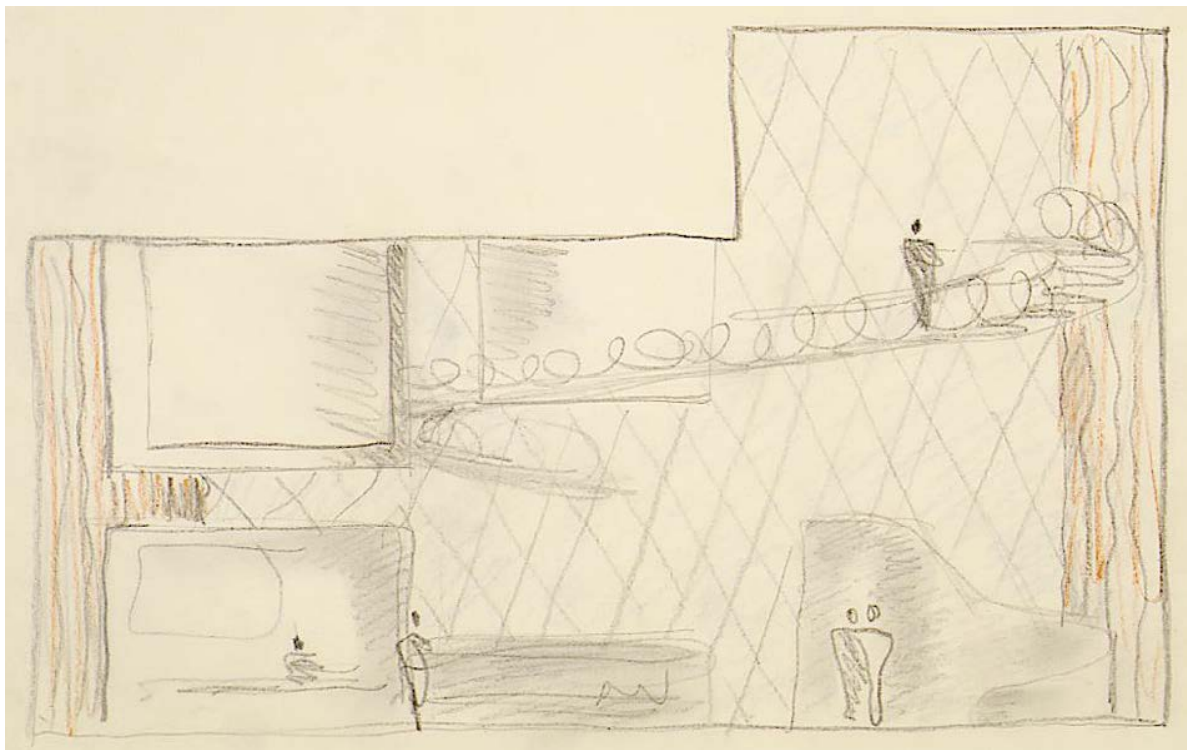

III. 35 La Maison Suspendue, Paul Nelson. croquis, sección transversal, ca. 1938.

por la periferia en actores y a los que ocupaban el espacio central en espectadores. Este proceso se revertía durante la noche mediante la focalización central de luz artificial.

Nelson combinó el uso de materiales metálicos y superficies brillantes con la aplicación de colores intensos sobre algunos elementos. Tanto los reflejos que se producían en las estancias suspendidas y en las piezas de mobiliario, como el color rojo de la rampa, generaban contrastes visuales que provocaban una sensación de movimiento en el espacio interior. El objetivo era incitar al visitante a recorrer ese espacio público, siguiendo la teoría de la promenade de Le Corbusier, un desplazamiento dentro de la casa que ofrecía diversos enfoques y diferentes maneras de entender la vivienda. Las piezas de mobiliario metálico se convertían en fragmentos de pantalla, que devolvían reflejada la imagen de la escena social, ofreciendo una realidad deformada, virtual, que el habitante-espectador montaba en un plano superpuesto a la acción real.

Se creó un paralelismo entre las estancias de la casa y el set cinematográficos. Así, en La Maison Suspendue, como en el cine, se proyectaron espacios de acción, espacios de segundo plano y espacios de elipsis. Y tanto en el cine como en la vivienda, las diferencias espaciales venían determinadas por la visualización de la acción. El espacio donde se desarrollaba la trama cinematográfica general coincidía con el salón, que era la estancia donde se producían las relaciones entre los 
habitantes, allí todo quedaba expuesto. Incluso algunos lugares de este volumen, como la rampa, eran escenarios destinados a la pura exhibición y a la coreografía. Los decorados para el segundo plano cinematográfico tenían su simetría en los espacios maquinistas de la vivienda, área de descanso y de servidumbre, que eran las estancias donde los movimientos estaban muy pautados y las escenas no ofrecían sorpresas. Finalmente, estaban los espacios de elipsis, que eran aquellos lugares donde la acción se producía sin la visión del espectador. En la casa, este ámbito lo ocupaban las células personales, donde se desarrollaba privadamente la actividad más significativa, que era el renacimiento personal.

A parte de construir referentes cinematográficos, en La Maison Suspendue también se reproducía el espacio teatral. El salón era el lugar dispuesto para la representación del hombre en la vida familiar, desde su nacimiento hasta su muerte ${ }^{249}$. La sala contaba con decorado y telón (III. 35) y tenía un escenario donde el público participaba en la obra. Igual que sucedía en el "teatro total ${ }^{250 "}$ de Walter Gropius, este espacio de ocio doméstico funcionaba de manera simultánea como patio de butacas y escenario. En unos casos, el escenario era el balcón interior de la planta primera y los espectadores ocupaban la platea pública de la cota cero y sus palcos privados de las habitaciones individuales y, en otros casos, el balcón interior funcionaba como un anfiteatro, desde el cual se podía contemplar la representación de la planta baja. Esta disposición provocaba un cruce de miradas entre la persona observada y el observador, en la que los papeles se intercambiaban. De esta manera, desaparecía el límite entre el espectador y el actor, que eran respectivamente el invitado y el habitante la casa, y se rompía la adjudicación predeterminada de ocupación espacial dentro de la estancia colectiva. Paradójicamente, la construcción visible de la privacidad generaba en el público invitado el deseo de ocuparla. Las personas que accedían al salón tenían la necesidad de ascender y controlar la obra desde una posición más confortable.

\footnotetext{
${ }^{249}$ Beatriz Colomina analizó la configuración espacial de las primeras casas de Adolf Loos en términos de escenario de la vida doméstica. Un lugar donde el hombre nacía, vivía y moría. En el texto se estudiaban las relaciones de percepción, de intimidad y los vínculos con el exterior de esas viviendas, como un espacio teatral. Véase : Beatriz Colomina, The SplitWall: Domestic Voyeurism, Raumplan versus plan libre: Adolf and Le Corbusier, 1919-1930. Rótterdam: Max Risselada, 2008, pp.32-51.

${ }^{250}$ El "Teatro total" ideado por Walter Gropius en 1926 era una propuesta para poner al espectador en el centro del espectáculo. Véase: Sigfried Giedion, Walter Gropius: Work and Teamwork, Nueva York: Reinhold Pulishing, 1954, pp.61-63.
} 


\section{Una matriz con espacio inútil para el individuo}

Walter Gropius pensaba que los arquitectos modernos debían jugar un papel activo en el cambio hacía una nueva sociedad, consideraba que desde la arquitectura se podía contribuir al bien común mediante la construcción de espacios individuales. $^{251}$

... El individuo perfecto es la meta del Estado y la construcción de la sociedad el medio para ello... Así comienza hoy- partiendo de la vida económica de los pueblos- la idea de la racionalización, para crear un gran movimiento espiritual en el que la actuación del hombre individual se transforma en una colaboración beneficiosa para el bien de la comunidad total... ${ }^{252}$

En sintonía con las preocupaciones de los arquitectos modernos por la creación de un ámbito individual dentro de la vivienda, Paul Nelson propuso humanizar el hábitat doméstico partiendo de los deseos personales de los habitantes. Construyó un modelo teórico basado en una revisión de las relaciones sociales, que afectaba tanto a los contactos internos entre los propios moradores como a sus vínculos con el mundo exterior a la casa. Por un lado, para resolver las relaciones entre los habitantes, se retomó la idea de Hugo Häring de separar el orden geométrico y el orden orgánico $^{253}$, y creó una estructura matricial permanente, en cuyo interior el individuo modelaba su propia carcasa habitable. El orden matricial no solo se manifestaba en términos físicos, sino también en términos de confort emocional. Y por otro lado, para resolver la relación con el entorno, proyectó un tipo de vivienda mixto, entre la cabaña americana y la casa patio europea, que permitía colonizar el territorio con pocos medios, a la vez que en su interior se creaba un ambiente natural controlado y observado sin filtros. Paul Nelson materializó la humanización de su arquitectura a través del espacio individual, trabajó con la ocupación, la morfología

\footnotetext{
${ }^{251}$ Walter Gropius, en su ponencia sobre la vivienda mínima para el II Congreso de los CIAM, defendió el establecimiento de los cambios humanos como punto de partida para elaborar un programa práctico de vivienda mínima. Walter Gropius tomó como referencia las tesis del sociólogo alemán F. Mülller Lyer, que entendía la sociedad como fruto del proceso evolutivo del individuo. Véase: Walter Gropius "Los fundamentos sociológicos de una vivienda mínima (para la población obrera de la ciudad)" en Carlo Aymonino, La vivienda racional. Ponencias de los congresos C.I.A.M 1929-1930, Barcelona: Gustavo Gili, 1973, pp.114-117.

${ }^{252}$ Ibídem, p. 115.

${ }^{253}$ En 1931, Hugo Häring estableció una separación entre el orden geométrico, encarnado por el espacio, el tiempo y el número, que representaban lo atemporal y lo inmóvil. Y el orden orgánico, que hacía referencia a lo relativo y lo dinámico y que representaba la vida misma.
} 
y el uso de este espacio dentro de la casa, obteniendo como resultado un equilibrio entre protección y libertad.

\subsection{La retícula funcional de la familia y el desarrollo individual.}

El mismo criterio de integración entre las partes y el todo, utilizado en la solución espacial, fue el que se aplicó para satisfacer los argumentos sociales de La Maison Suspendue. El proyecto surgió tras analizar el sentido de las incidencias entre el orden funcional de la vivienda y las unidades sociales que la habitaban: el individuo y la familia y llegar a la conclusión de que el sentido de las influencias era reversible. Arquitectos coetáneos, como Frederick Kiesler ${ }^{254}$, ya habían estudiado estos vínculos y consideraban la estructura y el orden familiar como factores determinantes del programa doméstico.

$\mathrm{Si}$, para Le Corbusier, la casa era a la vez un refugio contra las inclemencias ambientales y una máquina para mirar el mundo exterior para Paul Nelson, la vivienda también era resguardo y sus habitaciones individuales eran atalayas desde la cuales se podía observar la vida familiar, que transcurría en el espacio social. La casa, pensada para contemplarse a sí misma, albergaba diferentes grados de privacidad y de convivencia familiar, destinados a proporcionar un beneficio mental a las personas ${ }^{255}$. Esta jerarquización interior, del acceso y del uso de la casa, difuminaba el monopolio del cerramiento como límite entre el espacio público y el privado. Con la desmaterialización del muro, se mostraba el interior de la vivienda a la vez que se guardaba a los habitantes del universo externo. El objeto de La Maison Suspendue era crear un recinto de convivencia social donde las estancias de uso privado se hacían visibles, para integrarse como una parte más dentro del ámbito público. De esta manera, se transponía la construcción del espacio continuo de la vivienda al terreno del orden social. Se proyectó un espacio común, en el cual dos

\footnotetext{
${ }^{254}$ En 1933, Frederick Kiesler construyó una maqueta a escala real de su casa "Space House", un proyecto en el cual se mezclaban las investigaciones que estaba desarrollando sobre el espacio continuo, con un interés por las relaciones sociales entre los habitantes de la casa. Considerando la sociología como una de las variables determinantes del proyecto, por delante de la estructura y la tectónica. Véase: José Luis Luque Blanco, Contínuum cósmico:Frederick Kiesler(1890-1965),Barcelona: Fundación Caja de Arquitectos,2012, p.98.

${ }^{255}$ Para Paul Nelson el hombre debía desarrollarse en dos vías, una individual y otra colectiva, que discurrían paralelas y se retroalimentaban. Véase: Judith Applegate, "Paul Nelson: an interview", Perspecta n ${ }^{\circ} 13-14,1971$, p.102.
} 


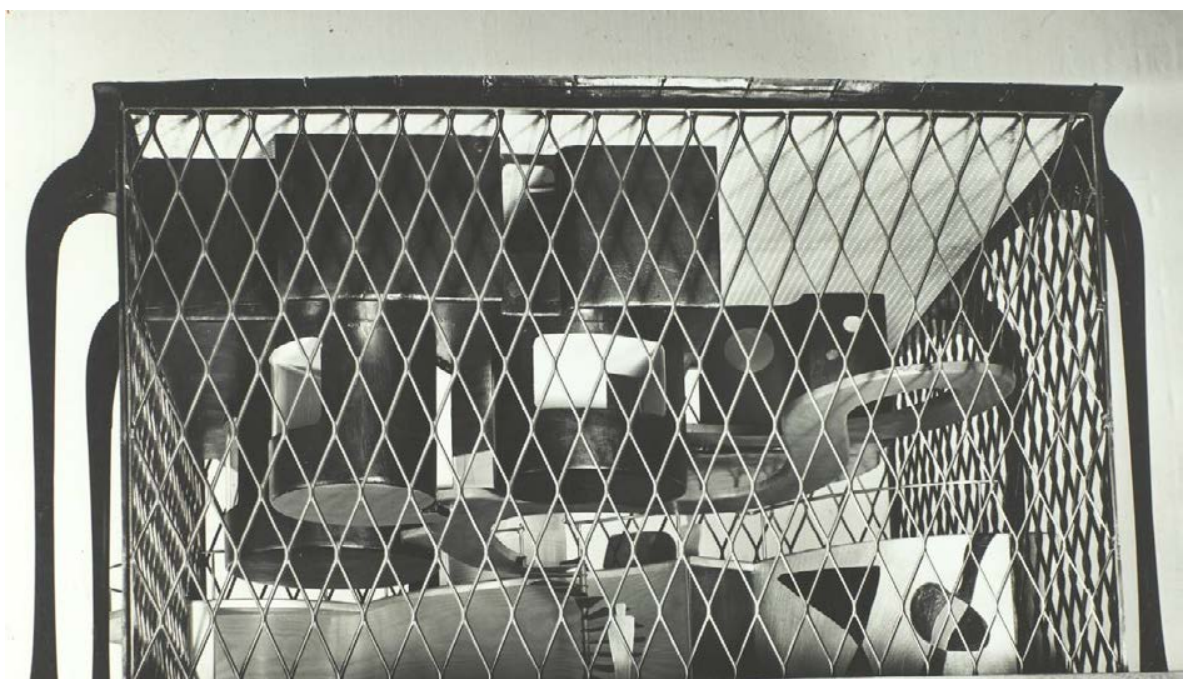

III. 36 La Maison Suspendue, Paul Nelson. Primera maqueta, ca .1938.

modelos de vida antitéticos, el inconformismo personal y la rigidez de la de la estructura familiar, debían convivir y mantener sus respectivas identidades.

La conservación de la propia singularidad dentro de la casa se construyó mediante el alejamiento físico y el control sobre el espacio socialmente opuesto. Esto convertía la planta de la vivienda en una delimitación de fronteras entre lo público y lo privado $^{256}$ para lo cual Paul Nelson centró su labor más en la fabricación de los límites del territorio individual que en la protección de la propia actividad que se desarrollaba en el interior de los ámbitos personales. La consecuencia directa de esta actuación fue la creación de unas estancias individuales, cuya cualidad era su indefinición funcional.

Paul Nelson solo consideraba el efecto liberador de la privacidad dentro de la casa, pero, como expresaba Hanna Arendt, el estado de lo privativo significaba literalmente: “...el estado de hallarse desprovisto de algo, incluso de las más elevadas y humanas capacidades"257. Por lo tanto, la delimitación del ámbito privado en La Maison Suspendue venía determinada por dos factores antagónicos: la imposición o la voluntad personal, siendo el retiro y la exclusión las dos únicas

\footnotetext{
${ }^{256}$ Antoine Prost en su texto Fronteras y espacios de lo privado, describe cómo la historia del espacio privado en Francia en el siglo XX era una cuestión de control de fronteras entre la esfera pública y la privada. Philippe Ariès y Georges Duby (dir.) Historia de la vida privada, Vol V Madrid: Taurus, 1989, p.15.

${ }^{257}$ Hanna Arendt, La condición humana, Barcelona: Paidós Ibérica, 1993, p.49.
} 
maneras de habitar el espacio individual ${ }^{258}$. Dentro de la vivienda, el lugar que obedecía a una disciplina de privacidad impuesta era el de la servidumbre ${ }^{259}$ y el que representaba la opción contraria, de elección personal, era el de las habitaciones individuales. Los dos territorios mantenían vínculos de exposición opuestos con respecto a los visitantes de la casa: el trabajo se ocultaba y el ocio se exhibía. La materialización de las diferencias entre ellos se consiguió mediante la aplicación de estrategias de separación, tanto espaciales como constructivas. ${ }^{260}$

La desintegración de las diversas funciones, (descanso, vestuario, aseo, estudio, etc) que habitualmente se desarrollaban dentro del dormitorio, tuvo como consecuencia directa la construcción de una habitación específica para la reflexión particular. La disposición exenta de estas celdas proporcionaba en la persona la sensación de habitar en la máxima expresión de la privacidad, superando el grado de intimidad de las cabinas para descanso, las cuales estaban proyectadas adosadas unas a otras y dentro de un bloque compacto. La configuración diseminada del ocio particular generaba tensión en las relaciones familiares ya que, por un lado, las celdas eran los lugares donde el individuo tenía mayor libertad para disfrutar aislado, y por otro, esa ubicación dispersa estaba acotada dentro de los límites del salón, lo cual facilitaba el control de los lugares de ocupación personal ${ }^{261}$ (III. 36).

La observación de las actividades desarrolladas en las estancias individuales y el deseo de Paul Nelson de convertir estas habitaciones en recintos de regeneración intelectual, aproximaban la estructura espacial de la casa al modelo de prisión

\footnotetext{
258 “...se identifican dos acciones que son el motor de la construcción del espacio individual: el retiro y la exclusión...”,Tesis doctoral de Ana Sofía Pereira La intimidad de la casa. UPM p.389.

259 Aunque en el área de servicio había estancias de trabajo colectivo, se considera que la servidumbre era un espacio privado, entendiendo que las actividades que allí se desarrollaban no lo hacían a la vista del resto de los habitantes de la vivienda.

${ }^{260}$ Las medidas de sectorización del área de servicio afectaban a su conexión con el resto de la vivienda, tanto con la parte privada como con las de uso social. Paul Nelson agrupó el espacio de trabajo en un bloque compacto y lo aisló del resto de la vivienda mediante un muro opaco. Se desdoblaron los recorridos y los accesos para evitar los encuentros entre los dos grupos de ocupantes de la casa e incluso los dos bloques se construyeron con materiales diferentes, el bloque de servicio con un material masivo y el resto de la casa con materiales ligeros.

${ }^{261}$ Las estancias interiores estaban iluminadas artificialmente y tenían ventanas abiertas al salón. Los huecos, convertidos en pantallas, suministraban información de las actividades de los ocupantes.
} 
descrito por Michel Foucault ${ }^{262}$, donde los prisioneros aislados en sus celdas eran controlados desde la distancia, a través de los huecos abiertos hacia el espacio central, donde se encontraba el vigilante. Por lo tanto, la propuesta de dispersar y aislar a los individuos para que estos pudiesen reconducir su conducta estaba cercana a los criterios enunciados por Michael Foucault ${ }^{263}$ en su descripción de los mecanismo utilizados por el poder para controlar lo anormal.

Al centrar la regeneración en un problema de conducta y prescindir de la incidencia de la función activa de las personas con la arquitectura, no se estaba contribuyendo a la creación de un espacio de libertad individual sino, como decía Hanna $\operatorname{Arendt}^{264}$ a la construcción del modelo conformista de la sociedad moderna. Así, el exhibicionismo de las habitaciones particulares condenaba al proceso de meditación a ser vigilado y juzgado desde el ámbito familiar.

\subsection{Cerrarse al exterior y abrirse en el interior.}

Paul Nelson consideraba que el avance de la sociedad era la consecuencia directa de la evolución paralela que experimentaban el individuo y el grupo. Y pensaba que con su labor como arquitecto podía contribuir a mejorar las condiciones de vida de la humanidad. La transposición de este pensamiento a la arquitectura se plasmó en la creación de las dependencias personales y en propiciar el avance del individuo dentro de su medio, que era la casa. Proyectó una vivienda descontextualizada, donde lo importante era proporcionar el mayor grado de retiro a la persona, para que su enriquecimiento moral repercutiese en el beneficio común. Con tal objetivo, se apoyó en la geometría y construyó el aislamiento mediante dos barreras, una racional y otra orgánica que eran, según Sifried Giedion ${ }^{265}$, las dos maneras de enfrentarse al entorno. La racional (externa) era el hueco abstracto que se recortaba con el muro para definir el orden del campamento frente al desorden de la naturaleza

\footnotetext{
${ }^{262}$ Michel Foucault, Vigilar y castigar. Nacimiento de la prisión, Buenos Aires: Siglo XXI, 1978, pp.120-121. [Surveiller et punir, París: Éditions Gallimard, 1975 ].

${ }^{263}$ Íbidem.

${ }^{264}$ Hanna Arendt, La condición humana, Barcelona: Paidós Ibérica, 1993, p.52.

${ }^{265}$ Sigfried Giedion, Espacio, tiempo y arquitectura. Origen y desarrollo de una nueva tradición, Barcelona: Reverté, 2009, (p.413) [Space, Time and Architecture: the Growth of a New Tradition. Cambridge: Harvard University Press, 1941].
} 


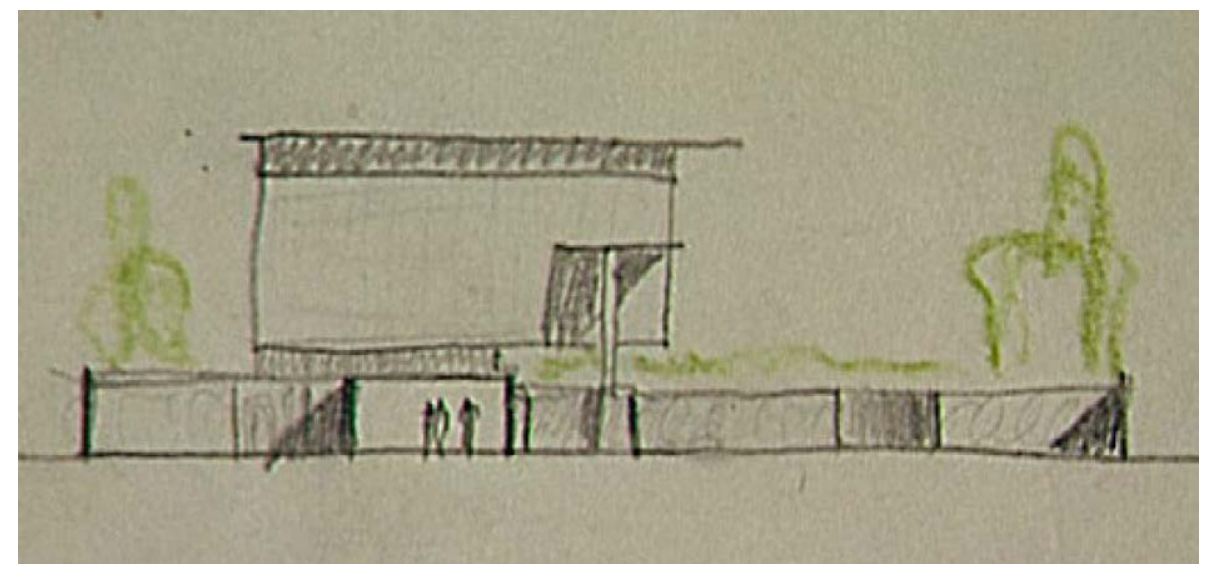

III. 37 Dibujos iniciales, alzado exterior, $c a 1936$.

y la orgánica (interna) era la geometría blanda y curva que se replegaba dentro del medio artificial para aislarse del cerramiento.

La adopción del modelo de casa patio romana proporcionaba, por un lado, el control sobre un fragmento del desorden natural y, por otro lado, suponía la identificación de la casa con el lugar del aislamiento, como apuntaba Hanna Arendt ${ }^{266}$. Por lo tanto, La Maison Suspendue generó un espacio cerrado de retraimiento, tanto físico como psíquico, del medio exterior, en cuyo centro se exhibían los recuerdos domesticados del mundo, con el objeto de que fueran reinterpretados ${ }^{267}$.

La vivienda era un lugar cerrado y autosuficiente, apoyado sobre la topografía plana, cuya relación con el paisaje era inexistente. La casa se mantenía en una posición de indiferencia y equidistancia respecto de la ciudad y de la naturaleza. Ni los huecos abiertos, ni la morfología de la vivienda estaban condicionados por el exterior. Tampoco la composición de la fachada, abstracta y neutra, transmitía información del interior, aunque la celosía era el borde activo que conectaba al habitante con el exterior $^{268}$.El vidrio curvo del comedor era el único hueco panorámico definido en

\footnotetext{
${ }^{266}$ La autora consideraba que la vivienda en Roma era un refugio temporal de la actividad en la res pública, Véase: Hanna Arendt, La condición humana, Barcelona: Paidós Ibérica, 1993, p.49.

${ }^{267}$ La zona central de la casa es ante todo un lugar en que los recuerdos del mundo exterior son "domesticados" y guardados para poder ser experimentados de nuevo. Véase: Kent.C.Bloomer y Charles W. Moore, Cuerpo, Memoria y arquitectura. Introducción al diseño arquitectónico. Madrid: H.Blume, 1982, p.63.

268 “...La arquitectura del filtro es consecuencia de este borde activo que enlaza dos lados inicialmente separados ...",Tesis doctoral de Miguel Guitart. Filtros de mirada y luz. Una construcción visual del límite arquitectónico. UPM, p.47.
} 


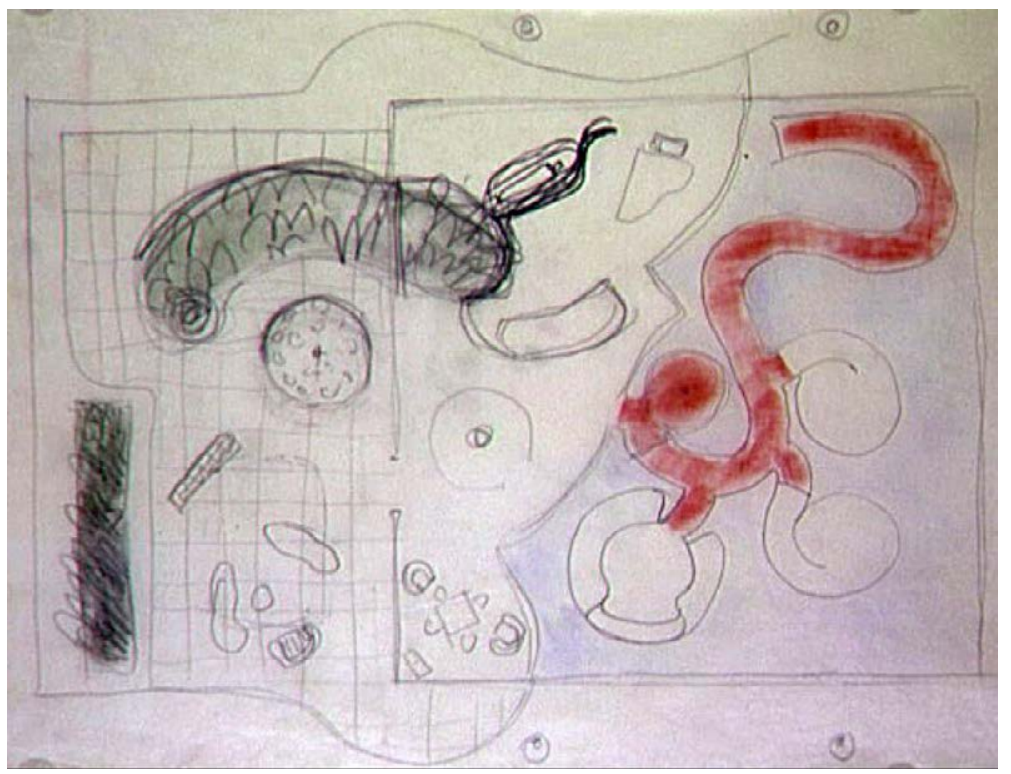

III. 38 Esquema de tratamiento de terraza y balcón de la planta primera. Paul Nelson, ca. 1938

proyecto, y los otros dos espacios abiertos al exterior, el gimnasio y la terraza del dormitorio principal, eran miradores ocultos tras la celosía continua del cerramiento.

Aunque en los dibujos iniciales (c.a.1936) aparecían elementos vegetales incorporados al contexto de la vivienda y un cerramiento previo a la propia vivienda (III. 37), este se fue difuminando y quedó reducido a una proyección en planta, donde se marcaban el acceso de vehículos y el contorno de parterres. La única referencia al emplazamiento que permaneció a lo largo del proyecto fue la orientación geográfica. Esta indicación generaba una "matriz de coordenadas psicofísicas"269, que ayudaba a las personas de la casa a mantener una primera relación general con el entorno.

Uno de los pocos intentos que se ensayaron para establecer una relación de la casa con el entorno cercano fue la terraza. En el croquis (III. 38), se apreciaba la actuación mediante una ordenación del mobiliario y las jardineras. Se proyectó una composición simétrica, que tomaba como eje el cerramiento de vidrio. Este orden creaba una continuidad espacial a partir de la asociación de duplicidades, cada objeto tenía su réplica al otro lado del muro de cristal y por lo tanto se introducía una tensión que vinculaba a los semejantes. Esto ayudaba a que las personas, a pesar de estar en un espacio exterior, no perdiesen la referencia de la casa al establecer

\footnotetext{
${ }^{269}$ Este concepto fue analizado al estudiar la relación entre el orden geográfico-físico y las experiencias corporales. Véase: Kent.C.Bloomer y Charles W. Moore, Cuerpo, Memoria y arquitectura. Introducción al diseño arquitectónico. Madrid: H.Blume, 1982, p.53.
} 
III. 39 Segunda maqueta, vista de los huecos de las estancias al salón, 1938.

mentalmente vínculos formales. Con esta disposición se prolongaba el orden doméstico en el exterior, con la misma estrategia que se había utilizado en el interior de la vivienda, la integración de los objetos exentos como parte de un conjunto superior se conseguía a través de sus relaciones internas. Finalmente, la intervención en la terraza quedó reducida a la disposición de las esculturas y la barandilla. Si la estrategia de relación de la casa con el exterior había sido cerrase, la relación entre las dependencias y el espacio común fue la contraria. El interior de la vivienda se proyectó como un espacio urbano, que tenía una plaza (el salón), una calle (la rampa), viviendas individuales (las celdas), residencias colectivas (los dormitorios) e incluso dotaciones deportivas (el gimnasio). Esta dimensión urbana convertía a la casa en un ensayo de la distribución de las relaciones humanas, que podían ser exportables a otros proyectos públicos, y provocaba confusión en el invitado ya que, al adentrase en este espacio central, desconocía si ocupaba un espacio interior o exterior y tampoco entendía si era público o privado, ya que era una residencia y lo que en ella sucedía era visible para todos los visitantes ${ }^{270}$.

${ }^{270}$ Beatriz Colomina, La doble exposición. Arquitectura a través del arte, Madrid: Akal, 2006, p.32. 


\subsection{El caparazón ergonómico individual flota sobre el salón}

Las estancias individuales se pensaron para ofrecer el confort psicológico que el individuo no podía conseguir en los espacios habituales de la vivienda. Y para eso se proyectaron unos caparazones que mantenían relación visual con el contexto inmediato, ya que, como afirmaba Gaston Bachelard, ${ }^{271}$ la concha estaba asociada al acto de salir y por lo tanto a la manera efusiva de abandonar un espacio confinado. Las celdas personales eran unas escafandras con máscara que, como sugería Beatriz Colomina ${ }^{272}$, permitían al hombre moderno avanzar introspectivamente, protegido y sin perder el contacto con el exterior. Estas unidades, también se proyectaron asumiendo el pensamiento expresado por László Moholy $\mathrm{Nagy}^{273}$ sobre la incapacidad de una simple envolvente de caparazón para generar por ella misma un espacio doméstico. Para superarlo, Paul Nelson combinó dos parámetros: la intimidad y el control sobre el exterior. (III. 39 )

La elección de la espiral, en forma de curva replegada sobre sí misma, como modelo de planta para las habitaciones individuales, fue adoptada por Paul Nelson como resultado de variables funcionales, sociales y antropomorfas. En primer lugar, la geometría curva, representativa el modelo de máxima funcionalidad según Adolf $B^{B e h n e} e^{274}$, fue la elegida para albergar las actividades que no eran maquinistas. En segundo lugar, la morfología de las estancias se explicaba como resultado de la categoría social que acogía y de sus previsibles relaciones con el entorno.

\footnotetext{
... En un principio parece que la idea de aislamiento del individuo sugiere (...)

la idea de una forma cerrada que contraste con la forma abierta de la arquitectura colectiva. ... ${ }^{275}$
}

\footnotetext{
${ }^{271}$ Gaston Bachelard, La poética del espacio, Mexico: Fondo de cultura económica, 1965 pp.107-109.

${ }^{272}$ Beatriz Colomina, Privacidad y Publicidad. La arquitectura moderna como medio de comunicación de masas, Murcia : Cendeac, 2010, p.43.

${ }^{273}$ Una vivienda no debería ser un repliegue para aislarse del espacio, sino una vida en el espacio. con esta afirmación, el autor marcaba una clara diferencia entre lo que significaba envolverse en un espacio y vivir en el espacio como elemento distintivo de la vivienda László Moholy Nagy, La nueva visión y reseña de un artista, Buenos Aires: Infinito, 1963, p.110.

${ }^{274}$ Adolf Behne, 1923. La Construcción Funcional Moderna Barcelona:.Serbal, 1994, p.55.

${ }^{275}$ Paul Nelson, La Maison Suspendue. Recherche de Paul Nelson. (L'Architecture Vivante), París: Albert Morancé, 1939
} 

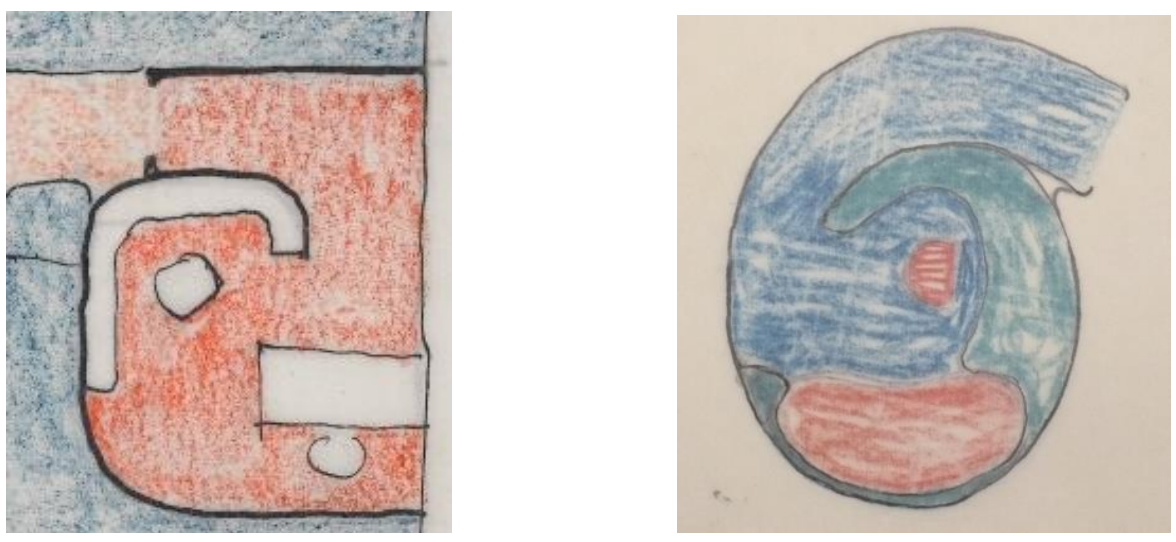

III. 40 Bocetos de las celdas individuales, $c a .1936$.

III. 41 Bocetos de las celdas individuales, $c a .1938$.

$\mathrm{Y}$, finalmente, los referentes antropomórficos fueron los que llevaron al proyecto a una línea de forma blanda, que simbolizaba lo orgánico (III. 40-III. 41).

La planta espiral de las capsulas incidía tanto en la manera de adentrase, tangencialmente a través de un cuello de transición, como en el modo de desplazarse en el interior, moviéndose por la estancia alrededor de un espacio vacío central, y en la forma de acomodarse en el mobiliario perimetral, aproximándose a los muros y dando la espalda al vacío central. Aunque para satisfacer las necesiades personales, se trató de que la arquitectura y el mobiliario contribuyeran a construir el mismo proceso ergonómico, la evolución formal de la estancia y la configuración del mobiliario discurrieron por caminos opuestos. Así, conforme la habitación adquiría mayor autonomía geométrica, el mobiliario la perdía, los muebles dejaron de ser objetos aislados e independientes y se fueron adaptando a la pared curva del muro hasta empotrarse dentro.

En el La Maison Suspendue se aplicaron unas jerarquías formales basadas en la aproximación corporal, similares a las que Kenneth Frampton ${ }^{276}$ apreció en la obra de Le Corbusier, donde las formas más puras eran las utilizadas para los recintos generales y la geometrías más ergonómicas para las estancias que se acercan al individuo. Así, cuando Paul Nelson proyectó los espacios comunes, de mayores dimensiones, optó por una geometría abstracta y regular, cuyo objetivo era que los individuos pudiesen relacionarse entre ellos con independencia del perímetro. $\mathrm{Y}$, por

\footnotetext{
${ }^{276}$ Kennet Framton, Le Corbusier, Madrid: Akal, 2002, p.22.
} 


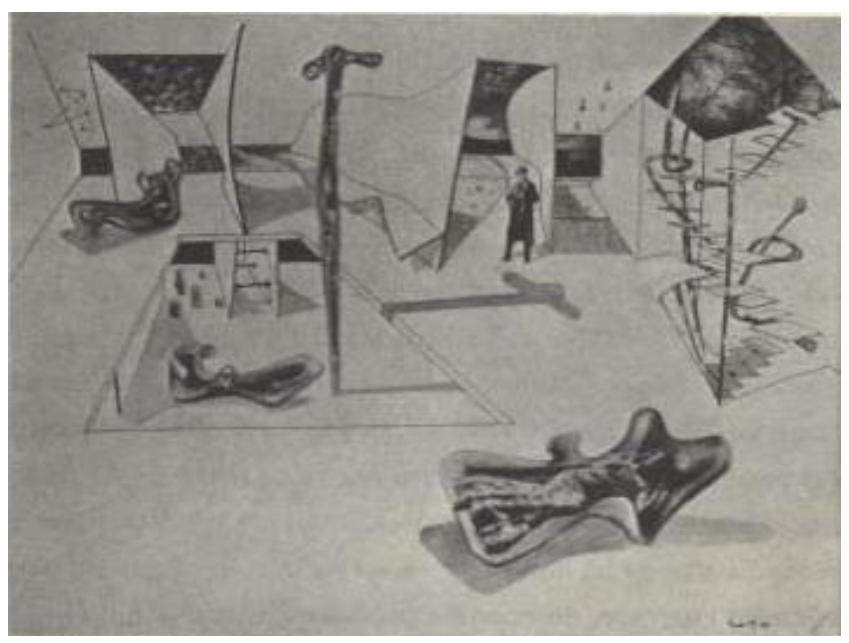

III. 42 Maqueta de apartamentos, Roberto Matta, 1938

el contrario, cuando creó las estancias privadas trabajó con formas curvas, que incidían de manera más intensa en la relación de la envolvente con el ocupante. Simultáneamente al desarrollo del proyecto, desde otras disciplinas creativas también se asociaban los conceptos de orgánico y antropomórfico con la arquitectura. Así para el poeta Tristan Tzara ${ }^{277}$, la arquitectura del porvenir sería "intrauterina", si realmente se ocupaba del problema del confort individual y se olvidaba del papel de intérprete y servidora de la burguesía. Y, para el pintor chileno Roberto Matta, la arquitectura debía ser lo suficientemente blanda como para facilitar el acogimiento de la persona ${ }^{278}$. Roberto Matta ilustró su idea mediante el dibujo que denominó "maqueta de apartamentos" (III. 42), que representaba un espacio que estaba conceptualmente próximo a La Maison Suspendue. Se trataba de un contenedor donde las estancias eran piezas exentas e independientes, que albergaba mobiliarios de líneas curvas.

Aunque Nelson adoptó el modelo antropomorfo para construir el interior de su casa, no intentaba simbolizar aspectos oníricos de los individuos y convertir el inconsciente en metáfora de la vivienda, sino que su objetivo era evocar la vida. Para lograrlo asumió como referente el funcionamiento orgánico y convirtió la caja torácica que albergaba las vísceras en la metáfora del espacio doméstico, donde las celdas individuales flotaban sobre el espacio del salón.

\footnotetext{
${ }^{277}$ Tristan Tzara, "D'un certain automatismo du goût", Minotauro, nº3-4,1933, p.84.

278 Roberto Matta, "Matemática sensible, arquitectura del tiempo", Minotauro 1938 Véase: Juan Antonio Ramirez, Edificios Cuerpo, Madrid : Siruela, 2003.
} 


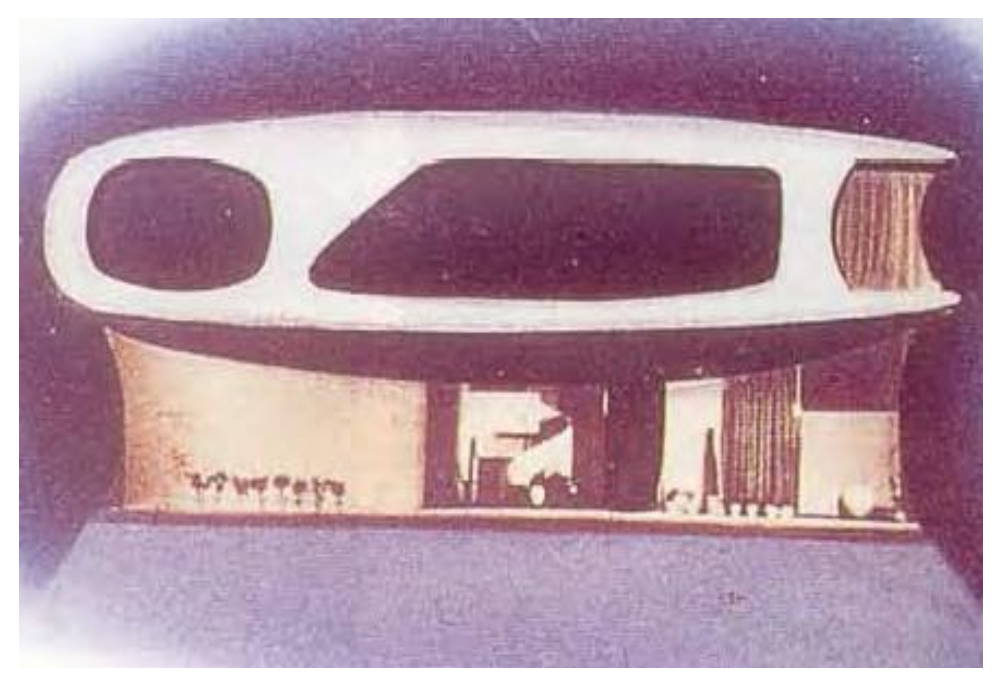

III. 43 The Space-House, vista frontal de la maqueta, Frederick Kiesler, 1933

El historiador Geoffrey Scott ${ }^{279}$ había analizado la incidencia que producían las organizaciones espaciales del Renacimiento en el observador y había llegado a la conclusión de que la creación de una arquitectura antropomórfica, que se acercase al hombre, solo era posible si se lograba transponer la imagen de las funciones humanas. Este trabajo sirvió de precedente a arquitectos como Paul Nelson y a Frederick Kiesler, en su búsqueda de una arquitectura más humana. Frederick Kiesler se anticipó a Nelson, cuando calificó la arquitectura de su vivienda "The Space-House" (III. 43) como "biotécnica". ${ }^{280}$ Se trataba de una casa pensada para satisfacer la tensión espacial creada entre los habitantes y el proyecto. En la casa de Paul Nelson la satisfacción se podía obtener de manera individual, siendo esta la vía más intensa por la que la persona y el hábitat doméstico llegaban a confluir.

\footnotetext{
${ }^{279}$ Geoffrey Scott, The Architecture of Humanism. A Study in the History of Taste. Boston: Houghton Mifflin Company, 1914, pp.211-217.

${ }^{280}$ La arquitectura como biotécnica, debía de ocuparse de establecer la interrelación del cuerpo con su entorno, espiritual, físico, social y mecánico. Con el objetivo de posibilitar un enfoque humanístico que contribuyera al desarrollo individual. Frederick Kiesler, "Notas on Achitecture, The Space-House. Annotations at Random", Hound and Horn, n ${ }^{\circ}$ 7.2, 1934, (p.293-297). visto de José Luis Luque Blanco, Contínuum cósmico:Frederick Kiesler(18901965), Barcelona: Fundación Caja de Arquitectos,2012, pp.97-99.
} 


\subsection{La defensa del espacio inútil}

En el año 1937, Abraham Fleexener, director del Institute for Advanced Study de Princeton, escribió un ensayo para defender la investigación libre de ataduras utilitaristas e inspirada en la mera curiosidad.

... Mi pretensión en este artículo es ocuparme del problema de hasta qué punto la búsqueda de estas satisfacciones inútiles se revela inesperadamente como la fuente de la que deriva una utilidad insospechada. ${ }^{281}$

El autor se preguntaba, como lo formularía Paul Nelson en 1938, si la definión de lo útil no era demasiado estrecha como para albergar las necesidades más caprichosas del espíritu humano, que eran aquellas que lograban satisfacer el alma individual para hacerla más pura y elevada. Siguiendo un criterio paralelo al de Abraham Fleexener, el espacio de La Maison Suspendue se clasificó en dos categorías acorde con el uso:"útil" e "inútil" ${ }^{282}$. Se entendía por útil aquel espacio que estaba proyectado para realizar actividades concretas y se entendía por inútil lo opuesto, aquel ámbito destinado a un uso intelectual indeterminado. Para Paul Nelson, la formación de pensamiento personal se podía adquirir tanto en estancias colectivas, a través del arte (§ III. 3.), como en las dependencias individuales, a través de la reflexión. Fue la construcción de estas habitaciones lo que dotó a la vivienda de nuevo contenido.

Esta variación de matices del uso doméstico enriquecía el concepto del espacio privado, y su aplicación permitía establecer diferencias entre las estancias individuales y el resto de las dependencias privadas ya que tanto los dormitorios como los baños estaban destinados a funciones íntimas predefinidas, mientras que las unidades individuales no lo estaban. De esta manera, la variedad del uso particular del espacio ampliaba el programa funcional de la vivienda a nuevas actividades intelectuales, que tenían la singularidad de desarrollarse solo de manera individual, a diferencia de lo que podía suceder con las experiencias de intimidad.

\footnotetext{
${ }^{281}$ En el artículo titulado " The Usefulness of Useless Knowledge" fue publicado en octubre de 1939 por Haper's Magazine, (pp.544-552). El autor elabora un discurso basado en el hallazgo inesperado de grandes descubrimientos científicos surgidos a partir de otras investigaciones. Se defendía la búsqueda libre de conocimientos inútiles como vía para lograr el avance científico. Véase: Nuccio Ordine, La utilidad de lo inútil. Manifiesto, Barcelona: Acantilado, 2013, p.153.

${ }^{282}$ Paul Nelson, La Maison Suspendue. Recherche de Paul Nelson. (L'Architecture Vivante), París: Albert Morancé, 1939.
} 
Los arquitectos del Movimiento Moderno también habían reflexionado sobre nuevos usos de ámbito personal. Walter Gropius reclamó un espacio individual para aislarse dentro de la vivienda moderna ${ }^{283}$ y Le Corbusier, en su enumeración de las habitaciones que debía tener la vivienda, mencionaba una estancia para trabajar diferenciada del ámbito colectivo ${ }^{284}$. En el caso de La Maison Suspendue, la construcción del espacio privado derivó de una manera maleable de habitar, que estimulaba el disfrute personal. Aunque los artefactos móviles de la Maison de Verre (§ II. 2.), fueron los referentes del uso flexible de una casa. Paul Nelson no proyectó una obra articulada, ni mediatizada por la relación corporal con elementos desplegables, se entendía que la maleabilidad espacial no se apoyaba en campo de lo físico sino que se construía con materia intangible.

El espacio "inútil" de la casa no era disfuncional, ni obsoleto, ni era un cuarto trastero, tampoco era una estancia sin función para no hacer nada, como la que buscaba Georges Perec ${ }^{285}$. Su función no estaba definida, pero estaba acotada en el territorio del ocio, tenía una forma concreta y una fabricación industrializada, contraviniendo las leyes de producción que habitualamente se han adjudicado a los objetos inútiles ${ }^{286}$. Así lo mostraban los planos finales de la vivienda, donde el mobiliario de estas dependencias individuales se dibujó con el mismo grado de detalle que aparecía en otras estancias funcionales, como los baños o los dormitorios. (III. 41). Las habitaciones inútiles representaba todo lo contrario de un espacio baldío, la estancia privada individual concentraba la esencia de La Maison Suspendue, era un espacio que tenía como objetivo interactuar con el ocupante e influir en su reflexión de eremita.

\footnotetext{
${ }^{283}$ Para Walter Gropius, la modernidad había transformado los límites entre la esfera pública y la privada provocando que algunas necesidades fuesen demandadas fuera de los dominios de la casa, como los estímulos espirituales. Para afrontar los cambios sociales, consideraba que en el programa de la vivienda se debería enunciar como exigencia mínima: "Una habitación, aunque pequeña para cada persona adulta", donde el individuo pudiese aislarse. Véase: Walter Gropius "Los fundamentos sociológicos de una vivienda mínima (para la población obrera de la ciudad)" en Carlo Aymonino, La vivienda racional. Ponencias de los congresos C.I.A.M 1929-1930, Barcelona: Gustavo Gili, 1973, p.121.

${ }^{284}$ Le Corbusier, Hacia una Arquitectura, Buenos Aires: Poseidon, 1964, ( p. 90) [Vers une architecture, París: Éditions Crès, Collection de "L'Esprit Nouveau", 1923].

${ }^{285}$ Georges Perec, Especies de espacios, Barcelona: Montesino, 1999.pp.59-61.

${ }^{286}$ Bernard Tschumi menciona que una de las cualiaddes de cualquier objeto inútili es su nulo valor de mercado. Véase Bernard Tschumi, Architecture and Disjunction, Cambridge: The MIT press, 1996, pp.28-35.
} 
La celda era una pieza que no sólo albergaba una función indeterminada, sino que tenía que incitar al desarrollo de otras actividades enriquecedoras y placenteras. Estas nuevas ocupaciones no debían estar vinculadas exclusivamente al hedonismo de la persona, ya que el concepto de inutilidad no sólo derivaba en placer, como asegura Bernard Tschumi $^{287}$, sino que también emanaba energía para reactivar la meditación. La habitación inútil debía funcionar como un organismo, que no sólo absorbiera programa, material o inmaterial, sino que también pudiera exudarlo. Por lo tanto, la interacción suponía que, además de la participación del ocupante, la arquitectura, aunque no fuese una máquina para fabricar individuos mejores y más felices, debía mantener un papel activo y provocador. Para conseguir ese efecto, Paul Nelson construyó lo que Herman Hertzberger califica como "forma polivalente" ${ }^{\text {288, }}$, una pieza que se adapta a una mutación permanente, pero manteniendo su identidad.

Con la defensa de un espacio "inútil" necesario, Paul Nelson marcaba una postura que era a la vez distante y continuista, con respecto a la arquitectura moderna precedente. Por un lado, suponía una mirada crítica respecto a una visión racionalista basaba en la eficiencia formal y funcional. Y, por otro lado, la fragmentación del uso privado en diferentes cualidades generaba una segregación en habitaciones específicas, que representaban una extensión del funcionalismo al terreno inmaterial. De esta manera, Paul Nelson confluía con la tesis de Adolf Behne, para quien el aislamiento y el individualismo absoluto, era la fuerza última del funcionalismo consecuente ${ }^{289}$.

Para Paul Nelson, el uso y la ocupación individual del espacio abrían una nueva vía de exploración para humanizar el hábitat doméstico. Se incorporó como función del programa la percepción inesperada del uso y la consecuencia inmediata de este proceso fue la reactivación de la manera de habitar. Se otorgó al proyecto una dimensión extra con la que no se contaba, la configuración del confort psicológico.

\footnotetext{
${ }^{287}$ Para el autor la sensación del placer espacial derivaba de dos conceptos: la inutilidad espacial, entendida como lo opuesto a la utilidad esperada por la sociedad y la disfunción espacial, entendiendo como tal la apropiación accidental o intencionada de un espacio para dedicarlo a un uso diferente al previsto. Vease Bernard Tschumi: "The Pleasure of Architecture", Architectural Desing n³, 1977, p.118.

${ }^{288}$ Es una forma que puede servir para diferentes usos sin tener que estar sometida a un cambio constante de sí misma, véase: Herman Hertzberger, Lessons for students in architecture, Rotterdam: Herman Hertzberger / Uitgeverij 010 Publishers, 1991
}

${ }^{289}$ Adolf Behne, 1923. La Construcción Funcional Moderna Barcelona: Serbal, 1994, p.62. 


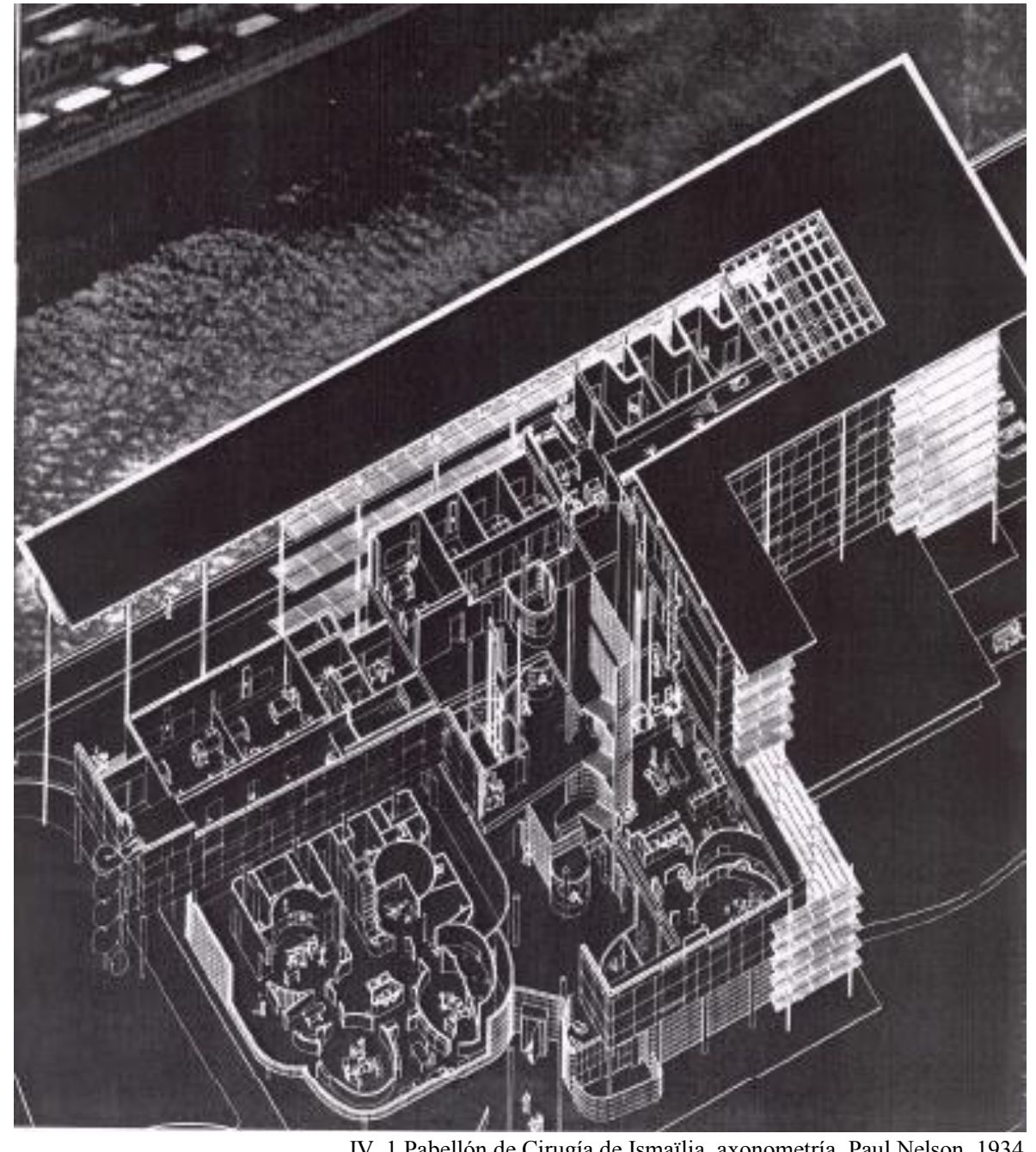

IV LA EXTENSIÓN DE LA MATRIZ DOMÉSTICA. 


\section{La proyección del espacio individual en la arquitectura residencial.}

De toda la carrera profesional de Paul Nelson, su arquitectura residencial ha sido la menos conocida. Este trabajo fue cuantitativamente inferior a sus encargos de arquitectura sanitaria, pero la obra doméstica le aportó un bagaje que repercutió de manera notable en el resto de sus proyectos, un proceso de influencia de escalas que había sido común en otros arquitectos coetáneos del Movimiento Moderno.

Toda su arquitectura residencial pivotaba alrededor de La Maison Suspendue. Desde su primer encargo profesional, la reforma de un apartamento en Chicago en 1927, hasta el último trabajo, su vivienda familiar cerca de Marsella en 1976, su objetivo fue la creación de un espacio doméstico que se pudiese habitar sin instrucciones. Existía un paralelismo entre la misión que se adjudicaba a la arquitectura con respecto a su uso y el papel que adoptaba La Maison Suspendue con respecto a toda la obra. De igual manera que la arquitectura, según Paul Nelson, debía cubrir y ampliar el programa de usos, La Maison Suspendue condensaba los ensayos domésticos previos y contenía las bases que servían de sugerencia para desarrollar los trabajos posteriores.

Los encargos de arquitectura residencial fueron en su mayor parte viviendas unifamiliares $^{290}$. De entre todos los proyectos, se han seleccionado aquellos que mantienen vínculos directos con La Maison Suspendue y permiten realizar un análisis contrastado. Dado que el objetivo es mostrar la repercusión de la casa, los proyectos se han ordenado cronológicamente y, excepto el primer ejemplo, el resto de las obras son herederas de la vivienda modelo. Todas las casas analizadas comparten la condición de ser individuales. Hay encargos particulares, obras oficiales y construcciones familiares de autoencargo. Paul Nelson construyó los vínculos entre sus casas a través de dos herramientas: la primera fue la utilización de elementos invariantes del proyecto doméstico (la chimenea, el porche, la entrada principal orientada al Norte) de manera reiterativa ${ }^{291}$, y la segunda fue el desarrollo práctico de algunos de los conceptos que sustentaban La Maison Suspendue (flexibilidad, continuidad, prefabricación, suspensión, arte y aislamiento)

\footnotetext{
${ }^{290}$ Paul Nelson desarrolló proyectos de vivienda colectiva, aunque los encargos fueron escasos. Durante la Segunda Guerra Mundial trabajó para la administración de los Estados Unidos y en la posguerra, en colaboración con otros arquitectos, y construyó unidades residenciales para el gobierno de Francia.

${ }^{291}$ En todas las viviendas de Paul Nelson, excepto en La Maison Suspendue, la chimenea era la pieza central, en torno a la cual se construía el corazón de la casa.
} 


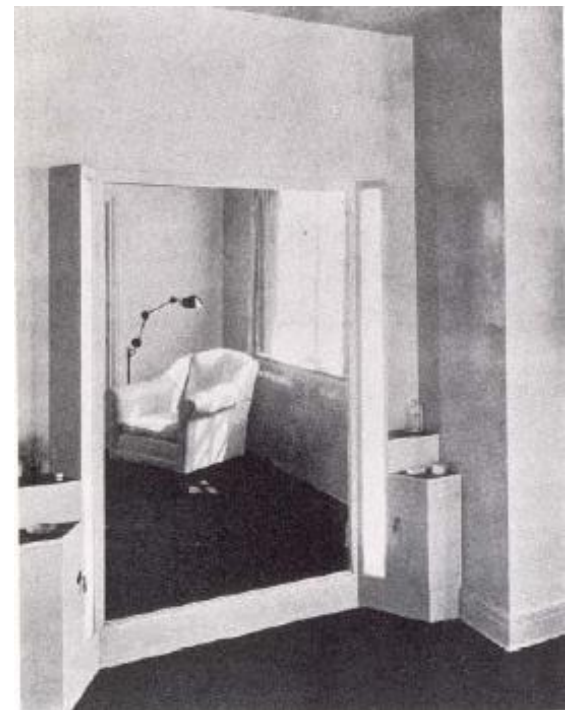

IV. 2 Reforma de apartamento en Chicago, Paul Nelson, ca. 1927

\subsection{Aproximaciones. Modernidad y racionalismo.}

En la primera etapa de su vida profesional, hasta el inicio de los años treinta, el trabajo de Paul Nelson resultó ser una consecuencia de su paso por Beaux Art, ya que utilizaba el orden estructural, las composiciones simétricas y la construcción masiva, heredadas de Auguste Perret, y las combinaba con la concepción espacial y con el lenguaje iconográfico de la arquitectura doméstica de Le Corbusier, como ya se ha analizado en ( $§$ II. 2.).

Reforma de apartamento en Chicago, 1927. La creación del rincón.

La primera obra residencial que abordó Paul Nelson, tras obtener su diploma en 1927, fue la reforma de un apartamento en Chicago (§ I. 2.). Se trataba de una intervención mínima, de la cual solo se conservan fotografías y que solo afectó a divisiones y mobiliario. El proyecto se resolvió con un lenguaje moderno basado en la línea recta y se ensayaron conceptos arquitectónicos que después fueron integrados en La Maison Suspendue, como la continuidad espacial entre dos piezas que estaban dispuestas a diferentes alturas, que se resolvió eliminando la puerta y liberando el hueco entre las estancias. La diversidad funcional de cada pieza del mobiliario se manifestaba con un volumen diferente y el ámbito de esparcimiento personal quedó definido con la ubicación del sillón, protegido en la esquina de la sala, aislado del exterior y dispuesto para el control el espacio interior de las dos estancias, de manera simultánea. (IV. 2). 
Casa Alden Brooks (1928-1930). La búsqueda de la función.

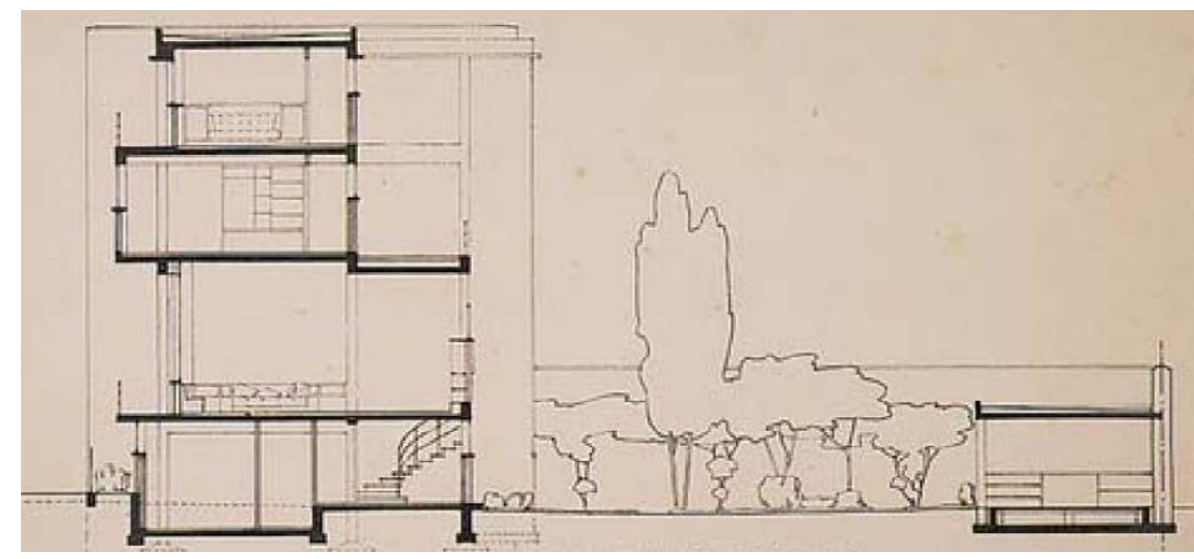

IV. 3 La Casa Alden Brooks, sección transversal, Paul Nelson, 1929.

El encargo fue realizado por el escritor americano Alden Brooks ${ }^{292}$ y su esposa, la pintora Hilma Chadwick. Se trataba de una casa en el Boulevard Arago de París. La vivienda ocupaba un solar estrecho, de $12 \mathrm{~m}$ x $29 \mathrm{~m}$, donde se proyectó un volumen de tres alturas más una planta baja, que estaba retranqueado y liberaba un pequeño jardín delantero . La casa tenía un único acceso centrado para vehículos y peatones, de manera que la calle quedaba comunicada, a través de un zaguán, con el jardín posterior y con la pieza de garaje dispuesta al fondo de la parcela. (IV. 3).

El proyectó fue el resultado de combinar el pensamiento racionalista con la arquitectura moderna. Por un lado, tanto el orden estructural de hormigón como la solución constructiva (el hormigón estructural visto y los ladrillos contrapeados) eran influencia de su maestro Auguste Perret (§ II. 2.) y por el otro, las divisiones internas y la búsqueda de una planta libre estaban inspiradas en Le Corbusier. Paul Nelson comprobó que la envolvente y el espacio interno podían funcionar de manera independiente y sin condicionantes previos y proyectó un orden estructural rígido, que, junto a una composición simétrica de la planta, creó una jerarquía espacial entre las estancias. El esquema de la planta se organizó mediante una pieza central, donde se ubicaba la función principal, y dos cuerpos laterales para actividades complementarias. Dentro de cada una de estas tres partes, la tarea más representativa

\footnotetext{
${ }^{292}$ La biografía de Alden Brooks (1882-1964) tiene algunos puntos en común con la de Paul Nelson. Ambos estudiaron en universidades norteamericanas y posteriormente, los dos participaron como voluntarios en apoyo de los aliados en La Gran Guerra. Durante el desarrollo del proyecto de su casa, Alden Brooks publicó el libro Battle in 1918, As Seen by an American in the French Army, en el cual contaba sus experiencias de la Guerra.
} 


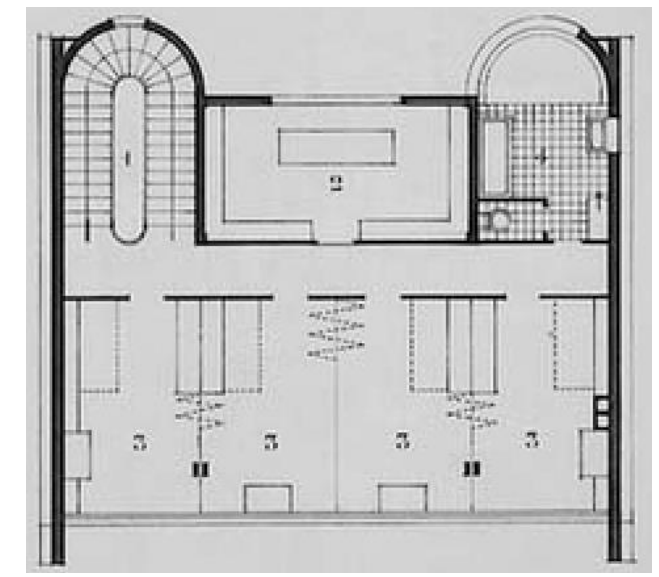

IV. 4 Casa Alden Brooks, planta segunda. Paul Nelson, 1929

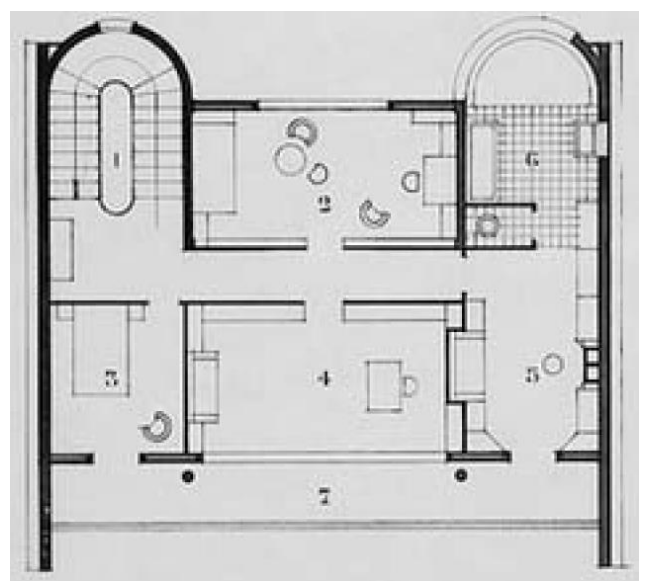

IV. 5 Casa Alden Brooks, planta tercera. Paul Nelson, 1929

se ubicaba en la estancia vinculada a la calle y la actividad menos singular se situaba al fondo, próxima al jardín. En este proyecto, Paul Nelson ya abordó conceptos como la continuidad, la flexibilidad, la funcionalidad, la privacidad y la construcción del espacio personal, que posteriormente desarrolló en La Maison Suspendue. Pero lo hizo utilizando forjados superpuestos y plantas independientes, lo que limitaba el efecto buscado.

Dado que las conexiones verticales estaban reducidas a los núcleos de comunicación, la continuidad espacial se quedaba confinada en cada altura y dependía de la liberación de la planta. En la Casa Alden Brooks, se trabajó con dos herramientas para conseguir la unidad espacial: por un lado, se suprimieron las divisiones interiores y se logró que todo funcionase como un solo espacio, como sucedió en la planta primera, donde estaba el salón y todas las actividades eran públicas y por otro lado, se crearon circulaciones múltiples, con nuevos recorridos 
alternativos a los ya predeterminados, los accesos entre las estancias contiguas se dispusieron enfrentados generando mayor continuidad. (IV. 5). Dado que la fragmentación espacial aumentaba con la altura por necesidades del programa, se decidió preservar las separaciones y conectar toda la planta, transformando las estancias en circulaciones. Estas dos herramientas se trasladaron a las tres dimensiones para hacer de La Maison Suspendue un lugar de espacio único.

Los tabiques fuelle de la planta segunda permitían configurar diferentes tipos de habitación entre los dormitorios contiguos (IV. 4). Los mecanismos de plegado proporcionaban una flexibilidad espacial, que alteraba tanto la funcionalidad como la privacidad, lo cual permitía una mejor adaptación de los espacios a las eventuales necesidades. Aunque los elementos desplegables fueron abandonados como herramientas para conseguir el confort doméstico, los tabiques fuelle representan el antecedente de las articulaciones desmontables que permitían eliminar o añadir habitaciones individuales en La Maison Suspendue.

Aunque, como ya se ha visto, la correspondencia entre las actividades y las estancias podía verse alterada, el esquema de planta adjudicaba a cada dependencia un uso principal previsible. Así, tanto las funciones mecánicas como las actividades espirituales o intelectuales tenían asociado un espacio determinado dentro de la casa. No todas las habitaciones estaban proyectadas con el mismo grado de rigidez funcional, los espacios sociales eran los más flexibles y las habitaciones privadas eran las más resistentes al cambio. En el salón que compartía estancia con el comedor, Paul Nelson utilizó la disposición del mobiliario, la presencia de obras de arte y la ubicación de la chimenea para consolidar espacios donde las personas se pudieran agrupar para compartir impresiones y este esquema fue retomado en $\mathrm{La}$ Maison Suspendue. En los dormitorios de los hijos, las funciones de descanso y trabajo podían variar de tamaño e incluso desaparecer según las necesidades. Dentro de la rigidez que marcaban las cajas de cada estancia, se intentó que las personas pudiesen disfrutar de sus relaciones adaptándose a un orden variable.

El programa doméstico de la Casa de Alden Brooks se organizó siguiendo criterios de privacidad, adelantándose al orden empleado en La Maison Supendue. Así, los espacios servidores se ubicaron en la planta baja, los espacios de relación en planta primera y el área de descanso en las plantas superiores. También se proyectaron dos núcleos de comunicación, uno de uso compartido y otro de uso exclusivo para la servidumbre. 


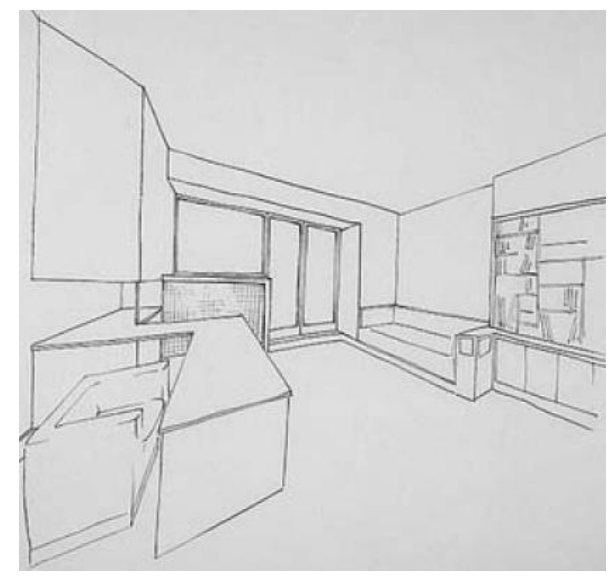

IV. 6 La Casa Alden Brooks, perspectiva del estudio del escritor. Paul Nelson, 1929

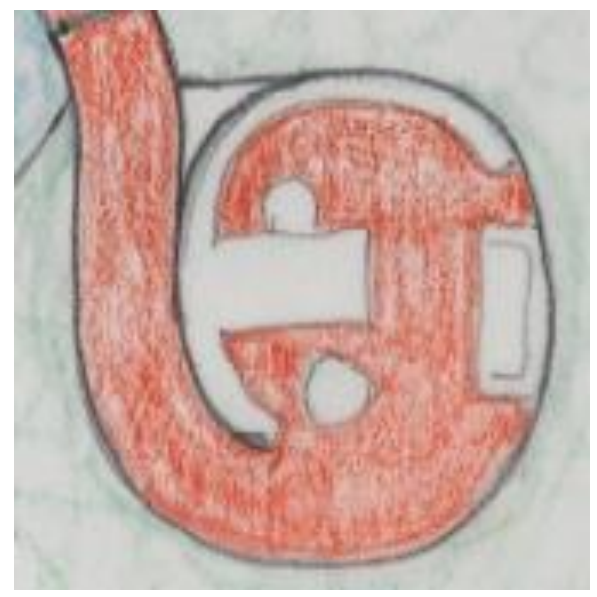

IV. 7 La Maison Suspendue, planta de la habitación de ocio individual. Paul Nelson, ca 1936

En la última planta se construyó un apartamento de uso exclusivo para el matrimonio, se fragmentó el programa funcional del dormitorio (descanso, vestuario, aseo y ocio) en diferentes estancias. Así mismo se dispusieron dos estancias respectivas para el desarrollo intelectual y laboral del matrimonio ( IV. 6). Estas dos habitaciones individuales destinadas a un uso concreto ( trabajo y ocio) fueron el germen de las celdas individuales que Nelson proyectó una década después. (IV. 7). 


\subsection{La aplicación de lo aprendido.}

A su vuelta de los Estados Unidos, tras la Segunda Guerra Mundial, Francia estaba destruida y los únicos encargos posibles eran los que procedían de la administración. En estos trabajos, Paul Nelson desarrolló una arquitectura eminentemente práctica, comparada con la década experimental de los años treinta y en ellos pudo aplicar los conocimientos de la industria de la construcción aprendidos en Norteamérica. Posteriormente, en la década de los cincuenta, tuvo encargos de viviendas unifamiliares, donde contó con la complicidad de los clientes para desarrollar sus propios conceptos arquitectónicos y donde pudo materializar algunos de los elementos que había dejado enunciados en La Maison Suspendue.

Maison mínimum en pierre, Noisy-le-Sec (1946-1947). La reconstrucción prefabricada del hábitat devastado.

El gobierno francés, a través del Ministère de la Reconstruction et de l'Urbanisme (M.RU), elaboró un plan de reconstrucción de todas las ciudades destruidas en la Segunda Guerra Mundial. Entre las propuestas de recuperación, se proyectó edificar un barrio experimental denominado "Merlan" en la ciudad de Noisy-le-Sec. ${ }^{293}$ Aunque el planteamiento urbanístico del nuevo asentamiento era heredero de las ciudades jardín del siglo XIX, el programa general era más ambicioso, ya que el (M.RU) pretendía usarlo como lugar de ensayo para realizar otros asentamientos posteriores. Se convocó un concurso y en las bases se solicitaba proyectar un alojamiento moderno, tanto en el exterior como en el interior, que garantizase el confort de los futuros habitantes. La propuesta debía resolver un prototipo de vivienda mínima prefabricada, que optimizase el orden del espacio interno e incorporase los avances tecnológicos, tanto en lo referente a materiales como a los

\footnotetext{
293 Tras la Segunda Guerra Mundial, el cinturón de ciudades situadas al noreste de París quedó devastado. El (M.R.U) desarrolló un programa de reconstrucción integral en estas poblaciones, una de las actuaciones más relevantes se desarrolló en la ciudad de Noisy-le-Sec, donde se intervino en dos zonas, con diferente densidad y distintos tipos de alojamientos. Por un lado, en 1946 se proyectó la Cité Expérimentale de Merlan, un barrio de 55 viviendas unifamiliares, donde equipos internacionales de arquitectos compitieron para levantar prototipos de casas experimentales. Por otro lado, en 1950 se planeó un barrio de alojamientos colectivos situado junto a la estación de tren. El gobierno encargo al equipo formado por Paul Nelson, Roger Gilbert y Charles Sebíllotte, un edifico en la Rue Jean Jaurés que terminaron en 1953. Era un conjunto de tres bloques exentos unidos en planta baja. La obra se ejecutó con elementos prefabricados y el revestimiento se realizó con piedra artificial. Véase, Benoît Pouvreau,"Quand communisme municipal rimait avec laboratoire urbain 1944-1986", jornadas, Les territories du communisme Élus locaux, politiques publiques et sociabilités militantes, París : Université Paris 1, 2009.
} 
procesos constructivos y las instalaciones ${ }^{294}$. En el proyecto también se debía aportar una propuesta de mobiliario, acorde a los principios de estandarización e industrialización de estos nuevos hogares.

Paul Nelson, en colaboración con los arquitectos Roger Gilbert y Charles Sebíllotte, proyectó una vivienda prefabricada en piedra, distribuidos en una sola planta (IV. 8). El Programa se organizó, siguiendo las bases del concurso, en tres zonas funcionalmente separadas e independientes (estar-ocio, descanso y trabajo doméstico). El objetivo era que cada actividad de la vida familiar se desarrollase en un espacio concreto, sin interferir negativamente en el desarrollo general de la vida de la casa. En su propuesta se permitía la convivencia de las actividades comunes en el espacio familiar con la privacidad del espacio individual.

La continuidad espacial de la planta estaba condicionada por el trazado de las circulaciones y la disposición de elementos de mobiliario, dos herramientas que ya habían sido ensayadas en La Maison Suspendue. Se proyectaron recorridos circulares que conectaban las unidades funcionales entre sí, generando diferentes alternativas de movimiento, y en el punto de intersección de los tres bloques de actividades se dispuso un mueble compartido, con acceso desde dichos ámbitos, que creaba un foco funcional y generaba una continuidad espacial en el centro de la vivienda.

\footnotetext{
${ }^{294}$ El (M.R.U) desarrolló en "Merlan" un sistema de control que abarcó todo el proceso de ejecución y la posterior respuesta de los habitantes. Se chequearon los sistemas de calefacción, refrigeración, iluminación y ventilación, y también se sometió a ensayos a los materiales de construcción. En las bases se del concurso, se tomó como modelo social la familia con dos hijos, en el cual la mujer solo trabajaba en casa. El organigrama doméstico, debería garantizar la especificidad funcional separando las actividades mediante un pragmatismo racional. Se fijaba que el baño, por cuestiones de higiene, debía estar separado de la cocina, y que esta a su vez, debía de estar vinculada mínimamente al espacio de salóncomedor, pero sin configurar un espacio único. El fin era poder controlar a los niños y facilitar las tareas del hogar. La cocina era una pieza fundamental, donde la madre pasaba gran parte del día, y por lo tanto debía contar con buena iluminación y ventilación. El (M.R.U.) constató que su planteamiento racionalista del uso del hogar había fracasado, ya que se había establecido un orden correcto de hacer las cosas, sin considerar la diversidad de los habitantes. Se había generado una ruptura entre tecnocracia e identidad. Véase, Nicole C. Rudolph, At Home in Postwar France. Modern Mass Housing and the Right to Comfort, Nueva York: Berghahn Books, 2015, pp.30-32.
} 


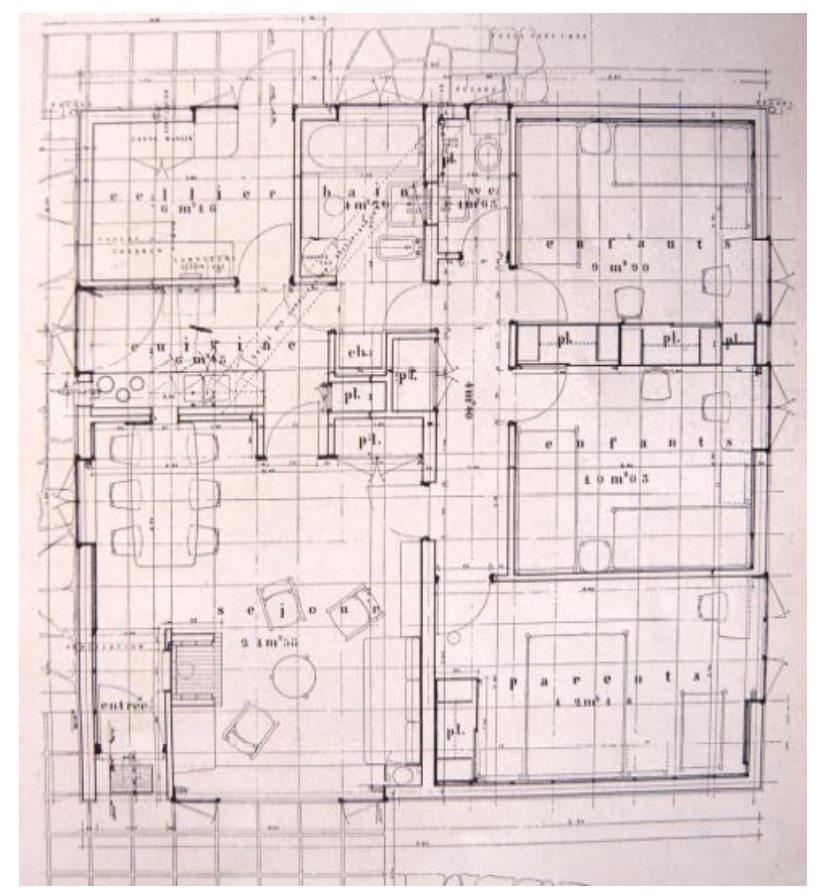

IV. 8 La Maison familiale minima en pierre, planta. Paul Nelson, Roger Gilbert y Charles Sebíllotte, 1946-1947

La vivienda proyectada tenía una planta cuadrada, con todas sus dependencias rectangulares, adosadas unas a otras y apoyadas en el perímetro en forma de L, dispuestas en torno a la pieza de mayor tamaño, que era el espacio de estar y comedor. A pesar de no disponer de espacios intermedios que aislaban las diferentes estancias individualmente, la casa aportaba una flexibilidad que permitía controlar el contacto social entre sus habitantes. El orden de la planta permitía mantener diferentes grados de privacidad, como sucedía en La Maison Suspendue. En la vivienda se levantaban sucesivos filtros para construir el espacio individual privado. A diferencia de lo dispuesto en las propuestas de los grupos de arquitectos norteamericanos ${ }^{295}$, Paul Nelson y su equipo proyectaron un recorrido que ganaba en privacidad al alejarse de la entrada y adentrarse en los espacios de descanso y de ocio. Había un espacio de entrada previo a la puerta principal y posteriormente se accedía a un pequeño vestíbulo que ocultaba el estar. Franqueada la parte pública, se

\footnotetext{
${ }^{295}$ Según se recogía en los informes realizados por los trabajadores sociales para el (M.R.U.), las quejas más comunes de los residentes tenían que ver con la falta de privacidad de las propuestas construidas por los equipos de arquitectos americanos, ya que en ellas los visitantes accedían directamente desde la calle al núcleo familiar del salón, e incluso en algunos casos a la visión del espacio de la cocina. Por lo tanto el espacio de reuniones sociales terminaba siendo algo confuso, similar a un sitio de paso. Véase: Nicole C. Rudolph, At Home in Postwar France. Modern Mass Housing and the Right to Comfort, Nueva York: Berghahn Books, 2015, p.32.
} 
pasaba al ámbito familiar, el cual a su vez estaba separado, mediante un pasillo, de los espacios privados, que eran los dormitorios y la cocina.

El vestíbulo del área de descanso marcaba el aislamiento de las habitaciones con respecto a los otros dos bloques, creando un ámbito más privado. Los tres dormitorios contaban con un espacio de trabajo, dispuesto frente al hueco mediante el cual el individuo se comunicaba con el exterior. En el caso de la cocina, su posición, retirada mediante espacios de transición que impedían la visión directa, también fortalecía la privacidad, en este caso del ámbito femenino y no por decisión personal sino por imperativo administrativo. La cocina disponía de un hueco pasaplatos que mantenía el contacto con el salón, con lo que el espacio de trabajo doméstico tenía la opción de mantener abierto el vínculo con el espacio colectivo o aislarse, como sucedía con las habitaciones individuales dentro de La Maison Suspendue y su vínculo con el salón. Los espacios de servicio y de ocio también tuvieron su eco en el prototipo de casa prefabricada, organizando los lugares de retiro individual por dos vías, una impuesta, para el trabajo doméstico, y otra elegida, para el desarrollo intelectual. En la casa prefabricada se construyó un almacén próximo a la cocina, donde se podían realizar actividades manuales y de esta manera se mantenía la idea de crear un espacio de ocio individual fuera del recinto del dormitorio, que ya había sido ensayada antes por Paul Nelson.

En el concurso, se demandaba algo más que una mera solución doméstica innovadora, la propuesta debía estar condicionada a una producción en serie y de calidad. Esta era una oportunidad para que Paul Nelson aplicase los conocimientos adquiridos durante su experiencia como arquitecto para el gobierno norteamericano en la Segunda Guerra Mundial ( I. 2.) y por lo tanto, el proyecto se abordó considerando la estandarización como el método que había tenido mayor incidencia en la producción industrial de la construcción, generando una importante transformación de la arquitectura. Se trabajó para crear una estandarización flexible que permitiese cubrir un amplio espectro de necesidades. Así, Nelson afirmaba:

\footnotetext{
...en una discusión sobre la transformación de la arquitectura, el problema primordial no es la arquitectura sino la transformación económica, de los sistemas de producción, de la técnica de organización de la industria de la construcción. Y se puede afirmar que una arquitectura viva- es decir funcional y adaptada a las necesiaddes reales- no puede aparecer en América, ni en otro lugar, antes que la
} 


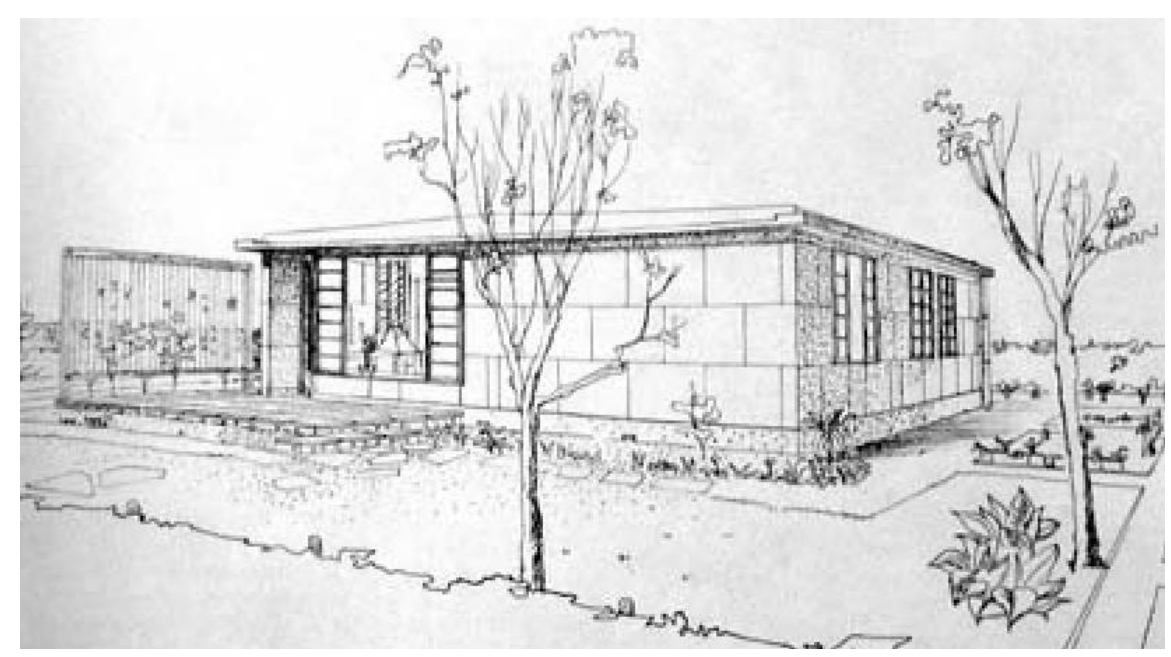

IV. 9 La Maison familiale minima en pierre, perspectiva. Paul Nelson, Roger Gilbert y Charles Sebíllotte, 1946-1947.

$$
\begin{aligned}
& \text { propia industria de la construcción no haya evolucionado en la dirección de poder } \\
& \text { satisfacer las necesidades humanas... }
\end{aligned}
$$

El equipo propuso prefabricar la mayor parte de la vivienda en taller y ensamblarla posteriormente en seco y, para facilitar el montaje, se unificaron las medidas y toda la casa se dimensionó utilizando como módulo 1,20. El proceso de industrialización se aplicó la totalidad de elementos de la vivienda. Se utilizó una estructura mixta de muros de carga prefabricados y jácenas metálicas y los acabados interiores de los muros de cerramiento estaban ejecutados con un panel de cartón yeso, que también contenía el aislante, el falso techo estaba compuesto por piezas desmontables e intercambiables y tanto el suelo como la cubierta eran registrables para el control de las instalaciones. Se utilizó la piedra para el cerramiento exterior, incorporándola en piezas recortadas en taller, abriendo una nueva vía industrial a la tradicional cantería. Esto, a su vez, permitía incorporar nuevos tipos de roca en función de los gustos de los futuros propietarios. (IV. 9)

Esta vivienda era un ejemplo real de los sistemas de construcción industrial que se había ensayado en La Maison Suspendue la década anterior. La estandarización no solo no restringía las posibilidades de elección de los habitantes, sino que ampliaba la diversidad del modelo. La tecnología constructiva permitía ofrecer al propietario un modelo donde los acabados podían ser seleccionados por él mismo e incluso con el paso del tiempo podían ser sustituidos por otros. Es decir, la construcción de la

\footnotetext{
${ }^{296}$ Paul Nelson, "La transformation de 1'Architecture aux États-Unis", Arts de France, no5, 1946, p.36.
} 


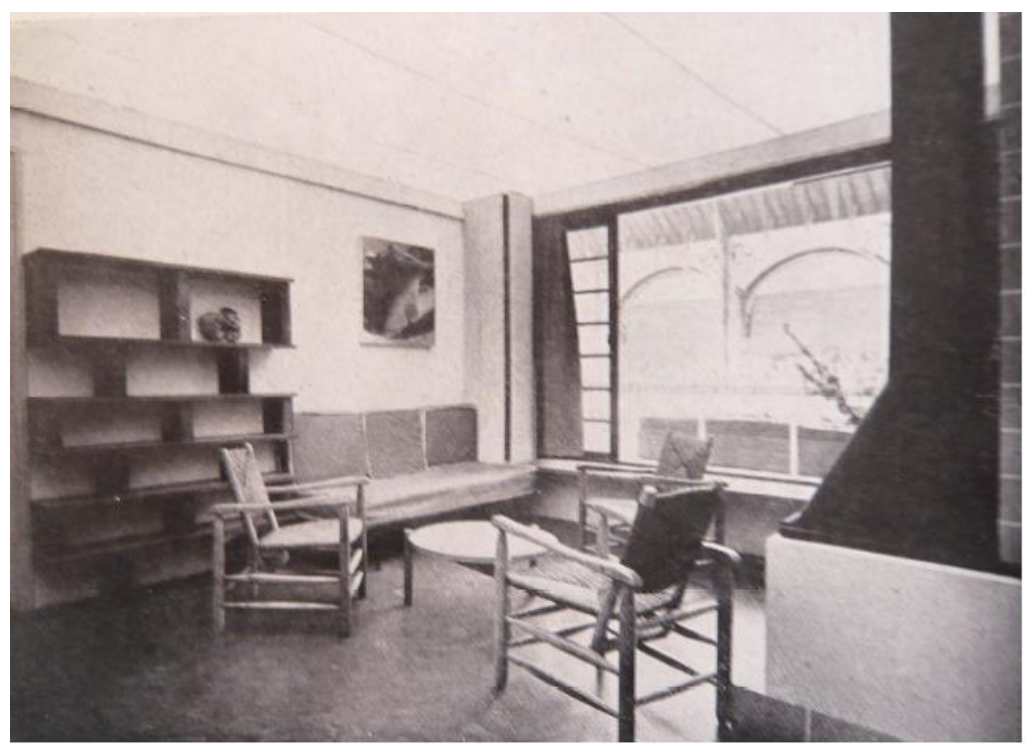

IV. 10 La Maison familiale minima en pierre, salón con mobiliario de Charlotte Perriand. Paul Nelson, Roger Gilbert y Charles Sebíllotte, 1946-1947.

domesticidad venía determinada la decisión de los habitantes por incorporar aquellos elementos más directos y cercanos, que incidían en su confort psíquico.

Por otra parte Paul Nelson solicitó la colaboración de Charlotte Perriand ${ }^{297}$ para un diseñar mobiliario moderno, acorde al concepto de fabricación estandarizada que se había utilizado en la vivienda (IV. 10). El mobiliario se resolvió con una geometría sencilla, donde predominaban las líneas rectas, y las piezas de mayor tamaño fueron elaboradas en taller y ensambladas en obra. La intervención no se limitó al mobiliario sino que también se trataron los acabados de los paramentos verticales. En cada habitación se pintó uno de los cuatro muros en color vivo con la intención de que se reflejase en los otras tres paredes pintadas en blanco, lo cual proporciona a las estancias diferentes matices cromáticos según la incidencia de la luz. La utilización en los paramentos verticales interiores de elementos prefabricados, que incorporaban su propio acabado, creó un juego cromático que rompía la homogeneidad del revoco continuo. Cada componente constructivo, desde un elemento de esquina a la chimenea, podía mostrarse sin ocultar su propio acabado. Paul Nelson volvió, una década más tarde y con una limitación extricta de presupuesto, a confiar en la capacidad de la intervención artística para incidir en la creación espacial.

297 Charlotte Pierrand, (1903-1999) arquitecta y diseñadora de muebles, fue una de las fundadoras de Union des Artistes Modernes, ( U.A.M ). Trabajó entre otros arquitectos con Le Corbusier y Pierre Chareau, y colaboró con Paul Nelson en el mobiliario para el hospital de Saint Lô. 
La Maison Badin, Sceaux (1954-1955). La construcción de la técnica suspendida.

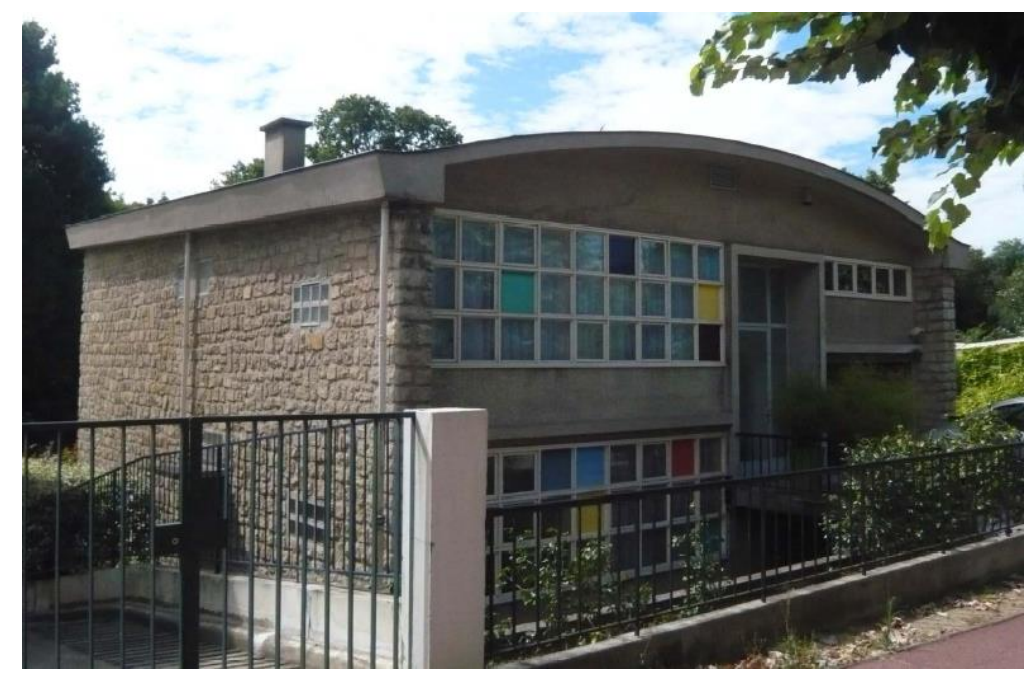

IV. 11 Maison Badin, perspectiva. Paul Nelson, 1954-1955.

Monsieur Badin era un banquero amigo de Paul Nelson que, en 1954, le encargó el proyecto de su residencia en la población de Sceaux, al Oeste de París. La buena sintonía con el cliente permitió que Paul Nelson pudiese construir algunas de las ideas con las que había experimentado en la década de los años treinta. Las limitaciones estaban circunscritas al cumplimiento urbanístico y al alojamiento familiar. La parcela tenía unas dimensiones de 17 metros de frente por 44 metros profundidad, limitaba al Sur con el parque de Sceaux ${ }^{298}$ y al Norte con la vía de acceso la topografía descendía un 18\% hacia el parque. La normativa obligaba a la construcción de un volumen exento por lo que se proyectó una casa de planta cuadrada con dos alturas, que liberaba un amplio jardín a Sur. La vivienda se cerró lateralmente y sólo se abrió en sus fachadas principal y trasera (IV. 11). El acceso era común para vehículos y peatones y se producía a través de una rampa-puente, que conectaba la calle con el garaje y con un vestíbulo situado a media altura entre los dos niveles. El programa se organizó con una planta baja conectada al jardín, donde se distribuyeron los espacios de servicio y los de reunión, y una planta superior, con vistas sobre el parque, donde se dispuso el descanso. ( IV. 12- IV. 13 ).

${ }^{298}$ El trazado del jardín fue diseñado por Andre le Notrê a finales del siglo XVII. Desde la planta superior de la vivienda se podían contemplar unas buenas vistas del conjunto. 

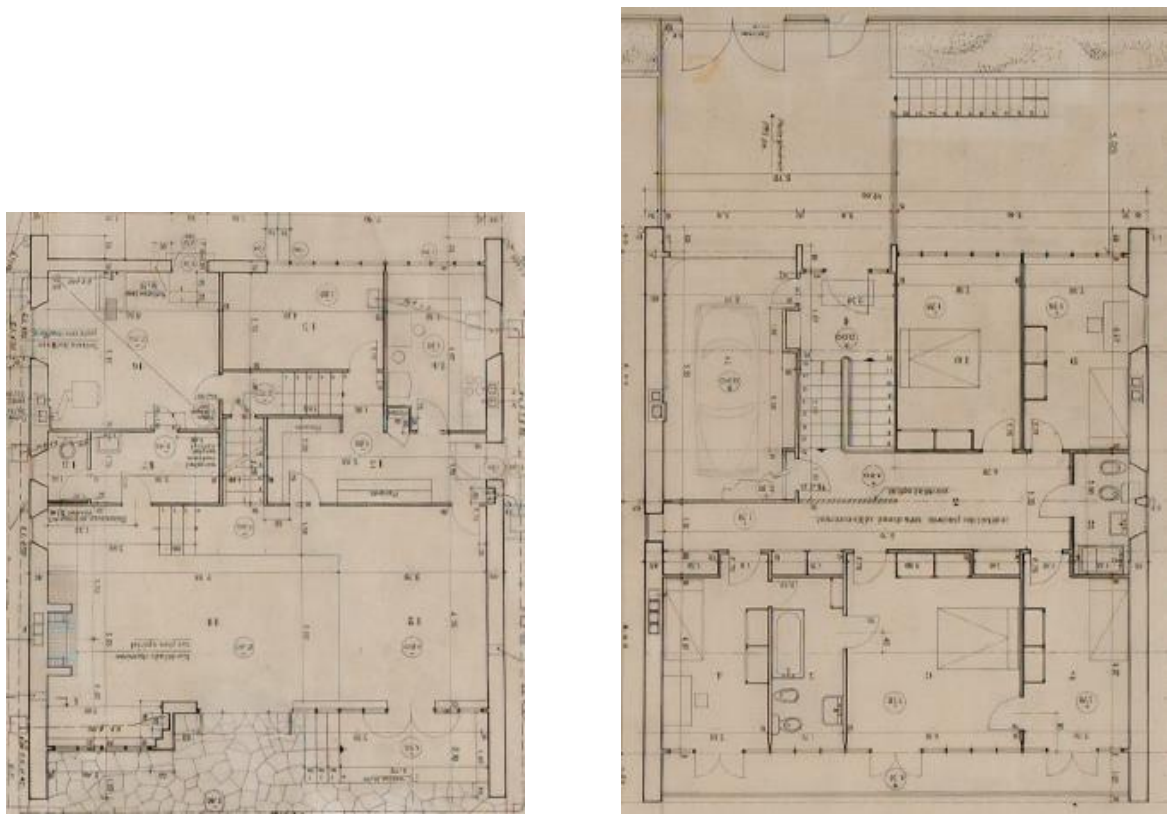

IV. 12 Maison Badin, planta baja. Paul Nelson,1954-1955

IV. 13 Maison Badin , planta primera. Paul Nelson,1954-1955

Las comunicaciones interiores se producían a través de la escalera, cuya meseta coincidía con el vestíbulo de la entrada principal.

El proyecto de La Maison Badin se solapó temporalmente con la construcción de las casas Jaoul ${ }^{299}$, donde Le Corbusier adoptó decisiones estructurales, constructivas y compositivas que marcaban un cambio respecto de sus principios como arquitecto moderno. En sintonía con la actitud marcada por Le Corbusier, Paul Nelson aplicó, en la construcción de su vivienda, medidas similares a las proyectadas en las casas Jaoul ${ }^{300}$. De esta manera, se utilizó un sistema estructural de muros de carga, la construcción se acabó con los materiales vistos, la cubierta abovedada marcada en los frentes y tanto la fachada como la entrada adquirieron un fuerte protagonismo que contrastaba con el cerramiento de las fachadas laterales, lo cual contribuyó a intensificar la relación de la casa con el entorno y a transformarla en una pieza de transición entre la calle y el parque urbano posterior. Paul Nelson que trabajó en $\mathrm{La}$ Maison Badin con el espacio interior de La Maison Suspendue, como modelo de

\footnotetext{
${ }^{299}$ En 1952 Le Corbusier recibió el encargo para proyectar las dos casas de la familia Jaoul en Neully- sur- Seine, al noroeste de París. Ese mismo año, y muy cerca de estas viviendas, Paul Nelson terminaba las obras de ampliación del Hospital Americano de Neully.

${ }^{300}$ María Teresa Muñoz Jiménez, "El dilema de las casas Jaoul” en Cerrar el círculo y otros escritos, Madrid: COAM, 1989
} 


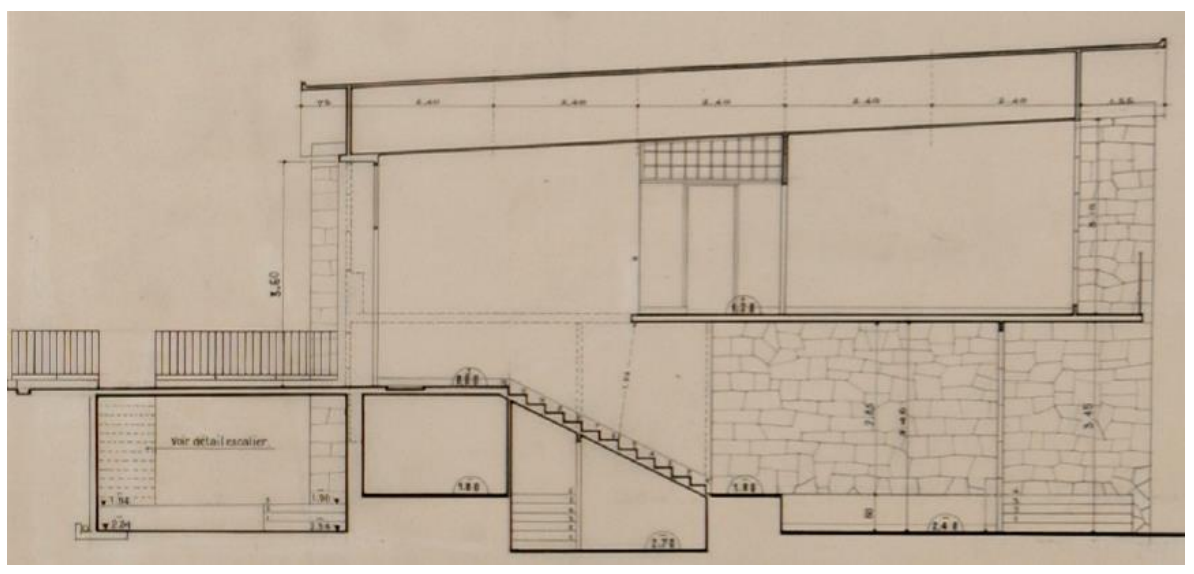

IV. 14 Maison Badin, sección longitudinal. Paul Nelson,1954-1955.

referencia, asumió las directrices marcadas por Le Corbusier en las casas Jaoul para configurar el aspecto externo.

En La Maison Badin se perdieron tres de los elementos más característicos de $L a$ Maison Suspendue. En primer lugar se establecía una nueva relación de la vivienda con su entorno, la casa pasó de ser un objeto abstracto dispuesto sobre un plano a ser un edificio asentado sobre un territorio concreto y esto se produjo por la alteración de la topografía, se construyó un patio inglés delantero, que permitía ventilar e iluminar naturalmente toda la planta, sin restringir el uso, a la vez que facilitaba el acceso a la planta baja y al jardín desde el exterior (IV. 14). La conexión de la casa con el entorno prolongaba el proyecto doméstico más allá de los límites del cerramiento, construyendo al Norte un puente de transición con la vía pública y al Sur un porche escalonado, que se completaba con una disposición de mobiliario de jardín. En el proyecto convivían así, la fragmentación de la entrada a la vivienda, construida a partir de la verja, la pasarela y el retranqueo de la puerta principal, con el gran vano de dos alturas, que marcaba la posición frontal de dicha entrada. De esta manera, la expansión del espacio interior por el entorno de la parcela estaba controlado por los cerramientos de vidrio de las fachadas Norte y Sur. que estaban retranqueadas respecto de la línea de cubierta y del remate de los muros laterales, generando porches abovedados de las mismas dimensiones. Estos elementos arquitectónicos reforzaban la condición frontal de la casa, lo que unido a la opacidad de los muros laterales la convertía en una vivienda entre medianeras. Por lo tanto, la fachada adquirió todo el protagonismo del exterior en detrimento del volumen y la puerta, modulada e integrada en la composición de la fachada, asumía el valor simbólico de la frontalidad (IV. 11). Como ya se ha descrito en (§ II. 3.), 
Paul Nelson construyó en estos cerramientos su modelo de "fachada claustral", con una retícula de metal y vidrio coloreado, a partir de una intervención de Fernand Léger y esto generaba una versatilidad en el cerramiento, similar a la ensayada en $L a$ Maiosn Suspendue, que proporcionaba al habitante una relación flexible y cambiante con el entorno real.

El mosaico provocaba que las vistas desde cada dormitorio hacia un mismo lugar, el parque, fueran diferentes y que a través de la visión exterior de la fachada no se pudiese hacer una lectura directa entre hueco y estancia ${ }^{301}$. Así, el muro de vidrio se materializaba a través de la pintura, que lo devolvía a una condición opaca, provocando con su aparición en la trama transparente, una alteración del espacio interior mediante la interrupción de sombras y colores.

El segundo elemento utilizado en La Maison Badin, que suponía un cambio de actitud respecto a los proyectos de entreguerras, fue la utilización de una estructura de muros de carga, en lugar de una estructura reticular. Aunque con esta decisión se adoptaban las directrices estructurales marcadas por Le Corbusier en las Casas Jaoul, que difuminaban el concepto de planta libre, Paul Nelson no renunció a construir el espacio libre que había propuesto en La Maison Suspendue y, para lograrlo, volvió a utilizar la técnica estructural de la suspensión. En este proyecto contó con la colaboración del ingeniero Bernard Lafaille ${ }^{302}$ y con los técnicos de la

\footnotetext{
${ }^{301}$ Judith Applegate, "Paul Nelson: an interview” Perpesta Nº13-14, 1971, p.115.

302 Bernard Lafaille (1900-1951) fue uno de los ingenieros más importantes en la Francia de posguerra, fue colaborador de Le Corbusier, con quien trabajó en La Unité d'Habitation de Marseille y en la de Nantes-Rezé. y su reconocimiento le vino por su concepción de la
} 
empresa Mecasol. La estructura se resolvió mediante seis cerchas metálicas de $12 \mathrm{~m}$ de luz, que se apoyaban sobre los muros laterales de carga, ejecutados con piedra y hormigón (IV. 15). De las cerchas colgaba una subestructura de tirantes metálicos, que a su vez soportaba el forjado de la planta primera, dejando la planta baja libre de apoyos. Esta disposición representaba la construcción real del concepto de habitación suspendida de los años treinta, pero mantenía dos diferencias con respecto al resultado conseguido. La primera era formal, y tenía que ver con la ocultación del proceso tecnológico frente al exhibicionismo utilizado en La Maison Suspendue y la segunda, con la incidencia real que la construcción de la suspensión tenía sobre el espacio, ya que toda la libertad de disposición vertical había quedado reducida a tres niveles en La Maison Badin,

$\mathrm{Y}$ el tercero de los elementos, en los que se sustentaba el cambio con respecto a la etapa anterior, afectaba a los sistemas y los materiales de construcción. Al igual que en los casos previos y siguiendo el modelo de las Casas Jaoul de Le Corbusier, en La Maison Badin se optó por una construcción masiva y por mantener los materiales vistos, mostrando los contrastes de texturas y evitando los revocos. Los muros laterales se ejecutaron en cantería, manteniendo su aspecto también en el interior, y los frontales en hormigón visto rugoso, como la escalera. Por su parte, la cubierta se resolvió al exterior mediante piezas curvas de hormigón prefabricado, que apoyaban sobre las cerchas metálicas, construyendo un encofrado perdido para la capa externa de hormigón visto, que daba el aspecto de una falsa bóveda inclinada. Y en el interior, se dispusieron unas placas horizontales, que construían un falso techo y escondían la estructura. Por lo tanto, el metal que había sido exhibido por Paul Nelson en La Maison Suspendue como un referente de modernidad, pasó a ser el único material que permanecía oculto en esta casa de los años cincuenta, en la que la sinceridad constructiva se consideraba un nuevo valor.

Como ya se ha descrito, el interior de La Maison Badin fue la primera oportunidad que tuvo Nelson para reconstruir los conceptos espaciales de continuidad, flexibilidad y privacidad que ofrecía La Maison Suspendue. Para lograrlo, adaptó las herramientas que ya había utilizado en este proyecto al nuevo contexto temporal en el que se construyó la vivienda. De esta manera, buscó la continuidad en planta a

estructura parabólica de la cubierta de Notre Dame de Royan, junto al arquitecto Guillaume Guillet, este proyecto fue coetáneo de la Maison Badin. 
través de las conexiones directas entre las estancias de cada unidad funcional y de los recorridos dispuestos entre las diferentes partes de la casa..

Aunque las particiones interiores determinaban las diferentes funciones, esto no supuso una discontinuidad espacial, ya que, tanto en la planta baja como en la planta primera, los huecos de comunicación generaban varias alternativas de conexión que conectaban todos los espacios ( IV. 12- IV. 13 ). En La Maison Badin, la continuidad de los espacios sociales se resolvió en un espacio único y de esta manera se producía una mejor continuidad con respecto al modelo de La Maison Suspendue, donde el comedor y el salón ocupaban estancias diferentes.

Aunque en las dos viviendas la continuidad espacial se desvanecía por la separación física entre las áreas de servicio y las de reunión, limitando su conexión a dos puntos, en La Maison Badin se proyectó un aseo de uso compartido, con dos accesos opuestos, que a su vez generaban una alternativa de conexión entre el salón y el bloque de servicio. En la planta primera, también se mantuvo el criterio de las conexiones múltiples, de este modo las estancias que miraban al jardín contaban con tres accesos, dispuestos en paredes diferentes, que las comunicaban entre sí e incluso con el baño. Estas conexiones generaban varios recorridos paralelos, que comunicaban el interior con el exterior. Paul Nelson, que había utilizado esta herramienta de conectar los espacios a través de los baños en una parte de la planta de descanso de La Maison Suspendue lo extendió a toda la casa dos décadas después. Lo que no había variado en la concepción de las dos viviendas era el objetivo de construir alternativas, para que los habitantes utilizasen la casa según sus necesidades temporales.

Por lo tanto, la utilización de los dobles accesos y de la continuidad de los recorridos también estaba vinculada a la flexibilidad de la planta y a la fluctuación del uso, ya que la transformación de las estancias en lugares de paso, como sucedía en el modelo de referencia, generaba una coexistencia temporal de funciones, que hacían de cada ocupación personal una manera diferente de habitar la casa. Este orden de convivencia también se producía en el salón, donde ante la ausencia de separaciones, Nelson utilizó diferentes recursos arquitectónicos con el objeto de suscitar una agrupación por afinidades de ocio. La posición centrada de la chimenea y la presencia de huecos laterales a diferentes alturas, en consonancia con las cotas del pavimento interior, ordenaban todo el espacio en tres áreas de ocio y reunión diferentes. Este esquema de organización del espacio común era una versión plana 


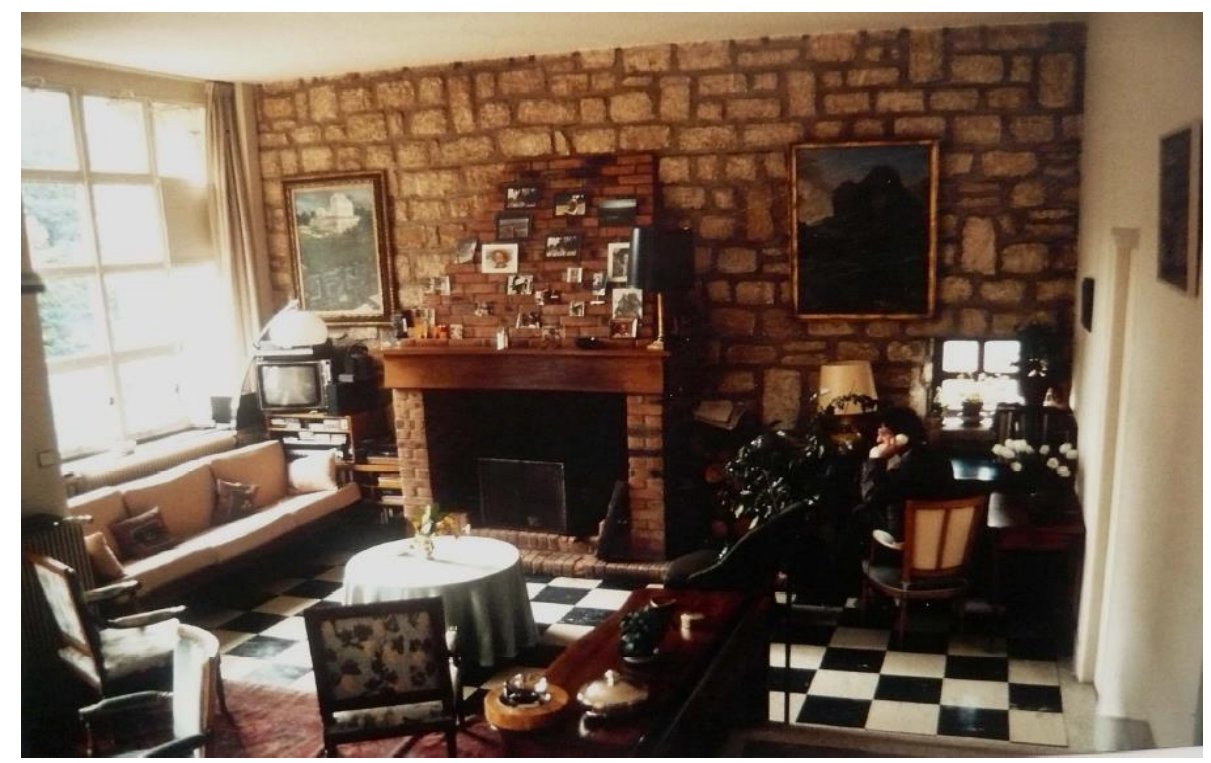

IV. 16 Maison Badin, salón. Paul Nelson,1954-1955.

de la estructura compuesta en dos niveles de La Maison Suspendue. El paralelismo también se producía en el exterior, en las terrazas de ambas viviendas.

Aunque la continuidad vertical quedó limitada por la disposición del forjado de la planta primera, Paul Nelson no renunció a su construcción. En La Maison Badin sólo había un punto desde el cual se podía entender el espacio en su totalidad, la meseta de la escalera. Desde este ámbito de entrada, se tenía una percepción simultánea de todos los niveles de la casa, desde el jardín hasta la cubierta.Así, la escalera, al igual que sucedió con la rampa, se convertía en protagonista de la continuidad espacial, tanto del espacio interior como de la vinculación con el exterior, al conectar visualmente el acceso de la entrada y el jardín posterior .

En las dos viviendas la privacidad aumentaba con la altura, situando las estancias de descanso en la planta superior. En La Maison Badin, los dormitorios albergaban, además del descanso, otras actividades de uso privado: vestuario, ocio y trabajo. En estas dependencias, los armarios se dispusieron en una posición centrada, con el objetivo de configura dos ámbitos diferenciados, uno para el descanso, próximo a la puerta y otro para el trabajo o desarrollo personal, al fondo de la habitación. La privacidad de los dormitorios que miraban al jardín quedaba comprometida temporalmente, al transformarse en recorridos de paso obligado para los habitantes que accedían al balcón. De esta manera, el límite entre el ámbito puramente privado y el familiar quedaban desdibujados. En contrapartida, en una esquina del salón se proyectó un uso individual, se trataba de un lugar delimitado por la chimenea, el 
muro separador del ámbito del servicio y la diferencia de cotas con el nivel del comedor (IV. 16). En esta equina se abrió un pequeño hueco de $(60 \times 60) \mathrm{cm}$ y se dispuso una mesa para uso personal, con esta configuración se sugería la ocupación del espacio social mediante un uso individual controlado. Este lugar representaba la transposición de las células individuales de La Maison Suspendue a un nuevo contexto, en el cual Paul Nelson manejó nuevos criterios de relación entre el individuo y su ámbito familiar. La persona, para desarrollarse, no necesitaba ni ocultarse privadamente ni levantar límites que evitasen la invasión de su dominio por el grupo. El individuo y familia estaban en igualdad de condiciones, la nueva arquitectura de Paul Nelson presumía la convivencia entre ambos grupos sociales y su interacción.

Vivienda de Nadia Léger, Gif-Sur Yvette ( 1956 ). La formalización orgánica.

Nadia Léger, tras la muerte de su marido, encargó a Paul Nelson el proyecto de una vivienda en 1956, en la población de Gif-Sur-Yvette ${ }^{303}$. Este trabajo, como ya se ha visto (§ II. 3.), fue una recompensa que ofreció Nadia Léger a Paul Nelson tras el fallido intento para construir un museo para Fernand Léger. Por lo tanto, en el encargo se contemplaba un espacio doméstico y un lugar para mostrar algunas de las obras de Léger. Nelson proyectó una vivienda suburbana semienterrada, en una parcela a media ladera que descendía hacia el Sur. La casa taller para artista, era un tipo de arquitectura que Paul Nelson había aprendido de su maestro Auguste Perret (§ II. 2.) y que le sirvió para organizar el espacio de La Maison Suspendue. Así, el programa se distribuyó en dos volúmenes adyacentes, de dos alturas y diferente tamaño. En el más pequeño, se organizó la vivienda y el estudio para Nadia Léger y, en el de mayor tamaño, se proyectó un lugar para albergar y mostrar los cuadros de la colección personal. (IV. 17)

\footnotetext{
${ }^{303}$ Nadia Léger,(1904-1982) era una pintora bielorrusa, que se formó con Kasimir Malevitch antes de ser alumna de Fernand Léger en París en 1925. Fernand y Nadia Léger se casaron en 1952 y se trasladaron a vivir a Gif-Sur-Yvette. Adquirieron una casa del siglo XIX con un gran salón de baile, que fue transformado en estudio por Fernand Léger. En este lugar, Fernand Léger pintó algunas de sus obras más importantes, entre ellas la serie dedicada al circo. Tras su muerte en agosto de 1955, Nadia pensó en construirse una casa para tener su propio taller.
} 


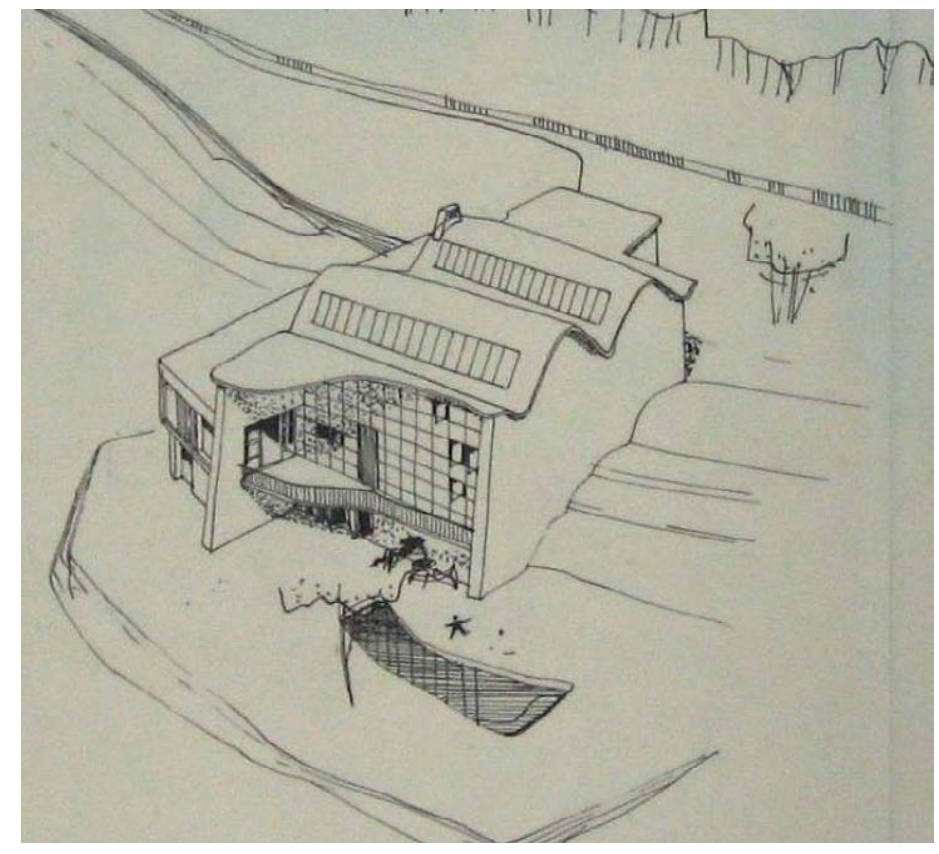

IV. 17 Casa de Nadia Léger, perspectiva. Paul Nelson,1956.

La proximidad temporal hizo que la casa de Nadia Léger fuese abordada con los mismos parámetros de arquitectónicos y el mismo contexto de los años cincuenta, que habían marcado La Maison Badin. Por lo tanto, las respuestas ofrecidas en matéria constructiva, estructural y de integración con el medio, mantenían ciertas similitudes, que las alejaba de las decisiones tomadas en la década de los años treinta. En estos proyectos, Paul Nelson afrontaba la creación de una arquitectura más humana, asumiendo una actitud moralizante sobre la verdad construida, donde la prevalencia de integración de la casa con el medio condicionaba las decisiones del proyecto. Pero como ya se ha señalado el objetivo de Paul Nelson era la creación espacial del confort individual y para conseguirlo utilizaba algunos de los recursos que ya había ensayado en La Maison Suspendue. Por lo tanto, la casa de Nadia Léger era el resultado de fusionar los sistemas constructivos, estructurales, compositivos, formales y ambientales de los años cincuenta con los criterios volumétricos, sociales y artísticos de los años treinta.

Se proyectó una vivienda estratificada que se adapta a la topografía, con una planta baja semienterrada y una planta primera a la cual se accedía directamente desde la cota superior. La única alteración del terreno era una explanación realizada en el espacio posterior de la vivienda donde se ubicaba la piscina (IV. 18). Por un lado, el tratamiento gráfico de la vegetación, con la incorporación de los árboles existentes al orden general del nuevo paisaje, la trayectoria del acceso rodado sin invadir la 


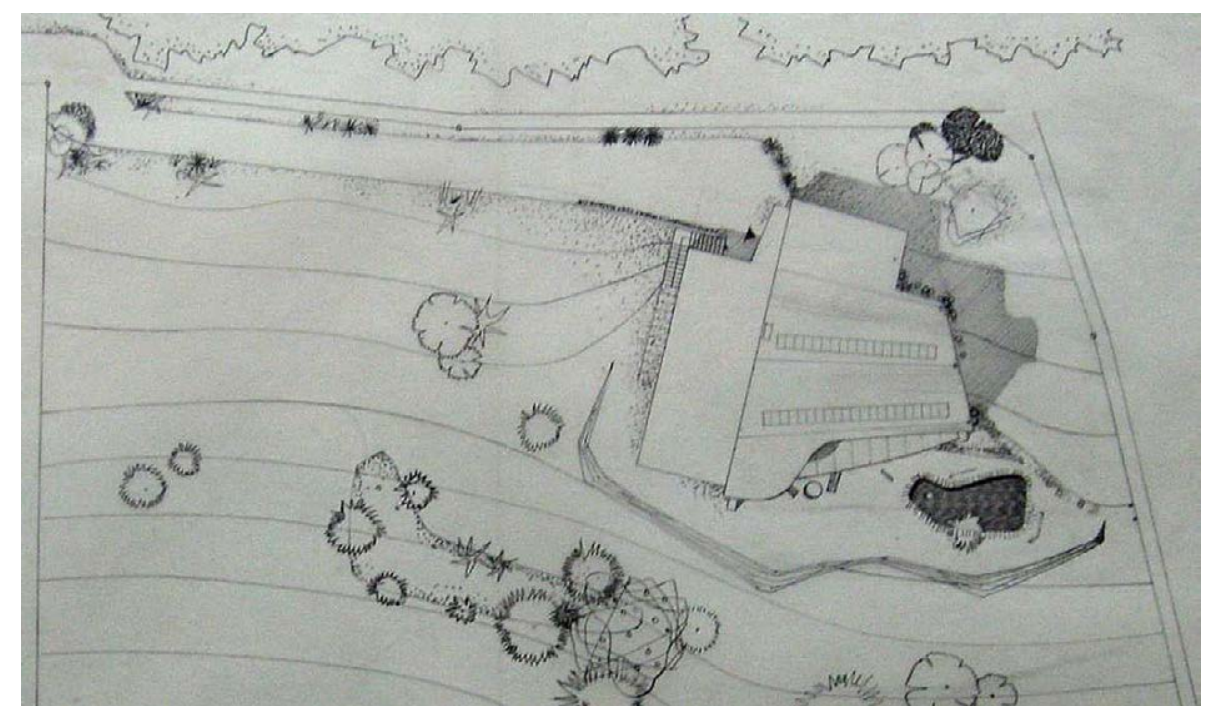

IV. 18 Casa de Nadia Léger, perspectiva. Paul Nelson, 1956

parcela y la organización exterior de las comunicaciones verticales, apoyadas en las cotas del terreno, mostraban que la topografía había sido utilizada como un elemento más del proyecto. Y por otro lado, la fragmentación de la entrada con diferentes puntos de acceso a diferentes alturas, la extensión de la terraza mirador de la planta primera y el tratamiento del ocio exterior en planta baja, con el espacio de porche abierto al terreno y la incorporación del vaso de la piscina a la misma cota, eran manifestaciones de la intención de prolongar el espacio doméstico más allá del propio volumen construido, integrándolo en el paisaje (IV. 19). Y finalmente estaba la utilización de una geometría irregular,de manera que ni la forma de la vivienda ni los trazados del jardín estaban definidos por una geometría pura apriorística, sino que se apoyaban en las directrices del territorio. Con estas intervenciones, Paul Nelson creaba unas condiciones concretas, para las relaciones naturales entre las personas y el medio habitado.

La prolongación del espacio doméstico en el exterior de la vivienda, incorporando el territorio, era una transposición del planteamiento de La Maison Suspendue a la casa de Nadia Léger. Así, los límites del antiguo contenedor de vidrio se habían trasladado al cerramiento de la parcela y la parte posterior de la vivienda se había convertido en el nuevo salón exterior, un lugar de ocio compartido dispuesto sobre un paisaje, que en este caso no estaba recreado artificialmente, como sucedía en $L a$ Maison Suspendue, sino que se asentaba sobre un paisaje natural. Incluso, Nelson volvió a utilizar los mismos recursos que había ensayado, hacía dos décadas, para configurar el espacio social. De esta manera, se podían reconocer en la escalera de caracol exterior que conectaba desde una posición exenta los dos niveles de la casa 

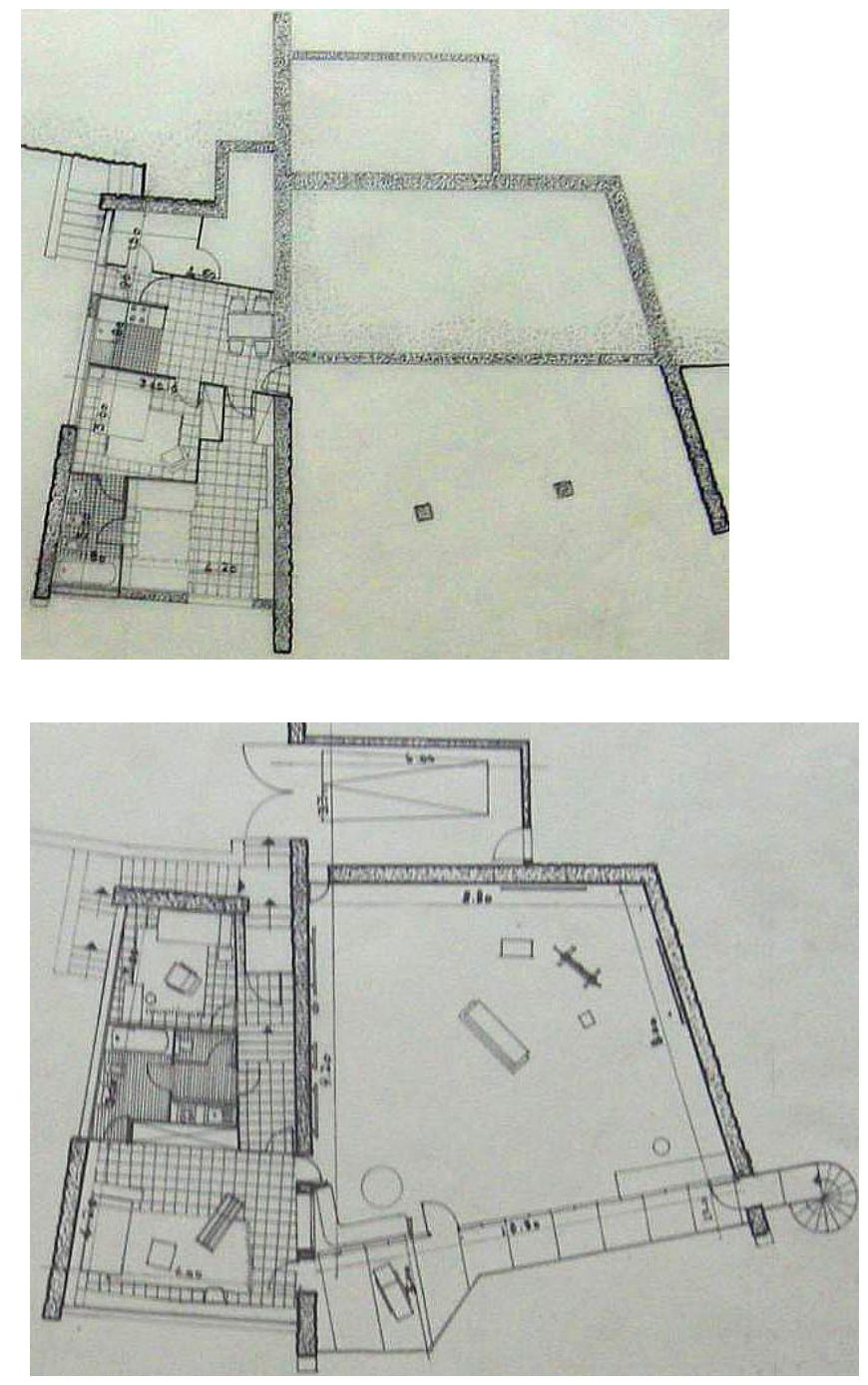

IV. 19 Casa de Nadia Léger, planta baja . Paul Nelson,1956.

IV. 20 asa de Nadia Léger, planta primera . Paul Nelson,1956.

en el balcón de la planta primera que permitía contemplar el espacio abierto de reuniones y en las intervenciones artísticas del cerramiento de la casa de Nadia Léger, las evoluciones respectivas de la rampa circular, el balcón interior y los murales de Joan Miró de la Maiosn Suspendue. Por lo tanto Paul Nelson trasladó a la casa de Nadia Léger los principios espaciales de La Maison Suspendue, aunque con un cambio de escala y la incorporación del paisaje. (IV. 20).

Esta nueva actitud frente al entorno, también llevó a Paul Nelson a tomar decisiones constructivas que, a su juicio, integraban mejor la vivienda en el paisaje. Así, los materiales utilizados se dejaban vistos y no procedían de procesos industriales, a diferencia de los empleados en sus proyectos de entreguerras. De esta manera, cada 
parte de la vivienda respondía a una condición constructiva y por lo tanto la imagen era el resultado de un proceso de ensamble, un collage de materiales. Se proyectó un sistema de muros de carga longitudinales ejecutados en piedra y hormigón visto, que contenían huecos resueltos mediante madera y metal. En el alzado Sur de la planta primera se volvió a utilizar su sistema de "fachada claustral" y la cubierta del volumen principal se resolvió con una cubierta ondulada de hormigón, con lucernarios longitudinales. Con estas decisiones, como sucedía en La Maison Badin, se construía una arquitectura más rígida que la de La Maison Suspendue, donde estructura y cerramiento volvían a coincidir, con las limitaciones de distribución interna que comportaba. Esto también sugería una idea de perdurabilidad en el tiempo, que ponía en tela de juicio las reflexiones de Paul Nelson sobre la flexibilidad. Aunque, a su vez, el sistema de constructivo de una falsa vivienda medianera y la ruptura del volumen cerrado mediante la prolongación de los muros, admitía el crecimiento de la vivienda adosando nuevos cuerpos. Así, en la casa de Nadia Léger, la utilización de diferentes materiales, tanto en los alzados como en el pavimento, propiciaban una sensación de movilidad y de cambio que acompañaban a las personas en sus recorridos por la casa. Esta sensación de espacio en movimiento era más difusa en la sala de exposiciones y, para ponerla de manifiesto, Nelson utilizó la variación de la luz cenital y el contraste que proporcionaba el mosaico de vidrio coloreado.

De la misma manera que en La Maison Suspendue, la casa de Nadia Léger se materializó en dos volúmenes semejantes, adosados a un muro central que funcionaba como eje de una composición abierta. La singularidad geométrica de la casa de Nadia Léger, la convertía en una pieza única en la carrera de Paul Nelson, ya que esta morfología orgánica, construida mediante trazados oblicuos, fue abandonada tras este proyecto a favor de la geometría ortogonal. También el sistema compositivo resultaba novedoso respecto de su práctica habitual, ya que se utilizó un método de yuxtaposición de partes muy acabadas en sí mismas, que carecían de relaciones de proporcionalidad con el resto. Sus vínculos formales estaban basados en las falsas simetrías, en las disonancias y en la repetición formal a diferentes escalas. Aunque los trazados que condicionaban la imagen externa de la vivienda eran inclinados para sintonizar con el paisaje, las divisiones interiores obedecían a un trazado ortogonal, donde tanto mobiliario como electrodomésticos se disponían adosados a las paredes. 
En la organización espacial de la casa de Nadia Léger, Paul Nelson volvió a recuperar la idea de compatibilidad entre continuidad y privacidad que había ensayado en La Maison Suspendue, aunque manteniendo la pervivencia de un espacio personal de aislamiento. En esta casa, como en 1938, el espacio de ocio y reuniones volvía a expandirse y las unidades de las funciones mecánicas (descanso, aseo, servicio) volvían a concentrarse. Nuevamente se proyectó un muro que fragmentaba la continuidad de la planta y que ocultaba todo el paquete funcional de la vivienda, estableciendo una clara separación entre lo público y lo privado. Y también se volvieron a utilizar los mismos recursos arquitectónicos que se habían proyectado en La Maison Suspendue para transformar esta aparente rigidez de la planta en un proyecto más flexible.

Mientras en la sala de usos comunes, la continuidad estaba garantizada por la condición de espacio único, en el otro cuerpo de la vivienda, se utilizaron las conexiones múltiples entre las estancias para generar la comunicación flexible en cada una de las plantas, propiciando diferentes alternativas de desplazamiento por la casa. Esta herramienta de comunicación interior, que producía la continuidad de las circulaciones, no sólo invadía los baños como sucedía en La Maison Suspendue, sino que la idea se extendió al resto de las dependencias, de tal manera que todas se convertían en habitaciones de tránsito, reservando a las personas la decisión de compartir su privacidad. Por esta razón, los criterios de privacidad ya no quedaban definidos por la distancia al acceso de la vivienda y por lo tanto la disposición de los dormitorios no se concentraba en una sola planta. Cada dormitorio albergaba un espacio de trabajo personal, donde los habitantes podían retirarse para disfrutar de manera individual. También se proyectó una estancia para el ocio privado fuera del ámbito de los dormitorios, este lugar era el estudio, y ejercía dentro de la casa de Nadia Léger un papel semejante al representado por las celdas individuales en $L a$ Maison Suspendue. Se trataba una estancia de uso individual, en la que se desarrollaba una actividad artística, que podía ser mostrada a otros habitantes de la vivienda. Esta era la única dependencia privada de la casa que mantenía una conexión directa con el espacio de reuniones. Paul Nelson utilizó la espontaneidad como herramienta para construir los vínculos entre las diferentes escalas e incidir en las relaciones sociales. 


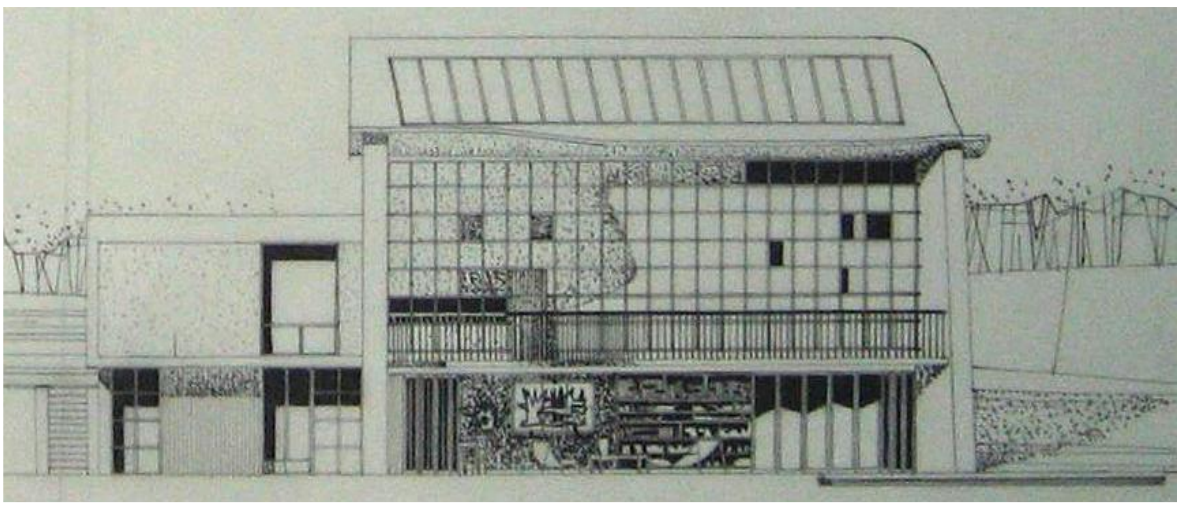

IV. 21 Casa de Nadia Léger, alzado sur . Paul Nelson,1956

En esta vivienda-taller-galeria, el arte desempeñaba dos funciones diferentes, que cualificaban al espacio: el arte como actividad era la seña de identidad del espacio privado de ocio y el arte como objeto de exhibición ocupaba los espacios públicos. Como ya se ha señalado, el estudio de Nadia Léger era la secuela de la búsqueda del espacio de trabajo individual dentro de la casa, inspirado en la idea de Auguste Perrert (§ II. 2.), del taller de pequeña escala dentro de un espacio expositivo más público y que culminó en La Maison Suspendue con las celdas individuales. La presencia del arte en los espacios sociales y su repercusión psicológica en la vida de los habitantes tenía su origen en los planteamientos de los años treinta y esto abrió nuevas vías de intervención en la casa de Nadia Léger, con la incorporación del paisaje como una nueva estancia de reuniones. Por lo tanto, a todas las reflexiones que ya se han realizado con respecto a la presencia del arte en los muros de la vivienda y al efecto que producía en los habitantes la materialización fragmentada del muro de vidrio coloreado, habría que añadirle los efectos que las intervenciones artísticas provocaban en el espacio del jardín (IV. 21). Las consideraciones del ajuste entre topografía y el proyecto provocaron que el alzado posterior fuese la fachada principal, mostrando la vivienda en toda su altura. Este frente se convirtió en el telón de fondo que Paul Nelson brindaba a Nadia Léger para intervenir siguiendo las directrices que había marcado Fernand Léger para La Maison Badin. El arte ayudaba a configurar el lugar, ese nuevo salón abierto entre el entorno y la vivienda. Las intervenciones en el mosaico de vidrio convertían al muro en un filtro que funcionaba en los dos sentidos, ya que no solo afectaban al interior, sino también revertían en el espacio abierto. Por su parte, las actuaciones pictóricas en planta baja, flotando sobre la línea de lamas, representaban la continuidad entre interior y exterior y sugerían la domesticidad del entorno. 


\subsection{La construcción del hogar personal.}

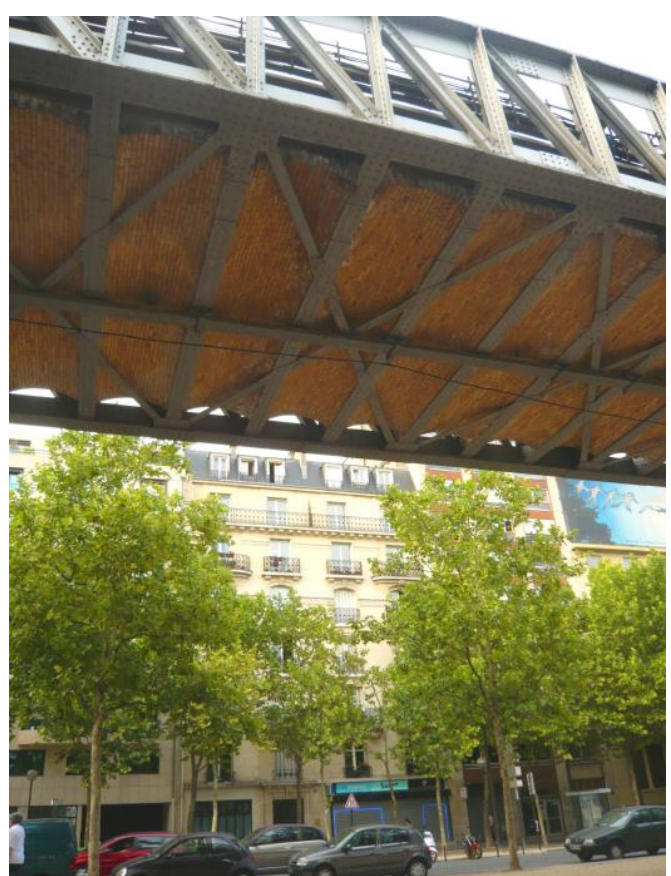

IV. 22 Boulevard Auguste Blanqui 98, el estudio de Paul Nelson al fondo, frente al metro elevado.

Paul Nelson siempre tuvo el deseo de construirse su propia casa ya que incluso $L a$ Maison Suspendue era un proyecto teórico de autoencargo, donde la idea de internacionalización se mezclaba con sus deseos personales. Finalmente, se construyó su primera vivienda en Trets, cerca de Marsella, tres años antes de su muerte. Paul Nelson ocupó diferentes apartamentos en París, que coincidieron en el tiempo con su evolución profesional. Durante su etapa de formación, vivió en Notre Dame des Champs en el barrio latino cerca de la colonia de expatriados americanos, a finales de los años veinte y coincidiendo con el inicio de su carrera se instaló en la rue des Petits Champs. Y en los años treinta, al inicio de la época más intensa de su carrera profesional, se trasladó al 98 del Boulevard Auguste Blanqui ${ }^{304}$, ubicando residencia y trabajo en plantas diferentes. El estudio permaneció allí hasta su marcha definitiva a Marsella en los años sesenta. El inmueble estaba situado en el distrito XIII, cerca del parque de Montsouris, en cuyo entorno se levantaron varias casastaller para artistas, entre ellas el taller para el pintor Ozenfant que construyó Le Corbusier y la casa para Georges Braque obra de Auguste Perret. Frente a la oficina, quedaba expuesta la estructura metálica de la línea de metro elevada, que liberaba el espacio urbano inferior, como sucedía en el proyecto de la Maison Suspendue.

\footnotetext{
${ }^{304}$ En los planos de La Maison des Docteurs aparecía el sello del Bd Blanqui 98 y la fecha era de febrero de 1933
} 
Casa familiar de Varengeville ( 1920- 1967). La experiencia doméstica personal.

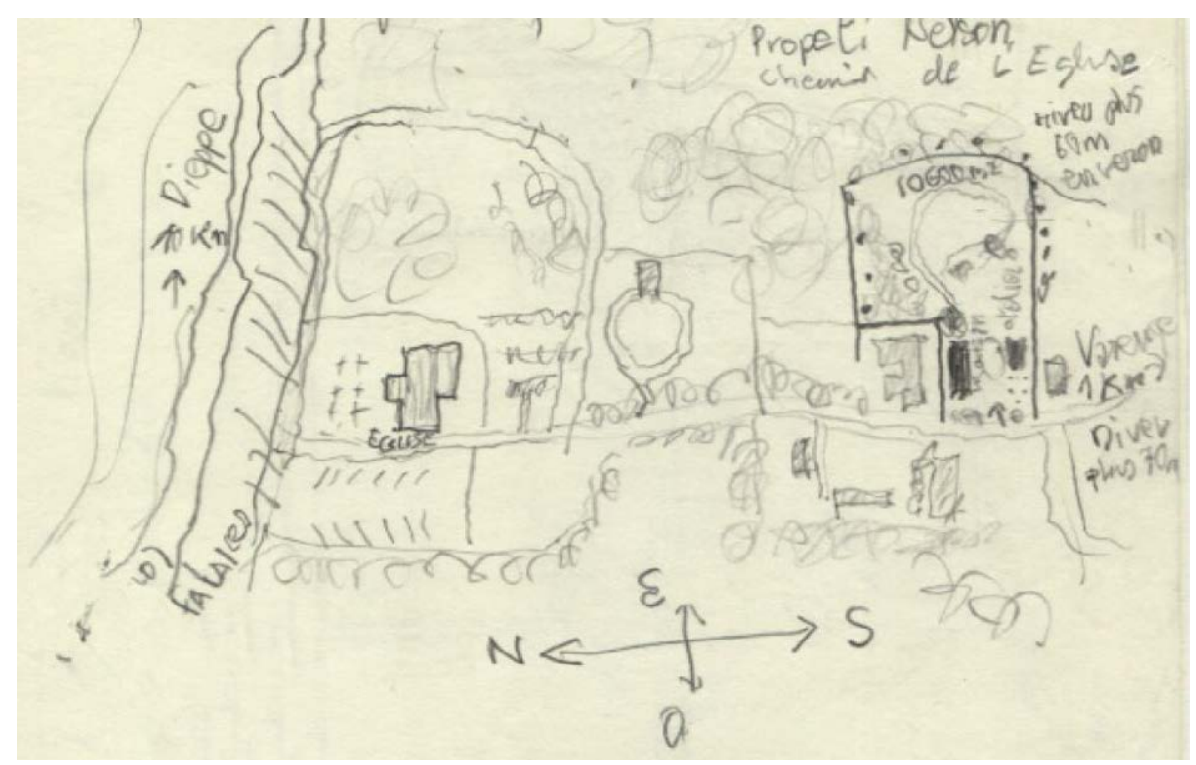

IV. 23 Casa familiar de Varengueville, plano de situación donde se identificaba la posición del mar, el cementerio, la iglesia y la propiedad con dos edificios, redibujado por el autor de la tesis en 2010 a partir del original de Paul Nelson, 1967

La casa de Varengeville representó para Paul Nelson algo más que un lugar el descanso $^{305}$. Tanto la manera de habitar la propia vivienda, como su relación con el entorno, suministraron a Paul Nelson una experiencia discontinua, durante más de cuatro décadas, que incidió en su manera de entender y proyectar el espacio doméstico $^{306}$. La propiedad contaba con dos edificaciones enfrentadas, construidas en el siglo XIX. La vivienda principal, adosada a la medianera Norte y el pabellón ${ }^{307}$, adaptado como estudio por Paul Nelson, adosado al lado opuesto. Para Nelson, una de las características más importantes de la casa era su disposición dentro de la parcela, ya que estaba protegida de los vientos del Oeste y con su

\footnotetext{
${ }^{305}$ Varengeville-sur-Mer era una población de la Alta Normandía, que debido a su posición geográfica y a su entorno pintoresco se había convertido en centro de vacaciones para la clase alta, tanto parisina como británica. Esto generó que allí también se instalase una comunidad de artistas e intelectuales. En 1927 André Breton escribió Nadja y en los años treinta llegaron algunos como Georges Braque o Joan Miró, animados por Paul Nelson. Véase: Solagne Louvet, Jacques de Givry, Mémoire de Varengeville \& Vasterival, Les Loges-en-Josas : JDG, 1994

306 Paul Nelson llegó a Varengeville-sur-Mer en el verano de 1920, cuando se casó con Francine Le Coeur, y vendió la casa en 1968. La vivienda estaba en el interior de una propiedad de 1 hectárea, rodeada de árboles y jardines, a poca distancia de la iglesia, del cementerio marítimo y de los acantilados, frente al Canal de La Mancha.

${ }^{307}$ Este pabellón había sido el estudio del pintor Claude Monet, durante su estancia en la Normandía en 1882. También, Paul Nelson se lo ofreció como taller temporal a Georges Braque, Joan Miró y Alexander Calder.
} 

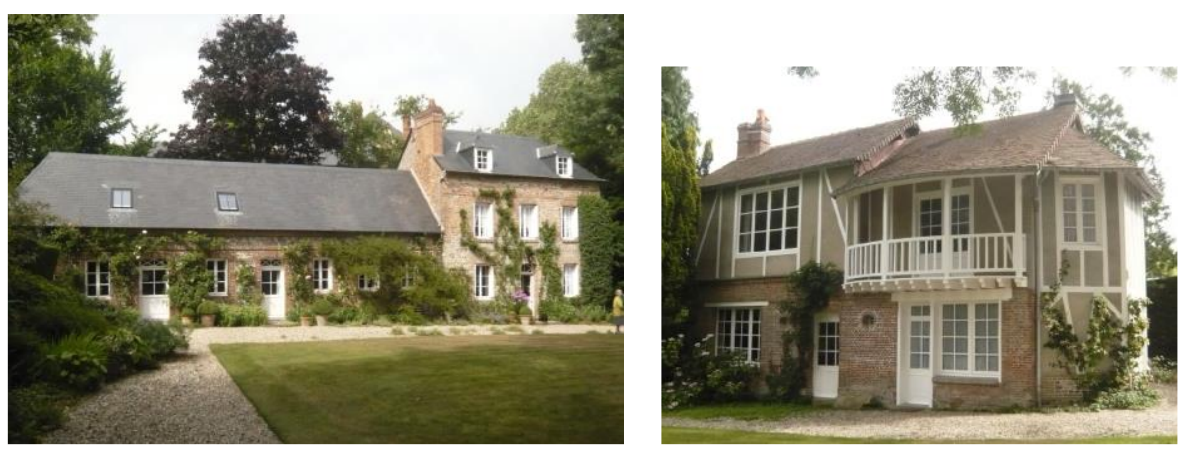

IV. 24 Casa familiar de Varengeville, edificio principal,1956.

IV. 25 Casa familiar de Varengeville, pabellón de jardín,1956.

fachada principal orientada a $\operatorname{Sur}^{308}$. Paul Nelson destacó que sus valores más significativos eran su carácter silencioso y sus vistas directas sobre el mar, sin construcciones intermedias. En la parte final, se explicaba la distribución del programa en las dos edificaciones que, en la casa principal, estaba repartido en dos plantas más buhardilla. En planta baja, se ubican los espacios de servicio y ocio común, y en las plantas primera y segunda los espacios de descanso, el pabellón tenía un apartamento en planta baja y una planta primera, con un gran hueco abierto al mar.

La casa de Varengeville proporcionó a Paul Nelson tres vivencias, que estaban en sintonía con las hipótesis utilizadas para proyectar La Maison Suspendue y que le ayudaban a construir su teoría de la incidencia psicológica de la arquitectura. La primera, previa al proyecto, fue obtenida de la percepción del entorno y de la relación entre las dos edificaciones dentro de la finca. La segunda, coetánea al desarrollo de la maqueta, fue resultado de la colaboración con los artistas. Y la tercera, posterior al proyecto, le fue sobrevenida tras el efecto de la Segunda Guerra Mundial.

La casa de Varengeville había sido el lugar de vacaciones de la familia Le Coeur antes de que en 1932 fuese propiedad de Paul Nelson y de su esposa Francine Le Coeur. $^{309}$

\footnotetext{
${ }^{308}$ La descripción del conjunto fue escrita por Paul Nelson el 9 de abril de 1967, con el objetivo de ensalzar los valores del lugar a los futuros compradores de la vivienda.

309 Esta información fue facilitada en 2010 por Marianne Le Coeur, en una entrevista mantenida en Varengeville. Marianne Le Coeur es arquitecto y descendiente de Francine Nelson. La casa aparecía en 1932 en el registro del Departament de la Seine Matitime.
} 


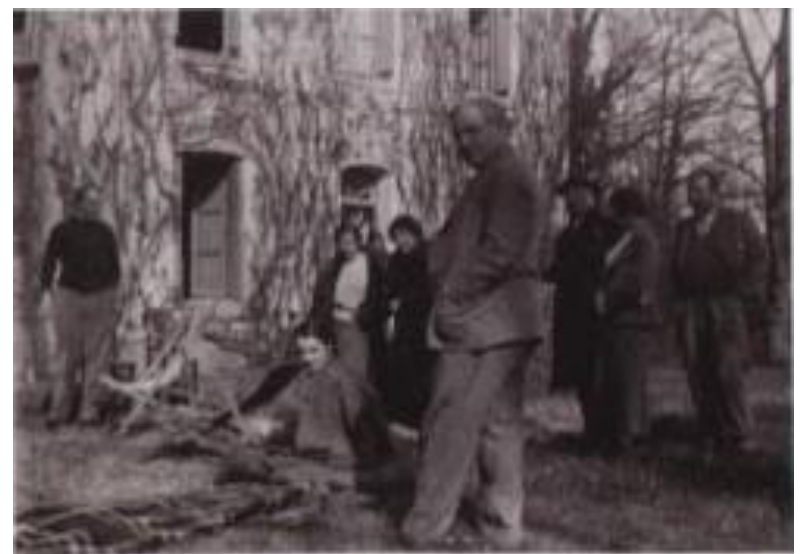

IV. 26 Jardín de Varengeville, el matrimonio Nelson con el editor Zervos y Kandinsky, ca 1938

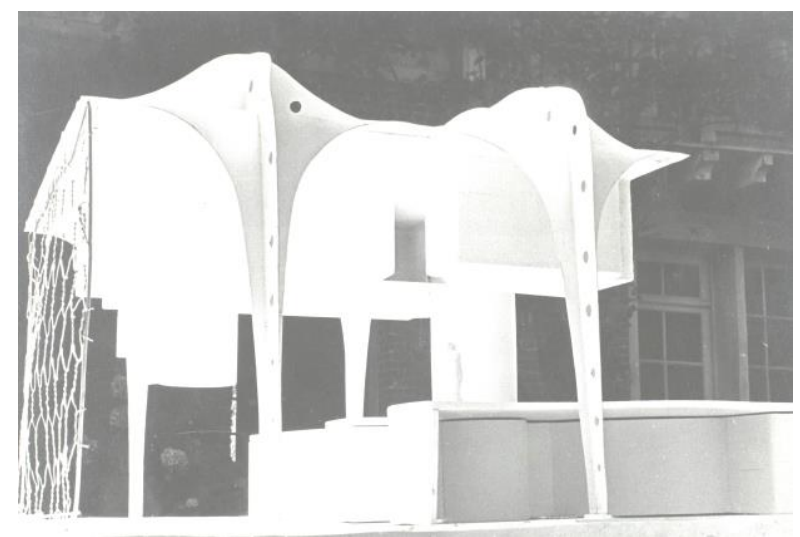

IV. 27 Maqueta de trabajo de La Maison Suspendue delante del pabellón de jardín, ca 1936

La propiedad estaba delimitada por un perímetro de árboles de gran tamaño, que configuraban un recinto tranquilo en un rico entorno natural. La disposición de un manto vegetal entre las dos edificaciones sirvió como lugar de encuentro para las reuniones al aire libre con sus amigos artistas (IV. 26). De esta forma, el jardín se incorporaba a los espacios domésticos del ocio colectivo, estableciendo una conexión física y visual con el salón de la planta baja a través de los huecos de puertas y ventanas. El jardín ofrecía la posibilidad de disfrutar del paisaje libremente ya que la ausencia de trazados geométricos regulares generaba en los invitados la sensación de tranquilidad y confort. La superficie de hierba, a la vez que mantenía la conexión y la integración de todos los elementos, también subrayaba la distancia espacial y la tensión entre la casa y el pabellón. La incidencia del jardín de Varengeville en la construcción del orden espacial fue transpuesta a La Maison Suspendue mediante la recreación del paisaje artificial interior, Así, en el salón de 
lacasa se lograba un medio controlado, a través de la arquitectura proyectada y de las intervenciones artísticas.

El pabellón, en palabras de Paul Nelson, era "un lugar que contaba con una buena altura libre, que resultaba ideal para lugar de trabajo". ${ }^{310}$ Este espacio externo al núcleo de la vivienda había sido ocupado por artistas para desarrollar su actividad intelectual. Paul Nelson comprobó las ventajas que le aportaban estas dependencias aisladas en los periodos de reflexión, como contrapunto de la vida familiar de reuniones. Nelson decidió convertir el pabellón en un estudio eventual, que ocupaba de manera privada para proyectar durante los periodos de descanso familiar. El taller de Varengeville estuvo muy vinculado al proceso de creación de La Maison Suspendue y así lo acreditan tanto las fotografías de la maqueta de trabajo tomadas en el jardín, justo delante del pabellón (IV. 27), como las cartas al maquetista en las cuales se le pedía que enviase la primera maqueta definitiva a este lugar ${ }^{311}$. En algunas ocasiones, este ámbito fue compartido con los artistas invitados y esto sirvió para establecer intercambios de ideas y comprobar cómo ocupaban y ordenaban sus amigos el espacio para realizar actividades diferentes a la arquitectura. El concepto de la pieza del pabellón, con sus características de aislamiento y autonomía funcional con respecto al resto de la vivienda, fue recuperada en La Maison Suspendue y transformada en celda para el desarrollo individual. Ambos espacios podían adaptarse a las necesidades de ocupación, funcionaban como refugio temporal y desde ellos se podía controlar el espacio común de la cota cero. Paul Nelson entendió su propiedad de Varengeville como un objeto único, donde las edificaciones eran partes independientes dentro del espacio abierto total que las integraba, y trasladó este modelo a menor escala a su vivienda experimental, Paul Nelson construyó en La Maison Suspendue un paisaje artificial de integración a imagen del que él disfrutaba en su casa de Varengeville.

\footnotetext{
310 Íbidem.

${ }^{311}$ Para comprender la importancia que Varengeville tuvo sobre la obra de Paul Nelson, resultaba muy interesante considerar la presencia de las maquetas en este lugar. Había que preguntarse qué motivos condicionaron el traslado de estas piezas desde París, ya que podían sufrir deterioros considerables. Para tomar las fotografías de la maqueta de trabajo, la pieza se orientó haciendo coincidir las coordenadas geográficas reales con las del plano, de esta manera se lograba conectar el entorno real con el proyecto.
} 


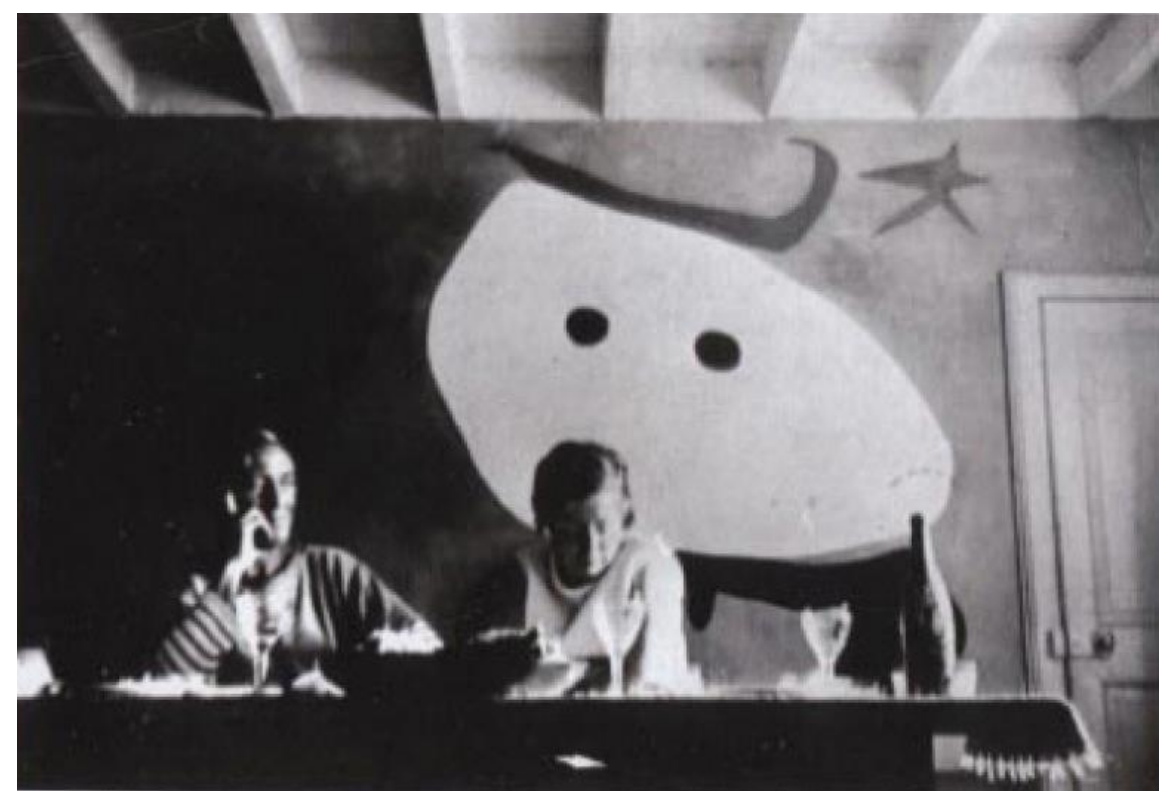

IV. 28 Frescos del salón de Varengeville, Joan Miró, ca 1938.

La segunda de las experiencias fue a través de los frescos que Joan Miró ${ }^{312}$ pintó en el salón de Varengeville (IV. 28). Este trabajo coincidió en el tiempo con la terminación de la primera maqueta de La Maison Suspendue, en la que Miró también había participado con su intervención en la sala principal, de la que formaba parte un mural. A pesar de las diferencias de escala, Joan Miró abordó el mural y los frescos con los mismos juegos compositivos y formales, que dejaban a sus figuras suspendidas en el espacio, desmaterializando el soporte pesado. Paul Nelson comprobó cómo la arquitectura perdía su condición de límite espacial en beneficio de la pintura y cómo Miró había aprovechado la superficie construida para sugerir un efecto espacial de su intervención. Así, en la casa de Varengeville, utilizó tres de los cuatro muros para romper la fragmentación de la caja y conseguir una mayor continuidad y fluidez en el salón mientras que en La Maiosn Suspendue, como ya se ha dicho (§ III.3.), se aprovechó la curvatura del muro para conseguir el mismo objetivo. De esta manera, Paul Nelson entendió cómo, mediante estas intervenciones pictóricas, la arquitectura perdía su papel hegemónico de protector de la humanidad, en ese momento la función podía ser asumida por la pintura. Pintura y arquitectura colaboraban para establecer una relación corporal con las personas y sugerían una interacción espacial donde el individuo pudiera sentirse más integrado.

312 Joan Miró pintó estos frescos en el verano de 1938, representaban el nacimiento de una ballena y estaban ejecutados sobre tres de las paredes del salón, con unas dimensiones de $5 \times 2,1 \times 2$ y $1 \times 1$. 
IV. 29 Intervención en el salón de Varengeville , Paul Nelson, ca 1947

Durante la Segunda Guerra Mundial, la casa fue ocupada por el ejército alemán y utilizada como establo, lo que provocó la destrucción parcial de los frescos de Joan Miró $^{313}$ y la eliminación del falso techo de madera que separaba el salón de una cámara superior abuhardillada. Esta tercera experiencia, en la que el paso del tiempo afectaba a la propia integridad de la vivienda, aportó a Paul Nelson un nuevo punto de vista, que le ayudó a constatar su concepto de casa como objeto adaptable y en constante mutación. La vivienda había sufrido sus propias transformaciones de manera descontrolada y así, cuando terminó la Guerra, Nelson reconstruyó la vivienda y decidió no restituir el forjado de madera y mantener la doble altura en el salón. La única parte que se mantuvo fue el entablado de una pequeña mezzanine dispuesta en el frente opuesto a la chimenea. En esta intervención sobre el salón, se dejaron vistas tanto la estructura de madera de la cubierta como la huella del antiguo forjado $^{314}$, además en el vacío generado por el ejercito alemán al destruir parte de los frescos de Joan Miró, se levantó la chimenea rematada por una campana ejecutada con ladrillos vistos (IV. 29). Así, Paul Nelson abandonaba la actitud moderna frente a los materiales y los sustituyó por un juego de contrastes, dando al interior de la vivienda a una imagen más vernácula.

\footnotetext{
${ }^{313}$ Los murales de Joan Miró quedaron muy deteriorados, así se recogía en la revista Partisan Review Vol 8 Mayo-Junio 1941, donde aparecían unas fotos de los murales realizadas por Suzy Frelingheusen.

${ }^{314}$ Esta información fue obtenida de las conversaciones mantenidas con los hijos de Nelson, Ugo y Rory.
} 
Hogar íntimo de Trets (1975-1976). La creación del refugio propio.

IV. 30 La Maison Nelson en Trets, versión 1, sección longitudinal, Paul Nelson, 1975

La Maison Nelson en Trets fue el último proyecto construido por Paul Nelson y la primera casa que proyectó para su familia y fue su testamento profesional. Se inició en 1975 y finalizó en 1976 tres años antes de morir. En el proyecto se concentró el aprendizaje de toda su carrera. Tras fracasar en su intento por construir una versión de La Maison Suspendue junto a L'École Nationale Supérieure d'Architecture de Marseille (§ III.2.), Nelson encontró un terreno en la localidad de Trets ${ }^{315}$, rodeado de pinares y con vistas al mar Mediterráneo.

El emplazamiento marcó la esencia del proyecto y ayudó a concebir la casa como el último refugio $^{316}$. La vivienda se planteaba como un recinto que obtenía beneficio del medio sin perturbarlo. El paisaje era un elemento más que podía ser utilizado para mantener el equilibrio entre la persona y su entorno, con el objetivo de humanizar la casa. Se proyectó una vivienda protegida del viento Noroeste gracias a la vegetación y abierta a Sureste, donde estaban el mar y la población de Trets, IV. 30) convirtiéndola en una casa con una sola fachada. El acceso compartido se producía por la fachada Noroeste, siguiendo la tradición que arrancaba en

\footnotetext{
315 Olivier Cinqualbre, "Paul Nelson. «Faire vivre l'espace ».Chronique d'une recherche partagée". Catálogo de exposición Musée des Beaux-Arts de Gaillac junio-septiembre 2007 : Un architecte des artistes. Paul Nelson, Léger, Calder, Brassaï, Hélion, Braque, Miró ... Gaillac : Musée des Beaux-Arts de Gaillac, 2007, p.17.

${ }^{316}$ El solar estaba situado junto al Mont de Sainte Victoire, un entorno rodeado de bosque Mediteráneo y próximo a la costa de Marsella. Este paisaje había sido retratado por Paul Cezánne en 1987.
} 


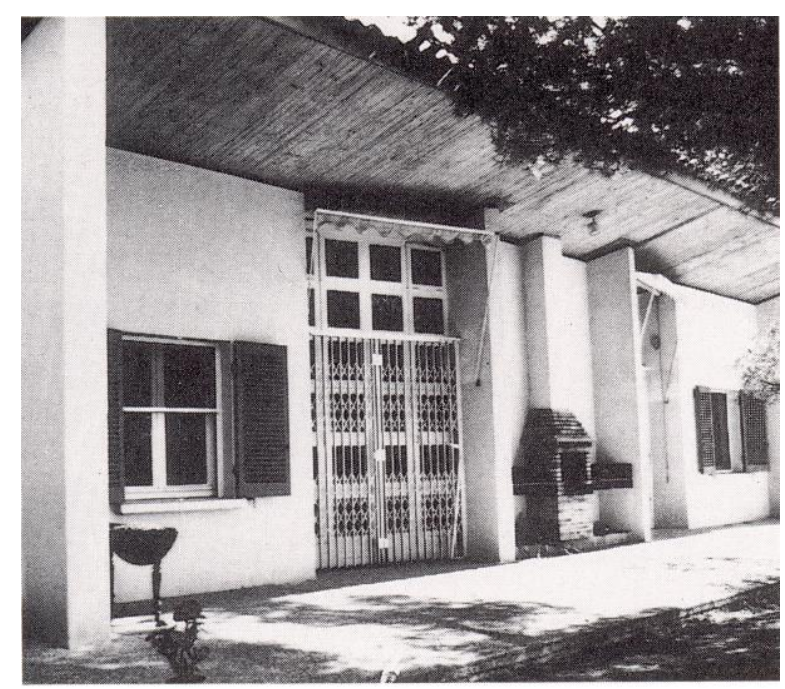

IV. 31 La Maison Nelson en Trets, versión 2, fachada meridional, Paul Nelson, 1976.

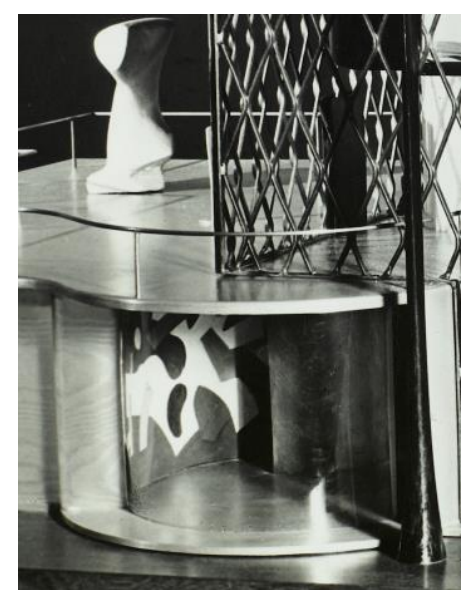

IV. 32 La Maison Suspendue, muro Sur del comedor, Paul Nelson, 1976.

Maison Suspendue y que se mantuvo en otras viviendas como la casa de Badin o la de Nadia Léger. También, como sucedía en estas viviendas, se dispuso la sala principal en la parte posterior, la opuesta al acceso, con objeto de intensificar la relación con el territorio. Este vínculo se vio reforzado en este proyecto de Trets con el porche, otro elemento tomado del pasado que adquiría una escala más monumental, ya que tenía el tamaño de toda la fachada. Nelson también utilizó la construcción de una chimenea centrada en la fachada meridional como herramienta para prolongar el espacio interior de la vivienda y convertir al porche en un nuevo salón de manera que este frente se convertía en la fachada principal en casa. El hábitat doméstico de Paul Nelson evolucionó así desde lo volumétrico a lo superficial, de tal manera que el contenedor continuo de los años treinta, con todas las fachadas iguales y sin relación con el exterior, evolucionó en los años cincuenta, 
hacia una falsa vivienda entre medianeras, debido a la dirección lineal que se establecía con el territorio, y finalmente se transformó en los años setenta en el telón de fachada única que focalizaba un punto de relación con el entorno. El muro panorámico del comedor de La Maison Suspendue (IV. 32), el único hueco de comunicación directa con el exterior, evolucionó hasta desaparecer en la casa de Trets y el espacio del comedor protegido se transformó en un lugar de reuniones familiares al aire libre, donde también estuvieron colgadas algunas obras de arte ${ }^{317}$. $\mathrm{Al}$ final de su carrera, Paul Nelson consideró que la persona y la naturaleza no eran antagónicos, sino que debían convivir. (IV. 31)

En la casa de Trets, Paul Nelson pudo proyectar un hábitat doméstico con total libertad, y retomó algunos de los conceptos enunciados en La Maison Suspendue, transponiéndolos al contexto arquitectónico de los años setenta, siguiendo los mismos criterios que había seguido en sus propuestas urbanísticas ${ }^{318}$.

El programa de La Maison Nelson en Trets también se organizó en dos partes como su modelo de referencia, una parte maquinista, concentrada, rígida y privada, y otra parte de ocio y esparcimiento, expansiva, flexible y social. Formalmente, también se mantuvo la intención de construir un cuerpo privado con la planta en forma de $\mathrm{U}$ que abrazaba a un cuerpo público, aunque en la vivienda de los años setenta se optó por incluir todas las funciones en un solo volumen y no distribuirlas en dos piezas específicas como se hizo en los años treinta. Las herramientas utilizadas para conseguir la continuidad espacial fueron las ya ensayadas anteriormente. El espacio social se resolvió mediante un solo volumen de doble altura, con una escalera circular vista que conectaba las dos alturas, mientras en el resto de las unidades funcionales, que tenían una mayor fragmentación espacial, la continuidad se resolvió a través de las conexiones múltiples entre las estancias y los recorridos alternativos.

\footnotetext{
${ }^{317}$ Alexander Calder regaló a Paul Nelson un móvil que pendía del techo del porche, Véase: Olivier Cinqualbre, "Paul Nelson. «Faire vivre l'espace».Chronique d'une recherche partagée". Catálogo de exposición Musée des Beaux-Arts de Gaillac junio-septiembre 2007 : Un architecte des artistes. Paul Nelson, Léger, Calder, Brassaï, Hélion, Braque, Miró ... Gaillac : Musée des Beaux-Arts de Gaillac, 2007, p.17.

318 Tras la reconstrucción de las ciudades destruidas por la Segunda Guerra Mundial, el planeamiento fue un intenso campo de trabajo para los arquitectos. Paul Nelson, coincidiendo con la construcción de la casa de Trets, escribió una artículo en defesa de un urbanismo orgánico, donde se proponía que el tamaño y la organización de las nuevas poblaciones estuviese función de los recursos naturales de cada territorio. Paul Nelson extendía sus reflexiones de los años treinta, sobre el papel que jugaba el espacio doméstico en la vida del hombre, a la escala urbana. Véase: Paul Nelson, "Introduction au thème sur les objectifs de l'urbanisme". Le carré bleu, nº4, 1975, p.3.
} 
IV. 33 La Maison Nelson en Trets, versión 1, planta baja, Paul Nelson, 1975

Nelson recuperó el mismo espíritu que animaba al habitante a recorrer y a ocupar $L a$ Maison Suspendsue de manera personal, eliminó los espacios de circulación e introdujo los recorridos a través de las sucesivas habitaciones. Todas las estancias podían quedar conectadas, con independencia de su función, a través de los recorridos. Por lo tanto, la flexibilidad en el uso y la convivencia entre lo público y lo privado quedaban sujetos a las necesidades y a los deseos de los ocupantes generando en estos la sensación de habitar en un espacio vivo. La casa estaba en constante mutación gracias al uso personal, como evidencia el dormitorio de sus hijos transformado en una sala de cine eventual. (IV. 33)

Paul Nelson siguió en la casa de Trets los criterios que había utilizado en la Maison Badin y posteriormente en la casa para Nadia Léger. Abandonó las referencias técnicas y constructivas de la arquitectura moderna y proyectó una solución basada en muros de carga construidos in situ, sobre los que apoyaba un forjado inclinado, cubierto con teja curva. El único elemento con ecos de modernidad eran las retículas de las carpinterías metálicas, que cerraban de suelo a techo parte de la fachada Sureste. (IV. 34). Con esta decisión, la casa de Trets se alejaba de los conceptos de planta libre, cubierta plana y fachada libre y mostraba una imagen más próxima a la arquitectura rural del entorno.Al igual que lo había hecho en las dos viviendas señaladas, Nelson volvió a trabajar por desarrollar una nueva actitud frente a la construcción en la que los materiales se dejaban vistos con sus diferentes texturas. 


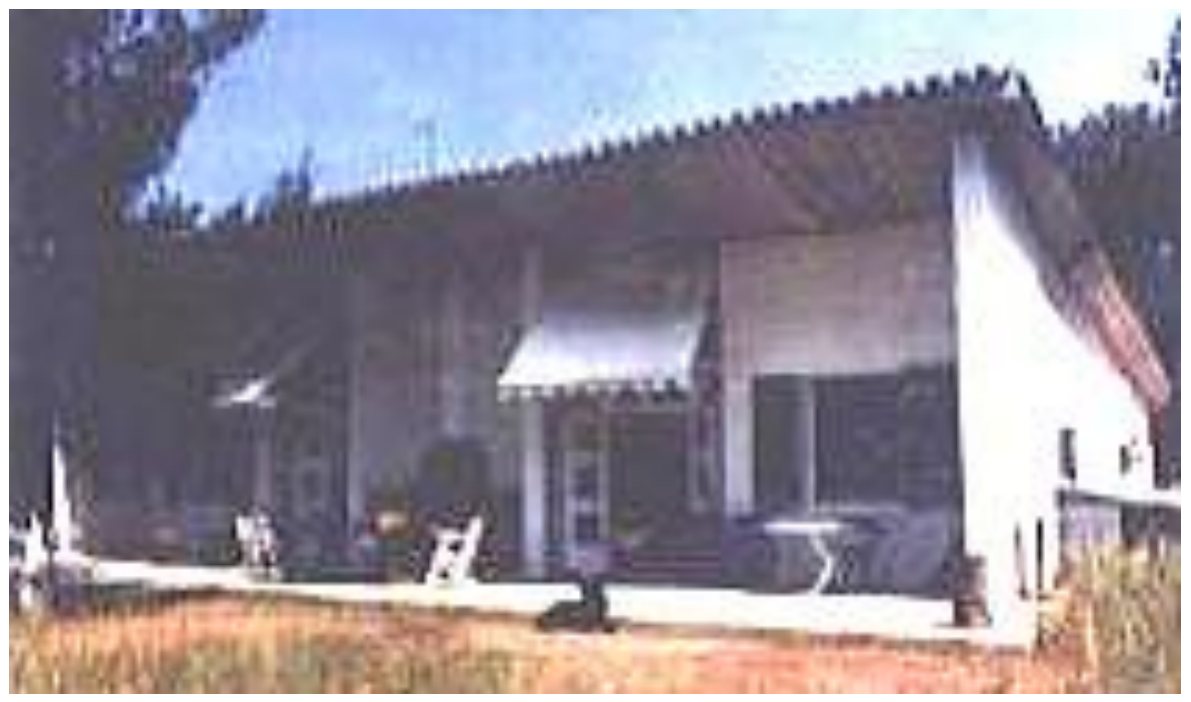

IV. 34 La Maison Nelson en Trets, versión 2, fachada Sur, Paul Nelson, 1976

Esa moralidad que buscaba la verdadera expresión de los materiales se convirtió en una herramienta decorativa en los acabados interiores.

La imagen masiva del volumen externo de la vivienda y la composición simétrica de la fachada posterior, con vuelo de la cubierta y los dos apoyos centrales trasdosados, otorgaban a la casa un aspecto de templo clásico. Así, mientras en el interior se había buscado mantener la continuidad espacial de La Maison Suspendue, en el exterior se generaba una rigidez volumétrica muy controlada, que ponía de manifiesto la vocación de permanencia de la casa en el lugar. Era la construcción de la estabilidad después de una vida de nómada ${ }^{319}$.

La ubicación de la vivienda en un entorno apartado y la reducción del programa al uso cotidiano del matrimonio ${ }^{320}$ repercutieron en la organización de la privacidad dentro de la casa. El acceso a la vivienda era más restringido, ya que el filtro más intenso no se fijaba en la propia puerta del edificio sino en el camino de entrada y el perímetro vegetal y la orografía otorgaban al jardín una primera condición de privacidad. A pesar de esta disposición, Paul Nelson mantuvo su interés por construir un espacio personal retirado del espacio público y proyectó dos espacios

\footnotetext{
${ }^{319}$ Paul Nelson obtuvo la nacionalidad francesa el 8 de enero de 1973 . Hasta ese momento, no se sintió plenamente integrado en Francia. Toda su vida había tenido la sensación de ser un extranjero.

${ }^{320}$ En esos momentos, sus hijos Ugo y Rory estaban estudiando en la Universidad y la familia sólo se reunía en los periodos de vacaciones. El matrimonio tampoco mantenía reuniones frecuentes con otros artistas como sucedía en la casa de Varengeville.
} 
IV. 35 La Maison Nelson en Trets, versión 1, sección transversal, Paul Nelson, 1975.

de trabajo en la planta primera, que eran el eco de las habitaciones individuales de La Maison Suspendue, destinados a taller para su mujer y a estudio para él. Eran unas estancias aisladas, con huecos mínimos abiertos al paisaje que recibían iluminación cenital (IV. 35). Finalmente, el proyecto se redujo a una sola altura y estos espacios se integraron dentro de las habitaciones. De esta manera, los dormitorios volvían a aglutinar funciones que antes se habían proyectado dispersas. Nelson aumentó el tamaño de las habitaciones y utilizó el mobiliario para configurar un ámbito de descanso y otro de ocio-trabajo. En el salón también recurrió al mobiliario arquitectónico estable, para construir diferentes grados de privacidad sin necesidad de levantar separaciones y, en uno de los laterales, volvió a utilizar la chimenea ${ }^{321}$ como foco de atracción de reuniones mientras que en el frente opuesto se proyectó una mesa de trabajo corrida para el eventual uso individual. Así, su concepto de privacidad asociada al aislamiento se había difuminado en favor de la integración.

${ }^{321}$ La chimenea y el porche fueron dos elementos recurrentes en la arquitectura doméstica de Paul Nelson, que le permitieron respectivamente, construir las relaciones sociales dentro de la vivienda y de la casa con el entorno 


\section{La presencia de lo doméstico en la obra pública.}

De toda la arquitectura no residencial de Paul Nelson, la más conocida es su arquitectura hospitalaria, fundamentalmente la realizada tras la Segunda Guerra Mundial y que se inició con la construcción del Hospital memorial de Saint Lô de 1946. El profesor Donato Severo ${ }^{322}$ utilizó este proyecto para reflexionar sobre la aportación que hizo Paul Nelson a la arquitectura moderna y concluyó que la aportación se produjo a través de la concepción humanista de sus hospitales. A partir de esta afirmación, se ha contrastado la arquitectura hospitalaria de Paul Nelson con la residencial y se ha analizado la repercusión que tuvieron sus viviendas y especialmente La Maison Suspendue en la construcción de una arquitectura pública más humana.

En 1940, Alvar Aalto teorizó sobre las herramientas para humanizar la arquitectura, y lo hizo en dirección contraria a la definida en esta tesis. Alvar Aalto partía de sus experiencias hospitalarias y analizaba su transposición a su obra residencial, considerando que los pacientes eran más sensibles a las formas arquitectónicas ${ }^{323}$. En el caso de Nelson, se ha observado lo contrario, cómo las herramientas utilizadas para construir el espacio individual de las viviendas eran retomadas para conseguir una cercanía entre las personas y los espacios públicos. Nelson readaptó las conclusiones de sus construcciones residenciales y domesticó su obra pública.

Con el fin de analizar la relevancia y la repercusión de La Maison Suspendue en su arquitectura no residencial, se han seleccionado tres proyectos contemporáneos, dos sanitarios y uno expositivo, y una obra del final de su carrera, un edificio representativo nunca publicado ni analizado, que mantenía una importante sintonía con el modelo de referencia y que evidenciaba el deseo de Paul Nelson por construirlo con independencia del uso final.

\footnotetext{
${ }^{322}$ Donato Severo es profesor en l'ENSA-Paris Val de Seine, Tesis doctoral : L'Hôpital Mémorial France-Etats Unis de Saint-Lô de Paul Nelson. Du projet à l'usage (1947-1999). Université Paris 1 - Panthéon -Sorbonne - 2010.

323 Alvar Aalto analizaba los efectos psicológicos de la arquitectura, “...He podido experimentar personalmente en la construcción de hospitales que las reacciones psíquicas y psicológicas de los pacientes proporcionaban indicaciones válidas para la construcción de las viviendas ordinarias..." Véase: Alvar Aalto, ["The Humanizing of Architecture", The Technology Review, nov, 1940]
} 


\subsection{Arquitectura sanitaria. La casa del paciente sano.}

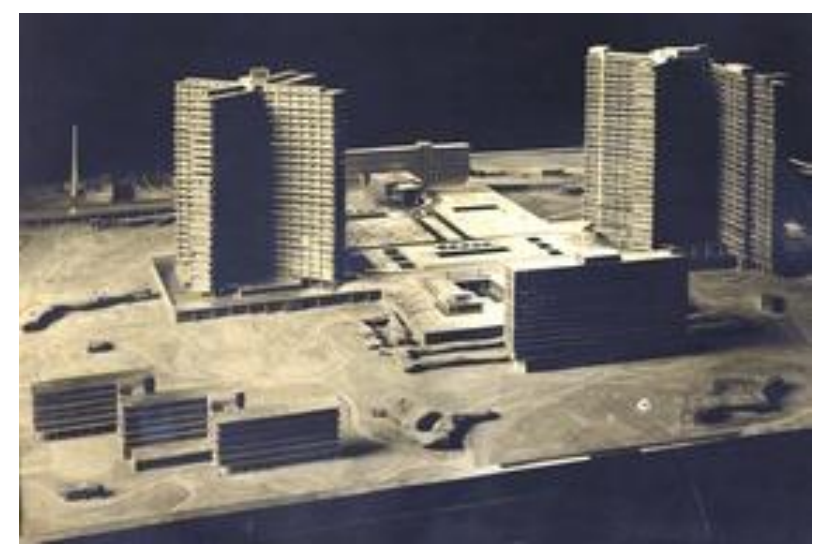

IV. 36 La Cité Hospitalière de Lille, maqueta, Paul Nelson, 1932

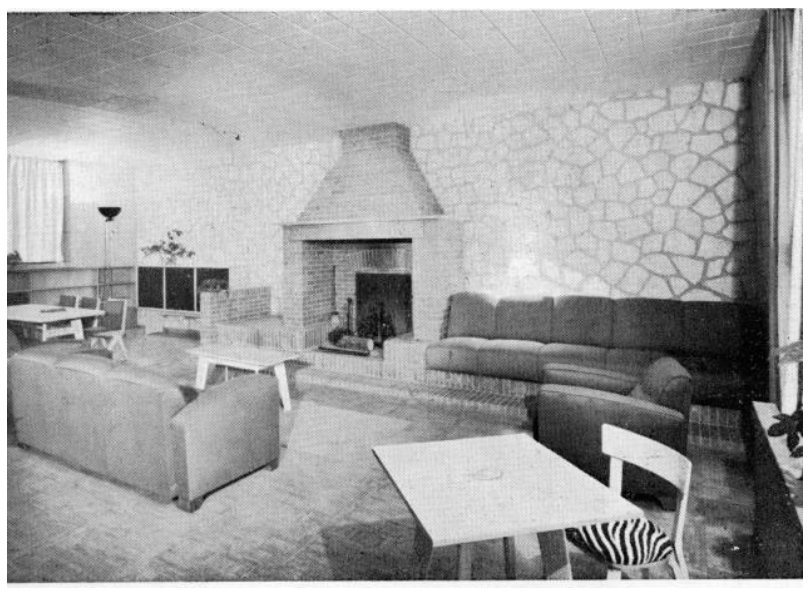

IV. 37 Hopital Américain de Paris, salón de acceso, Paul Nelson, 1952

La atracción de Paul Nelson por la arquitectura sanitaria se inició con el proyecto de un centro homeopático, como trabajo de diplomatura en 1927. La evolución de su arquitectura y de su concepto de hospital siguieron procesos paralelos. Así en 1932, cuando ganó el concurso para la Ciudad Hospitalaria de Lille (IV. 36), el programa se ordenó funcionalmente en edificios separados. A mediados de los años treinta, pasó de lo funcional a lo personal, de tal manera que el interés por el paciente comenzó a tener más importancia y su concepto de hospital se modificó, convirtiendo la habitación del enfermo en un objeto de investigación experimental para lograr el bienestar del enfermo, como en el Pabellón de Cirugía de Isamïlia. Tras la Guerra, su interés por incorporar la psicología a sus premisas de proyecto le llevó a pensar en el hospital como un lugar preventivo de la enfermedad, más que como un espacio curativo, este era el caso del Hospital memorial de Saint Lô. La evolución culminó 
en los años sesenta, con su preocupación por los problemas psicológicos de las personas y así comenzó a pensar en proyectos de salud mental. Este tipo de centro fue el ejercicio que propuso a sus alumnos de la Universidad de Yale en 1960. En general, el tamaño de las intervenciones sanitarias también se fue reduciendo y pasó de la escala urbana de Lille 1932 a la ampliación del Hospital Americano de Neuilly- sur-Seine 1952 (IV. 37). El objetivo final de Paul Nelosn era hacer de los hospitales lugares para mantener a la gente sana y evitar que enfermaran.

La Maison Santé Type Minimum, 1932. La habitación exterior.

Se trata de un proyecto no construido, pensado para ser ejecutado en un clima templado y la obra se enmarca en el contexto experimental que marcó la arquitectura de Paul Nelson durante los años treinta. El programa se resolvió con un lenguaje moderno y varios prismas funcionales adosados ortogonalmente (IV. 38). Se proyectó un edifico principal, para albergar a los enfermos, con una volumetría en cascada hacia el Sur, y una planta rectangular, elevado sobre pilotes dejando la planta baja libre para organizar los accesos y dar continuidad al jardín. Este cuerpo estaba rematado por una azotea transitable. Los servicios centrales se ordenaron en tres prismas adosados a la fachada principal y las dependencias del personal se ubicaron en otro volumen dispuesto al Oeste, para proteger al cuerpo principal de los vientos.

El hospital Type Minimun era un proyecto de investigación teórica, que no obedecía a ningún encargo concreto, como La Maison Suspendue y su objetivo principal era crear las condiciones arquitectónicas que garantizasen el bienestar de los enfermos residentes. Para resolverlo, Paul Nelson se enfrentó al programa siguiendo el esquema de organización de un espacio residencial y trabajó con las mismas herramientas que utilizaba en sus viviendas, para crear una arquitectura próxima a sus ocupantes. “ ... La sala de acceso está tratada como el hall de un hotel, completamente separada de la recepción médica y de la administración..."324.

\footnotetext{
${ }^{324}$ Paul Nelson, Architecture Hospitalière. Deux Études de Paul Nelson. Maison de Santé et Pavillion de Chirugie, Paris : Albert Morancé, 1936.
} 


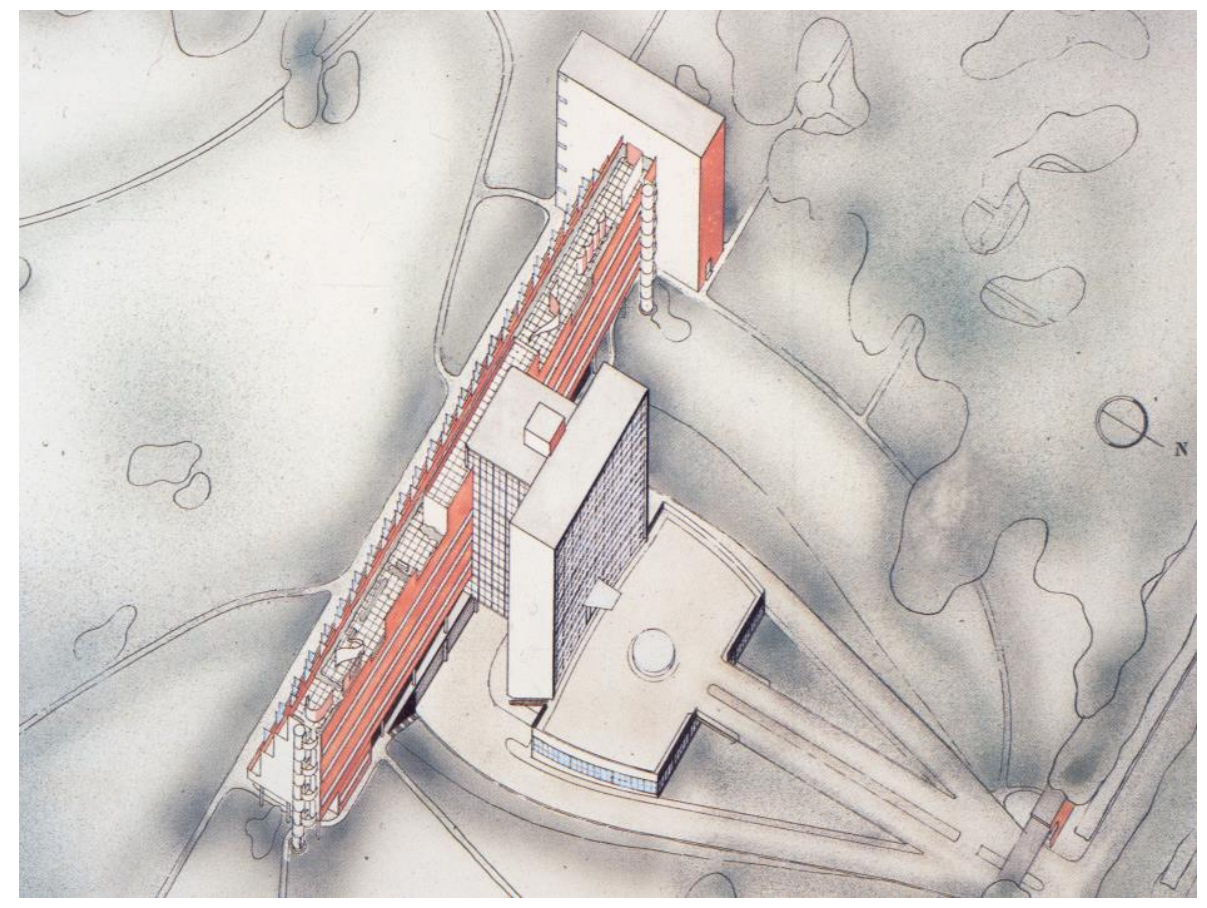

IV. 38 La Maison Santé Type Minimum, perspectiva Norte, Paul Nelson, 1932

Nelson trabajó a todas las escalas para conseguir el confort de las personas, desde la configuración de los espacios sociales hasta la definición de las habitaciones. El modelo de referencia era el laboratorio doméstico, con un orden general que mantuvo algunas constantes a pesar de los procesos evolutivos. Así situó el acceso público en la fachada Norte y fue construyendo diferentes filtros para conseguir mayor privacidad, tanto hacia el lado Sur como hacia la planta superior del edificio y ubicó las habitaciones de los enfermos en ese frente posterior más privado. La apertura del alzado trasero hacia el entorno convirtió a esa fachada en la principal, como sucedía en las viviendas .

El principal objeto de estudio del proyecto fue el espacio individual de los pacientes. Paul Nelson se planteó diferentes grados de aislamiento, para que los residentes pudiesen elegir su manera de compartir y de habitar el hospital. Igual que hizo en $L a$ Maison Suspendue, en este proyecto sectorizó los espacios del servicio (médico) y los aisló del resto del edificio. El área de estancia de los médicos era un bloque que podía funcionar de manera autónoma, tenía su propio acceso exterior y su funcionamiento interno no era visible por los enfermos, lo que garantizaba la privacidad de los sanitarios. (IV. 39) 


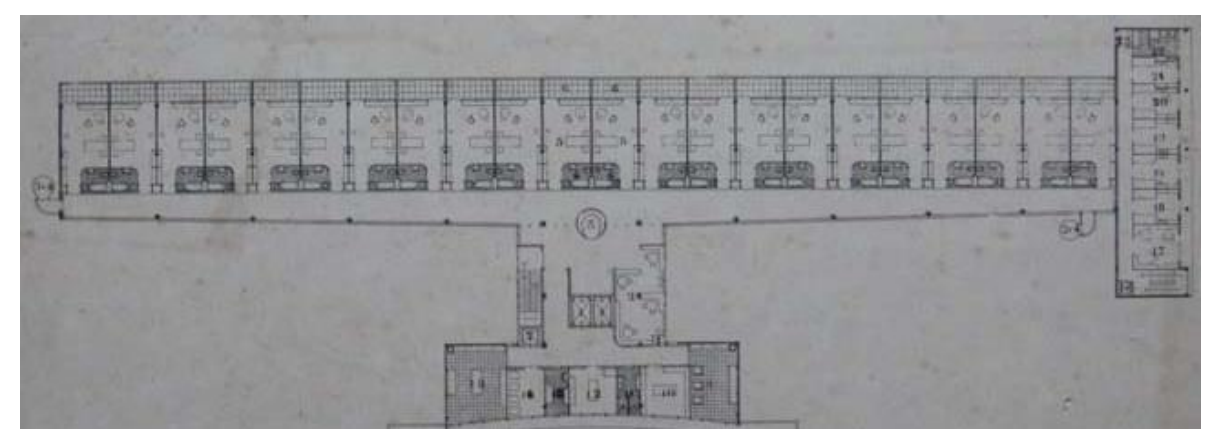

IV. 39 La Maison Santé Type Minimum, planta tipo, Paul Nelson, 1932

El cuerpo de cuidados del edificio principal tampoco era accesible para todas las personas, existía un muro de vidrio con una cabina centrada que separaba los espacios comunes centralizados y las habitaciones, así el vigilante podía controlar todos los espacios comunes y por lo tanto las relaciones sociales en el espacio público. Este mecanismo de control era el mismo que se podía ejercer en La Maison Suspendue desde las habitaciones individuales sobre el salón.

En este proyecto sanitario, Paul Nelson recurrió a la construcción de membranas transparentes para separar vestíbulos, pasillos, salas de espera y núcleos de comunicación. De esta manera, se establecía una continuidad visual entre todos los espacios públicos de la planta, mediante desmaterialización de los muros, pero se mantenían barreras físicas que fragmentaban el espacio y garantizaban la funcionalidad de cada ámbito. Este modelo compositivo de especificidad espacial fragmentado evolucionó en La Maison Suspendue hacia un sistema de contenedor de convivencia, donde los elementos intermedios de tránsito no se utilizarban para separar sino para conectar. 


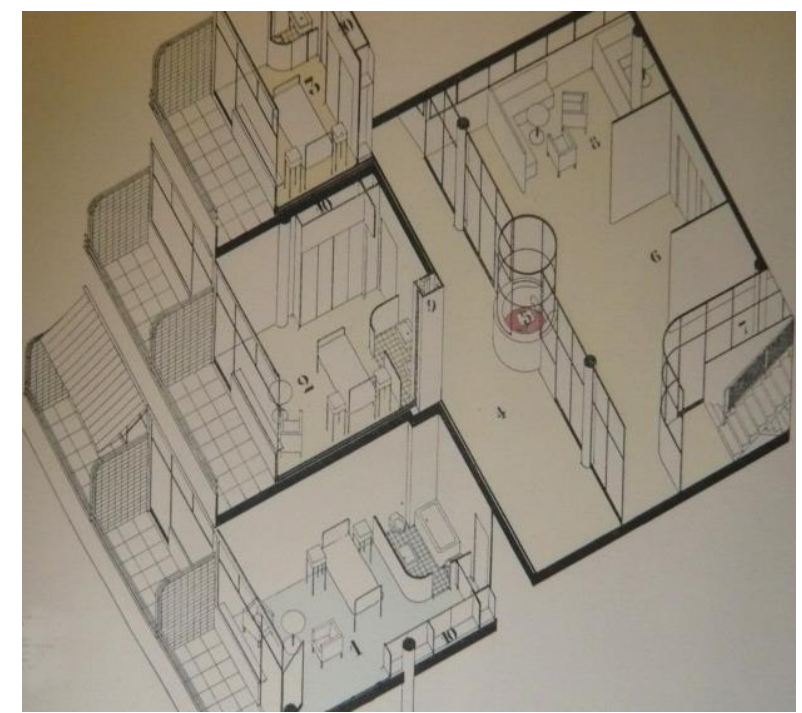

IV. 40 La Maison Santé Type Minimum, axonometría seccionada de dormitorios a Sur, Paul Nelson, 1932

Las habitaciones del hospital eran las unidades de vivienda temporal para cada uno de los residentes (IV. 40). Por lo tanto, el programa funcional de cada estancia era el mismo que se podía desarrollar en un apartamento. Había un baño individual, un espacio de descanso, un lugar de ocio y un espacio exterior que prolongaba la vida doméstica fuera del propio edificio. Nelson consideraba que estas terrazas contribuían al bienestar y la recuperación del enfermo con la misma intensidad que las propias habitaciones. Con independencia del tamaño de cada dormitorio, la terraza mantenía su superficie inalterada, la habitación exterior era un espacio para uso personal separado de los vecinos mediante mamparas y protegido por un toldo y configuraba un recinto seguro desde el cual beneficiarse de las condiciones que ofrecía el medio.

Paul Nelson quiso que los enfermos de La Maison Santé Type Minimum percibieran el hospital, en su conjunto, como una prolongación de su propia casa.Por lo tanto, consideró que los residentes podían hacer uso personal tanto de sus habitaciones como de los espacios comunes. Para resolver la compatibilidad de ocupación de los ámbitos sociales, adoptó el modelo que utilizaba en sus viviendas ${ }^{325}$, propuso acotar físicamente pequeños espacios para que las personas los identificasen con facilidad. Por otra parte la consideración del clima, como un factor que contribuía a la recuperación del enfermo, le llevó a proyectar una azotea transitable de libre acceso,

\footnotetext{
${ }^{325}$ En la Casa Alden Brooks 1929, el espacio del salón se organizó en diversos ámbitos con ayuda del mobiliario, la chimenea y pequeñas intervenciones en los muros
} 


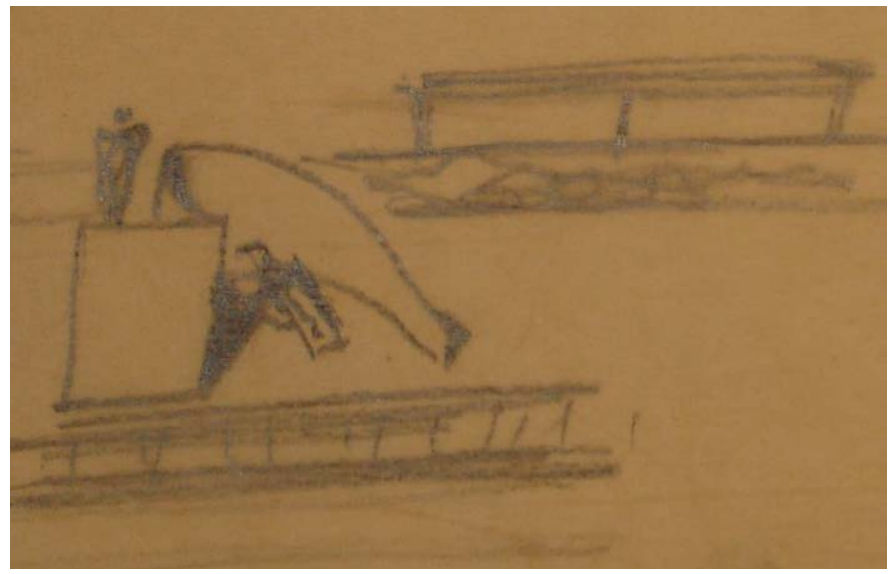

IV. 41 La Maison Santé Type Minimum, croquis de los protectores de la terraza, Paul Nelson, 1932

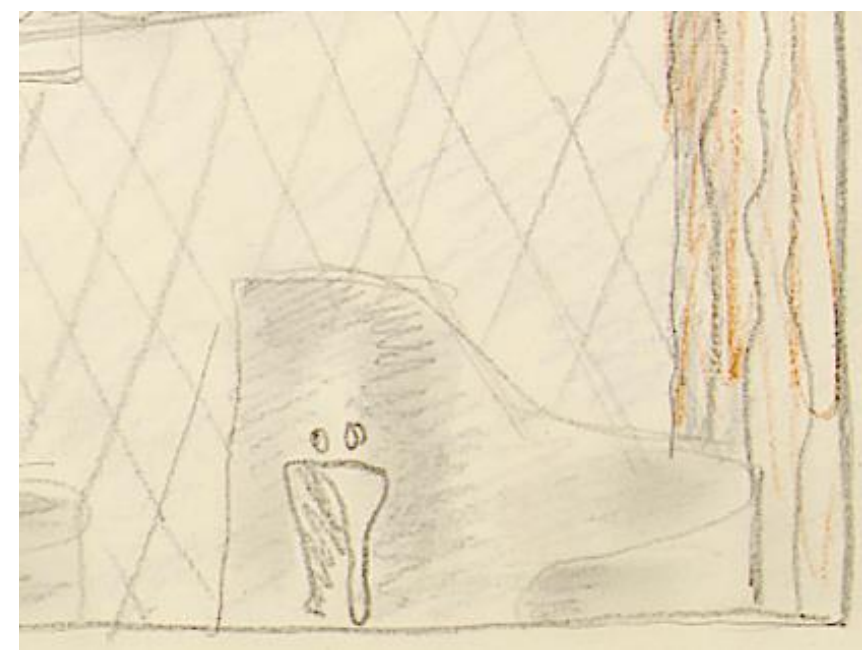

IV. 42 La Maison Suspendue, croquis del mobiliario del salón, Paul Nelson, ca. 1938

un lugar de esparcimiento fuera del dormitorio, en el que se compartía superficie con otros residentes. Paul Nelson proyectó unos paramentos ondulados verticales, con diferentes configuraciones y tamaños, que protegían a los enfermos de los vientos (IV. 41), estas láminas curvas estaban abiertas a mediodía y albergaban unas butacas donde los enfermos podían descansar y disfrutar del paisaje. Así se creaban las condiciones de contorno mínimas para inducir a los residentes a gozar de un deleite pasivo que se aprovechaba individualmente, protegido de otras miradas cercanas con la que se compartían experiencias. Estas láminas escultóricas tuvieron su eco en los biombos metálicos que proyectó para La Maison Suspendue. (IV. 42). 


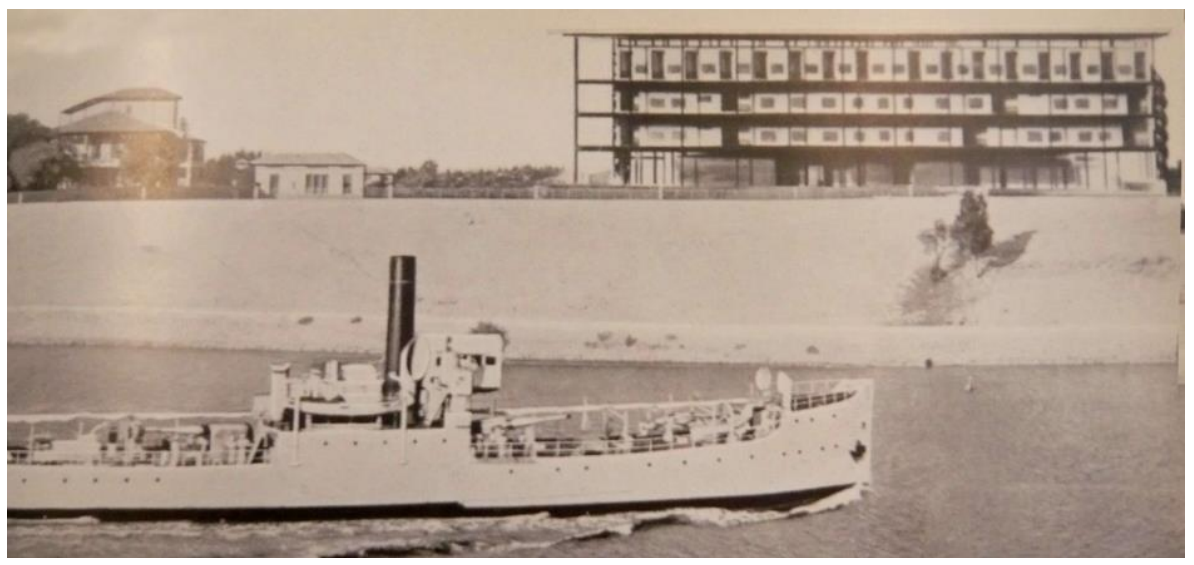

IV. 43 Pabellón de Cirugía de Ismaïlia, fotomontaje frente al Nilo, Paul Nelson, ca.1935

La compañía del Canal de Suez decidió construir en Ismaïlia, frente al río Nilo, un nuevo pabellón hospitalario próximo al ya existente, para atender a sus empleados en unas óptimas condiciones (IV. 43). ${ }^{326}$ Uno de los condicionantes que más tuvo en cuenta Paul Nelson para construir una arquitectura que ayudase a la recuperación, fue el entorno. Por un lado, la ubicación del hospital frente al río Nilo y a poca distancia del lugar de trabajo de los enfermos, llevó a Paul Nelson aproponer un edifico abierto y alineado con el río ${ }^{327}$, desde cuyos grandes huecos los enfermos podían ver su trabajo como un espectáculo. Por otro lado, debía considerarse el clima, húmedo y caluroso, la proximidad del polvo del desierto y las enfermedades que el propio río podía propagar. Estas condiciones le llevaron a proyectar un edifico protegido, donde la asepsia debía de ser la función principal. De esta manera, Paul Nelson se planteó el proyecto como la construcción de un edifico dentro de otro, un contenedor metálico y ligero que protegía un volumen interior más resistente y abierto al río Nilo (IV. 44). La técnica de una construcción moderna, ejecutada con metal, dotaba al edificio de una coraza de lamas manipulable que ayudaba a mejorar las condiciones térmicas del volumen interno a la vez que permitía mantener un contacto visual con el exterior.

\footnotetext{
${ }^{326}$ La Compañía del Canal ya contaba con un centro de curas dirigido por la Compañia de San Vicente de Paul. El cirujano jefe era el doctor Paul Plessier, que fue una persona muy receptiva a las sugerencias tecnológicas de Paul Nelson. La Compañía decidió construir un nuevo pabellón sanitario con el objetivo de poder atender a los empleados rápidamente, evitando los costes que suponía el traslado de los trabajadores extranjeros, más cualificados, para ser atendidos en sus países de origen.

${ }^{327}$ Paul Nelson supuso que el orgullo de formar parte de La Compañía del Canal sería un buen punto de partida para elevar el ánimo de los trabajadores enfermos.
} 


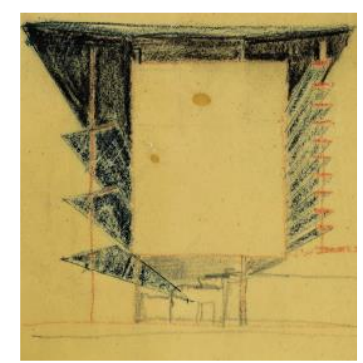

IV. 44 Pabellón de Cirugía de Ismaïlia, croquis de cerramiento, Paul Nelson,ca. 1934

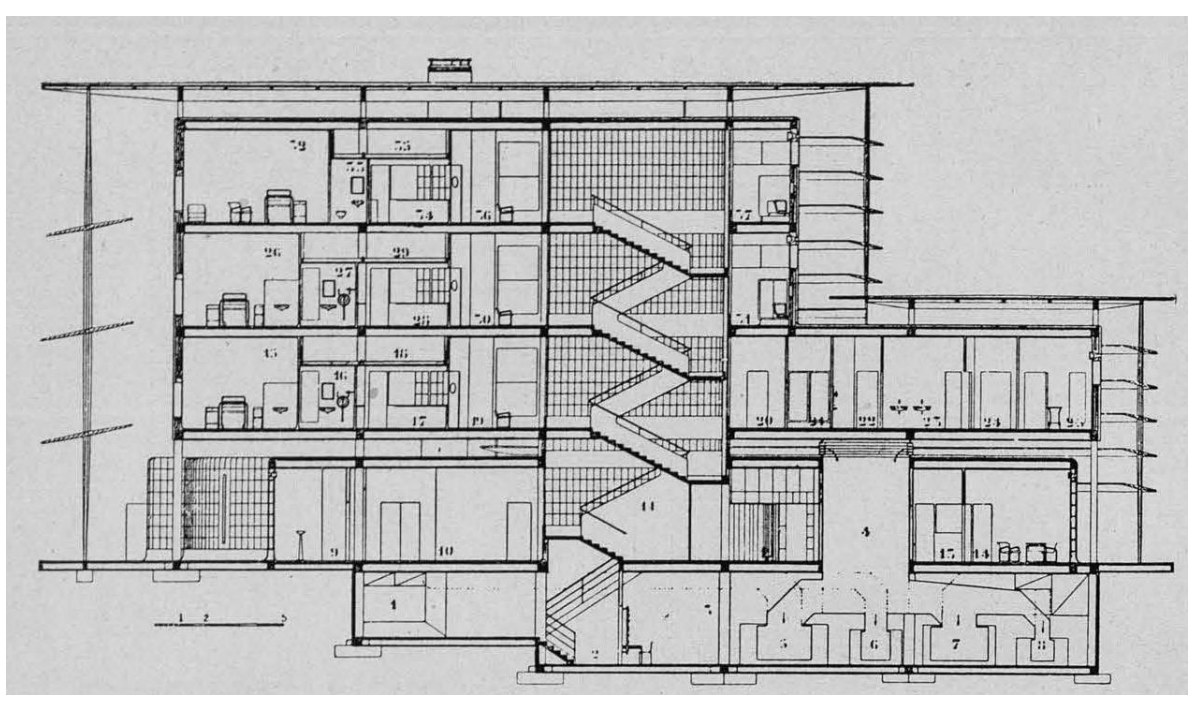

IV. 45 Pabellón de Cirugía de Ismaïlia, sección, Paul Nelson, ca.1935

El encargo del pabellón de Isamïlia se sitúa entre dos proyectos teóricos, uno sanitario y otro doméstico: la Maison Santé Type Minimum y La Maison Suspendue, con los que compartía hipótesis de partida y objetivos. El esquema de organización del programa de Ismaïlia era muy similar al de La Maison Santé Type Minimum, un prisma longitudinal que contiene las habitaciones, al que se adosa un cuerpo de servicios centrales. Los dos edificios también compartían la disposición de los núcleos de comunicación y los sistemas de control de la planta y habían surgido de aplicar el mismo criterio psicológico a la arquitectura en pro de lograr el confort emocional del paciente. El final del proyecto del pabellón de Ismaïlia se solapó en el tiempo con el inicio de la investigación de La Maison Suspendue y entre los dos trabajos se estableció una línea de continuidad que, más allá de la aplicación de aspectos formales o constructivos similares, estaba basada en una manera de entender la ocupación y el uso de la arquitectura. En las dos obras utilizó la técnica, la flexibilidad, la continuidad espacial y el aislamiento para construir un espacio que no sólo cumplíese una necesidad funcionalidad sino que aportar un valor extra, inmaterial. 


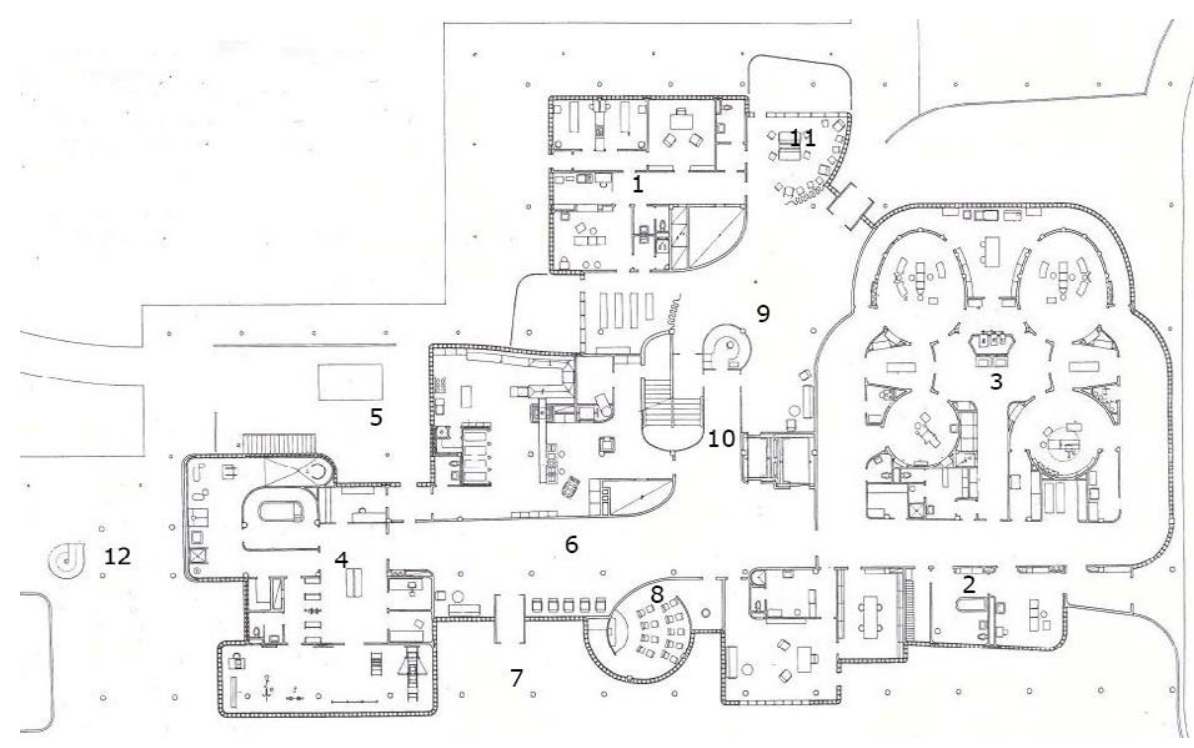

IV. 46 Pabellón de Cirugía de Ismaïlia, planta baja, Paul Nelson, 1934

1consultas externas, 2 admisión, 3 centro de operaciones, 4 salas fisioterapia, 5 entrada cuartos de servicio, 6 vestíbulo principal, 7 salida a jardín y al Canal, 8 capilla, 9 control, 10 comunicaciones verticales, 11 salas espera.

Paul Nelson utilizó un mismo juego volumétrico para resolver dos programas diferentes: el hospital y la vivienda. Recurrió al encuentro de un prisma ligero de varias alturas, que alojaba los espacios más privados del área de residentes, con otro cuerpo de dos alturas que contenía las áreas funcionales del hospital (IV. 45). En la intersección entre las dos piezas se ubicaron los espacios comunes, más públicos, destinados a salas de espera y de reuniones. Espacialmente, Isamaillia fue la versión plana del desarrollo volumétrico de La Maison Suspendue; los dos proyectos respondían al modelo del edificio contenedor, que albergaba diferentes volúmenes en su interior pero, mientras en el hospital, la superposición de forjados limitaba la percepción volumétrica de la planta, en la vivienda, la ausencia de planos intermedios dotaba al espacio de continuidad en toda la altura. Nelson trabajó en los proyectos para que la continuidad espacial fuese compatible con el funcionamiento de las partes, para lo cual utilizó tanto las composiciones formales y los condicionantes sociales. Su materia de trabajo fue el vacío, las conexiones entre diferentes espacios de transición y las estancias comunes generaban una continuidad espacial que se apoyaba en la diversidad formal, para facilitar la identificación de las unidades funcionales (IV. 46). El contraste volumétrico, desarrollado a diversas escalas en Ismaïlia, se convirtió en el precedente de $L a$ Maison Suspendue. 

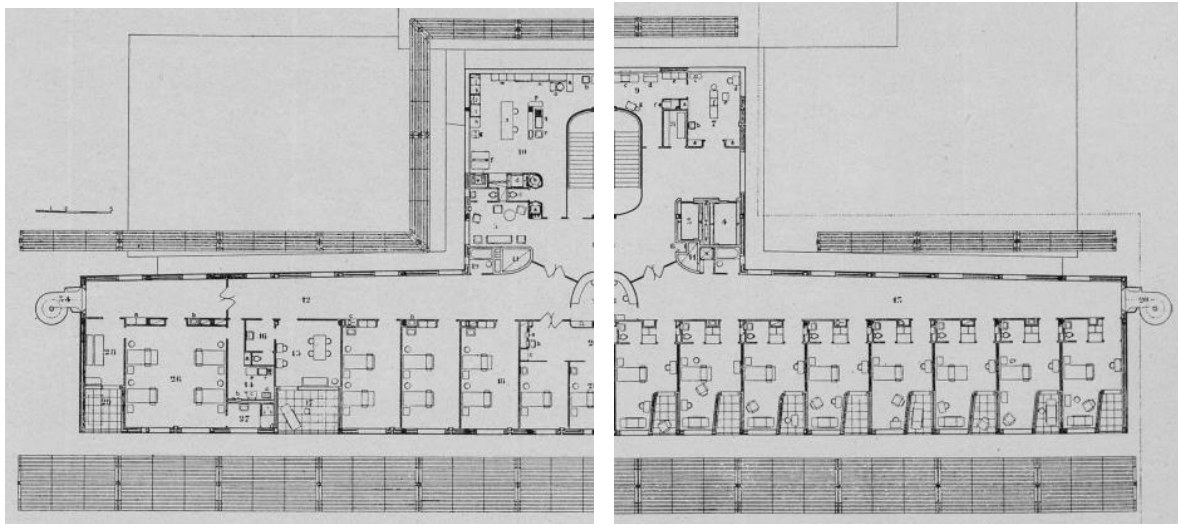

IV. 47 Pabellón de Cirugía de Ismaïlia, plantas segunda y tercera , Paul Nelson, 1934

Las relaciones sociales eran la otra hipótesis que sirvió para singularizar a las partes dentro del conjunto. $\mathrm{Si}$, en la casa, la construcción del espacio personal que permitía crecer al habitante, estaba condicionada por la creación de diferentes grados de aislamiento, en el hospital, a la necesidad espiritual del enfermo se le sumaba la función vital de la curación en un clima cálido, la asepsia. De esta manera, el aislamiento hospitalario para evitar los contagios por contacto, con sus connotaciones sociales, ${ }^{328}$ fue el precedente de la construcción de los espacios de retiro y aislamiento de la casa. Y un criterio funcional como la asepsia hospitalaria, que garantizaba la cura física del paciente, se convirtió en el germen del espacio inútil dentro de los espacios comunes de la vivienda, que garantizaban la cura moral del habitante. (IV. 47)

Si la construcción del aislamiento y del espacio individual en La Maison Suspendue se resolvieron por medio de un orden volumétrico interno, la cuarentena y la protección de los enfermos en Ismaïlia se consiguió mediante la interposición de barreras y filtros. Las puertas que separaban ámbitos diferentes aumentaban de espesor hasta convertirse en estancias de desinfección y la planta de las unidades con los niveles de asepsia más elevados, como el área de cirugía de la planta baja, se resolvió mediante un juego de homotecias que dejaban a las estancias principales en una composición flotante, de manera que la salubridad se fragmentaba

\footnotetext{
${ }^{328}$ El programa propuesto por La Compañía del Canal de Suez a Paul Nelson sugería la segregación por plantas de los enfermos de acuerdo a su categoría laboral, con independencia de su gravedad, de tal manera que los empleados de las categorías superiores estuviesen alojados en la última planta. Nelson en cambio utilizó la asepsia como condicionante y propuso situar a los enfermos con mayores riesgos de contagio en las plantas superiores. A esta estratificación vertical, le añadió una horizontal por sexos, con un ala de hombres y otro de mujeres, controladas por un vigilante dispuesto en una cabina central. Véase: Paul Nelson, Architecture Hospitalière. Deux Études de Paul Nelson. Maison de Santé et Pavillion de Chirugie, Paris : Albert Morancé, 1936.
} 


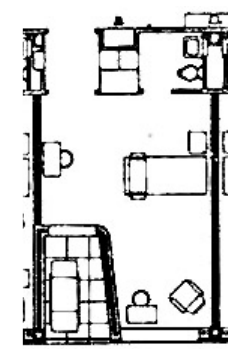

A

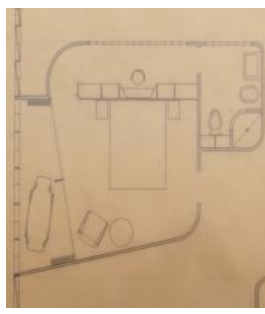

A

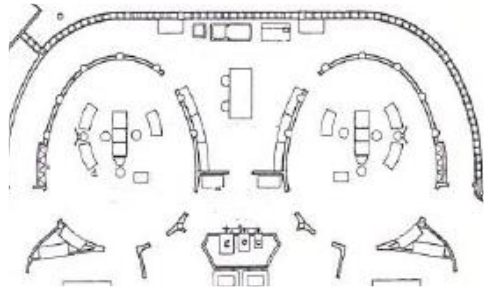

$\mathrm{B}$

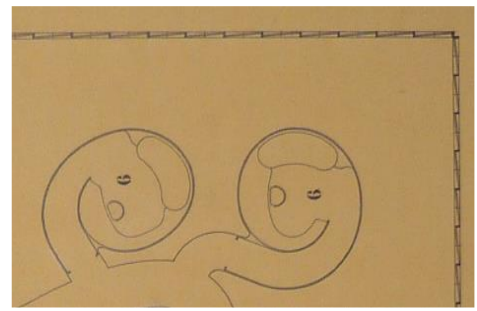

B
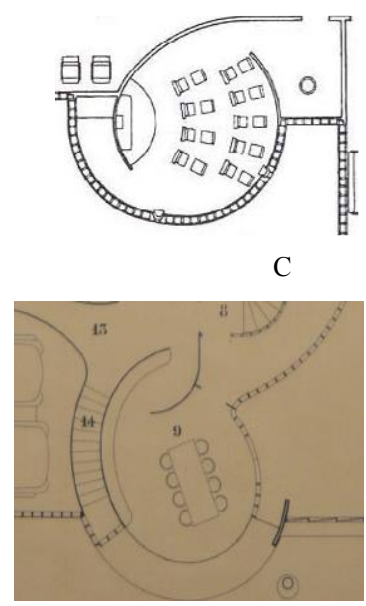

IV. 48 Pabellón de Cirugía de Ismaïlia, A- habitación, B-salas de cirugía, C- capilla, Paul Nelson, 1934

IV. 49 La Maison Suspendue, A- habitación pral., B-celdas individuales, C-comedor, Paul Nelson, 1938

espacialmente a través de diferentes corazas superpuestas. Por lo tanto, el avance de La Maison Suspendue con respecto de Ismaïulia consistía en mostrar el espacio de aislamiento a la vista, en lugar de esconderlo tras sucesivas murallas.

Como ya se ha señalado, el Pabellón de Cirugía de Ismaïlia sirvió a Paul Nelson como laboratorio, como ensayo morfológico y conceptual para crear posteriormente La Maison Suspendue. Así, los espacios de la casa destinados a dormitorio principal, estancia de investigación personal y la sala de comedor, tenían sus antecedentes respectivos en la habitación del enfermo, los quirófanos y la capilla del hospital.

(IV. 48A,B,C/ IV. 49. A,B,C). Los dos tipos de habitación respondían al mismo esquema conceptual (dormitorio, aseo, terraza), albergaban las mismas funciones (descanso, ocio e higiene) y mantenían la misma relación con el medio, lo que permitía a los residentes beneficiarse de los efectos climáticos y visuales desde una posición protegida tras el cerramiento.

Cuando Nelson proyectó las estancias individuales de la casa, lo hizo considerando que el espacio doméstico debía contar con una celda aislada donde el habitante desarrollase su capacidad intelectual, este espacio surgió de la evolución del quirófano, ya que este lugar también, requería las mayores cotas de aislamiento dentro del hospital y en él se trabajaba en silencio desarrollando una labor científica. Los dos ámbitos eran exentos, aislados y sin conexión con el medio exterior. Esta 
transposición del hospital a la vivienda no fue tanto formal, conservando la planta curva de las estancias y los accesos, como conceptual, ya que se equiparaba el espacio físico para la salvación corporal con el de la salvación espiritual. Podrían aplicarse los mismos paralelismos entre la capilla del hospital y el comedor de la casa, ya que la morfología de la planta, los accesos y la disposición de avance respecto de la línea de cerramiento eran elementos comunes a los dos proyectos. También existía una similitud en cuanto del uso de las dos estancias, ambos lugares eran ámbitos de reunión familiar y, teniendo en cuenta las connotaciones sagradas de la capilla, las dos salas estaban destinadas a la celebración alrededor de una mesa. La capilla era también un lugar de retiro, por lo que tanto también mantenía algunas semejanzas formales con las celdas personales. El caso de la trasposición de la capilla de Ismaïlia a la sala de comedor de La Maison Suspendue, esto representaba un proceso evolutivo inverso al binomio quirófano- estancia individual, ya que en este último caso se producía la transformación de un recinto de actividad espiritual en uno de función material. Por lo tanto, Paul Nelson inició con el proyecto del Pabellón de Cirugía de Ismaïlia una investigación que desembocó en el espacio inútil de La Maison Suspendue.

Dado el grado de funcionalidad que debía mantener el hospital, la flexibilidad del edificio quedó concentrada en el cerramiento. El sistema de fachadas superpuestas, con una hoja externa construida con lamas metálicas abatibles y orientables, hacía que el aspecto del edifico pudiese modificarse con el tiempo. Las lamas accesibles permitían la protección del edificio de las inclemencias temporales, mejoraban las corrientes de aire de manera natural y evitaban la erosión directa del polvo del desierto sobre las fachadas, a la vez que se facilitaban las vistas sobre el Canal. Esta estrategia para contener las inclemencias atmosféricas, facilitando que los residentes pudiesen modificar la relación con el entorno, evolucionó en La Maison Suspendue, hacia la incorporación de nuevos sistemas artificiales de control ambiental para toda la vivienda y la construcción de una fachada de vidrio cambiante. El pabellón de Cirugía de Ismaïlia, como el resto de los proyectos de los años veinte, no llegó a construirse ${ }^{329}$, pero con este trabajo Paul Nelosn fijó las bases del proyecto más importante de su carrera y el que más influyó en el resto de sus hospitales: una vivienda.

\footnotetext{
${ }^{329}$ Pese a los esfuerzos del Doctor Paul Plessier, la Compañía del Canal de Suez, aconsejada por su grupo de ingenieros, desconfiaba de la estructura ligera y proponía un edifico ejecutado en hormigón estructural, con un cerramiento masivo y unas fachadas menos modernas. El contrato se liquidó en 1936. Véase correspondencia entre Paul Nelson y la Compañía del Canal de Suez, Fonds Paul Nelson, Centre Pompidou.
} 


\subsection{El espectáculo doméstico.}

El Palais de la Découvete había que considerarlo como un epílogo de la Exposición Internacional de París de 1937, el final de la denominada Escuela de París y el momento en el cual todos los países tuvieron la oportunidad de mostrar sus mejores obras en unas arquitecturas efímeras, (§ II.1.)

...El Palais de la Découvete es un sujeto de nuestra época que, más que otros, pone en evidencia el carácter fundamental del periodo de la arquitectura dentro del cual nos encontramos, es decir la flexibilidad-desarrollo lógico y, por lo tanto, contrario al "Funcionalismo" del periodo de la arquitectura actual... 330

Paul Nelson se enfrentaba con este proyecto a dos novedades. La primera, el trabajo con un nuevo tipo de arquitectura, la expositiva, y la segunda, una obra pensada para un nuevo cliente, el Estado ${ }^{331}$. El final de la Exposición Internacional y el éxito de la muestra de los descubrimientos, le empujó a sugerir a la Administración la creación de un espacio estable en La Halle aux Vins, junto a la Universidad de París, donde poder mostrar los avances de la ciencia. Era una oportunidad para convertir al propio edificio en un elemento más a exhibir, el icono de una nueva época, que debía transmitir la misma evolución que los objetos mostrados en su interior. Era un edificio monumental en lo referente al tamaño, sin embargo contrario a toda referencia que lo vinculase con la pesadez, la rigidez y la perpetuidad de un edificio representativo.

Palais de la Découvete permanent (1937-1938). La técnica y la flexibilidad.

Paul Nelson desarrolló este proyecto en colaboración con los arquitectos Oscar Nitzchke y Frantz Jourdain, amigos y antiguos alumnos de Auguste Perret. Para desarrollar el programa, Nelson configuró un equipo multidisciplinar, a semejanza del formado el año previo en los Estados Unidos, y se rodeó de especialistas en las diferentes áreas científicas, con los que trabajó en una primera fase teórica del proyecto, en la que se definió el programa sin esquemas de diseño.

\footnotetext{
${ }^{330}$ Paul Nelson, Projet d'un Palais de la Découvete, París : Cahiers d'art, 1939.

${ }^{331}$ El proyecto no obedecía a ningún encargo formal de la Administración francesa, sino que en ausencia de trabajo, el proyecto se presentó como una propuesta al Estado.
} 


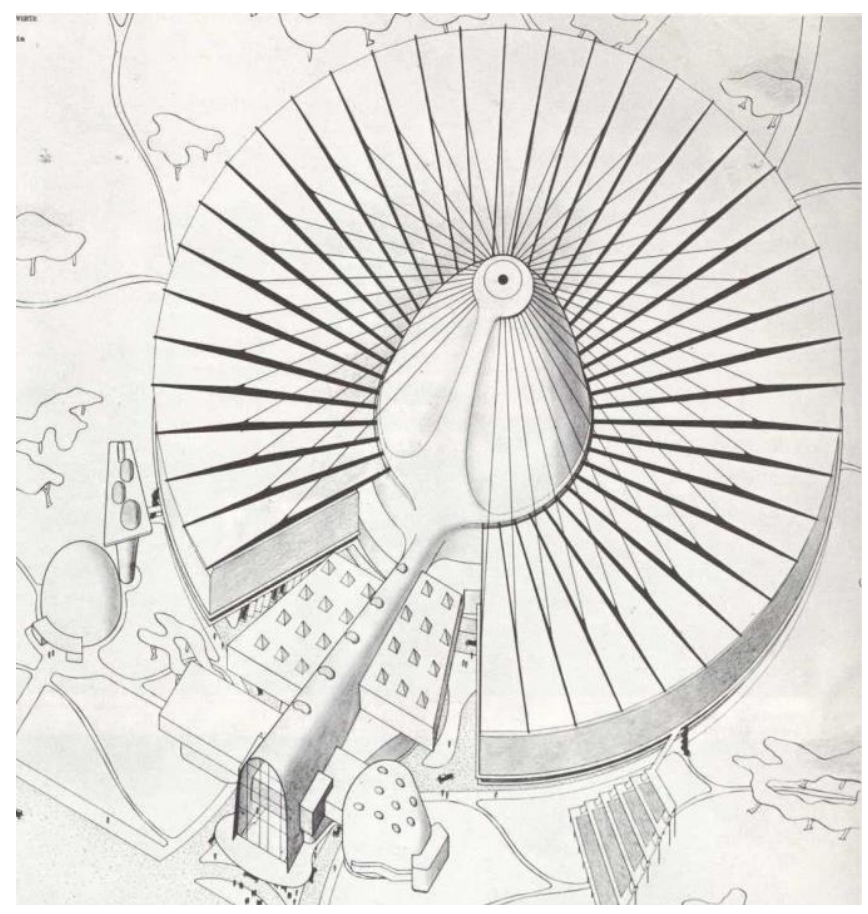

IV. 50 Palais de la Découverte, perspectiva, Paul Nelson, 1937

Los expertos le propusieron "crear una exposición viva de la ciencia en constante evolución" ${ }^{332}$, donde el visitante no solo pudiese observar las grandezas de la ciencia, sino que también tuviese una participación activa. Las disciplinas científicas se ordenaron configurando un anillo ${ }^{333}$ en torno a un gran hall de acceso donde se disponían los avances más espectaculares. A este espacio expositivo circular dispuesto en planta primera se accedía desde una rampa, que conectaba con la entrada en planta baja y con otras partes del edificio como la librería o el salón de actos.

El equipo de arquitectos pensaba, que como criterio general, se debía abandonar la rigidez funcional que impregnaba la arquitectura de determinismo, a favor de un espacio adaptable, para un hombre en movimiento y en constante cambio, y para desarrollarlo se requería una técnica y una industria flexibles en sí mismas. Los arquitectos consideraban que la propia arquitectura debía ser percibida por el visitante como un elemento más de la exposición. Por lo tanto, debía ofrecer a los

\footnotetext{
332 Se contó con la colaboración de los científicos Laugier, Perrin, Langevin y con el museólogo G.H. Rivière. Véase : Joseph Abram, "Palais de la Découvete permanent . 19371938'. A.M.C. $\mathrm{n}^{\circ} 15$, marzo 1987, p.86.

${ }^{333}$ Las materias se agruparon en parejas afines: matemáticas-astronomía, física-química y biología- medicina. El espacio de astronomía tenía asociada una pieza externa de planetario y el de biología un jardín botánico.
} 


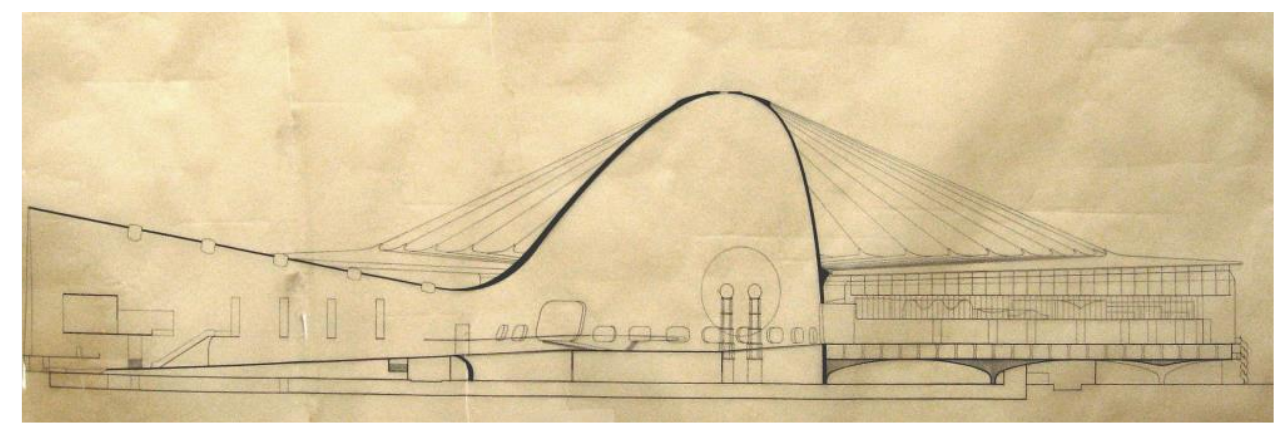

IV. 51 Palais de la Découverte, sección longitudinal, Paul Nelson, ca.1937.

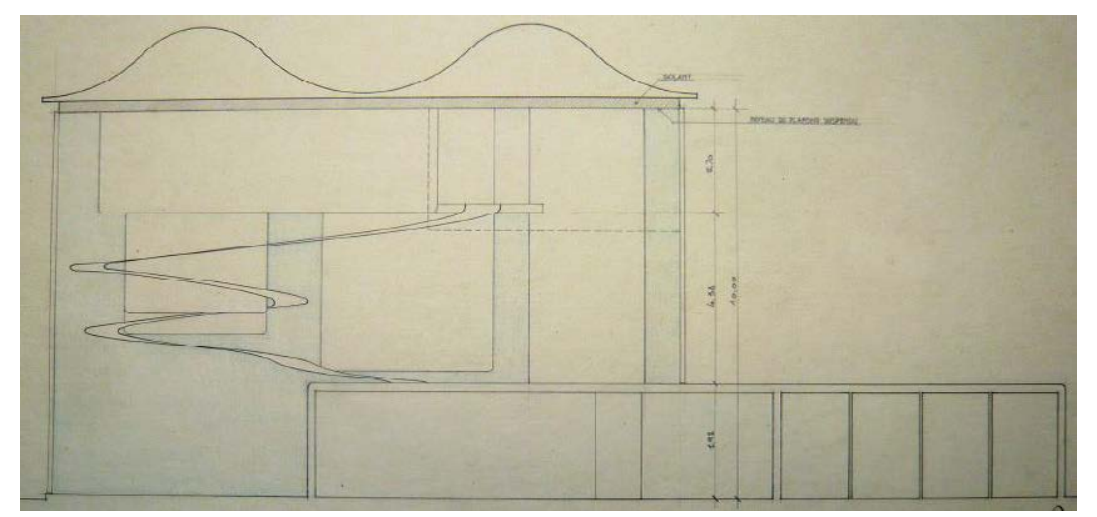

IV. 52 La Maison Suspendue, sección longitudinal, Paul Nelson, ca.1936.

espectadores una imagen nueva, que mostrase los avances técnicos que la habían hecho posible.El profesor Josep Abram calificó esta nueva imagen de la arquitectura de Paul Nelson de expresionismo tecnológico, situando su origen en la relación de Nelson con la pintura ${ }^{334}$. En realidad, como otros arquitectos ${ }^{335}$, este ya había trabajado con una iconografía similar, basada en la técnica, desde que proyectó Ismaïlia y posteriormente La Maison Suspendue.

En el Palais de la Découverte se siguió el mismo esquema estructural proyectado para La Maison Suspendue. El edificio expositivo estaba organizado a partir de la unión de dos cuerpos, uno rígido y monolítico que sujetaba otro flexible, como la vivienda. En el Palais de la Découverte había una cúpula central de volumetría ovoide, ejecutada con mortero de hormigón proyectado sobre una armadura metálica

\footnotetext{
334 Joseph Abram, “ Paul Nelson. Le crible de la raison. 1920-1939. Peinture / architecture. Projets experimentaux”, Bolletin I.F.A. n 130, abril 1989

${ }^{335}$ Le Corbusier en los años treinta, cambió la técnica del hormigón estructural por las estructuras traccionadas y atirantadas como en el Estadio para 100000 espectadores (1936) y el Pabellón de los Temps noveaux, (1937)
} 


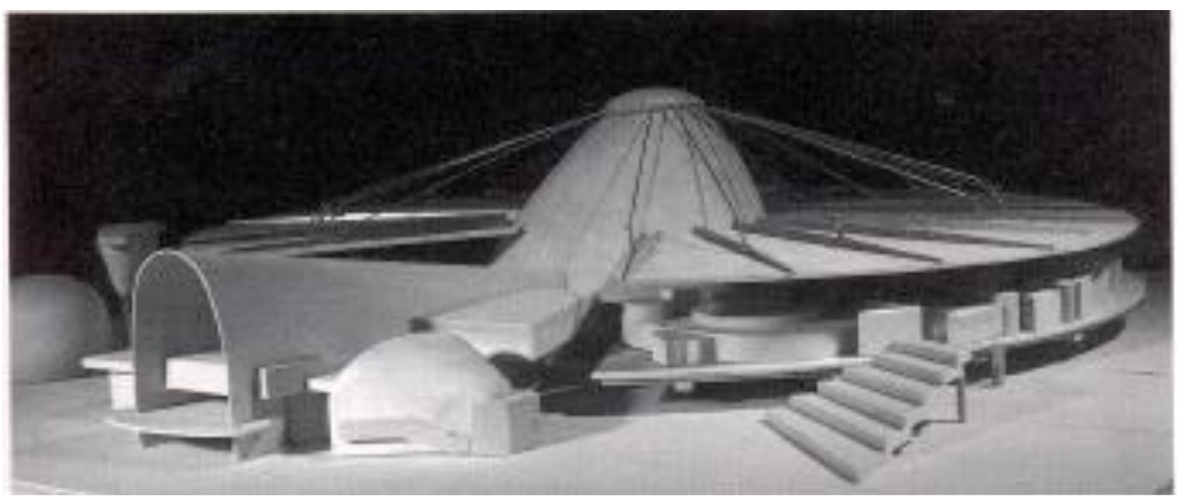

IV. 53 Palais de la Découverte, maqueta, Paul Nelson, ca.1937

de la cual pendía, mediante un sistema radial de atirantado metálico, una cubierta ligera en forma de anillo (IV. 51). De esta manera, se evitaba la disposición de soportes puntuales intermedios para sujetar el plano del techo y se dejaba la planta libre. Paul Nelson retomó el concepto de la estructuras traccionadas utilizado en $\mathrm{La}$ Maison Suspendue y lo aplicó en El Palais de la Découverte, con la colaboración del ingeniero Wladimir Bodianski ${ }^{336}$. (IV. 52).

Paul Nelson invirtió la estructura de la casa, cambiando la ubicación de los soportes, de tal manera que los cuatro puntos de apoyo externos a la vivienda se transformaron en un sistema cilíndrico central y la cubierta que en la casa pendía de los pórticos, en el espacio expositivo trabajaba en voladizo a partir de la cúpula central $^{337}$. Este proceso de focalización de la estructura supuso un cambio respecto al concepto de La Maison Suspendue, que también afectaba al concepto de versatilidad volumétrica del proyecto. De tal manera que, mientras la casa estaba confinada dentro de unos límites físicos y no podía crecer, el Palais de la Découverte podía desarrollarse y expandirse sin límites perimetrales ${ }^{338}$ (IV. 53). Así el avance técnico entroncaba con el objetivo fundamental del proyecto: la construcción de un espacio flexible.

\footnotetext{
${ }^{336}$ Wladimir Bodianski, colaboró con Paul Nelson en la La Maison Suspendue. (§.III.2.)

${ }^{337}$ Wladimir Bodianski y Paul Nelson llegaron a la conclusión de que se podían plantear tres puntos de articulación para evitar problemas con las dilataciones.

${ }^{338}$ Las transformaciones espaciales en la casa podían realizarse sólo en el interior, la casa era como un organismo vivo encerrado en una jaula. Por el contrario, el espacio expositivo podía crecer hasta donde la técnica del voladizo permitiera, la superficie expositiva podía ampliarse con un anillo exterior supletorio o reducirse modificando el cerramiento.
} 


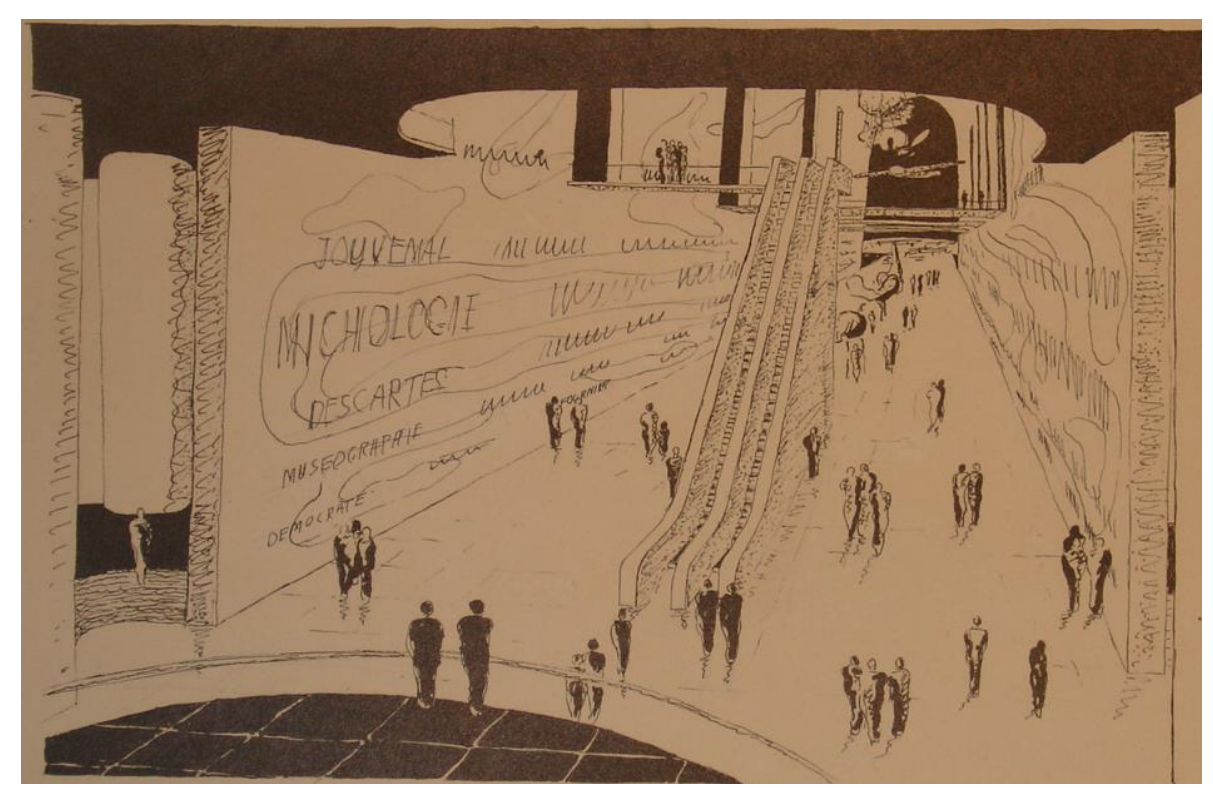

IV. 54 Palais de la Découverte, perspectiva, Paul Nelson, 1937.

La creación del conjunto expositivo a partir de dos cuerpos principales como sucedía en la casa, también se trasladaba al programa funcional y constructivo, aunque las soluciones adoptadas en el recinto expositivo fueron opuestas a las que se habían utilizado en sus referentes homónimas de la vivienda. Como sucedía en el proyecto de La Maison Suspendue, el espacio de mayor altura del Palais de la Découverte (el vestíbulo central) era el que albergaba las actividades más representativas y de reunión, mientras que el cuerpo de menor altura ( el espacio expositivo) estaba destinado a la parte más funcional, la exhibición. De esta manera, lo que resultaba más flexible del programa, a la inversa que en la casa, era la parte mecánica. Este mismo resultado inverso se producía en la construcción, así el espacio social doméstico se construía con una técnica ligera, mientras el espacio social público se construía con una técnica rígida y estable. Entre los sistemas constructivos de los espacios mecánicos y funcionales la transformación era la opuesta, pasando de una arquitectura masiva a otra ligera. El cambio de la escala del proyecto alteró la manera de entender el espacio social, convirtiéndolo en un lugar rígido que transmitía seguridad, mientras que el espacio funcional tenía una componente más humana, que invitaba a la exploración personal. 


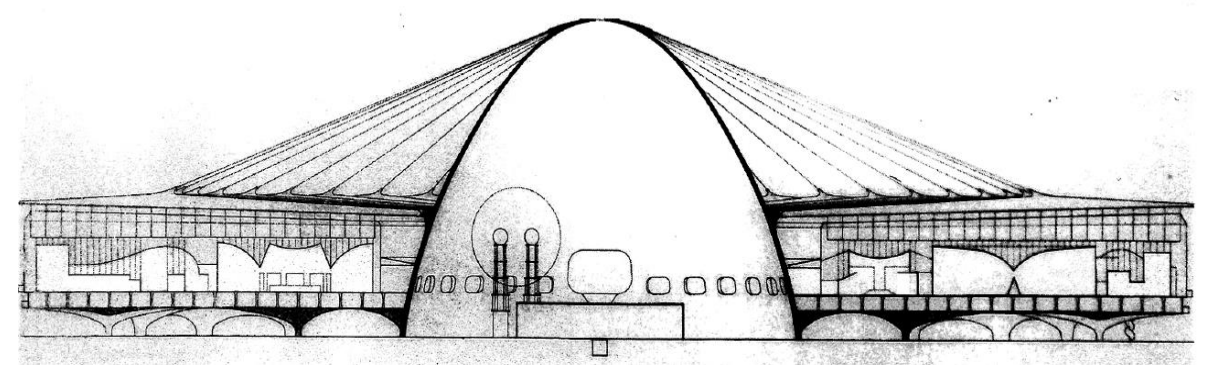

IV. 55 Palais de la Découverte, sección transversal, Paul Nelson, 1937

Paul Nelson trasladó todo el espectáculo escénico, teatral y cinematográfico que tenía su salón de La Maison Suspendue al gran vestíbulo del Palais de la Découverte y reutilizó elementos como la rampa, el balcón a media altura o los murales sobre las paredes al mismo tiempo que incorporó nuevos elementos como los contrastes de luz. Todo con el objeto de crear un dramatismo que mantuviese la atención del espectador (IV. 54). El visitante debía sentir la emoción del espacio público inducido por el efecto sorpresa y la incertidumbre de la actividad funcional hacía que cada observador entendiese el museo de una manera diferente. La interacción entre el visitante y el edificio era una de las consideraciones marcadas por los científicos para lograr que la muestra fuese un espacio vivo.

Esta concepción del uso expositivo de un espacio público de manera personal, además de incidir en la configuración espacial creando una arquitectura adaptable, marcó tanto la definición de los recorridos como la composición en planta y una vez más, Paul Nelson volvió a utilizar las herramientas de La Maison Suspendue para lograr a través de la continuidad espacial que las personas pudiesen encontrar su propio lugar individual dentro del ámbito público.

Aún cuando el falso techo del Palais de la Découverte podía variar en forma, tamaño y altura, la experiencia no era tan intensa como en el salón de la Maison Suspendue. El juego tridimensional de la casa se redujo a una ordenación bidimensional, por lo que la continuidad no generaba un espacio volumétrico. La continuidad espacial de la exposición se resolvió en planta con las mismas herramientas de la casa, se proyectó un contenedor de geometría rotunda sin puntos de contacto con el interior, y unas estancias interiores diferentes entre sí, con conexiones múltiples dentro de la misma unidad expositiva, separadas de otras unidades mediante espacios de transición. (IV. 55) 


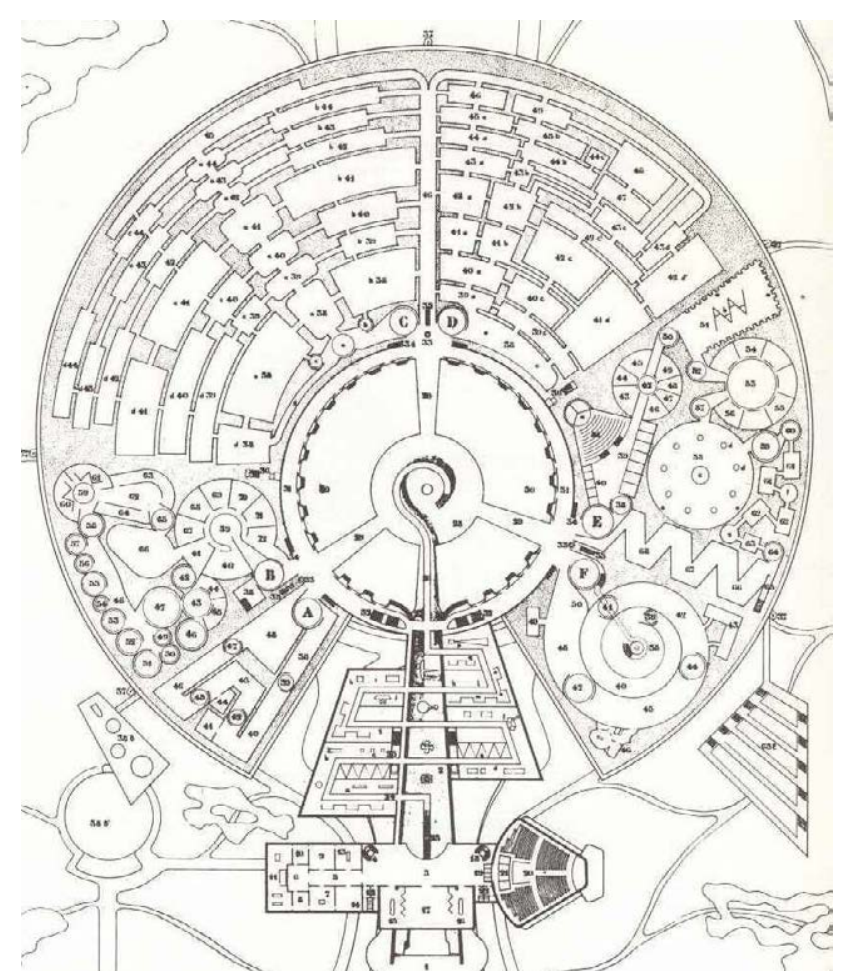

IV. 56 Palais de la Découverte, planta primera, Paul Nelson, 1937

El recorrido nunca se interrumpía, como sucedía en La Maison Suspendue, y se producía una contaminación entre las estancias y los lugares de paso, ya que todas las salas tenían esa doble función. De esta manera, el visitante podría decidir cómo recorrer la exhibición dependiendo de lo sugerido tanto la forma de la arquitectura como por el material expuesto. Incluso el visitante contaba con espacios inútiles intercalados entre las diferentes disciplinas expuestas, que funcionaban como lugar para la reclusión y la reflexión temporal, un espacio protegido que eventualmente se podía ocupar dentro de un ámbito público sin alterar la totalidad. 


\subsection{Nueva monumentalidad.}

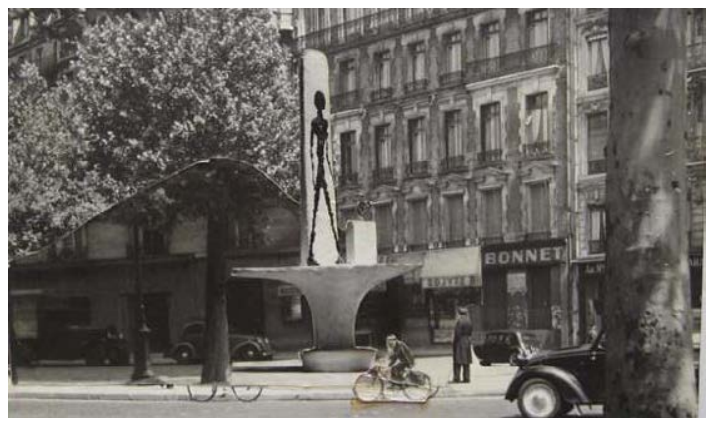

IV. 58 Propuesta in memoriam de Gabriel Perí en París, fotomontaje, Paul Nelson y Alberto Giacometti,

A finales de los años cuarenta, Paul Nelson trabajó en diferentes encargos, representativos y conmemorativos, para espacios urbanos. En 1946, colaboró con Alberto Giacometti en una propuesta in memorian de Gabriel Peri ${ }^{339}$ en París (IV. 58) y en 1947, junto al escultor Henri Laurens ${ }^{340}$, proyectó una fuente y una plaza en los Estados Unidos (IV. 57). Las dos intervenciones incorporaban algunos principios derivados de la llamada "Nueva monumentalidad" "341. Las propuestas tenían un carácter urbano, obedecían a criterios multidisciplinares, ejercían una función que rebasaba lo meramente simbólico, contaban con asientos, elementos naturales como el agua y cuerpos protectores de la lluvia y del sol. Eran hitos vivos

\footnotetext{
${ }^{339}$ Gabriel Perí (1902-1941) fue un héroe de la resistencia francesa durante la Segunda Guerra Mundial, miembro del partido Comunista Francés, fusilado por las tropas alemanas.

${ }^{340}$ Henri Laurens (1885-1954) fue un escultor cubista amigo de Paul Nelson. Su hijo C. Laurens trabajó como colaborador en el estudio de Paul Nelson y realizó la maqueta del Hospital de Lille.

${ }^{341}$ Sigfried Giedion, Fernand Léger y José Luis Sert escribieron en 1943 "Nine Points for a New Monumentality". Véase: Sigfried Giedion, Architecture, You and Me. The Diary of a Development, Cambridge, MA: Harvard University Press, 1958, pp.48-51.
} 
que incitaban a la actividad social. Las dos obras transmitían una rigidez, dada su construcción masiva, que se mantuvo en la toda obra final de Paul Nelson, con la excepción de un proyecto de 1971.

Consulado para la URSS en Marsella $c a$ 1971. La casa y el templo.

El Consulado para la URSS es un proyecto inédito, que nunca ha sido estudiado ni publicado. Su pertenencia a un legado privado y su exiguo contenido material han provocado que esta documentación no haya sido analizada hasta el momento por los investigadores de la obra de Paul Nelson ${ }^{342}$. Este proyecto está muy separado en el tiempo con La Maison Suspendue, pero dada la singularidad del material y sus vinculaciones tanto formales como conceptuales con la casa, se considera el consulado de Marsella un trabajo decisivo para completar el análisis de esta tesis. Tras haber proyectado los hospitales de Saint Lô, Dinan y Arles, con una arquitectura basada en la retícula de hormigón, con forjados superpuestos y acabados prefabricados, Paul Nelson retomó en los años setenta la imagen de $L a$ Maisón Suspendue y proyectó un nuevo volumen ligero. (IV. 59)

La documentación de este proyecto está compuesta por un diario de trabajo y unos bocetos, este contenido representa una novedad en la manera de trabajar de Paul Nelson, que siempre había partido de unos esquemas abstractos para organizar el programa, que posteriormente eran trasladados al desarrollo gráfico. En el caso del Consulado de Marsella, sin embargo, los bocetos fueron previos a la definición y al desarrollo del programa ${ }^{343}$, Paul Nelson estaba proyectando un espacio del cual se desconocía su destino funcional concreto. El Consulado tenía que albergar dos funciones en un mismo espacio, una oficial, que era la representación institucional de la URSS en Marsella, y otra de servicio público, la atención a los ciudadanos rusos. Y Nelson, partiendo de una concepción funcional muy genérica, resolvió este programa público siguiendo el modelo que le había proporcionado su investigación doméstica de La Maison Suspendue, Nelson consideró que probablemente era la

\footnotetext{
${ }^{342}$ La dispersión de la obra de Paul Nelson en diferentes archivos ha provocado que algunos proyectos estén sin catalogar, fuera de las grandes colecciones. La documentación se concentra en cinco A.5 de notas escritas, ordenadas en un calendario de trabajo durante la tercera semana de julio de 1971. El material se completa con tres hojas de bocetos.

${ }^{343}$ El calendario muestra como el trazado de los primeros croquis era previo a la concreción del programa funcional.
} 
IV. 59 Consulado de la URSS en Marsella, boceto alzado, Paul Nelson, 1971.

última oportunidad, para poder construir el concepto espacial de la casa, una idea que podía reciclarse en un uso diferente.

Tras recibir el encargo, Paul Nelson se trasladó al emplazamiento previsto, en el distrito de Sainte Anne en Marsella, y comenzó a trabajar a partir de la incidencia que podía ejercer el lugar sobre el edificio, lo que suponía una postura nueva con respecto a la relación de independencia que se había determinado entre La Maison Suspendue y el medio. El condicionante geográfico más singular del Consulado era la proximidad de un cauce navegable, que podía ser aprovechado para crear un acceso directo desde el barco. Con esta primera decisión, se introdujo un elemento vivo y cambiante, como era el agua, en el conjunto de herramientas que definían las hipótesis de partida del proyecto, y así, el límite del espacio habitado se prolongaba fuera del volumen del edificio, como sucedía en sus viviendas de los años cincuenta, La maison Badin y la Casa de Nadia Léger.

Paul Nelson proyectó su obra más simbólica a partir del ensamble de dos tipos de arquitectura, la casa y el templo y se configuraron dos tipos de espacio diferentes, el doméstico y el sobrenatural, que tenían como objetivo común dar cobijo y protección a los individuos. En este proyecto se produjo la convergencia del refugio social y del refugio espiritual, y para lograr la síntesis arquitectónica, en el Consulado se utilizaron las mismas herramientas geométricas, compositivas y tecnológicas que generaron la continuidad espacial en las tres direcciones de 


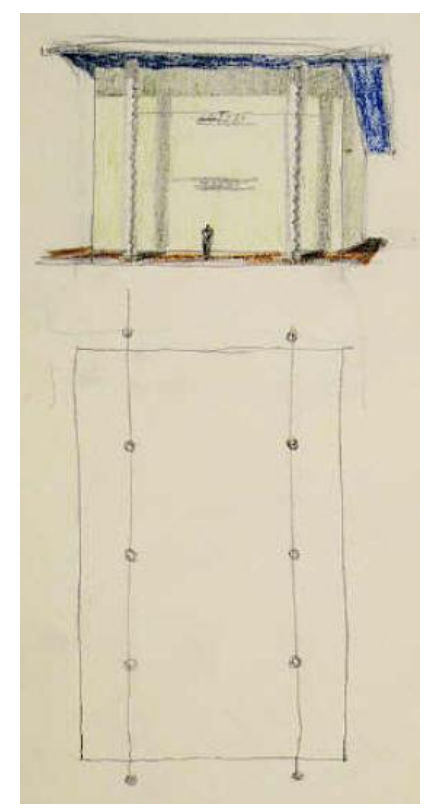

IV. 61 Propuesta arquitectónica recuerdo templos egipcios, perspectiva y planta, Paul Nelson

La Maison Suspendue. Nelson construyó un templo exterior que alojaba una casa en su interior, y utilizó la estructura, la construcción, la frontalidad de la fachada y el aumento de la escala para lograr una "nueva monumentalidad" que marcaba la relación del edificio con el contexto urbano ( IV. 60 ). Y trabajó con el orden formal, el juego volumétrico y el vacío para crear un espacio donde lo institucional se ponía al servicio de lo personal, que marcaba la relación del perímetro con las piezas alojadas en su interior. 


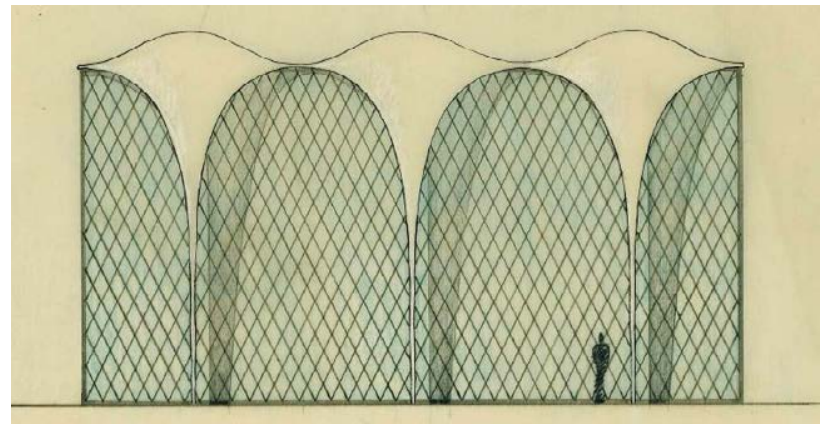

IV. 63 La Maison Suspendue, alzado, Paul Nelson, ca.1936

En Marsella, se proyectó una estructura metálica ( IV. 62) similar a la utilizada en La Maison Suspendue (IV. 63), con unos pórticos externos que sujetaban a una gran cubierta plana, pero la diferencia entre los dos proyectos la determinaba el sistema de sujeción de los volúmenes superiores con respecto de la cubierta, ya que las piezas habían pasado de estar suspendidas a disponerse apoyadas sobre la bandeja de la cubierta. Este sistema configuraba un remate escalonado que otorgaba al edificio un aspecto clásico. El cerramiento se pensó como una doble piel, con una hoja externa de lamas y otra hoja interna de trama de vidrio en forma de rombo, similar a la utilizada en la casa. En el proyecto del Consulado, la principal cualidad del vidrio era la transparencia, ya que los grados de opacidad estaban controlados por la hoja exterior y Nelson se apoyó en los avances técnicos para aumentar tanto el tamaño de los rombos de vidrio como la dimensión de los elementos estructurales. Proyectó un cerramiento que carecía de huecos, evitando la referencia doméstica, para transmitír la sensación de una escala institucional. Estas intervenciones que incidían en el tamaño del edificio se veían reforzadas por el tratamiento compositivo de la 


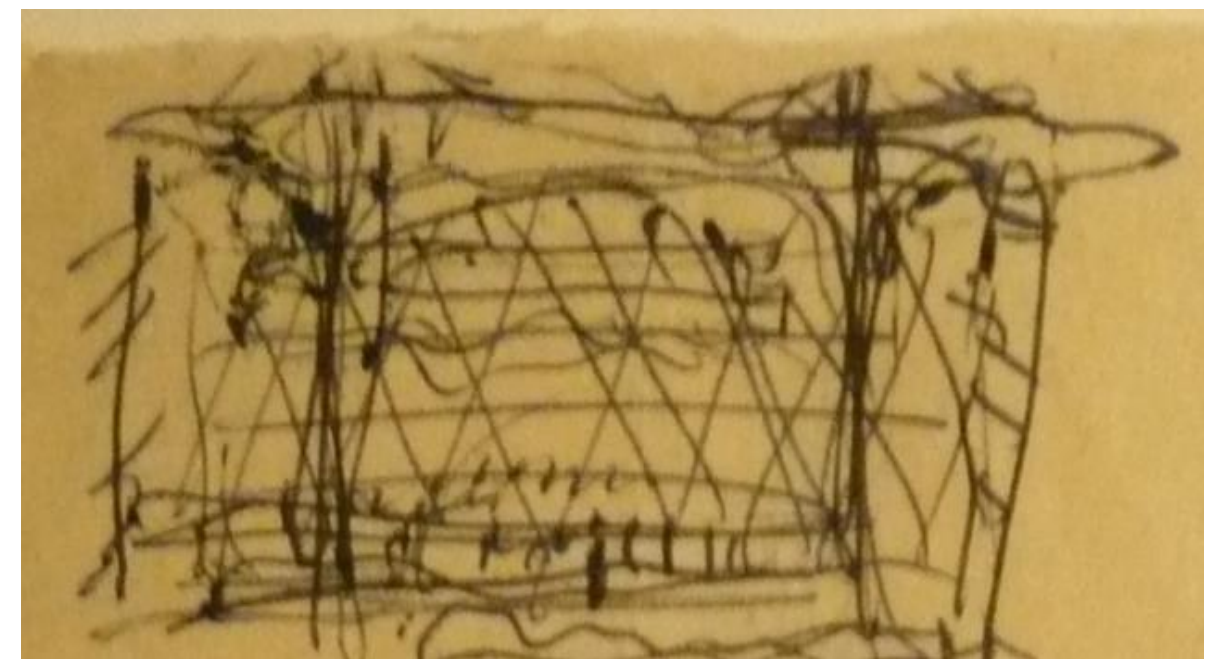

IV. 64 Consulado de la URSS en Marsella, espacio de reuniones, boceto alzado, Paul Nelson, 1971

fachada, recuperando la orientación y la frontalidad. La simetría, la disposición elevada del acceso sobre un pódium de escaleras y la coronación del edifico con un grupo escultórico, marcaban un aspecto monumental de la fachada, una monumentalidad en la cual lo simbólico y lo permanente de las esculturas convivía con lo flexible y lo cambiante del cerramiento.

El edificio se dispuso con su eje longitudinal ortogonal al curso fluvial, siguiendo el mismo emplazamiento que Paul Nelson había visto en los templos egipcios, (IV. 64), y para resolver el programa del Consulado, se propuso construir un prisma ortogonal, que funcionaba como un gran contenedor en cuyo interior había dos cuerpos exentos, con entradas independientes, alineados según un eje de simetría. Las dos piezas que tenían volumetrías complementarias se podían ensamblar, y estaban dispuestas aisladas y enfrentadas entre sí, esto generaba una tensión en el vacío liberado entre ellas que incidía en las personas que visitaban el recinto. A esta configuración del espacio interior, se le podría aplicar el análisis que se desarrolló sobre La Maiosn Suspendue y los resultados serían muy parecidos. La novedad con respecto a la vivienda es que el nuevo espacio interior que se proponía para el Consulado se había logrado con una geometría más rígida y una composición más clásica, se había producido una especie de vuelta atrás que abandonaba la modernidad y buscaba la seguridad en un modelo clásico. 
Paul Nelson reflexionaba sobre la importancia y la necesidad de construir espacios públicos, semejantes al ágora ateniense o a los foros romanos, donde los ciudadanos pudiesen exponer en público las conclusiones a las que habían llegado, tras sus retiros temporales domésticos. Con este proyecto, Paul Nelson cerraba su teoría del avance social apoyado en la arquitectura ${ }^{344}$. Siguiendo su línea de pensamiento, el centro cívico del Consulado era el espacio complementario al ámbito doméstico, ya que las personas disponían de diferentes recintos para desarrollarse intelectualmente a diferentes escalas. Para Paul Nelson, el libro Matrix of Man de Sibyl Moholy$\mathrm{Nagy}^{345}$ presentaba el ejemplo de los espacios urbanos que él consideraba imprescindibles para crear la nueva sociedad, un lugar público en el que la sociedad y el individuo podían convivir sin ocultarse.

\footnotetext{
${ }^{344}$ Paul Nelson defendía la teoría de la construcción social a partir de dos vías: la individual y la colectiva, y confiaba en la arquitectura como la herramienta que lo hacía posible. La casa y el centro cívico representaban los paradigmas espaciales de esta teoría. Las personas y por lo tanto la civilización crecían intelectualmente gracias tanto a los contactos como al aislamiento. Véase: Paul Nelson, La Maison Suspendue. Recherche de Paul Nelson. (L'Architecture Vivante), París: Albert Morancé, 1939.

345 Sibyl Moholy-Nagy, (1903-1971) historiadora de arte y arquitectura. Su marido, László Moholy-Nagy fue profesor de la Bauhaus. Tras su muerte en 1946, ella fue profesora en el Pratt Institute de Nueva York y en la Universidad de Columbia. Véase: Sibyl Moholy-Nagy, Matrix of Man:An Illustrated History of Urban Environment, Nueva York: Praeger, 1968.
} 


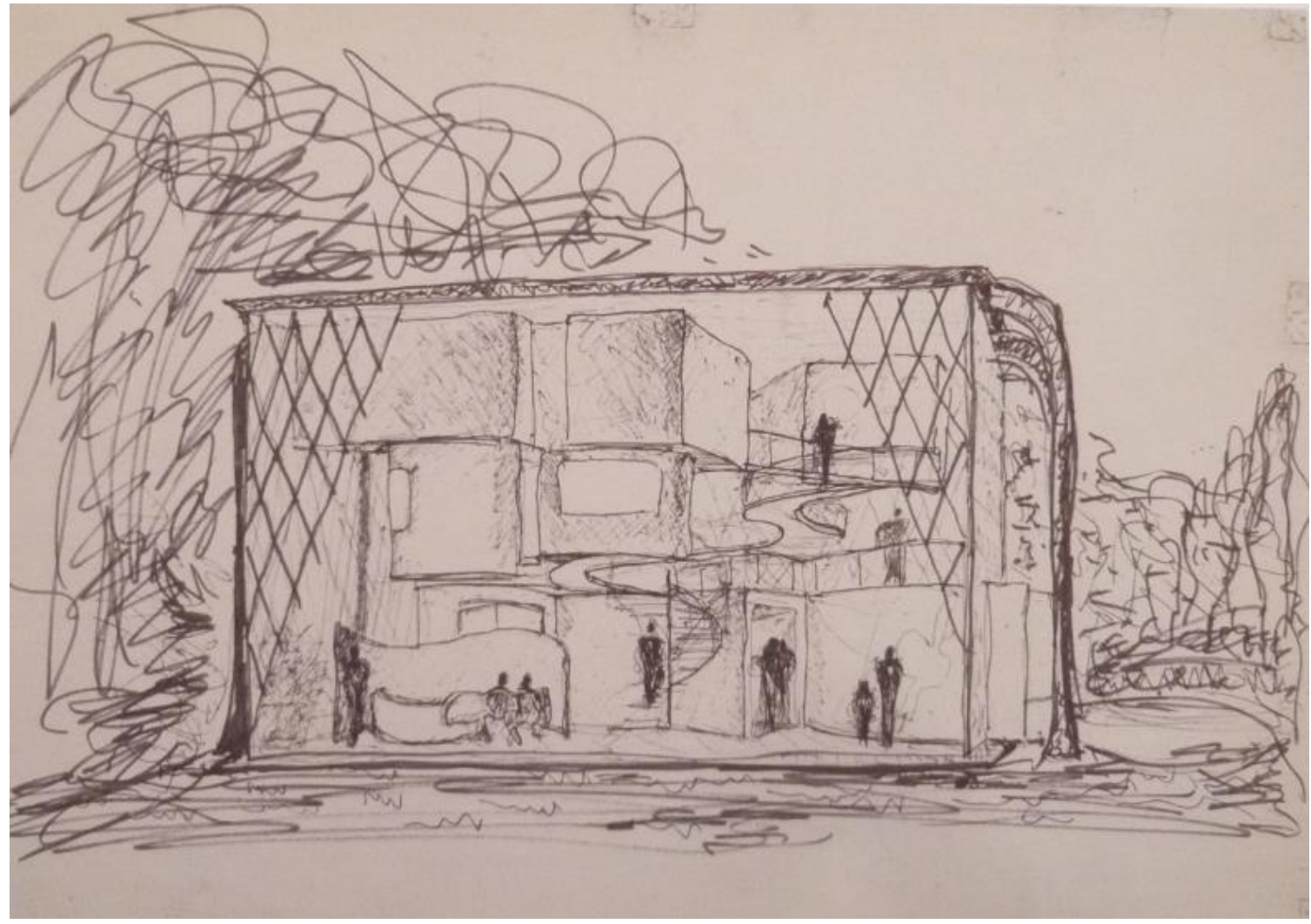

La Maison Suspendue, perspectiva seccionada, dibujo a mano alzada, Paul Nelson, ca 1938. 
Las reflexiones obtenidas a partir del análisis expuesto se han organizado en torno a cuatro bloques, en el primero se presenta la aportación principal de este trabajo, el segundo tiene como núcleo principal el compromiso de Paul Nelson con la arquitectura moderna, el tercero se crea a partir de las contradicciones que enriquecen La Maison Suspendue y el cuarto son las líneas de investigación que deja abiertas este trabajo.

La formalización del espacio inútil.

La contribución fundamental de esta tesis ha sido la constatación de que Paul Nelson humanizó su arquitectura a través de su investigación del espacio individual y que este proceso se puso de manifiesto especialmente en su proyecto de La Maison Suspendue. Paul Nelson condensó su pensamiento arquitectónico en la creación de un espacio "inútil" capaz de incidir en el desarrollo intelectual de la persona

(§ III.4.). Y esta es su aportación a la arquitectura moderna y la característica singular de su espacio arquitectónico, que ata y da continuidad a toda la obra, con independencia de su desarrollo temporal, programático, constructivo o formal. Paul Nelson no solo pensó en un lugar "inútil" dentro de la vivienda sino que fue el primer arquitecto moderno que dio forma a esa cualidad espacial.

Paul Nelson proyectó su arquitectura para liberar al hombre.

Para Paul Nelson la tarea arquitectónica era, ante todo, un acto de liberación que implicaba un avance para el hombre. Primero, lo experimentó personalmente cuando decidió estudiar arquitectura para evolucionar personalmente y más tarde lo utilizó como herramienta emancipadora y lo traspuso a la sociedad a través de su actividad. Así, su acceso a la disciplina no se produjo por vocación sino como la vía madurez. Y la traslación de la vivencia personal a su vida profesional provocó que la aproximación al hombre se convirtiera en el objetivo prioritario de su obra. $\mathrm{Su}$ propósito fue utilizar la arquitectura como instrumento para mejorar la vida de las personas, incluso llegó a considerarla un elemento sanador capaz de influir favorablemente en el pensamiento de los individuos. (§ III.1.).

Con esta visión de la arquitectura próxima a lo balsámico, Paul Nelson se convertía en un médico-proyectista, igual que algunos arquitectos modernos, obsesionados con crear espacios funcionalmente asépticos, higiénicos, protectores, y aislados del 
mundo. Pero este modelo se desvaneció cuando Nelson decidió incorporar el exterior como una parte de sus edificios, dotando a su obra de una dimensión medioambiental. Y así, en Isamïlia las terrazas de recuperación adquirieron la misma repercusión curativa que los espacios de cirugía. (§ IV.2.).

Paul Nelson construyó su método proyectual a partir de su experimentación biográfica.

Paul Nelson utilizó su vida como herramienta generadora de proyecto, ya que se apoyó en la experimentación cotidiana para sistematizar un método de trabajo y crear arquitectura. De tal manera, que sus viajes, sus contactos interdisciplinares, su apuesta por un modelo de sociedad y su convivencia con sus dos mujeres, están en la esencia de su pensamiento arquitectónico y viceversa. De esta observación se deduce que es difícil establecer una línea clara que separare la vida personal de Paul Nelson de su actividad profesional, igual que sucedió con otros arquitectos modernos. La novedad en el caso de Paul Nelson estuvo en su deseo por diseñar su biografía y plasmarla en esquemas de actuación para abordar su proyecto. (§ II.4.). Tanto su acción personal como sus relaciones interdisciplinares, sustentaban la primera fase de su sistema de trabajo.

La creación arquitectónica de Paul Nelson fue fruto de una investigación, a la que se llegaba a través de un método flexible y dinámico basado en la experimentación. Nelson afrontó la indagación de los objetivos desde un esquema ramificado y errático que le permitía abrir el campo de exploración libremente, y para desarrollarlo introdujo dos variables que se convirtieron en los recursos más decisivos de la fase experimental del proyecto. Por un lado y como ya se ha mencionado, se utilizó la propia biografía personal como fuente de inspiración y por otro, se introdujo el error como elemento de continuidad en el proceso. Paul Nelson aprendió, desde sus primeros proyectos, que la interpretación ámbigua de un uso espacial era fundamental para que la persona habitara su realidad y por lo tanto, el resultado equivocado, diferente o azaroso no era algo que se debía modificar para reconducirlo hacia un valor acertado, sino que debería permanecer visible y formar parte del conjunto. De tal manera, que en cada proyecto las soluciones quedaban abiertas para que el ocupante viviera el espacio desde su propia necesidad. 
Pero esta visión experimental de la arquitectura entraba en contradicción con el diseño previo del método de trabajo sistematizado y deductivo de la forma, sin duda otra de las claves de sus proyectos. Incluso a través de sus textos, Paul Nelson determinó unas funciones del arquitecto muy estrictas que empujaban hacia un resultado concreto, aparentemente incompatible con unos objetivos abiertos. Así por un lado, trabajaba para crear una arquitectura que proporcionase mayor libertad a las personas y por otro lado, decidía detalles personales muy concretos, e incluso las obras de arte para los clientes. Y cuando Paul Nelson reflexionaba sobre esta dicotomía lo justificaba anteponiendo su responsabilidad profesional, que según él, tenía como consecuencia real su conocimiento extremo de los gustos del cliente. (§ III.3.).

Paul Nelson fue un arquitecto investigador.

La condición investigadora de su trabajo se cumple no solo porque su pensamiento es el resultado de un proceso de indagación deductivo, estructurado y planificado para lograr resolver unas hipótesis iniciales, como expuso el crítico Johnson Sweeney (§ III.2.), sino porque la respuesta que ofrece es abierta y siempre sugiere nuevas líneas de trabajo que pueden ser desarrolladas en otros proyectos, por él mismo o por otros arquitectos. Por lo tanto, su trabajo también estaba destinado a la divulgación concitando dos hechos, por un lado, estaba la generosidad de compartir con la comunidad científica sus propias inquietudes y por otro, el deseo de trascender y hacerse un hueco autónomo en el espacio de influencia de la arquitectura moderna. Paul Nelson sintió, desde el inicio de su carrera, la obligación moral de justificar sus decisiones para dotar a sus argumentos de un rigor que los acercase a la pura labor científica, y para alcanzar este objetivo utilizó los textos que escribieron sus amigos artistas, editores e historiadores. Pero Nelson no solo utiliza los textos de los expertos como reclamo de atención, sino que los impulsa como parte integrada de su concepto de proyecto arquitectónico interdisciplinar. De tal manera, que a pesar de su formación literaria en Princeton Paul Nelson decide presentar la explicación de su obra como una labor de colaboración, siendo otros autores los que escriben sobre su trabajo, pero con un matiz, los textos siempre se articulan a partir de sus conclusiones. El único texto verdaderamente crítico con su obra fue el artículo escrito por su amigo el pintor Jéan Helion (§ III.3.). El escrito tuvo un doble efecto ya que por un lado, fue el revulsivo que indujo a Paul Nelson a 
plantearse La Maison Suspendue y por otro, provocó que Jéan Helion no fuese invitado a colaborar en ningún proyecto y que su amistad se resintiera.

Paul Nelson no quiso ser clasificado de "moderno".

Su manera heterogénea de proceder fue uno de los factores que contribuyeron a que la crítica arquitectónica tras la Segunda Guerra Mundial no lo encajase como un claro exponente de la arquitectura moderna, pero a la vez esta situación de arquitecto "no integrado" fue alimentada por el propio arquitecto. Ya que aunque formó parte de la muestra "The International Style" de 1932 (§ II.1.), a partir de 1933, en sus artículos trató de marcar distancias respecto de los arquitectos del Movimiento Moderno. Durante los años treinta, Paul Nelson mantuvo sentimientos contradictorios respecto de los arquitectos modernos que más incidieron en su obra, Auguste Perret y Le Corbusier, por un lado, admiraba y le interesaba la obra de los maestros ya que la criticaba, y por otro, necesitaba "matarlos" para avanzar. En su necesidad por alejarse, fue el propio Paul Nelson el que trató de borrar todos los vínculos que le habían clasificado como arquitecto moderno. No logró una autonomía y una madurez arquitectónica propia hasta el final de la Segunda Guerra Mundial, ya que su estancia en los Estados Unidos cambió su manera de entender la arquitectura. Y así, desactivada su actividad de entreguerras, el nuevo periodo de arquitectura hospitalaria fue el que comenzó a interesar a los críticos.

La Maison Suspendue se proyectó para no ser construida nunca.

La Maison Suspendue es un proyecto que nació para no ser construido nunca, no había un cliente concreto ni la casa era un prototipo y además, Paul Nelson tampoco contaba con un apoyo económico que hiciera posible su edificación. La vivienda fue pensada como proyecto teórico que debía entenderse a través de las maquetas, es decir era un trabajo creado para ser exhibido en un museo. Tanto el grado de definición constructiva y estructural del proyecto como los documentos que se generaron entorno a su creación, muestran que la principal intención de Paul Nelson era difundir su investigación de manera itinerante. En este punto, resulta interesante la propia biografía de las dos maquetas y la aportación que se hace en esta tesis sobre la pérdida del rastro de la primera (§ III.2.), acotando este momento y planteando el interés del propio autor por incidir en la idea de su perdida en el 
Atlántico, de vuelta a París, manteniendo una leyenda sobre el proyecto. Tras la primera propuesta para construir el modelo a escala real, recibida de la Exposición Internacional de New York, Nelson centró todos sus esfuerzos en la ejecución de la segunda maqueta y paradójicamente, no se avanzó hacia la definición de un proyecto de ejecución real. Incluso con el intento de construir La Maison Suspendue como un prototipo en el los jardines del MoMA en 1960, el objetivo era la difusión de unas ideas y no la construcción de un modelo para reproducir en serie. Por otro lado, un fracaso constructivo habría cercenado las posibilidades de exhibición posteriores. Y finalmente, los últimos intentos por construir la casa en Marsella, cuarenta años más tarde, resultaban ser más el deseo de un reconocimiento a su carrera profesional que un verdadero propósito por edificar la vivienda. El planteamiento de la casa como una indagación sobre el espacio doméstico ofrecía un resultado abierto e inacabado que reforzaba la idea de no construcción, ya que la casa no era ni un objeto terminado, ni un modelo canónico. Y Así, si la vivienda se hubiese construido a tamaño real, nunca hubiese adquirido la cualidad de vivienda, sino que seguiría siendo una maqueta de sí misma o un fragmento de maqueta de otros proyectos posteriores.

\section{La Maison Suspendue no es una casa}

El proyecto de La Maison Suspendue no es una casa sino un pretexto para realizar una investigación espacial. El programa doméstico es una excusa, algo anecdótico que se dibuja con la intención de esconderlo tras un telón de hormigón o expulsarlo hacia el techo. Su apariencia externa evita representar una casa, se utiliza un significante ambiguo en el que predomina una imagen industrial que se transforma en artesanal cuando acercamos la mirada y vemos la orfebrería de los vidrios. También resulta ambiguo su emplazamiento, se pretendía crear un refugio aislado pero la vivienda era una pieza urbana, ya que no era un recinto autónomo rodeado de bosques y retirado del mundo, sino que era un espacio individual que complementaba al espacio social de la ciudad. Así, a pesar de que Paul Nelson la identifica con un espacio de reclusión y aislamiento, la vivienda era una pieza territorial que forma parte de un entorno más amplio. Este pensamiento queda reforzado con la idea de crear un paisaje sincrético interno, de atrapar el exterior entre los muros de la vivienda. $\mathrm{Y}$ es este patio cerrado, el único elemento que se muestra de la esencia de una casa. De tal manera, que el resto de lo proyectado es una tramoya teatral y un invento que adorna el exterior-interno. En conclusión, Paul 
Nelson no construyó el programa de una vivienda moderna sino que solo proyectó un gran dosel con unas infraestructuras empaquetadas y unas cortinas de vidrio. Así La Maison Suspendue, un recinto para el retiro interior, surgió de la síntesis de dos exteriores: la casa-patio mediterránea y el porche de la casa del Oeste norteamericano.

La Maison Suspendue y la continuidad espacial no experimentada.

Como ya se ha analizado Paul Nelson utilizó la ausencia de programa de la $L a$ Maison Suspendue para experimentar con la libertad espacial en las tres direcciones y aunque la distribución de las piezas justifica esta observación, lo cierto es que el artificio de esta explosión espacial acaparó toda la atención del proyecto dejando sin resolver algunos elementos de conexión entre las partes, y reduciendo las comunicaciones verticales a dos variables. Asi, cuando se describe la diversidad de opciones para recorrer la vivienda, esta explicación resulta muy prolija en cada planta pero queda muy limitada cuando se refiere al desplazamiento entre cotas diferentes. De tal manera, que la percepción tridimensional del espacio total es más visual que experimental y que únicamente se percibe desde la rampa ya que el resto de los recorridos o no son abiertos o quedan limitados a una sola altura.

La Maison Suspendue y la contradicción del espacio inútil

Paul Nelson invirtió los criterios que definían el hábitat doméstico de los años treinta poniendo en cuestión la necesidad del programa y aportando una nueva cualidad de los espacios proyectados más representativos, que era su condición de "inútil" o sin uso predeterminado. Aunque Paul Nelson utilizó esta definición tanto para referirse a espacios comunes como a ámbitos individuales, cuando aplicaba este adjetivo a los espacios sociales los conceptos no encajaban con exactitud en su discurso, ya que estos lugares comunes estaban predestinados al uso de reunión. Paul Nelson justifica la condición de "inutilidad" de estos ámbitos como consecuencia de ser los lugares más adecuados para ubicar el arte, que a su vez es inútil por definición. Por lo tanto, el discurso se interrumpe y de la inutilidad del arte surge la necesidad de un espacio "útil y predeterminado" para albergarlo.De tal manera que el objeto artístico es el que determina el uso del espacio. En el caso de los recintos individuales, la definición de "espacio inútil" enunciada por Nelson se 
ajusta más a la pieza construida, y aunque las celdas estaban destinadas al retiro personal, el uso particular de estas unidades no estaba sujeto a condicionantes. También en este caso, como en el espacio de reuniones, se ensayó la posición de un par de muebles, uno para acomodar el cuerpo y otro para apoyarse, pero se mantuvo la incertidumbre funcional. Para Nelson, el acto de liberación del hombre respecto de un hábitat doméstico impuesto no se lograba con la disolución de la arquitectura sino con su presencia y así, lo que se buscaba con esta casa era la creación de pequeñas islas de uso privado imprevisto que convivieran en continuidad y sin pérdida de su identidad dentro del espacio público, y aunque este objetivo no se logró plenamente en La Maison Suspendue, ya que tuvo que utilizar elementos físicos y funcionales de separación, esta vivienda sirvió de ensayo para otros proyectos posteriores donde la realidad era más evidente.

La investigación a partir de la investigación.

Esta tesis, planteada ochenta años después de que Paul Nelson desarrollase su proyecto de La Maison Suspendue, abre nuevas vías de investigación que vendrán a confirmar la vigencia y la repercusión de esta obra y del pensamiento arquitectónico de su autor. Así tras presentar una nueva visión de la arquitectura de Paul Nelson en la que su obra residencial se convierte en el embrión de su reconocida arquitectura sanitaria, se reivindica el trabajo doméstico de Paul Nelson como laboratorio experimental de modernidad y se sugiere una línea de investigación que analice sus proyectos hospitalarios a la luz de su arquitectura doméstica.

Continuando con la indagación sobre los transvases conceptuales de La Maison Suspendue en otros proyectos y sobre su planteamiento como obra de investigación, sería interesante conocer si se pueden detectar posibles influencias en el trabajo de otros arquitectos, ya que algunos autores, como el historiador Jean-Paul Robert ${ }^{346}$, afirman que el proyecto tiene tanto valor por lo que encierra la obra en sí como por el rastro que deja. Pero seguramente resultaría más significativo preguntarse por qué no existen influencias directas, tratando de identificar las causas y valorando cómo

\footnotetext{
${ }^{346}$ Véase Jean-Paul Robert . "La maison qui n'existe pas". L'Architecture d'aujourd'hui, 316,1998, pp.38-74.
} 
afecta esta conclusión al planteamiento investigador mantenido por Paul Nelson sobre La Maison Suspendue.

Para completar el capítulo de las influencias, sería oportuno comprobar si el concepto transversal del que está impregnada La Maison Supendues tuvo un efecto reversible e incidió en el trabajo de algunos artistas en el entorno de Nelson. Hay que recordar que según Nelson ${ }^{347}$, Wassily Kandinsky consideró el proyecto como una síntesis de lo que buscaban los artistas coetáneos.

También resultaría muy interesante profundizar en el viaje realizado por Paul Nelson en el año 1934 a Egipto para analizar la influencia que la arquitectura vernácula ejerció sobre su pensamiento formado en la cultura de la arquitectura moderna. Esta investigación podría ampliar los estudios realizados sobre las intervenciones de Auguste Perret y de Le Corbusier desarrolladas en los años treinta en el Norte de África.

Para concluir, hay que señalar que Paul Nelson no es una figura maldita ni olvidada, ya que cada cierto tiempo sus hospitales y sus proyectos de los años treinta son objeto de trabajo y de estudio en alguna Universidad. Con esta tesis se pretende colaborar a su ubicación como miembro importante de un grupo de arquitectos secundarios, que por diferentes razones adoptaron una posición no dominante en el frente de la escena de la arquitectura de entreguerras, unos arquitectos que compartirían una condición heterogénea e internacional de búsqueda personal desarrollada desde la sombra de la historia de la arquitectura con todas las ventajas que esto supuso.

\footnotetext{
${ }^{347}$ Aunque Paul Nelson utilizó esta afirmación de Wassily Kandinsky en diversas ocasiones como aval artístico para su trabajo, no se ha podido encontrar una fuente primaria en la que el propio Kandinsky exprese esta percepción sobre La Maiosn Suspendue.
} 
Conclusiones 
CONCLUSIONS 
Les réflexions dégagées de la presente étude sur La Maison Suspendue de Paul Nelson s'organisent autour de quatre axes: la création de l'espace "inutile", l'engagement de Nelson avec l'architecture moderne, les contradictions inhérentes à La Maison Suspendue et les lignes de recherche ouvertes.

La formalisation de l'espace inutile.

L'apport fondamental de cette thèse est le constat de l'humanisation de l'architecture de Nelson par sa recherche sur l'espace individuel, notamment dans son projet de $L a$ Maison Suspendue. En effet, Nelson crée un espace "inutile" capable d'influencer le développement intellectuel de l'individu (§ III.4.). C'est cette contribution à l'architecture moderne qui caractérise son espace architectural et qui imprègne de continuité toute son œuvre, indépendamment du programme fonctionnel et des contraintes constructives ou formelles. Nelson conçoit non seulement un espace "inutile" au sein du logement, mais c'est aussi le premier architecte moderne à formaliser cette qualité spatiale.

Paul Nelson dessine son architecture pour libérer l'homme.

Sa carrière architecturale suppose pour Nelson avant tout un acte de libération, entraînant aussi le développement de l'individu comme sujet social. Effectivement, il décide d'entreprendre des études d'architecture pour son épanouissement personnel; il s'agit donc d'un choix lié à une démarche de maturité. Plus tard, il utilise l'architecture en tant qu'outil d'émancipation sociale, car il applique ses expériences personnelles à sa carrière, ce qui met "l'approche de l'homme" au centre de toute son œuvre. Le but de Nelson étant de se servir de l'architecture pour améliorer le bien-être de l'individu, il parvient même à la considérer comme un élément guérisseur capable d'influencer de façon positive la pensée humaine. ( $§$ III.1.).

Avec une telle approche bienfaisante de l'architecture, Nelson devient un médecinconcepteur, comme tant d'autres architectes modernes, obsédés par dessiner des espaces fonctionnellement aseptiques, hygiéniques, protecteurs et isolés du monde. Mais ce modèle s'estompe quand Nelson décide d'intégrer l'entourage dans ses bâtiments, en tant qu'élément à part entière, ce qui accorde à son œuvre une 
dimension environnementale. En effet, à Ismaïlia les terrasses pour le rétablissement des patients adoptent le même caractère guerisseur des espaces de chirurgie. (§ IV.2.).

Paul Nelson met au point sa méthode projectuelle à partir de ses expériences autobiographiques.

Paul Nelson s'inspire de sa propre vie comme outil de conception de projets. C'est, en effet, par le biais de ses expériences quotidiennes qu'il systématise sa méthode de travail et de création architecturale. Ses voyages, ses relations avec des artistes d'autres disciplines, son engagement social et ses deux épouses sont au cœur de sa pensée architecturale et réciproquement. D'où l'on peut conclure qu'il est très difficile de tracer une ligne qui sépare sa vie personnelle de sa carrière, de même que d'autres architectes modernes. La nouveauté chez Nelson est donc sa décision de dessiner sa propre biographie et d'en tirer différentes démarches créatives qu'il appliquera aux projets. ( $\S$ II.4.). Ses activités personnelles et ses relations interdisciplinaires nourrissent la première étape de son système de travail.

La création architecturale chez Nelson résulte d'une méthode souple et dynamique fondée sur l'expérimentation. Il définit ses objectifs selon des démarches ramifiées et erratiques qui lui permettent d'ouvrir librement de nouveaux champs d'exploration. Il introduit deux variables qui deviennent les ressources les plus décissives de l'étape expérimentale du projet. D'un côté, comme il a déjà été dit cidessus, il utilise sa propre biographie comme source d'inspiration et, de l'autre côté, il introduit l'erreur comme élément de continuité du processus. Nelson apprend, depuis ses premiers projets, que l'interprétation ambigue de la fonction d'un espace reste une valeur fondamentale pour que l'individu habite sa propre réalité. Le résultat erroné, différent ou hasardeux de cet usage de l'espace ne doit pas être assujeti à des modifications afin de le reconduire au bon usage; bien au contraire, il doit rester visible et faire part de l'ensemble. C'est ainsi que pour chaque projet les solutions restent ouvertes pour que ses utilisateurs occupent l'espace à partir de leurs propres besoins.

Mais cette approche expérimentale de l'architecture entre en contradiction avec sa méthode de travail systématique et déductive de la forme, sans doute une des clés de ses projets. À travers ses textes, Nelson définit très strictement les fonctions de 
l'architecte, de sorte qu'elles aboutissent à un résultat apparemment incompatible avec des objectifs ouverts. D'une part, il travaille pour créer une architecture qui donne plus de liberté aux individus et, d'autre part, il prend des décisions concernant des détails très personnels, même les œuvres d'art de ses clients. Quand l'architecte réfléchit à cette dichotomie, il en conclut que sa responsabilité professionnelle le met en mesure d'avoir une connaissance très approfondie des goûts de leurs clients. (§ III.3.).

Paul Nelson, un architecte chercheur.

Le caractère chercheur de son travail ne repose pas seulement sur un processus de quête déductive, structurée et planifiée afin de parvenir à résoudre les hypothèses de départ, comme le dit le critique Johnson Sweeney (§ III.2.), mais sur des résultats ouverts qui suggèrent de nouvelles lignes de travail qui peuvent être développées dans d'autres projets, par lui même ou par d'autres architectes. Son travail est donc destiné à la diffusion reliant deux éléments, d'une part, la générosité de partager avec la communauté scientifique ses propres inquietudes et, d'autre part, le désir de trouver sa place d'influence dans l'architecture moderne. Nelson éprouve, depuis le début de sa carrière, l'obligation morale de justifier ses décisions et d'assurer la rigueur de ses arguments afin de les rapprocher du travail scientifique par le biais des textes écrits par ses amis artites, éditeurs et historiens.

Mais Nelson utilise non seulement les textes des experts comme réclame, mais il s'en sert comme élément à part entière de son concept de projet architectural interdisciplinaire. De sorte que, malgré sa formation littéraire à Princeton, Nelson décide de présenter son œuvre comme un travail de collaboration, où d'autres auteurs écrivent sur son travail, mais ils sont toujours élaborés sur la base des conclusions de Nelson. Le seul texte vraiment critique sur son œuvre est celui de son ami, le peintre Jean Hélion (§ III.3.). Cet article a un double effet, d'un côté, il contraint Nelson à concevoir La Maison Suspendue et, d'un autre côté, provoque que Jean Hélion ne collabore plus avec lui et que son amitié s'en ressente. 
Paul Nelson ne veut pas être traité de "moderne".

Sa façon éclectique de se conduire est l'un des éléments qui contribuent à ce que la critique architectonique d'après la Seconde Guerre Mondiale ne le considère pas comme un clair exemple de l'architecture moderne. Pourtant, c'est, à son tour, le propre Nelson qui contribue à créer cette image d'architecte "non intégré", puisque, même s'il fait partie de l'exposition "The International Style" en 1932 (§ II.1.), dans ses articles à partir de 1933 il essaie de prendre ses distances à l'égard des architectes du Mouvement Moderne. Pendant les années trente, Nelson éprouve des sentiments contradictoires envers les architectes modernes qui ont le plus d'influence dans son œuvre, Auguste Perret et Le Corbusier. D'une part, il les admire et s'intéresse à leur travail et, d'autre part, il a besoin de les "tuer" pour avancer. C'est à cause de ce besoin de s'éloigner que Nelson tente d'effacer tous les liens qui le classent comme architecte moderne. Il ne parvient à obtenir une autonomie et une maturité architecturale qu'à la fin de la Seconde Guerre Mondiale, puisque son séjour aux États-Unis change sa manière de comprendre l'architecture. C'est donc ainsi que sa nouvelle étape architecturale hospitalière commence à intéresser de nouveau les critiques.

La Maison Suspendue est conçue pour ne jamais être construite.

La Maison Suspendue n'est pas un projet conçu pour être construit. Faute de commanditaire concret, la maison ne s'agissant pas d'un prototype, Nelson ne compte pas non plus sur le soutien économique indispensable pour sa réalisation. Cette maison est donc créée comme un projet théorique, destiné à être diffusé par des maquettes, c'est-à-dire un travail réalisé pour être exposé dans un musée. Le niveau de définition constructive et structurale du projet démontrent que l'objectif principal de Nelson était l'exhibition itinérante de sa recherche. À cet égard, il est intéressant de noter que la suite des péripéties des deux maquettes fait l'objet d'étude dans un chapitre précédent. Notamment, la perte de la première maquette ( $\S$ III.2.) et l'intérêt de l'architecte à insister sur le fait qu'elle se produit dans l'océan Atlantique, à l'occasion de son renvoi à Paris, ce qui continue de nourrir la légende sur le projet.

Suite à une première tentative de réaliser le modèle à l'échelle réelle, commandé par l'Exposition Internationale de New York, Nelson concentre tous ses efforts sur 
l'exécution de la deuxième maquette. Ce qui semble étonnant, c'est qu'il ne progresse pas dans la concrétisation du projet. Plus tard, en 1960, une possibilité se présente de réaliser un prototype du projet pour les jardins du MoMA, avec pour objectif de diffuser ses idées et non pas un modèle fabriqué en série. Un échec constructif aurait gâché d'éventuelles exhibitions postérieures. Enfin, les derniers essais de réaliser la maison à Marseille, quatre ans plus tard, répondent plutôt à un désir de reconnaissance à sa carrière qu'à un véritable intérêt de voir construire son projet.

Une maison proposée sous forme de recherche offrait un résultat ouvert et inachevé qui renforçait l'idée de la non-construction, puisqu'elle n'était ni un produit fini, ni un modèle canonique. De cette façon, même si la maison avait été construite à l'échelle réelle, elle n'aurait jamais acquis la qualité de logement, en effet, elle aurait continué d'être une maquette d'elle même ou le fragment d'une maquette d'un projet postérieur.

La Maison Suspendue n'est pas une maison.

La Maison Suspendue n'est pas une maison mais un prétexte pour réaliser une recherche sur l'espace. Son programme domestique est une excuse, une "couverture" dessiné afin d'être caché sous un rideau de béton ou soulevé vers le plafond. Son image de l'extérieur évite de l'identifier à celle d'une maison. Effectivement, elle adopte une apparence ambigue, proche de l'architecture industrielle, mais qui pourtant devient artisanale dès que l'on s'approche de l'orfèvrerie de ses losanges de verre. D'ailleurs, son emplacement devient aussi paradoxal. Car on prétend créer un refuge pour l'isolement et la retraite individuels; néanmoins, le logement est un élément urbain, conçu comme un espace individuel qui complète l'espace public et social de la ville.

Cette idée est renforcée par la création d'un paysage intérieur syncrétiste, essayant d'attraper l'extérieur entre les murs de la maison. La cour fermée devient le seul élément qui montre l'essence d'une maison, alors que le reste du logement constitue un décor théâtral, une invention qui orne "l'extérieur-interne". En conclusion, Nelson ne met pas au point le programme d'une habitation moderne, il dessine juste un grand baldaquin avec des infrastructures empilées et des rideaux de verre. C'est ainsi que La Maison Suspendue, une enceinte de retraite individuelle, surgit de la 
synthèse de deux espaces extérieurs: la "casa-patio" méditerranéenne et le porche d'entrée de maison de l'ouest américain.

La Maison Suspendue et la continuité spatiale non expérimentée.

Comme il a déjà été dit ci-dessus, Paul Nelson se sert de l'absence de programme de La Maison Suspendue pour expérimenter la liberté spatiale dans les trois directions. Même si la distribution des pièces justifie cette remarque, il n'en reste pas moins que cette "explosion" artificieuse retient toute l'attention du projet et laisse sans solution la liaison entre les différents niveaux et réduit les communications verticales à deux éléments. C'est ainsi que, quand on décrit la diversité de parcours intérieurs, ceux-ci foisonnent dans un même étage, mais restent très limités quand il faut se déplacer entre différents niveaux. La perception tridimensionnelle de l'espace reste donc plus visuelle que réelle, puisqu'elle n'est perçue que depuis la rampe, le reste des parcours étant limités à un seul niveau.

La Maison Suspendue et la contradiction de l'espace inutile.

Paul Nelson inverse les critères définissant l'habitat domestique des années trente, d'une part en remettant en cause la nécessité d'un programme et, d'autre part, en apportant une nouvelle qualité aux espaces les plus représentatifs: leur condition d'espaces "inutiles" ou sans fonction déterminée. Même si Nelson emploie ce terme ("inutile") aussi bien pour les espaces communs que pour les individuels, quand il parle des espaces communs, cette idée d'espace "inutile" n'est pas exacte, puisque ce sont des lieux destinés à la réunion. Nelson se justifie en prétendant qu'il s'agit des espaces les plus appropriés pour l'installation d'œuvres d'art, qui sont "inutiles" par définition. Son discours présente donc une faille: l'art "inutile" a besoin d'un espace utile, conçu spécifiquement pour l'héberger. C'est donc l'objet artistique qui détermine la fonction de l'espace. Dans le cas des pièces individuelles, la définition d'espace "inutile" est plus conforme à la réalité; en effet, même si les cellules sont destinées à l'isolement individuel, leur fonction n'est pas soumise à contraintes.

Pour Nelson, la libération de l'homme par rapport à l'habitat domestique, qui lui est imposé, n'a pas lieu par la dissolution de l'architecture, mais justement par sa présence. Ce qu'il prétend donc dans cette maison, c'est la création de petites "îles" 
à usage privé et indéterminé, qui ne perdent ni leur identité ni leur continuité au sein de l'espace public. Même si cet objectif n'est pas pleinement atteint dans La Maison Suspendue, puisque finalement Nelson doit utiliser des éléments de séparation, cette maison sert d'essai pour des projets ultérieurs.

La recherche à partir de la recherche.

La présente thèse, soulevée quatre-vingts ans après la réalisation de La Maison Suspendue, ouvre de nouvelles lignes de recherche qui ratifieront la validité et la répercussion de cette œuvre et de la pensée architecturale de son auteur. En effet, cette nouvelle approche de l'œuvre résidentielle de Nelson la situe à l'origine de sa réputée architecture hospitalière, et revendique le travail domestique de Nelson comme un laboratoire expérimental de modernité. On propose donc une ligne de recherche qui puisse analyser ses projets hospitaliers à la lumière de son architecture domestique.

En ce qui concerne les éventuelles influences de La Maison Suspendue sur d'autres projets, il serait intéressant d'approfondir à ce sujet, car certains auteurs comme l'historien Jean-Paul Robert ${ }^{348}$, affirment que le projet a autant de valeur pour ce qu'il enferme que pour les traces qu'il laisse. Peut-être serait-il donc plus pertinent de s'interroger sur les causes de l'absence d'influences directes, et puis d'analyser comment cela affecte les points de départ adoptés par Nelson dans la recherche de La Maison Suspendue.

Pour compléter le chapitre des influences, il faudrait vérifier si l'esprit de transversalité qui imprègne La Maison Suspendue s'est répandu dans le sens inverse, c'est-à-dire, s'il a influencé le travail d'autres artistes de l'entourage de Nelson. Il convient de noter ici que, d'après Nelson ${ }^{349}$, Wassily Kandinsky a considéré ce projet comme une synthèse de tout ce dont les artistiques contemporains étaient en quête.

\footnotetext{
${ }^{348}$ Voir Jean-Paul Robert. "La maison qui n'existe pas". L'Architecture d'aujourd'hui, 316, 1998, pp. 38-74.

349 Bien que Paul Nelson se serve à plusieurs reprises de ces propos de Wassily Kandinsky comme une garantie artistique de son travail, aucune source primaire du propre Kandinsky recueillant cette opinion sur La Maison Suspendue n'a pu être trouvée.
} 
Il serait aussi intéressant d'approfondir dans le voyage de Nelson en Egypte en 1934, afin d'analyser l'influence de l'architecture vernaculaire de ce pays sur sa pensée, forgée dans le cadre de l'architecture moderne. On pourrait ainsi élargir les études existentes sur les interventions d'Auguste Perret et de Le Corbusier en Afrique du Nord dans les années trente.

Pour conclure il faut remarquer que Nelson n'est ni une figure maudite ni tombée dans l'oubli. En effet, ses hôpitaux et ses projets des années trente font régulièrement l'objet de différentes études universitaires. Notamment cette thèse prétend revendiquer son importance au sein d'un groupe d'architectes secondaires qui, pour une raison ou autre, ne jouent pas un rôle dominant dans la scène de l'architecture de l'entre-deux-guerres. Des architectes engagés dans une quête personnelle -éclectique et internationale-, développée dans une zone d'ombre de l'histoire, et pourtant avec les avantages que cette prise de position comporte. 
BIBLIOGRAFÍA 


\section{Bibliografía general}

AALTO, Alvar. La Humanización de la arquitectura, Barcelona : Tusquets Editores, 1977. [“The humanizing of architecture," The Technology Review, noviembre 1940].

ABRAM, Joseph. Perret et L'Ecole du Clasiccisme Structurel (1910-1960), Tomo 1-2, Nancy : École d'Architecture de Nancy- S.R.A, 1985.

ALBRECHT, Donald. Designing dreams. Modern Architecture in the movies, New York: Marge Horvitz, 1986.

ANTLIFF, Mark. "Cubism, Futurism, Anarchis: The Aestheticism of the Action d'art Grou, 1906-1920”. Oxford Art Journal, 21 de febrero de 1998, pp. 99-120.

ARENDT, Hanna. La condición humana, Barcelona: Paidós Ibérica, 1993.

ARIÈS Philippe y Georges DUBY, (dir.). Historia de la vida privada, Vol V, Madrid: Taurus, 1989, p. 15.

AYMONINO, Carlo. La vivienda racional. Ponencias de los Congresos C.I.A.M 1929-1930, Barcelona: Gustavo Gili, 1976. [L'abitazione racionale. Atti dei Congressi C.I.A.M 1929-1930, Padua : Carlo Aymonino, 1971].

BACHELARD, Gaston. La poética del espacio, Mexico: Fondo de cultura económica, 1965, pp.107-109.

BACON, Mardges. Le Corbusier in America, Detroit: New Archives, 2001.

BANHAM, Reyner. Teoría y diseño en la primera era de la máquina, Buenos Aires: Nueva Visión, 1965. [Theory and Design in the First Machine Age, Londres: Architectural Press, 1960].

BEHRENDT, Walter Curt. Arquitectura Moderna. Su Naturaleza, sus problemas y formas, Buenos Aires: Infinito, 1975. [Modern Buildings. Its Nature,Problems and Form. Nueva York: Brace and Company, 1937]. 
BEHNE, Adolf. 1923. La Construcción Funcional Moderna, Barcelona: Serbal, 1994, [Der moderne Zweckbau, Múnich: Drei Masken Verlag 1926].

BENÉVOLO, Leonardo. Historia de la arquitectura moderna, Barcelona: Gustavo Gili, 1977.[ Storia dell'architectura moderna, Bari: Laterza, 1960 ].

BERGDOLL, Barry, Ken TADASHI y Rasmus WÆRN. Home Delivery: Fabricating the Modern Dwelling, New York: Barry Bergdoll y Peter Christensen,2008.

BLOOMER Kent.C. y Charles W. MOORE. Cuerpo, memoria y arquitectura. Introducción al diseño arquitectónico, Madrid: H.Blume, 1982, p.63.

BRITTON, Karla. Auguste Perret, Londres: Phaidon Press, 2001.

CALDER, Alexander, Calder. Autobiographie, París: Maegh éditeur, 1972.

CALVO SERRALLER, Francisco. "Calder: la gravedad y la gracia", catálogo de la exposición La Levedad y la gracia. Museo Guggenheim, Bilbao: Guggenheim 2003.

CINQUALBRE, Olivier. "Un rendez-vous à jamais reporté. Léger et l'architecture", catálogo de la exposición Fernand Léger (1981-1955). Centre Pompidou MNAMCCI mayo-septiembre de 1997, París : Editions Centre Pompidou,1997.

---- "Braque Bâtisseur", catálogo de la exposición George Braque L'espace, Museo Malraux de Le Havre, París: Adam Biro,1999, p. 97.

Olivier. Pierre Chareau : La Maison de verre1928-1933, París : Jean Michel Place, 2001

COBBERS, Arnt y Olivier JAHN. Prefab Houses, Colonia: Taschen, 2010.

COLLINS, Peter. Los ideales de la arquitectura moderna; su evolución, Barcelona: Gustavo Gili, 1970. [Changing Ideals in Modern Architecture, 1750-1950, Montreal: McGill-Queens University Press, 1965]. 
COLOMINA, Beatriz. Doble exposición. Arquitectura a través del arte, Madrid: Akal, 2006.

----- "The Split Wall: Domestic Voyeurism", Raumplan versus plan libre: Adolf and Le Corbusier, 1919-1930, Rótterdam: Max Risselada, 2008, pp. 32-51.

----- Privacidad y Publicidad. La arquitectura moderna como medio de comunicación de masas, Murcia : Cendeac, 2010, p.43.

DANCHEV, Alex. Georges Braque a life, Nueva York: Arcade Publishing, 2005.

EMERY Marc y Pierre GOULET. Guide-Architecture en France 1945-83, París : Le Moniteur, 1983.

FORD, James y Katherine MORROW. The Modern House in America, Nueva York: Architectural Book Publishing Co, 1940.

FOUCAULT, Michel. Vigilar y castigar. Nacimiento de la prisión, Buenos Aires: Siglo XXI, 1978, [Surveiller et punir, París: Éditions Gallimard, 1975 ].

FRAMPTOM, Kenneth. Le Corbusier, Madrid: Akal , 2002. [Le Corbusier, París: Hazan, 1997].

GIEDION, Sigfried. Espacio, tiempo y arquitectura: el futuro de una nueva tradición, Barcelona: Reverté, 2009. [Space, Time and Architecture: the Growth of a New Tradition, Cambridge: Harvard University Press, 1941].

----- Walter Gropius: Work and Teamwork, Nueva York: Reinhold Pulishing , 1954, pp. 61-63.

---- Architecture, You and Me. The Diary of a Development, Cambridge, MA: Harvard University Press, 1958.

----- La Arquitectura fenómeno de transición: las tres edades del esapcio en arquitectura. Barcelona : Gustavo Gili, 1975. [Architecture and the phenomena of transition: the three space conceptions in architecture, Cambridge: Harvard University Press, 1971]. 
GOLAN, Romy. Modernity and Nostalgia: Art and politics in France between the wars, New Haven:Yale Uiversity Press, 1995.

GRAWE, Michael. Expatriate American Authors in Pais. Disillusionment with the American Lifestyle as Reflected in Selected Works of Ernest Hemingwayand Scott Fitzgerald, Munich: Grin Verlag, 2008.

GUITART, Miguel. Filtros de mirada y luz. Una construcción visual del límite arquitectónico. (Tesis doctoral) Universidad Politécnica de Madrid. 2014.

HERTZBERGER, Herman. Lessons for students in architecture, Rotterdam: Herman Hertzberger / Uitgeverij 010 Publishers, 1991.

----- Space and the Architect. Lesson in Architecture 2, Rotterdam: Herman Hertzberger / Uitgeverij 010 Publishers, 2000.

HITCHOCK, Henry-Russell y Philip JONSON. El Estilo Internacional: Arquitectura desde 1922. Murcia: Colegio Oficial de Aparejadores y Arquitectos Técnicos, Galería-Librería Yebra, Consejería de Cultura y Educación de la Comunidad Autónoma de Murcia, 1984. [The Internacional Style, Architecture Since 1922, Nueva York: W.W. Norton \& Co, 1932].

KELLY, Burnham. The prefabrication of houses, Cambridge: M.I.T. Technology Press and John Wiley and Sons, 1951, pp. 28-30.

KNERR, Douglas. Suburban Steel: The Magnificent Failure of the Lustron Corporation, 1945-1951, Columbus: The Ohio State University Press, 2004.

KENTGENS-CRAIG, Margaret. The Bauhaus and America. First contacts 19191936, Cambridge: MIT Press, 2001.

LE CORBUSIER. Hacia una Arquitectura, Buenos Aires: Poseidon, 1964. [Vers une architecture, París: Éditions Crès, Collection de "L'Esprit Nouveau", 1923].

LECCIA, Jean Baptiste. À l'école d'architecture: Chroniques grinçantes 19682011. París : L'Harmattan, 2011. 
LÉGER, Fernand. Funciones de la pintura. Barcelona: Paidós Ibérica, 1990. [Fonctions de la Peinture. París : Gonthier, 1965].

LEMELIN, Èmile. ¿Qu'est-ce France forever? Le Travailleur, 6 de abril 1944, 1

LONBERG-HOLM, Knud y Theodore LARSON. Planing for Productivity, Nueva York: International Industrial Relations Institute New York, 1940.

LOUVET, Solagne, Jacques de GIVRY. Mémoire de Varengeville \& Vasterival, Les Loges-en-Josas : JDG, 1994.

LUCAN, Jacques. Composition, non-composition. Architecture et théories, XIXeXXe siècles, Lausana : Presses polytechniques et universitaries normandes, 2009.

LUQUE BLANCO, José Luis. Contínuum cósmico :Frederick Kiesler(1890-1965), Barcelona: Fundación Caja de Arquitectos, 2012, p.98.

MARURI, Nicolás. La cabina de la máquina. Evolución del espacio vertical en los proyectos domésticos de Le Corbusier. (Tesis doctoral) Universidad Politécnica de Madrid. 2006.

MIES VAN DER ROHE, Ludwing. Ludwing Mies van der Rohe. Escritos, Diálogos y Discursos, Madrid: Colegio oficial de aparejadores y arquitectos técnicos de Madrid, 1992.

MOHOLY-NAGY, László. La nueva visión y reseña de un artista, Buenos Aires: Infinito, 1963, p.110.

MOHOLY-NAGY, Sibyl. Matrix of Man:An Illustrated History of Urban Environment, Nueva York: Praeger, 1968.

MONNIER, Gérard. L'architecture en France : une histoire critique, 1918-1950, Paris : Philippe Sers, 1990.

MUÑOZ, María Teresa. "El dilema de las casas Jaoul", Cerrar el círculo y otros escritos, Madrid: COAM, 1989. 
NEDER, Federico. Fuller Houses. R. Buckminster Fuller's, Dymaxion Dwellings and Other DomesticAdventures, Zürich: Lars Müler Publishers, 2008.

ORDINE, Nuccio. La utilidad de lo inútil. Manifiesto, Barcelona: Acantilado, 2013, p.153.

PEREC, Georges. Especies de espacios, Barcelona: Montesino, 1999, pp.59-61.

PEREIRA, Ana Sofía. La intimidad de la casa. (Tesis doctoral) Universidad Politécnica de Madrid, 2013.

PRIETO GOZÁLEZ, José Manuel. Aprendiendo a ser Arquitectos, creación y desarrollo de la escuela de arquitectura de Madrid 1844-1914, Madrid: CSIC, 2004.

POUVREAU, Benoît. "Quand communisme municipal rimait avec laboratoire urbain 1944-1986". Jornadas de estudio Université Paris 1. Les territories du communisme. Élus locaux, politiques publiques et sociabilités militantes, París, 2009.

PROST, Antoine. "Fronteras y espacios de lo privado", Philippe Ariès y Georges Duby (dir.) Historia de la vida privada, Vol V, Madrid: Taurus, 1989, p.15.

QUETGLAS, Joseph. Les Heures Claires: proyecto y arquitectura en La villa Savoye de Le Corbusier y Pierre Jeneret, Barcelona: Associació d'idees, 2009.

RAMIREZ, Juan Antonio. Edificios Cuerpo: cuerpo humano y arquitectura: analogias, metáforas, derivaciones, Madrid : Siruela, 2003.

RAGOT, Gilles. "Georges Braque-Mela Muter-Chana Orloff." Encyclopédie Perret, París: Éditions du patrimoine y Éditions du Moniteur, 2002.

RUDOLPH, Nicole C. At Home in Postwar France. Modern Mass Housing and the Right to Comfort, Nueva York: Berghahn Books, 2015.

SWEENEY, James JOHNSON. Alexander Calder, exhibition, catálogo de la exposición en The Museum of Modern Art, Nueva York : The Museum of Modern Art, 1943. 
SCOTT, Geoffrey. The Architecture of Humanism. A Study in the History of Taste, Boston : Houghton Mifflin Company, 1914.

SUAREZ, María Candela. Las Villas Meyer y Hutheesing-Shodhan de Le Corbusier. (Tesis doctoral) Universitat Politécnica de Cataluña 2006.

THE MUSEUM OF MODERN ART. Modern architecture: international exhibition, New York, Feb. 10 to March 23, 1932, New York : The Museum of Modern Art,1932.

TSCHUMI, Bernard. Architecture and Disjunction, Cambridge: The MIT press, 1996, pp. 28-35.

----- "The Pleasure of Architecture", Architectural Desing n³3, 1977, p.118

TZARA, Tristan. "D'un certain automatismo du goût", Minotauro, nº3-4,1933, p.84 ZEVI, Bruno. Historia de la arquitectura moderna, Barcelona: Poseidon, 1980. [Storia dell'architettura moderna. Turín: Einaudi, 1950]

----- Saber ver la arquitectura, Buenos Aires: Poseidón, 1958. [Saper vedere l'architettura: saggio sull'interpretazione spaziale dell'architettura. Turín: Einaudi, 1948] 


\section{Bibliografía específica sobre Paul Nelson}

AA. VV. “Paul Nelson. 1895-1979”.Bulletin Ifa, 130, 1989.

AA. VV.Un Architecte Des Artistes. Paul Nelson. Léger, Calder, Brassaï, Hélion, Braque, Miró ... Catálogo de exposición, Musée des Beaux-Arts de Galliac,2007.

ABRAM, Joseph. "Paul Nelson: le crible de la raison. 1920-1939: Peinture/ Architecture. Projets experimentaux", Bulletin d'Informations Architecturales (IFA) $n^{\circ} 130$ abril 1989.

“Paul Nelson à Columbia”. L'Arquitecture d'aujourd'hui,269, 1990, p.63.

APPLEGATE, Judith. "Paul Nelson: an interview". Perspecta, 13-14, 1971, pp.75127.

CALDER, Alexander. Calder. Autobiographie, París: Maegh éditeur, 1972.

CINQUALBRE, Olivier. “ Paul Nelson, faire vivre l'espace : chronique d'une recherche partagée ". Les Cahiers du Musée National d'Art Moderne. 95, 2006, pp.78-89.

CCEUR, Marc Le. Charles Le Cour (1830-1906), architecte et premier amateur de Renoir. Catálogo de exposición, Musée d'Orsay de París, 1996-1997, Paris : Réunion des musées nationaux, 1996.

EMANUEL, Muriel. Contemporary architects. Londres: The Macmillan Press, 1980.

EPRON, Jean-Pierre. "Un enseignement suspendu. PaulNelson, Professeur", Bulletin d'Informations Architecturales (IFA) n 130, abril 1989, pp.21-23.

FRAMPTON, Kenneth. "Paul Nelson et 1'École de Paris-1923-1938”. Bulletin d'Informations Architecturales (IFA) 130, 1989, pp.3-4.

GALPÉRINE, Charles. "Un americain a Paris. Interview de Paul Nelson”. Notre Republique, 3 de febrero de 1967. 
HÉLION, Jean. "Termes de vie-Termes d'espace". Cahiers d'art, 7-10, 1935, pp.268-273.

----. Lettres d'Amérique. Correspondance avec Raymond Queneau 1934-1967, Paris : IMEC Éditions, 1996.

"Hôpital américain de Paris", L'Architecture d'Aujourd'hui no 40, abril 1952, p.74.

JACK, James y Pisani EARLE. The Story of the Golden Gate International Exposition, Old Masters and Art in Action, San Francisco: Pisani printing and publishing Co,1941.

KANDELMAN Anne. Paul Nelson.Notes biographiques 1978, révisée par Anne Kandelman, mecan, fonds Paul Nelson, MNAM/CCI Centre national d'art et de culture Georges Pompidou

LACOSTE, Michel-Louis. "Paul Nelson.Un architecte humaniste". Informations et Documents, U.S. Embasy, 189, 1963, pp.21-25.

LE CORBUSIER, "La Cité hospitalière de Lille", Cahiers d'Art, 1932, p.57.

RILEY Terence y Joseph ABRAM. The Filter of Reason. Work of Paul Nelson, Nueva York: Rizzoli / cba, 1990.

SEVERO, Donato. L'Hôpital de Saint-Lô. Du project a l'usage (1946-1999).( tesis doctoral) Université Paris I Panthéon-Sorbonne, 2010.

SEYMOUR, Josiah. Chicago: its history and his builders, a Century of Marvelous Growth. Chicago: S.J. Clarke Publishing, 1912.

VALEIX, Danielle. "Vers un nouvel humanisme". L'Architecture d'aujour'hui,72, (1957), pp.V - VII.

ZERVOS, Christian. “ «Introduction»".Cité Hospitalière de Lille. Paul Nelson París: Cahiers d'Art, 1933. 
Bibliografía sobre La Maison Suspendue

ABRAM, Joseph. "Paul Nelson: La Maison Suspendue". AMC, 15, 1987, pp.80-95.

“A Correction”. New York Times, 27 de octubre de 1938, 21.

ALDEN JEWELL, Edward. "In the realm of art: exhibitions here and elsewere. Carnegie american painters at international". New York Times, 30 de octubre de 1938, p. 9.

----- "Suspended House is exhibited here". New York Times, 26 de octubre de 1938, p.24.

“Architect's Talk Planned ". The Christian Science Monitorcsm, 28 de noviembre de 1938, p.10.

"Architects: they learn way to desing suspended houses ". The Christian Science Monitorcsm, 30 de noviembre de 1938, p.11.

“Art Museum here scene of reception”. The New York Times, 9 de febrero de 1940, p.22.

BLOMSTEDT, Aulis. "La deshumanización de la arquitectura", Le Carré Bleu,2, 1958, pp.2-4.

----- "La Forme architectural", Le Carré Bleu, 1, 1969.

JACK, James y Earle WELLER PISANI. The Story of the Goden Gate Internacional Exposition, Old Masters and Art in Action, capítulo XI, San francisco: Pisani printing and publishing Co, 1941, pp. 133.

JEWETT, Eleanor. "City Maintains a Full Quota of Art Exhibitions", Chicago Daily Tribune, 11 de diciembre de 1938, p.5

----- "Critic Urges Pictures for Yule Presents". Chicago Daily Tribune, 18 de diciembre de 1938, p.4 
----- "Modernist, but Intelligible One". Chicago Daily Tribune, 9 diciembre de 1938, p.27.

“La Maison Suspendue". Marianne, Courrier des Arts, 12 de octubre de 1938, p.9.

"New Type House Like Suspended Bird Cage". The Christian Science Monitorcsm, 14 de noviembre de 1938, pp.1-2.

"New use of space determines design of proponed house". Architectural Record, V$84,6,1938$, pp.38-41.

PROVINES, June. “The Suspended house”. Chicago Daily Tribune, 7 diciembre 1938, 20.

"S C Displays Future Architecture", Tower Light weekly, 4 de octubre de 1963, pp.3-4.

SOSA DÍAZ-SAAVEDRA. José Antonio. "Una nube en una jaula. La Maison Suspendue de Paul Nelson”. Arquitectura COAM n 328, 2002, p.23.

SWEENWY JOHNSON, James. "The Suspended House", Official Catalog department of fine arts, division of decorative arts. Golden Gate Exposition, San Francisco, 1939, pp.74-75 
Artículos y monografía de Paul Nelson

NELSON, Paul. "Modern Architecture is Based on Current Life. Great Building Art Product of Necessity ". Chicago Evening Post. Magazine of the art world. 17 de abril de 1928, p.3.

----- “Cité Hospitalière de Lille. Paul Nelson”. Cahiers d'Art, 8-10, 1932.

----- “La Maison de la rue Saint Guillaume”. L'Arquitecture d'aujourd'hui, 9, 1933, p.9.

----- “Etude d'un Pavillon de Chirugie à Ismaïlia, Canal de Suez”. Cahiers d'Art, 710,1935, pp.263-268.

---- "A Method of Procedure in Architectural Design". Architectural Record, 6, 1937, pp.52-57.

-----“Peinture spatiale et architecturale. Á propos des dernières oeuvres de Léger". Cahiers d'Arts, 1-3, 1937, pp.85-89.

----- La Maison Suspendue. Recherche de Paul Nelson. (L'Architecture Vivante), París: Albert Morancé, 1939.

----- “Projet d'un Palais de la Découverte, 1937”. Cahiers d'art, 3-4, 1940.

----- “ La Transformation de 1'architecture aux États-Unis”. Arts de Franc,5, 1946, pp.35-45.

----- “Preface”. L'Architecture d'Aujourd'hui, 15, 1947, p.2.

--- "l'industrialisation du bâtiment... et le rôle de l'architecte". Arts de France, 2526,1948, pp. 52-60.

----- “ Le principe de la forme”. L'Architecture d'Aujourd'hui. 27, 1949, pp. 50-52

-----“La salle d'opérations ovoide” L'Architecture d'Aujourd'hui. 27, 1949, pp.5255 
----- "Mon ami Georges Braque. Souvenirs de Paul Nelson, souvenirs recueillis par Georges Boudaille”. Les Lettres françaises, 942, 1962, p. 11.

----- "L'homme, l'architecture et l'industrie du batiment ". Technique et architecture, 4, 1965, pp.110-111.

----- "Mutation ou cessation". Le carré bleu, 3-4, 1969, p.1, p. 8.

----- “Auguste Perret, 1'Enseignant. Premier atelier de 1'Ecole des Beaux-Arts". Architectes, 1974. 


\section{Actividad Profesional.}

1927 Obtiene el diploma en arquitectura en Beaux-Arts de París.

Reforma de apartamento en Chicago.

1928 Proyecto de vivienda para el escritor americano Alden Brooks, Boulevard Arago, París. (1928- 1930).

1929 Director artístico de la película What a Widow, dirigida por Allan Dwan (1929-1930)

Proyecto para un edificio de aparcamiento en altura, Chicago.

1930 Proyecto de sala de cine para la residencia del productor Joseph Kennedy, Bronxville.

Proyecto de centro de salud para el doctor Léon Vannier, París.

1931 Casa y estudio para Georges Braque, Varengeville.

Farmacia, París

1932 Gana el concurso de la Ciudad Hospitalaria de Lille.

Proyecto de La Maison Santé Type Minimum, Paris.

Participa en la exposición "The International Style", Museum of Modern Art de New York (MoMA).

1933 Proyecto para la Maison des Docteurs, Paris

1934 Proyecto para Pabellón de Cirugía de Ismaïlia, Egipto

1936 Exposición colectiva de pintura en la galería Pierre Loeb de Paris

Primeros planos de La Maison Suspendue, firmados y fechados el 27 de abril.

Proyecto para nueva sede Columbia Broadcasting System (C.B.S) en Park Avenue, Nueva York.

1937 Proyecto del Palais de la Découverte, Paris, en colaboración Oscar Nitzchke y Frantz Jourdain.

Diseño mobiliario doméstico.

1938 Planos definitivos de La Maison Suspendue, firmados y fechados el 9 de junio.

Exposición de la primera maqueta de La Maison Suspendue en Paris, Nueva 
York, Chicago, Massachusetts, Princeton y San Francisco.

Proyecto de reforma del auditorio de la W.G.N Broadcasting Radio, Chicago, en colaboración con Fernand Léger .

1939 Exposición de la segunda maqueta de La Maison Suspendue en Paris y en Nueva York.

1940 Inicio de estancia en los Estados Unidos tras la invasión de Francia por Alemania.

1941 Arquitecto asesor de la United States Housing Authority.

Presidente de la comisión "France Forever", para la reconstrucción de Francia.

1942 Consultor para la Federal Public Housing Authority.

1943 Asesor para la agencia nacional del alojamiento en tiempos de guerra.

1944 Jefe de la División de las Industrias de Urbanismo y Construcción.

1945 Regreso a Francia

Asesor técnico del el Ministerio Francés del Urbanismo y la Reconstrucción (MRU)

1946 Exposición "Techniques Américaines de I' Habitation et de I'Urbanisme 1939-194X”, Grand Palais Paris.

Hospital Franco-Americano, Saint-Lô, en colaboración con Roger Gilbert, Charles Sébilloette y Marcel Mersier. (1946-1954).

Propuesta in memorian de Gabriel Perí, París, colaboración de Alberto Giacometti.

1947 Concurso para fuente y plaza, Nueva York, en colaboración con Henri Laurens

Maison mínimum en pierre, "Merlan", Noisy-le-Sec, en colaboración con Roger Gilbert, Charles Sébilloette y Charlotte Perriand, (1947-1952).

1949 Proyecto para el monumento a los Héroes de Chateaubriand, en colaboración con Roger Gilbert, Charles Sébiollette y el escultor Antoine Rohan.

1950 Residencia colectiva junto a la estación, Noissy- le Sec, en colaboración de Roger Gilbert y Charles Sébilloette. (1950-1953).

Propuesta de alojamientos colectivos, Villeneuve-Saint-Georges, en colaboración con Marcel Lods, Roger Gilbert y Charles Sébillotte

Reforma del Hospital Franco-americano, Neully- sur- Seine, Paris, 
decoración en colaboración con Francine e Ivonne Le Coeur. (1950-1952).

Policlínica François I, le Havre. (1950-1955)

1951 Prototipo de colegio, Peyzac-le-Moustier, en colaboración con Roger Gilbert y Charles Sébillotte.

1954 La Maison Badin, Sceaux (1954-1955).

Proyecto de casa para el actor Mr G. Philippe, Cergy, Pontoise.

1955 Proyecto para el museo Fernand Léger, Biot.

1956 Proyecto vivienda para Nadia Léger, Giff- sur-Yvette.

Proyecto para reformar el Hotel de Ville y el Théatre Municipal, Remise des Pompes.

Profesor en el Pratt Institute School, Nueva York.

1957 Profesor en Princeton University.

Beca de la Graham Foundation, Chicago.

Profesor en el Pratt Institute School, Nueva York

1958 Profesor en Yale University.

Socio de la firma Ketchum \& Sharp, Nueva York.

1959 Asesor técnico de la United States Public Health Service.

Profesor en el M.I.T.

1960 Profesor en Harvard University.

Profesor en el M.I.T.

Profesor en Princeton University.

1961 Asesor Técnico del Ministerio Francés de Sanidad Pública y Población.

Concurso para Centro administrativo de la Sociedad Mundial de la publicidad J.Walter Thompson, en colaboración con Vladimir Bodiansky y Jean Prouvé y Alexander Calder.

1963 Hospital de Dinan, en colaboración con Pierre Devinoy y R.Lamourec, (1963-1968)

Director del taller Franco-Americano en la École Nationale Supérieure des Beaux- Arts, París

1965 Complejo hospitalario, Arles, en colaboración con Pierre Devinoy y André Remondet. (1965-1974). 
1967 Profesor del taller Franco-Internacional de Arquitectura en la Escuela de Marsella-Luminy.

1971 Consultor técnico para el Ministerio de Sanidad de Túnez.

1975 Casa familiar, Trets. (1975-1976) 
Proceso evolutivo de La Maison Suspendue

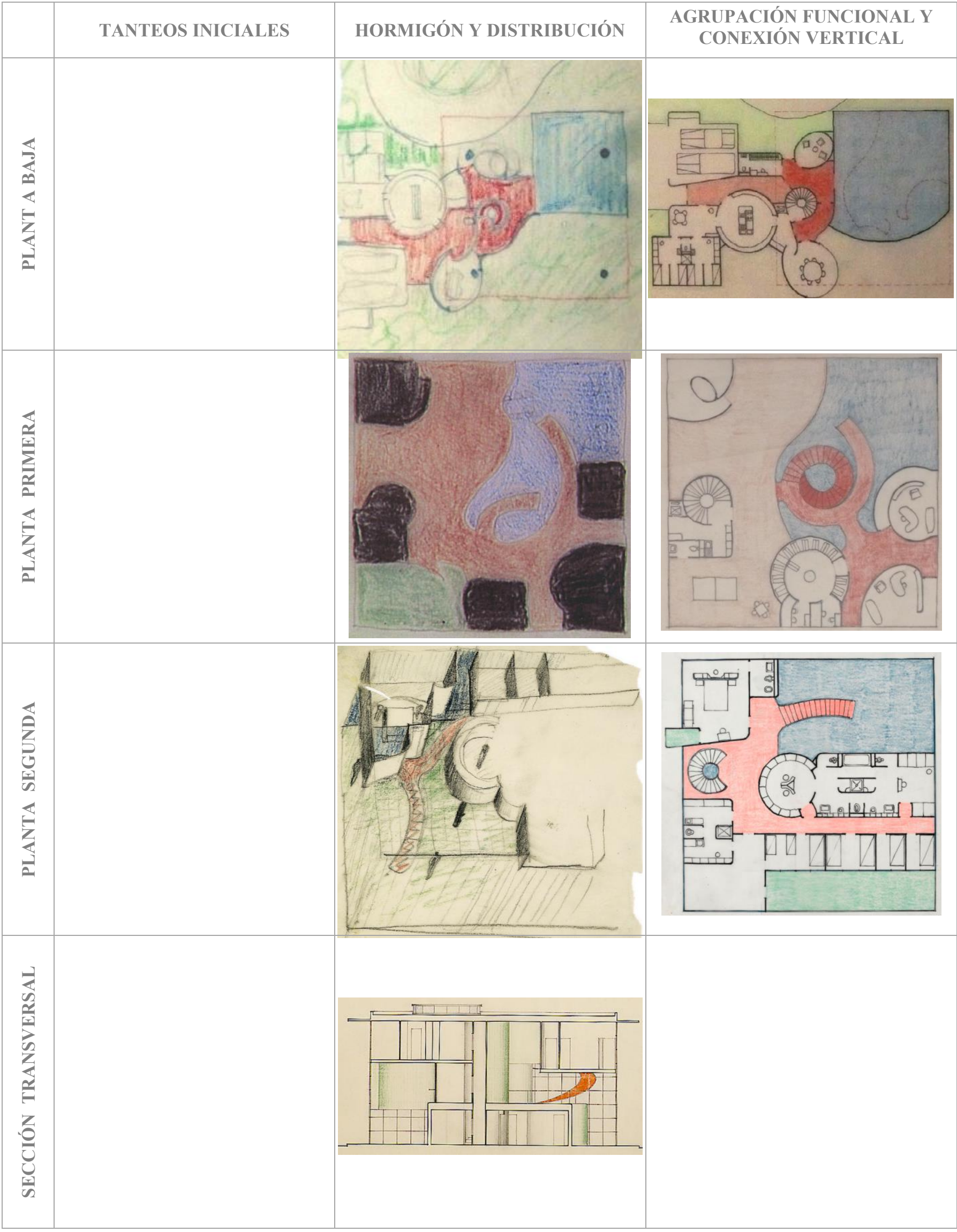




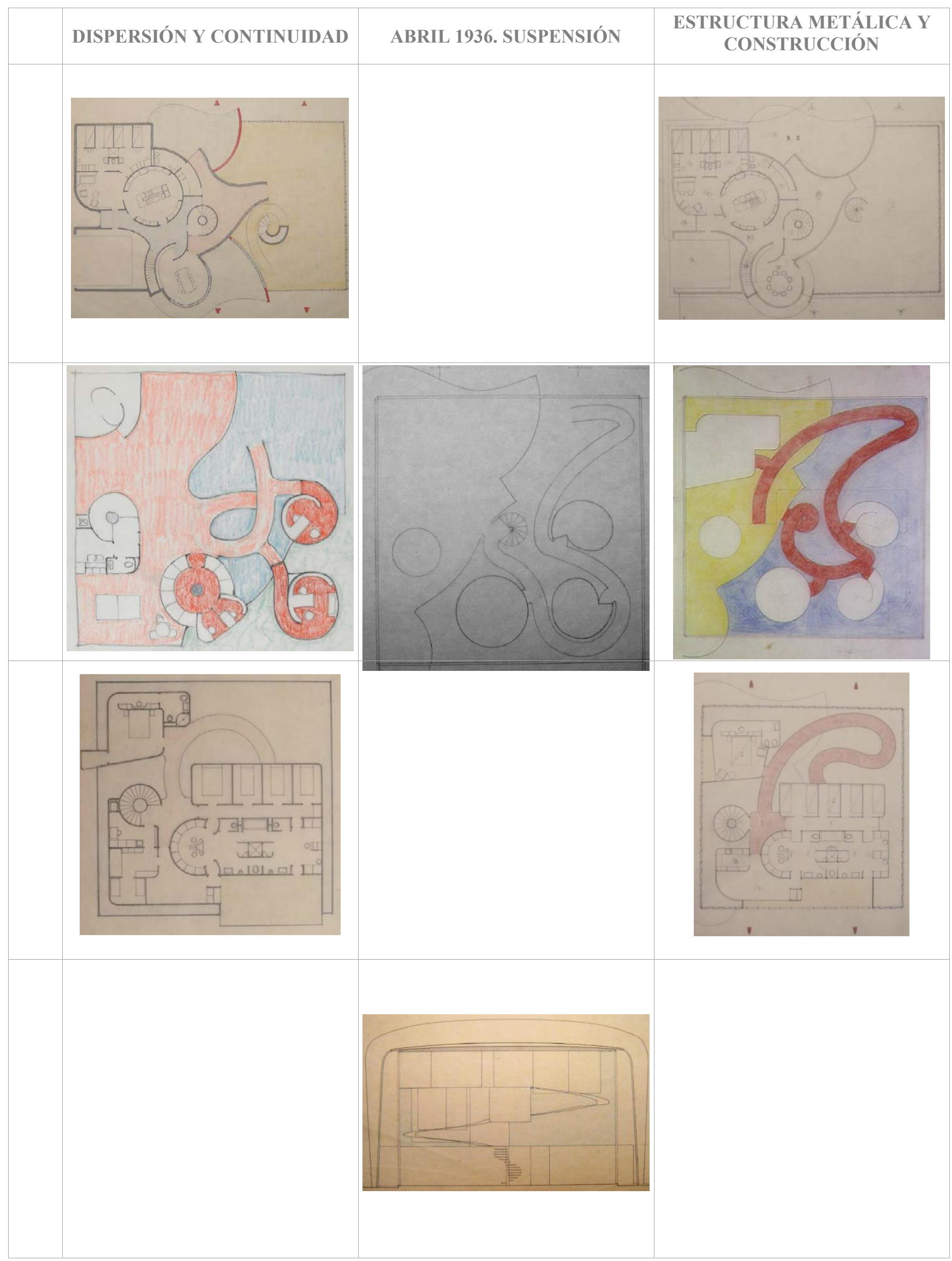




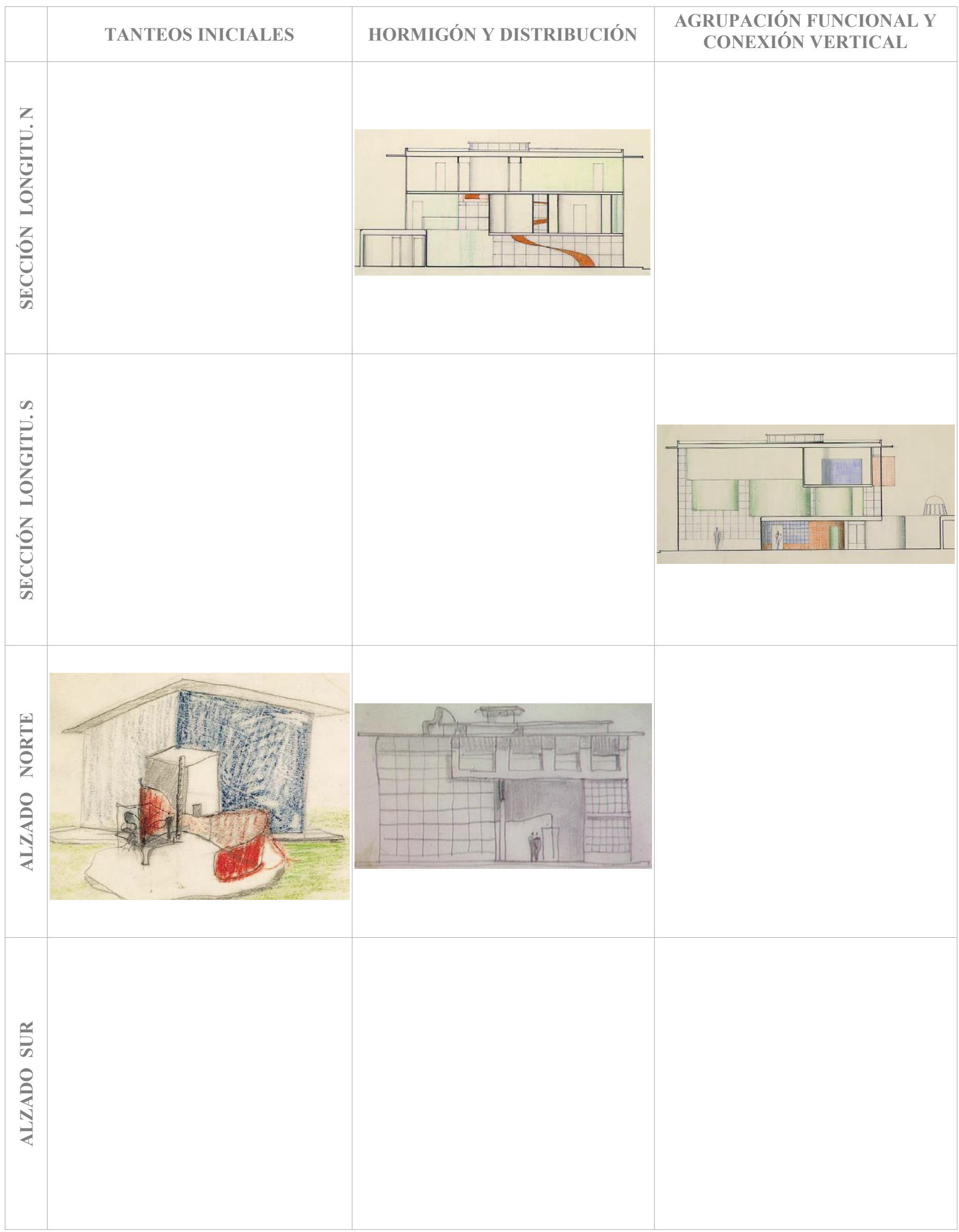




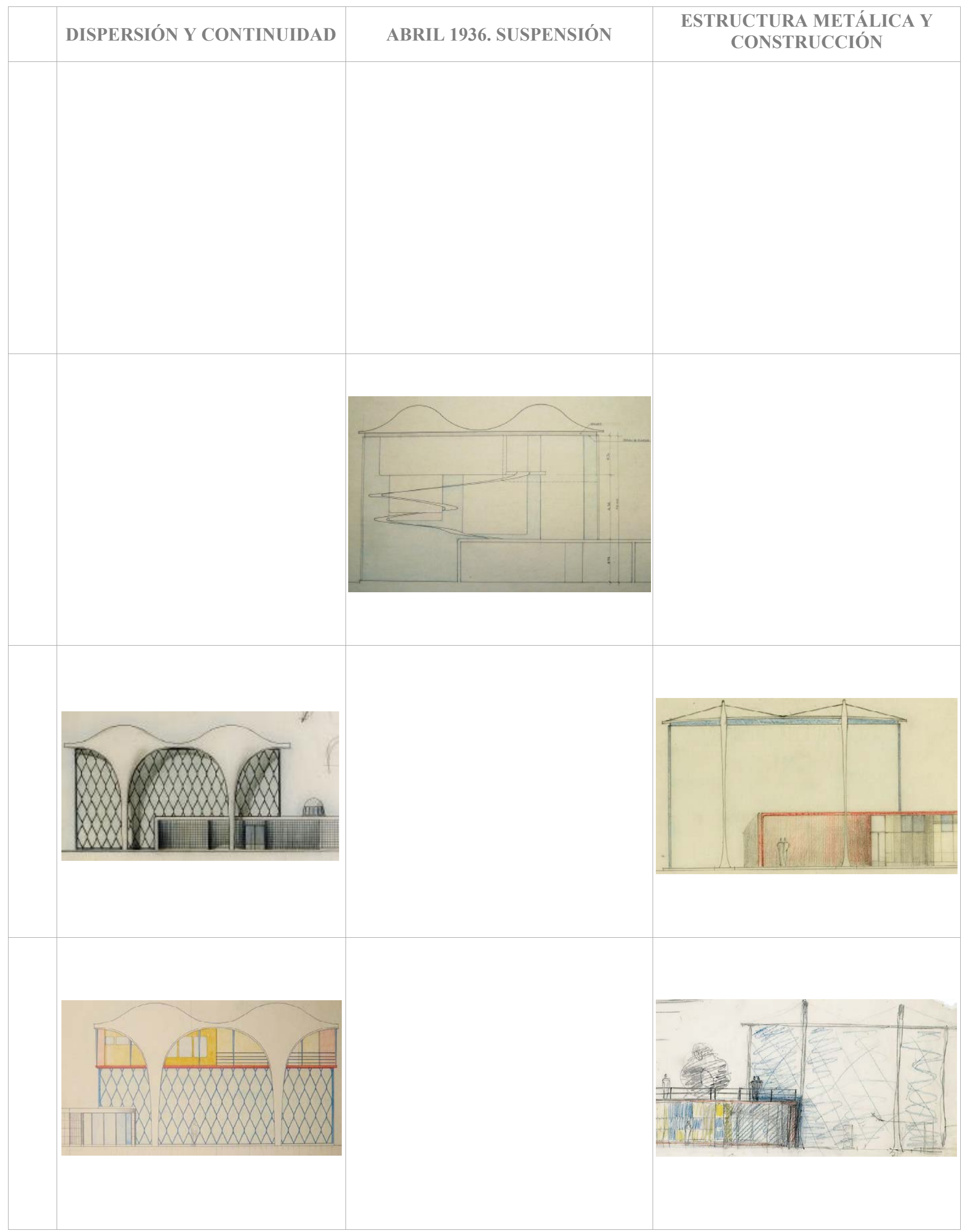




\begin{tabular}{|l|l|l|l|}
\hline TANTEOS INICIALES & HORMIGÓN Y DISTRIBUCIÓN & AGRUPACIÓN FUNCIONAL \\
\hline & & \\
\hline
\end{tabular}




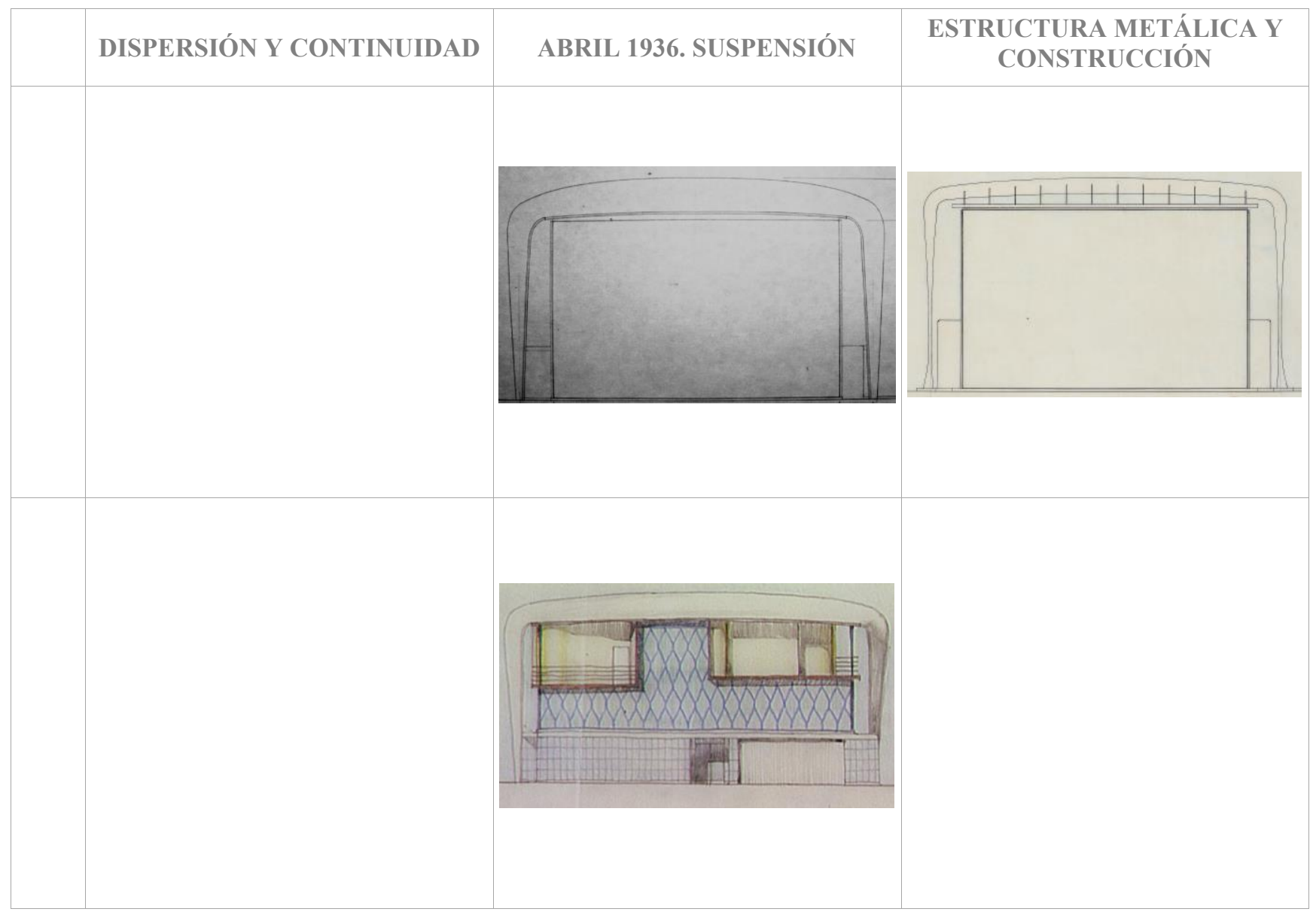

